Facultad de Informática

\title{
Diseño de un modelo de evaluación de entornos virtuales de enseñanza y aprendizaje basado en la usabilidad
}

Autor: Lic. Ariel Ferreira Szpiniak

Director: Dra. Cecilia V. Sanz

Tesis presentada para obtener el grado de Magister en Tecnología Informática Aplicada en Educación

Facultad de Informática - Universidad Nacional de La Plata 



\section{Resumen}

El impacto de las Tecnologías de la Información y la Comunicación a nivel social, y sus múltiples posibilidades de integración en la educación, han permitido desarrollar gran cantidad de espacios virtuales, con la intensión de favorecer los procesos de enseñanza y aprendizaje mediados por tecnología. Los Entornos Virtuales de Enseñanza y Aprendizaje (EVEA) surgieron dentro de este ámbito con el objetivo de integrar los principales servicios de Internet, y proveer recursos para facilitar la interacción entre docentes, alumnos y materiales de aprendizaje. Para poder analizar las ventajas y desventajas que cada EVEA posee, de acuerdo al contexto donde se los desee aplicar, es necesario evaluarlos de alguna manera. La mayoría de los modelos de evaluación analizados, previo y durante el desarrollo de este trabajo, evalúan los EVEA desde le punto de vista funcional. En general, el usuario final no participa del proceso, y no se tiene en cuenta la forma en que cada uno de los usuarios toma contacto con las funcionalidades del EVEA para realizar las tareas necesarias, y así poder satisfacer sus objetivos.

Por este motivo, la intensión es proponer un modelo que posibilite evaluar la calidad de los EVEA, considerando como eje central a la usabilidad. El énfasis puesto en la usabilidad se debe fundamentalmente a su creciente importancia dentro de la calidad de los productos Web. El modelo se denomina MUsa, dado que se trata de un Modelo basado en la Usabilidad, y está orientado hacia una evaluación de productos en uso. La evaluación se realiza mediante escenarios reales de uso, teniendo especial consideración por los alumnos y docentes, los objetivos que se proponen, las tareas específicas que realizan durante las actividades de enseñanza y aprendizaje, el equipamiento e infraestructura que disponen, el lugar físico donde habitualmente se desenvuelven, y el entorno social en el cual están insertos. Las ideas generales de MUsa están basadas en una estrategia de cuatro niveles o capas de evaluación, que parten de lo general para llegar a lo particular, donde las definiciones de usabilidad, junto con los atributos y las heurísticas forman el núcleo del modelo.

Para tener dimensión de las cualidades y defectos de MUsa, se lo aplicó sobre un caso concreto, el EVEA SIAT, desarrollado y utilizado por la Universidad Nacional de Río Cuarto. El caso de estudio sirvió para realizar un recorrido completo por las cuatro capas de MUsa, tomar las decisiones correspondientes en cada una de ellas de acuerdo a la magnitud de la evaluación, tiempo y recursos disponibles, y afrontar una aplicación efectiva del modelo dentro de un contexto conocido y acotado.

En este informe de tesis se presenta el diseño de MUsa, su aplicación en el caso de estudio y los resultados obtenidos. Los trabajos a futuro se orientan hacia una revisión de todo el modelo de evaluación, la mejora del mismo de acuerdo a la información recogida a partir del caso de estudio, y su efectiva utilización. 



\section{Agradecimientos}

En primer lugar, nobleza obliga agradecer profundamente a Cecilia, mi directora, sin cuyo aporte hubiera sido imposible culminar esta tesis. Han pasado muchos años desde que comenzamos a transitar este camino, con momentos que fueron muy difíciles para ella. Tan largo se hizo el camino que hubo tiempo para que su familia creciera al ritmo que la tesis trataba de tomar su rumbo. Sin la dedicación que ella puso en acompañarme, aconsejarme, responder a mis consultas, y analizar a fondo cada una de las páginas de la tesis, no estarían leyendo estos agradecimientos.

A mi esposa, Sonia, por permitirme compartir con ella el sueño de formar una familia, por su ternura, su amor, sus ideales, su empuje. Sos el amor de mi vida y agradezco todos los días que estés a mi lado.

A mis tres princesas, Agustina, Ailén y Ana Lucía, quienes me llenan de felicidad y orgullo día tras día. Disfruto al verlas vivir a pleno, haciendo gimnasia, aprendiendo, jugando, creando, bailando, actuando, brillando como estrellas.

A mis viejos, Beatriz y Víctor, por haberme dado educación y el privilegio de ser su hijo, porque la lucharon siempre, y me enseñaron los mejores valores del ser humano predicando con el ejemplo. En especial a mi mamá, por leer más de 300 páginas con un solo ojo y aportar comentarios para la mejora de la redacción de la tesis.

A mi hermana, Analía, que gracias a su inteligencia y tesón se transformará muy pronto en flamante Doctora, y excelente investigadora en genética (herencia de sus padres).

A mis compañeros de trabajo por estar siempre ahí, y por darme una mano cuando la necesité. A los docentes que colaboraron en la revisión de los instrumentos de evaluación y a los que participaron del caso de estudio. A mi prima Antonella que tradujo fragmentos de un libro en italiano. A Jordi Adell por responder a mis consultas vía correo electrónico.

A mi querida Universidad, la de Río Cuarto, por ser mi lugar de trabajo y facilitarme el desarrollo de las tareas de perfeccionamiento.

A la Universidad Nacional de La Plata, lugar de debate, de resistencia, de generación de conocimiento, de aporte a la sociedad, de la cual han surgido grandes hombres y mujeres comprometidos con un país para todos. Particularmente a la Facultad de Informática, a sus directivos, docentes y personal de apoyo, por posibilitarme ser alumno de sus carreras de posgrado y apoyarme cada vez que los necesité.

A todos los que contribuyen para que tengamos educación gratuita de calidad. ¡Al Gran Pueblo Argentino, Salud! 



\section{Tabla de Contenidos}

Capítulo 1: Introducción, motivación, objetivos, estructura de la tesis ............................ 9

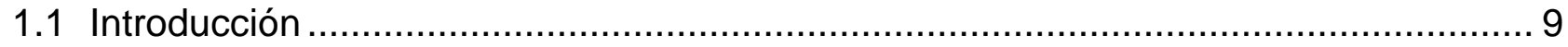

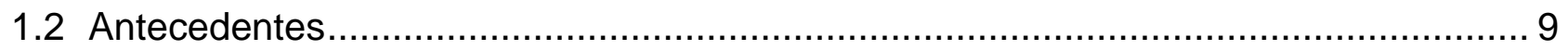

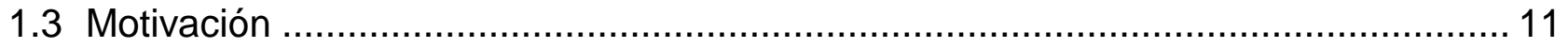

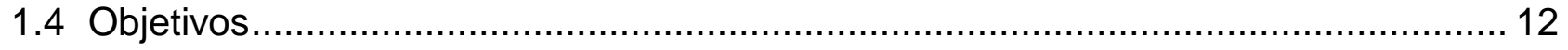

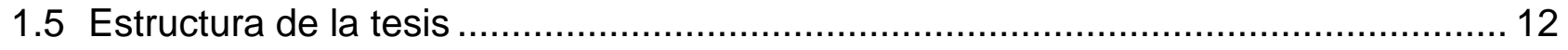

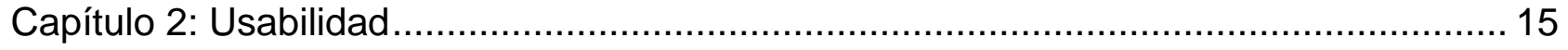

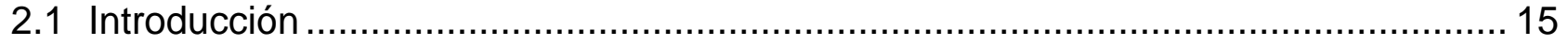

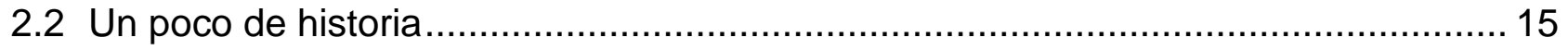

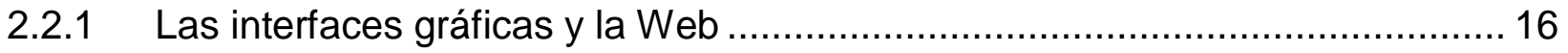

2.3 Características vinculadas al software ......................................................... 17

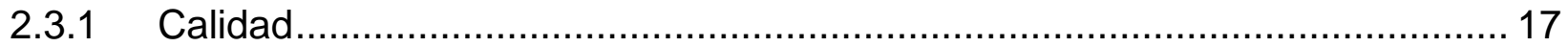

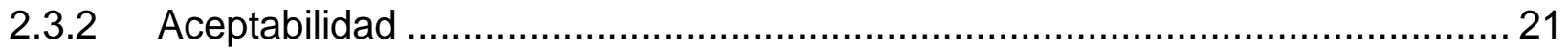

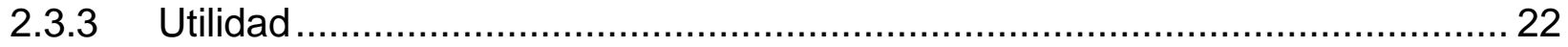

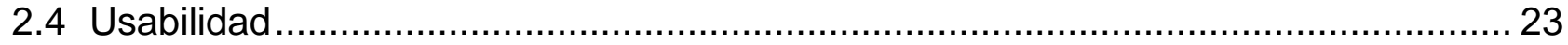

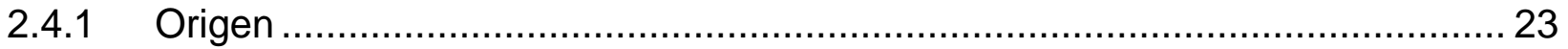

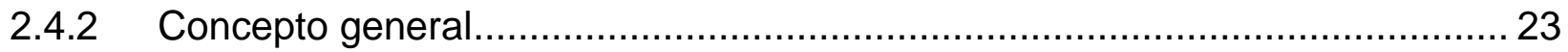

2.4.3 Usabilidad versus Calidad en uso ........................................................ 35

2.4.4 Atributos de la usabilidad ....................................................................... 36

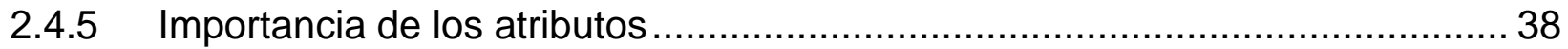

2.4.6 Heurísticas o principios de usabilidad .................................................... 39

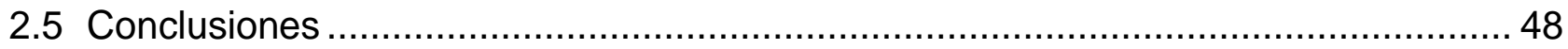

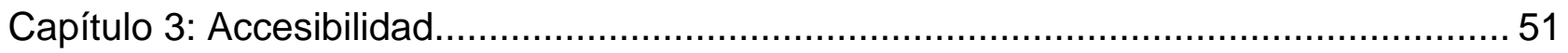

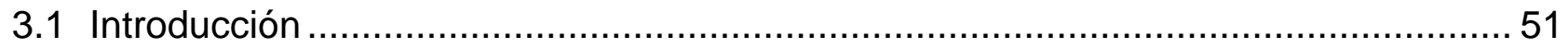

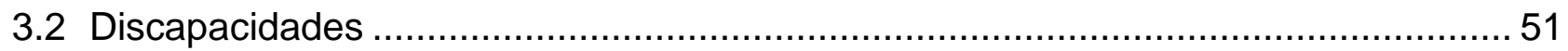

3.2.1 Discapacidades visuales ..................................................................... 52

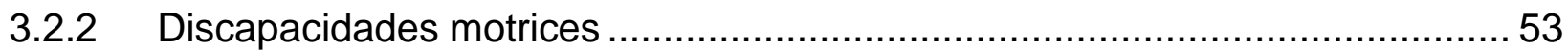

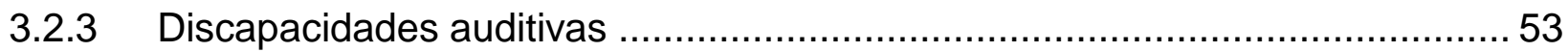

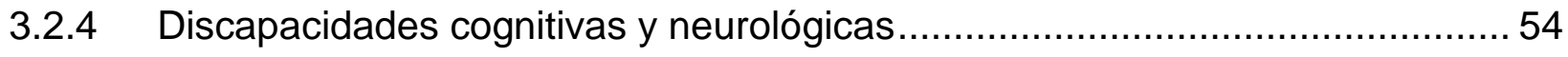

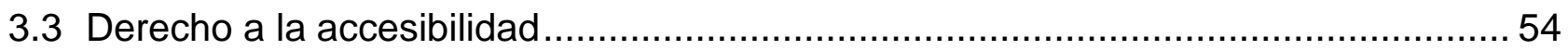

3.4 Guías y pautas de accesibilidad ........................................................... 55

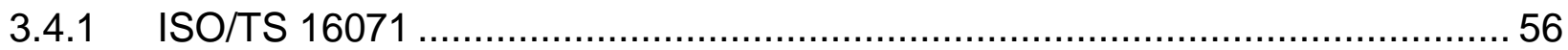

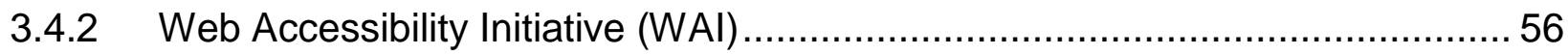

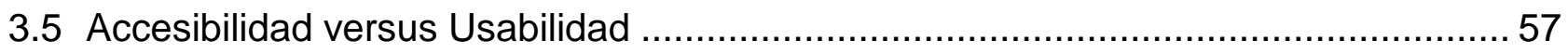


Capítulo 4: Métodos de evaluación de usabilidad......

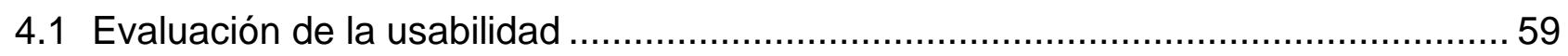

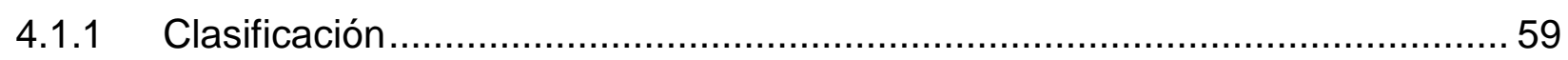

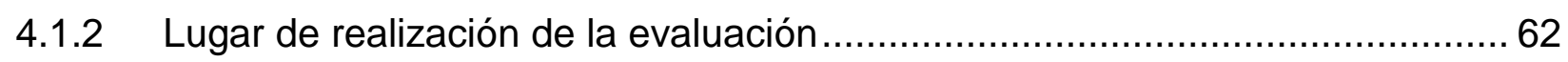

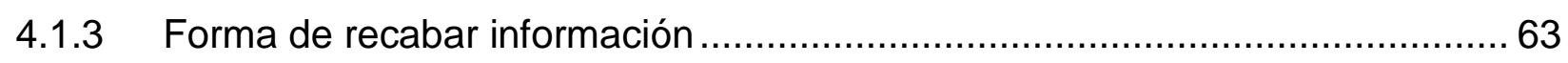

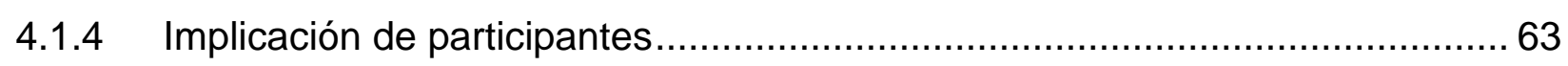

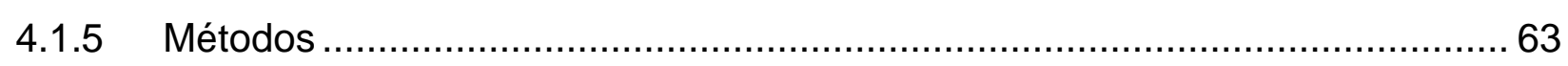

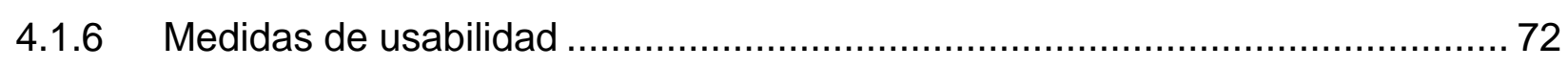

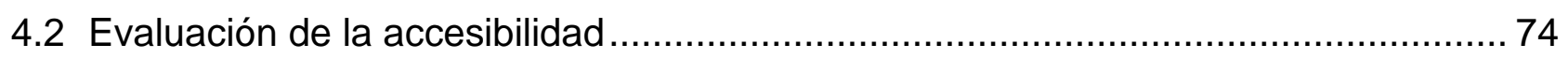

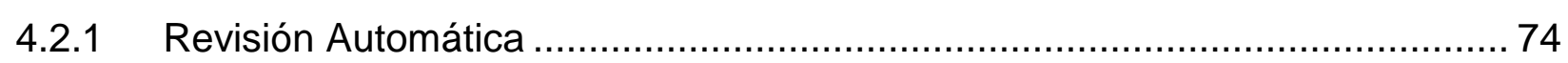

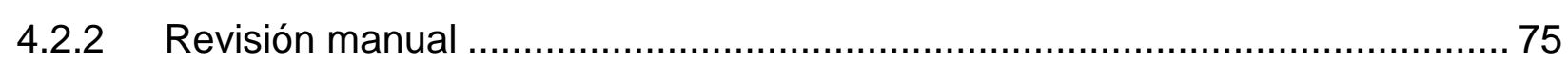

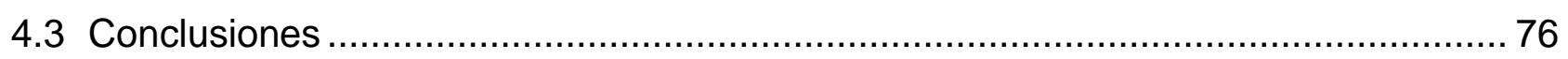

Capítulo 5: Entornos Virtuales de Enseñanza y Aprendizaje, y su evaluación ................. 79

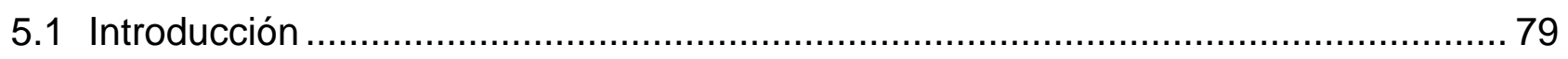

5.2 Entornos Virtuales de Enseñanza y Aprendizaje ……...................................... 80

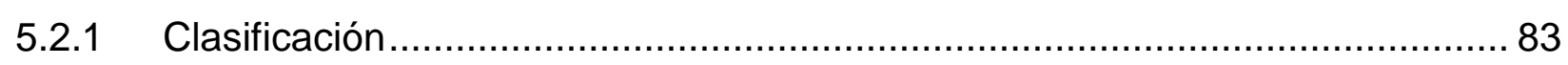

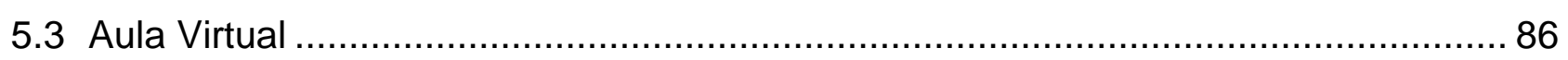

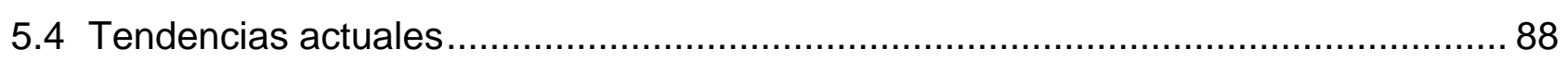

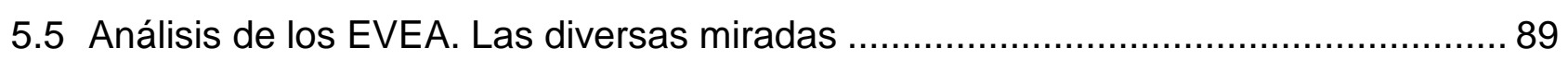

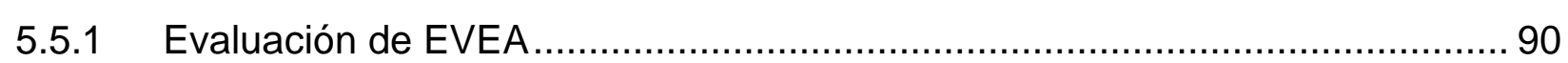

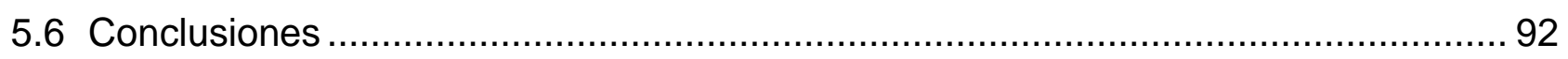

Capítulo 6: Métodos, técnicas, herramientas y evaluadores............................................ 93

6.1 Métodos de evaluación de usabilidad seleccionados ............................................. 93

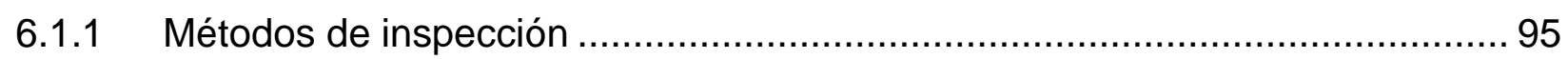

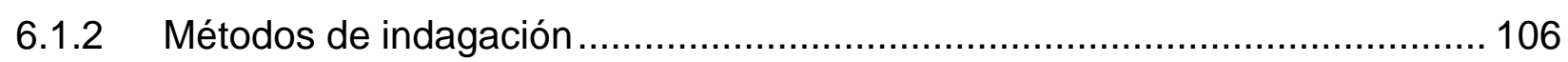

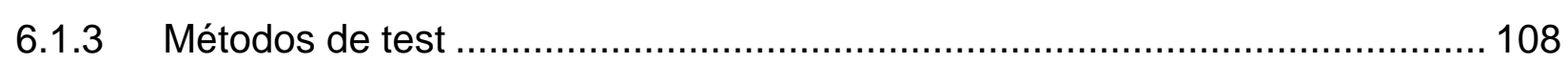

6.2 Técnicas seleccionadas para considerar en el modelo de evaluación propuesto ... 110

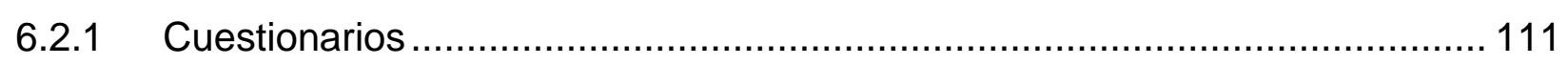

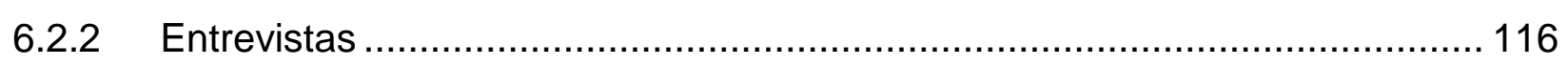

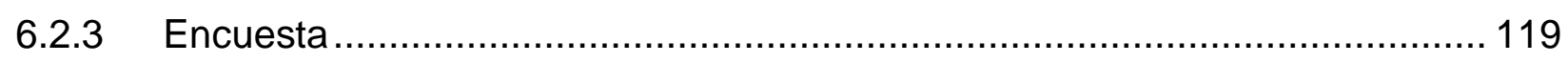

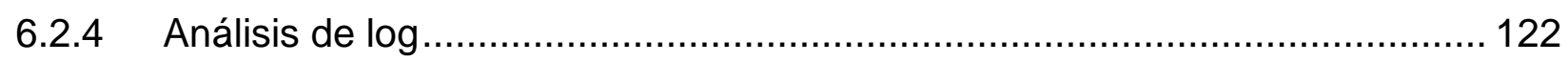

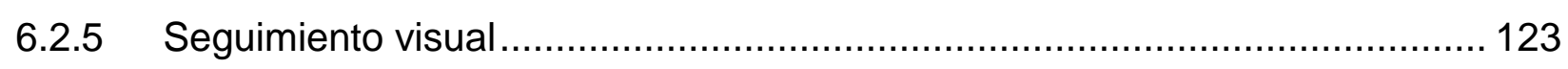

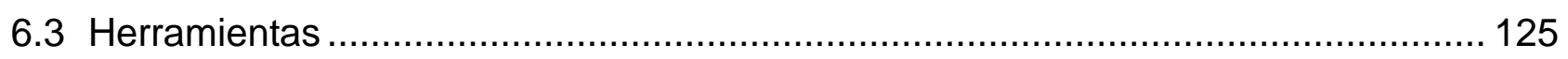

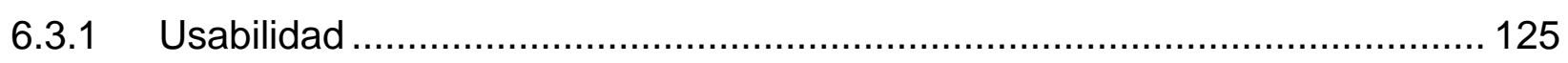




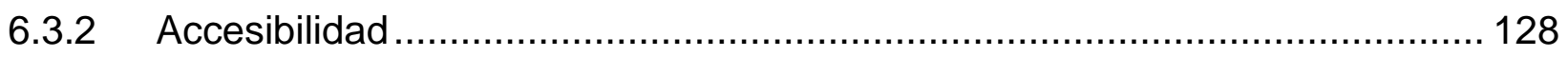

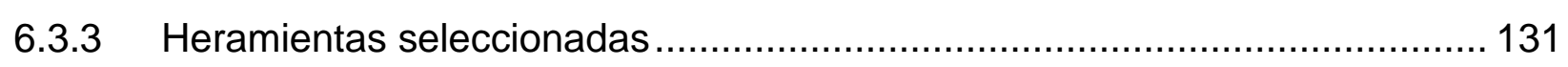

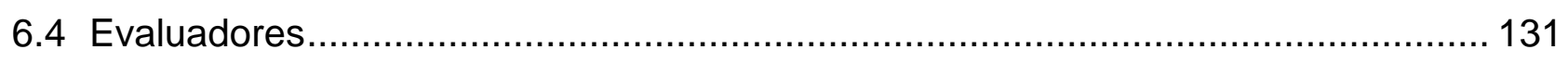

6.4.1 Clasificaciones en relación a los evaluadores.............................................. 132

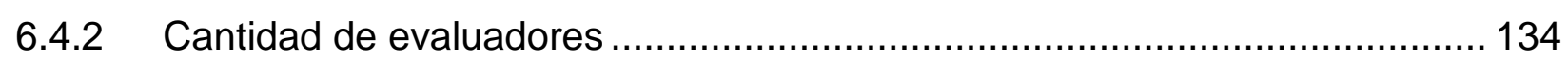

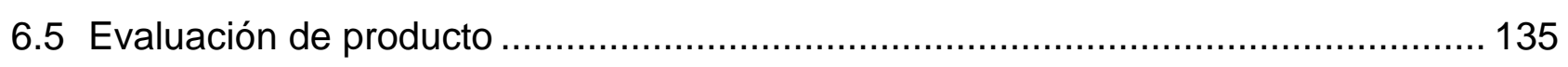

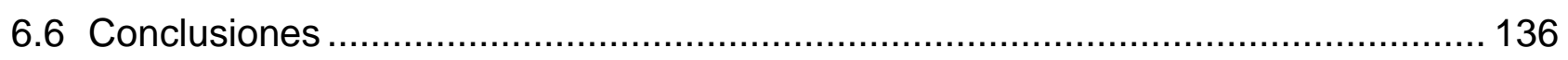

Capítulo 7: MUsa: Modelo centrado en la Usabilidad para evaluación de EVEA .... 139

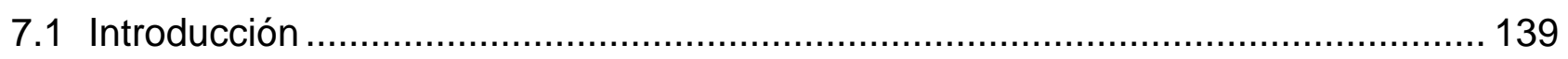

7.2 Puntos de partida propuestos para un nuevo modelo de evaluación de EVEA....... 139

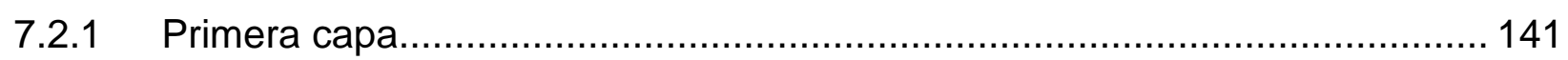

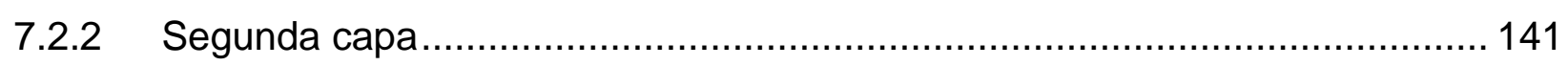

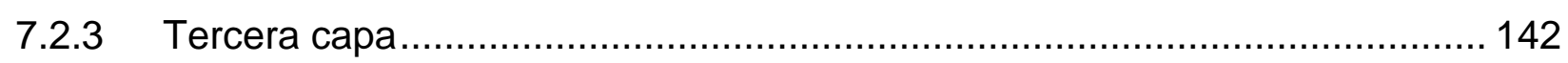

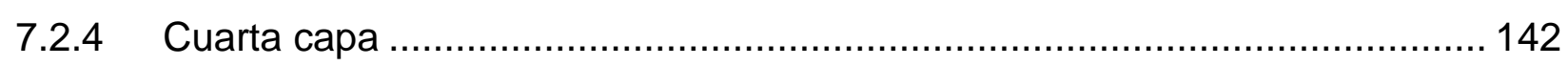

7.2.5 Aplicación de MUsa a distintos contextos ................................................. 143

7.3 Decisiones respecto a los métodos, técnicas, herramientas y evaluadores ............ 146

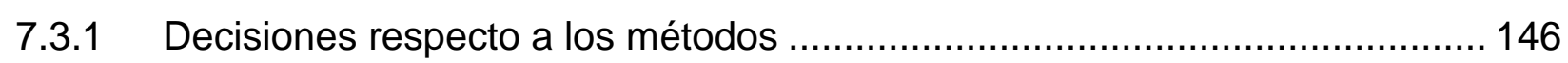

7.3.2 Revisión respecto a las técnicas............................................................. 146

7.3.3 Decisiones respecto a las herramientas ..................................................... 148

7.3.4 Decisiones acerca del tipo de evaluadores................................................. 148

7.3.5 Decisiones acerca de la cantidad de evaluadores ....................................... 149

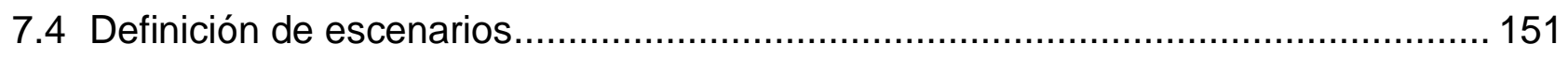

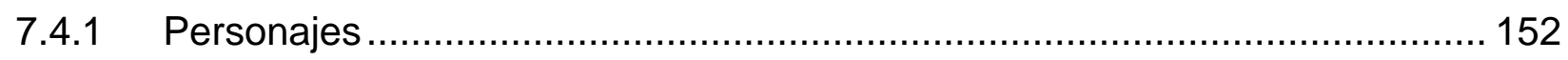

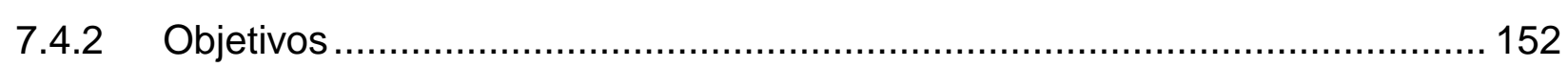

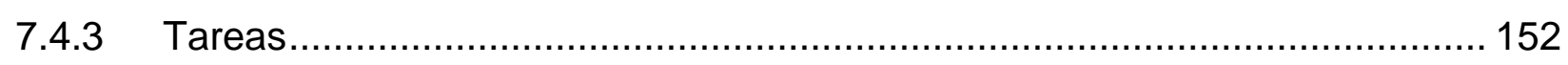

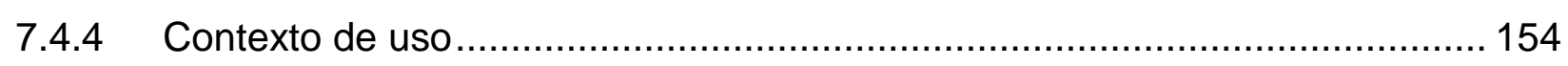

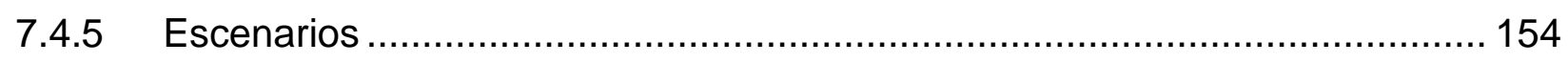

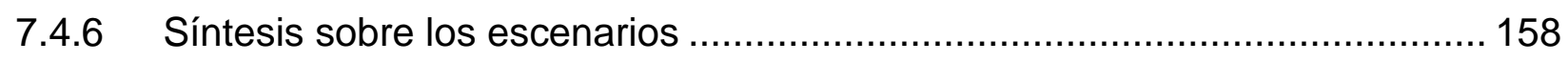

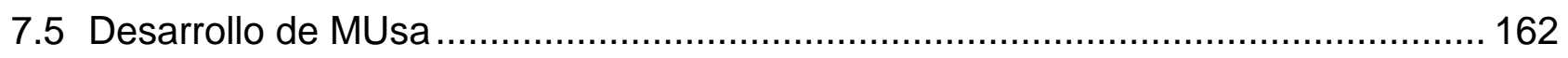

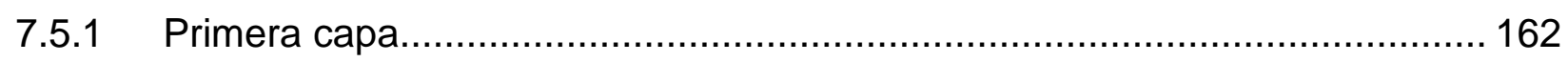

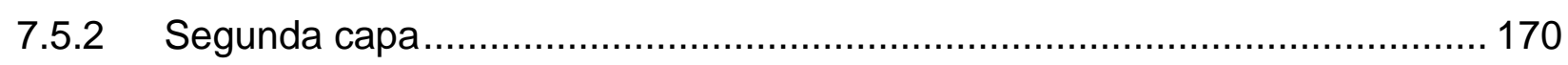

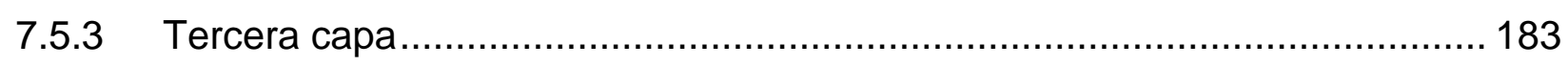

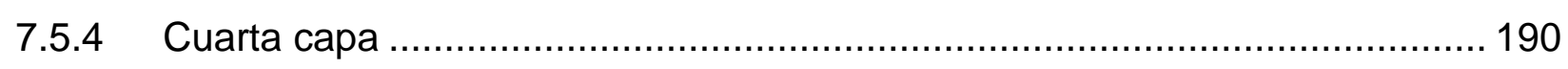

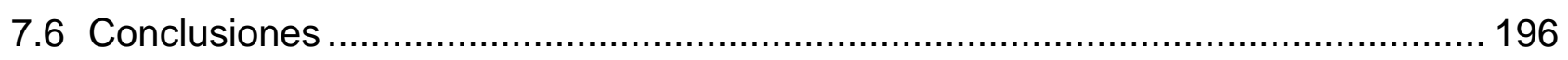

Capítulo 8: Caso de estudio. Aplicación de MUsa ......................................................... 199 
8.1 Sistema Informático de Apoyo a la Teleformación - SIAT ..................................... 199

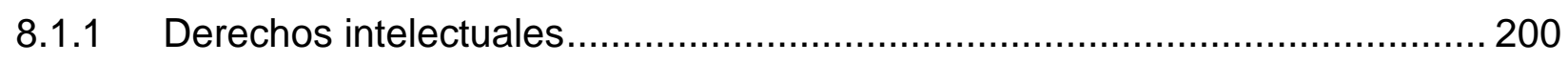

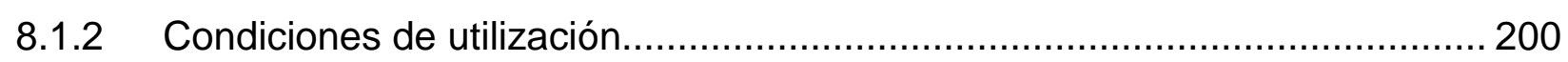

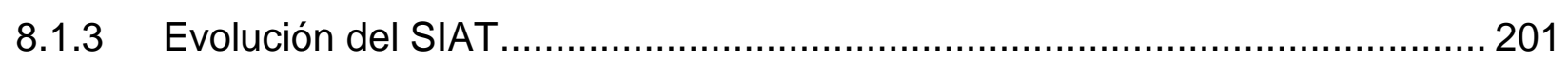

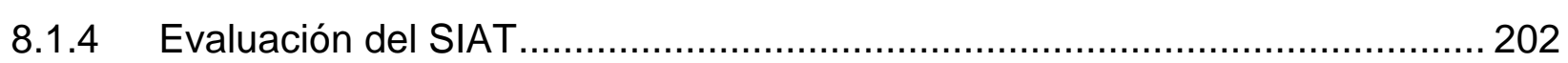

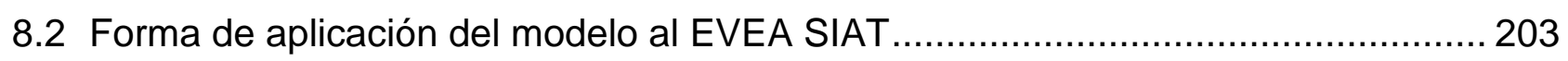

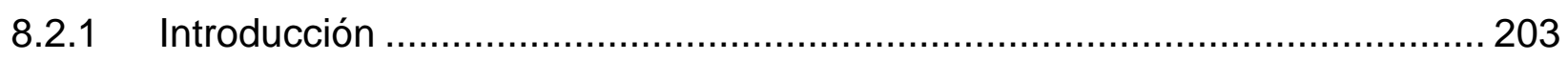

8.2.2 Que decisiones se tomaron en los puntos abiertos .................................... 203

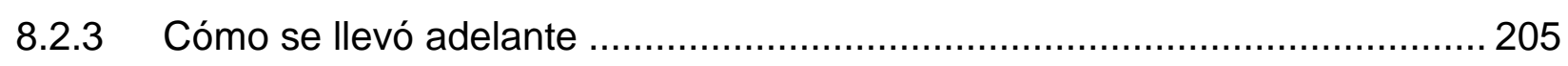

8.2.4 Resultados cualitativos obtenidos por capa ............................................... 210

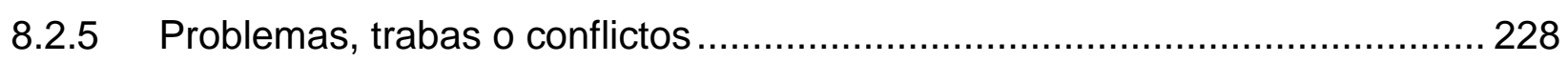

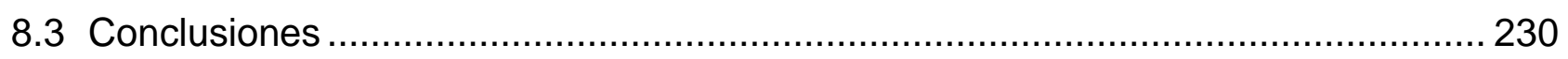

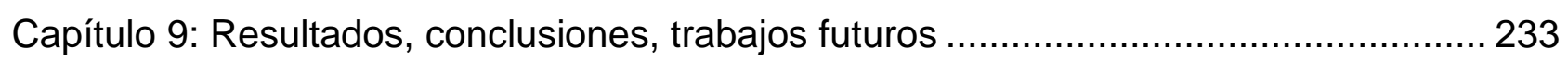

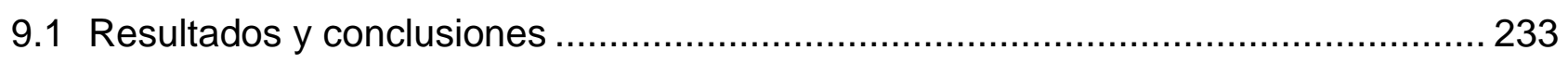

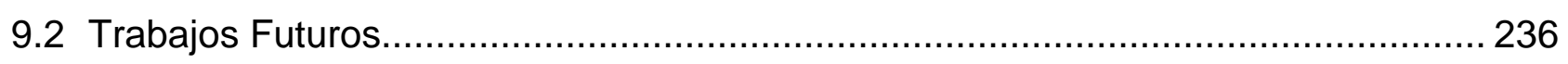

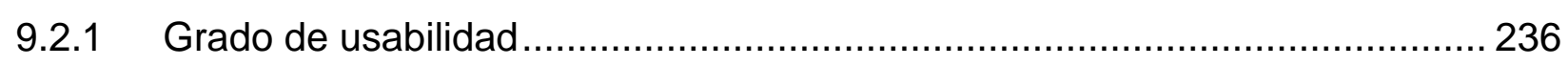

9.2.2 Ajustes del modelo y análisis por expertos .............................................. 236

9.2.3 Extender la aplicación del modelo .......................................................... 237

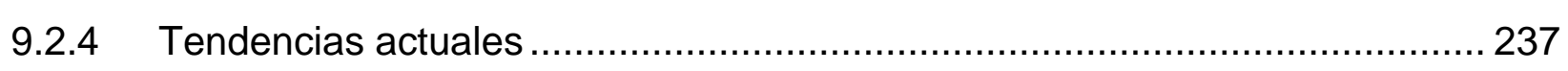

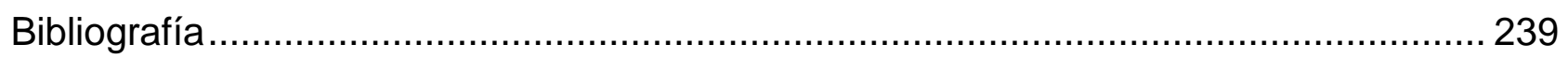

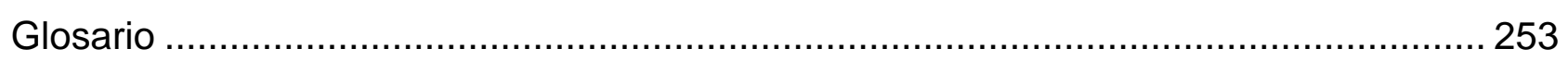

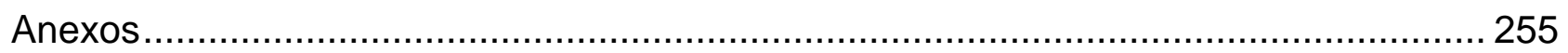

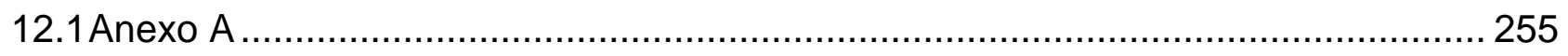

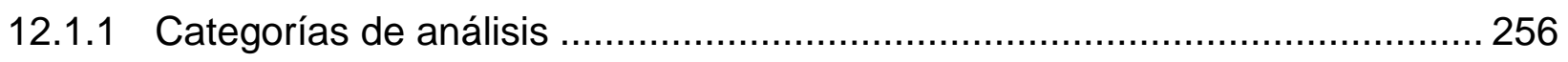

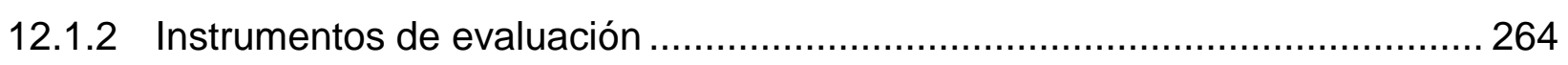

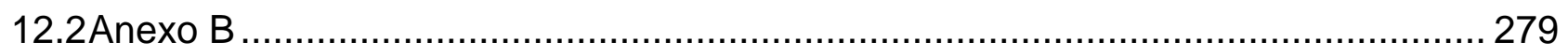

12.2.1 Identificación de tareas importantes y frecuentes en el EVEA SIAT .............. 279

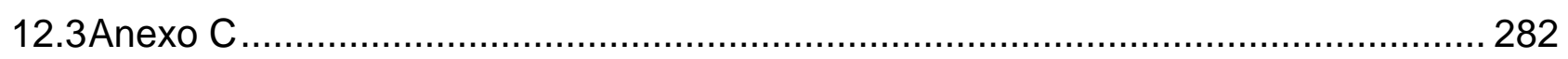

12.3.1 Evaluación de alto nivel orientada a la tarea............................................ 282

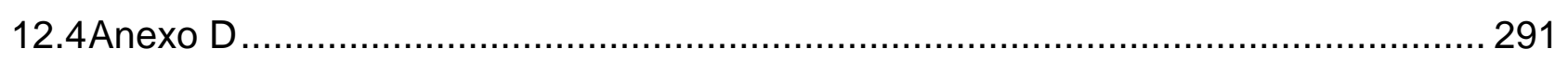

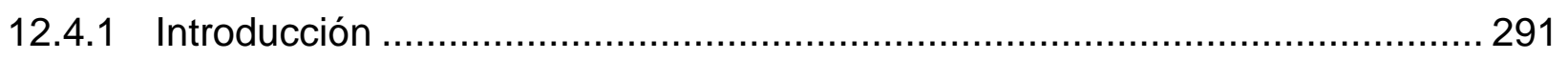

12.4.2 Cuestionario para evaluación en detalle orientada al diseño ........................ 291

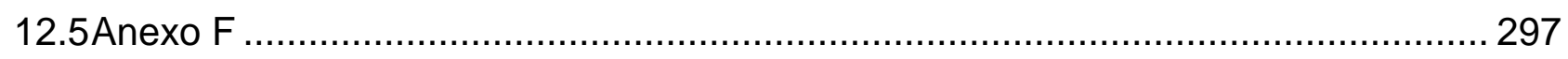

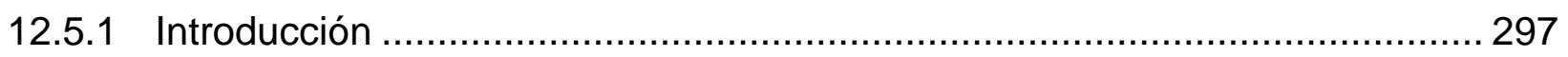

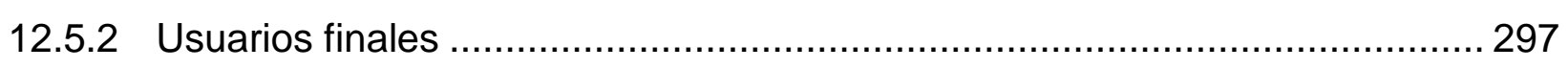




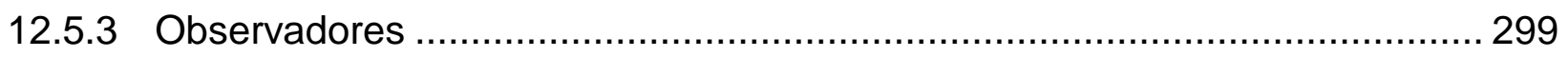

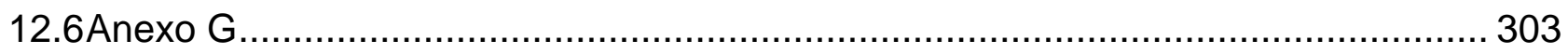

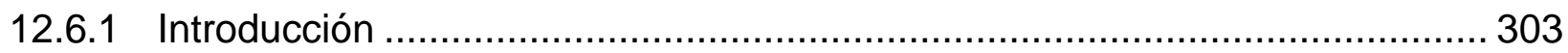

12.6.2 Selección de alumnos evaluadores ….................................................. 303

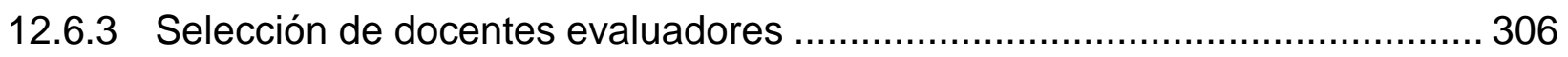

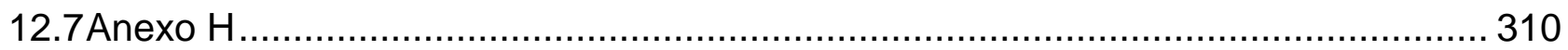

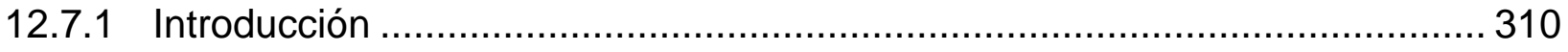

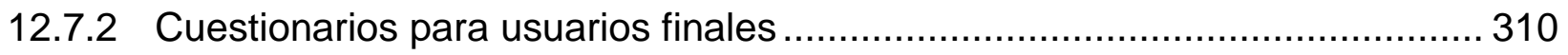

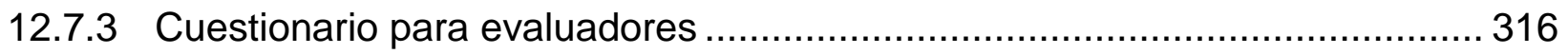

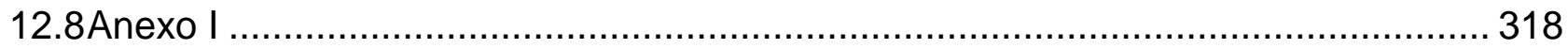

12.8.1 Selección de un entorno virtual para la Universitat Jaume I .......................... 318

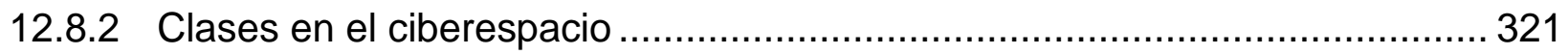

12.8.3 Indicadores para evaluar entornos para la formación por Internet................. 322

12.8.4 Indicadores de calidad en las plataformas de formación virtual..................... 327

12.8.5 Evaluación de un Sistema de Gestión del Aprendizaje................................. 329

12.8.6 Criterios de calidad para los sistemas de teleformación .............................. 335

12.8.7 Análisis comparativo de características ................................................... 337

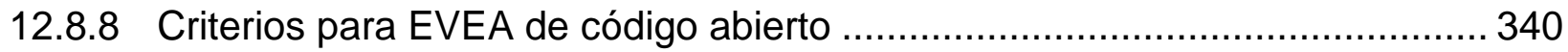

12.8.9 Evaluación de herramientas para gestión de cursos Web ........................... 342

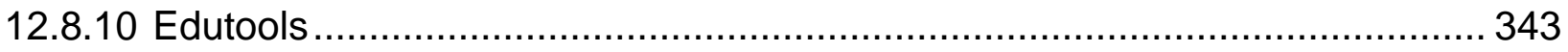





\section{Capítulo 1: Introducción, motivación, objetivos, estructura de la tesis}

\subsection{Introducción}

En los últimos años se ha visto un creciente grado de integración de las Tecnologías de la Información y la Comunicación (TIC) al ámbito educativo, dando lugar a diferentes escenarios y modalidades. La presencia de Internet, la creciente masividad en su uso y las ventajas que posee, han permitido explorar nuevas alternativas para los procesos de enseñanza y aprendizaje [Car2004][Pog2006].

Las posibilidades para favorecer los procesos de interacción es uno de los aportes más interesantes de las TIC. Ellas facilitan el diálogo educativo entre docentes y alumnos, a la vez que permiten desarrollar programas de educación más flexibles, basados en principios pedagógicos modernos, con metodologías centradas en el estudiante, basadas en la interactividad, la personalización y el desarrollo de la capacidad de aprender y pensar de manera autónoma [Sig2001].

La red de redes, Internet, ha puesto al alcance de la mano una serie de recursos que favorecen el aprendizaje activo. En un lapso breve de tiempo es posible comunicarse con otros pares, formar grupos de estudio para trabajar en entornos virtuales, realizar consultas sincrónicas o asincrónicas a docentes, participar en foros de discusión, grupos colaborativos, acceder a información actualizada sobre los temas estudiados, entre otros.

Inicialmente se fueron incorporando diferentes herramientas tecnológicas en los procesos de educativos, pero no de una manera integral. De allí que muchos cursos se reducían al uso del correo electrónico como medio de comunicación y tutoría, y/o la Web como medio de acceso a información. En este marco surgieron los Entornos Virtuales de Enseñanza y Aprendizaje (EVEA) cuyo objetivo fue integrar los principales servicios de Internet $y$, al mismo tiempo, proveer recursos para facilitar las tareas pedagógicas relacionadas con el seguimiento del proceso de aprendizaje de los alumnos, sumado a la posibilidad de monitorear el accionar de los docentes, la dinámica generada dentro del curso, las tareas administrativas y el apoyo para el correcto desenvolvimiento del mismo [Fer2007].

En la actualidad los EVEA son un componente tecnológico de vital importancia, particularmente en la Educación Superior, para el desarrollo de propuestas educativas innovadoras basadas en el uso de Internet. La calidad de dichos entornos es clave en la mediación de los procesos de enseñanza y aprendizaje. En la medida que los EVEA sean más usables, seguros y funcionales posibilitarán que el espacio entre docentes, alumnos, materiales de aprendizaje, y tecnología disminuya, intentando que esta última sea invisible.

\subsection{Antecedentes}

Como trabajo previo a la tesis se realizó una revisión de los principales modelos de evaluación de EVEA. El detalle de los modelos analizados se presenta en el anexo I.

El modelo desarrollado por Adell [Ade2004] sostiene que los criterios planteados están pensados conforme con las necesidades y los tipos de uso educativo que se pretende realizar del EVEA. Se trata de un análisis de corte cualitativo realizado en función de tres criterios: flexibilidad didáctica, usabilidad, y flexibilidad tecnológica. La flexibilidad didáctica se enfoca hacia las facilidades para el diseño y organización de cursos. Además, incluye a las herramientas de aprendizaje disponibles. La usabilidad tiene en cuenta a la facilidad de uso, los conocimientos técnicos de los usuarios, ayuda, trabajo off-line, accesibilidad e idiomas. Por último, la flexibilidad tecnológica tiene en cuenta los 
siguientes aspectos: requisitos técnicos, escalabilidad, posibilidades de integración con otros sistemas, mecanismos de autenticación de los usuarios, adaptación visual y costes de implementación, administración y mantenimiento.

Por su parte, Pallof y Pratt [Pal2001] sugieren tomar en cuenta cinco aspectos que deberían estar presentes en un buen entorno: interacción, introspección, innovación, integración e información. La interacción tiene que ver con los aditamentos necesarios para establecer procesos comunicacionales síncronos y asíncronos entre todos los participantes: correo electrónico, enlaces web, foros de discusión, chats, desarrollo de páginas web personales. La introspección se asocia con la posibilidad de que las herramientas comunicacionales permitan generar el desarrollo de pensamiento crítico y creativo por medio de una serie de recursos, en donde se acompañe de audio, video y texto, junto con espacios para actividades a desarrollar por parte de los estudiantes. Sin embargo, la propuesta didáctica sigue siendo un elemento fundamental en estos casos, ya que la herramienta puede contar con las mejores características, pero ser usada de forma inadecuada. La innovación permite al profesor generar actividades diferentes a las acostumbradas en una clase convencional, permitiendo a los estudiantes participar cada vez más, sacando provecho de su propio estilo de aprendizaje. De la misma manera, el proceso de evaluación del curso amplía su gama de alternativas, gracias al apoyo de la tecnología. La integración tiene que ver con la manera en que los recursos tecnológicos incorporan la información a un proceso de generación de conocimientos, partiendo de una base relacional (entre todos los participantes del curso), lejos de posturas eminentemente individualistas. La información refiere a la posibilidad de contar con aquellos hechos o datos necesarios para el buen desarrollo del curso a la mano del estudiante, sin importar en qué lugar se encuentre: bases de datos especializadas, bibliotecas digitales, portafolios electrónicos, datos del curso, producciones del docente, etc.

También el Gabinete de Tele-Educación de la Universidad Politécnica de Madrid [Gab2002] ha elaborado una serie de indicadores que pretenden ser una ayuda para establecer una relación entre los objetivos que se buscan y la oferta disponible. Estos indicadores hacen referencia a la información técnica, edición de materiales, proceso de enseñanza - aprendizaje, administración y gestión académica, y otras características. Puede observarse que existe una mayor preponderancia de análisis de elementos referidos a lo tecnológico y algunas cuestiones relacionadas con la usabilidad.

Torres Toro y Ortega Carrillo [Tor2003] realizaron una serie de investigaciones y elaboraron indicadores de calidad a tener presentes en los entornos de formación virtual. Ellos proponen cuatro categorías para analizar la calidad: técnica, organizativa y creativa, comunicacional y didáctica.

El modelo de evaluación propuesto por Zapata Ros [Zap2003], se apoya en cinco categorías que posibilitan examinar de forma muy pormenorizada las características de un entorno. En general, cada categoría se desglosa en una serie de preguntas o ítems que pueden ser identificados o no dentro de la herramienta analizada. Ellos son características básicas, utilidades que generan ambientes de comunicación y de trabajo, funciones formativas que permite desarrollar, roles que se identifican y evaluación sobre la intervención psicopedagógica del sistema que soporta.

Pere Marquès elaboró una serie de criterios de calidad para los sistemas de teleformación [Mar2001] donde no se abordan únicamente las herramientas sino también la calidad de los materiales formativos, la labor de los docentes y tutores, el plan docente y la metodología del curso. Esta concepción sostiene que la calidad del entorno dependerá en gran manera de la actuación de los docentes que interactúan con los estudiantes en el 
marco de un determinado modelo pedagógico. Los criterios están agrupados en: aspectos relacionados con el entorno telemático, aspectos funcionales del curso on-line, aspectos relacionados con el plan docente y el modelo pedagógico, aspectos relacionados con los servicios complementarios. En varios de los criterios aparecen cuestiones relacionadas con usabilidad y accesibilidad

Por último, el estudio realizado por Whitmyer Grimes [Whi2000], denominado Comparative Features Analysis of Leading Course Management Software, identifica un extenso conjunto de características deseables, 94 en total, para dar un correcto soporte a la enseñanza y el aprendizaje en línea. El propósito de sus investigaciones se orienta en dos sentidos: por un lado ayudar a las instituciones académicas a tomar decisiones sobre el entorno más conveniente a utilizar, y por el otro, asesorar a los desarrolladores de este tipo de herramientas respecto a nuevas funcionalidades que sería provechoso fueran incorporadas en un futuro no muy lejano.

En general, la mayoría de los modelos estudiados están orientados hacia las funcionalidades que ofrece el EVEA. Se trata de modelos donde el usuario final no participa sino que son expertos quienes realizan la evaluación, asumiendo los diferentes roles para los cuales el entorno será utilizado. Esto se debe a que dichos instrumentos fueron pensados principalmente para la toma de decisiones sobre el entorno a adoptar, por parte de las universidades o de los centros de formación. Por ello, en gran parte de los casos, se realiza una extensa categorización de características deseables o ideales que debería tener un sistema de este tipo. En la actualidad, muchos de los entornos que han logrado buenos niveles de aceptación disponen de las características buscadas en estos modelos de evaluación.

A partir de ese análisis se seleccionó el modelo elaborado por Adell [Ade2004] y se evaluaron algunos de los EVEA más utilizados en el ámbito universitario, tales como: WebCT, Moodle, Ilias, Dokeos, Claroline, y Atutor. Esta tarea formó parte del trabajo final de Especialización en Tecnología Informática Aplicada en Educación [Fer2007].

\subsection{Motivación}

Los Entornos Virtuales de Enseñanza y Aprendizaje (EVEA) forman parte del conjunto de aplicaciones informáticas diseñadas para la utilización de Internet con fines educativos. Su principal característica es la interactividad, como estrategia para favorecer el contacto entre docentes, alumnos, y materiales de aprendizaje. En término generales, suelen ser versátiles para poder adecuarse a diferentes propuestas y procurar que el diseño tecnológico acompañe al modelo pedagógico. En realidad, los EVEA coadyuvan a la concreción de objetivos educativos al proveer una serie de herramientas que facilitan la gestión de usuarios y cursos, y los procesos de comunicación, evaluación, colaboración, y distribución de contenidos [Thü2011b]. Presentan una serie de funcionalidades para lograr que los procesos de enseñanza y aprendizaje, donde juega algún rol la virtualidad, puedan desenvolverse de la mejor manera. Pero, ¿cómo se puede saber si ese objetivo se logra? Para averiguarlo es necesario realizar una evaluación.

La evaluación puede orientarse de diferentes maneras, según lo que se pretenda evaluar. En general, los modelos de evaluación existentes analizan los EVEA desde el punto de vista funcional [Fer2007]. Sin embargo, el análisis de las funcionalidades ideales no tiene en cuenta la forma en que se puede poner en práctica todo el potencial del EVEA. En la actualidad, la mayoría de estos sistemas posee un núcleo común de herramientas, con lo cual carece de sentido seguir analizándolos casi exclusivamente desde el punto de vista de sus características funcionales [Fer2007]. 
Por tal motivo, se cree necesario incorporar una forma de evaluar, donde no se pierdan de vista éstas características, pero se prioricen otros aspectos centrados en el modo en que los usuarios finales toman contacto con la funcionalidad. En este sentido, la usabilidad es un concepto muy útil ya que tiene estrecha relación con la utilidad funcional. La usabilidad busca analizar cuán bueno es un sistema como para satisfacer todas las necesidades y requerimientos de los usuarios [Sha1991][Nie1993][Lau1995][Sch1998][Nor1998] [ISO1998b][ISO1998c][Red99][Nie2000][ISO2001][Kei2003][Nie2003]. La usabilidad aporta una mirada centrada en el usuario y el contexto de uso, analizando en que medida se satisfacen los objetivos de docentes y alumnos de la forma más simple, amena, e intuitiva posible. Por ello se entiende a la usabilidad como el punto de vista en el que las necesidades, requerimientos y limitaciones del usuario final son el foco del diseño, sumado a la efectividad, eficiencia y satisfacción con la que el producto permite alcanzar los objetivos propuestos por los usuarios en un contexto de uso determinado [Mor2007].

\subsection{Objetivos}

El objetivo central de la tesis se vincula con la evaluación de calidad de EVEA. Se ha partido de un trabajo de investigación previo, donde se abordaron diferentes modelos de evaluación existentes, y esto ha permitido orientar el objetivo a la búsqueda de modelos que hacen foco en la usabilidad. Como consecuencia, se aborda aquí el diseño de un modelo de evaluación centrado en la usabilidad, que pueda ser aplicado a EVEA que estén en pleno funcionamiento. Con la definición de este modelo se pretende brindar una herramienta para analizar las ventajas y desventajas que cada EVEA posee en el marco de un contexto de uso determinado, teniendo especial consideración por los alumnos y docentes, los objetivos que se proponen, las tareas específicas que éstos realizan dentro del entorno virtual durante las actividades de enseñanza y aprendizaje, el modelo mental que utilizan, el equipamiento e infraestructura del que disponen, el lugar físico donde habitualmente se desenvuelven, y el entorno social en el cual están insertos.

\subsection{Estructura de la tesis}

El capítulo 2 introduce el concepto de usabilidad, sus diferentes miradas y definiciones.

El capítulo 3 hace lo propio con el concepto de accesibilidad, su relación con los derechos de los usuarios, guías y pautas.

El capítulo 4 analiza la forma de evaluar la usabilidad, la clasificación y los métodos más importantes.

El capítulo 5 centra la mirada sobre los EVEA, su evolución, clasificación, el concepto de aula virtual, las tendencias actuales, y análisis de los principales modelos de evaluación revisados.

El capítulo 6 describe los métodos, técnicas, y herramientas existentes para evaluar la usabilidad de aplicaciones basadas en Web, y los distintos tipos de evaluadores.

El capítulo 7 detalla las características del método que se propone para la evaluación de EVEA, que toma a la usabilidad como eje. Los puntos de partida para este modelo se basan en una estrategia de cuatro capas, que parten de lo general para llegar a lo particular.

El capítulo 8 presenta el caso de estudio realizado a partir del modelo de evaluación propuesto. Este trabajo de campo se realizó en el contexto institucional de la Universidad Nacional de Río Cuarto, con el objetivo de validar el modelo a través de un caso real, y 
aportar una valoración del EVEA SIAT desde el punto de vista educativo basado en la usabilidad.

Finalmente, el capítulo 9 resume los resultados, conclusiones, y sugiere algunos trabajos futuros. 



\section{Capítulo 2: Usabilidad}

\subsection{Introducción}

La usabilidad es un concepto joven, subjetivo, algo complicado de definir. Dentro del ámbito de la Informática, nació al calor de las interfaces gráficas y la World Wide Web (Web) [Cat2000][Mon2006]. Alrededor de la usabilidad existen una serie de conceptos relacionados semánticamente, que es frecuente confundirlos entre sí. Nos estamos refiriendo a la facilidad de uso, amigabilidad, manejabilidad, operatividad, ergonomía, utilidad, accesibilidad, entre los más recurrentes. Se trata de una palabra controvertida puesto que es una traducción literal del inglés que formalmente no existe en castellano. La usabilidad puede ser analizada desde distintas ópticas, disciplinas, para diferentes propósitos, e incluso, aplicada a cualquier tipo de objetos de la vida cotidiana [Nor1998] [Fer2001][Kei2003] [Lei2003].

Existen características que son más generales que la usabilidad, y otras que están subordinadas a la misma. La calidad de un producto software es una de esas características más generales, mientras la accesibilidad podría considerarse como menos general [Mon2006]. Este recorrido de lo general a lo particular es el que seguiremos en nuestro análisis.

En lo que respecta a los productos informáticos, tomaremos a la usabilidad como uno de los atributos más importantes que hacen a la calidad. Se trata de un atributo considerado clave, aunque no el único [Nie1993][Fer2001]. La importancia de la usabilidad radica en el hecho de ser el atributo más visible para el usuario, y el que determina el grado de satisfacción del mismo respecto del producto, que a su vez trae aparejada su utilización o no. Por otra parte, la usabilidad es el primer atributo donde los usuarios tienen un papel activo en su evaluación [Cat2000]. En la actualidad, la usabilidad está adquiriendo cada vez mayor importancia, a tal punto que es tenida en cuenta de forma explícita por diversas clasificaciones de atributos de calidad, como los de la Organización Internacional para la Estandarización (ISO) y el Instituto de Ingenieros Eléctricos y Electrónicos (IEEE). La percepción de la importancia de la usabilidad se afirma en que es uno de los atributos de calidad que se consideran más críticos en el proceso de desarrollo de software, y de los que aportan mayores beneficios [Con1999][Fer2001][Kei2003]. En síntesis, la usabilidad es considerada como una de las principales características de la calidad de un producto de software [ISO2001].

Nuestro objetivo es definir y aplicar el concepto de usabilidad desde el punto de vista de las aplicaciones Web, en particular desde entornos virtuales que guarden relación directa con actividades de enseñanza y de aprendizaje. Debido a ello, describiremos en primer término, los conceptos principales dentro de los cuales se enmarca la usabilidad, a posteriori abordaremos su definición, los elementos que influyen en relación de este atributo en un producto de software, y el por qué tomaremos este concepto como punto de análisis de los Entornos Virtuales de Enseñanza y Aprendizaje (EVEA).

\subsection{Un poco de historia}

A menudo se asocia la usabilidad con la interfaz entre la computadora y el hombre, incluyéndola como parte de la corriente de estudio multidisciplinar denominada Human Computer Interaction ( $\mathrm{HCl}$ ). Esta investiga la manera en que el hombre se comunica con la computadora desde el punto de vista de los procesos psicológicos, comunicativos, 
físicos, ergonómicos, etc. [Cob2005]. Donald Norman ${ }^{1}$ señala que en la medida que los sistemas sean más usables, seguros y funcionales, posibilitarán acercar la persona a la computadora. Eventualmente, se podría llegar al caso ideal en que la computadora sea considerada como invisible [Nor1998b].

Dentro del campo informático, la usabilidad cobró especial importancia con la aparición de las interfaces gráficas de usuario, más conocidas como Graphical User Interface (GUI) [Bev1991][Nie1993]. A comienzos de los años 80 no se hablaba de usabilidad sino de amigabilidad de la interfaz con el usuario. Todo sistema informático buscaba, por sobre todas las cosas, ser amigable con el usuario, fácil de usar [Mon2006]. Es decir, que no obligara al usuario a expresarse de manera innatural, ya que eso, más allá de constituir un peso psicológico, induce a cometer errores. La interfaz debía ser tal que posibilitara al usuario concentrarse sobre el problema a resolver, no sobre como "luchar" con la aplicación para hacerle resolver el problema [Ghe1991]. La amigabilidad, ser amigo de, denotaba implícitamente muchos otros conceptos: confianza, seguridad, interacción, facilidad de diálogo, etc. La vaguedad del término amigabilidad, y sus connotaciones subjetivas hicieron que fuera reemplazado por el de usabilidad [Bev1991].

La masificación de Internet, particularmente luego del surgimiento de la World Wide Web (Web) y de su rápida evolución, hizo imperiosa la necesidad de adaptar los desarrollos informáticos a esta nueva realidad [Lei2003]. Ello implicó un cambio muy importante ya que los sitios Web se transformaron en la interfaz principal con el usuario [Nie1993]. Así, la usabilidad se convirtió en una de las premisas básicas para diseñar buenos sitios Web [Bae2002].

\subsubsection{Las interfaces gráficas y la Web}

Las aplicaciones basadas en la Web presentan un escenario bastante diferente de las diseñadas para ser usadas localmente (stand-alone) [Bae2002]. La naturaleza misma de la Web, prácticamente sin barreras y accesible desde cualquier punto con el sólo uso de un navegador, hacen que la manera de atacar los problemas de usabilidad requieran de un enfoque distinto al de una aplicación de software tradicional [Mur1999]. En el diseño tradicional de interfaces gráficas de usuario, el desarrollador del software puede realizar un control de la pantalla, es decir, se puede estar seguro del aspecto que tendrán los objetos en la misma, y las posibilidades disponibles en cada momento, incluso se puede tomar posesión de la computadora usando pantallas modales que no permiten al usuario realizar nuevas acciones hasta que se hayan cerrado. Los sitios Web, en cambio, pueden ser accedidos desde equipos informáticos muy disímiles entre sí, tanto desde el punto de vista del hardware como del software. Además, la navegación suele ser controlada por quien utiliza la aplicación Web, con lo cual si el diseñador no ha tomado los recaudos necesarios, y no ha desarrollado el sitio en el marco de un proyecto planificado, donde la estructura haya sido pensada exhaustivamente, puede que el usuario siga caminos que no fueron previstos. Esto lleva a que el diseño del software tenga que estar pensado para la libertad de movimiento [Nie1993]. Otra diferencia importante entre las GUI y la Web, es que las primeras contaron con expertos en interfaces que desarrollaron directrices para

\footnotetext{
${ }^{1}$ El profesor Donald A. Norman es un reconocido investigador que trabaja principalmente en el área de ciencia cognitiva relacionada con usabilidad y la Web. Estudió ampliamente el diseño de objetos, especialmente objetos informáticos, y su relación con el usuario (persona), desde el punto de vista psicológico. Ha escrito varios libros referidos al tema que son ampliamente referenciados por la comunidad científica.
} 
ayudar a implementar buenas ideas de diseño [Nie1993]. Desafortunadamente, no se pueden aplicar a la Web muchas de las directrices para GUI, ya que los usuarios pueden acceder a la Web a través de computadoras tradicionales, dispositivos de mano como Palms, teléfonos celulares, vehículos, etc. [Nie1993]. Cada usuario que visita el sitio Web lo hace con un equipamiento, software, y conexión diferente. No debemos perder de vista que habrá usuarios con computadoras de última generación, con la versión de navegador más actualizada, y una conexión de banda ancha a la red, así como también habrán otros con equipos más lentos, conexión a Internet por vía telefónica y software no actualizado. Si el objetivo es que el sitio Web sea utilizado por la mayor cantidad de usuarios posibles con el mismo nivel de calidad, entonces, debemos diseñarlo para que se adapte a las posibles limitaciones de cada uno [Bae2002]. Por ejemplo, en el diseño GUI tradicional se considera que la diferencia entre el área de la pantalla en una computadora personal y una notebook es de factor 6 , mientras que en la Web este factor se eleva a 100 para el área de pantalla, y a 1.000 en lo relativo al ancho de banda entre módems y conexiones de alta velocidad. Es decir, que en lugar de tratar de recrear exactamente el mismo aspecto visual de las páginas para todos los usuarios, hay que adecuarlas para que los navegadores optimicen la pantalla, en base a las circunstancias particulares desde donde se produzca la visualización [Nie1993].

\subsection{Características vinculadas al software}

Entre las características vinculadas al software, se encuentra la usabilidad, tal como se mencionó en la introducción de este capítulo. Sin embargo, también se explicó que existen otras características de suma importancia. Se mencionan aquí algunas de ellas y se explican en función de ser luego requeridas para un completo entendimiento de esta investigación.

Las características que se abordarán serán: calidad (calidad de producto y calidad en uso), aceptabilidad, utilidad, usabilidad y accesibilidad.

\subsubsection{Calidad}

Actualmente la usabilidad está reconocida como un atributo de calidad del software, habiéndose ganado un lugar importante entre los atributos tradicionales [Fer2001]. De modo general, podemos definir a la calidad de un producto o servicio como la totalidad de las características que le confieren aptitud para satisfacer necesidades establecidas e implícitas [ISO1995]. Del mismo modo, el estándar ISO/IEC 9126 [ISO2001] reconoce que el objetivo de calidad del software es satisfacer las necesidades del usuario, tanto explícitas como implícitas [Gon2001]. En particular, para los productos de software, la calidad es la concordancia del software producido con los requisitos funcionales y de rendimiento, explícitamente establecidos, con los estándares de desarrollo documentados, y con las características implícitas que se espera de todo software desarrollado profesionalmente [Pre1995].

Sin embargo, desde el punto de vista del usuario, no hay consenso sobre la definición de cuáles son los factores de calidad relacionados [Mon2005]. En el caso particular de productos Web, esto tiene su explicación en que la evaluación de calidad no es para nada sencilla, en función de que es difícil considerar todas las características y atributos deseables y obligatorios. Para ello, es necesario contar previamente con un modelo de calidad que permita a los evaluadores especificar ordenadamente dichas características y atributos [Gon2001]. La calidad es de gran importancia, puesto que evitará al usuario pérdidas de tiempo (eficiencia), le posibilitará concentrarse en las tareas más que en las herramientas (productividad), reducirá considerablemente los errores humanos 
provocados por inconsistencias, ambigüedades o diseños deficientes, y mejorará la aceptación del sistema [Bev1999].

El concepto de calidad del software, en particular de calidad Web, es la suma de muchos otros conceptos observables directa o indirectamente [Cat2000][Lei2003]. Si bien hay distintas propuestas sobre cuáles son esos atributos, los más recurrentes apuntan a definir la calidad desde la perspectiva del usuario y de los desarrolladores, a través de un alto nivel de abstracción. Mc Call [McC1977] plantea un modelo normalizado para poder evaluar y comparar productos sobre la misma base. Los conceptos utilizados en las propuestas más importantes como, la ISO/IEC 9126 [ISO2001], giran alrededor de conceptos tales como: usabilidad, funcionalidad, fiabilidad, eficiencia, mantenibilidad y portabilidad [ISO2001][Lei2003]. A su vez, cada una de estas características están definidas por sub-características, de menor nivel de abstracción, y atributos en consideración de una meta de evaluación y un perfil de usuario dados [Gon2001].

La calidad de un sistema se distingue entre calidad de producto (inherente del software), y la calidad en uso (producto en uso) [ISO1998a]. Por calidad de producto se entiende a la calidad interna y a la externa [Ghe1991][ISO2001]. Es decir que tenemos:

1. Calidad de producto:

i. Calidad Interna: que se mide a partir de las características intrínsecas como las propiedades estáticas del código fuente.

ii. Calidad externa: que se mide por las propiedades dinámicas del código cuando éste se ejecuta, en el comportamiento del producto.

2. Calidad en uso: que se mide en función de las percepciones, reacciones y necesidades del usuario en el entorno de trabajo para el que fue construido, es decir, durante la utilización efectiva por parte del usuario.

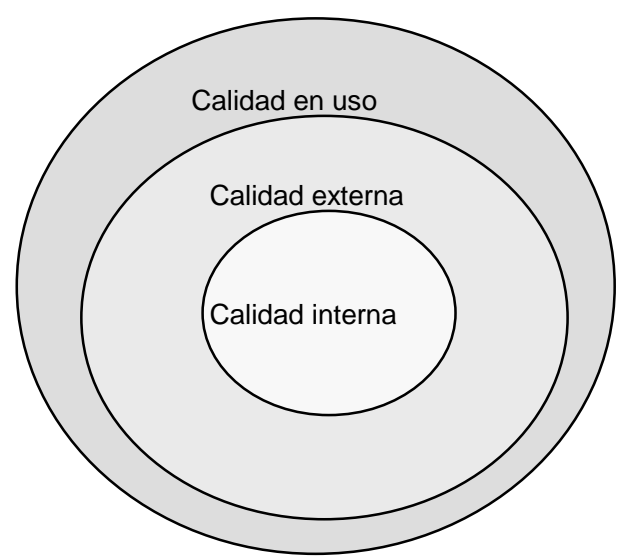

Figura 1 - ISO/IEC 9126-1: Calidad de un sistema

Estos tres tipos de calidad en el desarrollo de software, son extrapolables a las aplicaciones Web [Lei2003]. Se podría considerar a la calidad como un modelo de capas donde la calidad interna forma la capa interior, la externa forma una capa intermedia, y la calidad en uso la capa de más afuera [Bev1999][ISO2001]. Los tres tipos de calidad están muy relacionados entre sí, ya que la calidad en uso es dependiente de la calidad externa, la que a su vez depende de la calidad interna. Es decir que, para poder alcanzar calidad en uso, hay que alcanzar previamente calidad externa e interna. La calidad interna representa el modo en el que la calidad externa pueden ser alcanzada, es decir, las calidades internas implementan (son un modo para realizar) las calidades externas [Ghe1991]. Las mediciones se requieren normalmente en los tres niveles, ya que alcanzar criterios para mediciones internas no resulta suficiente para asegurar alcanzar criterios 
para mediciones externas. A su vez, lograr satisfacer criterios para mediciones externas de sub-características no es normalmente suficiente para asegurar alcanzar criterios de calidad en uso [ISO2001]. La evaluación de la calidad interna y externa (calidad de producto) están en manos de los desarrolladores, mientras que la evaluación de la calidad en uso es competencia de los usuarios del producto. En definitiva, la calidad no es un concepto absoluto, y depende de condiciones y contextos de uso específicos, para usuarios específicos.

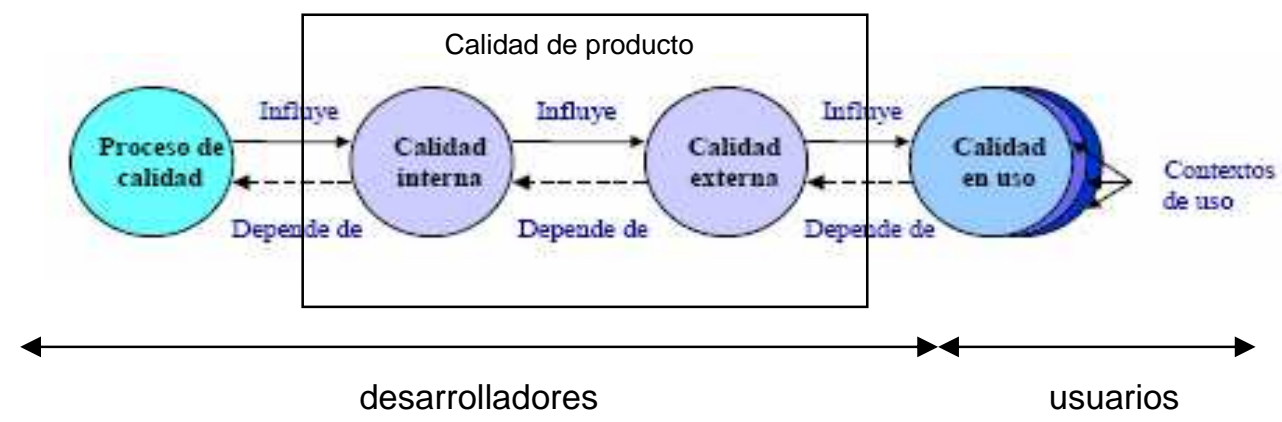

Figura 2 - ISO/IEC 9126-1: La calidad en el ciclo de vida

El estándar de calidad de los productos software ISO/IEC 9126 [ISO2001], es uno de los más importantes en este tema y está dividido en 4 partes. En su parte 1 especifica el modelo de calidad de producto, en la 2 proporciona las métricas ${ }^{2}$ externas, en la parte 3 las métricas internas y en la 4 las de calidad en uso. Como complemento a este estándar se definió la norma ISO 14598 que establece el proceso de evaluación del producto software [Gon2006].

\subsubsection{Calidad de producto}

Como se ha señalado, la calidad de producto se conforma de la calidad interna y externa. La calidad interna está definida como "la totalidad de atributos de un producto que determina su capacidad de satisfacer necesidades explícitas e implícitas cuando es usado bajo condiciones específicas" [ISO2001], pero sin considerar su comportamiento y entorno. Se refiere a las propiedades estáticas del código. Puede ser medida y evaluada por medio de atributos estáticos de documentos, tales como especificación de requerimientos, arquitectura o diseño, piezas de código fuente, etc. La calidad interna se debe asegurar en las etapas de desarrollo del software [ISO2001].

La calidad externa es "el grado en que un producto satisface necesidades explícitas e implícitas cuando se utiliza bajo condiciones especificadas" [ISO2001]. Se refiere a las propiedades dinámicas del código, cuando se está ejecutando en un entorno generalmente simulado. Puede ser medida y evaluada durante la etapa de prueba 0 cuando un módulo, o la aplicación completa, se está ejecutando en un ambiente real, pero sin la presencia del usuario final.

La calidad de producto, desde el punto de vista del usuario, está definida por las características denominadas usabilidad, funcionalidad, confiabilidad, eficiencia, mantenibilidad y portabilidad [ISO2001]. A su vez, cada una de las características se descompone en sub-características y atributos, de acuerdo a la meta de evaluación y al perfil de usuario [Gon2001].

\footnotetext{
${ }^{2}$ Métrica: una medida cuantitativa del grado en que un sistema, componente o proceso posee un atributo dado [Eji1991].
} 
A continuación se describen brevemente cada una de dichas características y sus respectivas sub-características. La Figura 3 muestra un cuadro resumen de esta clasificación.

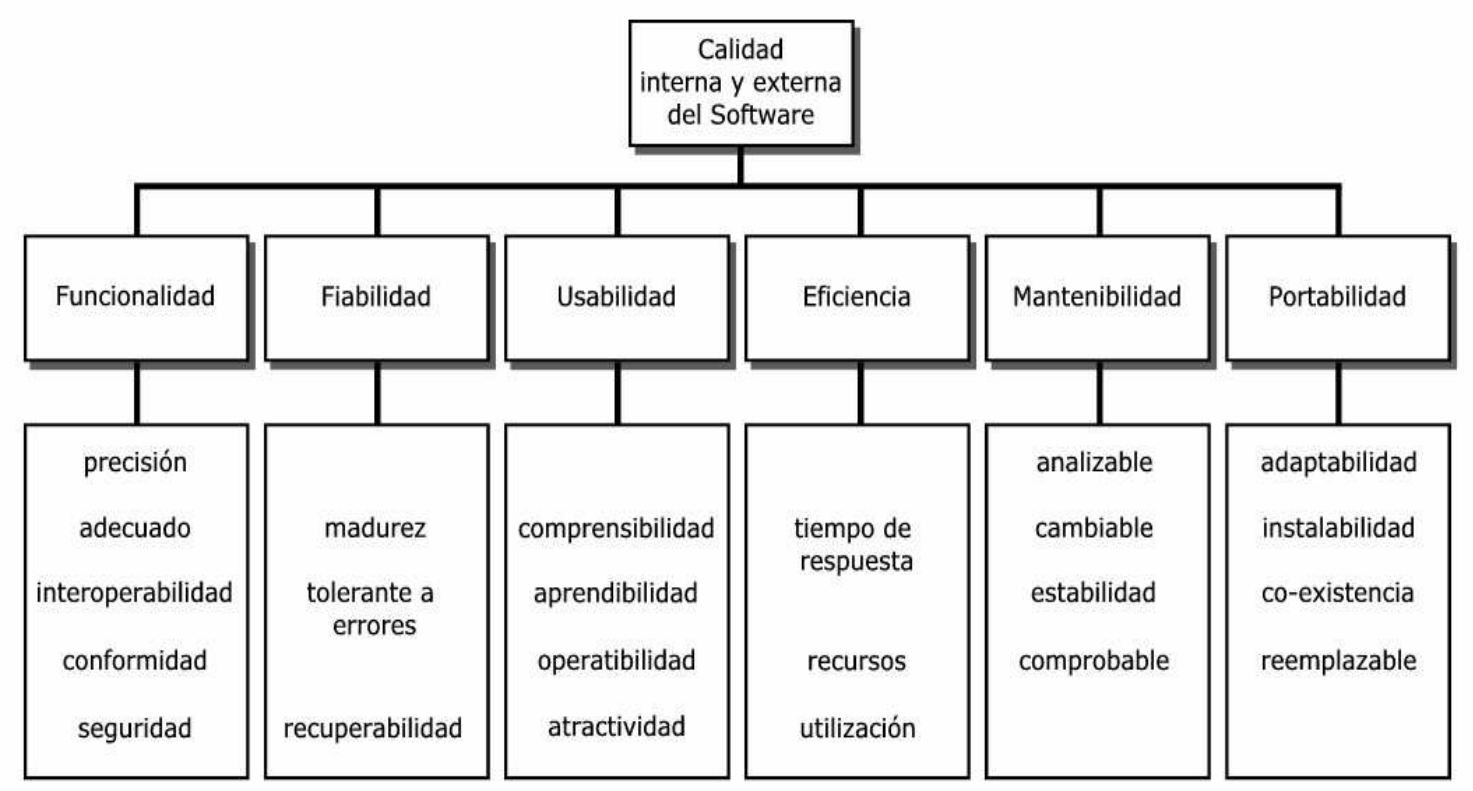

Figura 3 - ISO/IEC 9126-1: Modelo de calidad para calidad interna y externa

\subsubsection{Calidad en uso}

El estándar ISO/IEC 9126-1 define la calidad en uso como "la capacidad de un producto de software de facilitar a usuarios específicos alcanzar metas específicas con eficacia, productividad, seguridad y satisfacción en un contexto específico de uso" [ISO2001]. Agrega además que "calidad en uso es la visión de calidad de los usuarios de un ambiente conteniendo software, y es medida sobre los resultados de usar el software en el ambiente, antes que sobre las propiedades del software en sí mismo" [ISO2001]. En otras palabras es la calidad percibida por los usuarios en contextos reales de uso de productos software [Cov2005].

Las características de calidad en uso para productos de software son agrupadas en cuatro categorías [ISO2001]:

- Eficacia: la capacidad para facilitar a los usuarios alcanzar metas específicas con exactitud y completitud en un contexto específico de uso.

- Productividad: la capacidad para invertir la cantidad apropiada de recursos en relación a la eficacia alcanzada en un contexto específico de uso.

- Seguridad: la capacidad para alcanzar niveles aceptables de riesgo de dañar a las personas, el negocio, el software, la propiedad o el ambiente en un contexto especifico de uso.

- Satisfacción: la capacidad para satisfacer a los usuarios en un contexto específico de uso. Es la respuesta del usuario a la interacción con el producto, e incluye la actitud hacia el uso del producto.

Esta definición integra a la calidad con las necesidades de una clase de usuario específico que puede alcanzar metas específicas en un ambiente particular de trabajo. En el contexto de un proceso para alcanzar altos niveles de calidad de un software, los atributos de calidad interna y externa deberían ser el medio, y la calidad en uso el fin, el objetivo a alcanzar [Cov2005]. 
La calidad en uso se asocia en muchos casos a usabilidad, y podrían utilizarse como sinónimos. Lo discutiremos más adelante.

\subsubsection{Aceptabilidad}

Desde otra perspectiva, la usabilidad puede formar parte de la aceptabilidad de un software. La aceptabilidad de un software es una combinación de su aceptabilidad social y práctica [Nie1993]. La aceptabilidad social tiene que ver con la aceptación que un grupo de usuarios puede otorgarle a un sistema. Esto depende del objetivo con el cuál el software será utilizado y si su uso tiene un buen propósito. La aceptabilidad práctica es más compleja, ya que depende de otras variables como la utilidad (utilización, aprovechamiento o usefullness en inglés), los costos, la compatibilidad con otros sistemas, la confiabilidad, el soporte, etc. [Zur1999]. La utilidad está vinculada al hecho de que el sistema pueda ser usado para alcanzar alguna meta deseada. A su vez, está determinada por la utilidad funcional (utility), conjugada con la usabilidad (usability). La utilidad funcional se refiere a si el sistema hace lo que es necesario que haga, es decir, si responde a las metas para las que el sistema fue creado. La usabilidad busca analizar cuán bueno es un sistema para satisfacer todas las necesidades y requerimientos de los usuarios.

Algunos autores incorporan a la accesibilidad como otro factor clave de la utilidad cuando nos referimos a sistemas que funcionan vía Web [Gra2005]. Ello se debe al hecho de que una de las mayores ventajas de la Web está dada por su universalidad, y por lo tanto, la aceptación del software también depende de que posibilite el acceso universal. Todos los factores que contribuyen a la aceptabilidad de un software se pueden representar por medio del modelo jerárquico de la figura 4, propuesto por Nielsen [Nie1993] y extendido por Granollers [Gra2005].

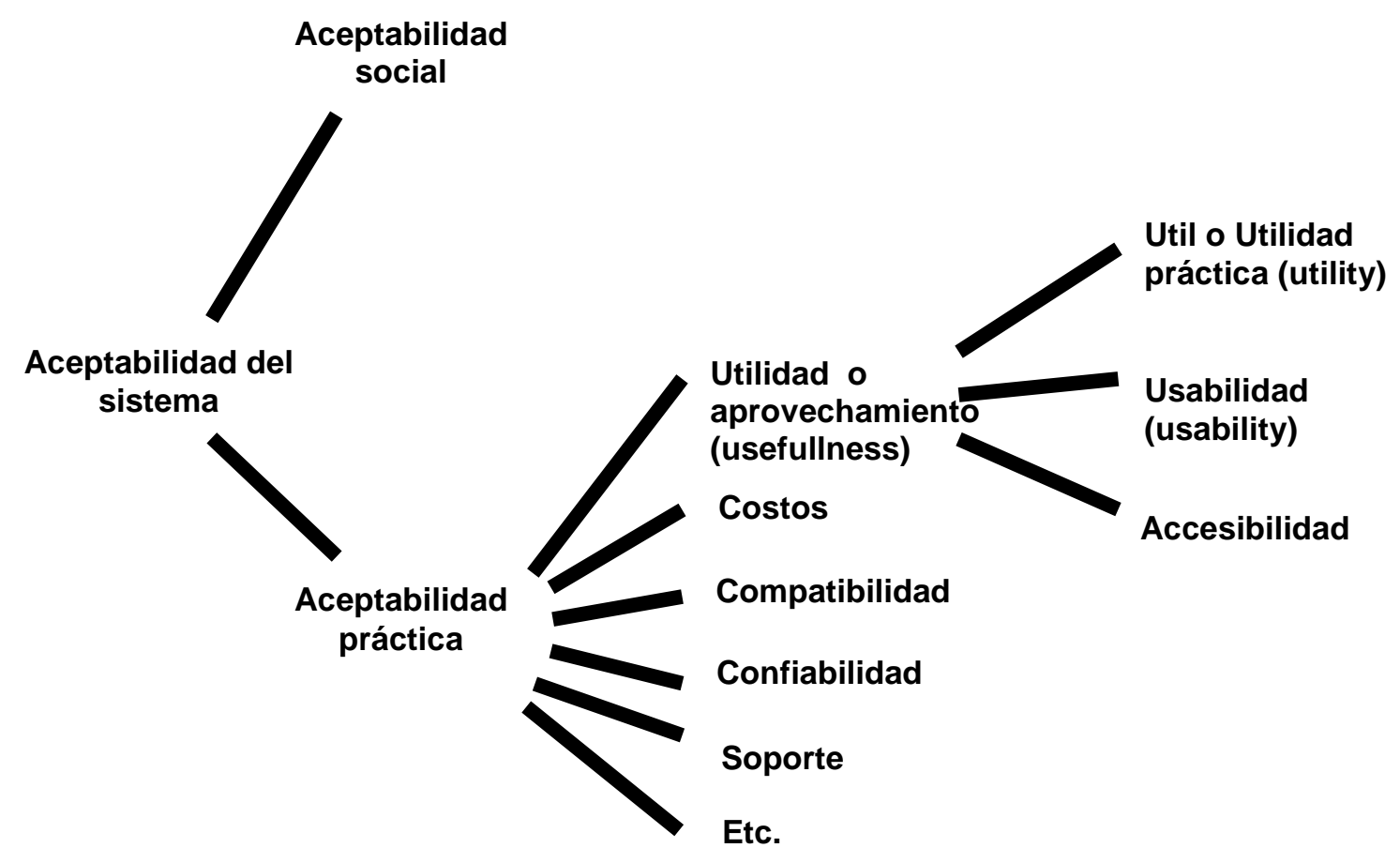

Figura 4 - Factores que definen la aceptabilidad de un sistema interactivo 
Por ejemplo, las aplicaciones desarrolladas para uso educacional son muy útiles si sus usuarios aprenden por medio de ellas, al igual que los juegos u otros programas con fines de entretenimiento son útiles si sus usuarios disfrutan de ellos. Por lo tanto, la usabilidad también se asocia al grado de aceptación de un producto [Nie1993].

\subsubsection{Utilidad}

La utilidad se basa en dos pilares: por un lado la consecución de los servicios que el producto quiere proporcionar, y por otro lado, la forma en que esos servicios son proporcionados. El primero trata de proporcionar un medio para lograr un objetivo, y el segundo el modo en que los usuarios pueden tomar contacto con la funcionalidad [Flo2000][Mon2006]. La usabilidad cubre ambas vertientes, y el éxito en su consecución depende de cómo sean tenidas en cuenta las necesidades del usuario, tanto explícitas como implícitas.

El concepto de usabilidad tiene implicaciones asociadas con la utilidad que ofrece el producto [Fer2001]. La utilidad está relacionada con las necesidades del usuario. Si un producto no es útil para el usuario, la usabilidad del mismo carece de importancia puesto que dicho producto no será utilizado [Cat2000].

La utilidad puede definirse como la capacidad de una herramienta de ayudar a cumplir tareas específicas. Una herramienta que es muy usable para una tarea, puede ser muy poco usable para otra similar [Mer1999].

Específicamente en lo que respecta al software, la utilidad tiene una componente de utilidad funcional (utility), definida por lo que el software puede hacer (requisitos funcionales), y otra componente de usabilidad (usability), basada en cómo los usuarios pueden utilizar dicha funcionalidad (de una forma sencilla, eficiente, etc.).

También se entiende a la utilidad como el valor que alguien le da a algo. Una herramienta, por sí sola, no es útil sino que depende de su capacidad de ofrecer mejoras al usuario, en la forma en que se realizan las tareas y de ayudarlo a pensar, comunicarse, observar o decidir [Cat2000]. El concepto de utilidad se refiere al grado en que un producto ofrece la posibilidad al usuario de conseguir sus metas, y como valoración de la motivación del usuario por utilizar ese producto [Rub94].

Algunos autores plantean que la utilidad no tiene por qué ir de la mano de la usabilidad, pero la primera es condición necesaria para la segunda [Cob2005]. La utilidad se refiere a si las funcionalidades del sistema permiten hacer lo que es necesario, en cambio la usabilidad está relacionada con la forma en que los usuarios pueden utilizar esa funcionalidad [Nie1993]. La relación entre estos dos conceptos puede situarse dentro de uno de los siguientes casos:

1) Baja utilidad y baja usabilidad

2) Baja utilidad y alta usabilidad

3) Alta utilidad y baja usabilidad

4) Alta utilidad y alta usabilidad

Los casos que interesan realmente son el 3 y el 4 . Si un producto no es útil, se situará dentro de los casos 102 , y por lo tanto no interesará demasiado saber si es usable y no.

Otros autores señalan que utilidad y usabilidad son conceptos diferentes, pero que no pueden disociarse porque su relación es de mutua dependencia. La usabilidad representa el grado en que el usuario puede explotar la utilidad, y también el grado en que esta utilidad es percibida por el usuario [Has2009]. Por ello, no es posible hablar de usabilidad 
y utilidad como factores desconectados o independientes [Dil1999]. Sería un error creer que lo que motiva el uso de un producto o aplicación es su usabilidad. Los usuarios no buscan usabilidad, buscan utilidad, entendida como el aprovechamiento, beneficio e interés que produce su uso [Has2009]. En otras palabras, lo que motiva al usuario es la capacidad que percibe del producto para resolver sus necesidades o deseos. De hecho, no sólo la utilidad es dependiente de la usabilidad, pues la dependencia también se produce en sentido contrario. Podemos afirmar que un producto o aplicación será usable en la medida que el beneficio obtenido al usarlo (utilidad) justifique el esfuerzo necesario para su uso (aprendizaje, atención, tiempo, etc.) [Has2009].

\subsection{Usabilidad}

\subsubsection{Origen}

El término usabilidad es algo controvertido. Si bien no es una palabra incluida en el diccionario de la lengua castellana, es utilizada ampliamente por los especialistas relacionados con este tema [Cob2005]. Usabilidad es la traducción de usability. Esta palabra tiene origen latino, uti, que está relacionado con los conceptos de práctica, utilidad, provecho, uso, usar a menudo, y bilis, que significa capacidad, posibilidad o facilidad de hacerse la acción [Cob2005]. Este término en español significa capacidad de uso, es decir, la característica que distingue a los objetos diseñados para su utilización de los que no lo son. Sin embargo, la acepción inglesa es más amplía y se refiere a la facilidad o nivel de uso, es decir, al grado en el que el diseño de un objeto facilita o dificulta su manipulación [Man2002]. Otras traducciones posibles de usability son amigabilidad, operatibilidad, ergonomía, o manejabilidad. La razón por la que se utiliza la palabra usabilidad, en lugar de cualquier otra, es porque se trata de la traducción literal del concepto usability, ampliamente aceptado por la comunidad de investigadores [Boo89].

Es decir que la usabilidad tiene dos perspectivas, una centrada en la facilidad de uso y otra centrada en la funcionalidad de un sistema o herramienta. Significa, por lo tanto, centrarse en la audiencia potencial y estructurar el sistema o herramienta según sus necesidades, y organizar el diseño y los contenidos de forma que permitan cumplir los objetivos para los que se ha desarrollado [Gra2005].

\subsubsection{Concepto general}

El concepto de usabilidad carece de definiciones perfectamente asentadas al contexto de la Web. Dentro de este ámbito aún se está descubriendo de qué se trata [Cat2000][Bra2003]. Puede ser analizado desde diferentes enfoques: desde el proceso de desarrollo, desde las características del producto terminado, desde el usuario, entre otros. [Kei2003].

\subsubsection{Idea intuitiva}

La usabilidad podría definirse coloquialmente como: "lo fácil de utilizar que es" [Nie1993], "la propiedad que tiene un determinado sistema para que sea fácil de usar o de utilizar y de aprender" [Sch1998], "facilidad de uso, ya sea de una página o sitio Web, una aplicación informática o cualquier otro sistema que interactúe con un usuario" [Man2003], "la característica de un sistema que pretende ser utilizado por el rango más amplio de personas, en el conjunto más extenso de situaciones" [ISO2001] o "un atributo de calidad que mide lo fáciles de usar que son las interfaces Web" [Nie2003]. 
Sin embargo estas definiciones no están completas ya que el término usabilidad engloba muchas más connotaciones. Centrar la usabilidad principalmente a la facilidad de uso es restringir el concepto para referirse específicamente a las características de un producto que lo hacen fácil de usar, cuando los atributos requeridos para hacer a un producto más o menos usable dependen también del contexto de uso [San2001][Gra2005][Mon2006].

\subsubsection{Primeros acercamientos}

La usabilidad es un atributo de suma importancia para los sitios Web debido a que las instituciones ofrecen cada día mayor cantidad de información, y servicios, a través de la red. En este sentido, la usabilidad se ha transformado en un factor estratégico fundamental para conseguir el máximo aprovechamiento de los recursos. Por estos motivos se la considera cada vez más como parte del proceso del desarrollo del producto [Kei2003]. En el ámbito de la Web, se la trabaja como una disciplina relacionada con la Ingeniería de Software, que estudia la forma de diseñar sitios para que los usuarios puedan interactuar con ellos de la forma más fácil, cómoda e intuitiva posible [Mon2002]. Se trata de una mirada orientada al proceso.

Otro acercamiento posible a la usabilidad es como un atributo de calidad de un producto [Kei2003] más que del proceso, una típica calidad externa [Ghe1991]. La usabilidad es la calidad del sitio Web según la perciben los usuarios que acceden. Resulta más relevante cuanto más novato es el usuario, y debe poder usar el producto sin ser obligado a aprender términos y conceptos extraños para él [Ghe1991]. El contenido debe presentarse de manera clara, con un lenguaje simple y con mecanismos obvios de navegación para moverse entre las páginas. El usuario debe encontrarse a gusto mientras utiliza el producto. Además incluye aspectos como la facilidad de aprendizaje, o la posibilidad de realizar búsquedas [Rom2001]. Un sitio Web con buena usabilidad debería permitir que cualquier persona con conocimientos o habilidades medias, pueda navegar por él y cumplir con sus propósitos de la manera más natural posible [Kru2000].

A menudo se habla del grado de usabilidad de un sistema valorándolo en una escala cualitativa (por ejemplo: bajo, medio, alto) o cuantitativa (por ejemplo: 1 a 100\%). El grado de usabilidad es una medida empírica y relativa de la usabilidad del producto. Es empírica porque se basa en pruebas realizadas en laboratorio u observadas mediante trabajo de campo. Es relativa porque el resultado no es ni bueno ni malo, sino que depende de las metas planteadas o de una comparación con otros productos similares.

Hasta hace poco, se asumía que la usabilidad era una propiedad exclusiva de la presentación de la información, es decir, la capa decorativa del producto. Se creía que encapsulando la capa de presentación y separándola del resto, se podía desarrollar la aplicación y obtener altos grados de usabilidad. Sin embargo, este modelo de desarrollo ha fracasado debido a que muchos problemas de usabilidad requieren realizar cambios profundos en la funcionalidad de una aplicación [Cas2004].

Además de la presentación de la información, conocida como look and feel, la usabilidad de una interfaz debe ser analizada también desde el modelo de usuario [Ber2000]. El modelo de usuario está constituido por los objetivos que el usuario quiere alcanzar con sus tareas. Se relaciona con el modelo de objetos propio de la interfaz de usuario, que incluye, entre otras cosas, los objetos y las metáforas de la interfaz. Este modelo de objetos es el que permite al usuario relacionar sus objetivos con la funcionalidad del sistema. La usabilidad se compara con un iceberg, donde los aspectos relacionados con la presentación afectan en un $40 \%$ a la usabilidad (10\% el aspecto visual y $30 \%$ aspectos interactivos), y el $60 \%$ restante está influenciado por el modelo de usuario, que está 
constituido por los objetivos que el usuario quiere alcanzar con sus tareas [Ber2000]. Es decir, la mayor parte de los aspectos que involucran a la usabilidad no están a la vista, por lo cual para conseguir una buena usabilidad no basta con tener en cuenta solo la capa de presentación, sino que es preciso que se contemple también en el momento de la definición de la funcionalidad de la aplicación [Cas2004].

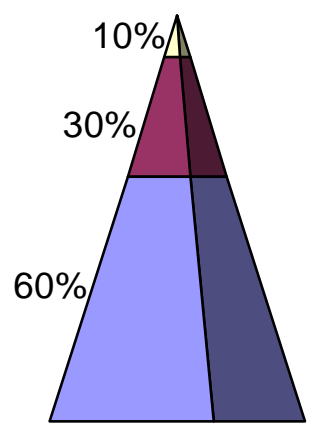

$\square$ modelo de usuario $\square$ presentación - aspecto interactivo $\square$ presentación - aspecto visual

Figura 5 - Aspectos que involucran a la usabilidad

\subsection{La usabilidad como parte del proceso de desarrollo}

La calidad es un modelo de tres capas fuertemente relacionadas, como ya se expresó, donde la capa superficial es la calidad en uso, la intermedia es la calidad externa y la interior es la calidad interna. A los efectos de que la usabilidad sea tenida en cuenta como un requisito del software no hay otro camino que incorporarla dentro del ciclo de vida del mismo, desde el inicio del proceso hasta la puesta en funcionamiento [Mon2006]. De esta forma, la usabilidad pasa a formar parte del proceso de desarrollo apoyándose en las dos capas no superficiales, es decir la externa y la interna.
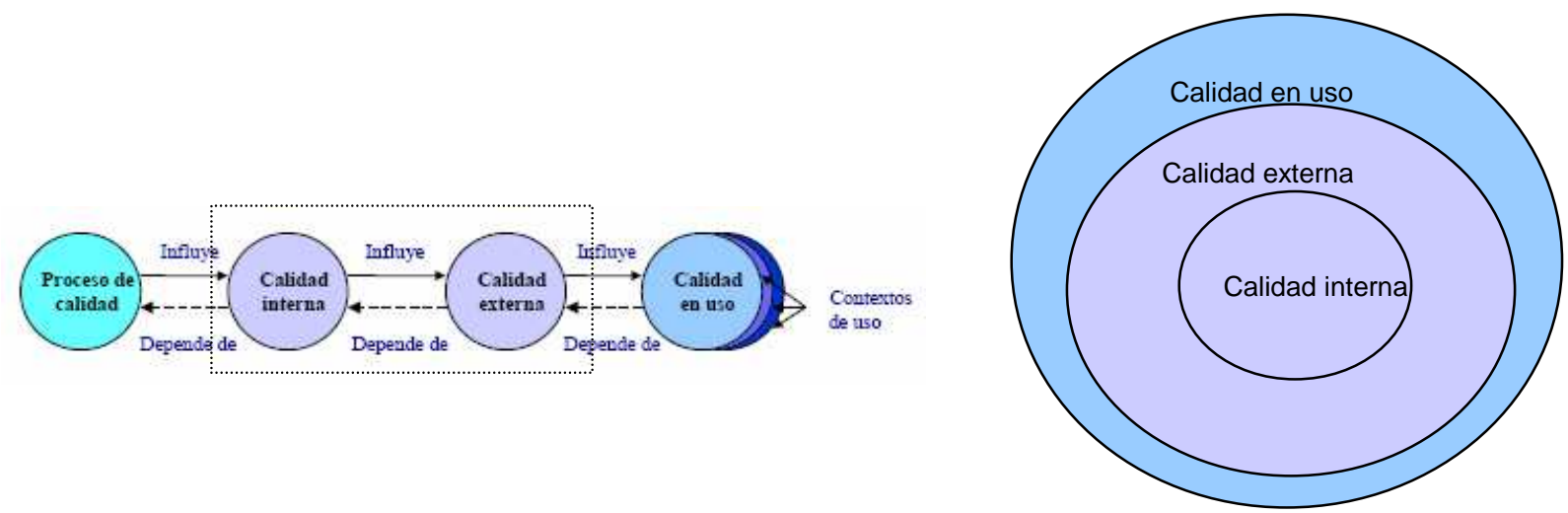

Figura 6 - La usabilidad como parte del proceso de desarrollo

\subsection{Diseño centrado en el usuario}

La usabilidad es una característica de calidad que debiera ser considerada en todo momento, incorporando evaluaciones de esta en cada etapa de desarrollo para asegurar un producto con altos niveles de usabilidad [Bae2002][Mon2006]. Esto implica que antes de iniciar el desarrollo, es esencial, tener una idea acerca de las características de los usuarios y de los aspectos del producto de mayor interés y necesidad.

La usabilidad debiera partir de los principios del diseño universal o el diseño para todos. En este sentido tiene una vinculación con la accesibilidad (aspecto que trataremos en una 
sección posterior). El diseño de la funcionalidad debe ser dirigido para y con los usuarios [Bae2002], y no centrarse únicamente en el uso [Mon2006]. Buenos niveles de usabilidad pueden lograrse mediante, lo que se conoce como, el diseño centrado en el usuario. Este método es contrapuesto al diseño centrado en la tecnología o al diseño centrado en la creatividad $u$ originalidad. Centrarse en el usuario significa contemplar lo que el usuario quiere, sus necesidades, tanto explícitas como implícitas, conocer sus características y el contexto en el que se mueve. Las condiciones de trabajo también pueden decantar la elección entre determinadas opciones. El usuario se sentirá satisfecho cuando vea que puede realizar lo que desea de forma fácil, intuitiva, sin saturarse ni desorientarse. En definitiva el usuario será el que tenga la última palabra y el que determine si un producto es fácil de usar o no [Mon2006].

Los métodos de diseño centrado en el usuario nos permiten lograr metas de usabilidad mucho más altas que las que podríamos lograr aplicando sólo la intuición, las recetas, o calculando lo que nosotros suponemos que los usuarios harán con el producto [Bae2002]. Es decir, la usabilidad y el diseño centrado en el usuario van de la mano.

Muchas de las técnicas, se basan en involucrar a los usuarios en todas las etapas del desarrollo. Los usuarios pasan a ser el foco de atención y las funcionalidades del sistema se implementan de acuerdo a sus características [Gra2005].

El diseño centrado en los usuarios posee las siguientes características [Gra2005]:

- Dirigido por el usuario.

- Enfocado por la solución.

- Conformado por equipos de trabajo multidisciplinares que incluyen a usuarios, desarrolladores, expertos en usabilidad, en interfaces, etc.

- Enfocado por los atributos de usabilidad: efectividad, eficiencia y satisfacción.

- Basado en una definición de la calidad que involucra la usabilidad.

- Basado en soluciones acordes a partir de la comprensión del contexto de uso: usuarios, tarea, y entorno.

\subsection{Ingeniería de Usabilidad}

La usabilidad ha pasado a cobrar importancia en el área ingenieril a punto tal de ser tenida muy en cuenta en el proceso de desarrollo de software. La Ingeniería de Usabilidad es un área de la Human Computer Interaction $(\mathrm{HCl})$ que da pautas para obtener productos con un alto grado de usabilidad mediante la aplicación de distintos métodos en diferentes etapas del proceso de diseño y desarrollo, de una manera estructurada y sistemática [Lec1998]. Se puede definir como una aproximación al desarrollo de sistemas en la que se especifican niveles cuantitativos de usabilidad [Kei2003].

La Ingeniería de Usabilidad proporciona un modo práctico de asegurar que el software desarrollado alcance un cierto nivel de usabilidad e involucra la evaluación mediante test de usabilidad con participación principal de los usuarios. En Ingeniería de Usabilidad se trata de decidir qué atributos del concepto de usabilidad deben de ser priorizados, con el fin de lograr metas verificables y medibles en relación a esta característica. Por ejemplo [Bae2002]:

- Medir el desempeño de un usuario ejecutando una serie de tareas específicas, con respecto al tiempo de terminación de las tareas o en base al número de errores cometidos.

- Determinar los niveles de preferencia subjetiva o el grado de satisfacción. 
- Medir la facilidad de aprendizaje en base al número de tareas completadas en cierto periodo, número de errores cometidos, o respecto al número de veces que utilizó la opción de ayuda.

Es un área que está cobrando cada vez mayor importancia y donde hay mucha investigación. Algunas de las investigaciones apuntan a mejorar la usabilidad de los sistemas aplicando un proceso específico de rediseño. La investigación llevada a cabo dentro del proyecto STATUS (SofTware Architectures That support USability) [STA2001] de la Unión Europea, relacionado con el desarrollo de técnicas y procedimientos para mejorar la usabilidad desde momentos tempranos del desarrollo de software, es un ejemplo en este sentido [Mor2004]. Esta aproximación propone centrarse en la posible mejora de la usabilidad en el momento del diseño de software, identificando lo que se ha denominado patrones de usabilidad.

Otros estudios sugieren una reestructuración de los modelos de desarrollo de software. Ello tiende a facilitar la inclusión de actividades vinculadas a la usabilidad en los modelos tradicionales, como el evolutivo y el incremental. También, se propone una metodología de diseño que agrupa ideas de Norman en una serie de pasos que facilitan la reflexión y evaluación en el diseño de interfaces [Say2003].

La integración del diseño centrado en el usuario es necesaria para comenzar a mejorar de forma sustantiva la usabilidad de las aplicaciones. Aunque se están dando pasos significativos en esta dirección, y el diseño de interfaces va mejorando, es necesario seguir introduciendo de forma sistemática la Ingeniería de Usabilidad.

\subsection{La usabilidad como un atributo del producto}

Otra perspectiva de la usabilidad, es aquella que evalúa el sistema una vez que ha concluido su proceso de desarrollo, intentando asignar valores a los atributos de usabilidad clásicos: aprendizaje, eficiencia, fiabilidad y satisfacción [Sha1991][Nie1993] [Con1999][Mor2004]. A eso se le llama usabilidad como un atributo del producto, donde la calidad evaluada es la capa superficial, es decir, la calidad en uso. Debido a que nuestro trabajo tiene como objetivo evaluar la usabilidad de productos ya desarrollados, tomaremos como perspectiva de análisis la usabilidad como un atributo del producto.
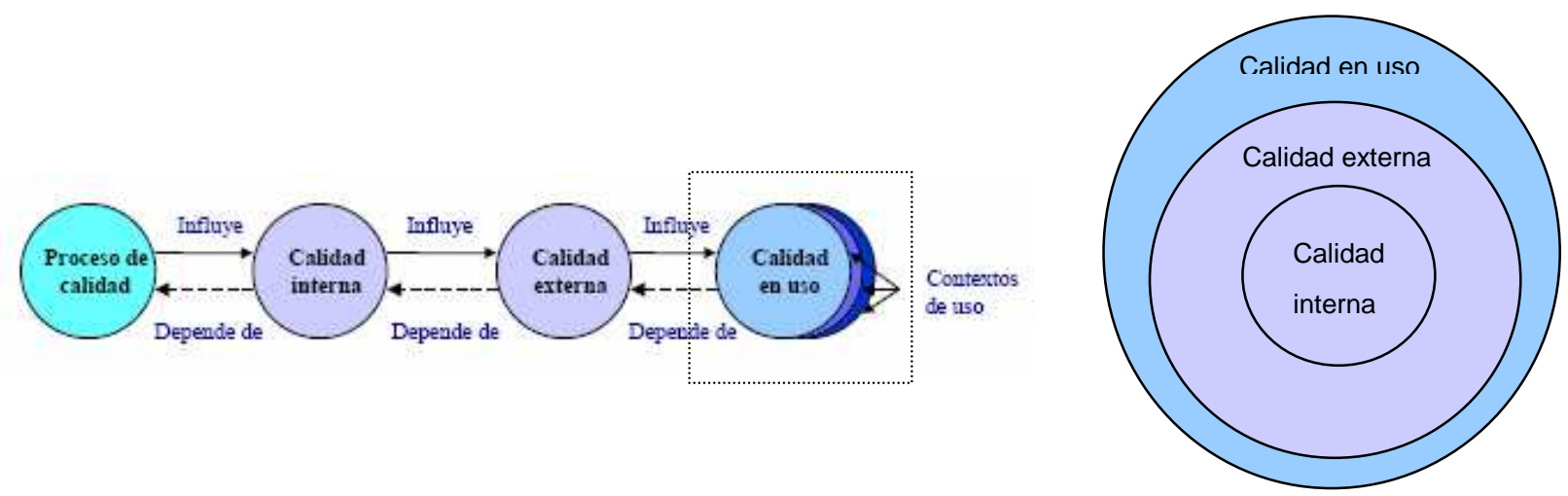

Figura 7 - La usabilidad como atributo del producto

\subsubsection{Definiciones}

Existen muchas definiciones del concepto de usabilidad, algunas generales como las presentadas anteriormente, y otras más específicas que son ampliamente citadas y 
reconocidas. A estas últimas haremos referencia a continuación realizando un apartado para cada una de las definiciones analizadas:

\subsection{ISO}

La Organización Internacional para la Estandarización (ISO) propone una serie de definiciones de usabilidad en sus estándares, que han ido evolucionando a lo largo del tiempo. Se dividen en dos tipos, los orientados al producto, denominadas ISO 9126-1 [ISO2001], ISO 14598 [ISO1999a] e ISO 25000 [ISO2005], y las orientadas al proceso: ISO 9241-11 [ISO1998b] e ISO 13407 [ISO1999b].

\subsection{ISO/IEC 9126-1}

ISO/IEC 9126 es un estándar para evaluar la calidad del software que está dividido en cuatro partes: ISO/IEC 9126-1, ISO/IEC 9126-2, ISO/IEC 9126-3 e ISO/IEC 9126-4.

El estándar ISO/IEC 9126-1 [ISO2001] define a la usabilidad como una de las características de calidad de producto, es decir, de calidad interna y externa. La usabilidad comparte la definición con otras cinco características: funcionalidad, fiabilidad, eficiencia, mantenibilidad y portabilidad. El estándar define a la usabilidad como la capacidad que tiene un producto software para ser entendido, aprendido, operable, atractivo para el usuario y conforme a estándares/guías, cuando es utilizado bajo unas condiciones específicas [ISO2001]. Considera que la usabilidad es un atributo que forma parte de la calidad del software. El término es utilizado para referirse a la capacidad de un producto para ser usado fácilmente. La usabilidad es analizada en términos de cinco subcaracterísticas: comprensibilidad, aprendizaje, operabilidad, atractividad y conformidad [Bev1997].
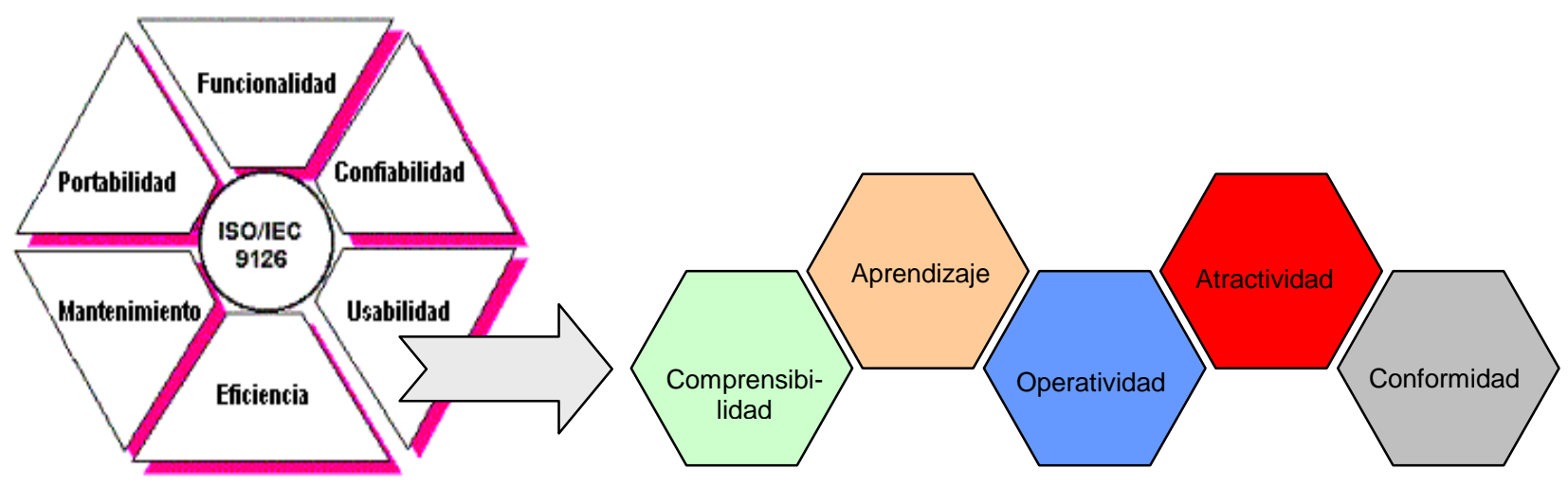

Figura 8 - Las seis características de calidad y las cinco subcaracterísticas de usabilidad

- Comprensibilidad: define la capacidad del producto software para permitir al usuario entender si el software es adecuado, y como puede ser usado para tareas y condiciones de uso particulares.

- Aprendizaje: referido a la capacidad del producto software para permitir a los usuarios aprender a usar sus diferentes posibilidades.

- Operabilidad: es la capacidad del producto software para permitir al usuario operarlo y controlarlo. Aspectos de conformidad, mutabilidad, adaptabilidad e instalación pueden afectar a la operabilidad. También este atributo corresponde a la tolerancia de error, y conformidad con las expectativas del usuario. En un 
sistema, sobre el que opera un usuario, la combinación de funcionalidad, confiabilidad, usabilidad y eficiencia pueden ser medidas externamente por la calidad en uso.

- Atractividad: es la capacidad del producto software para atraer y seducir al usuario. Está referido a los atributos del software tales como el uso de color y la naturaleza del diseño grafico.

- Conformidad: referido a la capacidad del producto software para adherirse a estándares, convenciones, guías de estilo o regulaciones relacionadas con la usabilidad.

Esta definición se basa en una evaluación de carácter cualitativa, hace énfasis en los atributos internos y externos del producto, los cuales contribuyen a su funcionalidad y eficiencia [Cat2000]. La usabilidad depende no sólo del producto sino también del usuario, no puede ser valorada estudiando un producto de manera aislada [Bev94]. Por ello, un producto no es en ningún caso intrínsecamente usable, sólo tendrá la capacidad de ser usado en un contexto particular y por usuarios particulares.

El estándar ISO/IEC 9126-2 [ISO2003] se encarga de describir las métricas externas que se pueden utilizar para evaluar el comportamiento del software cuando es operado por el usuario, el estándar ISO/IEC 9126-3 [ISO2003] describe las métricas internas que se pueden utilizar para describir propiedades estáticas de la interfaz, sin necesidad de poner en funcionamiento el software, mientras que el ISO/IEC 9126-4 [ISO2003] describe las métricas de calidad que se pueden utilizar para evaluar el efecto del producto software cuando son operados por el usuario en determinados contextos de uso. Las métricas definidas se denominan efectividad, productividad, seguridad y satisfacción.

Dado que el estándar ISO 9126 se limita a la especificación de un modelo de calidad general, éste debe aplicarse en conjunto con el estándar ISO 14598 que provee una serie de guías para la evaluación [Car2012], y que describiremos brevemente a continuación.

\subsection{ISO/IEC 14598}

El estándar ISO 14598 [ISO1999a] se denomina Information technology - Software product evaluation. Es el encargado de proporcionar un marco de trabajo para evaluar la calidad de cualquier producto software, e indica los requisitos para los métodos de medición y el proceso de evaluación. Está dividido en seis partes: ISO/IEC 14598-1, ISO/IEC 14598-2, ISO/IEC 14598-3, ISO/IEC 14598-4, ISO/IEC 14598-5, e ISO/IEC 14598-6.

El estándar ISO/IEC 14598-1 [ISO1999c] provee una visión general de resto y explica la relación entre la evaluación del producto software y el modelo de calidad definido en la ISO/IEC 9126 [Car2012]. EI ISO/IEC 14598-2 [ISO2000a] contiene requisitos y guías para las funciones de soporte, tales como, planificación y gestión de la evaluación del producto del software. El estándar ISO/IEC 14598-3 [ISO2000b] provee los requisitos y guías para la evaluación del producto software cuando la evaluación es llevada a cabo en paralelo con el desarrollo del mismo. EI ISO/IEC 14598-4 [ISO1999d] provee los requisitos y guías para que la evaluación del producto software sea llevada a cabo en función a los compradores que planean adquirir o reutilizar un producto de software existente 0 predesarrollado. El estándar ISO/IEC 14598-5 [ISO1998d] provee los requisitos y guías para la evaluación del producto software cuando la evaluación es llevada a cabo por 
evaluadores independientes. Por último, el estándar ISO/IEC 14598-6 [ISO2011] provee las guías para la documentación del módulo de evaluación.

\subsection{ISO 25000}

El estándar ISO 25000 [ISO2005] se denomina Software Quality Requirement Evaluation (SQUARE) y es una revisión de los estándares ISO/IEC 9126 e ISO/IEC 14598 con la intensión de unificarlos, cubrir una serie de necesidades no resueltas por ellos, y solucionar problemas causados por cambios en el entorno y el avance de las tecnologías de la información. Las diferencias principales son la introducción a un nuevo modelo de referencia general, guías dedicadas y detalladas para cada división, y elementos de medida de calidad. Se trata de un estándar de segunda generación que conserva las mismas características de calidad del software que ISO/IEC 9126 [Rui2009]. El objetivo principal que persigue es guiar el desarrollo de los productos de software con la especificación y evaluación de requisitos de calidad. Está dividida en cinco partes: ISO/IEC 2500n, ISO/IEC 2501n, ISO/IEC 2502n, ISO/IEC 2503n, e ISO/IEC 2504n [Car2012].

El estándar ISO/IEC 2500n está orientado a la gestión de calidad y definen todos los modelos comunes, términos y referencias a los que se alude en las cinco secciones restantes. El ISO/IEC 2501n presenta un modelo de calidad detallado, incluyendo características para la calidad interna, externa y en uso. El estándar ISO/IEC 2502n se dedica a las mediciones de calidad por lo que incluye un modelo de referencia de calidad del producto software, definiciones matemáticas de las métricas de calidad y una guía práctica para su aplicación. EI ISO/IEC 2503n ayuda a especificar los requisitos de calidad que pueden ser usados en el proceso de especificación de requisitos para un producto software que va a ser desarrollado ó como entrada para un proceso de evaluación. Finalmente, el estándar ISO/IEC $2504 n$ se destina a la evaluación proporcionando requisitos, recomendaciones y guías para la evaluación de un producto software, tanto para evaluadores, como clientes o desarrolladores.

\subsection{ISO 9241-11}

EI ISO 9241-11 [ISO1998b] es un estándar orientado al proceso denominado Ergonomic requirements for office work with visual display terminals (VDTs). Describe los requisitos ergonómicos para trabajo de oficina con terminales de despliegue visual y explica algunos de los principios básicos subyacentes. Su apartado 11, denominado Guidance on Usability, define como especificar y evaluar la usabilidad de productos y aquellos factores que tienen un efecto en la usabilidad desde el punto de vista ergonómico como parte de un sistema de calidad, por ejemplo, uno que sea conforme con el estándar ISO 9001 [Gra2005]. Posibilita que evaluadores, consultores, instituciones o empresas no involucrados en el desarrollo del producto puedan medir la usabilidad del mismo. En el año 2006 se le simplificó el nombre y se renumeraron sus partes para poder cubrir más temas como la interacción táctil, con formularios o interfaces Web [Car2012].

El estándar ISO 9241 define a la usabilidad como el grado de efectividad, eficiencia y satisfacción con la que un producto permite alcanzar objetivos específicos a usuarios específicos, en un contexto de uso específico [ISO1998b]. Se trata de una definición muy similar a la dada en el ISO 9126 para el concepto de calidad en uso, pero excluyendo la seguridad para las personas. 


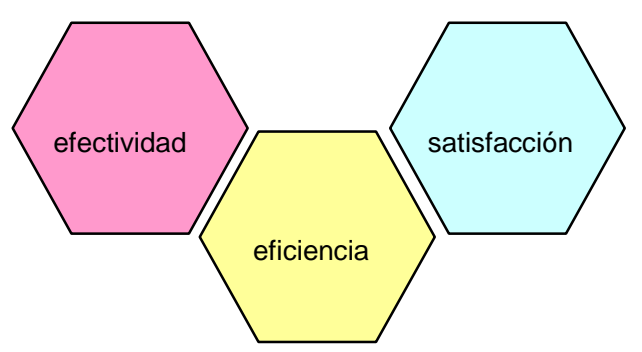

Figura 9 - ISO 9241-11: Usabilidad

Esta definición deja bien en claro que la usabilidad de un sistema está en directa relación con los usuarios, necesidades y condiciones específicas. Por tanto, la usabilidad del sistema no es un atributo inherente al software exclusivamente, y no puede especificarse independientemente del entorno de uso y de los usuarios concretos que vayan a utilizarlo. Para especificar o medir la usabilidad es necesario identificar las metas y descomponer la efectividad, eficiencia y satisfacción, así como los componentes del contexto de uso en sub-componentes con atributos medibles y verificables.

- Efectividad: se define la efectividad como la precisión y plenitud con que los usuarios alcanzan los objetivos especificados en un ambiente particular. Se asocia a la facilidad de aprendizaje en la medida en que esta sea lo más amplia y profunda posible, al control de errores y a la disposición del sistema para recordar las funcionalidades y los procedimientos.

- Eficiencia: hace mención a los recursos empleados en relación con la precisión y plenitud con que los usuarios alcanzan los objetivos especificados, es decir recursos de tiempo, financieros y humanos. El usuario desea que sus objetivos sean cumplidos realizando operaciones totalmente eficientes; es decir, que las tareas se desarrollen de la mejor forma posible. Se asocia también a la facilidad de aprendizaje, en tanto supone un coste en tiempo, así como al acceso continuo a mecanismos de ayuda, tasa de errores y facilidad del sistema para ser recordado, o sea para evitar una asimilación inapropiada que pueda traducirse en errores de usuario.

- Satisfacción: evalúa el confort o comodidad y la aceptabilidad del trabajo del sistema para sus usuarios y otras personas afectadas por su uso. Se relaciona con la ausencia de incomodidad y una actitud positiva en el uso del producto. Pese a que las tareas que se pueden hacer con la aplicación se resuelven de forma eficiente y eficaz para el usuario, puede que el producto no satisfaga plenamente al usuario. Se trata de un factor subjetivo.

- Contexto de uso: comprende a los tipos de usuarios, las tareas, el equipamiento y el entorno físico y social en que un producto es utilizado [San2001]:

a) Tipo de usuario: conocimientos, habilidades, experiencia, educación, entrenamiento, características físicas y capacidades motoras y sensoriales. En algunos casos puede ser necesario definir las características de diferentes tipos de usuario, por ejemplo, con diferentes niveles de experiencia, o que ejerzan diferentes roles.

b) Equipamiento: descripción del hardware, del software y documentos.

c) Entorno físico y social: características del entorno técnico, del entorno físico (lugar de trabajo, mobiliario), el entorno ambiental (temperatura y humedad) y el entorno social y cultural (prácticas de trabajo, estructura de la organización, actitudes).

El contexto de uso puede ser algo ya existente o bien referirse al de un futuro sistema proyectado. 


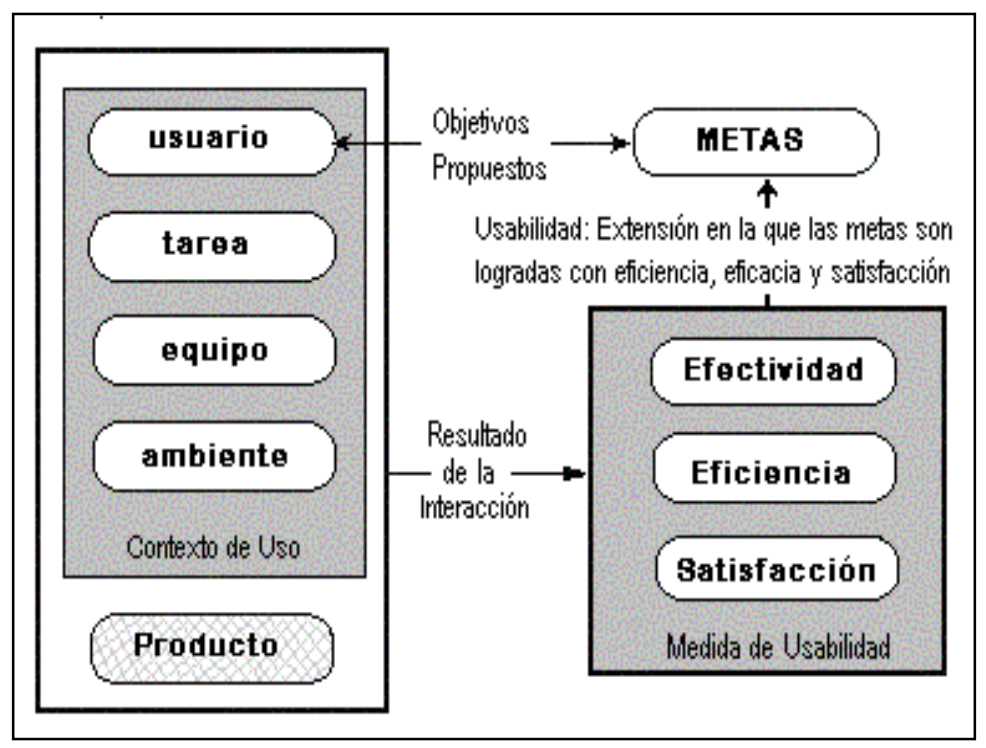

Figura 10 - Marco de trabajo de la Usabilidad

Esta definición se basa en una evaluación de carácter cualitativa que está centrada en el concepto de calidad en uso [Man2003]. La calidad en uso depende de todos los factores que pueden influenciar el uso de un producto en el mundo real: organizacionales (prácticas de trabajo, ubicación o apariencia de un producto), diferencias individuales entre usuarios (factores culturales y preferencias), experiencia, etc. Tiene la ventaja de concentrarse en los propósitos reales de diseño de una aplicación, que es encontrar las necesidades de usuarios concretos, ejecutando tareas reales en un ambiente técnico, físico y de organización real [Alv2005].

\subsection{ISO 13407}

El estándar ISO 13407 [ISO1999b] se denomia Human centred design processes for interactive systems. Proporciona una guía para alcanzar la calidad en el uso mediante la incorporación de actividades de naturaleza iterativa involucradas en el diseño centrado en el usuario. Luego de una década fue revisado por el estándar ISO 9241-210 [ISO2010] Ergonomics of human-system interaction - Part 210: Human-centred design for interactive systems, el cual describe seis principios clave que caracterizan al Diseño Centrado en el Usuario [Tra2011]:

- El diseño está basado en una comprensión explícita de usuarios, tareas y entornos.

- Los usuarios están involucrados durante el diseño y el desarrollo.

- El diseño está dirigido y refinado por evaluaciones centradas en usuarios.

- El proceso es iterativo.

- El diseño está dirigido a toda la experiencia del usuario.

- El equipo de diseño incluye habilidades y perspectivas multidisciplinares

Dado que el estándar ISO 9241-11 recomienda un enfoque basado en procesos para evaluar la usabilidad a través del Diseño Centrado en el Usuario, es conveniente aplicarla en conjunto con ISO 13407 [Car2012]. 


\subsection{Definición abordada por J. Nielsen}

La definición dada por la ISO 9241-11 es tomada como base para ampliar el concepto de usabilidad de un producto. Nielsen sugiere que la usabilidad es un término multidimensional que influye en la aceptación del producto [Nie1993]. Parte del concepto de utilidad, que es parte de la aceptabilidad práctica, la cual a su vez constituye un componente de la aceptabilidad del sistema.

Nielsen define usabilidad como la medición de la calidad de la experiencia del usuario en interacción con un sistema [Nie1993]. Al respecto dice que "la usabilidad se refiere a la capacidad de un software o sistema interactivo de ser comprendido, aprehendido, usado fácilmente y atractivo para un usuario, en condiciones específicas de uso. También es la efectividad, eficiencia y satisfacción con la que un producto permite alcanzar sus objetivos específicos" [Nie2000]. La usabilidad no es algo simple o una propiedad que ofrezca una única cara relacionada con la interfaz de usuario ofrecida, en contraposición, tiene múltiples componentes e involucra cinco atributos de calidad más específicos [Nie2003]:

1. Facilidad de aprendizaje: rapidez con la que los usuarios que no han usado nunca el software aprenden a realizar correctamente las tareas básicas. Se refiere a la consecución de tareas básicas por parte de un usuario novato.

2. Eficiencia o velocidad de desempeño: rapidez con la que los usuarios pueden realizar sus tareas una vez que han aprendido a manejar el software.

3. Recuerdo o retención en el tiempo: rapidez con la que los usuarios pueden volver a realizar las tareas que ya sabían, luego de un período prolongado de tiempo, sin necesidad de volver a aprenderlo todo de nuevo. El software debe posibilitar una curva de aprendizaje significativamente menor en el caso del usuario que alguna vez lo usó frente a aquel que por primera vez se enfrenta al mismo. Esto es de primordial importancia para sistemas usados intermitentemente.

4. Tasa de errores por parte de los usuarios: cuántos errores pueden cometer los usuarios al utilizar el software, gravedad de los mismos y la facilidad que presenta el software para que los usuarios se puedan recuperar ante un error. Una aplicación ideal evitaría que el usuario cometiera errores, y funcionaría de manera óptima frente a cualquier petición por parte del usuario. En la práctica esto difícilmente se logra.

5. Satisfacción: cuánto de agradable es utilizar el software para los usuarios. Es el atributo más subjetivo. Muestra la impresión que el usuario obtiene del sistema.

En sintonía con ello, Bevan, uno de los gestores de la definición de usabilidad en el estándar ISO 9241-11, define a la usabilidad como la "facilidad de uso y la aceptabilidad de un sistema o producto para una clase particular de usuarios que llevan a cabo tareas específicas en un entorno específico" [Bev1991].

\subsection{Definición abordada por Redish}

La definición de Redish, más orientada a la Web, se basa en la necesidad de diseñar sitios Web para que los usuarios sean capaces de "encontrar lo que necesitan, entender lo que encuentran y actuar apropiadamente... dentro del tiempo y esfuerzo que ellos consideran adecuado para esa tarea" [Red1999]. En este caso el término usabilidad no se refiere solamente a hacer que los sistemas sean simples, sino que abarca además la comprensión de los objetivos de los usuarios, el contexto de su trabajo, y cuál es el conocimiento y la experiencia de que disponen [Red1999]. Es decir, usabilidad significa 
que la gente que utilice un producto, pueda realizar rápida y fácilmente sus tareas. Esta definición descansa en cuatro puntos [Flo2000][Loz2003]:

1. Una aproximación al usuario: para desarrollar un producto usable se tiene que conocer, entender y trabajar con las personas que representan a los usuarios actuales o potenciales del producto.

2. Un amplio conocimiento del contexto de uso: las personas utilizan los productos para incrementar su propia productividad. Un producto se considera fácil de aprender y usar, en términos del tiempo que toma al usuario llevar a cabo su objetivo, el número de pasos que tiene que realizar para ello, y el éxito que tiene en predecir la acción apropiada para llevarla a cabo. Para desarrollar productos usables hay que entender los objetivos del usuario, hay que conocer los trabajos y tareas del usuario que el producto automatiza, modifica o embellece.

3. El producto ha de satisfacer las necesidades del usuario: los usuarios son gente ocupada intentando llevar a cabo una tarea. Se va a relacionar usabilidad con productividad y calidad. El hardware y el software son las herramientas que ayudan a la gente ocupada a realizar su trabajo y a disfrutar de su ocio.

4. El usuario tiene la última palabra: son los usuarios y no los diseñadores o los desarrolladores, los que determinan cuando un producto es fácil de usar.

\subsection{Definición abordada por Shackel}

Para este autor la usabilidad está circunscripta al concepto de aceptación, al igual que lo planteado por Nielsen. Así, la aceptación es una función de la percepción de utilidad, usabilidad, agrado y costes. La utilidad hace referencia a la armonía entre las necesidades del usuario y la usabilidad del producto, mientras que el agrado refiere a las evaluaciones afectivas, los costes refieren al ámbito financieros y a las consecuencias sociales y de organización [Kei2003].

La usabilidad está definida como la capacidad de un producto de ser utilizado por los seres humanos con facilidad y efectividad [Sha1991]. Es una característica que no es constante sino relativa a los usuarios, a su entrenamiento, ayuda, a las tareas y a los ambientes. Así, la evaluación es dependiente del contexto [Kei2003]. Para que un sistema sea usable tiene que alcanzar niveles definidos en los siguientes criterios operacionales [Sha1991]:

- Efectividad: desempeño en relación con el cumplimiento de las tareas durante la interacción, en términos de celeridad y errores.

- Aprendizaje: relación del funcionamiento al entrenamiento y a la frecuencia del uso, es decir, el tiempo que requiere un usuario principiante para aprender a utilizar el sistema con un entrenamiento específico.

- Flexibilidad: adaptación a las tareas y a los diferentes ambientes.

- Actitud: niveles aceptables de costes humanos en términos del cansancio, molestia, frustración, y esfuerzo personal.

En esta misma línea, Mandel [Man1997] señala que la usabilidad de una interfaz consiste en que sea sencilla de aprender y divertida de usar, además de fácil de utilizar. También Preece [Pre1994] señala que el concepto de usabilidad mide la facilidad con la que un sistema puede ser aprendido o usado, incluyendo además la seguridad, efectividad, eficiencia y actitud de los usuarios con respecto al sistema. Landauer [Lau1995] coincide con Preece, y expresa que el concepto de usabilidad se basa en la estandarización del 
comportamiento y funcionamiento de las interfaces, sumado a la facilidad de uso y capacidad de aprendizaje [Cat2000].

\subsection{A modo de síntesis}

Las definiciones presentadas anteriormente poseen atributos comunes entre sí, como también aspectos que las distinguen [Fer2007b].

\begin{tabular}{|c|c|c|c|c|c|c|}
\hline \multirow[b]{2}{*}{ Autor } & \multicolumn{6}{|c|}{ Atributos } \\
\hline & Efectividad & Eficiencia & Satisfacción & Contexto & Aprendizaje & Flexibilidad \\
\hline Bevan & $\bullet$ & $\bullet$ & $\bullet$ & $\bullet$ & & \\
\hline Nielsen & $\bullet$ & $\bullet$ & $\bullet$ & $\bullet$ & $\bullet$ & \\
\hline Redish & $\bullet$ & $\bullet$ & $\bullet$ & $\bullet$ & & \\
\hline Shackel & $\bullet$ & & $\bullet$ & $\bullet$ & $\bullet$ & • \\
\hline
\end{tabular}

Tabla 1 - Atributos de la usabilidad según los principales autores

En la mayoría de los casos están presentes, como elementos a considerar, la efectividad, eficiencia, satisfacción por parte del usuario, y contexto de uso. Shackel incorpora el concepto de flexibilidad, pero por la manera de definirla también incluye al contexto de uso.

Los atributos considerados en las definiciones presentadas anteriormente no son los únicos. Existen otros como la consistencia y el estilo comunicativo. También es muy común que la efectividad sea expresada en función de tres sub-atributos: facilidad de aprendizaje, tasa de errores y recuerdo en el tiempo.

\subsubsection{Usabilidad versus Calidad en uso}

De acuerdo al estándar ISO 9241 la usabilidad se define como "el grado en el que un producto puede ser utilizado por usuarios específicos para conseguir objetivos específicos con efectividad, eficiencia y satisfacción en un determinado contexto de uso" [ISO1998b], mientras que en el estándar ISO 14598-1 se define calidad en uso de forma análoga [ISO1998a]. Por otra parte, el estándar ISO/IEC 9126-1 define en primer término a la usabilidad como una característica principal de la calidad de un producto de software, y posteriormente ofrece una idea más amplia utilizando calidad en uso, en lugar de usabilidad, y agregando la seguridad como otra de las características: "capacidad de un producto de software de facilitar a usuarios específicos alcanzar metas específicas con eficacia, productividad, seguridad y satisfacción en un contexto específico de uso" [ISO2001]. En base a las definiciones de la ISO, varios autores emplean directamente calidad en uso en lugar de usabilidad, es decir, los utilizan como sinónimos. Podría entenderse que el concepto de usabilidad tuvo como raíz la amigabilidad con el usuario, y a lo largo de los últimos años ha evolucionado hacia calidad de uso. Sin embargo, Bevan considera que el concepto de calidad en uso es más amplio que el de usabilidad, porque la calidad en uso puede ser influenciada por cualquiera de las características que definen a la calidad del producto [Bev1995]. Por lo tanto, en el caso de entender la usabilidad como sinónimo de calidad en uso, no debemos perder de vista el entorno de uso ni los usuarios concretos que vayan a utilizar el sistema. 


\subsubsection{Atributos de la usabilidad}

A partir de las definiciones presentadas anteriormente podemos observar que la usabilidad es un concepto de calidad demasiado abstracto como para ser medido directamente o definido como un simple atributo de un sistema [Fer2001]. Las características para medir la usabilidad son de alto nivel de abstracción, con lo cual no pueden cuantificarse directamente [Gon2001]. La compleja relación existente entre la usabilidad y los criterios de calidad que la definen, conlleva a descomponerla en una serie de aspectos o atributos cuantificables que posibiliten su medición [Gon2001][Gra2005]. Así, la usabilidad puede ser definida mediante un conjunto de atributos tales como: eficiencia, consistencia, estandarización, estilo comunicativo, capacidad de aprendizaje y de retorno, actitud o satisfacción del usuario [Cat2000]. Cada uno de estos atributos puede, a su vez, ser desglosado en sub-atributos más específicos o definir una métrica específica para poder medirlo. Las definiciones sobre usabilidad la descomponen en función del punto de vista desde el que se enfoca. En algunos casos se utilizan diferentes denominaciones como principios de usabilidad, componentes o características. Sin embargo, la denominación con mayor nivel de aceptación es la que descompone la usabilidad en una serie de atributos [Fer2001]. Esta denominación es utilizada por la ISO, Nielsen, Bevan y Redish, entre otros [Gra2005]. A continuación presentaremos los atributos principales, cuyo núcleo central gira alrededor de los clásicos (aprendizaje, eficiencia, fiabilidad y satisfacción) propuestos por Shackel [Sha1991], Nielsen [Nie1993] y Precce [Pre1994].

\subsubsection{Eficiencia}

Por eficiencia se entiende a los recursos empleados en relación con la precisión y plenitud con que los usuarios alcanzan los objetivos especificados, es decir, recursos de tiempo, financieros y humanos [ISO1998b]. Eficiencia también es la rapidez con la cual los usuarios que ya aprendieron a manejar el software pueden realizar sus tareas. Se puede medir como el número de transacciones por unidad de tiempo que el usuario puede realizar usando el sistema. Lo que se busca es la máxima velocidad de realización de tareas por parte del usuario, ya que éste desea que sus objetivos sean cumplidos realizando operaciones totalmente eficientes, es decir, que las tareas se desarrollen de la mejor forma posible. Cuanto mayor sea la usabilidad de un sistema, el usuario realizará el trabajo con mayor rapidez. El concepto de eficiencia está muy ligado al de efectividad, ya que el sistema no sólo debe funcionar internamente de forma efectiva, sino que el usuario final debe percibir su correcto funcionamiento. La relación está determinada por la consecución de los objetivos de trabajo, y por el conocimiento y experiencia del usuario con la interfaz [Cat2000].

El atributo de eficiencia puede llegar a confundirse con la característica de eficiencia que forma parte de la calidad de un producto. En este último caso, se trata de un concepto más general que involucra a otros aspectos como el comportamiento en el tiempo, los recursos de que dispone y de su utilización.

\subsubsection{Efectividad}

Se refiere a la precisión y la plenitud con las que los usuarios alcanzan los objetivos especificados. La efectividad es algo sumamente ambiguo puesto que una acción que a un usuario le resulta totalmente eficaz, para otro (o para el mismo pero en otro momento) puede llegar a ser completamente ineficaz. A esta idea va asociada la facilidad de aprendizaje, la tasa de errores del sistema, y la facilidad para ser recordado. A continuación se describen estos conceptos: 
- Facilidad de aprendizaje: es uno de los atributos de usabilidad más importantes [Nie1993]. Se refiere al grado de dificultad o de facilidad con que un usuario aprende las funcionalidades básicas de un sistema, como para ser capaz de realizar correctamente las tareas. La habilidad del usuario para trabajar con la interfaz con cierta facilidad, después de un período determinado de formación, permite conocer si la interfaz será productiva para el usuario desde un primer momento [Cat2000]. La facilidad de aprendizaje de los sistemas se está orientando hacia la sencillez y la intuición en el uso de la interfaz. Se debe tender a que el usuario no necesite recurrir a un manual ni sistema de ayuda. También, es considerada como una medida del tiempo requerido para trabajar con cierto grado de eficiencia en el uso del sistema. Normalmente, se mide por el tiempo que emplea el usuario con el sistema hasta ser capaz de realizar ciertas tareas en menos de un tiempo dado. Este tiempo testigo se establece en función del empleado habitualmente por los usuarios expertos. Es un atributo muy importante para usuarios que por primera vez utilizan el sistema, puesto que reduce los tiempos de capacitación, costes y demandas. También, es de vital importancia para sistemas que periódicamente incorporan nuevos usuarios, de diferentes lugares, edades y contextos, en tanto simplifica los procesos de adopción por parte de éstos. El desafío no está en diseñar interfaces con gran facilidad de aprendizaje de cara únicamente a usuarios nuevos u ocasionales, sino hacerlas lo suficientemente sencillas, intuitivas y valiosas para que sean usables por un amplio abanico de usuarios.

- Tasa de errores: este atributo contribuye de forma negativa a la usabilidad de un sistema. Se refiere al número de errores cometidos por el usuario mientras realiza una determinada tarea. Un buen nivel de usabilidad implica una tasa de errores baja. Los errores reducen la eficiencia y satisfacción del usuario, pueden verse como un fracaso en la transmisión al usuario del modo de utilizar el sistema.

- Recuerdo en el tiempo: es un atributo de usabilidad que se refiere a la habilidad de los usuarios ocasionales para hacer productiva la interfaz, tras un período más o menos prolongado de no interaccionar con ella. Para usuarios que no utilizan el sistema regularmente, es de vital importancia que cada vez que vuelvan a usarlo no tengan que aprender cómo funciona partiendo desde cero. Este atributo refleja el recuerdo que tiene el usuario acerca de cómo funciona el sistema, cuando vuelve a utilizarlo tras un periodo de tiempo.

\subsubsection{Satisfacción}

Este atributo es el objeto principal de todo estudio de usabilidad. La satisfacción del usuario podría definirse como "la capacidad de la interfaz de interaccionar con el usuario de forma agradable" [Cat2000].

Por satisfacción se entenderá la ausencia de incomodidad y la actitud positiva en el uso del producto. Se trata, pues, de un factor subjetivo [Flo2000]. Es una medida de las percepciones, opiniones, sentimientos y actitudes generadas en el usuario por el sistema. Lo importante de esta medida, no es tenerla en forma absoluta sino compararla o analizarla en forma relativa. Esta comparación puede ser contra la competencia, contra la versión anterior del mismo producto, contra otras posibilidades que se estén tomando en cuenta.

El otro punto importante es tratar de analizar hasta donde afecta al resto de las medidas. Un usuario al que "no le gusta" una interfaz, puede generar más errores, o tardar más en aprenderla. 


\subsubsection{Consistencia}

Es el principio por el cual los elementos relacionados deben ser presentados de forma idéntica e inequívocamente. El concepto se refiere a la coherencia del significado de objetos, formas y métodos de trabajo en contextos similares, y al grado de similitud de la representación de un concepto en relación con su uso en la vida real [Pre1994]. Las interfaces inconsistentes son aquellas en las que los usuarios deben emplear diferentes métodos en contextos diversos, para llevar a cabo las mismas tareas. Como consecuencia, la inconsistencia provoca que la experiencia del usuario no pueda ser aprovechada, que la puesta en práctica de una tarea determinada sea más complicada y que la formación de los usuarios sea infructuosa. La consistencia es un concepto aplicable a [Cat2000]:

- Tipografía: la presentación de la información debe seguir una coherencia.

- Iconos, comandos y menús: deben representar lo que el usuario espera de una acción del sistema de acuerdo con su elección.

- Contexto: el sistema debe funcionar igual en cualquier contexto y/o plataforma.

- Percepción: el sistema debe ser igual para todos los usuarios.

- Estructura: las metáforas utilizadas en el sistema deben representar adecuadamente el universo de trabajo del usuario.

La estandarización es un concepto importante en relación a la consistencia y puede definirse como la "adaptación de la interfaz a la relación de reglas, convenciones y características técnicas por las que han de regirse las especificaciones de los productos en un cierto campo" [Cat2000]. Estas reglas, convenciones y características pueden ser definidas por organismos competentes, por grupos de empresas o por usuarios interesados en expresar sus necesidades.

\subsubsection{Estilo comunicativo}

Se refiere a la "caracterización del tipo de interacción que puede darse entre un usuario y un sistema" [Pre1994]. Está muy relacionado con el tipo de interfaz con la que interacciona el usuario. Por ejemplo, la comunicación que se establece entre un usuario y una interfaz del tipo GUI, es distinta a la que se establece entre un usuario y una interfaz Web, o una en modo comando. Se puede extraer información del proceso comunicativo a través de la monitorización de las tareas del usuario. Variables como la velocidad de respuesta, el número de pasos que se han necesitado para llevar a cabo una acción, el número de veces que se ha elegido la opción "deshacer", o el número de iconos y menús seleccionados darán al evaluador una idea bastante precisa de cómo ha sido el diálogo entre usuario y sistema [Cat2000].

\subsubsection{Importancia de los atributos}

La usabilidad del sistema no es una simple adición del valor de estos atributos, sino que se define para cada sistema como un nivel a alcanzar para algunos de ellos. Cada uno de los atributos puede descomponerse para conseguir mayor precisión en los aspectos de usabilidad sobre los cuales se quiere poner mayor énfasis. Por ejemplo, rendimiento en uso normal y uso de opciones avanzadas, son ambos sub-atributos de eficiencia, mientras que primera impresión, es un sub-atributo de satisfacción. Algunos de estos atributos no contribuyen a la usabilidad del sistema en la misma dirección, pudiendo ocurrir que el aumento de uno de ellos tenga como efecto la disminución de otro. Por ejemplo, si se desea un sistema con alta facilidad de aprendizaje y eficiencia, es conveniente no 
sobrecargar la interfaz y agregar el uso de teclas rápidas para ejecutar operaciones de uso habitual [Fer2001].

En otros casos, un atributo puede ser mucho más relevante que otro y tener una ponderación acorde a la actividad que se quiera realizar con el sistema, de las características de la audiencia objetivo y de las circunstancias en las cuales se usará el software [Bae2002]. Por ejemplo, un sistema para la pantalla táctil de la sala de un museo será usado por la mayoría de usuarios una sola vez en su vida, por lo tanto debe requerir un entrenamiento mínimo y la eficiencia (número de tareas que se pueden realizar por hora) no es un atributo relevante, mientras que la facilidad de aprendizaje es vital para el éxito del sistema. Por otra parte, el software que utiliza una teleoperadora para recoger los mensajes a enviar a un buscapersonas, puede requerir de un período de formación apreciable, pero interesa fundamentalmente que pueda realizar cada operación en el menor tiempo posible (eficiencia), para reducir el tiempo de espera de los clientes que utilizan el servicio [Fer2001].

La usabilidad encuentra relación con otros conceptos íntimamente ligados el usuario, tales como: quiénes son los usuarios, cuáles son sus conocimientos, qué pueden aprender, qué quieren o necesitan hacer, cuál es la formación general, cuál es el contexto en el que está trabajando, qué debe dejarse a la máquina y qué al usuario, el tipo de producto del que se trata, el tipo de usuario que hace uso del producto y las prestaciones que logren los usuarios haciendo uso del producto [Mon2002][Nie2003].

Por lo expuesto, se observa la inexistencia de un atributo principal en los estudios de usabilidad. Es cierto que unos son más importantes que otros, pero no utilizar los de "menor importancia" puede sesgar la evaluación. Lo que sí queda claro es que el papel del usuario en todo proceso evaluador es vital, puesto que sin usuario no hay evaluación [Cat2000].

\subsubsection{Heurísticas o principios de usabilidad}

La heurística trata de aplicar normas convencionales a la interacción entre el hombre y la máquina. Su objetivo es reducir la brecha entre el usuario y el sistema para favorecer el logro de los objetivos. Se habla de heurísticas en el sentido de directrices o reglas realizadas por expertos, que pueden ser utilizadas como guía para los diseñadores, como ayuda a los evaluadores, para explicar problemas de usabilidad observados y para dar pautas de por qué los usuarios cometen ciertos errores [Gon2006b]. Estas heurísticas no proveen una definición concreta del concepto de usabilidad sino que lo definen enfocando las metas del diseño [Kei2003]. Como podremos observar, las heurísticas guardan relación con los atributos de usabilidad. Pueden tener diferente nivel de especificidad, ya que podemos encontrar orientaciones genéricas para el diseño de todo un sitio, como lo es la adecuación a ciertos estándares, o sugerencias tan concretas como cual debería ser la longitud del texto de un enlace. A continuación presentamos las heurísticas más generales y relevantes postuladas por expertos en la materia.

\subsubsection{Reglas de Schneiderman}

Las reglas para el diseño de interfaces de Schneiderman son entendidas como heurísticas generales, que pueden guiar tanto el diseño como la evaluación de la usabilidad de un sistema interactivo [Gon2006b]. Estas reglas son conocidas como las ocho reglas de oro de Schneiderman [Sch1998]:

1. Esforzarse por la consistencia. Las secuencias constantes de acciones se deben repetir en situaciones similares; la misma terminología se debe utilizar en avisos, 
menús, y pantallas de ayuda; y los comandos constantes se deben emplear en todas partes del mismo modo.

2. Permitir a los usuarios frecuentes utilizar atajos. Cuando la frecuencia de uso aumenta, los usuarios agradecen reducir el número de interacciones. Las abreviaturas, los comandos ocultos, y las macro son muy útiles para un usuario experto.

3. Ofrecer retroalimentación informativa. Para cada acción del usuario, debe haber una cierta regeneración del sistema. Para las acciones frecuentes y de menor importancia, la respuesta puede ser modesta, mientras que para las acciones infrecuentes e importantes, la respuesta debe ser más sustancial.

4. Diseñar el diálogo para mostrar trabajo pendiente. Las secuencias de acciones se deben organizar en grupos con un inicio, un medio y un final. La regeneración informativa en la terminación de un grupo de acciones, da a los usuarios la satisfacción de la realización, y una indicación clara para prepararse para el grupo siguiente de acciones.

5. Ofrecer un manejo simple del error. El sistema ha de estar diseñado para que el usuario no pueda causar un error grave. En el caso que ocurra un error, el sistema debe poder detectarlo, y ofrecer mecanismos para poder recuperarse o manejar ese error.

6. Permitir fácilmente la revocación de acciones (deshacer). Esta característica ofrece tranquilidad al usuario, puesto que sabe que los errores pueden ser deshechos; anima así la exploración de opciones poco conocidas. La recuperación puede ser una sola acción, una entrada de datos, o un grupo completo de acciones.

7. Soportar el apoyo interno del control. Los usuarios experimentados desean tener el control total del sistema, y que el sistema responda a sus acciones. El diseño del sistema debe responder a las acciones del usuario, y que éstos sean los iniciadores de las acciones, no sólo los que respondan a acciones del sistema.

8. Reducir la carga de la memoria de corto plazo. La limitación humana del tratamiento de la información en memoria a corto plazo requiere que lo que se muestra por pantalla sea simple.

\subsubsection{Heurísticas de usabilidad según Nielsen}

Las diez heurísticas de usabilidad que enumeró Nielsen [Nie1990] están orientadas a interfaces de usuario en general. Estas heurísticas hacen una serie de recomendaciones para verificar puntos críticos en las interfaces que son significativos a la hora de mejorar el grado de usabilidad del sistema:

1. Visibilidad del estado del sistema. El sistema debe siempre mantener a los usuarios informados sobre lo que ocurre, a través de una retroalimentación apropiada dentro de un tiempo razonable.

2. Similitud entre el sistema y el mundo real. El sistema debe hablar el lenguaje de los usuarios, con las palabras, las frases y los conceptos familiares, en lugar de que los términos estén orientados al sistema. Utilizar convenciones del mundo real, haciendo que la información aparezca en un orden natural y lógico.

3. Control y libertad para el usuario. Los usuarios eligen a veces funciones del sistema por error y necesitan a menudo una salida de emergencia claramente marcada, esto es, salir del estado indeseado sin tener que pasar por un diálogo extendido. Es importante disponer de la posibilidad de deshacer y rehacer acciones. 
4. Consistencia y estándares. Los usuarios no deben tener que preguntarse si las diversas palabras, situaciones, o acciones significan la misma cosa. Se deben seguir las normas y convenciones de la plataforma sobre la que está implementando el sistema.

5. Prevención de errores. El diseño del sistema debe evitar la aparición de errores, en lugar de generar buenos mensajes de error cuando ocurre un problema.

6. Reconocimiento por sobre recuerdo. Los objetos, las acciones y las opciones deben estar visibles. El usuario no tendría por qué recordar información de una parte del diálogo a otra. Las instrucciones para usar el sistema deberían estar visibles o fácilmente recuperables dondequiera que sea apropiado.

7. Flexibilidad y eficiencia de uso. Los aceleradores, no vistos por el usuario principiante, mejoran la interacción para el usuario experto de manera tal que el sistema puede servir para usuarios inexpertos y experimentados. Es importante que el sistema permita al usuario personalizar sus acciones frecuentes.

8. Diálogos estéticos y diseño minimalista. Los diálogos no deben contener información que sea irrelevante o se necesite de vez en cuando. Cada unidad adicional de información en un diálogo compite con las unidades relevantes de información y disminuye su visibilidad relativa.

9. Ayudar a reconocer, diagnosticar y recuperarse de los errores. Los mensajes de error recibidos por los usuarios se deben expresar en un lenguaje claro, sin códigos, se debe indicar exactamente el problema, y sugerir de manera constructiva una solución.

10. Ayuda y documentación. Aunque es mejor que el sistema se pueda usar sin tener que recurrir a información adicional, puede ser necesario disponer de ayuda y documentación. Cualquier información tiene que ser fácil de buscar, centrada en las tareas del usuario, disponer de pasos concretos a realizar y no ser demasiado extensa.

\subsubsection{Heurísticas de usabilidad para la Web por Instone}

El éxito alcanzado por la Web hizo que rápidamente se posicionara como uno de los más utilizados. Inclusive muchos sistemas migraron hacia la Web o generaron versiones específicas. Con el transcurso del tiempo, la propuesta de Nielsen se transformó en una las más importantes en el campo de la usabilidad de interfaces. Sin embargo, cuando Nielsen presentó sus heurísticas, en 1990, la Web aún no existía. En función de ello, en 1997, Instone las reformuló con la intensión de adecuarlas a la Web y aportar las primeras ideas sobre usabilidad, específicas para esta nueva plataforma [Bae2002]. Para cada heurística realizó un comentario que permitió luego su adaptación para el caso de interfaces construidas en lenguaje HTML. Estos comentarios fueron presentados en un informe técnico sobre principios básicos a tener en cuenta al diseñar una interfaz [Ins1997a].

A partir de estos comentarios, las heurísticas de usabilidad de Nielsen, fueron adaptadas para la Web por Keith Instone en un artículo escrito específicamente para desarrolladores Web sobre el tema de usabilidad [Ins1997b]. Estas siguen siendo las más conocidas y referenciadas hasta la actualidad y se enumeran a continuación:

1. Visibilidad del estado del sistema. El usuario siempre debe saber exactamente qué es lo que el sistema está haciendo. Esto se puede lograr informándole dónde se encuentra en cada momento. Uno de los mayores problemas para los usuarios al navegar por la red es la desorientación. Es vital asegurar una consistencia de 
todo el sitio Web. Otro aspecto, no menos importante, es ofrecer una permanente retroalimentación sobre las acciones que realice en cada página.

2. Similitud entre el sistema y el mundo real. El sistema debe hablar el lenguaje del usuario, es decir, que las frases, palabras y conceptos deben serle familiares. Además, se deberán seguir las convenciones usadas en el mundo real, haciendo que la información aparezca en un orden lógico y natural. La utilización de metáforas, ya sea visuales o textuales, ayuda a este punto.

3. Control por parte del usuario y libertad. Los usuarios frecuentemente eligen funciones por error y necesitan "salidas de emergencia" claramente marcadas. Se debe proveer al usuario funciones para deshacer y rehacer las acciones que haya realizado.

4. Consistencia y cumplimiento de estándares. Los usuarios no tienen por qué preguntarse si distintas palabras, situaciones o acciones significan lo mismo. Hay que tratar de seguir las convenciones usuales del software de base en cuanto a íconos, botones, imágenes, ventanas y diálogos. Se debe procurar el uso de estilos por defecto en botones, barras de scroll, etc.

El cumplimiento con las recomendaciones emitidas por el W3C referidas a tecnologías Web (HTML, CSS, XML, etc.) aseguran, en muchos casos, una portabilidad absoluta del sitio. Existe una gran cantidad de herramientas (validadores) que permiten verificar si un sitio Web cumple con las especificaciones del W3C.

Es importante usar de manera consistente el fraseo, imágenes, y fuentes, a través del sitio para dar la imagen de consistencia. El uso de hojas de estilo facilita mantener la consistencia del diseño gráfico.

5. Prevención de errores. Aún mejor que el desarrollar buenos mensajes de error es tener un diseño cuidadoso que evite la ocurrencia de errores. Debe asegurarse que las instrucciones estén escritas de una manera clara, y que éstas sean desplegadas de manera conveniente, evitando cualquier tipo de contaminación visual. Por ejemplo, si se requiere el llenado de un formulario con campos obligatorios, se deben destacar por sobre el resto de las entradas.

6. Preferencia al reconocimiento frente a la memorización. Se debe hacer que los objetos, acciones y opciones sean visibles. El usuario no tiene la obligación de recordar información de una parte de un diálogo a otra parte. Las instrucciones de uso del sistema deben de ser visibles y accesibles cuando el usuario lo considere necesario. Se deben tener mecanismos de búsqueda.

7. Flexibilidad y eficiencia de uso. Los aceleradores (invisibles para el usuario novato) pueden hacer más rápida la interacción para el usuario experto. El sistema debe tratar eficientemente tanto a los usuarios expertos como inexpertos. Para lograr esto, es conveniente permitir a los usuarios que personalicen ciertas acciones.

Los sitios Web se deben cargar lo más rápidamente posible, independientemente del tipo de conexión utilizado por el usuario. Para ello debe priorizarse el uso de HTML y el reuso de imágenes en el sitio Web.

8. Estética y diseño minimalista. Los diálogos no deben contener información que sea irrelevante o que rara vez sea de utilidad. Cada información extra en un diálogo compite con unidades relevantes de información y disminuye su visibilidad relativa. Se recomienda reducir el número de imágenes al mínimo. Hay que recordar que cada imagen implica una descarga desde el servidor, y esto en conexiones lentas puede ser un problema serio. 
Es altamente recomendable que la información más importante sea colocada en la parte superior de la página, pues está es la región que siempre es visible en el navegador.

9. Ayuda para que el usuario reconozca, diagnostique y se recupere de los errores. Los mensajes de error deben ser expresados en un lenguaje claro (sin ambivalencias), indicando exactamente el problema, y proveyendo constructivamente una solución. Los mensajes de error pueden ayudar a restablecer la confianza en el sitio Web.

10. Ayuda y documentación. Lo ideal es que un sistema no requiera de documentación. Sin embargo, aunque muy pocos la leen, es necesaria, así como también la ayuda en línea. Cualquier información debe ser fácil de buscar, y debe estar orientada a las acciones del usuario. En cuanto un sitio Web ofrezca alguna característica fuera de la norma, o ligeramente complicada, será necesario prestar ayuda y dar documentación a los usuarios.

\subsubsection{Principios para el desarrollo de interfaces de Constantine}

Constantine estudió e investigó sobre el diseño de interacciones e identificó varios principios para aplicar en el desarrollo de una interfaz a los efectos de que las mismas sean altamente usables [Con1999]:

1. Estructura. Organizar la información de acuerdo a su significado.

2. Simplicidad. Hacer fáciles las tareas comunes que el usuario realiza habitualmente.

3. Visibilidad. Mostrar toda aquella información necesaria para una tarea que deba ser realizada por el usuario.

4. Retroalimentación. Mantener informados a los usuarios en todo momento según las acciones que hayan realizado.

5. Tolerancia. Permitir a los usuarios cancelar, deshacer o rehacer acciones.

6. Reutilización. Reducir la necesidad de que los usuarios recuerden.

\subsubsection{Principios para el diseño centrado en el usuario de Mayhew}

Mayhew elaboró una serie de principios para el diseño de sistemas centrados en el usuario, con el fin de lograr incorporar la usabilidad al ciclo de vida de un producto [May1999].

1. Compatibilidad del usuario, del producto, de las tareas y de los procesos del sistema. La compatibilidad es necesaria para que esté todo coordinado adecuadamente y para que el producto final se adapte perfectamente al usuario que lo usará.

2. Consistencia y robustez. Que el sistema no sea vulnerable a errores.

3. Familiaridad. Un usuario que ya esté familiarizado con un sistema similar o anterior, se adaptará mejor al nuevo producto.

4. Simplicidad. Un sistema simple es más fácil de usar.

5. Manipulación directa. El usuario maneja directamente los elementos del sistema.

6. Control. El usuario en todo momento ha de tener el control del sistema.

7. WYSIWYG (What You See Is What You Get). Lo que ve el usuario durante la edición es lo que realmente obtiene como interfaz. Esto permite trabajar con un documento con el aspecto real que tendrá.

8. Flexibilidad. Si el sistema es flexible, puede adaptarse a cualquier tipo de usuarios.

9. Sensibilidad y feedback. Que el sistema interactúe con el usuario. 
10. Tecnología invisible. Que la tecnología usada en un sistema se mantenga invisible al usuario.

11. Protección. Un sistema en el que sus datos queden a salvo de intrusos.

12. Facilidad de aprendizaje y facilidad de uso. Para que un usuario pueda usar el sistema fácilmente.

\subsubsection{Principios del diseño cognitivo de Norman}

En el año 1998 Donald Norman presentó cuatro principios del diseño cognitivo. Se trata de principios generales que deberían ser tenidos en cuenta por el diseñador de cualquier producto para lograr un uso intuitivo, simple y lógico del mismo. Norman considera que estos principios constituyen una forma de psicología de cómo interactúan las personas con los objetos [Nor1998]:

1. Modelo conceptual. El diseñador debe proporcionar un buen modelo conceptual al usuario, es decir, debe permitir predecir los efectos de los actos realizados por el usuario. Dicho modelo debe estar adaptado a las acciones y los resultados. Si el modelo conceptual no es bueno, el usuario actúa de memoria, a ciegas sin comprender del todo por qué, qué efectos esperar, ni qué hacer si las cosas salen mal.

2. Visibilidad. Tiene estrecha relación con el modelo conceptual puesto que es entendida como la necesidad de que solo estén visibles, y que comuniquen el mensaje correcto, las partes que tengan un fin específico para el usuario. Las acciones posibles en cada momento deben ser las trascendentes para el usuario, no todas las posibles en el sistema. El diseñador debe aportar señales que le indiquen al usuario de manera natural lo que se debe hacer, debe orientar y ayudar lo forma implícita, sin necesidad de que tenga conciencia de tales señales. Para ello, hace falta que no vea ni más ni menos que lo necesario, ya que el exceso de visibilidad confunde e intimida, y la falta de visibilidad dificulta el manejo. Ello lleva a lo que Norman denomina diseño natural.

3. Topografía. Tiene que ver con la posibilidad de que sea posible determinar las relaciones entre las acciones y los resultados, entre los mandos y sus efectos, y entre el estado del sistema y lo que es visible. La topografía relaciona lo que uno quiere hacer y lo que parece ser posible de hacer, es decir, la correspondencia entre las funciones de un sistema y su interfaz o elementos de control. La topografía busca conseguir que los objetos sean autoexplicativos, a través de relaciones significativas entre su naturaleza y su forma, evitando recordar cosas de memoria y logrando que la información esté contenida en el propio mundo exterior. La topografía se aprende con facilidad y se recuerda siempre. La topografía natural aprovecha las analogías físicas, las normas culturales, y las biológicas para lograr una comprensión inmediata.

4. Retroalimentación. Se define como el envío de información al usuario acerca del acto que se ha realizado efectivamente y del resultado que se ha logrado. Es un concepto muy conocido en la ciencia de la teoría del control y la información. Cuando el usuario recibe una retroalimentación completa y constante acerca de sus actos, puede conocer el estado actual del sistema fácilmente y llevar su control.

Años más tarde, en 2004, Norman presenta otra faceta del diseño que denomina emocional, donde declara que "las cosas atractivas funcionan mejor" [Nor2004]. Fundamenta su afirmación en el hecho de que el diseño está relacionado con las emociones, de muchas formas distintas, ya que a veces uno se divierte usando ciertos objetos, y otras veces se enoja o desanima cuando cuesta usarlos. Para algunos 
investigadores, se trata de un cambio de opinión de Norman, y para otros de un complemento a los cuatro principios anteriores debido a que ya no basta con que los objetos sean funcionales para que funcionen, sino que además, si son atractivos funcionan mejor. Para ello se basa en estudios realizados por investigadores japoneses e israelíes sobre la utilización de cajeros automáticos donde se concluye que la apariencia estética, hace creer al usuario que los objetos funcionan mejor. Según Norman, "las cosas atractivas hacen que las personas se sientan mejor, lo que los lleva a pensar de forma más creativa" [Nor2004]. El proceso por el que se odia o desea a un objeto se ajusta a tres funciones cognitivas: visceral, conductiva y reflexiva. La respuesta visceral a los objetos es la primera reacción instintiva. La respuesta conductiva es la que se produce por efecto del placer de usar un objeto de forma eficiente. La respuesta reflexiva es la que se produce a largo plazo como el orgullo o la nostalgia.

\subsubsection{Heurísticas para la Web de Tognazzini}

Según Tognazzini, el diseño de sitios Web debe seguir los siguientes principios para el diseño de interacciones [Tog2003]:

1. Anticipación. El sitio Web debe anticiparse a las necesidades del usuario.

2. Autonomía. Los usuarios deben tener el control sobre el sitio Web. Estos sienten que controlan un sitio Web si conocen su situación en un entorno abarcable y no infinito.

3. Colores. Deben utilizarse con precaución para no dificultar el acceso a los usuarios con problemas de distinción de colores que representan aproximadamente un 15\% del total.

4. Consistencia. Las aplicaciones deben ser consistentes con las expectativas de los usuarios, es decir, con su aprendizaje previo.

5. Eficiencia del usuario. Los sitios Web se deben centrar en la productividad del usuario, no en la del propio sitio Web. Por ejemplo, en ocasiones las tareas con mayor número de pasos son más rápidas de realizar para una persona que otras tareas con menos pasos, pero más complejas. La pirámide invertida donde lo más importante está antes y lo menos importante está situado más abajo, es una técnica que favorece la eficiencia.

6. Reversibilidad. Un sitio Web ha de permitir deshacer las acciones realizadas.

7. Ley de Fitts. Indica que el tiempo para alcanzar un objetivo con el ratón está en función de la distancia y el tamaño del objetivo. A menor distancia y mayor tamaño más facilidad para usar un mecanismo de interacción. La ley de Fitts nos dice que debemos poner lo habitual cercano y muy a la vista del usuario.

8. Reducción del tiempo de latencia. Hace posible optimizar el tiempo de espera del usuario, permitiendo la realización de otras tareas mientras se completa la previa e informando del tiempo pendiente para la finalización de la tarea.

9. Aprendizaje. Los sitios Web deben requerir un mínimo proceso de aprendizaje y deben poder ser utilizados desde el primer momento.

10. Uso adecuado de metáforas. Facilita el aprendizaje de un sitio Web, pero su uso inadecuado puede dificultarlo enormemente.

11. Protección del trabajo de los usuarios. Es prioritario, se debe asegurar que los usuarios nunca pierdan su trabajo como consecuencia de un error.

12. Legibilidad. El color de los textos debe contrastar con el del fondo, y el tamaño de fuente debe ser suficientemente grande. 
13.Seguimiento de las acciones del usuario. Conociendo y almacenando información sobre su comportamiento previo, se ha de permitir al usuario realizar operaciones frecuentes de manera más rápida.

14. Interface visible. Se deben evitar elementos invisibles de navegación que han de ser inferidos por los usuarios, menús desplegables, indicaciones ocultas, etc.

\subsubsection{Principios de usabilidad de Keionen}

Los principios o heurísticas presentadas hasta el momento mencionan reglas de distinto tipo y diverso alcance. En algunos casos hacen referencia a los mismos aspectos pero de diferentes maneras. En otros casos algunas dimensiones son desglosadas en varias subdimensiones como una lista de chequeo. Algunas heurísticas hacen explícitos ciertos aspectos mientras que otras lo hacen implícitamente. En un intento por sintetizar los principios destacados por la mayoría de las heurísticas, y por reconocer a la usabilidad como un atributo del producto, Tukka Keionen propone la siguiente síntesis [Kei2003]:

1. Consistencia. Se refiere a que la interfaz utilice siempre los mismos principios sobre un conjunto de casos o situaciones individuales. Las secuencias constantes de acciones se deben repetir en situaciones similares. La consistencia hace más fácil el aprendizaje porque las cosas nuevas tienen que aprenderse solamente una vez, ya que la próxima vez serán familiares. La consistencia visual aumenta la estabilidad percibida, que mantiene la confianza en nuevos ambientes.

2. Control interno por parte del usuario. El principio de soportar el control interno del usuario se relaciona con su sensación subjetiva de participación e interacción. La idea es que la interacción es más satisfactoria si los usuarios sienten que ellos mismos son los que pueden influenciar sobre los objetos directamente, en vez de simplemente dar instrucciones al sistema para actuar.

3. Presentación visual. Está relacionada con el control interno por parte del usuario. La presentación visual ha dominado el diseño del interfaz por mucho tiempo. Para tener el control, el usuario tiene que disponer de toda la información necesaria. Las operaciones exitosas se deben indicar explícitamente en cada nivel de la interacción.

4. Manejo y recuperación tras el error. La gestión del error contiene advertencias que el sistema informa antes de ejecutar comandos peligrosos, como por ejemplo la información sobre las acciones que no se pueden cancelar, estrategias de prevención del error, detección de los errores cometidos, revocación fácil de acciones, y la posibilidad para que los usuarios corrijan su trabajo sin necesidad de realizar todo nuevamente. La capacidad de notar inmediatamente las acciones erróneas y la posibilidad para deshacerlas es uno de los requisitos centrales de estas reglas. La recuperación de error posibilita aliviar la ansiedad, permitiendo a los usuarios descubrir nuevas alternativas, es decir, facilita el aprendizaje.

5. Reducción de la carga de memoria. Es un principio básico de la cognición humana. La gente no recuerda exactamente pedazos de información sin relación alguna. Cuando se requiere el recuerdo exacto es de esperar muchos errores. La interacción debe confiar más en el reconocimiento del usuario que en la memoria. La memoria es propensa al error, mientras que la gente es muy buena en el reconocimiento de objetos.

6. Aptitud para la tarea. Los diseñadores deben ofrecer exactamente la información que el usuario necesita, ni más, ni menos. La información debe estar en el orden en que el usuario prefiere utilizarla. 
7. Guía y apoyo. Tanto las guías como las ayudas deben ser provistas de manera fácil de utilizar, relevante e informativa, tanto en la computadora (vía una alternativa de ayuda en línea) como en forma de documento, para ayudar al usuario a entender y utilizar el sistema.

\subsubsection{A modo de síntesis}

Como podemos observar, estas heurísticas poseen similitudes y diferencias, algunas son generales y otras particulares. Sin embargo, existe un núcleo de heurísticas que son de un nivel de importancia mayor. Éstas son mencionadas por muchos autores, aunque de diferente manera o incluso solapadas unas con otras. En la tabla 2, se especifican las que consideramos más importantes [Fer2007b]:

\begin{tabular}{|l|c|c|c|c|c|c|c|}
\hline & $\begin{array}{c}\text { Schneider } \\
\text { man }\end{array}$ & $\begin{array}{c}\text { Nielsen e } \\
\text { Instone }\end{array}$ & Constantine & Mayhew & Norman & $\begin{array}{c}\text { Togna } \\
\text { zzini }\end{array}$ & Keionen \\
\hline Consistencia & $\bullet$ & $\bullet$ & $\bullet$ & $\bullet$ & $\bullet$ & $\bullet$ & $\bullet$ \\
\hline Visibilidad & & $\bullet$ & $\bullet$ & & $\bullet$ & $\bullet$ & $\bullet$ \\
\hline Retroalimentación & $\bullet$ & $\bullet$ & $\bullet$ & $\bullet$ & $\bullet$ & & $\bullet$ \\
\hline $\begin{array}{l}\text { Control por parte } \\
\text { del usuario }\end{array}$ & $\bullet$ & $\bullet$ & $\bullet$ & $\bullet$ & $\bullet$ & $\bullet$ & $\bullet$ \\
\hline Reversibilidad & $\bullet$ & $\bullet$ & $\bullet$ & & & $\bullet$ & $\bullet$ \\
\hline Manejo del error & $\bullet$ & $\bullet$ & $\bullet$ & $\bullet$ & & $\bullet$ & $\bullet$ \\
\hline Intuitividad & $\bullet$ & $\bullet$ & $\bullet$ & & $\bullet$ & & $\bullet$ \\
\hline Simplicidad & $\bullet$ & $\bullet$ & $\bullet$ & $\bullet$ & $\bullet$ & $\bullet$ & \\
\hline Topografía & & $\bullet$ & & & $\bullet$ & $\bullet$ & \\
\hline $\begin{array}{l}\text { Diseño y } \\
\text { organización }\end{array}$ & $\bullet$ & $\bullet$ & $\bullet$ & $\bullet$ & $\bullet$ & $\bullet$ & $\bullet$ \\
\hline Productividad & $\bullet$ & $\bullet$ & $\bullet$ & $\bullet$ & & $\bullet$ & \\
\hline $\begin{array}{l}\text { Ayuda y } \\
\text { documentación }\end{array}$ & & $\bullet$ & & & & & $\bullet$ \\
\hline Estándares & & $\bullet$ & & & & & \\
\hline
\end{tabular}

Tabla 2 - Heurísticas de usabilidad según los principales autores

La síntesis realizada permite visualizar claramente que existe un grupo de heurísticas que están presentes en prácticamente todas las propuestas analizadas. Por ello, se intenta agruparlas bajo una denominación común que permita contemplar todas las que tienen alguna similitud. También existen heurísticas que pueden fusionarse. Tal es el caso de Reversibilidad con Manejo de error, y Simplicidad con Productividad. En el primer caso, ambas tienen que ver con la posibilidad de gestionar errores involuntarios o cambios de parecer del usuario. En el segundo, están orientadas a la eficiencia en la utilización. Una heurística que no cosecha muchos adeptos pero que consideramos de suma importancia es la de estándares, ya que seguir una normativa internacional es de vital importancia en un ambiente como la Web donde el usuario con un solo "clic" puede transitar de un espacio virtual a otro totalmente diferente. En la siguiente tabla se especifican las 
heurísticas que forman el núcleo básico de partida para el modelo de evaluación de EVEA, y se detalla el lugar de aparición en cada una de las propuestas.

\begin{tabular}{|l|c|c|c|c|c|c|c|}
\hline & $\begin{array}{c}\text { Schneider } \\
\text { man }\end{array}$ & $\begin{array}{c}\text { Nielsen e } \\
\text { Instone }\end{array}$ & Constantine & Mayhew & Norman & $\begin{array}{c}\text { Togna } \\
\text { zzini }\end{array}$ & Keionen \\
\hline Consistencia & 1 & 4 & 1 & 2 & 3 & 4 & 1 \\
\hline Visibilidad & & 1 & 3 & & 2 & 2 & 6 \\
\hline Retroalimentación & 3 & 1 & 4 & 9 & 4 & & 3 \\
\hline $\begin{array}{l}\text { Control por parte } \\
\text { del usuario }\end{array}$ & 7 & 3 & 5 & 6 & 1,3 & 2 & 2 \\
\hline Reversibilidad & 6 & 3 & 5 & & & 6 & 4 \\
\hline Manejo del error & 5 & 9,5 & 5 & 2 & & 10 & 4 \\
\hline Intuitividad & 8 & 6 & 6 & & 1 & & 5 \\
\hline Simplicidad & 2 & 7 & 2 & 4 & 2 & 5,12 & \\
\hline Topografía & & 2 & & & 3 & 9 & \\
\hline $\begin{array}{l}\text { Diseño y } \\
\text { organización }\end{array}$ & 4 & 8 & 1 & 7 & 2,3 & 1,3, & 3 \\
\hline Productividad & 2 & 7 & 2 & 4 & & 5,12 & \\
\hline $\begin{array}{l}\text { Ayuda y } \\
\text { documentación }\end{array}$ & & 10 & & & & & 7 \\
\hline Estándares & & 4 & & & & & \\
\hline
\end{tabular}

Tabla 3 - Heurísticas de usabilidad seleccionadas

\subsection{Conclusiones}

La usabilidad, a pesar de ser un concepto muy joven, es fundamental para las aplicaciones informáticas, ya que forma parte de los atributos destacados que hacen a la calidad de producto. Por este motivo, el objetivo del capítulo fue definir el concepto de usabilidad desde el punto de vista de las aplicaciones Web.

La usabilidad es reconocida como uno de los atributos más importantes dentro de la calidad de productos software. En este sentido, el estándar ISO/IEC 9126 [ISO2001] la incorpora explícitamente dentro de su modelo de calidad, como parte de la calidad interna y externa del software, e implícitamente dentro de la calidad en uso. También el estándar ISO 9241 [ISO1998b] la tiene en cuenta a la hora de especificar y evaluar los requisitos ergonómicos de los productos informáticos. Es decir, la usabilidad está presente dentro del ambiente en que se desarrolla el producto, como así también desde el punto de vista del usuario que lo utiliza dentro de un contexto de uso en particular. Desde otra perspectiva, la usabilidad también forma parte de la aceptabilidad de un software, entendida esta como la combinación de su aceptabilidad social y práctica [Nie1993].

A partir del concepto de calidad se desprenden una serie de definiciones de usabilidad planteadas por expertos [Sha1991][Nie1993][Pre1994][Lau1995][Man1997][Red1999] [Cat2000]. Al ser un concepto de calidad demasiado abstracto como para ser medido y cuantificado directamente [Fer2001][Gon2001], puede ser definida mediante un conjunto de atributos, tales como: eficiencia, consistencia, estandarización, estilo comunicativo, capacidad de aprendizaje y de retorno, actitud o satisfacción del usuario [Cat2000]. Los expertos coinciden en varios de estos aspectos o atributos: efectividad, eficiencia, 
satisfacción por parte del usuario, y contexto de uso [Fer2007b]. A su vez, cada uno de los atributos puede ser desglosado en sub-atributos más específicos, o definir una métrica específica para poder medirlo.

La importancia otorgada a las interfaces dentro de las aplicaciones Web llevó a buscar alguna manera de aplicar normas de interacción entre el usuario y el sistema. Así surgen las heurísticas, como directrices o reglas que pueden ser utilizadas como guía para los diseñadores, como ayuda a los evaluadores, para explicar problemas de usabilidad observados, o para dar pautas de por qué los usuarios cometen ciertos errores [Gon2006b]. Las heurísticas guardan relación con los atributos de usabilidad y pueden tener diferente nivel de especificidad de acuerdo a las necesidades. La síntesis realizada a partir del aporte de los expertos en dicha materia [Nie1990][Ins1997b][Sch1998] [Nor1998][Con1999][Tog2003][Kei2003] permite distinguir un grupo de heurísticas que están presentes en la mayoría de las propuestas analizadas: consistencia, visibilidad, retroalimentación, control por parte del usuario, reversibilidad, manejo del error, intuitividad, simplicidad, topografía, diseño y organización, productividad, ayuda y documentación, y estándares [Fer2007b].

Las definiciones, junto con los atributos y heurísticas mencionadas, forman el núcleo básico de partida para definir un modelo de evaluación de EVEA que utiliza como eje central la usabilidad, y es lo que se propone en esta tesis. 



\section{Capítulo 3: Accesibilidad}

\subsection{Introducción}

El rápido crecimiento y masificación de la Web a escala mundial posibilita la difusión y disponibilidad de la información de manera muy sencilla e instantánea. Cualquier persona que disponga de una computadora conectada a Internet puede, potencialmente, visitar el sitio Web que desee, independientemente de su origen geográfico, cultural, generacional o motivacional [Bae2002]. Si a ello le sumamos las herramientas para diseño Web y para auto-publicación, como por ejemplo los Weblogs, estamos frente a la posibilidad de que prácticamente cualquier usuario de la Web se transforme en emisor, algo imposible de hacer en otros medios de comunicación como la radio o la televisión. Sin embargo, las limitaciones y el uso inadecuado de las tecnologías de generación y publicación de contenido para la Web, están dando lugar a situaciones de imposibilidad de acceso a la información por una parte considerable de usuarios [Mon2004b]. En otros casos, aunque sin llegar a tal extremo, hay numerosos problemas para la visualización e interpretación de la información, producto de limitaciones físicas de los usuarios o de barreras tecnológicas. La búsqueda de soluciones a este tipo de problemas es de lo que se ocupa la accesibilidad. Accesibilidad significa proporcionar flexibilidad para acomodarse a las necesidades de cada usuario, a sus preferencias y/o limitaciones [Gra2005].

\subsection{Discapacidades}

Los usuarios con limitaciones físicas forman un grupo importante de los internautas. Estos usuarios frecuentemente no son tenidos en cuenta a la hora de diseñar sitios Web. Probablemente, esto sea producto de desconocer que ellos representan una buena porción del total de usuarios, o por creer que les está vedado el acceso a la red de redes debido a sus propias limitaciones.

En general, la Web es un medio que se utiliza para presentar información, debido a las ventajas que proporciona respecto a la información en formato impreso. Es decir que la Web, y la computadora en general, lejos de ser un obstáculo puede ser una ayuda para muchos usuarios limitados físicamente, puesto que les otorga autonomía para realizar gestiones, les facilita el acceso a todo tipo de información y recursos, y les posibilita realizar tareas que de otro modo les hubiera resultado más costosas o imposibles de llevar a cabo en el mundo real [Nie2000][Mon2004b][Goi2004].

Generalmente la limitación física se asocia a la discapacidad, aunque no siempre es realmente así. La discapacidad física es un concepto muy amplio cuando se trata de usuarios de la Web. Se relaciona mucho la discapacidad física con el hecho de estar en silla de ruedas, por ejemplo. Sin embargo, cuando hablamos de aplicaciones informáticas, la discapacidad física engloba a todo tipo de problemas que dificulten el uso de las computadoras [Nie2000]. Las discapacidades físicas a las que habitualmente se hace referencia están relacionadas con problemas de visión, de audición, de cognición, o motores. También se incluyen aquí a las personas que pierden transitoriamente alguna capacidad producto de operaciones, quebraduras o lesiones $\mathrm{y}$, fundamentalmente, a los adultos mayores, puesto que se considera que a determinada edad se pierden paulatinamente algunas capacidades como la motricidad fina, la visión, o el oído. Tal vez estos últimos sean el grupo más importante dentro de los usuarios considerados con discapacidad física ya que en muchos países, sobre todo los desarrollados, conforman el sector demográfico de mayor crecimiento a raíz del aumento de la esperanza de vida [Bae2002]. Por lo tanto, diseñar sitios Web accesibles será cada vez más prioritario 
debido a que la cantidad de usuarios con diferentes tipos y niveles de discapacidades se va a incrementar a medida que la población de internautas envejezca [Nie2000].

Por otra parte, no solamente la discapacidad física dificulta la accesibilidad de contenidos sino que hay otro tipo de limitaciones tecnológicas derivadas del contexto de uso y del dispositivo de acceso empleado, tanto hardware como software [Van2000][Mon2004b]. En ambos casos, las barreras para el acceso a la información son similares, ya que un usuario con visión reducida posee el mismo problema que un usuario que tiene deshabilitada la opción de visualización de imágenes, posee monitor con baja resolución, o utiliza pantallas pequeñas de dispositivos de mano. Es decir que la accesibilidad no sólo facilita el acceso a las personas con discapacidad física sino que también trae aparejado el beneficio adicional de hacerlas más accesibles para todos los usuarios que navegan con las manos ocupadas, en condiciones de poca luz o elevado ruido, mientras manipulan otro tipo de equipamiento, utilizan navegadores diferentes, telefonía celular con tecnología WAP, sistemas basados en voz, o equipos portátiles [Rom2001b][Gon2007].

Desde el punto de vista conceptual puede definirse a la accesibilidad como el arte de garantizar que, tan amplia y extensamente como sea posible, instalaciones (como por ejemplo el acceso a la Web) estén disponibles para las personas, independientemente de que tengan o no algún tipo de deficiencia [Ber1999]. Para el W3C, un sitio accesible es el que puede ser usado correctamente por personas con discapacidad [W3C99a]. Una de las características principales que poseen las páginas Web accesibles, es que reproducen correctamente su contenido independientemente del navegador utilizado por el usuario, a pesar de las posibles deficiencias físicas, sensoriales, y cognitivas que posean los mismos, o de las barreras tecnológicas y del entorno de trabajo existente [Rom2001]. Según las Pautas de Accesibilidad del W3C, para que un sitio sea accesible debe albergar un contenido que sea fácilmente comprensible y navegable [W3C1999]. El contenido debe presentarse de manera clara, con un lenguaje simple y con mecanismos obvios de navegación para moverse entre las páginas. La mejor manera de asegurar altos niveles de accesibilidad es separar el contenido de la presentación, codificando el significado de la información y dejando que la apariencia de la misma esté a cargo de los dispositivos de navegación que utiliza cada usuario [Nie2000][Mon2004b].

\subsubsection{Discapacidades visuales}

Debido a que la Web pone gran acento en lo visual, los problemas más serios de accesibilidad hacen referencia a los usuarios con ceguera, visión reducida o daltonismo [Nie2000][Mon2004].

Los usuarios ciegos necesitan de la ayuda de un programa lector de pantalla que les reproduzca la información obtenida por el navegador, a través de un sintetizador de voz. Otros, utilizan navegadores solo texto, o directamente navegadores de voz [Bre2001].

A los efectos de contemplar este tipo de discapacidad existen una serie de pautas que deben ser tenidas en cuenta a la hora de diseñar un sitio Web. Algunas de ellas son [Nie2000]:

- Mantener un alto contraste entre los colores de fuente y fondo, y evitar patrones de fondo con textura porque interfieren con la lectura. La falta de legibilidad del texto provoca que la lectura sea mucho más lenta y forzada, o que directamente esté por debajo del límite de lo que un usuario con visión parcial puede leer.

- Aunque existen instrumentos como los sintetizadores de voz, para posibilitar a los usuarios ciegos o con deficiencias visuales puedan "escuchar" el texto, hay numerosos problemas cuando las páginas son largas, ya que es mucho más difícil realizar un 
análisis rápido de las partes principales. Para facilitar este análisis se recomienda diseñar la estructura de cada página mediante la utilización de encabezados: $<\mathrm{H} 1>$ para el más alto nivel, $<\mathrm{H} 2>$ como partes principales de la información, y $<\mathrm{H} 3>$ en adelante, para lo menos importante. Ello posibilitará al usuario no vidente obtener una visión global de la estructura de una página y concentrarse en lo más importante.

- Los usuarios con visión reducida necesitan que las fuentes sean de mayor tamaño que el habitual. Para posibilitar su modificación se debe permitir que el tamaño de la letra sea ajustable por parte del usuario. La técnica más utilizada es la de codificar la información con tamaños de fuente relativos, usando hojas de estilo y estableciendo el atributo de tamaño de fuente a un porcentaje del tamaño predeterminado. Al hacer esto el texto aumentará o disminuirá automática y armoniosamente cuando el usuario accione comandos en el navegador para cambiar el tamaño de fuente.

- Las imágenes son otro de los grandes problemas para este tipo de usuarios. Como no pueden visualizarlas, o les cuesta mucho hacerlo, se utiliza la técnica de reemplazar la imagen por un texto que haga referencia al contenido de la imagen, siempre que la misma sea significativa. El uso del atributo ALT en las imágenes posibilita que los usuarios no videntes, o aquellos que han deshabilitado la opción de carga de imágenes, puedan ver u oír un texto alternativo que hace referencia a la imagen. Ello solo debe hacerse para las imágenes que no cumplen un cometido decorativo como las líneas, flechas, viñetas. etc. Para este tipo de imágenes deberá ponerse un texto vacío en su atributo ALT.

Sin lugar a dudas este tipo de pautas impactan directamente no solo en los usuarios con discapacidades visuales sino también en usuarios que están accediendo a la Web en circunstancias donde no pueden utilizar un navegador visual, poseen monitores de baja resolución o intentan hacer menos forzada y más amena la lectura [Nie2000]. Es decir, que las recomendaciones enunciadas tienen carácter general en el diseño Web.

\subsubsection{Discapacidades motrices}

Se trata de problemas relacionados con la movilidad del usuario. Aquí se incluyen problemas de debilidad, limitaciones de control muscular (movimientos involuntarios, falta de coordinación, o parálisis), limitaciones de sensibilidad, problemas con las articulaciones, o falta de miembros [Bre2001]. Algunas discapacidades físicas pueden incluir dolor que impide el movimiento. Estas condiciones pueden afectar las manos y los brazos, además de otras partes del cuerpo. En algunos casos, estos usuarios utilizan dispositivos de entrada especiales como teclados con disposición específica de teclas, mouse de cabeza, licornio, adaptador bucal, o sistemas de seguimiento de ojos. En otros casos menos severos, se trata de minimizar el uso de dispositivos como el mouse. Para mejorar la accesibilidad desde el punto de vista de la motricidad se debe posibilitar un uso intensivo del teclado, ya sea mediante teclas de función o teclas rápidas. Ello también es beneficioso para los usuarios que realizan un uso intensivo del sitio, o que buscan reducir el uso del mouse debido a problemas musculares o articulares [Nie2000].

\subsubsection{Discapacidades auditivas}

Están relacionadas con problemas de sordera de distinta magnitud, que implican distintos grados de pérdida de la capacidad auditiva en ambos oídos. Para usar los contenidos sonoros en la Web muchas personas sordas necesitan que el sonido esté traducido a una versión textual, siempre que sea posible. Este tipo de discapacidad puede ser considerada de menor importancia en función de que el audio no es un rasgo destacado en la Web. En tal sentido un usuario que no posea kit multimedia está en las mismas 
condiciones que aquel que no puede oír. Los casos donde hay que tener cuidado es en los clips de audio o de video. Para superar ese inconveniente debe existir una versión transcripta de cada clip y los videos deben estar subtitulados [Nie2000].

\subsubsection{Discapacidades cognitivas y neurológicas}

Son las más difíciles de paliar ya que están relacionadas con usuarios que presentan problemas en el uso del lenguaje, la lectura, percepción, memoria o salud mental. Las personas con dislexia pueden experimentar dificultades con el lenguaje escrito o con imágenes, por lo cual hay que ofrecerles la información mediante múltiples modalidades de manera simultánea. Las personas con trastornos psíquicos o de déficit de atención necesitan poder desactivar las animaciones para poder concentrarse en los contenidos. Aquellos con falta de memoria dependen de una estructura de navegación coherente e intuitiva, a través de todo el sitio para no verse obligados a recordar la forma de realizar cierto tipo de tareas. Las personas con discapacidad mental o emocional necesitan información clara y concisa para evitar desconcentrarse o abrumarse. Algunas personas con trastornos epilépticos son vulnerables a los destellos visuales o sonoros a ciertas frecuencias, por lo que necesitan desactivar las animaciones, texto parpadeante, 0 sonido. También se considera en este grupo a las personas que se encuentran alteradas temporalmente producto del alcohol, el tabaco o las drogas [Bre2005].

\subsection{Derecho a la accesibilidad}

La falta de niveles aceptables de accesibilidad en los sitios Web es un problema importante en los tiempos actuales y futuros. Para tener una idea de su magnitud haremos referencia a diversos estudios internacionales que poseen directa relación con el tema. Hacia fines del siglo XX, en EE.UU., casi el $20 \%$ de las personas tenían problemas de discapacidad física, en Europa cerca de 40 millones, mientras que en el año 2002, en España, este número estaba en el 9\%, casi 4 millones de personas [Mon2003]. Según un informe de la Organización para la Naciones Unidas (ONU), se calcula que actualmente en el mundo hay más de 650 millones de habitantes en esta condición, es decir, un 10\% de la población [ONU2001]. En lo que respecta a los usuarios de la Web el porcentaje alcanza el 9,2\% aproximadamente [Mon2003], es decir, que casi uno de cada diez usuarios presenta problemas de discapacidad. Es muy probable que con el paso del tiempo las cifras aumenten en función de que el porcentaje de la población con discapacidades puede incrementarse producto del aumento de la longevidad, sobre todo en los países ricos. El número de personas mayores de 60 años en los países desarrollados está en torno al 20\% de la población. En el año 2001 habitaban en Europa 77 millones de personas con más de 60 años. Hacia el 2050 se calcula que esta cifra alcanzará un tercio o más de su población, habiendo dos personas mayores por cada niño. En España, por ejemplo, el 44\% de la población será mayor de 60 años. En los países subdesarrollados, la proporción de la población mayor de 60 años o de tercera edad se cuadruplicará hacia el 2050 estando en el orden del 20\%. El mismo informe de la ONU estima que en el 2050 varios países o regiones tendrán poblaciones con más del $10 \%$ por encima de los 80 años de edad [ONU2001].

La situación actual y las proyecciones a futuro indican que la accesibilidad será un requisito que irá en aumento. Por ello, a nivel mundial se han producido avances importantes de la legislación sobre accesibilidad, sobre todo en EE.UU y Europa, donde ya existen disposiciones especiales para garantizar el acceso equitativo a los sistemas informáticos por parte de los usuarios con discapacidades. Se estima que en el corto plazo será una obligación legal adecuarse a las políticas de accesibilidad, sobre todo si 
ese es el medio que utilizan las personas con discapacidad para trabajar, producir o estudiar [Nie2000]. La adecuación del entorno virtual $\mathrm{WebCT}^{2}$ a las reglamentaciones definidas por EE.UU. y Australia en materia de accesibilidad son un claro ejemplo [Dey2002].

En el caso de EE.UU., los derechos de los ciudadanos con discapacidades se encuentran protegidos por la Americans with Disabilities Act (ADA) de 1990 [Mon2003]. El apartado III del ADA prohíbe la discriminación por discapacidad en los locales públicos y requiere la adaptación de éstos para asegurar su accesibilidad. Desde 1996 se aplica a los sitios Web, luego de un dictamen del Departamento de Justicia que consideró a los sitios Web como lugares públicos [She2001][Jac2002]. Por otra parte el Acta de Rehabilitación de 1998, más precisamente su Sección 508, requiere que todos los estamentos gubernamentales del país aseguren que los productos o servicios digitales que empleen, ya sean desarrollos propios o adquiridos a terceros, sean accesibles para personas con discapacidad [RAA1998].

En el caso de Europa, está vigente el plan de acción e-Europe 2005 cuyo objetivo es acercar la Sociedad de la Información a los ciudadanos de la Unión Europea. Uno de los planes de acción específicos se denomina e-Accessibiliy, que recomienda la adopción de directrices sobre accesibilidad de la Web. Sumado a ello, muchos países miembros tienen su propia legislación. Tal es el caso del Reino Unido, Suiza, España, Portugal, Italia, Irlanda, Alemania, Francia, Suecia, Findandia, y Dinamarca [Sha2006]. No solo EE.UU. y la Unión Europea poseen legislación al respecto sino que también han avanzado en este sentido otros países como Canadá, Israel, India, Japón, Australia, y Nueva Zelanda [Sha2006].

En nuestro país fue sancionada recientemente la ley 26.653, que establece las normas y requisitos que deberán implementar los organismos públicos y privados, que tengan, 0 deseen tener, algún tipo de relación con el Estado Argentino. Esta ley busca garantizar el acceso a la información en páginas Web a todas las personas con discapacidad. La iniciativa, denominada "Ley de accesibilidad de la información en las páginas Web" establece el cumplimiento de un conjunto de pautas de diseño que aseguren condiciones de igualdad y trato en el acceso a contenidos digitales, evitando cualquier forma de discriminación. Además, establece que las normas y requisitos de accesibilidad deberán ser implementados en un plazo máximo de veinticuatro meses para aquellas páginas existentes con anterioridad a la entrada en vigencia de la ley (noviembre de 2010), y de 12 meses, para las que se encuentren en proceso de elaboración. La ley busca ampliar las posibilidades y oportunidades de navegación, participación o acceso efectivo a los sitios y entornos virtuales a todos los usuarios, independientemente de sus capacidades perceptuales o motrices, o las diversas configuraciones de software o hardware que utilicen [INA2010].

\subsection{Guías y pautas de accesibilidad}

Para poder desarrollar sitios Web accesibles por todo tipo de usuarios hay que tener en cuenta una serie de principios. Los más conocidos y aceptados por la comunidad informática internacional son los elaborados por la ISO y el W3C. En el primer caso, la ISO/TS 16071, enmarcada dentro de las especificaciones ergonómicas, proporciona una guía sobre accesibilidad para interfaces hombre-máquina y orientaciones para el diseño

\footnotetext{
${ }^{2}$ WebCT (Web Course Tools) es un entorno virtual de enseñanza y aprendizaje de carácter comercial que adquirió gran relevancia en los EEUU.
} 
de software accesible [ISO2003]. EI W3C cuenta con un grupo de trabajo denominado Web Accessibility Initiative (WAI) que busca promover un alto grado de accesibilidad a la Web para las personas con discapacidad mediante el aporte de estrategias, guías y recursos [WAI2005].

\subsubsection{ISO/TS 16071}

La ISO ha generado una especificación técnica que proporciona guías en el diseño de software, a los efectos de lograr que el producto final desarrollado sea accesible para el usuario, y se pueda conectar e interaccionar con otras herramientas de apoyo como lectores de pantalla, Braille, o amplificadores de pantalla. Esta norma se denomina "Ergonomic of human-system interaction. Guidance on accessibility for human-computer interfaces", y apunta a mejorar la interfaz, así como también hacer un uso óptimo de los recursos mediante la incorporación, en etapas tempranas del diseño, de aquellos rasgos de accesibilidad que hayan sido requeridos específicamente por los usuarios. Se basa fundamentalmente en el acceso desde entornos laborales, educativos y hogareños, por usuarios con un amplio rango de discapacidades (visuales, auditivas, cognitivas, motoras, etc.) así como también adultos mayores y personas afectadas por impedimentos temporales [ISO2003].

\subsubsection{Web Accessibility Initiative (WAl)}

La WAl se basa en la necesidad de que las personas con discapacidad tengan acceso a la Web debido al papel cada vez más importante que tiene en la sociedad. Esta iniciativa desarrolla pautas para la accesibilidad de los sitios Web, los navegadores y las herramientas de edición, a los fines de facilitar el uso de la Web por las personas con discapacidad. La WAI es parte del W3C y posee cinco áreas de trabajo: tecnología, directrices, herramientas, formación y difusión, e investigación y desarrollo. Este grupo ha definido una serie de pautas de accesibilidad Web que buscan verificar que las tecnologías creadas para la Web tengan en cuenta la accesibilidad [WAl2005]. El objetivo de dichas pautas es facilitar la creación de sitios Web accesibles para todos, incluidas las personas con discapacidad [W3C99a]. Constituyen un estándar que apunta a establecer los criterios básicos que deben respetarse en el diseño Web a los efectos de garantizar buenos niveles de accesibilidad [Nie2000]. Dentro del área de guías o normas de accesibilidad han desarrollado tres tipos de pautas: Web Content Accessibility Guidelines, User Agent Accessibility Guidelines, y Authoring Tool Accessibility Guidelines [WAI2005].

\subsubsection{Web Content Accessibility Guidelines (WCAG)}

Son las más utilizadas por el usuario final a los efectos de comprobar el grado de accesibilidad de un sitio Web. Durante casi una década estuvo vigente la versión 1.0, hasta que hacia fines de 2008, dos años después de lo previsto, fue aprobada por la W3C la versión 2.0 (pueden consultarse en http://www.w3.org/TR/WCAG20/).

\subsubsection{User Agent Accessibility Guidelines (UAAG)}

Son recomendaciones para que los navegadores Web y los programas multimedia sean accesibles para todos. Las UAAG muestran cómo hacer para que los navegadores, reproductores multimedia y software especial para usuarios con discapacidad, sean accesibles, en especial cómo incrementar la accesibilidad al contenido Web. Las UAAG están pensadas para los desarrolladores de navegadores Web, reproductores multimedia y otros tipos de software específicos. Contienen un conjunto de puntos de verificación que incluyen el acceso a todo el contenido, control del usuario sobre la forma en que se 
muestra el contenido, control del usuario sobre la interfaz e interfaces de programación de estándares.

\subsubsection{Authoring Tool Accessibility Guidelines (ATAG)}

Son recomendaciones para que las herramientas de diseño de páginas Web y sus resultados sean accesibles para todos. Las ATAG sirven de guía para los desarrolladores de aplicaciones que generan código para la Web. Estas herramientas son software que se utiliza para crear páginas y contenido Web. Uno de los objetivos principales de las ATAG es definir la forma en la que las herramientas ayudan a los desarrolladores Web a producir contenido que cumpla las Pautas de Accesibilidad en la Web. Las herramientas de autor a las que hace referencia tienen que ver con edición para producir contenido Web, almacenamiento de contenido en formato Web, transformación de documentos a un formato Web, producción multimedia, administración o publicación de sitios Web y diseño. Contienen 28 puntos de verificación que proporcionan información sobre la producción de contenido accesible, solicitud de información sobre accesibilidad al autor de contenido, formas para corroborar y corregir el contenido que no es accesible, integración de la accesibilidad en el estilo, ayuda y documentación, formas de hacer la herramienta en sí misma accesible para personas con discapacidad, y formato de documento técnico.

\subsection{Accesibilidad versus Usabilidad}

Como se ha señalado anteriormente, la accesibilidad y la usabilidad pueden ser consideradas como factores claves a la hora de definir la utilidad de un sitio Web [Gra2005]. Existen diferentes miradas respecto a la relación que guardan estos dos conceptos.

Hay autores que plantean que se trata de dos aspectos complementarios pero íntimamente relacionados, que se refuerzan mutuamente, en el sentido que cuanto más accesible sea un sitio más usable será, y viceversa [Rom2001]. No se puede hablar de subordinación sino que tanto la accesibilidad como la usabilidad estarían a un mismo nivel. Además, muchos aspectos de la accesibilidad afectan directamente a la usabilidad de un sitio Web. Esto es así porque la accesibilidad mejora o aumenta la usabilidad en el sentido de que la misma asegura que los sitios Web sean más fácilmente navegables y se pueda acceder a ellos a través de una diversidad de dispositivos, y no solamente desde un navegador gráfico [Rom2001b]. En consecuencia, al igual que la usabilidad, podría definirse la accesibilidad como el atributo de calidad de un producto o servicio Web. Este atributo de calidad haría referencia a la posibilidad de que el producto o servicio pueda ser accedido y usado por el mayor número posible de personas, independientemente de las limitaciones propias del individuo o de las derivadas del contexto de uso [Mon2004b]. El estándar ISO/TS 16071 apoya esta idea diciendo que "la usabilidad de un producto, utilidad, entorno o equipo es que pueda ser utilizado por personas con el rango más amplio de capacidades" [ISO2003]. Es decir, que la accesibilidad permite que los adultos mayores y las personas discapacitadas puedan acceder sin inconvenientes al contenido de la Web, mientras que la usabilidad permite que cualquier persona, discapacitada o no, pueda utilizarla de una manera sencilla, productiva y eficaz [Goi2004]. En definitiva la usabilidad y accesibilidad serían disciplinas complementarias, y lo deseable, rentable y eficaz es que se apliquen conjuntamente [Rom2001].

Otros autores, en cambio, plantean que la accesibilidad no sólo implica la necesidad de facilitar acceso, sino también la de facilitar el uso. Es decir, que la accesibilidad haría suyas algunas de las características propias de la usabilidad. En este sentido, es difícil e innecesario, en muchos casos, distinguir entre usabilidad y accesibilidad [Hen2002]. Sin 
embargo, si ponemos el acento desde la usabilidad, entendida como la búsqueda del mayor grado posible de efectividad, eficiencia, y satisfacción de los usuarios, la accesibilidad sería una condición necesaria pero no suficiente para lograr altos índices de usabilidad. Es decir, para que un sitio Web sea usable, entre otras cosas, necesariamente debe ser accesible. Desde esta mirada, no existe la misma relación a la inversa, debido a que un sitio Web puede cumplir con todas las pautas de accesibilidad requeridas y no ser usable. En tal caso, la accesibilidad sería entendida como parte de la usabilidad, como requisito para la usabilidad. Este último enfoque es el que será considerado para este trabajo.

\subsection{Conclusiones}

La rápida masificación del acceso y uso de la Web a escala mundial ha posibilitado que los usuarios se transformen en prosumidores, es decir, que al mismo tiempo de ser consumidores, son productores de contenidos. Sin embargo, las limitaciones y el uso inadecuado de las tecnologías de generación y publicación de contenido para la Web, presentan nuevos desafíos para el acceso universal [Mon2004b]. La accesibilidad se ocupa de esta problemática estableciendo pautas para tener en cuenta las necesidades de cada usuario, sus preferencias y/o limitaciones [Gra2005].

En general, se asocia la accesibilidad con las personas que poseen algún tipo de discapacidad, pero esto no es realmente así, porque también existen otro tipo de limitaciones tecnológicas, derivadas del contexto de uso y del dispositivo de acceso empleado, tanto hardware como software [Van2000] [Mon2004b].

En este sentido, la accesibilidad busca garantizar que la mayor cantidad de usuarios posible pueda acceder a los contenidos Web, independientemente del dispositivo empleado, edad, idioma, deficiencia visual, motriz, auditiva, o cognitiva. Para que el contenido sea accesible debe presentarse al usuario de manera clara, con un lenguaje simple y con mecanismos de navegación intuitivos para moverse entre las páginas, separando el contenido de la presentación, para que puedan utilizarse múltiples dispositivos de navegación según las necesidades de cada usuario.

Es un tema tan importante que ya forma parte de los derechos de los usuarios, y muchos países han legislado al respecto [Dey2002] [Mon2003] [She2001] [Jac2002] [RAA1998], incluso nuestro país [INA2010], de modo de garantizar el acceso equitativo a la Web.

Para poder desarrollar sitios Web accesibles se han establecido una serie de principios. Los más conocidos y aceptados por la comunidad internacional son los elaborados por la ISO [ISO2003] y el W3C [WAl2005].

Hay autores que sostienen que accesibilidad y la usabilidad son aspectos complementarios, pero íntimamente relacionados, que se refuerzan mutuamente [Rom2001]. Otros plantean que la accesibilidad no sólo implica la necesidad de facilitar acceso, sino también facilitar el uso, con lo cual no sería necesario distinguir entre usabilidad y accesibilidad [Hen2002]. En este trabajo se adopta otra mirada, considerando a la accesibilidad como requisito para la usabilidad, dado que un sitio Web usable necesariamente debe ser accesible, aunque no así a la inversa. 


\section{Capítulo 4: Métodos de evaluación de usabilidad}

\subsection{Evaluación de la usabilidad}

La principal actividad en el proceso de usabilidad es la evaluación [Fer2001]. La evaluación comprende un conjunto de métodos y técnicas que analizan la usabilidad de la versión final de un sistema o a lo largo de sus diferentes etapas de desarrollo. Evaluar la usabilidad de un sitio Web es extremadamente útil ya que permite descubrir qué errores, y qué aciertos de diseño puede tener el sitio [Mon2006]. La evaluación de la usabilidad ayuda a determinar cuál es el nivel actual de la aplicación, y si el diseño elegido realmente funciona. Los datos que se recaban mediante la observación del desempeño del usuario frente a la aplicación son muy valiosos, puesto que ayudan a detectar posibles falencias del sistema [Bae2002].

Varios autores coinciden en que la usabilidad puede ser medida cuantitativamente siempre que se utilicen las variables y métodos adecuados [Nie1993][Man1997]. Por ejemplo, se podría medir la usabilidad a través del tiempo empleado en localizar una función o menú determinado, el número de pasos que se necesitan para llevar a cabo una función, el tiempo empleado en realizar una tarea específica, o el tiempo que tarda un usuario en aprender a dominar el sistema. Aunque sin perder de vista que no todos los atributos de la usabilidad se evalúan de la misma manera, en algunos casos será necesario utilizar tests, expertos, u otros métodos.

Por ejemplo, para especificar o medir la usabilidad desde la definición propuesta por la ISO 9241 [ISO1998b], es necesario descomponer los factores de eficacia, eficiencia y satisfacción, así como los aspectos relevantes del contexto de uso, en atributos que puedan ser medidos y verificados. La especificación o medida de la usabilidad puede entonces expresarse por el grado en que se logran los objetivos que se pretenden del sistema (eficacia), los recursos que han de gastarse para lograr dichos objetivos (eficiencia), y el grado en que los usuarios encuentran aceptable el conjunto del sistema (satisfacción). El contexto de uso integra las características o atributos relevantes de la tarea, usuario, equipamiento, y medio ambiente que tienen influencia en la usabilidad [San2001].

\subsubsection{Clasificación}

Existen numerosas propuestas y relevamientos sobre métodos de evaluación. De acuerdo al relevamiento realizado por Alva [Alv2004], se encuentran las siguientes propuestas de clasificación, las cuales presentaremos cronológicamente: Scriven (1967) apunta a los objetivos de la evaluación y los divide en evaluación formativa y sumativa. Nielsen y Molich (1990) distinguen los métodos de evaluación en cuatro categorías: formal, automática, empírica y heurística. Whitefield, Wilson, y Dowell (1991) proponen una clasificación de acuerdo a los recursos que están disponibles durante la evaluación usando cuatro categorías: usuarios reales, computadoras reales, usuarios representativos, y computadoras representativas. En base a ello ubican estas categorías en una matriz de dos por dos, y proponen clasificarlos en: método observacional, reporte de especialistas, reportes de usuarios, y método analítico. Preece (1993), en cambio, establece cuatro categorías: evaluación de expertos (heurística), evaluación observacional, evaluación por investigación y evaluación experimental. Hix y Hartson (1993) distinguen dos tipos de evaluación: analítica y empírica. Coutaz y Balbo (1994) definieron cinco dimensiones que delimitan el tipo de método a utilizar: recursos de conocimiento, recursos de ambiente, recursos humanos, recursos hardware, y resultados. 
Nielsen (1995) reelabora la clasificación realizada junto a Molich en 1990 y establece la siguiente: métodos formales, métodos informales o de inspección, métodos empíricos 0 de test, y métodos automáticos. Baecker (1995) considera los siguientes métodos: experimentales, observacionales, basados en preguntas, de evaluación cooperativa, GOMS (Goals Operators Methods and Sequences), inspecciones cognoscitivas, y evaluación heurística. En tanto que Wixon y Wilson (1997), basados en el diseño centrado en el usuario, proponen clasificarlos en: evaluación formativa vs. sumativa, método de evaluación de descubrimiento vs. método de decisión, evaluación formalizada vs. evaluación informal, evaluación con usuarios comprometidos vs. no comprometidos, y evaluación completa vs. evaluación de componente.

De las propuestas presentadas se puede observar que hay algunas coincidentes 0 similares como los métodos donde participan expertos, aquellos donde el usuario es el evaluador que emite el juicio final, o los métodos en los cuales el comportamiento del usuario mientras utiliza el producto es observado por expertos que determinan el grado de usabilidad. También, se destacan los métodos que pueden ser utilizados en la fase de aceptación del producto o durante todo el ciclo de vida del desarrollo, así como también aquellos donde el resultado de la evaluación puede ser o no cuantificable.

Desde un punto de vista más general, Olsina [Ols2002] propone una posible clasificación de la calidad Web, que incluye a la usabilidad y comparte muchos de sus instrumentos de medición. Esta propuesta agrupa los métodos de acuerdo a su clase, su tipo, forma de aplicación, y nivel de esfuerzo (figura 11). 


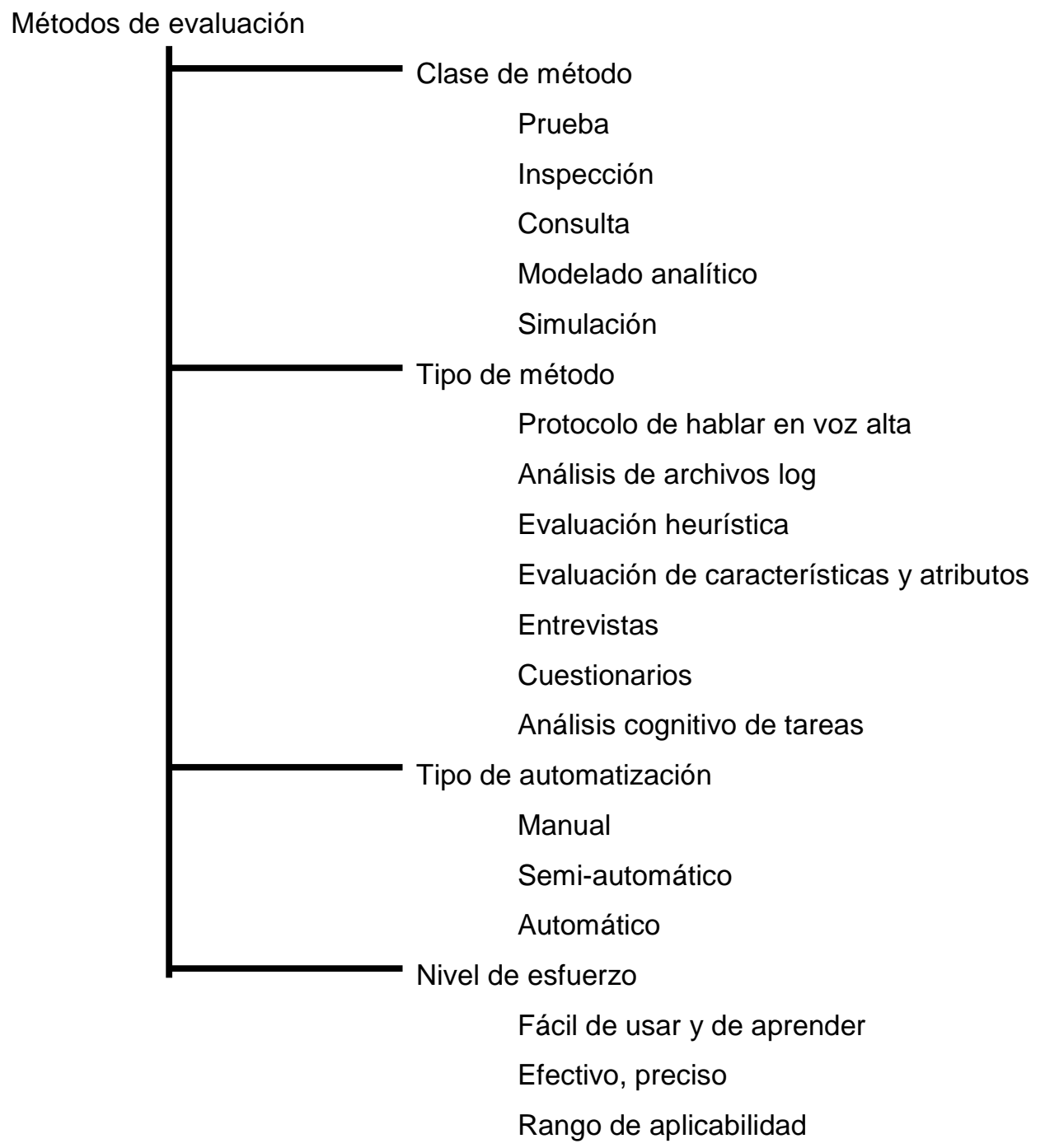

Figura 11 - Olsina: métodos de evaluación de calidad web

Otro criterio posible es el planteado por Granollers [Gra2005] donde se clasifican según el lugar de realización, tipo de método, forma de aplicación, y tipos de implicación de los usuarios finales (figura 12). 


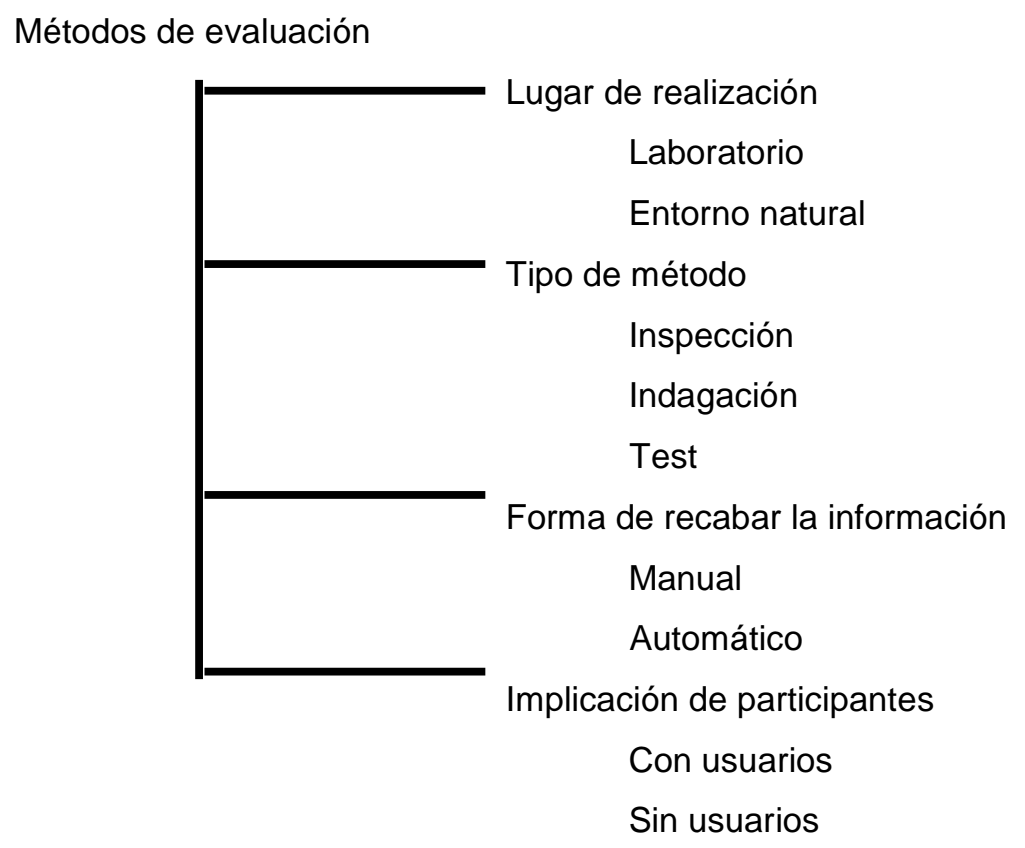

Figura 12 - Granollers: métodos de evaluación

Dentro de la clasificación anterior los tipos de métodos de evaluación son lo realmente interesante, puesto que determinan el lugar de realización, el tipo de automatización y el grado de implicación de los participantes. Los métodos de evaluación por inspección, indagación, y test son ampliamente analizados por numerosos autores destacando sus características principales, formas aplicación, etc. [Alv2004][Gra2005]. Es muy común advertir que a menudo se confunde el método de evaluación con la técnica, de allí que para referirse a los métodos de evaluación varios investigadores utilizan el término técnica.

\subsubsection{Lugar de realización de la evaluación}

Existen dos maneras de realizar las evaluaciones: en laboratorios especialmente preparados para tal fin o en el entorno natural donde el usuario realiza su tarea. Cada una de las alternativas tiene sus ventajas y desventajas.

- Laboratorios de usabilidad

Ventajas:

- Permite evaluar la acción de un usuario aislado sin distracciones ni interrupciones.

- Permite la evaluación en entornos no accesibles.

- Permite la creación de situaciones poco comunes y controladas.

Desventajas:

- Ausencia de un contexto. Situación antinatural.

- No se consideran las distracciones e interrupciones que forman parte del entorno de trabajo normal del usuario.

- Entorno natural

Ventajas: 
- Permite evaluar el producto en situaciones reales.

- Mejora el análisis de requisitos al trabajar con el usuario en su entorno de trabajo.

Desventajas:

- Ruido ambiental, interrupciones: dificultad del trabajo.

- Influencia del evaluador en el lugar de trabajo.

\subsubsection{Forma de recabar información}

- Automática: se disponen de mecanismos de hardware y software que facilitan la comprobación de los aspectos a evaluar. Son aplicables a sistemas ya finalizados.

- Manual: precisan de más tiempo para recabar la información. Permiten evaluar aspectos que no se corresponden con ningún patrón preestablecido. Se pueden realizar en cualquier parte del proceso de desarrollo y con cualquier prototipo del sistema.

\subsubsection{Implicación de participantes}

Los usuarios finales son en definitiva a quienes está dirigido el producto. Según el grado de participación de los mismos es posible determinar dos tipos de evaluación:

- Con usuarios

- Son los usuarios reales y representativos o implicados en el sistema los que realizan las pruebas.

- Permiten implicar a los usuarios en el proceso de diseño de la aplicación.

- Es difícil reclutar a usuarios reales.

- Sin usuarios

- Es difícil dar con el perfil del usuario representativo.

- El sistema es evaluado por expertos.

- Son más rápidos y, generalmente, más económicos.

- Se carece de la información que puede aportar un usuario real.

- Permite detectar problemas de consistencia, estandarización, o de funcionalidad.

\subsubsection{Métodos}

Existen distintos métodos para evaluar la usabilidad de un sistema que intentan medir diferentes aspectos de esta [Cob2005][Gra2005]. Su uso depende de variables tales como grado de implicación del usuario, escenarios de tarea, costo, disponibilidad de tiempo, personal calificado para interpretar los datos, entre otros factores [Bae2002]. Incluso, es altamente beneficioso no utilizar un solo método de evaluación, sino varios que se complementen mutuamente y permitan observar las características del producto desde diferentes puntos de vista.

Hay acuerdo en clasificar las formas de evaluar la usabilidad de una aplicación Web en tres grandes métodos: inspección, indagación y test [Cat2000][Flo2000b][Hom2003] [Lei2003][Alv2005][Cob2005][Gra2005][Mon2006]. A su vez cada método consta de diferentes formas o variantes de aplicación denominadas técnicas. Estas técnicas pueden ser clasificadas por numerosos criterios, ya que no existe un criterio común que permita agruparlas. Incluso muchas veces los criterios impiden una clasificación del todo clara, debido a que no son totalmente independientes unos de otros [Rod2001]. En este sentido Hom [Hom191998] presenta una revisión de más de 30 técnicas para la evaluación de usabilidad, a partir de la clasificación en métodos de inspección, indagación, y test. A continuación se detallan: 
- Inspección

- Evaluación heurística

- Inspecciones formales de usabilidad

- Inspección de características

- Inspección de consistencia

- $\quad$ Inspección de estándares

- Paseo cognitivo

- Listas de comprobación

- Indagación

- Indagación en el contexto

- Estudio etnográfico / Observación de campo

- $\quad$ Entrevistas y Grupos orientados

- Encuestas

- Cuestionarios

- Sesiones guiadas

- $\quad$ Registro por el usuario

- Test

- $\quad$ Realización de medidas

- $\quad$ Protocolo de preguntas

- $\quad$ Protocolo del pensamiento manifestado

- $\quad$ Protocolo del descubrimiento conjunto

- $\quad$ Seguimiento visual

Por su parte Floría [Flo2000b], toma como base la clasificación anterior y la reformula de la siguiente manera:

- Inspección

- Inspecciones

- $\quad$ Evaluación heurística

- Recorridos

- $\quad$ Listas de comprobación

- $\quad$ Otras perspectivas

- Indagación

- $\quad$ Aproximación

- $\quad$ Participación remota

- $\quad$ Generación de ideas

- $\quad$ Observación experta

- Test

- $\quad$ Protocolos de expresión del usuario

- $\quad$ Medida de desempeño

- Variantes: tutorado, descubrimiento conjunto, seguimiento, instrucción previa. 
En un trabajo más reciente realizado por Granollers [Gra2005], relacionado con la definición del modelo de Diseño Centrado en el Usuario denominado MPlu+a (acrónimo de Modelo de Proceso de la Ingeniería de la usabilidad y de la accesibilidad), propone la siguiente clasificación:

- Inspección

- Evaluación heurística.

- Recorridos.

- Recorrido cognitivo.

- Recorrido de usabilidad plural.

- Recorrido cognitivo con usuarios.

- Inspección de estándares.

- Indagación

- Observación de campo.

- Estudio de campo.

- Grupo de discusión dirigido.

- Entrevistas.

- Cuestionarios.

- Grabación del uso o análisis de logs.

- Test

- Medida de las prestaciones.

Pensando en voz alta.

Interacción constructiva.

Test retrospectivo.

Test remoto.

Método del conductor.

Ordenación de tarjetas.

Cada uno de los métodos, posee características propias que lo diferencian claramente de los otros dos. Los de indagación, por ejemplo, se basan fuertemente en el análisis del producto o prototipo mediante la participación de expertos. Los de test implican la participación del usuario en la evaluación. Por otra parte, son claramente complementarios y factibles de aplicar en diferentes etapas del desarrollo, así como también sobre productos que ya están siendo utilizados.

A efectos de éste trabajo se entiende a los métodos como el tipo de procedimiento utilizado y a la técnica como una forma determinada de aplicar dicho método. De allí que consideremos tres tipos de métodos: Inspección, Indagación, y Test. Dentro de cada método se aglutinan las diferentes técnicas o formas de implementarlo, de acuerdo a las propuestas analizadas [Cat2000][Flo2000b][Hom2003][Lei2003][Alv2005][Cob2005] [Gra2005][Mon2006]. En virtud que el interés está puesto en elaborar un instrumento de evaluación para entornos virtuales de enseñanza y aprendizaje que tome como eje la usabilidad, se describirán sintéticamente los métodos principales y sus técnicas relacionadas, basándose en las distintas revisiones. En el capítulo 6, se retoma el tema analizando en detalle cada método de manera tal de abordar luego la propuesta de evaluación de esta tesis con las bases conceptuales ya revisadas y tratadas. Es importante aclarar que el nombre del método puede variar en función del autor o de las traducciones que se hayan realizado. 
- Método de Inspección

Técnicas

- Inspecciones: formal, de características, de consistencia, de estándares

- Evaluación heurística o por criterios

- Recorridos: cognitivos, pluralistas, con usuarios

- Listas de comprobación

- Método de Indagación

Técnicas

- Aproximación: contextual, por grupos, individual

- Participación remota o sesiones guiadas

- Registro por el usuario

- Captura de pantallas

- Generación de ideas

- Observación experta

- Pantallazos de situación

- Encuestas

- Cuestionarios

- Entrevistas

- Seguimiento visual

- Seguimiento de uso

- Método de Test

\section{Técnicas}

- Clásico o formal

- Variantes del clásico: tutorado, seguimiento, instrucción previa, descubrimiento conjunto, retrospectivo, rastreo visual remoto.

- Protocolos de expresión del usuario: en voz alta, preguntas

- Evaluación de desempeño.

\subsubsection{Método de Inspección}

Está basado en normas generales y en la experiencia, habilidad y conocimiento de los evaluadores. De allí que es llevado a cabo por expertos. Los expertos realizan un examen de la interfaz y emiten un juicio sobre la misma. Generalmente uno de los participantes actúa como moderador, destacando las fortalezas y las debilidades de la aplicación. Las técnicas de aplicación del método de inspección son las siguientes:

1. Inspecciones: de acuerdo a sus características hay varias aproximaciones.

- Inspección Formal: los inspectores recorren meticulosamente las tareas con los propósitos y objetivos de los usuarios en mente, de forma similar a los paseos cognitivos, aunque el énfasis radica menos en la teoría cognitiva y más en el hallazgo de errores.

- Inspección de Características: la inspección de características analiza únicamente un conjunto de características determinadas del producto, proporcionándose escenarios de usuario para el resultado final a 
obtener del uso del producto. Así, se trabajará frecuentemente con prototipos verticales ${ }^{1}$.

- Inspección de Consistencia: el objetivo de las inspecciones de consistencia es asegurar dicha consistencia a través de múltiples productos procedentes del mismo esfuerzo de desarrollo, como pueda ser una suite de ofimática o un sitio Web.

- Inspección de Estándares: las inspecciones de estándares garantizan el ajuste a los estándares industriales. No hay que olvidar que productos diseñados para ser comercializados en un país en particular, deben poseer la conformidad con los estándares de ergonomía del país en cuestión.

2. Evaluación Heurística: es una variante de la Inspección Formal donde los especialistas en usabilidad analizan que cada elemento de la interfaz de usuario siga los principios de usabilidad establecidos.

3. Recorridos: se realiza una revisión detallada de todas las acciones asociadas a la consecución de una o más tareas que el usuario debe poder satisfacer con el uso del sistema. Inicialmente fueron pensados para ser realizados por expertos evaluadores con la ayuda de diseñadores. En la actualidad también incorporan usuarios.

- Recorridos o Paseos Cognitivos: derivan de los análisis cognitivos y reciben este nombre porque el especialista que realiza la sesión recorre un escenario de tareas determinado como habría de hacerlo un usuario tipo. Combina el recorrido de software con un modelo cognitivo de aprendizaje por exploración. Permite evaluar la facilidad de aprendizaje a través de prototipos del sistema, haciendo posible evaluar el software en las etapas iniciales de desarrollo, aún cuando no está del todo claro el contexto de uso. Los recorridos cognitivos pueden ser individuales o de conjunto según se plantee la sesión de forma individual o en grupo (usuarios, desarrolladores y profesionales de la usabilidad).

- Recorridos pluralistas: se trata de una reunión integrada por usuarios, desarrolladores, y expertos de usabilidad que recorren un escenario de tareas, discuten y evalúan cada elemento de diálogo. Consta de cinco características:

- Incluye tres tipos de participantes: usuarios, desarrolladores, y expertos en usabilidad.

- El sistema es presentado con paneles impresos en el mismo orden en que deberán aparecer en la aplicación.

- Todos los participantes toman el rol del usuario del sistema.

- Los participantes escriben las acciones que ellos harían para completar la tarea dada.

- El grupo discute las soluciones. Los usuarios hablan primero y, sólo después, los desarrolladores, y los expertos de usabilidad ofrecen sus opiniones.

El recorrido pluralista de usabilidad es aplicable en las fases tempranas de un producto en desarrollo, cuya documentación y

\footnotetext{
${ }^{1}$ Los prototipos verticales muestran la funcionalidad exacta de un producto para una pequeña parte del conjunto completo.
} 
ayuda no está disponible y donde no hace falta un sistema en funcionamiento. Sin embargo, si está disponible un prototipo, el administrador podrá usarlo para mostrar como son los diálogos y dar una visión del estilo general de la interfaz.

- Recorridos con usuarios: se realiza un recorrido cognitivo por expertos (tradicional), y una vez concluido se incorporan los usuarios para realizar de manera individual y sin explicaciones, las tareas definidas. Se pide a los usuarios que expresen libremente en voz alta sus pensamientos, sentimientos y opiniones (similar al protocolo de pensamiento en voz alta). Al finalizar las tareas cada usuario debe anotar los principales defectos encontrados y puede comentar con el evaluador los problemas identificados para dar a conocer su punto de vista de forma más detallada. Finalmente, los expertos documentan los resultados finales.

4. Listas de Comprobación: ayudan a asegurar que los principios de usabilidad sean considerados en un diseño. Normalmente, las listas de comprobación se utilizan en combinación con algún otro método de inspección y sirven de referencia. Hay dos tipos:

- Listas de Comprobación (también conocidas como guías): se le proporciona al experto una lista de aspectos a comprobar.

- Listas de Comprobación Basadas en Escenarios: se puede entender como una particularización de la anterior en la que la inspección se lleva a cabo a través de tres escenarios: usuario novato, usuario experto, y manejo de errores. Para cada uno se proporcionará una lista de aspectos a comprobar.

Los más destacados son la inspección formal, la evaluación heurística, y el paseo cognitivo.

\subsubsection{Método de Indagación}

Es llamado también método de investigación o sondeo. Consiste en hablar y/o observar al futuro usuario en su ambiente natural de trabajo. Se utiliza para capturar requerimientos en etapas tempranas de desarrollo, mediante prototipos o maquetas, sin necesidad de tener la versión final de la aplicación. Dentro de las técnicas podemos encontrar diversas formas de interactuar con el usuario:

1. Aproximación Contextual: es posible distinguir dos variantes claramente diferenciadas.

- Indagación en el Contexto: se trata de un método estructurado de entrevista de campo caracterizado por la necesidad de comprender el contexto, de asimilar al usuario en el proceso de diseño y de plantear un objetivo en su aplicación.

- Estudio etnográfico u Observación de Campo: consiste en la observación del usuario y su interacción con el producto en su entorno habitual, prescindiendo de las ventajas del laboratorio a la hora de captar y registrar datos.

2. Aproximación por Grupos:

- Grupos Orientados: hay un moderador y su proceder es determinante para el éxito de la sesión.

- Grupos de Debate: el moderador ya no tiene la misión de estimular y guiar la discusión sino que conduce, establece y propone los temas a 
tratar en las sesiones. Los usuarios debaten ideas y opciones de diseño según tres etapas básicas: crítica a la situación presente, fantasía en la generación de ideas e implementación de las mismas.

3. Aproximación Individual: consisten en relacionarse con cada usuario cara a cara. Pueden utilizarse diversas técnicas de acuerdo al nivel de profundidad deseada de las respuestas. Las técnicas más utilizadas son las encuestas, cuestionarios o entrevistas.

4. Participación Remota o Sesiones Guiadas: incluye participantes remotos en la evaluación, con el objetivo de probar un producto sin la distancia como obstáculo. Se deja al usuario utilizar el sistema libremente y se va registrando su accionar. Luego, se trata de estudiar el uso del sistema para encontrar problemas de usabilidad que no se pueden hallar cuando simplemente se observa al usuario. Para la obtención de la información se utilizan diferentes técnicas como cuestionarios remotos, sistemas computarizados de captación y colección de datos, registro del usuario, registro de uso real, informe de incidencias criticas del usuario.

5. Registro por el usuario: consisten en sesiones de lápiz y papel en las que se solicita de los usuarios que registren sus acciones y observaciones mientras están interactuando con un determinado producto. Al igual que en las Sesiones Guiadas, se podrá llevar a cabo una evaluación de usuario a distancia. Sin embargo, esta técnica requiere mucho más trabajo por parte de los sujetos participantes. Se utilizan cuando no hay tiempo o recursos para realizar Sesiones Guiadas, o cuando no se requiere tanto nivel de detalle.

6. Generación de Ideas: Se presentan varias posibilidades:

- Generación de estímulos e impresiones mediante escenarios

- Secuencias de Escenarios

- Creación de Escenarios

- Distintas formas de análisis cognitivos

- Cuadros de Organización de Tareas

- Análisis de Tareas

- Matriz de Funcionalidad

- Perspectivas de carácter etnográfico

- Análisis de Usabilidad del Contexto

- Test No Directivo: test de diferentes prototipos por diferentes grupos de usuarios con el objetivo de obtener fuentes no influenciadas.

- Test de Preferencias: sobre una variedad de prototipos del mismo producto, el usuario muestra sus preferencias.

- Estimular la Creatividad: se basa en utilizar información actual, métodos de observación y tendencias, para construir escenarios para hacer el futuro real, comprensible y creíble.

7. Métodos de Observación Experta: hacen referencia a la contratación de los servicios de consultoras o laboratorios especializados.

8. Pantallazos de situación: el usuario captura pantallas en determinados momentos especificados durante una secuencia de acciones llevadas a cabo durante la prueba de un sitio Web. Se usa especialmente cuando las pruebas de usabilidad de un sistema involucran a usuarios separados por grandes distancias o cuando el número de usuarios de prueba es muy grande. Se aplica fundamentalmente en las primeras fases desarrollo del proyecto, y es muy 
adecuada cuando no se requiere un análisis exhaustivo del sitio Web sino más bien de aspectos concretos.

9. Encuestas: involucra la colección formal de datos sobre las impresiones subjetivas del usuario de la interfaz. Los datos son fáciles de obtener y analizar estadísticamente. Son interactivas y pueden ser abiertas o cerradas.

10. Cuestionarios: son listas de preguntas que se distribuyen a los usuarios y que deben retornar respondidas. No son interactivos y requieren del esfuerzo del usuario para leer, comprender la pregunta y responderla escribiendo la respuesta. Permiten obtener información sobre las opiniones, deseos y expectativas de los usuarios potenciales.

11. Entrevistas: se basan en el estímulo y la respuesta. Es necesario contar con una persona que lea las preguntas y anote las respuestas del entrevistado. Este método proporciona resultados inmediatos, contando con la ventaja de la profundidad a la que se puede llegar con el usuario.

12. Seguimiento visual: conocido también como eye tracking, consiste en un aparato de seguimiento ocular que estudia la forma de observar de un ser humano. Captura una amplia variedad de datos como las diferentes trayectorias recorridas en cada observación y la dilatación de las pupilas. Comprenden una variada gama de dispositivos que pueden clasificarse en intrusivos (casco o lentes) y no-intrusivos (cámara que enfoca a la cara).

13. Seguimiento de uso: llamado también logging, consiste en grabar y analizar los datos de navegación de los usuarios en un sitio Web. Pueden utilizarse varias alternativas: los datos grabados en los logs de los servidores o herramientas de análisis Web recogen los datos que nos interesan de los usuarios y los envían a una base de datos, que posteriormente es posible consultar.

\subsubsection{Método de Test}

También llamado empírico, se basa en que los usuarios reales a los que va dirigido el producto trabajen en tareas concretas utilizando el sistema, mientras los evaluadores utilizan los resultados para ver cómo la interfaz soporta las tareas que debe realizar el usuario. Consiste en seleccionar una muestra representativa de personas para que realicen ciertas tareas, mientras se los observa a efectos de determinar si existen problemas en el uso. El objetivo del test no es aprobar o desaprobar el sistema sino permitir la toma de decisiones para adaptar el software a los estilos de trabajo reales de los usuarios, en lugar de forzar a los usuarios a adaptar sus estilos de trabajo al software. Es una de las mejores formas de extraer información sobre el nivel de usabilidad de un sitio Web [Mar03]

El test intenta realizar experimentos para obtener información específica acerca de un diseño. Registra los problemas que encuentran los usuarios cuando tratan de realizar las acciones concretas designadas por el evaluador, así como los tiempos empleados en cada una de ellas. Los test no aportan soluciones a los problemas de diseño, pero sí posibilitan relevar cuales son los aspectos problemáticos que deben solucionarse. Las técnicas más utilizadas son:

1. Protocolos de Expresión del Usuario: el objetivo es captar las impresiones y sensaciones que el usuario manifiesta oralmente. Se distinguen dos tipos:

- Pensamiento en voz alta o manifestado: mientras el participante está realizando una tarea, como parte de un escenario de usuario, se le solicita que exprese en voz alta sus pensamientos, sensaciones, y opiniones mientras interactúa con el producto. Es particularmente útil 
en las etapas iniciales de desarrollo, cuando el margen y flexibilidad para realizar los cambios es alto.

- Preguntas: este método es muy similar al anterior ya que el evaluador, además de pedirle al usuario que exprese sus pensamientos, formula preguntas directas acerca del producto o la tarea que el usuario está realizando.

2. Evaluación de desempeño: el usuario ejecuta tareas predefinidas en un ambiente de laboratorio controlado para obtener datos cuantitativos. Las pruebas deben ser grabadas en video para permitir la obtención de datos, de modo que algunos de ellos puedan ser verificados posteriormente mediante la revisión de la grabación. Involucra observación y análisis del uso del sistema por usuarios representativos ejecutando tareas previamente seleccionadas. Se lleva a cabo en un laboratorio formal de usabilidad, de modo que los datos puedan ser recolectados con precisión y minimizar así posibles interferencias inesperadas. No está permitido que el experimentador interactúe con el usuario durante la prueba, en virtud de preservar los datos cuantitativos de desempeño generados por el usuario durante la tarea.

3. Variantes del Test de Usabilidad clásico

- Método Tutorado: además del propio usuario, se incluye la participación de una persona cuyo rol es el de tutor. Se trata de instruir al usuario en un conjunto de procesos y registrar los requisitos de aprendizaje que requiere este último para alcanzar las tareas.

- Método de Seguimiento: participan del test dos usuarios, uno experto en el dominio de la tarea, y otro inexperto. El usuario inexperto debe realizar la tarea en silencio. Mientras tanto, el usuario experto le explica al evaluador los problemas y reacciones del usuario inexperto. El usuario experto se sitúa, habitualmente, ligeramente por detrás del evaluador "como si fuera su sombra". El evaluador asume con mayor facilidad el modelo mental del usuario experto y se concentra en la interacción entre usuario y sistema. El método es especialmente indicado para tareas muy complejas, que requieren mucha concentración, o para testear sistemas que requieren atención audiovisual del usuario, y, por lo tanto, impiden utilizar el protocolo de pensamiento en voz alta.

- Método de Instrucción previa: en una fase previa se permite a los participantes interaccionar con el sistema para adquirir cierta soltura en su manejo. Después, habrán de ayudar a un usuario inexperto a realizar las tareas que se le encomienden.

- Método del Descubrimiento Conjunto: dos participantes intentan realizar las tareas juntos, mientras están siendo observados. Tal circunstancia se aproxima a la situación real del contexto de uso y aporta más datos. A este método también se lo denomina Aprendizaje por Descubrimiento Conjunto.

- Test Retrospectivo: consiste en la revisión de los registros realizados durante el test.

- Seguimiento o rastreo visual: permite a los evaluadores identificar lo que los participantes miran a lo largo del test de usabilidad. Se utilizan diferentes tecnologías, incluyendo electrodos para la piel, lentes de contacto, y cámaras para el procesamiento de imágenes para determinar qué está mirando el usuario. 
El test de usuarios es el método de evaluación más importante ya que proporciona información de su uso real, observando a los usuarios finales mientras utilizan el sitio para realizar determinadas tareas, siendo la única forma válida de recoger datos fiables de usabilidad [Nie1999].

\subsubsection{Medidas de usabilidad}

De acuerdo a las definiciones de usabilidad analizadas, y sus posibles métodos de evaluación, es necesario contar con algún mecanismo que permita medir el nivel o grado usabilidad de los sistemas. Para ello, debe llevarse a cabo una medición de los atributos que desean ser evaluados en el producto a los efectos de obtener un juicio, es decir, un proceso mediante el cual se asignen valores a esos atributos. Para realizar las mediciones de los atributos se utilizan métricas. La métrica es un valor numérico asignado a algún evento del mundo real, sistema, sitio Web, etc. Una métrica contiene la definición de un método de medición y la escala asociada (nominal, ordinal, etc.). Los tests de usabilidad permiten definir qué porcentaje o grado de usabilidad tiene un sistema, sin perder de vista que los usuarios cumplen un rol fundamental en este proceso, a los efectos que las mediciones sean representativas. Estos tests miden los atributos del producto, no la inteligencia de los usuarios [Rho2000], es decir que, si un usuario no realiza las tareas de acuerdo a lo esperado, le cuesta orientarse dentro del sistema, o no le resulta fácil aprender su manejo, no significa que el usuario sea el problema sino que el producto desarrollado necesita mejorar sus niveles de usabilidad, aún cuando está claro que el tipo de usuario y nivel de experiencia previo cumplen una función importante. Teniendo presente este aspecto existen una serie de criterios para medir la usabilidad planteados por diferentes autores. Por ejemplo, Dix [Dix1998] enumera más de 20 criterios posibles, Rhodes [Rho2000] realiza una categorización y síntesis en términos de la definición de usabilidad presentada en el estándar ISO 9241-11 [ISO1998b], es decir, efectividad, eficiencia, y satisfacción, basándose en las propuestas de Mayhew, Nielsen y Whiteside [Whi1988][May1992][Nie1993b]. El estándar ISO 9241 destaca que no existe una regla general que indique cómo deben ser elegidas o combinadas las mediciones, ya que la importancia de los aspectos depende del contexto de uso y del propósito para el cual se determina la usabilidad [ISO1998b]. En tal sentido, las mediciones de efectividad, eficiencia, y satisfacción se deben repetir en diferentes contextos. En el caso de la efectividad, su medición expresa la precisión y plenitud con los que se logran los objetivos totales o parciales de un sistema en uso. La medida de la eficiencia expresa el nivel de efectividad conseguido en función de los recursos invertidos (esfuerzo, tiempo, materiales y coste financiero). Las medidas de satisfacción expresan la comodidad y aceptabilidad percibida por los usuarios, sobre todo el sistema o partes del mismo. El estándar mencionado aporta una serie de ejemplos al respecto:

- Efectividad: si el objetivo deseado es elaborar un documento de dos páginas en un formato específico, la precisión puede medirse por el número de errores ortográficos y desviaciones respecto al formato de referencia, mientras que la plenitud puede medirse por el número de palabras del documento trascripto dividido por el número de palabras del documento original.

- Eficiencia: si el objetivo deseado es imprimir copias de un documento, entonces la eficiencia puede ser expresada por el número de copias utilizables dividido entre los recursos gastados en la tarea (horas de trabajo, materiales consumidos y gastos del proceso). La eficiencia humana puede ser medida como la eficacia dividida por el esfuerzo, mientras que la 
eficiencia temporal, como la eficacia dividida por el tiempo, y la eficiencia económica, considerando el coste.

- Satisfacción: puede especificarse y medirse mediante una escala de actitudes o bien a través de entrevistas con cuestionario o cómputos de los comentarios negativos y positivos durante su uso.

Las mediciones de usabilidad pueden especificarse a través de los objetivos globales de la tarea o propiedades específicas del sistema. El estándar ISO 9241-11 propone los siguientes ejemplos de medidas asociadas a la usabilidad según los objetivos y propiedades deseadas que pueden ser útiles para organizar tests de usabilidad [ISO1998b]

En sintonía con el estándar ISO 9241-11, Rhodes propone una serie de métricas generales que están orientadas a dar una idea de cómo construir nuevas métricas de acuerdo a lo que desee medir [Rod2000]:

- Efectividad

- Porcentaje de tareas completadas.

- Tasa de éxito versus fracasos.

- Carga de trabajo.

- Número de comandos usados.

- Eficiencia

- Tiempo para completar una tarea.

- Tiempo de aprendizaje.

- Tiempo ocupado en errores.

- Porcentaje o número de errores.

- Frecuencia del uso de la ayuda o documentación.

- Número de repeticiones o comandos fallidos.

- Satisfacción

- Escala de utilidad del producto o servicio.

- Escala de satisfacción con respecto a las funciones y características.

- Número de veces que el usuario expresa frustración o enojo.

- Escala de control de la tarea por parte del usuario versus la tecnología.

- Percepción de que la tecnología da soporte a las tareas según las necesidades del usuario.

Por su parte, Olsina [Ols2002] también define diferentes métricas para medir usabilidad, funcionalidad, confiabilidad y eficiencia, aunque desde nuestro punto de vista están orientadas a una medición mucho más global del sitio:

- Usabilidad

- Comprensibilidad Global del Sitio

- Mecanismos de Ayuda y Retroalimentación en línea

- Calidad de la ayuda

- Indicador de última actualización

- Directorio de direcciones

- Retroalimentación

- Aspectos de Interfaces y Estéticos

- Permanencia y Estabilidad en la presentación de los controles principales

- Aspectos de estilo

- Misceláneas 
- Funcionalidad

- Aspectos de Búsqueda y Recuperación

- Mecanismo de Búsqueda en el Sitio

- Mecanismos de Recuperación

- Aspectos de Navegación y Exploración

- Navegabilidad

- Objetos de Control Navegacional

- Predicción Navegacional

- Confiabilidad

- No Deficiencia

- Errores de Enlaces

- Errores o Deficiencias Varias

- Eficiencia

- Performance

- Accesibilidad

- Accesibilidad de Información

- Accesibilidad de Ventanas

Las métricas sugeridas por Rhodes serán de utilidad para el desarrollo del modelo de evaluación propuesto en esta tesis.

\subsection{Evaluación de la accesibilidad}

En general, la evaluación de la accesibilidad se realiza tomando como base algún estándar internacional de referencia. El estándar perteneciente a la WAI de la W3C es el más utilizado en la actualidad, y se lo considera como un estándar de facto en materia de accesibilidad. A pesar de ello, no hay una norma internacional de accesibilidad aceptada por todos los países, aunque algunos están avanzando en este sentido. Por ejemplo, España posee una norma específica que proporciona una serie de requisitos para conseguir que un portal Web pueda ser utilizado por el mayor número de personas. Dicha norma es compatible con la especificación WCAG 1.0, e incluso contiene un anexo en el que se presenta la equivalencia entre los puntos de la norma española y los de WCAG 1.0 [AEN2004].

Existen diferentes maneras de evaluar el grado de accesibilidad de un sitio Web: de forma automática, o manual. El primer caso hace uso exclusivo de herramientas informáticas, mientras que en el segundo también participan expertos en accesibilidad o usuarios finales del sitio Web. De todas formas, ninguno de los métodos es el ideal sino que cada uno presenta sus ventajas e inconvenientes.

\subsubsection{Revisión Automática}

La revisión automática se lleva a cabo mediante programas informáticos o servicios online que hacen el trabajo de evaluación más eficiente, sobre todo en tiempo. Tanto los expertos como los usuarios pueden utilizar las herramientas como guía durante la evaluación ya que el proceso de evaluación de accesibilidad es muy complejo y costoso.

Entre las ventajas de este tipo de revisión se pueden mencionar que son herramientas que permiten un funcionamiento rápido y sistemático, con solo introducir una URL se revisan varios aspectos simultáneamente. Muchas de ellas, ofrecen la posibilidad de elegir entre más de un estándar para realizar la evaluación, así como también brindan una calificación global de la accesibilidad del sitio analizado. 
Entre las desventajas se menciona que el idioma de la herramienta no es similar al del usuario, la interpretación de los resultados del análisis es compleja y exige conocer los principios básicos de accesibilidad. Asimismo muchos aspectos de accesibilidad no pueden verificarse automáticamente. Este último punto es tal vez el más importante puesto que ninguna herramienta por sí sola puede determinar si un sitio cumple o no las pautas de accesibilidad o los estándares, así como tampoco es posible hacerlo validando una sola página de un sitio Web completo. De allí que si bien la revisión automática puede servir para determinar que existen problemas de accesibilidad, no es confiable para demostrar la ausencia de problemas. Para determinar este tipo de cuestiones es necesaria la revisión humana, mediante expertos o usuarios. Estudios realizados por consultoras de accesibilidad y usabilidad muestran que las herramientas automáticas solo detectan el $20 \%$ de los problemas de accesibilidad [Rod2006]. Con la evaluación automática sólo se puede comprobar la conformidad respecto a un subconjunto de puntos de verificación. Además, presenta algunos problemas respecto a la fiabilidad, dado que es posible burlar a las herramientas para que no detecten ciertos puntos. Es decir, que la evaluación automática no puede utilizarse como indicador general de la accesibilidad de un sitio, aunque puede ser de ayuda para un experto a los fines de identificar rápidamente gruesas problemas al respecto.

Por su facilidad y rapidez de administración existe un uso excesivo de las herramientas de evaluación automática. En este sentido la W3C ha manifestado su preocupación por la falta de rigor de algunos informes sobre accesibilidad, y ha insistido en que la utilización de herramientas de revisión automática para evaluar la calidad de los sitios Web no es suficiente, sino que hace falta la revisión humana [Que2006].

\subsubsection{Revisión manual}

Pueden llevarse a cabo por expertos o por usuarios, dependiendo del rigor demandado por la aplicación. Los evaluadores pueden apoyarse en el uso herramientas automáticas para facilitar el análisis, pero muchos aspectos solo pueden ser chequeados manualmente. La principal ventaja de la participación humana es que se pueden determinar barreras que los métodos automáticos pasan por alto [Wab2006]. Sin embargo las desventajas son muchas:

- Son bastante especializadas y no suelen resultar adecuadas cuando se requiere comprobar demasiados aspectos.

- Se trata de un proceso mucho más costoso en tiempo, debido a la cantidad de pautas que se deben evaluar.

- Hacen falta navegadores alternativos, simuladores de navegadores, o probar configuraciones distintas del mismo navegador.

- Exige el juicio personal del revisor. Esto puede hacer que sea menos objetiva.

- Hay que conocer mejor los problemas para detectarlos, pues algunos no aparecen de manera obvia.

- Puede no detectar algunos fallos de accesibilidad si no se simula esa situación concreta. Por ejemplo, distinto tipo y configuraciones de monitor.

Para superar algunos de estos inconvenientes la WAI recomienda realizar la verificación del correcto funcionamiento de las páginas de un sitio Web bajo las siguientes pautas:

- Utilizar un navegador sólo-texto o un emulador.

- Utilizar varios navegadores gráficos:

- Con sonidos y gráficos habilitados.

- Sin gráficos habilitados.

- Sin sonidos habilitados. 
- Sin mouse.

- Sin marcos, scripts, hojas de estilo y applets habilitados.

- Utilizar varios navegadores, y diferentes versiones de cada uno de ellos.

- Utilizar un navegador por voz, un lector de pantallas, un software de magnificación, un visualizador pequeño.

- Utilizar varios tipos de monitores. Para cada tipo de monitor analizar el comportamiento del sitio con diferentes configuraciones de pantalla y cantidad de colores.

De todas maneras, con estas pautas solamente no alcanza para detectar problemas de accesibilidad. También es necesario interactuar con el sitio navegando por todas sus páginas, buscando información, usando los formularios disponibles y realizando las tareas concretas que los usuarios desarrollan habitualmente en el sitio.

\subsection{Conclusiones}

La evaluación es la principal actividad para determinar la usabilidad de un producto [Fer2001]. Esta comprende un conjunto de métodos y técnicas que permiten medir cuantitativamente la usabilidad, tanto del producto final como de sus diferentes etapas de desarrollo.

Existen numerosas propuestas y relevamientos sobre métodos de evaluación [Alv2004], donde es posible observar coincidencias respecto a los métodos en los cuales participan expertos: aquellos donde el usuario es el evaluador que emite el juicio final, o aquellos en los que se observa al usuario mientras utiliza el producto para poder determinar su grado de usabilidad. Otra distinción importante, tiene que ver con el momento en que son aplicados los métodos: puede ser durante la fase de aceptación del producto o durante el desarrollo. Finalmente, se clasifican entre aquellos donde el resultado de la evaluación puede ser o no cuantificable.

Los métodos de evaluación determinan el lugar de realización, la forma de recabar la información (automática o manual), y el grado de implicación de los usuarios y expertos. Ellos pueden clasificarse en métodos de inspección, indagación, y test [Cat2000] [Flo2000b][Hom2003][Lei2003][Alv2004][Gra2005][Cob2005][Mon2006]. A su vez, cada método consta de diferentes formas o variantes de aplicación denominadas técnicas.

Los métodos de inspección se basan en normas generales y en la experiencia, habilidad y conocimiento de expertos, los cuales realizan un examen de la interfaz y emiten un juicio sobre la misma. Los más destacados son la inspección formal, la evaluación heurística, y el paseo cognitivo.

Los métodos de indagación consisten en observar al futuro usuario en su ambiente natural de trabajo y/o dialogar con él. Son utilizados frecuentemente en etapas tempranas de desarrollo.

Los métodos de test apuntan a que los usuarios trabajen en tareas concretas utilizando el producto, mientras los evaluadores evalúan la forma en que la interfaz soporta las tareas que éste debe realizar. Algunos autores afirman que es una de las mejores formas de extraer información sobre el nivel de usabilidad de un sitio Web [Mar03] y la más importante [Nie1999].

De acuerdo a las definiciones de usabilidad analizadas, y sus posibles métodos de evaluación, es necesario contar con algún mecanismo que permita medir el nivel o grado usabilidad. Existen una serie de criterios basados en métricas para medir la usabilidad 
[Dix1998][Whi1988][May1992][Nie1993b][Rho2000]. Las métricas propuestas por Rhodes [Rod2000] están relacionadas con la efectividad, eficiencia, y satisfacción contenidas en el estándar ISO 9241-11 [ISO1998b]. Dan una idea de cómo construir nuevas métricas de acuerdo a lo que desee medir, y serán de utilidad para el desarrollo del modelo de evaluación propuesto en esta tesis.

Al igual que la usabilidad, la accesibilidad debe ser evaluada porque complementa el análisis de calidad de cualquier sitio Web. El grado de accesibilidad puede evaluarse de manera automática o manual. El primer caso, hace uso exclusivo de herramientas informáticas, mientras que en el segundo también participan expertos en accesibilidad o usuarios finales. El estándar más utilizado para este tipo de evaluación son las Pautas de Accesibilidad al Contenido en la Web (WCAG), perteneciente a la Iniciativa de Accesibilidad Web (WAI) de la W3C [WAI2005]. Si bien las pautas y las herramientas son importantes, con ello no alcanza para detectar problemas de accesibilidad, sino que es necesario que expertos y/o usuarios interactúen con el sitio Web, realizando las tareas concretas que los usuarios desarrollan habitualmente. Este capítulo resulta de especial interés para esta tesis, ya que da contexto a las decisiones posteriores en relación a los métodos de evaluación que se considerarán en el modelo propuesto para los EVEA. 



\section{Capítulo 5: Entornos Virtuales de Enseñanza y Aprendizaje, y su evaluación}

\subsection{Introducción}

Una de las primeras aplicaciones de la informática en el ámbito educativo estuvo marcada por la enseñanza asistida por computadora, Computer Based Training (CBT) de acuerdo a la terminología inglesa, o también conocida como Computer Aided Instruction (CAI). Su metodología consistía en distribuir los contenidos de aprendizaje a través de CD-ROM, que incluían textos, gráficos, animaciones, secuencias de audio, etc.

A los efectos de proveer un soporte más eficaz para los procesos de enseñanza y aprendizaje basados en tecnología informática y telecomunicaciones, comenzaron a desarrollarse aplicaciones más específicas. La aparición de Internet, y el rápido posicionamiento que tuvo en la esfera de la educación, produjo la evolución de la enseñanza asistida por computadora hacia una nueva forma de trabajar denominada Comunicación Mediada por Computadora (CMC) [Lop2003]. La CMC hace referencia al conjunto de servicios principales que provee Internet (Web, correo, foro, chat, videoconferencia) para la comunicación directa y bidireccional entre personas y/o comunidades de aprendizaje, cuya utilización posibilita la creación de un nuevo escenario que apoya los procesos comunicativos y didácticos [Mar2006]. El acento puesto en la comunicación a través de la computadora marcó una tendencia, con lo cual se abandonó el desarrollo de cursos en formato CD-ROM para dar lugar al uso de redes, en función de las posibilidades ofrecidas por Internet para optimizar los recursos de formación facilitando las tareas de instalación, actualización, control interactivo, entre otros.

La evolución siguió su curso producto del rotundo éxito conseguido por la Web. Paulatinamente muchos servicios se integraron de manera tal que pudieran ser usados con la sola ayuda de un navegador. El foco puesto en la Web llevó al desarrollo de un tipo especial de CMC denominado educación o entrenamiento basado en Web, Web Based Training (WBT). El término hace referencia tanto a entornos Intra o Internet, incorporando sus recursos a la enseñanza y posibilitando la aplicación de metodologías innovadoras [Alv2006]. Así surgieron nuevas alternativas de formación, primero en el mundo empresarial, y luego en el ámbito universitario [Lop2003]. El fortalecimiento de Internet a nivel mundial, el uso masivo de las computadoras y su aplicación dentro del campo educativo, fundamentalmente en la educación superior, comenzó a ofrecer nuevos escenarios y posibilidades para la manera de enseñar y aprender, así como la de interactuar entre docentes y alumnos. Aunque esta tendencia tiene aproximadamente una década de desarrollo, avanza a pasos agigantados y existen muchísimas opciones comerciales y gratuitas para WBT.

La WBT aportó al campo educativo un nuevo soporte para compartir los contenidos de aprendizaje. EI CD-ROM cedió paso al alojamiento en computadoras conectadas a Internet, con la posibilidad de actualizarlos de manera permanente, y así contar con el conocimiento más reciente. Las actividades educativas comenzaron a desarrollarse en red, a partir de la integración de los diferentes recursos disponibles en Internet, los principales servicios y las herramientas que permitían el acceso a ellos. El audio, el video, y fundamentalmente el hipertexto, formaron parte de los recursos que se incorporaron con extrema facilidad, tanto en cursos presenciales como a distancia [Rod2000].

La mayor ventaja de la WBT, comparada con la CBT, fue la interacción, es decir, la posibilitad de que alumnos y docentes se comunicaran directamente, realizaran preguntas 
e intercambiaran experiencias, dejando de lado aquella relación solitaria entre el alumno y la computadora donde disponía fundamentalmente del contenido de aprendizaje.

De forma paralela a la educación basada en Web, hacia finales de la década del '90 aparece en el ambiente profesional el concepto de e-learning como una forma de denotar al aprendizaje basado en el uso de Internet, fundamentalmente la Web, permitiendo el acceso a la formación interactiva y algunas veces personalizada, para desarrollar competencias a través de un proceso de aprendizaje independiente del tiempo y el lugar. El e-learning está fuertemente asociado con expresiones tales como aprendizaje on-line o aprendizaje virtual [Rit2002]. En general, se llama e-learning al conjunto de tecnologías, aplicaciones y servicios orientados a facilitar la enseñanza y el aprendizaje a través de Internet/Intranet, que facilitan el acceso a la información y la comunicación con otros participantes. De allí que muchas veces se hable de e-learning para hacer referencia a temas relacionados con WBT [Alv2006].

Dependiendo del enfoque epistemológico y el tipo de herramienta utilizada, es posible encontrar denominaciones diversas para la enseñanza mediante redes. Entre las más conocidas encontramos las ya mencionadas, y otras como: educación en-línea, aprendizaje basado en Internet, telemática, aprendizaje distribuido, educación a distancia, aprendizaje a distancia, e-learning, entrenamiento on-line, educación on-line, educación basada en la Web, aprendizaje basado en la Web [Jac2001]. De todas formas, muchos autores realizan una discriminación entre estos términos, que quedan fuera del foco de esta tesis.

\subsection{Entornos Virtuales de Enseñanza y Aprendizaje}

Como se expresó anteriormente, los comienzos de la WBT estuvieron signados por la explotación independiente de los servicios de Internet. El uso predominante consistía en publicar los contenidos educativos en la Web, o enviarlos por correo electrónico a los alumnos, generalmente divididos en módulos, y luego resolver las dudas o discutir los contenidos a través del contacto por foro, listas de distribución, o consultas puntuales por correo electrónico [Tor2003]. El conjunto de aplicaciones informáticas disponibles en Internet, adecuadamente integradas, permitió crear un entorno muy rico en formas de interacción y, por tanto, muy flexible en estrategias didácticas [Gis1998]. A los efectos de proveer un soporte más eficaz a esta nueva modalidad educativa, con el paso del tiempo, y la masificación del uso de Internet, junto con sus potencialidades como vehículo para el aprendizaje, se fueron desarrollando una serie de entornos, ambientes o herramientas genéricas que sirvieron de base para optimizar las distintas fases del proceso de enseñanza y aprendizaje.

La principal ventaja ofrecida por este tipo de entornos fue la integración de diferentes herramientas y servicios con un fin educativo, capaz de gestionar y desarrollar actividades de formación de carácter virtual. La articulación y centralización de los recursos, servicios y herramientas facilitó y optimizó la labor de los administradores, y simplificó el trabajo de docentes y alumnos [Rit2002]. La WBT dio un salto de calidad hacia lo que hoy se conoce como Entornos Virtuales de Enseñanza y Aprendizaje (EVEA), llamados Learning Managment Systems (LMS) en la literatura inglesa.

Es muy común encontrar diferentes denominaciones para los EVEA que, si bien pueden tener otros matices, tomaremos como sinónimos. Las más conocidas son: Entornos Virtuales de Aprendizaje (EVA), Entornos de e-learning, Ambientes Virtuales de Aprendizaje (VLE), Plataformas Virtuales de Aprendizaje (PVA), Plataformas de Teleformación, Plataformas educativas, y Plataformas de e-learning [Lop2003]. Otro 
sinónimo es Campus Virtual, o Campus on-line, proveniente del ámbito universitario. Un buen número de instituciones están adoptando este término para referirse a su EVEA [Alv2006]. Sin embargo, este término implica la integración de servicios más abarcativos que los que provee un EVEA, ya que incluye funciones generales más allá del manejo de cursos, tales como biblioteca de la institución, cafetería, foros generales, entre otros.

Podemos definir los EVEA como aplicaciones informáticas que funcionan vía Web, y que fueron diseñados con el propósito de facilitar la comunicación pedagógica entre los participantes en un proceso educativo, fundamentalmente docentes y alumnos, sea éste completamente a distancia, presencial, o de una naturaleza mixta, es decir, que combine ambas modalidades en distintas proporciones (blended). Los EVEA sirven para distribuir materiales educativos en formato digital (textos, imágenes, audio, simulaciones, juegos, etc.) y acceder a ellos. También se utilizan para realizar debates y discusiones on-line sobre aspectos del programa de la asignatura, para integrar contenidos relevantes de la Web o para posibilitar la participación de expertos o profesionales externos en los debates o charlas. Se caracterizan por contar con herramientas para el docente, herramientas para el alumno, materiales o contenidos educativos, y herramientas administrativas. En general, posibilitan la comunicación sincrónica y asincrónica, gestión de cursos, materiales de aprendizaje, usuarios participantes, sistemas de seguimiento, y evaluación del progreso de los estudiantes.

Los EVEA ponen énfasis en la interactividad como estrategia para favorecer los procesos educativos. En general, los buenos EVEA son lo suficientemente versátiles como para no condicionar la propuesta pedagógica y permitir un amplio abanico de posibilidades en cuanto a los modelos susceptibles de ser utilizados, es decir, desde un modelo centrado en el docente hasta uno centrado en el alumno. Lo importante en este caso es que el diseño tecnológico acompañe al modelo pedagógico, sin perder de vista que la herramienta tecnológica solamente, aunque sea la mejor, no garantiza el cumplimiento de los procesos educativos.

Si analizamos los entornos como recurso didáctico vemos que actúan como soporte tecnológico para docentes y alumnos a los fines de favorecer las distintas fases del proceso de enseñanza y de aprendizaje tales como planificación, implementación, desarrollo, y evaluación del currículum [Ade2004].

Los EVEA han sufrido una rápida evolución en los últimos 10 años, fundamentalmente aquellos especializados en el sector universitario. Ello ha determinado que en muchas instituciones de Educación Superior coexistan varios entornos virtuales. Esto puede deberse a varios factores, entre los cuales pueden mencionarse los siguientes:

1. Fueron adoptados por diferentes Unidades Académicas en distintos momentos o etapas.

2. Alguna Unidad Académica decidió migrar a otro entorno con mejores prestaciones o características.

3. Hubo cambios en la política institucional.

4. Las organizaciones, instituciones o grupos de desarrollo del entorno virtual establecieron nuevas reglas de licenciamiento.

Otra discusión que siempre está presente es la de tratar de determinar cuál es el mejor EVEA. En este sentido tampoco hay consenso ya que intervienen diversos factores que tienen que ver con el contexto social, cultural, institucional, político, y económico donde se insertará [Ade2004]. 
El entorno debe estar diseñado para ofrecer todas las prestaciones necesarias para la formación. Actualmente, podemos encontrar una enorme diversidad, aunque la mayor parte de ellas presentan elementos muy similares como, por ejemplo, posibilitar la distribución de contenidos multimedia, contar con herramientas de comunicación síncronas o asíncronas (chat, correo electrónico, foros, etc.) y herramientas de gestión. Las herramientas de gestión son de distintos tipos según sus objetivos [Alv2006]:

1. Gestión de usuarios: según su perfil, cada usuario dispone de una serie de permisos y actividades permitidas, administración, edición, creación de itinerarios formativos, etc.

2. Gestión de alumnos: permite la gestión administrativa de los alumnos, altas, bajas, comunicación de incidencias, etc.

3. Diseño de itinerarios: posibilidad de diseñar itinerarios y construir entornos individualizados.

4. Diseño de cursos virtuales: permite la configuración sin necesidad de conocimientos especiales, la creación y gestión de espacios con diferentes herramientas, servicios y espacios.

5. Seguimiento de la actividad del alumno: el seguimiento tiene como objetivo controlar la evolución del alumno y, basándose en sus resultados, orientarlo en el transcurso de la acción formativa. Se puede supervisar tanto los resultados de pruebas como el tiempo que los alumnos dedican a visualizar los contenidos de cada tema, las horas de conexión, y el número de interacciones realizadas con el resto del grupo y con el docente.

6. Planificación: posibilidad de acceder a un indicador de los hitos más relevantes del curso, es decir, sesiones de chat, fechas para la realización de exámenes, etc.

Existe una gran cantidad de entornos orientados a la educación universitaria, en algunos casos se habla de más de ciento treinta [Bau2002], en otros, si se suman los desarrollos propios de las universidades el número aumenta a varias centenas [Her2002].

Muchos de estos EVEA se utilizan en ámbitos específicos o muy reducidos, otros se han fusionado o discontinuado en su desarrollo. Algunos, al no tener un fin comercial, no trascienden y es muy difícil conocerlos en detalle. Luego de la "fiebre de entornos" que se produjo hacia fines del siglo XX, donde cada institución o empresa creaba su propia solución, sobrevino otra etapa caracterizada por un análisis pormenorizado de ellos desde la óptica educativa, donde los investigadores en educación, y docentes criticaron el excesivo peso que, hasta el momento, se había puesto sobre los criterios técnicos en desmedro de los pedagógicos, didácticos, y comunicacionales. Con el paso del tiempo, se produjo por un lado una decantación, y por el otro, una vertiginosa evolución de los entornos que contaban con mayor calidad y apoyo, tanto desde el punto de vista institucional, económico, de la comunidad de usuarios o desarrolladores. En la actualidad, dentro del ámbito internacional se encuentran aproximadamente 40 productos de este tipo que han logrado preponderancia en el sector [Fer2007b]. En la tabla 4, se presentan los 15 productos con mayor difusión y aceptabilidad a nivel internacional [Mar2008].

\begin{tabular}{|l|l|l|}
\hline Moodle & Saba Enterprise & $\begin{array}{l}\text { PeopleSoft Enterprise } \\
\text { Lerning Management }\end{array}$ \\
\hline Blackboard & $\begin{array}{l}\text { Saba Learning } \\
\text { Suite }\end{array}$ & $\begin{array}{l}\text { Oracle Learning } \\
\text { Management }\end{array}$ \\
\hline
\end{tabular}




\begin{tabular}{|l|l|l|}
\hline TotalLMS & SkillSoft SkillIPort & ResultsOnDemand \\
\hline $\begin{array}{l}\text { In-house } \\
\text { Development }\end{array}$ & LearnCenter & Mzinga Learning \\
\hline $\begin{array}{l}\text { Plateau } \\
\text { Learning } \\
\text { Management } \\
\text { System }\end{array}$ & GeoMaestro LMS & $\begin{array}{l}\text { Meridian Knowledge } \\
\text { Solutions LMS }\end{array}$ \\
\hline
\end{tabular}

Tabla 4 - EVEA de mayor relevancia internacional

Sin embargo, los que más se han destacado, y mayor penetración han tenido en el ámbito universitario, son presentados en la tabla 5 [Fer2009d]

\begin{tabular}{|l|l|}
\hline Código abierto & Comerciales \\
\hline Moodle & Blackboard-WebCT \\
\hline .LRN & e-College \\
\hline Sakai & Desire2Learn \\
\hline
\end{tabular}

Tabla 5 - EVEA más utilizados en las universidades

\subsubsection{Clasificación}

Los entornos virtuales pueden agruparse de diferentes maneras. Uno de los puntos de vista que más auge e importancia ha tomado es aquel que los divide en software propietario y software libre, una clasificación que no sólo atañe a los entornos virtuales sino al software en general. Es trascendente este análisis debido a varias cuestiones que atraviesan la educación, como las socioculturales y las económicas. Las instituciones de carácter público han prestado gran atención a los desarrollos libres, más aún luego de los cambios en la política de algunos productos como Blackboard, que al fusionarse con WebCT pasó a ser en producto pago y dejó a gran cantidad de centros educativos en la disyuntiva de comenzar a pagar por el uso del EVEA o migrar todos sus cursos a otro entorno, con los costos que ello implica. Sin embargo, dentro del campo del software libre también se han producido cambios que dificultaron el accionar de los centros educativos. Algunos desarrollos libres de gran éxito, pronto abandonaron sus ideas fundacionales y se orientaron hacia el ámbito empresarial. Claroline es el caso más notorio dado que uno de sus principales creadores se separó del proyecto y creó Dokeos (tomando como base el código fuente de Claroline). El quiebre se produjo porque deseaba orientar el sistema hacia las empresas en lugar de mantenerlo dentro del contexto académico. Claroline mantuvo su política, pero Dokeos la sobrepasó ampliamente gracias a la gran cantidad de 
programadores que siguieron vinculados al proyecto, las mejoras producidas y la promoción del producto. Sin embargo, a comienzos de 2010 se conoció que Dokeos también sufrió una división de su comunidad de desarrollo producto de desacuerdos sobre el uso de la marca, el nivel de la apertura del código a la comunidad, y la imposibilidad que los voluntarios participaran en la toma de decisiones sobre la orientación del proyecto. Así surgió Chamilo, sostenido por la mayoría de los ex-desarrolladores de Dokeos.

Si bien los EVEA desarrollados bajo políticas de software libre garantizan independencia y autonomía, exponen a los usuarios a los vaivenes de las decisiones que toman sus comunidades, instituciones que los financian o líderes del proyecto. Por otra parte, las posibilidades que brinda el software libre, de modificar su código para adecuarlo a las necesidades institucionales, no son explotadas en toda su dimensión porque generalmente se cuenta con un escaso grupo de soporte para la gestión del entorno virtual. En definitiva, la mayoría de los entornos libres se utilizan como si fueran "enlatados gratuitos".

Otro aspecto de vital importancia que llevó a poner la mirada sobre los desarrollos libres, es el tema económico. Si bien "software libre" no significa "software gratis", los costos para mantener operativo un EVEA libre son mucho menores que los de uno propietario, ya que no hay que pagar por el producto ni por licencias de uso.

En la actualidad, dentro del ámbito de la educación superior, se observa que entornos de gran relevancia están logrando imponerse por sobre los demás. Estos comparten la característica de haber surgido desde universidades y de ser utilizados mayoritariamente por ellas. Observamos que WebCT es el EVEA propietario con mayor trayectoria, el más importante y utilizado en la actualidad, fundamentalmente luego de que la empresa Blackboard, su principal competidor, decidiera comprarla y fusionarlos. WebCT se comercializa bajo una política de licencias, ha sido históricamente el entorno más evolucionado y el espejo donde mirarse para todos aquellos que trabajan en el desarrollo de herramientas similares. Dentro del campo de software libre las diferencias no son tan claras, y aunque Moodle fue el entorno virtual que más rápido se posicionó por la gran comunidad de desarrolladores, usuarios, y adeptos que cosechó en poco tiempo, en los últimos años también adquirieron gran notoriedad otros EVEA entre los que destacamos a: ILIAS, Claroline, Dokeos y ATutor. Las apuestas por los entornos virtuales de código abierto alcanzaron rápidamente un importante nivel de desarrollo, gracias la gran participación de instituciones, docentes, alumnos y, principalmente desarrolladores. En muy poco tiempo lograron ponerse a la altura de los EVEA propietarios, incluso superando a muchos de ellos, logrando proveer un servicio destacado desde el punto de vista técnico así como también educativo.

La mayoría de los entornos virtuales, tanto propietarios como libres, poseen en la actualidad herramientas suficientes como para desarrollar acciones educativas bajo diferentes modalidades. No obstante, evolucionan tan rápidamente que los análisis de sus principales características van quedando desactualizados. Las nuevas versiones apuntan a mejorar algunos inconvenientes y limitaciones que dificultan la personalización de los itinerarios formativos, la adaptación de los contenidos y actividades a los intereses y necesidades de docentes y alumnos, el intercambio de objetos de aprendizaje, usuarios y cursos, la usabilidad, accesibilidad, etc.

A los efectos de comprender el lugar que ocupan los entornos virtuales de enseñanza y aprendizaje realizaremos una breve categorización de estos sistemas según el tipo de información que permiten gestionar. Cuando se habla de sistemas centrados 
exclusivamente en la gestión del contenido de aprendizaje se refiere a los Sistemas de Gestión de Contenido (SGC), mientras que al hablar de sistemas centrados en el aprendizaje existen dos tipos: Ios Sistemas de Gestión de Aprendizaje (SGA) o Entornos Virtuales de Enseñanza y Aprendizaje (EVEA), y los Sistemas de Gestión de Contenidos de Aprendizaje (SGCA):

- Sistemas de Gestión de Contenido: denominados también Content Management System (CMS), están pensados para la edición de materiales de aprendizaje on-line, su administración y difusión. Tienen como objetivo separar el contenido de la presentación, facilitar los flujos de trabajo (workflow), otorgar y/o restringir el acceso a los materiales, controlar las versiones y temporizar la publicación. Sin embargo, no tienen la capacidad de gestionar el proceso de aprendizaje debido a que no poseen herramientas para la comunicación, evaluación, etc. Suelen llamarse también Authorware y pueden clasificarse en 5 tipos según el punto de vista pedagógico: CMS "puros", Weblogs, CMS orientados a la colaboración, CMS comunitarios y colaborativos, y Wikis. Los Sistemas de Gestión de Contenido vendrían a ser bibliotecas de contenidos genéricos que permiten una publicación del contenido de manera integrada, controlando las versiones de los documentos.

- Entornos Virtuales de Enseñanza y Aprendizaje: conocidos como Learning Managnent Systems (LMS), son el software que automatiza la administración de acciones de formación. Su objetivo es planificar, implementar y evaluar el proceso de aprendizaje de acuerdo a las necesidades de los usuarios. Son evolución de la Computer Based Training donde se añaden funcionalidades para la gestión y el seguimiento de los alumnos, junto con las herramientas de comunicación, calendario, exámenes, grupos, etc. Los EVEA registran usuarios, organizan los diferentes cursos en un catálogo, almacenan datos sobre los usuarios y proveen informes para la gestión. Generalmente, no incluyen posibilidades de autoría, en su lugar, se centra en gestionar cursos creados por gran variedad de fuentes diferentes [Alv2006].

- Sistemas de Gestión de Contenidos de Aprendizaje: también llamados Learning Content Managnent Systems (LCMS), integran los dos anteriores, es decir, los Sistemas de Gestión de Contenido con los Entornos Virtuales de Enseñanza y Aprendizaje. Son una especie de mega-entorno que incorpora la gestión de contenidos para personalizar los recursos a cada alumno. Son ambientes estructurados, diseñados para que las organizaciones puedan implementar mejor sus procesos y prácticas con el apoyo de cursos, materiales y contenidos on-line. Permiten una creación mucho más eficiente de materiales, evitan redundancia y posibilitan administrar también la participación de diversos desarrolladores, expertos, colaboradores o instructores en la creación de contenidos.

Es importante conocer el estado actual de los entornos más relevantes a los efectos de contar con elementos de juicio tendientes a facilitar la definición de políticas educativas y la toma de decisiones, tanto para la adopción de este tipo de tecnología, la integración de las mismas al ámbito universitario o el desarrollo de nuevas herramientas. La decisión de qué entorno adoptar para una institución universitaria no es tarea sencilla y puede variar de una a otra de acuerdo a diversos factores [Lop2001][Haz2002][Ade2004]. Distintos EVEA pueden ser tan o más eficaces que otros en función de los objetivos perseguidos por los diseñadores, y del particular estilo de aprendizaje de un alumno con respecto a otros [Alv2006]. 


\subsection{Aula Virtual}

El escenario fundamental en la formación presencial es el aula, como un sistema de comunicación que abarca todos los sentidos humanos, donde se establece una marcada coincidencia espacio-temporal. En general se sitúan en un espacio cerrado, como lo es un aula en una institución educativa, utilizando los materiales habituales (libros, cuadernos, mesas, sillas, etc.) y con procesos de comunicación cara a cara. Las aulas arquitectónicamente tangibles son el espacio donde se produce el conjunto de actividades, intercambios y relaciones comunicativas que constituyen el eje fundamental de la enseñanza y el aprendizaje. También existen otros lugares importantes como laboratorios, bibliotecas, pasillos, cafeterías, casas o residencias estudiantiles, oficinas de los docentes, y diversos espacios para la relación interpersonal. No todo el trabajo se da en clase sino que se realizan seminarios o sesiones en pequeños grupos, trabajo cooperativo entre alumnos, estudio individual y múltiples actividades [Gis1998].

La educación basada en Web, en cambio, se lleva a cabo en lugares no existentes más que como experiencia subjetiva, compartida por personas que utilizan un conjunto de formas de intercambio de información basadas en redes telemáticas y aplicaciones informáticas. Los entornos virtuales de formación refieren a un espacio de comunicación que integra un extenso grupo de materiales y recursos, diseñados y desarrollados para facilitar y optimizar el proceso de aprendizaje de los alumnos, basado en técnicas de comunicación mediadas por la computadora [Gis1998].

El concepto fundamental implícito en las últimas experiencias de educación apoyadas en Internet es el de aula virtual. Se trata de un intento por alcanzar la calidad de la comunicación que posee la formación presencial pero mediante aplicaciones telemáticas. En la actualidad el aula virtual es el concepto que agrupa las posibilidades de la enseñanza vía Internet. En principio, un aula virtual es un entorno de enseñanza y aprendizaje basado en un sistema de comunicación mediada por computadora que facilita la interacción, la evaluación y la cooperación entre iguales, permitiendo la interacción social y la construcción del conocimiento [Har1995][Gis1998]. Se refiere al entorno informático, multimedia e interactivo en el que se va a desarrollar un proceso de enseñanza y aprendizaje determinado [Alv2006].

Un aula virtual es un espacio para el aprendizaje que debe centrarse fundamentalmente en tres objetivos [Alv2006]:

- Facilitar al participante el aprendizaje y el autoestudio, integrando los materiales didácticos necesarios y los mecanismos de control adecuados, conforme al diseño pedagógico del curso y a las necesidades particulares de formación.

* Proporcionar las herramientas necesarias para facilitar la comunicación, la participación y la colaboración.

- Proporcionar herramientas y mecanismos de gestión, que permitan automatizar ciertas tareas administrativas, y sirvan de apoyo a los agentes implicados en el seguimiento y evaluación de las actividades realizadas.

Es decir, el objetivo principal de las aulas virtuales es mejorar el acceso a experiencias educativas avanzadas, permitiendo a los estudiantes y formadores participar en comunidades de aprendizaje remoto por medio del uso de las computadoras personales en la casa o en el trabajo, y mejorar la calidad y la eficacia de la educación, empleando la computadora como base de un proceso de aprendizaje colaborativo [Har1995].

El aula virtual, como espacio educativo, posee características tanto técnicas como pedagógicas. Las características técnicas están marcadas por los aspectos propios de la 
tecnología utilizada y tiene que ver con la flexibilidad y capacidad de adaptarse al cambio. Desde este punto de vista, son un espacio en formato de sitio Web, que permite el desarrollo de actividades de una forma diferente al cara a cara tradicional. En el aula virtual el alumno tiene acceso al programa del curso, los materiales, las actividades y diversas herramientas de interacción con sus pares y sus docentes, tales como foros de discusión, charlas en vivo y correo electrónico. Las características pedagógicas tienen que ver específicamente con el proceso de enseñanza y aprendizaje. En tal sentido deben tenerse en cuenta aspectos referidos al seguimiento del progreso del estudiante, comunicación interpersonal, trabajo colaborativo, gestión y administración de los alumnos, creación de ejercicios de evaluación y autoevaluación, acceso a la información y contenidos de aprendizaje e interacción.

El aula se transforma en un espacio de intercambio y de discusión a partir de una serie de posibilidades que el usuario puede seleccionar para incorporar sus producciones, discutir sobre determinados temas o transferir contenidos que le son de utilidad para su proceso de aprendizaje. Se trata de un espacio abierto y dinámico enriquecido con los aportes de los propios alumnos y de los docentes, quienes pueden disponer, en términos didácticos, de materiales equivalentes a los que tiene en el aula presencial. Su configuración final muestra la dinámica de trabajo y el resultado de la aplicación de diferentes estrategias de aprendizaje.

Las aulas virtuales cuentan con los elementos necesarios a los efectos de poder cursar, tutorizar, gestionar, administrar, y evaluar las actividades educativas. Además, facilitan la generación de procesos de comunicación entre docentes y alumnos que no pueden llevarse a cabo de manera presencial. Los procesos de enseñanza y aprendizaje, mediados por el aula virtual, combinan momentos de trabajo personal, contacto con profesores y de trabajo colaborativo. Los materiales elaborados por alumnos y docentes se confeccionan con distinto tipo de software y se trasmiten en formato digital por medio de redes [Ort2000].

Se trata de una metáfora que incluye espacios para las clases en grandes grupos, biblioteca, tutoría personalizada, actividades en pequeños grupos, espacio para el trabajo cooperativo, e incluso espacios para charlas informales [Ade1998]. En la actualidad la denominación está cambiando, ya que la metáfora de aula presencial, nos remite a un espacio compartido en el cual se desarrollan diferentes cursos, con distintos alumnos y docentes, mientras que el aula virtual está caracterizada por la interacción de un mismo grupo de alumnos, docentes y materiales de aprendizaje, a lo largo de un determinado proceso educativo. Podríamos decir que un aula real, presencial, es vehículo para el desarrollo de varios cursos o asignaturas en diferentes días y horarios, mientras que un aula virtual es un espacio único para el desarrollo de un curso. De allí que la metáfora resulte un tanto confusa, aunque muy utilizada. A los efectos de evitar apartarnos de las denominaciones comunes encontradas en la bibliografía, pero sin dejar de reconocer los problemas que ocasiona el término, tomaremos aula virtual como sinónimo de curso, asignatura o materia virtual.

La función de los EVEA es poner a disposición espacios virtuales que utilizan los diferentes servicios de Internet, herramientas y recursos, registrando todo el flujo de información producido a lo largo de la actividad educativa, para luego ser consultada de diferentes maneras a los efectos de extraer información útil para el desarrollo, seguimiento y evaluación. 


\subsection{Tendencias actuales}

Los EVEA se utilizaron exclusivamente en un primer momento para la formación a distancia, pero en los últimos años se han venido incorporando también a los cursos presenciales, adoptando formas mixtas denominadas aprendizaje combinado o blendedlearning. Por medio de estos nuevos escenarios integrados se ha logrado aprovechar las características de accesibilidad y cooperación entre los usuarios de la red, orientando fundamentalmente el proceso educativo hacia nuevas maneras de aprender apoyadas en el trabajo colaborativo, acompañadas de una serie de recursos, más allá de la mera presencia del profesor [Rod2000].

Tanto la terminología como las características y las funcionalidades de estos entornos han variado con el correr del tiempo, a punto tal de coexistir diversos puntos de vista tanto en la investigación como en el desarrollo. Los avances más importantes se observan en los siguientes sentidos [Ade2004]:

- Integración con los sistemas de gestión de estudiantes y docentes.

- Modularización de los sistemas monolíticos en arquitecturas de niveles y en componentes interoperables y estandarizados.

- Gestión separada de los contenidos y su creación, distribución e integración en unidades didácticas.

- Mayor preocupación por los aspectos pedagógicos del aprendizaje y la enseñanza on-line.

- Rápida expansión de entornos de código abierto de muy buena propuesta funcional y sofisticación didáctica, mayor flexibilidad y posibilidades de integración.

Así, la primera generación de entornos basados en la distribución de materiales y la evaluación mediante pruebas automáticas, dio paso a una segunda generación inspirados en los nuevos conocimientos sobre la forma de aprender usando recursos on-line. Esta segunda generación está más orientada hacia la comunicación didáctica, el diseño, y monitorización del flujo de trabajo colectivo con los materiales y, en general, hacia la actividad didáctica o experiencia de aprendizaje. Todo ello sin olvidar la necesaria estandarización de los contenidos, si pretendemos reutilizarlos y compartirlos [Ade2004].

Cada entorno está diseñado consciente o inconscientemente desde una filosofía pedagógica. Algunos privilegian la creación y distribución de contenidos formativos, asumiendo que el contacto de los estudiantes con materiales relevantes, cuidadosamente diseñados, es el elemento clave del aprendizaje. Otros, en cambio, potencian la comunicación entre los participantes en la convicción de que el aprendizaje es producto de la interacción social y la construcción compartida de significados en un ambiente rico en información y en oportunidades de conocimiento. Es posible observar tres tipos de entornos bien definidos [Ade2004]:

1- Centrados en la creación, gestión y distribución de contenidos que además incorporan algunas herramientas de comunicación añadidas.

2- Centrados en la comunicación y las actividades de enseñanza / aprendizaje que incluyen además herramientas para gestionar materiales.

3- De trabajo en grupo para comunidades académicas que agregan algunas funcionalidades utilizables en la enseñanza.

Por ello, los distintos módulos, componentes, o herramientas incorporadas en los entornos poseen distintas funcionalidades y están dispuestos de modo diferente. Sin embargo, un buen entorno debe ser sumamente flexible para no imponer un estilo docente en particular, sino posibilitar la mayoría de ellos a fin de que los docentes y los 
estudiantes lo experimenten como un aumento de posibilidades y no como una limitación, un elemento distorsionador o un freno a su creatividad y a su capacidad de innovación [Ade2004].

Los EVEA actuales ofrecen servicios y capacidades muy similares. Esto ha llevado a que el acento no se ponga tanto en las funcionalidades sino en las posibilidades de mejorarla y adaptarla a nuevas necesidades. Aunque ello no elimina la necesaria etapa de análisis de necesidades, sin la cual a menudo se toman decisiones equivocadas o se realizan grandes inversiones innecesarias [Rub2003].

\subsection{Análisis de los EVEA. Las diversas miradas}

La mayoría de los EVEA poseen herramientas suficientes como para desarrollar con cierta calidad (dependiendo de la propuesta docente y otros factores) las acciones formativas. No obstante, se observan ciertos inconvenientes y limitaciones que dificultan la personalización de los itinerarios formativos y la adaptación de los contenidos y actividades a los intereses y necesidades del alumnado [Ade2004].

La evaluación de estas plataformas tecnológicas está orientada a valorar la calidad a través del cual se implementan acciones formativas. La dimensión y funcionalidad puede variar sustancialmente según se trate de dar soporte a un curso, o cursos, o a una institución entera, como es el caso de las universidades virtuales [Rub2003].

Los principales indicadores que pueden tenerse en cuenta a la hora analizar un entorno virtual, están relacionados con el tipo de actividad educativa a desarrollar (cursos, carreras, comunidades virtuales), la modalidad, las características de los destinatarios y de las posibilidades y limitaciones técnicas disponibles (ancho de banda, equipamiento informático y disponibilidad de tiempo, entre otros). Existen gran cantidad de enfoques e instrumentos para llevar a cabo esta tarea. La mayoría están orientados a determinar las características de los entornos en función de una serie de categorías de análisis [Rub2003].

o Coste: general y de los servicios extras.

- Requerimientos de hardware y software: bajo qué sistemas operativos y navegadores funciona, lenguajes que soporta, base de datos.

- Características: técnicas, servicios y soporte que ofrece.

- Capacidad de desarrollo: posibilidad de implementar nuevas funciones, de realizar reportes, tests, integración con otros sistemas.

- Herramientas para el estudiante: interacción que permite (síncrona/asíncrona, grupal/individual), acceso a recursos (biblioteca, secretaría, etc.), trabajo en grupos, evaluación.

- Herramientas para el instructor: posibilidades para generar tests, contenidos, diseño instructivo.

- Herramientas para el administrador: posibilidades para realizar autorizaciones, soporte al usuario, al docente, registro, personalización de mensajes.

Aunque las categorías varíen de un enfoque a otro, es muy común encontrar cierta recurrencia en las cuestiones centrales. Algunos instrumentos son netamente técnicos a partir de una lista de chequeo de funcionalidades, servicios y herramientas, y otros adoptan miradas desde lo educativo, a partir de las potencialidades que poseen a efectos pedagógicos y didácticos [Fil1998][Whi2000][Pal2001][Mar2001][Haz2002][Gab2002] [Com2003][Tor2003][Zap2003][Ade2004][Edu2006]. En su mayoría se trata de instrumentos para evaluar y comparar entornos a los efectos de seleccionar el más adecuado para ser utilizado en un contexto particular. Podríamos decir que encontramos 
en un extremo a los planteos de índole exclusivamente tecnológica, y generalmente cuantitativos, en el otro extremo a los planteos educativos y generalmente cualitativos. Entre ambos existe gran variedad de matices. Por otra parte, en los últimos tiempos también han tomado relevancia una serie de iniciativas que, sobre la base de estas categorías, han elaborado modelos o estándares de calidad de entornos virtuales [Rub2003].

A continuación mencionaremos los enfoques principales estudiados a fin de esbozar un breve estado del arte al respecto.

\subsubsection{Evaluación de EVEA}

El modelo desarrollado por Adell [Ade2004] sostiene que los criterios planteados están pensados conforme con las necesidades y los tipos de uso educativo que se pretende realizar del EVEA. Se trata de un análisis de corte cualitativo realizado en función de tres criterios: flexibilidad didáctica, usabilidad, y flexibilidad tecnológica. La flexibilidad didáctica se enfoca hacia las facilidades para el diseño y organización de cursos. Además, incluye a las herramientas de aprendizaje disponibles. La usabilidad tiene en cuenta a la facilidad de uso, los conocimientos técnicos de los usuarios, ayuda, trabajo off-line, accesibilidad e idiomas. Por último, la flexibilidad tecnológica tiene en cuenta los siguientes aspectos: requisitos técnicos, escalabilidad, posibilidades de integración con otros sistemas, mecanismos de autenticación de los usuarios, adaptación visual y costes de implementación, administración y mantenimiento.

Por su parte, Pallof y Pratt [Pal2001] sugieren tomar en cuenta cinco aspectos que deberían estar presentes en un buen entorno: interacción, introspección, innovación, integración e información. La interacción tiene que ver con los aditamentos necesarios para establecer procesos comunicacionales síncronos y asíncronos entre todos los participantes: correo electrónico, enlaces web, foros de discusión, chats, desarrollo de páginas Web personales. La introspección se asocia con la posibilidad de que las herramientas comunicacionales permitan generar el desarrollo de pensamiento crítico y creativo por medio de una serie de recursos, en donde se acompañe de audio, video y texto, junto con espacios para actividades a desarrollar por parte de los estudiantes. Sin embargo, la propuesta didáctica sigue siendo un elemento fundamental en estos casos, ya que la herramienta puede contar con las mejores características, pero ser usada de forma inadecuada. La innovación permite al profesor generar actividades diferentes a las acostumbradas en una clase convencional, permitiendo a los estudiantes participar cada vez más, sacando provecho de su propio estilo de aprendizaje. De la misma manera, el proceso de evaluación del curso amplía su gama de alternativas, gracias al apoyo de la tecnología. La integración tiene que ver con la manera en que los recursos tecnológicos incorporan la información a un proceso de generación de conocimientos, partiendo de una base relacional (entre todos los participantes del curso), lejos de posturas eminentemente individualistas. La información refiere a la posibilidad de contar con aquellos hechos o datos necesarios para el buen desarrollo del curso a la mano del estudiante, sin importar en qué lugar se encuentre: bases de datos especializadas, bibliotecas digitales, portafolios electrónicos, datos del curso, producciones del docente, etc.

También el Gabinete de Tele-Educación de la Universidad Politécnica de Madrid [Gab2002] ha elaborado una serie de indicadores que pretenden ser una ayuda para establecer una relación entre los objetivos que se buscan y la oferta disponible. Estos indicadores hacen referencia a la información técnica, edición de materiales, proceso de enseñanza - aprendizaje, administración y gestión académica, y otras características. 
Puede observarse que existe una mayor preponderancia de análisis de elementos referidos a lo tecnológico y algunas cuestiones relacionadas con la usabilidad.

Torres Toro y Ortega Carrillo [Tor2003] realizaron una serie de investigaciones y elaboraron indicadores de calidad a tener presentes en los entornos de formación virtual. Ellos proponen cuatro categorías para analizar la calidad: técnica, organizativa y creativa, comunicacional y didáctica.

El modelo de evaluación propuesto por Zapata Ros [Zap2003], se apoya en cinco categorías que posibilitan examinar de forma muy pormenorizada las características de un entorno. En general, cada categoría se desglosa en una serie de preguntas o ítems que pueden ser identificados o no dentro de la herramienta analizada. Ellos son características básicas, utilidades que generan ambientes de comunicación y de trabajo, funciones formativas que permite desarrollar, roles que se identifican y evaluación sobre la intervención psicopedagógica del sistema que soporta.

Pere Marquès elaboró una serie de criterios de calidad para los sistemas de teleformación [Mar2001] donde no se abordan únicamente las herramientas sino también la calidad de los materiales formativos, la labor de los docentes y tutores, el plan docente y la metodología del curso. Esta concepción sostiene que la calidad del entorno dependerá en gran manera de la actuación de los docentes que interactúan con los estudiantes en el marco de un determinado modelo pedagógico. Los criterios están agrupados en: aspectos relacionados con el entorno telemático, aspectos funcionales del curso on-line, aspectos relacionados con el plan docente y el modelo pedagógico, aspectos relacionados con los servicios complementarios. En varios de los criterios aparecen cuestiones relacionadas con usabilidad y accesibilidad

El estudio realizado por Whitmyer Grimes [Whi2000], denominado Comparative Features Analysis of Leading Course Management Software, identifica un extenso conjunto de características deseables, 94 en total, para dar un correcto soporte a la enseñanza y el aprendizaje en línea. El propósito de sus investigaciones se orienta en dos sentidos: por un lado ayudar a las instituciones académicas a tomar decisiones sobre el entorno más conveniente a utilizar, y por el otro, asesorar a los desarrolladores de este tipo de herramientas respecto a nuevas funcionalidades que sería provechoso fueran incorporadas en un futuro no muy lejano.

En el Anexo I se desarrollan cada uno de los modelos mencionados, destacando sus características principales.

En general, la mayoría de los modelos para evaluar EVEA están orientados hacia las funcionalidades que ofrece el entorno. Se trata de modelos donde el usuario final no participa sino que son expertos quienes realizan la evaluación, asumiendo los diferentes roles para los cuales el entorno será utilizado. Esto se debe a que dichos instrumentos fueron pensados principalmente para la toma de decisiones sobre el entorno a adoptar, por parte de las universidades o de los centros de formación. Por ello, en la mayoría de los casos, se realiza una extensa categorización de características deseables o ideales que debería tener un sistema de este tipo. En la actualidad, los entornos que han logrado buenos niveles de aceptación, disponen de gran parte de las características buscadas en estos modelos de evaluación.

Es de destacar que en solo dos modelos está presente la usabilidad como uno de los ejes de evaluación: el propuesto por Adell [Ade2004], que lo explicita claramente, pero lo acota demasiado en el análisis, y el de Pere Marquès [Mar2001], que trabaja solo algunos aspectos relacionados con la interfaz. 


\subsection{Conclusiones}

El uso de tecnologías informáticas en la educación se remonta a la enseñanza asistida por computadora, conocida como Computer Based Training (CBT), y basada en el uso del CD-ROM. El avance de las telecomunicaciones, produjo una evolución conocida como Comunicación Mediada por Computadora (CMC) [Lop2003]. El rápido dominio de la Web, entre los servicios de Internet, incentivó el desarrollo de la Web Based Training (WBT) como nuevo soporte para compartir los contenidos de aprendizaje e interactuar con ellos. Posteriormente, la WBT dio un salto de calidad hacia los Entornos Virtuales de Enseñanza y Aprendizaje (EVEA), que integran diferentes herramientas y servicios con un fin educativo, capaz de gestionar y desarrollar actividades de formación de carácter virtual.

Los EVEA son aplicaciones informáticas que funcionan vía Web, y que fueron diseñados con el propósito de facilitar la comunicación pedagógica entre los participantes en un proceso educativo bajo diferentes modalidades. Existe una gran cantidad de EVEA en el ámbito internacional, más de cien [Bau2002][Her2002], de los cuales aproximadamente cuarenta han logrado preponderancia [Fer2007b], siendo Moodle, .LRN, Sakai (código abierto), Blackboard-WebCT, e-College, y Desire2Learn (comerciales), los de mayor difusión a nivel universitario.

La evaluación de cada EVEA está orientada a valorar su calidad, para llevar adelante procesos de enseñanza y aprendizaje de forma on-line. Los modelos de evaluación sintetizados analizan los EVEA poniendo el foco sobre las funcionalidades que ofrecen [Fer2007b]. Sin embargo, la validación no ha de centrarse únicamente en el acceso a las herramientas concretas sino al ensayo con alumnos reales [Sal2006], en contextos de uso reales. Estos modelos fueron pensados cuando las características diferían bastante entre un EVEA y otro. En la actualidad, las cuestiones ligadas a la usabilidad son centrales porque tienen directa relación con la calidad de estos productos Web. De los modelos analizados, sólo dos mencionan la usabilidad, pero acotada a la facilidad de uso, el cumplimiento de ciertos estándares, o a la interfaz [Fer2009].

Por ese motivo se cree necesario definir un nuevo modelo, que tomando las experiencias e investigaciones existentes, proponga una nueva manera de evaluar los EVEA, desde una mirada centrada en la usabilidad. 


\section{Capítulo 6: Métodos, técnicas, herramientas y evaluadores}

\subsection{Métodos de evaluación de usabilidad seleccionados}

En la actualidad existen diferentes propuestas que han sido desarrolladas para evaluar la usabilidad de aplicaciones basadas en la Web, en su mayoría orientadas a sitios comerciales. Hasta el momento no se ha logrado establecer un acuerdo respecto a los criterios de evaluación, ni entre ellos, ni respecto a los estándares establecidos. Es difícil que ello ocurra porque la mayoría fueron desarrollados para dar soporte a la evaluación de una aplicación particular en un contexto muy específico.

Ante esta situación se considera oportuno generar un nuevo modelo de evaluación de usabilidad, orientado específicamente a las aplicaciones educativas que usan la Web como soporte, que contemple los objetivos propios de este dominio, y aspectos tales como las necesidades de la audiencia destino y el perfil del usuario final.

En el capítulo 4 se ha mencionado que uno de los puntos centrales de la usabilidad es la evaluación [Fer2001]. Esta evaluación comprende un conjunto de métodos y técnicas que posibilitan descubrir errores y determinar aciertos, pero fundamentalmente ayuda a determinar cuál es el nivel actual de la aplicación, y si el diseño elegido funciona de acuerdo a lo esperado. Los actores involucrados en esta tarea son múltiples: expertos, usuarios, observadores, moderadores, desarrolladores. Su participación depende del método o de la técnica empleada.

También se indicó, en el capítulo 4, que existen numerosas propuestas y relevamientos sobre métodos de evaluación [Alv2004]. Las propuestas en general son coincidentes en varios aspectos: necesidad de la participación de expertos y usuarios, momento en que pueden utilizarse cada uno de los métodos (fase de aceptación del producto o del desarrollo actual que tenga), así como también a la posibilidad de obtener resultados cuantitativos o cualitativos.

Al momento de presentar los métodos se advirtió que a menudo se confunde el método de evaluación con la técnica, de allí que para referirse a los métodos de evaluación varios investigadores utilizan el término técnica. Por ese motivo, tomaremos a los métodos como el tipo de procedimiento utilizado, y la técnica como una forma determinada de aplicar ese método, con lo cual, un método puede ser aplicado mediante el uso de varias técnicas de recolección de datos.

También se presentaron distintos métodos para evaluar la usabilidad de un sistema, que intentan medir diferentes aspectos de la misma [Cob2005][Gra2005]. Cada método está orientado a observar características del producto desde diferentes puntos de vista. Su uso depende de variables, tales como grado de implicación del usuario, escenarios de tarea, costo, disponibilidad de tiempo, personal calificado para interpretar los datos, entre otros factores [Bae2002]. Por ello, se considera recomendable no utilizar un solo método de evaluación, sino varios que se complementen mutuamente y permitan observar las características del producto desde diferentes miradas. La coexistencia de varios métodos aporta riqueza a la evaluación, de la misma forma que varias opiniones enriquecen un debate. Estos métodos pueden ser clasificados por numerosos criterios, ya que no existe una clasificación perfecta ni un acuerdo común que permita agruparlos. Incluso muchas veces existe cierto solapamiento entre ellos [Rod2001]. La clasificación que se considera más adecuada, en este trabajo, es la siguiente [Gra2005]:

- Lugar de realización: en un laboratorio de usabilidad o en un entorno natural. 
- Tipo de método: inspección, indagación o test.

- Tipo de técnica utilizada para la recolección de datos.

- Tipo de automatización: manual o automático.

- Implicación de participantes: con usuarios implicados o sin ellos.

Dentro de los diferentes tipos de métodos propuestos por los principales investigadores en usabilidad, que se analizaron en el cuarto capítulo, se utilizará la clasificación de Floría [Flo2000b] que los agrupa en: inspección, indagación, y test. Posteriormente, se describirá en detalle aquellos que mejor se adecuan al ámbito de evaluación de EVEA.

- Métodos de Inspección

- Inspecciones: Formal, de Características, de Consistencia, de Estándares.

- Evaluación Heurística o por criterios

- Recorridos: cognitivos, pluralistas

- Listas de Comprobación

- Métodos de Indagación

- Aproximación: Contextual, por Grupos, Individual

- Participación Remota o sesiones guiadas

- Registro por el usuario

- Captura de pantallas

- Generación de Ideas

- Observación Experta

- Pantallazos de situación

- Métodos de Test

- Clásico o formal

- Remoto

- Protocolos de Expresión del Usuario: en voz alta, preguntas,

- Evaluación de desempeño

- Variantes del test clásico: tutorado, seguimiento, instrucción previa, descubrimiento conjunto, retrospectivo, rastreo visual

Desde el punto de vista del momento de aplicación de cada método durante el ciclo de desarrollo de una aplicación Web y posterior al mismo, se puede decir que, si bien, existe cierto grado de solapamiento, los métodos de indagación están más orientados hacia las etapas tempranas de desarrollo, los métodos de inspección a las etapas medias y los métodos de test las etapas avanzadas y tardías, como lo muestra la figura 13. 


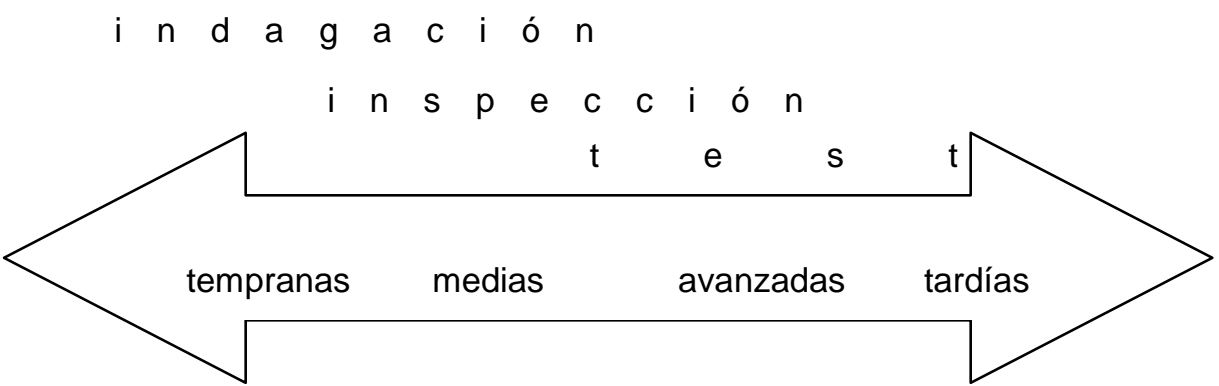

Figura 13 - Aplicación de los métodos dentro del ciclo de desarrollo de una aplicación Web

A continuación se desarrollarán los métodos de evaluación de usabilidad que consideramos más interesantes, o que más nos pueden ayudar, a la hora de evaluar sitios Web orientados a favorecer los procesos de enseñanza y aprendizaje en contextos virtuales (figura 14).

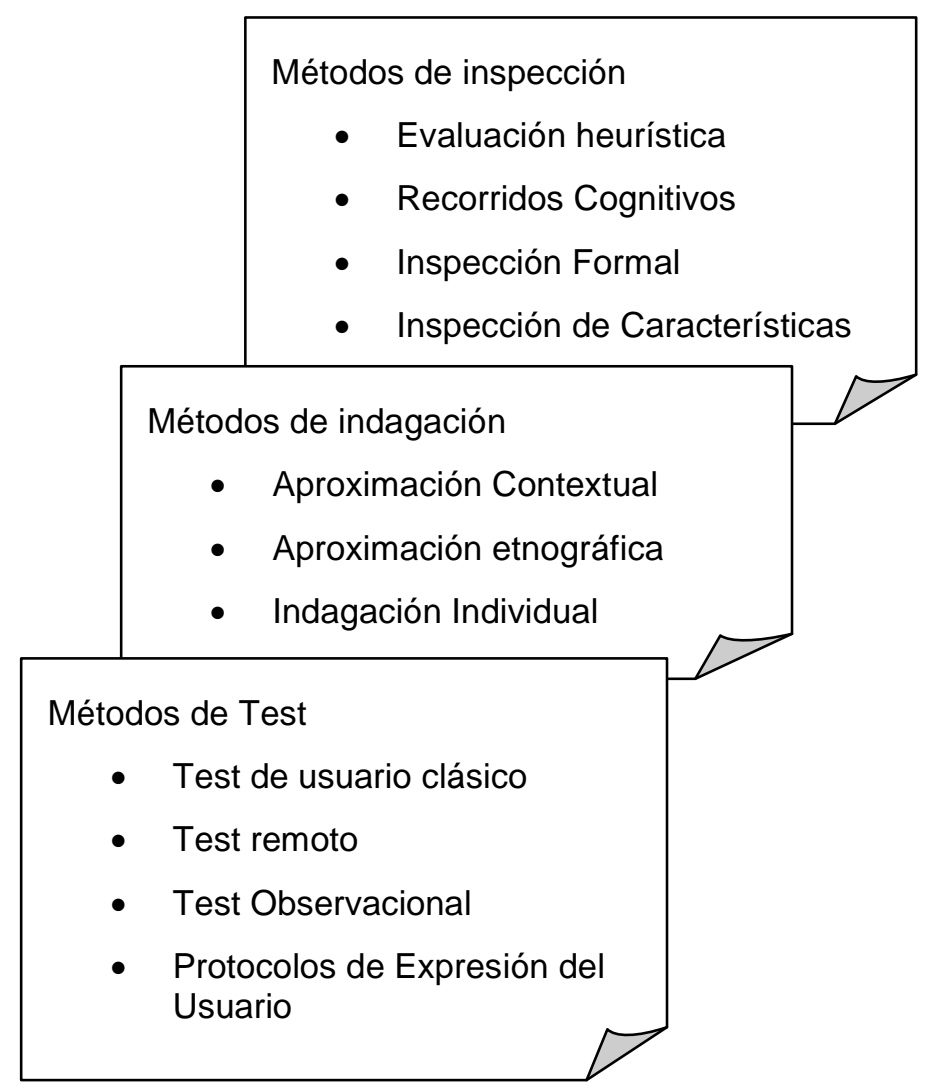

Figura 14 - Métodos de evaluación de usabilidad

\subsubsection{Métodos de inspección}

La evaluación por inspección agrupa al conjunto de métodos basados en examinar, mediante evaluadores especialistas en diferentes áreas, los principios relacionados con la usabilidad de un software o sitio Web, confiando en la experiencia y conocimiento del evaluador [Scr1967][Nie1994b][Rii2000]. Estos métodos permiten encontrar problemas de usabilidad en el diseño del software [Mac1994] o en la interfaz de usuario [Nie1990c]. En general se trata de métodos que sirven como complemento de otros. Pueden aplicarse 
muy tempranamente en el ciclo de desarrollo del software [Des1991] así como también en la etapa final o a un producto terminado.

Existen varios métodos que pueden catalogarse como de inspección. Una buena parte de ellos, como las inspecciones formales o sus variantes, tienen su raíz en las revisiones estáticas de código [Jur2006], y su forma de aplicación es similar a ellas.

Las inspecciones de usabilidad son tenidas en cuenta debido a su rentabilidad y rapidez de aplicación respecto a otros métodos tradicionales [Alv2005]. Por ejemplo, las observaciones directas o por video demandan muchos recursos y tiempo, y no siempre aportan buenos resultados debido a que se desarrollan en un escenario poco natural [Nie1993b].

De todas maneras, los métodos de inspección tampoco son perfectos. Su uso combinado puede ayudar a mejorar los resultados obtenidos. La idea es hacer una evaluación de la usabilidad por expertos (desarrolladores, especialistas, usuarios seleccionados) basándose en una serie de criterios pre-establecidos. Los casos más habituales son, la evaluación heurística y el recorrido cognitivo.

\subsubsection{Evaluación heurística}

La evaluación heurística es uno de los métodos de evaluación por inspección más conocidos y utilizados en la actualidad. Este método, también llamado evaluación por criterios, fue desarrollado en la década del 90 con el objetivo de probar las interfaces Web de forma sencilla [Alv2005]. Se trata de una evaluación ampliamente aceptada para diagnosticar problemas potenciales de usabilidad en la interfaz de usuario. Está basado en la inspección sistemática de usabilidad del diseño de la interfaz de usuario. Nielsen y Molich, lo definen como un método de ingeniería de la usabilidad, utilizado para encontrar problemas de usabilidad (errores más comunes) en el diseño de las interfaces de usuario, de forma rápida, barata y sencilla [Nie1990b].

La evaluación heurística puede aplicarse en diferentes etapas del ciclo de desarrollo, proporcionando un buen porcentaje de los problemas de usabilidad existentes en el diseño de la interfaz de usuario, con el objeto de que puedan ser atendidos como parte de un proceso de diseño iterativo. Sin embargo, a pesar de tener esa flexibilidad, no debe ser el único método en aplicarse, sino que necesita ser enriquecido con otros, fundamentalmente alguno de los cuales involucre usuarios finales.

El proceso de inspección es llevado a cabo por un grupo de evaluadores, expertos en usabilidad, que tienen como misión examinar críticamente el grado de acercamiento que posee la interfaz de usuario, con una serie de reglas, guías o directrices básicas de diseño, llamadas heurísticas [Mac1993][Con2005]. Las heurísticas utilizadas son elaboradas previamente de acuerdo a las necesidades propias del sitio a evaluar, y en general están basadas en las diferentes propuestas realizadas por especialistas en la materia como Nielsen [Nie1990], Instone [Ins1997a], Schneiderman [Sch1998], Constantine [Con1999], Mayhew [May1999], Norman [Nor1998][Nor2004], Tognazzini [Tog2003] y Keionen [Kei2003]. No hay heurísticas más importantes que otras, sino que cada una de ellas permiten detectar distinto tipo de errores [Nie191990]. Estas heurísticas son de índole general para todo tipo de sitio Web y no es necesario aplicarlas todas, sino que previamente debe realizarse una selección de acuerdo a tres criterios como mínimo:

1. El tipo de sitio Web que se evalúe: algunas heurísticas tienen sentido aplicarlas y otras no, de acuerdo a la clase de sitio evaluado. Por ejemplo, un sitio informativo orientado a la visualización de noticias a nivel mundial, generadas por diferentes 
agencias y en varios idiomas, necesitará ser evaluado con un conjunto de heurísticas distintas a las de un sitio bancario, de acceso nacional, con mecanismos de autenticación de usuarios y protocolos de seguridad para la realización de transacciones y consultas.

2. El grado de participación del usuario: los sitios Web donde el usuario tiene un rol activo y puede participar libremente en la construcción del contenido, como las Wikis o los Blogs, no pueden ser evaluados con las mismas heurísticas que los sitios estáticos, donde los diseñadores son los únicos responsables de la actualización de información y los usuarios sólo navegan por él.

3. El tamaño del sitio: cuando un sitio Web está compuesto por gran cantidad de páginas, es necesario aplicar heurísticas que posibiliten evaluar aspectos como la organización, consistencia, visibilidad y reutilización, de forma tal que el usuario pueda navegar lo más cómodo posible, encuentre rápidamente lo que necesita, y no abandone el sitio por sentirse abrumado. Este tipo de análisis carece de sentido en un sitio compuesto por pocas páginas.

El proceso de evaluación se lleva a cabo mediante varios expertos que realizan el análisis por separado y luego confeccionan un informe con la lista de problemas encontrados, y su explicación de acuerdo a los principios de usabilidad, ordenados de acuerdo al grado de gravedad. La jerarquización de la gravedad de los problemas del sitio facilitará la aplicación posterior de políticas de rediseño más efectivas. La gravedad de los problemas de usabilidad es medida por tres factores [Man2003b]:

1. La frecuencia con la que el problema ocurre.

2. El impacto que tiene el problema para el usuario.

3. La persistencia del problema.

Para llevar a cabo este análisis, los evaluadores utilizan una lista de principios heurísticos. A esta lista se la conoce comúnmente como "checklist" y es confeccionada previamente por especialistas en usabilidad y el dominio de aplicación. Cada heurística es presentada de una manera estructurada, con uno o más de los siguientes elementos [Alv2005]:

- Preguntas de conformidad: qué debe hacer el sistema o el usuario para satisfacer las heurísticas.

- Evidencia de conformidad: qué aspectos de diseño deben considerarse que indiquen satisfacción o infracción de la heurística.

- Motivación: captura los aspectos no conformes a las heurísticas (defectos) en un informe donde los evaluadores describen el problema, su severidad, y sugieren cómo arreglarlo.

Previo a la evaluación, se solicita a los expertos que naveguen integralmente el sitio Web, por lo menos en dos ocasiones, a efectos de familiarizarse con él. En el primer recorrido el evaluador debe centrarse en el flujo de la interacción y el desarrollo general del sistema, mientras que en el segundo, pone énfasis sobre los elementos específicos de la interfaz y su modo de funcionamiento [Nie1993b]. El proceso de evaluación tiene una duración que oscila entre 1 y 2 horas. De allí que se lo considere como un método de gran importancia debido a la rapidez de aplicación, la calidad de los resultados obtenidos y el bajo costo.

Una de las ventajas que ofrece la evaluación heurística es que se cuenta con informes escritos realizados por especialistas. Ello evita la necesidad de realizar interpretaciones $u$ 
observaciones en el uso del sitio Web. Además, al trabajar con pocos evaluadores es posible dialogar con ellos, colaborar, evacuar dudas o realizar un análisis más fino de puntos clave dentro del sitio.

\subsection{Evaluadores}

La evaluación heurística es un método de inspección de la interfaz de un sitio Web, donde el usuario final no tiene participación en el proceso [Cat2000]. Los evaluadores del sitio son especialistas en usabilidad cuya experiencia es directamente proporcional a la cantidad de problemas encontrados [Nie1992]. Existe un acuerdo general respecto a que diferentes evaluadores encuentran distintos tipos de problemas en un sitio Web y que el incremento del número de evaluadores contribuye a mejorar el porcentaje de problemas encontrados [Jac1998]. La cantidad de errores detectados respecto a la cantidad de evaluadores sigue una escala logarítmica, por lo tanto, es de vital importancia utilizar más de un evaluador. El problema es determinar cuál es la cantidad óptima, ya que, a mayor cantidad de evaluadores también se necesita mayor disponibilidad de tiempo, logística y recursos.

Al respecto existen diferentes propuestas: Nielsen [Nie1994] sugiere un mínimo de tres y un máximo de cinco, debido a que una mayor cantidad de evaluadores reduce el beneficio drásticamente y la proporción de rentabilidad es más alta cuando la cantidad oscila entre estos valores. Quinn [Qui1996] establece que el número óptimo de evaluadores se encuentra entre 6 y 8 , sobre todo en los casos donde la usabilidad es un criterio clave. Otros estudios establecen que 5 evaluadores detectan el $80 \%$ de los problemas, mientras que 15 detectan el 100\%. La determinación de estos parámetros es empírica, producto de numerosos ensayos y experiencias. Más allá de las diferentes propuestas, lo concreto es que no puede delegarse la tarea de inspección a una sola persona, es necesario por lo menos 3 evaluadores. La cota superior puede determinarse en función del tamaño del sitio, la importancia de los estándares en el mismo, el tipo y cantidad de usuarios que harán uso de él, y los recursos disponibles. Sin embargo, para poder aprovechar las principales ventajas del método, como rapidez y facilidad de aplicación, la cota superior podría establecerse en 5 expertos, un número que es aceptado dentro de la comunidad de investigadores en el área.

\subsection{Forma de aplicación}

En primer término los especialistas realizan un recorrido de todo el sitio para familiarizarse con su estructura, forma de navegación y objetivo.

Luego, se realiza una evaluación individual donde los evaluadores dedican entre 1 y 2 horas a las siguientes tareas:

- Inspección de los elementos de cada página Web.

- Comparación con una lista de heurísticas establecidas previamente.

- Confección de una lista de problemas encontrados, ordenada de acuerdo al grado de importancia, conteniendo la explicación del problema de acuerdo a los principios de usabilidad.

- Clasificación de los problemas de acuerdo a [Nie1995]:

- La frecuencia con la que el problema ocurre: siempre o de vez en cuando.

- El impacto del problema cuando sucede: el usuario puede superarlo fácilmente o no. 
- La persistencia del problema: aparece repetidamente o una vez resuelto no vuelve a presentarse.

Por último, los evaluadores realizan una puesta en común, debaten y elaboran un único informe donde se ve reflejado el análisis realizado por cada uno de ellos y los acuerdos alcanzados. Los problemas encontrados se clasifican de acuerdo a su gravedad, con el propósito de servir como base para la mejora del sitio. Dependiendo de la cantidad de evaluadores, la importancia del sitio, y los recursos disponibles, la clasificación puede hacerse más o menos granular:

- Grave o leve: es la forma más sencilla de clasificarlos. Los problemas graves deben ser solucionados de manera inmediata, mientras que los leves pueden dejarse para más adelante o directamente no solucionarse.

- Mayor, Medio o Menor: incorpora un nuevo grupo de problemas que tienen gravedad intermedia, es decir, deben ser solucionados pero no son los principales.

- Muy grave, Mayor, Menor, Estético, No significativo: los problemas clasificados como muy graves deben solucionarse inmediatamente, los mayores son de alta prioridad y es importante arreglarlos, los menores son de baja prioridad pero deben ser tenidos en cuenta y resueltos en algún momento, los estéticos pueden no ser tenidos en cuenta si no hay tiempo disponible. Finalmente, los no significativos no pueden considerarse un problema sino que se trata de alguna acotación o sugerencia.

\section{Las fases de una evaluación heurística}

La evaluación heurística sigue los siguientes pasos:

- Entrenamiento previo a la evaluación: hay que dar a los evaluadores conocimiento del tema e información. No obstante, si se trata de una interfaz del tipo "llegar y usar" los evaluadores no necesitan esta introducción. Este tipo de interfaces son los que los usuarios deberían ser capaces de utilizar por sí mismos directamente. En general, las páginas en Internet suelen tener ese formato.

- Evaluación: los sujetos evalúan la interfaz y detectan los errores de usabilidad. Los errores son después agregados.

- Puntuar la severidad: en este punto se tiene que determinar la severidad de cada uno de los problemas encontrados. Esto se hace distribuyendo la lista completa de errores encontrados a todos los evaluadores.

- Revisión: la revisión de los problemas encontrados se hace con el equipo de diseño del sistema.

\subsubsection{Recorrido Cognitivo}

El recorrido o paseo cognitivo se apoya en la teoría de aprendizaje exploratorio, denominada CE+ [Pol1992][Lew1993][Wha1994]. Esta teoría es un modelo que intenta explicar la forma en que las personas procesan la información cuando interactúan con una computadora. El modelo está formado por tres componentes: resolución de problemas, aprendizaje, y ejecución. Este método de inspección involucra los tres tipos de información de contexto [Alv2005]:

- una descripción de los usuarios y el conocimiento que ellos poseen. 
- las descripciones de las tareas que los usuarios realizarán con el sistema.

- una lista de las acciones correctas que un usuario debe realizar para lograr las tareas con un prototipo particular.

El recorrido cognitivo combina la navegación del sitio Web con la teoría CE+. Es un método que se centra en evaluar mediante exploración la facilidad de aprendizaje de un diseño. Está motivado en que muchos usuarios prefieren aprender a utilizar una aplicación en base a explorar sus posibilidades [Wha1992]. Consiste en simular todos y cada uno de los pasos (dudas, decisiones, etc.) que se plantea el usuario al navegar por un sitio Web, con el objeto de predecir problemas de usabilidad pero sin realizar tests con usuarios reales.

La evaluación, utilizando el recorrido cognitivo, puede aplicarse tanto en las etapas tempranas de diseño, como antes de la puesta en marcha del sistema [Cat2000] [Alv2005]. En el primero de los casos se pueden utilizar prototipos en papel, maquetas Web, o prototipos tempranos realizados sobre la base de páginas html estáticas, donde el comportamiento sea simulado o pueda deducirse. Esto permite estimar la facilidad de aprendizaje a través de prototipos del sistema, haciendo posible evaluar el software en las etapas iniciales de desarrollo, aún cuando no está del todo claro el contexto de uso, y por ende, no hace falta recurrir a los usuarios finales. Algunos autores interpretan que esto es beneficioso debido a que puede reducirse el tiempo y el costo de la evaluación [Pol1992], mientras que otros lo ven como un punto débil, puesto que representa una carga muy pesada en tiempo para los evaluadores y genera resistencia por parte de los mismos [Row1992].

Para aplicar el método, los evaluadores expertos construyen escenarios para las tareas a partir de una especificación o prototipo inicial, y después asumen el rol del usuario trabajando con esa interfaz como si estuviera completamente construida, es decir, mediante la realización de tareas imitan a los usuarios finales de esa interfaz. Dando un paseo por la interfaz, ejecutan y recorren las funciones más usuales del sistema. Durante la realización de cada tarea se controla y registra cada paso que el usuario debe realizar. Se pone especial atención a la presencia de callejones sin salida, caminos complejos o sinuosos a través de las secuencias de funciones. Aquellos pasos en los que el usuario se bloquea, se torna dificultoso completar la tarea o directamente no consigue terminarla, implican que la interfaz presenta algún problema, o bien falta alguna función que simplifique la ejecución de la misma [Hom2003]. Es decir, se intenta establecer el comportamiento que tendrá el usuario frente a la interfaz, y prever los posibles errores con los que pueda encontrarse.

Para evaluar la interfaz de la forma más realista posible, los evaluadores, además de situarse en el lugar de los usuarios finales, deben recibir el mismo trato que recibirán ellos, como por ejemplo, acceder a versiones demo, leer manuales, interactuar con tutoriales, realizar un seminario, concurrir a una charla, completar guías de tareas, o recibir ayuda de parte de personal capacitado [Cat2000].

En el caso que el método se aplique a un sistema en su fase final de desarrollo, la interfaz utilizada será la real. La ventaja de aplicar la metodología en una etapa avanzada es que no hace falta imaginarse, mediante un prototipo, cómo funcionaría el sistema en un entorno real. La desventaja principal radica en que pueden aparecer problemas de difícil solución que obliguen al rediseño de buena parte del sistema y la interfaz.

\subsection{Evaluadores en el recorrido cognitivo}


El recorrido cognitivo puede ser aplicado por el diseñador de la interfaz y un grupo de miembros del equipo, o por especialistas en el dominio de aplicación. Uno de los evaluadores hace las veces de moderador, otro es el encargado de registrar los resultados de la evaluación y el resto del grupo asume el rol de usuarios finales. El hecho de que los expertos asuman el rol de usuarios a la hora de evaluar interfaces se basa en la idea de que ellos conocen lo que los usuarios están pensando, mejor que los mismos usuarios [Dix2003]. La cantidad de evaluadores dependerá de la cantidad de roles o de usuarios distintos que harán uso de la interfaz. Puede suceder que no todos los usuarios accedan a la misma interfaz, o que de acuerdo al rol que le toca desempeñar, la misma interfaz esté compuesta por más o por menos elementos. Por ejemplo, en una aplicación para compra y venta on-line, un usuario que desea vender un producto utilizará interfaz diferente a los usuarios que desean comprar dicho producto. También puede darse el caso que un usuario editor de una cartelera de noticias visualice opciones que permitir gestionarlas (agregar, editar o borrar) mientras que un usuario lector no.

\subsection{Forma de aplicación}

- Determinación de usuarios: se identifican las características de los futuros usuarios, incluyendo la experiencia específica acumulada y el conocimiento adquirido. Estos dos factores son determinantes para la comprobación del factor "cognitivo" durante el recorrido [Gra2005].

- Determinación de tareas: se evalúan las especificaciones del sistema en términos de qué tareas realizarán los usuarios. Cada tarea implica una acción cognoscitiva y una acción física. Si la tarea es compleja puede subdividirse. Cada tarea implicará pre-requisitos o tareas que habrá sido necesario realizar previamente.

a. Se enumeran las tareas concretas a desarrollar.

b. Para cada tarea se enumeran las acciones necesarias para completarla.

c. Se especifica una lista de pasos a realizar formada por la acción a ejecutar por el usuario, la respuesta brindada por el sistema y la crítica del evaluador.

- Recorrido: los evaluadores deben tener como meta estudiar el grado de complejidad de la interfaz y si es asimilable por el usuario o no. Para ello realizan cada una de las tareas determinadas anteriormente siguiendo los pasos especificados. El evaluador utilizará la información del factor cognitivo (experiencia y conocimiento adquirido) de los usuarios para comprobar si la interfaz es adecuada para ellos o no [Gra2005]. Los evaluadores, en rol de usuarios, deben ejecutar cada una de las acciones especificadas anteriormente, verificar si la respuesta obtenida se condice con la esperada, y registrar para cada una de las acciones los posibles obstáculos con los cuales se podría encontrar el futuro usuario. Los principales interrogantes que los evaluadores deben intentar responderse durante la ejecución de cada acción son [Dix1998][Gra2005]:

- ¿Son adecuadas las acciones disponibles de acuerdo a la experiencia y al conocimiento del usuario?

- ¿Percibirán los usuarios que están disponibles las acciones correctas en el momento adecuado?

- ¿El efecto producido por la acción realizada se corresponde con lo esperado por los usuarios? 
- ¿Entienden los usuarios la retroalimentación producida por la acción y pasan con confianza a la próxima?

- ¿Serán capaces los usuarios de esta aplicación de entender determinado icono o metáfora?

- ¿Dispondrán del conocimiento necesario cuándo accedan a determinada función?

- Informe de resultados: Al finalizar cada tarea, el diseñador del sistema debe proceder a comentar cuál es la respuesta correcta que se espera de los usuarios, y los evaluadores deben confrontar esta respuesta con sus registros para poder determinar si a su entender la interfaz presenta inconvenientes o no. El encargado de registrar el resultado de la evaluación debe documentar, para cada tarea, la opinión de los evaluadores. El informe producido servirá para determinar el grado de complejidad de la interfaz y la asimilación por parte del usuario. Además, el informe puede incluir un anexo con un reporte de problemas de usabilidad detallando los aspectos negativos de la evaluación y el grado de severidad de los mismos [Dix1998]. Para algunos autores este reporte es el resultado más importante de la evaluación ya que contiene los problemas a solucionar [Gra2005].

Este método se ha mostrado eficaz como suplemento a los métodos de indagación para evaluar la utilidad de sistemas del software [Lew1990][Jef2001]. Además, no solo puede aplicarse en etapas tempranas y medias sino también en el resto de etapas [Gra2005]. Sin embargo, tiene varios puntos débiles [Gaf1999][Cat2000]:

- Pretende ser demasiado abarcativo, puesto que está pensado para todo tipo de interfaz, cuando no todas las interfaces son iguales, ni tampoco todas son simples de utilizar sin antes haber pasado por una explicación previa o haber recibido la capacitación correspondiente.

- Está pensado para evaluar un sistema en particular, en lugar de una familia de sistemas con características similares. Si bien las tareas pueden ser las mismas, las acciones y lista de pasos que debe seguir el usuario dependen de cada sistema.

- La ausencia de usuarios reales no permite que se pongan de manifiesto todos los aspectos que tendrían en consideración los verdaderos destinatarios.

- El evaluador debe buscar respuesta a una serie de preguntas basándose en la descripción de las características de los usuarios en términos de su conocimiento adquirido y de su experiencia. En esta simulación pueden introducirse errores.

- No favorece el diseño participativo.

\subsubsection{Recorrido Cognitivo Plural}

El método de recorrido cognitivo plural consiste en el debate y la puesta en común de los recorridos cognitivos realizados por diferentes tipos de evaluadores. Las pruebas se realizan con prototipos en papel u otros materiales utilizados en un escenario concreto. Comparte algunas características con los recorridos tradicionales, pero tiene particularidades que lo diferencian, entre las que cabe destacar la intervención de usuarios finales.

\subsection{Evaluadores}


Los evaluadores que participan del recorrido cognitivo plural son de tipos diferentes, buscando miradas de diverso origen, de allí deviene la pluralidad. Los evaluadores se clasifican en tres tipos: los usuarios representativos, los desarrolladores del producto, y los expertos en usabilidad [Bia1994b]. Todos los evaluadores asumen el papel de usuarios.

\subsection{Forma de aplicación}

- Se especifican las tareas a realizar en el prototipo.

- Se realiza el recorrido cognitivo de la manera tradicional mediante los desarrolladores del producto y los expertos en usabilidad.

- Se seleccionan usuarios representativos del perfil que se desea evaluar.

- Se explica a los usuarios la prueba, el método, los objetivos y el prototipo.

- Cada participante dispone de una copia del escenario de la tarea con datos que se puedan manipular.

- Se pide a cada usuario que realice, de manera individual, el grupo de tareas definidas en el recorrido correspondiente a su perfil de usuario, sin recibir explicaciones. Si lo desean, pueden expresar en voz alta sus pensamientos, sentimientos y opiniones sobre cualquier aspecto.

- Al finalizar cada tarea deben complementar la información anotando los principales defectos detectados.

- Una vez que el usuario ha finalizado las tareas pueden comentarse los potenciales problemas identificados por los desarrolladores y expertos para conocer sus puntos de vista.

- Finalmente, los expertos documentan los resultados en base a la información recogida.

El principal beneficio de esta técnica radica en el fuerte enfoque hacia las tareas de los usuarios [Pre2002]. Aumenta considerablemente el número de errores detectados y es de gran aceptación por parte de los equipos multidisciplinares [Gra2005]. El recorrido realizado por un experto aporta la imparcialidad necesaria que los usuarios no pueden aportar. A su vez, proporciona un primer acercamiento para la evaluación a cargo de los usuarios, permitiendo que el evaluador observe cómo responde el usuario en aquellos puntos que le resultaron más confusos o erróneos. La participación del usuario es más fluida que ubicándole en un laboratorio donde puede sentirse observado. Las dudas o errores que pueden haber surgido durante la evaluación de los expertos pueden ser contrastadas rápidamente con usuarios finales y evitar así que se creen indecisiones nocivas para el proyecto, así como también detectar problemas que no fueron capturados por los expertos.

En cuanto a las desventajas, la principal es que suele resultar dificultoso agrupar tanta gente en una sola sesión. También requiere más recursos para su realización porque el evaluador necesita invertir mucho más, es necesario reclutar usuarios, prepararlos y dedicarles atención.

\subsubsection{Inspección Formal}

El método de inspección formal de usabilidad, adapta la metodología de inspección del software para la evaluación de la usabilidad. Ha sido diseñado para reducir el tiempo 
requerido en descubrir defectos. Es similar a los métodos de inspección de código, ya que consiste en una prueba de validación y verificación del código. Es adecuado principalmente en las etapas tempranas, ya que el evaluador puede trabajar simplemente con una especificación, sobre el papel o con un prototipo temprano [Alv2005].

\subsection{Evaluadores}

Los expertos que participan de este tipo de métodos son especialistas que pertenecen a diferentes áreas de la ingeniería de software: diseño, desarrollo, calidad, documentación y supervisión. De acuerdo a la cantidad de áreas que abarcan los evaluadores se considera razonable un grupo de entre 4 y 8 expertos.

\subsection{Forma de aplicación}

Este método combina inspecciones individuales y grupales en un procedimiento de seis pasos con roles estrictamente definidos [Alv2005]:

- Constitución del equipo: se forma un equipo compuesto de 4 a 8 evaluadores.

- Asignación de funciones: cada experto está encargado de evaluar de forma individual deficiencias de usabilidad. Además, en las reuniones del equipo de trabajo, cada evaluador representará un determinado rol: moderador, propietario, secretario, inspector.

- Moderador: distribuye y recoge los materiales requeridos, programa las reuniones de trabajo, asigna tareas de corrección de deficiencias.

- Propietario, autor o diseñador del producto: se le asignan las correcciones de los defectos encontrados.

- Secretario: recoge en un documento formal los defectos de usabilidad encontrados durante las reuniones de trabajo.

- Inspectores: inspeccionan el diseño y realizan los informes de deficiencias presentadas.

- Distribución de la documentación: incluyen descripciones del producto, perfiles de usuario, tareas típicas, heurísticas y patrón de registro para los defectos encontrados.

- Inspección del diseño: los expertos registran, en un formulario preestablecido, los defectos que encuentran sobre la base de las heurísticas proporcionadas. De cada defecto, debe darse una descripción y ubicación exacta.

- Realización de reuniones formales de trabajo: el moderador conduce al equipo a través de cada tarea y los expertos intervienen indicando los defectos que encontraron durante su propia inspección, asumiendo el punto de vista del usuario. El secretario confecciona un acta con los defectos consensuados por el equipo. El moderador deberá evitar que durante la reunión se busquen soluciones a los defectos, debido a que no es ese el objetivo de la reunión. Tampoco debe permitir que el propietario justifique las decisiones de diseño tomadas que han sido registradas como deficiencias.

- Fijación y priorización de defectos: los defectos registrados durante la reunión se asignan al personal responsable para su solución. El moderador efectúa un seguimiento y dispone reuniones de tormenta de ideas para encontrar soluciones. 


\subsubsection{Inspección de Características}

El método de inspección de características tiene como objetivo averiguar si las características de un producto satisfacen las necesidades y exigencias del usuario [Bel1992]. Se utiliza principalmente en las etapas medias de desarrollo, cuando ya son conocidas las funciones del producto y las características que los usuarios usarán para producir los resultados deseados. Los expertos deben asumir el rol de usuarios, centrando su análisis en las funciones que el sistema debe proveer para completar cada una de las tareas específicas. Este método se caracteriza, no solo por realizar la evaluación de las funciones del sistema respecto a los usuarios finales, sino también porque involucra el diseño de dichas funciones.

La inspección de características es identificada como un procedimiento adyacente a otros métodos de evaluación de usabilidad debido a que se verifica no sólo la usabilidad de la interfaz, sino también el beneficio de su función [Mac1994b].

\subsection{Evaluadores}

Es necesario contar con expertos en usabilidad con conocimiento exhaustivo de estándares Web como los planteados por el W3C.

\subsection{Forma de aplicación}

- Se establece una lista de características que deberían cumplirse para la realización de las diferentes tareas del usuario.

- Se comprueba la dificultad o imposibilidad del usuario final de alcanzar dichas características durante la realización de las tareas.

- Se elabora un documento descriptivo analizando los niveles de dificultad del usuario en alcanzar las características en cada momento.

\subsubsection{Inspección de Estándares}

Se trata de un método encargado de verificar que la interfaz cumpla con los estándares que rigen en la Web. Este método se aplica en las fases intermedias del desarrollo, en las que ya se han implementado módulos con su correspondiente interfaz de usuario.

\subsection{Evaluadores}

Para llevarlo a cabo se recurre a un experto en usabilidad con un conocimiento exhaustivo de Internet.

\subsection{Forma de aplicación}

- Se elabora una lista de los estándares tanto oficiales como "de facto" que rigen en Web, en las distintas tipologías de aplicaciones y sus correspondientes interfaces de usuario.

- Un experto analiza la interfaz de usuario chequeando el cumplimiento de dichos estándares.

- Se elabora un documento de incumplimientos de los estándares que se hace circular a los equipos de desarrollo. 


\subsubsection{Listas de Comprobación}

Las listas o guías de comprobación ayudan a asegurar que los principios de usabilidad sean considerados en un diseño. También se las conoce con el nombre de Revisión por recomendaciones previas. El método se basa en una serie de reglas o interpretaciones detalladas que deben seguirse a la hora de crear interfaces, definir sus elementos, su apariencia o su comportamiento [Cat2000]. Estas recomendaciones, en general, están orientadas al diseño físico, sintáctico y semántico de la interfaz. El diseño físico está relacionado con el hardware necesario para soportar la interfaz gráfica, el diseño sintáctico hace referencia a las reglas sobre la presentación de la información, y el diseño semántico, al significado de los elementos sintácticos.

Un caso particular, son aquellas denominadas listas de comprobación basadas en escenarios. Con este tipo de listas la inspección se llevan a cabo a través de tres escenarios: usuario novato, usuario experto, y manejo de errores. Para cada escenario se proporciona una lista de aspectos a comprobar. Normalmente, las listas de comprobación se utilizan en combinación con algún otro método de inspección, y sirven a modo de referencia.

\subsection{Evaluadores}

Es necesario contar, al igual que en la evaluación heurística, con un grupo de expertos en usabilidad.

\subsection{Forma de aplicación}

- Se elabora una lista de recomendaciones basada en estándares previamente establecidos por la empresa u organización generadora del producto.

- Con esta lista de recomendaciones, se elabora un documento compuesto por un conjunto de ítems que es entregado a los expertos en forma de lista de chequeo.

- Los expertos disponen de un tiempo para familiarizarse con esta lista de recomendaciones y luego proceden a determinar si la interfaz cumple o no con cada ítem de la lista.

- Como resultado de la evaluación cada experto entrega al diseñador de la interfaz el documento debidamente completado señalando cuáles son los ítems que a su entender se cumplen y cuáles no.

- Tomando como base los documentos recibidos, el diseñador realizará una síntesis de aciertos y errores de la interfaz y, en función de ello, determinará los cambios que debe realizar.

\subsubsection{Métodos de indagación}

Los métodos de indagación permiten identificar los requisitos tanto del usuario como del producto. De allí, que generalmente la mayoría de las propuestas están pensadas para aplicarse en etapas tempranas del proceso de desarrollo. Para ello suelen utilizarse, al igual que en algunos de los métodos de inspección, maquetas o prototipos de la aplicación. Son muy útiles para capturar las necesidades del usuario, y posteriormente satisfacerlas de forma eficaz y efectiva, a través de las funciones del sistema. Es decir, los métodos de indagación permiten descubrir y aprender para generar ideas de diseño, especialmente para obtener información de usabilidad sobre un producto que se desea producir. De allí que se los defina como métodos contextuales que posibilitan aproximarse al usuario desde diferentes perspectivas para recopilar información y avanzar en el diseño 
del producto. Si bien la indagación tiene mayor sentido en las etapas tempranas de desarrollo, no se descarta su utilización en otros momentos, inclusive luego de liberado el producto.

\subsubsection{Aproximación Contextual}

La aproximación contextual es un método de análisis e investigación, un proceso de descubrimiento y aprendizaje que sintetiza aspectos de investigación de contexto y etnográficos [Alv2005]. Una de las suposiciones fundamentales de este método es que el ambiente donde las personas trabajan influye en la manera en que se usan los productos. El propósito es aportar a los diseñadores conocimiento profundo y detallado del trabajo del usuario, sus escenarios y la terminología que utilizan. Consiste en que un grupo de diseñadores entreviste a futuros usuarios en su propio lugar de trabajo, mientras ellos ejecutan sus tareas reales [Hug1995]. Las entrevistas están relacionadas con el producto a desarrollar, o en desarrollo. Los entrevistadores están autorizados a interrumpir a los usuarios en cualquier momento y hacerles todas las preguntas que sean necesarias [Sar2001]. La información recolectada por los diseñadores constituye la base del diseño. Este método distingue dos variantes: pura y etnográfica.

\subsection{Aproximación contextual pura}

Es un método estructurado de entrevista, basado en un conjunto de principios que busca descubrir y aprender sobre el modo de trabajo de los usuarios finales [Hug1995] [Hug1997]. Los principios sobre los que se basa son:

- Comprensión del contexto.

- Comprensión del usuario como socio en el diseño.

- Comprensión del enfoque.

Este método es utilizado en etapas tempranas de desarrollo porque permite conseguir gran cantidad de información subjetiva respecto a cómo se sienten las personas en sus trabajos, cómo trabajan, y cómo es el flujo de información a través de la organización.

\subsection{Aproximación etnográfica u observación de campo}

Consiste en la observación del usuario y su interacción con el producto en su entorno habitual, en lugar de un escenario artificial o experimental como los laboratorios de usabilidad, prescindiendo de las ventajas del laboratorio a la hora de captar y registrar datos. Este método busca entender los ambientes de trabajo y las actividades de los usuarios, desde el punto de vista de las personas que trabajan allí, permitiendo visualizar aspectos físicos y sociales de un escenario real. Es útil para todo tipo de contexto y tecnología. Permite analizar cómo se integra una tecnología en su ambiente real de uso, qué problemas existen, y qué prácticas o usos emergen en el ambiente, que sean difíciles de predecir o anticipar mediante el análisis de la interacción de usuarios individuales con una herramienta en un ambiente de prueba artificial [Alv2005].

\subsubsection{Indagación Individual}

Aunque existen diferentes estructuras y procedimientos, el factor común de este método, y el más importante, es la formulación de preguntas efectivas [Nie1993b]. Las técnicas utilizadas en este método para la colección de información más comunes son: encuestas, cuestionarios y entrevistas. 


\subsubsection{Participación Remota o sesiones guiadas}

Este método se utiliza para poder incluir participantes remotos en la evaluación, con el objetivo de probar un producto. La distancia no debe suponer un obstáculo. Es un método rentable para identificar problemas de usabilidad en productos prototipo. Anima al equipo de diseño, y a usuarios, a colaborar para identificar problemas de usabilidad y sus soluciones. Proporciona información cualitativa sobre las dificultades de la experiencia del usuario cuando intenta completar tareas y otros elementos de la interfaz que dan origen a problemas. Hace uso de diferentes técnicas para la obtención de información, como cuestionario o encuesta remota, sistemas computarizados de captación y colección de datos, registro del usuario, registro de uso real, informe de incidencias críticas del usuario, procedimientos mediante servicios comerciales de usabilidad, etc.

\subsubsection{Métodos de test}

Los métodos de test, empíricos o de prueba de usabilidad, forman parte de los métodos de evaluación clásicos [Woo1998]. Son considerados los más importantes a la hora de recabar información de la interacción entre el usuario y el sistema. En ellos, un grupo de usuarios utiliza la aplicación ya desarrollada y en uso, a los efectos de evaluarla y recolectar información que no fue tenida en cuenta durante el diseño de la aplicación. También pueden aplicarse a sistemas que se encuentran en su etapa de diseño pero que poseen prototipos en funcionamiento. A raíz de estas alternativas se desprenden dos formas básicas de comprobación empírica [Nie1992b]:

- Probar una interfaz prácticamente terminada para verificar si las metas de usabilidad han sido logradas. Este tipo de prueba implica hacer alguna forma de medida cuantitativa.

- Evaluación formativa de un sistema que todavía está diseñándose para ver qué aspectos de la interfaz de usuario han sido bien logrados y cuáles causan problemas de usabilidad. Esta prueba es mejor hacerla usando métodos cualitativos.

En general, los métodos de test utilizan la primera forma, ya que para etapas tempranas de desarrollo, existen otros métodos de evaluación más eficaces. Una característica de este tipo de métodos es que pueden aplicarse bajo la supervisión de evaluadores o dejando a los usuarios actuar libremente en su propio contexto. En estos métodos los usuarios prueban el sistema (o un prototipo viable) y el evaluador los observa y comenta, a medida que van trabajando. A partir de esas observaciones y comentarios se pueden extraer las conclusiones de usabilidad.

\subsubsection{Test de usuario clásico o formal}

En este tipo de test se recurre a la utilización de laboratorios de usabilidad y a evaluadores especializados que supervisan las tareas realizadas por el usuario. Los laboratorios permiten a los evaluadores observar y analizar a un grupo de usuarios finales utilizando la aplicación, registrar sensaciones u opiniones vertidas por ellos durante y después de la realización de las tareas, brindarles ayuda en caso que la requieran, o realizar preguntas directas. Los evaluadores realizan un registro de los problemas de uso con los que se encuentran los usuarios para poder solucionarlos posteriormente. Una desventaja es la gran demanda de tiempo y la necesidad de recursos económicos, tanto para montar el laboratorio como para organizar cada sesión de evaluación (logística, viáticos). Además, la cantidad de datos recopilados y usuarios involucrados en las pruebas es en general mayor que en otros métodos. Ello posibilitará un mejor análisis, 
pero también requerirá de más tiempo tanto para implementarlo como para obtener los resultados.

\subsubsection{Test remoto}

En el caso de no utilizar laboratorio debe dejarse actuar libremente al usuario en su propio contexto de trabajo. Esto aporta una serie de ventajas sobre el test clásico:

- es más fácil de realizar ya que un único equipo de evaluadores puede realizar todo el proceso de evaluación.

- permite obtener resultados similares al test clásico.

- posibilita ampliar aún más la muestra de usuarios que realizan el test.

- los usuarios no necesitan moverse de sus lugares habituales de trabajo o residencia.

- $\quad$ son igual de útiles, pero más baratos y rápidos porque no es necesario trasladar a usuarios y evaluadores.

- puede llevarse a cabo simultáneamente en varios puntos geográficos.

- a pesar de contar con mayor cantidad de testeadores no insume más tiempo que el test clásico.

La evaluación realizada en el contexto de uso natural del usuario impacta positivamente en la calidad del test y las respuestas que éstos proporcionan. El uso de instrumentos online agiliza notablemente la obtención de los datos y el procesamiento de la información, aunque se pierde la riqueza del contacto con el usuario. Los testeos remotos utilizan técnicas cuantitativas que no sustituyen a la obtención de información cualitativa, pero que aportan otras ventajas sobre las cualitativas.

\subsubsection{Test Observacional}

Para contrarrestar el problema de la falta de contacto con el usuario existen una serie de métodos considerados observacionales. Consisten en que el evaluador se empape del contexto de uso real del sistema percibiendo en "vivo y en directo" la forma en que el usuario realiza su trabajo, pero sin interferir. Si bien sería lo óptimo, tiene cierto costo implementar esta modalidad cuando la muestra de usuarios finales es amplia y se encuentra dispersa geográficamente.

La meta es que el evaluador observe a los usuarios cuando trabajan, tome nota sobre lo que ve y las actividades que éstos realizan. El observador debe parecer invisible para que los usuarios trabajen de la misma forma que lo hacen siempre. En determinadas ocasiones, dependiendo la variante del método, se puede interrumpir al usuario, para hacerle preguntas acerca de las actividades que lleva a cabo, con el fin de comprenderlas, pero esto debe hacerse lo menos posible [Nie1993b].

El evaluador puede trazar conclusiones de la conducta y reacciones del usuario. Generalmente hay tres formas de observación:

- Observación presencial: el evaluador está presente físicamente en el lugar del test durante la tarea.

- Observación directa: el evaluador no está presente físicamente en el lugar del test durante la tarea, pero sigue el test en directo mediante el uso de cámaras, circuito cerrado de televisión, o paredes espejadas. 
- Observación indirecta: el evaluador analiza el test luego de realizado mediante grabaciones de video o fotografías.

\subsubsection{Protocolos de Expresión del Usuario}

Los protocolos hacen referencia al modo mediante el cual se extrae la información sobre los comportamientos e intenciones de los usuarios en el test. Es un método de observación presencial que permite la captación de las impresiones y sensaciones que el usuario manifiesta oralmente. Hay dos tipos de protocolos de expresión del usuario: pensamiento en voz alta y en base a preguntas:

- Pensamiento en voz alta: durante el transcurso del test, donde el participante está realizando una tarea como parte de un escenario de usuario, se le solicita que exprese en voz alta sus pensamientos, sensaciones, intenciones, y opiniones mientras interactúa con el producto. Es particularmente útil en las etapas iniciales de desarrollo del producto, cuando el margen y flexibilidad para realizar los cambios es alto. También para detectar muchos de los problemas de usabilidad de los sistemas de información [Nie2006]. El usuario, con su comportamiento y comentarios ante la tarea, contribuye al análisis del problema. Sin embargo, sus expresiones acostumbran a ser ambiguas, poco concretas 0 incluso diferir en ciertos aspectos de sus pensamientos [Eri2002]. Debido a ello, a lo largo del tiempo han surgido técnicas y tecnologías para extraer datos más objetivos.

- Preguntas: este método profundiza más el protocolo de pensamiento en voz alta. El evaluador debe provocar las manifestaciones del usuario respecto del producto mediante la formulación de preguntas directas acerca del mismo.

\subsubsection{Evaluación de desempeño}

Es un método de observación que conjuga el método directo e indirecto. Involucra la observación y análisis del uso del sistema por parte de usuarios representativos, ejecutando tareas previamente seleccionadas. Se lleva a cabo en un laboratorio formal de usabilidad, de modo que los datos cuantitativos puedan ser recolectados con precisión y minimizar así posibles interferencias inesperadas. No está permitido que el experimentador interactúe con el usuario durante la prueba, en virtud para preservar los datos cuantitativos del desempeño generados durante la tarea. Las pruebas deben ser grabadas en video para conservar los datos, de modo que algunos de ellos puedan ser verificados posteriormente. El método puede utilizar un solo evaluador o un equipo de evaluadores de acuerdo a las necesidades de evaluación y la disposición del laboratorio. Puede combinarse con otros métodos de obtención de datos cualitativos para realizar un análisis más integral. Los resultados obtenidos pueden ser usados para certificar que el sistema satisface ciertas metas de usabilidad o para comparar diferentes productos [Mcl1994b], ofreciendo medidas objetivas de usabilidad referente a la satisfacción del usuario.

\subsection{Técnicas seleccionadas para considerar en el modelo de evaluación propuesto}

Cada uno de los métodos de evaluación analizados requiere de la utilización de una o más técnicas para recolección de datos. Estas técnicas no son de uso exclusivo de un método determinado, sino que pueden ser compartidas por varios de ellos. Es decir, dos métodos distintos pueden utilizar la misma técnica, como por ejemplo la entrevista o el cuestionario. Como se mencionó en el capítulo 4, no hay consenso respecto a una taxonomía para los métodos de evaluación. Sumado a esto, tampoco existe acuerdo en lo 
referido a las técnicas. Algunos autores no diferencian entre método y técnica, otros sí lo hacen, pero con miradas diferentes. Están aquellos que catalogan como método lo que otros interpretan como técnica y viceversa. Según Alva [Alv2005], las técnicas existentes son los grupos de enfoque, pensamiento en voz alta, co-descubrimiento, cuestionarios, entrevistas, encuestas y listas de verificación. En tanto para Cobo [Cob2005], es lo mismo método y técnica, incluyendo también algunas herramientas: evaluación heurística, test de usuarios, paseo cognitivo, pensamiento en voz alta, análisis de log, cuestionario, entrevista, SUMI y QUIS (estos dos últimos se explican más adelante).

Desde nuestro punto de vista, nos parece más adecuado diferenciar entre métodos, técnicas, y herramientas por las siguientes razones:

- Los métodos están orientados a la forma de evaluar atributos importantes de usabilidad de un producto.

- Las técnicas definen un conjunto de actividades a ejecutar por los evaluadores con el objetivo de obtener una colección de datos válidos para la evaluación del producto.

- Finalmente, las herramientas son las encargadas de apoyar y agilizar el proceso de recolección de datos.

A continuación presentamos una revisión de las técnicas más relevantes de apoyo a la evaluación y medición de usabilidad de sitios Web. Por otro lado, realizaremos un análisis de las ventajas y desventajas que presenta cada una de ellas.

\subsubsection{Cuestionarios}

Los cuestionarios son un medio útil y eficaz para recoger información en un tiempo relativamente breve [Oso2000]. Se trata de una técnica basada en preguntas dirigidas a los usuarios potenciales del producto respecto a una o más variables a medir. El cuestionario puede aplicarse a grupos o individuos, estando presente el investigador o el responsable de recoger la información, o puede enviarse por correo electrónico o postal a los destinatarios seleccionados en una muestra [Man2004]. Las personas que responden el cuestionario proporcionan información por escrito sobre sí mismos o sobre un tema dado. En su construcción pueden considerarse preguntas de todo tipo. La elección del tipo de preguntas que contenga el cuestionario depende del grado en que se puedan anticipar las posibles respuestas, los tiempos de que se disponga para codificar y si se quiere una respuesta más precisa o profundizar en alguna cuestión. El objetivo es obtener información sobre las actitudes, opiniones, deseos y expectativas de los usuarios [Ant1995][Gam2003]. El diseño de los cuestionarios puede estar a cargo del diseñador del producto, del evaluador del mismo, o de un experto en la materia. Algunos cuestionarios son listas de verificación muy estructuradas, denominadas también entrevistas estructuradas, mientras que otros son totalmente abiertos. Por lo general un buen cuestionario está balanceado entre preguntas abiertas y estructuradas. El evaluador, de alguna forma, debe entregar el cuestionario a los usuarios para que éstos lo contesten y luego recibir la respuesta de los mismos [Flo2000]. Los cuestionarios son útiles e informativos en todas las fases de diseño y desarrollo de la aplicación, pero es necesario un número adecuado de usuarios de prueba para poder encontrar las preferencias subjetivas del usuario [Alv2005]. Requieren esfuerzo adicional del usuario para leer, comprender la pregunta y responderla, escribiendo la respuesta. Cuanto más estructurado sea un cuestionario menor probabilidad de sesgo presenta. 


\subsubsection{Tipos de cuestionarios}

Podemos distinguir 3 tipos diferentes de cuestionarios: cerrado, abierto y mixto.

- Cuestionario Cerrado o Restringido: Es aquel que solicita respuestas breves, específicas y delimitadas. Para que un cuestionario sea considerado cerrado, todas sus preguntas deben ser cerradas. Para poder formular preguntas cerradas es necesario anticipar las posibles alternativas de respuestas. Los cuestionarios cerrados son muy ventajosos debido a que son fáciles de contestar, clasificar y analizar, requieren de un menor esfuerzo por parte de los encuestados, y limitan las posibles respuestas.

- Cuestionario Abierto o No Restringido: Este tipo de cuestionarios son opuestos al anterior, es decir, todas las preguntas que lo componen son abiertas, por lo que no delimitan de antemano las alternativas de respuesta. Las ventajas del cuestionario cerrado desaparecen por completo, pero las respuestas pueden aportar información mucho más valiosa que los anteriores.

- Cuestionario Mixto: Es aquél que considera en su construcción tanto preguntas cerradas como abiertas.

\subsubsection{Tipos de preguntas}

Como vemos, el tipo de cuestionarios está definido en función del tipo de preguntas que puedan incluirse en ellos [Gam2003]. Los distintos tipos de preguntas pueden ser:

- Preguntas generales: usadas para establecer referencias del usuario como: edad, sexo, ocupación, experiencia previa en el uso de computadoras, entre otras.

- Preguntas abiertas: usadas para permitir al usuario expresar su opinión con completa libertad y en sus propias palabras. Son útiles cuando no tenemos información sobre las posibles respuestas de los usuarios o cuando esta información es insuficiente. Proporcionan respuestas de mayor profundidad aunque son de difícil tabulación, resumen e interpretación.

- Preguntas de multi-selección: usadas cuando se quiere ofrecer un conjunto cerrado de opciones en la que el usuario debe marcar su preferencia. El nivel de detalle es determinado por el evaluador de acuerdo a sus intereses. Permite obtener información sobre la experiencia del usuario.

Por ejemplo, si preguntamos al usuario ¿con qué frecuencia usa el sistema?, podemos ofrecer como respuesta: Diariamente, Por lo menos una vez por semana, Por lo menos una vez por quincena, Por lo menos una vez al mes.

- Preguntas de escalamiento: se pide al usuario clasificar el orden de los ítems de una lista. Es útil para capturar preferencias del usuario.

Por ejemplo: ordenar de mayor a menor la manera en que más le gustaría obtener ayuda al usar este sitio Web: manual de usuario impreso, manual de usuario on-line, ayuda sincrónica on-line (chat), ayuda asincrónica on-line (e-mail, foro), teléfono fijo, teléfono celular.

- Preguntas cerradas: se solicita al usuario respuestas breves, específicas y delimitadas. Son utilizadas para obligar al usuario a seleccionar una opción entre un conjunto de dos o más alternativas fijas. Estas respuestas pueden ser contestadas de dos formas: 
- Dos alternativas de respuestas: se trata de respuestas dicotómicas del tipo Si o No, Verdadero o Falso, Acuerdo o Desacuerdo.

- Varias alternativas de respuestas: el usuario tiene la posibilidad de elegir sólo una opción entre en una lista de respuestas sugeridas. En caso de utilizar este tipo de preguntas es recomendable agregar una pregunta adicional para prever las situaciones donde ninguna de las posibles respuestas satisface al usuario, como por ejemplo Otros, Ninguna de las anteriores, según sea el caso. En otras ocasiones, el usuario tiene que jerarquizar opciones o asignar un puntaje a una o diversas cuestiones.

Las preguntas cerradas requieren establecer una escala de valoración que permita resultados con cierta precisión.

\subsubsection{Escalas}

Una escala es una serie de ítems o frases que han sido cuidadosamente seleccionados, de forma que constituyan un criterio válido, fiable y preciso para medir. Dependiendo del nivel de medición deseado, las escalas pueden ser:

- Escala nominal: también conocida como escala de categoría. Está basada en la selección de una alternativa entre un conjunto limitado. Estas alternativas representan diferentes grados de subjetividad [Itu1995].

Por ejemplo: indicar como considera la velocidad de carga de la página $\mathrm{H}$.

A: Excelente, B: Muy Bueno, C: Bueno, D: Regular, E: Malo

- Escalas de comparación: está basada en la comparación que debe realizar el usuario entre dos tareas o condiciones de acuerdo a un atributo determinado.

Por ejemplo: califique velocidad de carga de las páginas del sitio A respecto del sitio $B$, y marque la opción que mejor exprese su opinión:

Mucho mejor, mejor, igual, peor, mucho peor.

- Escala de valoración continua: consiste en una línea sin divisiones, representando puntos continuos o solo un punto medio entre ellos. Cada punto es definido por una etiqueta característica de definición o adjetivo.

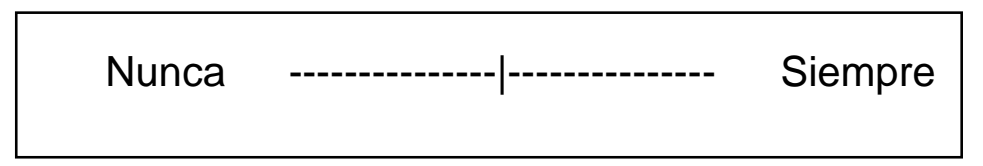

Figura 15 - Escala contínua

- Escala Likert: es una de las más utilizadas, también conocida como método de evaluaciones sumarias, método de rangos sumatorizados, o escala de valoración numérica discreta [Tro2002]. Es un tipo de instrumento de recolección de datos utilizado en investigación social. Se trata de una escala para medir actitudes del usuario. Fue desarrollada por el sociólogo Rensis Likert en la década del '30. Consiste de una serie de frases que expresan ciertas afirmaciones, juicios o preguntas ante los cuales el usuario expresa su reacción. Es decir, se presenta cada frase expresando una postura, a favor o en contra, y se solicita al usuario que responda eligiendo entre uno de los puntos de la escala. Dicha escala está basada en números discretos que representan intervalos de igual magnitud de medida. La escala posee varias alternativas o puntos, generalmente se utiliza la escala de 1 a 5 , pero también puede emplearse de 1 a 3, 1 a 7, 1 a 9, etc. Dicho continuo varía entre un valor máximo de 
acuerdo con la afirmación hasta un máximo desacuerdo. A cada punto de la escala se le otorga un valor numérico. Existen tres formas de escala:

- Descriptiva:

muy de acuerdo, de acuerdo, indiferente, en desacuerdo, muy en desacuerdo

Figura 16 - Escala Likert descriptiva

- Numérica:

\begin{tabular}{|lllllll|}
\hline Acuerdo & 1 & 2 & 3 & 4 & 5 & Desacuerdo \\
\hline
\end{tabular}

Figura 17 - Escala Likert numérica

- Gráfica:

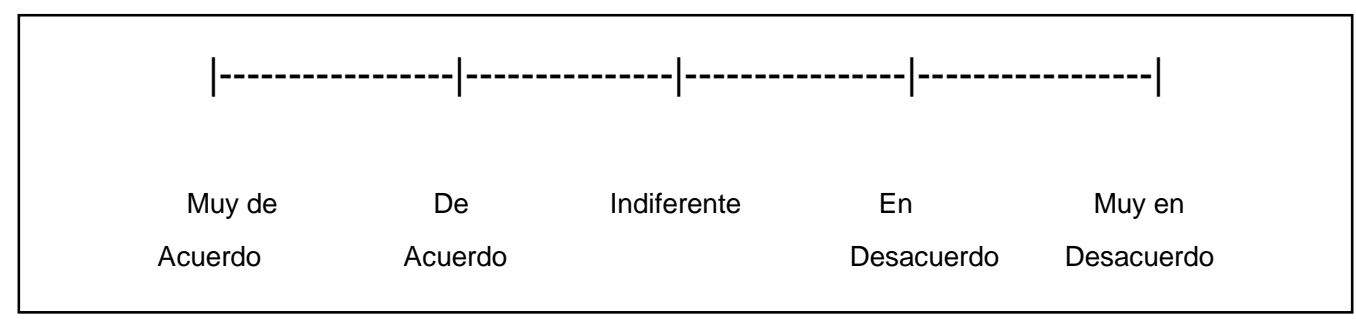

Figura 18 - Escala Likert gráfica

Hay otras maneras de utilizar este tipo de escala que pueden resultar más claras para el usuario:

- (5) Muy de acuerdo, (4) De acuerdo, (3) Indiferente, (2) En desacuerdo, (1) Muy en desacuerdo.

- (5) Totalmente de acuerdo, (4) De acuerdo, (3) Neutral, (2) En desacuerdo, (1) Totalmente en desacuerdo.

○ (5) Definitivamente sí, (4) Probablemente sí, (3) Indeciso, (2) Probablemente no, (1) Definitivamente no.

- (5) Completamente verdadero, (4) Verdadero, (3) Ni falso, ni verdadero, (2) Falso, (1) Completamente falso.

Para obtener las puntuaciones finales primero se suman los valores obtenidos respecto de cada frase y se multiplican por el valor dado a cada una. Luego se realiza la sumatoria de todos los valores obtenidos para cada ítem. Esto permite analizar rápidamente las respuestas y obtener recomendaciones para el diseño.

Se trata de una escala muy utilizada debido a las numerosas ventajas que posee:

- es barata y fácil de aplicar a una muestra grande de usuarios.

- se puede repetir todas las veces que sea necesario.

- proporciona rápidamente datos cuantitativos y cualitativos.

- encuentra preferencias subjetivas del usuario.

- evalúa juicios de manera formal y estandarizada. 
- opiniones y sentimientos subjetivos sobre la usabilidad del sistema.

- permite verificar la aceptación del mismo con el ambiente normal de operación del usuario.

Aunque tampoco está exenta de riesgos:

- las preguntas son fijas,

- en algunos casos requiere la presencia del evaluador para clarificar las preguntas y ayudar al usuario,

- el evaluador no siempre puede controlar la situación o la manera en la cual el cuestionario es respondido,

- la falsedad de la muestra puede producir resultados errados,

- requiere de un trabajo piloto para su validación.

\subsubsection{Ventajas}

Los cuestionarios son ampliamente utilizados debido a ventajas que se les atribuyen:

- La eficacia, facilidad y rapidez para obtener la información deseada, cuantificarla, analizarla e interpretarla, sobre todo cuando se trata de cuestionarios altamente estructurados. De allí su popularidad y uso extensivo.

- Pueden aplicarse en todas las fases de diseño y desarrollo.

- Resultan menos costoso que entrevistar, por ejemplo, a cientos de empleados.

- Requieren poco tiempo para reunir información sobre grupos numerosos, en caso de ser altamente estructurado.

- Proporcionan información sobre un mayor número de usuarios en un periodo corto de tiempo.

\subsubsection{Desventajas}

- La falta de sinceridad en las respuestas escondiendo la verdad o produciendo alteraciones en el afán de causar buena impresión.

- La tendencia a decir que "si" a todo.

- La uniformidad de los resultados puede ser aparente, pues una misma palabra puede ser interpretada en forma diferente por personas distintas, o ser comprensibles para algunas y no para otras.

- Las respuestas pueden ser poco claras o incompletas, haciendo muy difícil la tabulación.

- Los usuarios pueden evadir la respuesta a ciertas preguntas o no darle la importancia necesaria a las respuestas proporcionadas.

- La sospecha de que la información puede volverse en contra del usuario que la aporta.

- El esfuerzo del usuario para leer, comprender la pregunta y responderla escribiendo la respuesta.

- La influencia de la simpatía o la antipatía, tanto con respecto al evaluador como con respecto al producto que se evalúa. 
- La necesidad de requerir un número importante de usuarios.

- Mucho tiempo para procesar la información si hay demasiadas preguntas abiertas y la cantidad de usuarios es amplia.

- Es poco flexible, puesto que la información no puede variar ni profundizarse.

- Si el cuestionario es enviado por correo se corren varios riesgos:

- No llegar al destinatario o no obtener respuesta de los usuarios.

- Es difícil obtener una tasa alta de respuestas.

- Debe utilizarse una muestra amplia de usuarios para contrarrestar el porcentaje de cuestionarios no respondidos.

\subsubsection{Entrevistas}

Es una técnica para obtener datos que consisten en un diálogo entre dos personas. Se trata de un proceso de interacción dinámica de comunicación entre el entrevistador y el entrevistado, bajo control del primero. La finalidad es conseguir información lo más implicante posible, sobre el objeto de análisis que se plantea.

Las entrevistas posibilitan al evaluador realizar preguntas a los usuarios acerca de sus experiencias y preferencias respecto de una aplicación Web, solicitando que expresen sus opiniones y comentarios acerca de la misma [Flo2000]. Ayudan al evaluador a establecer el grado de satisfacción del usuario en el uso del producto, y conocer acerca de las características que le agradan y las que no [Nie1992b].

Las entrevistas son muy utilizadas en casos donde es necesaria una gran flexibilidad tanto para las preguntas como para las respuestas. Sin embargo, no están recomendadas para cuando se desea utilizar una muestra grande de usuarios, debido a que la diversidad de respuestas obtenidas dificulta una estandarización y requiere de un análisis cualitativo. Frecuentemente son utilizadas luego de distribuir el producto con el objeto de valorar la satisfacción del usuario, aunque también pueden resultar útiles en etapas tempranas de desarrollo [Cla1999].

Las preguntas de una entrevista deben ser objetivas y estar bien planificadas. Ello es muy importante para asegurar consistencia entre entrevistas a diferentes usuarios y por diferentes entrevistadores.

Suelen utilizarse cuando se requiere obtener información muy compleja o confidencial. Se estima que este método es más eficaz que el cuestionario, ya que permite obtener una información más completa. A través de ella, el evaluador puede explicar el propósito del estudio y especificar claramente la información que necesita, si hay una interpretación errónea de la pregunta permite aclararla, asegurando una mejor respuesta. En general, las entrevistas pueden servir de base y de complemento a los cuestionarios. En tal sentido pueden aplicarse al inicio de una evaluación para recoger información general y luego construir un cuestionario que se apoye en la información recogida previamente. Una vez aplicado el cuestionario, y analizados los datos, puede utilizarse la entrevista nuevamente a los efectos de clarificar sus resultados. De todos modos no hay reglas absolutas para el uso de entrevistas, ya que depende de las circunstancias y el tipo de aplicación Web que pretende ser evaluada.

Las entrevistas se utilizan cuando el universo de usuarios es pequeño y manejable, o cuando se considera necesario que exista interacción y diálogo entre el evaluador y el usuario. 


\subsubsection{Tipos de entrevista}

Pueden clasificarse de diferentes formas, según la óptica desde la cual se las mire: la estructura que posee, el número de personas que intervienen, o quien toma la iniciativa.

Según la estructura de la entrevista, los tipos más comunes para la evaluación de usabilidad son:

1. No estructurada: permite a los entrevistados proporcionar sus ideas libremente. No existe esquema o plan previo, ni impone control alguno y actúa como una conversación exploratoria. Las entrevistas no estructuradas son buenas para la investigación de problemas emocionales potenciales y/o la sensibilidad personal. Resultan más flexible y abierta, y aunque los objetivos de la investigación rigen a las preguntas, su contenido, orden, profundidad, y formulación, se encuentra por entero en manos del entrevistador. Este puede modificar el orden de las preguntas, la manera de formularlas para adaptarlas a las diversas situaciones y características particulares de los sujetos de estudio. Este tipo de entrevista es muy útil en los estudios descriptivos y en las fases de exploración para el diseño del instrumento de recolección de datos. Sin embargo, casi no se utilizan debido a que siempre existe alguna idea sobre la información que se requiere obtener del entrevistado.

2. Semi-estructurada: no contiene una secuencia de preguntas fijas, sino que se vale de una guía temática que indica las preguntas que el entrevistador debe formular. Es la más utilizada y ofrece una guía sobre un esquema general.

Tienen la ventaja que se realizan cara a cara, con lo cual se pueden analizar aspectos no verbales. También se puede improvisar a medida que avanza la entrevista, añadiendo preguntas que no estaban preparadas. Son una forma de reducir las probabilidades que el entrevistado no diga toda la verdad.

Entre las desventajas encontramos que el entrevistado puede sentirse incómodo ante la presencia del entrevistador, y esto puede afectar de alguna manera las respuestas del sujeto.

Se utilizan en situaciones donde se requiere analizar los problemas ampliamente para ser entendidos, o bien el rango de reacciones a estos problemas no es conocido, o se sospecha que es incompleto. Este tipo de entrevista es principalmente aplicable a situaciones donde se requieren referencias cualitativas y cuantitativas.

3. Estructurada: se caracteriza por estar rígidamente estandarizada. Se sigue un texto o secuencia prefijada de preguntas, pudiendo ser las mismas abiertas o cerradas. Se replantean idénticas preguntas y en el mismo orden a cada uno de los usuarios. Resultan útiles en situaciones donde el rango de respuesta puede ser estimado y hay una necesidad para clarificar detalles, opiniones o ideas. Las entrevistas estructuradas funcionan bien cuando las metas de valoración son claras. Inclusive los comentarios introductorios y finales se formulan de la misma manera en todas las situaciones. Para orientar mejor la entrevista se elabora un formulario con todas las preguntas. Sin embrago, al utilizar este tipo de entrevista, el investigador tiene limitada libertad de formular preguntas independientes generadas por la interacción personal.

Según el número de personas que intervienen, existen cuatro grupos:

1. Individual: 1 entrevistador y 1 entrevistado. 
2. Panel: varios entrevistadores y 1 entrevistado.

3. En grupo: 1 o más entrevistadores y varios entrevistados.

4. Secuencial: varios entrevistadores y 1 entrevistado, donde cada entrevistador realiza una entrevista individual con el entrevistado.

De acuerdo al tipo de iniciativa podemos encontrarnos con:

1. Iniciativa del entrevistador o interrogatorio: se formulan preguntas cerradas, claras y concisas al entrevistado. Es lo más parecido a un interrogatorio. El entrevistador demanda respuestas del mismo tipo.

2. Iniciativa del entrevistado: el entrevistador deja que el entrevistado se exprese libremente. El entrevistador realiza muy pocas preguntas, de carácter abierto o generales. Luego de cada pregunta debe permanecer en silencio para que el entrevistado no se sienta presionado.

3. Iniciativa de ambos o conversación: se combinan los dos tipos de entrevistas anteriores, aunque predominan las preguntas abiertas. Esto favorece una comunicación más fluida y una situación más relajada. Las respuestas deben ser acordes a cada tipo de preguntas. Algunas respuestas pueden dar lugar a otra pregunta por parte del entrevistador que no estaba prevista inicialmente.

\subsubsection{Ventajas}

Las entrevistas poseen muchas ventajas, de allí que sean tan utilizadas:

- Permiten el uso de preguntas variadas para ajustar el contexto.

- Posibilitan indagar más profundamente sobre nuevos problemas que surgen.

- Son adecuadas para realizar estudios exploratorios.

- Frecuentemente conducen a sugerencias constructivas específicas.

- Son eficientes para evaluación de alto nivel: preferencias, impresiones, actitudes, y opiniones.

- Resultan útiles para identificar posibles áreas que necesitan de un análisis más detallado.

- Son muy directas, fáciles de dirigir, y más rápidas que las técnicas observacionales.

- Los análisis estadísticos pueden ser ejecutados sobre las respuestas de los usuarios. Los datos recogidos proporcionan información sobre reglas y principios generales.

- Son útiles para investigar eventos que no ocurren frecuentemente y pueden ser grabadas para análisis futuros.

- Son relativamente fáciles de repetir, por lo que proporcionan resultados a lo largo del tiempo.

\subsubsection{Desventajas}

- El problema principal de esta técnica es la distorsión de la información, ya sea debido a una falsificación directa o una simple equivocación.

- Los datos obtenidos son subjetivos. 
- Demandan mucho tiempo.

- Los evaluadores pueden sesgar fácilmente la entrevista.

- La reconstrucción del usuario puede ser equivocada.

- Puede ser problemático codificar los resultados si las entrevistas no son estructuradas.

- La personalidad y el estilo de la entrevista puede afectar la respuesta.

- El entrevistador puede necesitar adquirir conocimiento del dominio para conocer qué preguntas hacer.

- La información subjetiva obtenida podría ser engañosa o inexacta.

- La selección del lugar para la entrevista, y cómo conducirla, pueden influir en las respuestas obtenidas.

\subsubsection{Encuesta}

Es una técnica cuantitativa muy empleada dentro de los test de usuario [Rey2007]. Está destinada a obtener datos de varios usuarios cuyas opiniones impersonales interesan al evaluador. Consiste en una investigación realizada sobre una muestra representativa de usuarios. Se utilizan procedimientos estandarizados de interrogación con el fin de conseguir mediciones cuantitativas sobre una gran cantidad de características objetivas y subjetivas de los encuestados.

A diferencia de la entrevista, se utiliza un listado de preguntas escritas que se entregan a los usuarios, a fin de que las contesten igualmente por escrito. Ese listado se denomina habitualmente cuestionario.

Es impersonal porque no lleva identificación de la persona que lo responde, ya que no interesan esos datos. Se puede aplicar a una muestra importante de usuarios debido a que resulta mucho más económica que las entrevistas.

En muchas ocasiones se utiliza encuesta y cuestionario como sinónimos. Sin embargo, la encuesta es el proceso de investigación, mientras que el cuestionario es la herramienta para llevar a cabo la investigación. Es decir, la encuesta es la forma de recopilar la información, mientras que el cuestionario es el instrumento de recogida de datos con el cual se realiza la recopilación [Rey2007].

Existen varias formas de suministrar las encuestas:

- Personalmente: se realizan cara a cara con el usuario. A diferencia de las entrevistas, el entrevistador no es el evaluador sino un encuestador que solo se limita a aplicar la encuesta y recabar los datos. Aporta muchas ventajas ya que permite preguntar sobre cuestiones más complejas con mayor detenimiento, produce por parte del entrevistado mayor participación, aunque económicamente es más costosa. Este hecho hace que se utilicen menos que las autoadministradas.

- Autoadministradas: son completadas por el mismo usuario. Se utilizan técnicas remotas.

- Por correo electrónico: son las más baratas, fáciles, rápidas de contestar, y no es necesario usar tiempo del personal para recopilar las respuestas de los usuarios. Puede ser anónimo y llegar a lugares difíciles de acceder personalmente. Tienen el inconveniente de poseer un bajo índice de respuestas, lo que puede hacer que la muestra no sea representativa. 
Puede requerir seguimiento y demasiado tiempo para recibir suficientes respuestas. Los usuarios que responden son seleccionados por ellos mismos, lo que introduce un sesgo potencial.

- Por la Web: en lugar de enviar la encuesta por correo electrónico se suministran mediante una página Web. Poseen las mismas ventajas y desventajas que por correo electrónico aunque resultan más cómodas y fáciles de responder.

- Por correo postal: son similares a las de correo electrónico. Solo cambia la forma de entrega y recepción de la encuesta. Suelen tener índices de respuesta más bajos incluso que el correo electrónico.

- Telefónicas: es más costosa que el correo ya que es necesario contar con varios encuestadores. Los usuarios suelen ser reacios a entablar comunicación. Presenta menor influencia del encuestador que la personal. El índice de participación es superior al correo electrónico pero está por debajo de la personal. Al no estar cara a cara, no es posible controlar a la persona que responde.

Las preguntas abiertas no son convenientes en encuestas telefónicas o por correo, solamente funcionan bien cuando se hacen personalmente.

Esta técnica involucra la colección formal de datos sobre las impresiones subjetivas del usuario. Los datos son fáciles de obtener y pueden realizarse análisis estadísticos, siempre que la encuesta haya sido diseñada apropiadamente.

Muchas encuestas son hechas a lo largo del tiempo de desarrollo del producto para rastrear el cambio de opinión en los potenciales usuarios. La etapa más importante de cualquier diseño de encuesta es el muestreo. Una muestra es un subconjunto representativo de la población destino, que es seleccionada aleatoriamente, intentando garantizar que todos los componentes de la población tengan la misma probabilidad de entrar en la muestra.

\subsubsection{Tipos de encuesta}

Pueden distinguirse dos tipos de encuesta:

1. Cerradas: se solicita al encuestado seleccionar entre un conjunto de respuestas disponibles.

2. Abiertas: el encuestado es libre para responder como desee. Generalmente son usadas para obtener referencias del usuario usando la aplicación. Lógicamente, para utilizar este tipo de encuesta debe tenerse el sistema funcionando y que los encuestados sean personas que lo usen actualmente.

Los tipos de preguntas contenidas dentro de la encuesta las podemos agrupar según: la contestación que admitan, su función, o su contenido.

- Según la contestación que admitan:

- Abiertas: no establece categorías de respuesta. Se deben utilizar muy poco porque después de la encuesta hay que cerrarlas y luego estandarizarlas.

- Cerradas: establecen sólo 2 alternativas de respuesta, "Si o No", y a veces $\mathrm{Ns} / \mathrm{Nc}$. Se deben utilizar sólo para temas muy bien definidos que admiten 2 alternativas como respuesta. 
- Categorizadas: además de la pregunta, establecen las categorías de respuesta. A su vez se subdividen en:

- De respuesta espontánea: el encuestador no debe leerle la respuesta al encuestado.

- De respuesta sugerida: el entrevistador lee las preguntas al encuestado.

- De valoración: el entrevistador lee una escala de intensidad creciente o decreciente de categorías de respuesta.

- Según su función:

- Filtro: se utilizan para eliminar aquellas preguntas que no les afecten determinadas personas, es decir, que marcan la realización o no de preguntas posteriores.

- Batería: todas las preguntas tratan sobre un mismo tema y que siempre deben ir juntas en el cuestionario en forma de batería, empezando por las más sencillas y luego las más complejas.

- De control: se utilizan para comprobar la veracidad de las respuestas de los encuestados. Normalmente, se coloca la misma pregunta pero redactada de forma distinta en lugares separados una de la otra.

- Amortiguadoras: se refiere a una forma de preguntar cuando los temas son polémicos, o pensamos que serán reticentes a contestar. Hay que preguntar suavizando la pregunta y no preguntar de modo brusco y directo.

- Según su contenido:

- Identificación: sitúan las condiciones en la estructura social, como por ejemplo edad, sexo, y profesión.

- Acción: tratan sobre las acciones de los encuestados, como por ejemplo ¿va al cine?, ¿fuma?

- Intención: indagan sobre las intenciones de los encuestados, como por ejemplo ¿va a votar?

- Opinión: tratan sobre la opinión de los encuestados sobre determinados temas.

- Información: analizan el grado de conocimiento de los encuestados sobre determinados temas.

- Motivos: tratan de saber el por qué de determinadas opiniones o actos.

\subsubsection{Ventajas}

- El método de muestreo, si se aplica apropiadamente, puede producir resultados de alta calidad sobre las actitudes y opiniones de una población.

- Son fáciles de repetir, proporcionando así resultados a lo largo del tiempo.

- Permiten obtener información de casi cualquier tipo de población y hechos pasados de los encuestados.

- Poseen gran capacidad para estandarizar datos, lo que permite su tratamiento informático y el análisis estadístico.

- Son relativamente baratas para la información que se obtiene con ello. 


\subsubsection{Desventajas}

- Aunque depende de cuán apropiada sea la muestra, conseguir todas las personas planeadas para participar en la investigación es muy difícil y costoso.

- Normalmente el muestreo es muy complejo, y siempre hay grupos de la población imposibles de investigar.

- La encuesta tiene que ser fija para todos los participantes, lo que hace difícil el estudio de casos particulares.

- No permite analizar con profundidad temas complejos. Para ello es necesario recurrir a grupos de discusión.

\subsubsection{Análisis de log}

El análisis de log, también conocido como grabación del uso [Gra2005] o logging [Cob2005], es una técnica muy conocida y ampliamente utilizada para realizar test de forma rápida y económica. Esta técnica se basa en registrar automáticamente la forma de navegación que lleva adelante el usuario dentro de la aplicación Web, para luego analizar con detenimiento la forma de uso del sistema. Es decir, no hace falta estar en contacto con el usuario mientras utiliza el sistema, ni tampoco son necesarias grabaciones $u$ otros medios de registro que lo incomodan. Esta técnica produce un registro de la huella que deja el usuario cada vez que navega por el sitio. Para realizar esta tarea es necesario contar con una aplicación que se encargue de la labor. La información se recolecta de forma indirecta dado que el usuario no se da cuenta que mientras está navegando sus acciones son registradas. En este sentido, presenta mayor validez que los datos recogidos bajo formularios o encuestas debido a que la subjetividad no está presente.

Es una técnica muy útil porque muestra cómo los usuarios realizan su trabajo real, y porque es fácil recoger automáticamente datos de una gran cantidad de usuarios que trabajan bajo diversas circunstancias.

Generalmente, la información registrada sobre el uso de la interfaz del sistema está relacionada con el día, hora, y tiempo durante el cual ha hecho uso del programa, cada lugar que ha recorrido, y los eventos de interés que han ocurrido.

El volumen de datos registrados se incrementa considerablemente a medida que el sistema es utilizado por gran cantidad de usuarios a lo largo del tiempo. Esto es lo que le aporta riqueza a la técnica, pero a la vez hace complejo el análisis de los datos. De allí que existen diversas herramientas relacionadas con la minería de datos que posibilitan el procesamiento y extracción de información útil para el proceso de evaluación.

El registro de los datos se puede realizar de diferentes formas:

- Incorporando a la aplicación un nuevo módulo que se encargue de este tipo de registro. Esta forma es la más utilizada en sistemas que cuentan con su propio equipo de desarrollo ya que es posible decidir libremente qué tipo de acontecimiento se debe registrar y la forma de procesarlo.

- Modificando drivers del sistema, como por ejemplo del mouse o del teclado que permitan registrar las acciones del usuario. Esta alternativa no es demasiado utilizada debido a las características propias del uso de las aplicaciones Web, las cuales son accedidas desde cualquier computadora conectada a Internet, que hace imposible adecuarlas a esta forma de registro. 
- Suscribiendo la aplicación Web a sitios especializados en el registro y estadísticas de los usuarios visitantes. Estos sitios, como Google Analytics [Goo2011] o Motigo Webstats [Mot2011], analizan el tráfico del sitio Web deseado y proporcionan una serie de estadísticas automáticas como por ejemplo mapas de calor, país y ciudad desde donde el usuario accede al sitio, navegador que usa, resolución de pantalla, etc. Debido a su facilidad de implementación se utilizan en el caso de sitios Web que son desarrollados por otras personas o por aficionados al diseño que no conocen sobre programación.

\subsubsection{Ventajas}

Las principales ventajas son:

- Especialmente adecuado para analizar sitios Web.

- Muy económico, puesto que pueden analizarse las acciones de un número de usuarios muy elevado.

- No se necesita la presencia física de los usuarios ni un espacio especial para la tarea.

- Al poder realizarse remotamente, permite evaluar un gran número de datos de infinidad de usuarios sin desplazarse a su lugar de procedencia.

- Los datos suelen tener un formato estándar, lo que facilita la comparación de datos según diferentes criterios (meses, días, semanas, países, etc.).

- Los resultados se obtienen de manera instantánea. No es necesario esperar a un análisis especial de expertos para entender qué ha pasado, ni se necesitan transcripciones.

- Permite tener al usuario en su entorno habitual ya que el registro se recoge con el usuario en su computadora sin sentirse observado y ofreciendo datos más reales sobre el uso.

- Muestras amplias de usuarios.

- Muestreo de los usuarios a lo largo del tiempo, recogiendo así su variabilidad.

- Se detecta fácilmente el verdadero uso del sitio: páginas más vistas, palabras más buscadas, entre otras.

- Se puede utilizar en etapas de prueba de versiones avanzadas del sistema, pruebas beta, lanzamientos recientes, o nuevas versiones. También son especialmente indicadas para el rediseño de aplicaciones existentes.

Puede observarse que el análisis de log es muy apropiado para saber las acciones que los usuarios realizan en los sitios Web. El análisis de los archivos de log, que los usuarios anónimamente van dejando en los servidores Web, permite realizar reajustes al sitio para mejorar, entre otros aspectos, la usabilidad del mismo.

\subsubsection{Seguimiento visual}

Se trata de una técnica enfocada al estudio de la percepción y el comportamiento humano. Es utilizada no solo en el campo de la usabilidad sino también en otros como la investigación médica, rendimiento deportivo, seguridad, aviación, marketing y publicidad. También es conocido como seguimiento del ojo, seguimiento de la mirada o eye tracking. 
Busca lograr mayor objetividad que otras técnicas que son dependientes de las expresiones y comentarios del usuario. Además, aporta información valiosa sobre qué elementos de una interfaz son realmente vistos por un usuario.

El seguimiento visual permite seguir los movimientos oculares de una persona para evaluar la forma en la que esta dirige su mirada a una escena o imagen, en qué áreas se fija, durante cuánto tiempo y el orden que sigue en su exploración visual. Esto se consigue mediante una serie de dispositivos tecnológicos conocidos generalmente como eyetracker. Estos dispositivos siguen los cambios de posición y movimiento de la pupila mediante rayos infrarrojos que son lanzados a los ojos del usuario, estos rayos rebotan en su pupila y vuelven al aparato, permitiendo así calcular con precisión donde está mirando. Hay varios tipos de dispositivos, generalmente, compuestos por una cámara de vídeo de alta resolución y LEDs de luz infrarroja situados al lado de la pantalla. Los fotogramas capturados por la cámara son procesados mediante un software que calcula, en base a la localización de la pupila, en qué parte de la pantalla se está mirando. En otros casos, existen monitores que integran los infrarrojos y una Webcam, con el objetivo de pasar totalmente desapercibidos para el usuario.

Los dispositivos son combinados con programas específicos, como ClearView [Cle2011] y VisioAnalyzer [Vis2011], que procesan los datos registrados y producen imágenes donde se señala con diferentes colores los lugares que registran más o menos atención por parte del usuario. Las imágenes proporcionan, de manera muy clara, el comportamiento visual del usuario. Otros programas también registran los clics y movimientos del mouse para lograr mapas más completos. Existen diferentes tipos de mapas: de calor, de zonas ciegas, y de puntos y líneas:

- El mapa de calor presenta las zonas donde el usuario ha fijado más su atención.

- El mapa de zonas ciegas indica cuáles han sido las únicas zonas en las que el usuario se ha fijado.

- Los puntos y líneas representan donde se ha fijado el usuario. Si el punto es de mayor tamaño significa que la fijación ha sido mayor. Los puntos van unidos con una línea para poder seguir mejor el movimiento de los ojos.

Los dispositivos de seguimiento visual son caros y necesitan de cierta calibración antes de ser utilizados por cada usuario, sin embargo aportan un rendimiento excepcional para analizar dónde miran los visitantes de un sitio Web.

En materia de usabilidad, esta tecnología permite nuevas posibilidades de observación y análisis, y supone un aporte significativo para los test de usuarios. Sin embargo, está acotada a laboratorios de usabilidad donde esté montada toda esta tecnología.

En general, estos dispositivos no producen molestias al usuario puesto que ellos no tienen contacto con el aparato ni se obstruye su campo de visión. Este aspecto es especialmente relevante en los test de usabilidad, donde es importante que el usuario se sienta en un entorno lo más normal y cómodo posible.

Muchas conclusiones sobre usabilidad se han podido comprobar a partir del uso de los dispositivos de seguimiento visual, como por ejemplo:

- El texto atrae más la atención que las imágenes.

- La parte superior izquierda de la pantalla es la que mayor atención conlleva en un primer momento para el usuario, para después fijar su atención progresivamente hacia abajo y hacia la derecha. 
- Los usuarios ignoran los banners y el texto con formato "divertido".

- El texto grande es escaneado.

- Los textos con una columna son mejores que con dos o tres.

- Los usuarios ocupan mucho tiempo mirando los menús y los botones.

- Los listados aumentan la atención visual.

- Las herramientas de ayuda a la navegación son más efectivas en la zona superior de la pantalla.

\subsection{Herramientas}

Actualmente existentes herramientas que apoyan la evaluación de usabilidad en productos software o artefactos Web. Para el caso específico de la accesibilidad también existe una gran cantidad de herramientas de revisión automática. A continuación se hace una revisión de estas herramientas.

\subsubsection{Usabilidad}

Por lo general se trata de cuestionarios on-line que deben ser completados por un experto, luego de realizar la evaluación sistemática del sitio Web. Posibilitan obtener una valoración del grado de usabilidad del sitio según distintos criterios.

\subsubsection{SUMI}

SUMI (Software Usability Measuring Inventory) [Bev1995b] es un cuestionario de 50 ítems basados en el estándar ISO 9241-10 [ISO1998c] y el ISO/IEC 9126-1 [ISO2001], utilizado para medir la satisfacción y valorar la percepción del usuario de la calidad del software. SUMI proporciona un método válido para la comparación de productos diferentes y versiones del mismo producto.

Para poder obtener resultados confiables, este cuestionario debe ser aplicado a una muestra de 10 usuarios representativos y con alguna experiencia con el tipo de software que va a evaluarse. Los resultados proporcionados están basados en una base de datos estandarizada que consta de perfiles de usabilidad de más de 2.000 clases diferentes de aplicaciones (procesadores de textos, hojas de cálculo, paquetes CAD, programas de comunicaciones, entre otros).

SUMI está disponible en varios idiomas pero no es gratuito.

\subsubsection{WAMMI}

WAMMI (Web site Analysis and MeasureMent Inventory) [Kir1998] es un cuestionario basado en escenarios para la evaluación de la calidad en uso para sitios Web. Se trata de una extensión de SUMI orientada hacia la medición de la usabilidad en la Web. Permite obtener una medida de la satisfacción desde la perspectiva del usuario a través de cinco dimensiones: atractividad, control, eficiencia, utilidad y aprendizaje. Puede ser utilizada de tres modos básicos, de acuerdo a la etapa de desarrollo del sitio:

- Predicción: para determinar la reacción de los visitantes antes del lanzamiento definitivo.

- Monitorización: para conocer las razones de la conducta del usuario.

- Referencia: para conocer lo que piensan los usuarios del sitio respecto de otros similares. 
El cuestionario WAMMI está disponible en varios idiomas pero tampoco es gratuito.

\subsubsection{IsoMetrics}

IsoMetrics (IsoMetrics Usability Inventory) [Ged1999] es un cuestionario de evaluación de usabilidad basado en cuestionarios ya existentes y validados. Consta de 151 preguntas basadas en el estándar ISO 9241-10 [ISO1998c] cuyos principios son los siguientes:

- Adecuación a la tarea: en qué medida la interfaz soporta el trabajo eficiente y eficaz del usuario en la realización completa de la tarea.

- Auto-descripción: en qué medida el sistema ofrece retroalimentación para hacer la secuencia de dialogo más comprensible al usuario, o si explica al usuario sobre los requisitos de información más relevante.

- Control: en qué medida el usuario mantiene la dirección sobre el curso de la interacción hasta que la meta haya sido lograda.

- Conformidad con las expectativas del usuario: si se corresponde con el conocimiento de la tarea, educación, experiencia del usuario y las convenciones adoptadas normalmente.

- Tolerancia de error: en qué medida, a pesar de la evidencia de errores en la entrada, los resultados propuestos pueden ser logrados con ninguna o con las mínimas acciones correctivas.

- Adecuación para la individualización: representa en qué medida el sistema de diálogo puede ser modificado o ajustado a las necesidades y habilidades individuales del usuario para una tarea dada.

- Adecuación para el aprendizaje: en qué medida se guía al usuario a través de las secuencia de uso de la aplicación, minimizando el tiempo de aprendizaje.

IsoMetrics formó parte de un proyecto que no tiene continuidad actualmente.

\subsubsection{QUIS}

QUIS (Questionnaire for User Interaction Satisfaction) [Qui2003] es un cuestionario de evaluación de usabilidad centrada en el usuario para sistemas de computación interactiva. Aplica métodos de construcción de prueba psicológica para la creación y validez empírica de las preguntas, y para evaluar su fiabilidad. La usabilidad global está dividida en subcomponentes que constituyen escalas psicométricas independientes: legibilidad de los caracteres, utilidad de ayuda en línea y mensajes del error. La evaluación en estos aspectos es realizada por las valoraciones del usuario así como por atributos específicos del sistema como contraste, fuente, y espacio para la escala de legibilidad de caracteres.

\subsubsection{MUMMS}

MUMMS (Measuring the Usability of Multi-Media Systems) [Mum2003] también es un cuestionario orientado a evaluar la calidad en uso de los productos multimedia.

MUMMS surge como una extensión de SUMI, concretamente trata de evaluar la usabilidad de los productos multimedia, en general, y es realizado por los propios usuarios finales. Está enfocado en obtener el conocimiento adquirido por los usuarios. 


\subsubsection{SMEQ}

SMEQ (Subjective Mental Effort Questionnaire) [Zij1993] es un cuestionario que permite valorar la cantidad necesaria de esfuerzo invertido por los individuos durante la ejecución de la tarea. Es adecuado para ser utilizado en laboratorios y campos de estudio para la obtención de valores confiables del volumen de trabajo global.

\subsubsection{PROKUS}

PROKUS (PROgramm system zur Kommunikations ergonomischen UnterSuchung rechnerunterstützter Verfahren) [Zul2000] es una herramienta para el diseño de procedimientos de evaluación para llevar a cabo evaluaciones de usabilidad de acuerdo a diferentes situaciones de evaluación. Está basada en el diseño ergonómico de la interfaz de usuario. Por ello utiliza el estándar ISO 9241-10 [ISO1998c] como criterio de evaluación. Esta evaluación puede realizarse en distintas etapas del ciclo de vida del software:

- Durante el proceso de desarrollo de los productos: cuya finalidad es evaluar si la interfaz es la adecuada, empleando para ello pruebas de calidad (evalúa el funcionamiento del producto) y pruebas de conformidad (compara el producto con los requisitos del estándar).

- Durante la selección de un producto: realizado por clientes o futuros usuarios, mediante pruebas de comparación (examinando y comparando los productos existentes en el mercado), y pruebas de conformidad (evaluando la adherencia del producto a los estándares de amigabilidad al usuario).

- Durante la instalación del producto: con la finalidad de dar soporte a la fase de rediseño, mediante pruebas de usabilidad (para medir el logro de las metas de usabilidad y las necesidades adicionales).

\subsubsection{DRUM}

DRUM (Diagnostic Recorder for Usability Measurement) [Mcl1993] es una herramienta que permite el análisis de video asistido por computadora como soporte para la evaluación observacional de la usabilidad. Las principales características de esta herramienta son las siguientes:

- Soporta evaluación cuantitativa.

- Tiene una amplia aplicabilidad asistiendo a la generación y entrega de diagnóstico de retroalimentación, proporcionando a los diseñadores problemas potenciales derivados del análisis de datos.

- Soporta la administración y análisis de evaluaciones de usabilidad.

- Identifica incidentes críticos definidos por el evaluador para diagnóstico de la evaluación.

\subsubsection{WebQEM}

WebQEM (Web Quality Evaluation Methodology) [Ols2002] es una metodología cuantitativa para evaluar calidad de producto, es particular de aplicaciones y sitios Web. Utiliza un modelo de calidad jerárquico basado en el estándar ISO/IEC 9126-1 -1 [ISO2001] adaptado a las sub-características propias de la Web. Es un instrumento orientado al uso por parte de evaluadores expertos y se basa en la inspección de características, sub-características y atributos. Permite comprender el estado actual de la 
calidad de aplicaciones Web, mediante la detección de requerimientos pobremente implementados, sub-características y atributos ausentes, problemas de interfaz, de navegación, de contenido, y de performance.

\subsubsection{Accesibilidad}

Para las revisiones automáticas de accesibilidad existen muchas herramientas que posibilitan la evaluación. Por lo general, se trata de aplicaciones on-line que posibilitan elegir la URL a evaluar y el estándar o norma con el que se desea contrastar. Dentro de las herramientas más conocidas y utilizadas podemos mencionar:

\subsubsection{TAW}

TAW (Test de Accesibilidad Web) [TAW2010] es uno de los más conocidos. Se trata de un test gratuito basado en la WAI [WAI2005] del W3C para el análisis de la accesibilidad de sitios Web. Posibilita comprobar el nivel de accesibilidad alcanzado en el diseño y desarrollo de páginas Web con el fin de permitir el acceso a todas las personas, independientemente de sus características. TAW dispone de diferentes tipos de herramientas según las necesidades (on-line, para descargar, o un plug-in para incorporar en el navegador).

\subsubsection{HERA}

HERA (Hojas de Estilos para Revisión de la Accesibilidad) [HER2010] es una utilidad online gratuita desarrollada por la Fundación SIDAR (Seminario Iberoamericano sobre Discapacidad y Accesibilidad a la Red) para revisar la accesibilidad de las páginas Web de acuerdo con las recomendaciones de las Directrices de Accesibilidad para el Contenido Web 1.0 (WCAG 1.0) de la WAI [WAI2005]. Esta herramienta realiza un análisis automático de la página e informa si se encuentran errores, que sean posibles de detectar automáticamente, además de los puntos de verificación de las pautas que deben ser revisados manualmente.

HERA aplica diferentes hojas de estilos a la página evaluada para identificar visualmente los elementos que presentan problemas de accesibilidad y que necesitan ser revisados. De esta forma, facilita la revisión manual proporcionando información acerca de los elementos a verificar, instrucciones sobre cómo realizar ese control, y dos vistas modificadas de la página, una en modo gráfico y la otra en código HTML con los elementos más importantes destacados con iconos y colores distintivos.

El análisis de los sitios se realiza de forma on-line. Mediante un formulario Web provisto por HERA es posible modificar los resultados automáticos, agregar comentarios a cada punto de verificación, e indicar el nombre del revisor. También es posible generar un informe final sobre la revisión, para imprimir o descargar. Los datos de la evaluación son conservados por el término de una semana en una base de datos que posibilita retomar el trabajo, si no hubiera sido finalizado.

\subsubsection{Bobby}

Bobby [BOB2011] permite determinar el nivel de accesibilidad de las páginas Web de acuerdo con las recomendaciones de WCAG 1.0 y la Sección 508 del Acta de Rehabilitación de los EE.UU. Fue desarrollado originalmente por el Centro de Tecnología Especial Aplicada (Center for Applied Special Technology - CAST). Permite realizar pruebas on-line o descargar una aplicación gratuita para funcionar sin estar conectado a 
Internet. Este programa puede instalarse en una computadora y realizar el análisis de páginas alojadas dentro de la misma.

En el año 2002 Bobby fue adquirido por Wathfire, y a partir de ese momento el único servicio gratuito disponible fue el on-line. Este servicio se realizaba mediante una herramienta denominada WebXACT, que disponía del mismo motor de análisis que Bobby. WebXACT permitía analizar la accesibilidad de una página Web de manera online. Hasta el año 2007 fue uno de los revisores automáticos de accesibilidad gratuitos más utilizados. Sin embargo, a partir de ese año pasó a manos de IBM, y en febrero de 2008 dejó de estar disponible públicamente, aunque de forma temporal según la empresa [BOB2011].

\subsubsection{WAVE}

WAVE (Web Accessibility Evaluation Tool) [WAV2010] es una herramienta gratuita de evaluación de la accesibilidad Web provista por WebAIM (Web Accessibillity in Mind), una organización sin fines de lucro creada en 1999 por el Centro para las Personas con Discapacidad de la Universidad del Estado de Utah. Permite verificar las pautas WCAG 1.0, en cualquiera de sus niveles de prioridad, así como también la Sección 508 del Acta de Rehabilitación de los EE.UU. Pretende ayudar a los desarrolladores a realizar aquellas tareas que exigen una toma de decisiones de tipo personal, mostrando información sobre los elementos de la página (textos alternativos, información estructural, orden de lectura, etc.). Luego de realizado el análisis de la página, WAVE provee un informe intuitivo y fácil de entender. Para ello muestra la página Web original con una serie de iconos e indicadores que revelan la información de accesibilidad dentro de su página. Posee una serie de opciones de configuración que permiten seleccionar qué tipo de elementos de la página se tienen que mostrar en el informe (tablas, imágenes, objetos multimedia) e indicar qué características de análisis se tienen que incluir (errores, alertas o información estructural sobre el documento). La evaluación puede realizarse de diferentes formas (online, subir la página a analizar, copiar y pegar el código, o incorporar un plug-in en el navegador).

\subsubsection{Cynthia Says}

Cynthia [CYN2011] es un proyecto educacional promovido por varias organizaciones y empresas, creado para divulgar entre los desarrolladores la accesibilidad Web. Es un software para la validación automática de accesibilidad de páginas Web desarrollado por HiSoftware, la International Center for Disability Resources on the Internet, y el Capítulo sobre Discapacidad de la Internet Society. Esta herramienta on-line permite comprobar la conformidad con la Sección 508 del Acta de Rehabilitación de los EE.UU. y las Directrices WCAG en sus distintos niveles. Para mostrar el resultado del análisis se basa en la Tabla de Puntos de Verificación de la W3C. Permite además la revisión de la calidad de los textos alternativos, la detección de animaciones y destellos en las páginas. No es gratuito, pero posee una versión demo on-line.

- Modo del reporte: se puede elegir entre las siguientes revisiones: Sección 508 del Acta de Rehabilitación de los EE.UU, WCAG 1.0 Prioridad 1, Prioridad 1 y 2 , Prioridad 1, 2 y 3 . Además pueden agregarse una serie de opciones para advertir si la página posee errores Prioridad 2 y 3 , incluir un informe sobre calidad de texto alternativo, o incluir el archivo fuente en los fracasos de accesibilidad.

- Emular un determinado navegador: posibilita realizar la comprobación simulando la utilización de un navegador y versión determinada. Con esto se evita tener 
instalados varios navegadores (Firefox, Opera, Internet Explorer, Link, etc.) en la computadora y realizar la comprobación mucho más rápidamente. La variedad de navegadores y versiones es muy amplia.

\subsubsection{A-Prompt}

A-Prompt (Accessibility Prompt) [WAC2010] es un software gratuito creado por el Adaptive Technology Resource Center (ATRC) de la Universidad de Toronto para ayudar a los diseñadores Web a mejorar la accesibilidad de las páginas desarrolladas en formato HTML. Está basada en WCAG 1.0 y Sección 508. Esta herramienta evalúa el código HTML de la página e identifica las posibles barreras de accesibilidad para personas con discapacidades. A-Prompt no sólo se queda en la detección de los problemas sino que provee al diseñador Web una manera rápida y fácil de realizar los arreglos que posibiliten superar estas barreras. La aplicación debe descargarse e instalarse en la computadora del diseñador. Está disponible en inglés y francés, y únicamente para versiones del sistema operativo Windows.

La evaluación puede ser personalizada mediante una serie de opciones agrupadas en 4 categorías:

- Nivel de conformidad: WCAG 1.0 A, WCAG 1.0 AA, WCAG 1.0 AAA o Sección 508.

- Reparaciones automáticas: Dependiendo en el nivel de conformidad seleccionado, permite elegir hasta 6 tipos diferentes de modificaciones al archivo original que serán realizadas de forma automática. El usuario será notificado del problema de accesibilidad encontrado pero no intervendrá en la decisión de reparar o no la barrera encontrada.

- Almacenamiento de archivos: Posibilita reemplazar directamente el archivo original con el reparado, renombrarlo, dejarlo intacto, o generar un nuevo nombre para el archivo reparado.

- d-Links (description links): Permite agregar una descripción a las imágenes mediante el atributo longdesc.

Sin embargo, a pesar de su versatilidad y facilidad para evaluar y adecuar una página Web a los estándares más usados de accesibilidad, A-Prompt fue discontinuado a partir de 2007 con el objetivo de que el grupo de desarrollo pudiera concentrar sus esfuerzos en un nuevo programa que permite realizar la evaluación de forma on-line [WAC2010].

\subsubsection{Web Accessibility Checker}

Web Accessibility Checker (WAC) [WAC2010] es un evaluador de accesibilidad desarrollado por la Universidad de Toronto con el objetivo de posibilitar el testeo de páginas Web de forma on-line. Se trata de un proyecto de software libre superador de APrompt, desarrollado por el mismo centro. WAC permite analizar páginas que están online o alojadas localmente en una computadora. A-Prompt contaba con la desventaja de tener que estar instalado en la computadora, solo funcionaba en entornos Windows, y validaba únicamente WCAG 1.0 y Sección 508. En cambio, WAC funciona on-line, y con ello se independiza de la plataforma. Por otra parte, posee una variedad de estándares mucho mayor que A-Prompt. Posibilita utilizar una importante cantidad de guías de testeo:

- WCAG: versión 1.0, niveles A, AA, AAA.

- WCAG: versión 2.0, niveles 1, 2 y 3 .

- Section 508

- Stanca: Ley Italiana sobre discapacidad y accesibilidad. 
- BITV: Barrierefreie InformationsTechnik-Verordnung versión 1.0, nivel 2. Estándar Alemán.

\subsubsection{ASES}

Para analizar el nivel de visibilidad de usuarios con baja visión o ceguera pueden utilizarse herramientas libres como el Avaliador e Simulador de AcessibilidadE para Sítios (ASES) [ASE2011]. Este producto ha sido desarrollado entre el Departamento de Gobierno Eletrónico de Brasil y la OSCIP Acessibilidade Brasil, y es distribuido de forma gratuita bajo licencia LGPL-GNU. ASES permite la evaluación, simulación y corrección de páginas, sitios y portales.

Algunas de sus funcionalidades son:

- Evaluador de accesibilidad (e-MAG y WCAG)

- Evaluador de CSS

- Evaluador de HTML (4.01 y XHTML)

- Simuladorer de lector de WWW y baja visión (daltonismo, miopía, catarata)

Las herramientas descriptas, si bien pueden considerarse como las principales, no son las únicas, ya que existe un importante número de alternativas tales como: Total Validator, Truwex On-line, UITest.com, Webnauts, Accessibility Wizard, Functional Accessibility Evaluator, Accessibility Valet, Color Blindness Simulator, Flicker Rate Test, GrayBit, Color Laboratory, Firefox Web Developer Toolbar, 1-Hit Load Time Analyzer, AccvERIFY, AnyBrowser, CSS Analyzer, EvalAccess y Hermish, entre otras.

\subsubsection{Herramientas seleccionadas}

Esta revisión de herramientas de evaluación de usabilidad y accesibilidad, ha permitido hacer un análisis a los efectos de seleccionar las más apropiadas para utilizar en el modelo de evaluación propuesto en el marco de esta tesis. Si bien es imposible tener un estudio exhaustivo sobre el tema ya que la disponibilidad de productos es dinámica y evoluciona rápidamente, se ha buscado dar un panorama sobre estos productos, que permite luego contextualizar algunas de las decisiones abordadas para el trabajo. Para este proyecto se utilizará TAW como herramienta general de soporte para el análisis de accesibilidad, ASES para visibilidad reducida, y Cynthia Says como complemento. Las herramientas relacionadas con usabilidad no se utilizarán por diferentes razones: no ser gratuitas, estar discontinuadas, ser demasiado extensas o abarcativas.

En la siguiente sección se abordará un tema central en la evaluación que se vincula con los evaluadores involucrados en los diferentes métodos que se han ido revisando.

\subsection{Evaluadores}

Los diferentes métodos de evaluación de usabilidad de aplicaciones Web requieren, entre otras cosas, de distinto tipo de evaluadores [Car2002]. Por ejemplo, para la evaluación heurística es necesario gente experimentada en el diseño de interfaces e interacción humano-computadora, mientras que para realizar un recorrido cognitivo será de mayor utilidad contar con profesionales relacionados con el dominio de la aplicación. En todo modelo los evaluadores cumplen un rol fundamental. El juicio emitido por ellos puede llevar a descartar el uso de un determinado producto o a desencadenar un profundo proceso de cambios en la aplicación. Determinar el tipo de evaluadores a seleccionar, y los conocimientos que deben poseer, es de vital importancia para la aplicación de los 
métodos de evaluación. Una vez superada esta instancia, la obtención de datos fiables está sujeta a varios factores:

- la adecuada selección de los evaluadores para posibilitar que las personas elegidas estén lo más próximas posible al perfil buscado, es decir, al evaluador "ideal".

- la cantidad de personas involucradas en la evaluación.

- el tiempo que dispondrán para realizar la evaluación.

- el compromiso que asumirán con la tarea.

- los recursos materiales y económicos que se pondrán en juego.

Por otra parte, de nada sirve contar con un excelente modelo de evaluación, y una apropiada determinación del perfil de los evaluadores, si a la hora de ponerlo en práctica no se utilizan con seriedad los instrumentos, y se emiten juicios sesgados o poco objetivos.

La diversidad de aspectos que deben analizarse en un sitio Web, y en particular en un EVEA, hace imposible que un solo tipo de evaluador realice la tarea de forma confiable y completa. En virtud de ello es necesario contar con evaluadores dedicados al análisis del diseño de interfaz, la utilización de estándares, otros abocados a los aspectos educativos generales, y finalmente, aquellos que serán los beneficiarios directos del producto. Por tal motivo, de acuerdo al tipo de método de evaluación a utilizar (inspección, indagación, o test), es necesario clasificar a los usuarios en función de las tareas que llevará a cabo.

\subsubsection{Clasificaciones en relación a los evaluadores}

Existen diferentes propuestas sobre la forma de clasificación de los evaluadores. En general la clasificación depende del tipo de sitios Web (objeto a evaluar) y del momento en que se desarrolle la evaluación, es decir, si se trata de un producto que se encuentra en desarrollo o es una versión final. También, es importante tener en cuenta los instrumentos y métodos que se utilizarán para recoger la información.

\subsubsection{Clasificación general}

Una clasificación bien amplia de evaluadores (en particular para sitios Web) es aquella que los agrupa de acuerdo al grado de conocimiento y familiaridad que tienen con los entornos Web. Desde este punto de vista, existen diferentes formas de agrupar a los evaluadores. Una de ellas es dividirlos en expertos y no expertos. Otra clasificación más amplia los agrupa en novatos, intermedios, avanzados, y expertos [Cob2005]. Sumado a ello, debe tenerse en cuenta que es necesario poseer conocimiento y experiencia en la aplicación específica a evaluar.

\section{Experto}

Por experto se considera a las personas relacionadas directamente con la Informática, ya sea porque estudian o trabajan haciendo uso de las tecnologías de la información y la comunicación, o porque utilizan habitualmente la computadora e Internet.

\section{No experto}

Son aquellos que no están relacionados directamente con la Informática, no tienen preparación especial en la materia, utilizan Internet a modo de usuarios no especializados, y con una frecuencia menor que los expertos. 


\section{Novatos, intermedios, avanzados y expertos}

Esta clasificación no dicotómica, sino gradual, hace hincapié en el nivel de experticia del evaluador, es decir, al conocimiento que éste posee sobre la utilización de Internet. En un extremo se tiene a los usuarios sin experiencia, llamados novatos, y en el otro a las personas expertas, es decir, aquellas con amplio dominio de Internet, no solo a nivel de navegación sino de utilización de todos los servicios que provee la red.

\subsubsection{Clasificación específica}

Desde una mirada más centrada en la usabilidad de los sitios Web, que puede ser aplicada también a los entornos educativos, es posible dividir a los evaluadores en dos tipos: expertos y usuarios [Nie1993b][Lan1999][Car2002][Alv2005].

\section{Expertos}

En este caso la definición de experto difiere de la clasificación anterior. Un experto se define como aquel individuo en el cual su situación y sus recursos personales le posibilitan contribuir positivamente a la consecución del objetivo que ha motivado la iniciación del trabajo [Lan1999]. Existen varias formas de clasificar a los expertos dependiendo fuertemente del tipo de método utilizado.

- La forma más genérica es aquella que entiende al experto como un especialista en usabilidad y en la tecnología informática empleada por el software [Car2002].

- Otra alternativa, utilizada en los métodos de inspección como el heurístico, es clasificarlos según su experticia en las áreas de usabilidad e interfaz [Nie1993b]:

- novatos: sin conocimientos en usabilidad pero con conocimientos de computación.

- casi expertos: especialistas en usabilidad pero no en interfaz.

- doblemente expertos: especialista tanto en usabilidad como en interfaz.

- Una tercer alternativa es clasificarlos de acuerdo a sus condiciones, no a su conocimiento [Alv2005]:

- Especialistas: quienes poseen conocimientos, experiencia, capacidad predictiva y objetividad.

- Afectados: los que están implicados en el área que es objeto de estudio pero no poseen conocimientos superiores a la media.

- Facilitadores: aquellos que tienen capacidad para clarificar, sintetizar, estimar y organizar, sin necesidad de ser expertos o afectados.

\section{Usuarios}

Este tipo de evaluadores puede distinguirse de acuerdo a la experiencia con:

- el software.

- las computadoras en general.

- el dominio de la tarea. 
Estas tres dimensiones son conocidas como el cubo de usuarios [Nie1993]. En la primera dimensión encontramos usuarios novatos en el uso de producto, hasta expertos en la utilización del mismo. En la segunda tenemos usuarios con mínima experiencia en operación de computadoras hasta personas con amplia práctica. Finalmente, en la tercera dimensión agrupamos a los que ignoran el dominio de aplicación, hasta los que lo conocen adecuadamente. Según las características reunidas por cada usuario respecto al conocimiento del producto utilizado, la operación de computadoras, y el dominio de tareas, se ubicará en algún lugar dentro del cubo.

\subsubsection{Cantidad de evaluadores}

No existe consenso sobre cuál es la cantidad óptima de evaluadores a incorporar. Hay muchas variables en juego, como el tipo de método y técnica seleccionada, el tipo de evaluadores, la posibilidad de interactuar personalmente entre ellos, los tiempos, los recursos, entre las más importantes.

Seguramente, cuantos más evaluadores participan, mayor es la confiabilidad de los resultados, pero ello puede ir en desmedro de la rapidez para obtener los juicios, así como también correr el riesgo de contar con la información cuando haya dejado de ser útil. Por lo tanto, hay que buscar un equilibrio que posibilite garantizar operatividad y objetividad de la evaluación. El número óptimo de evaluadores resultará del análisis particular de cada caso. Spyridakis [Spy1992] estima que para una prueba de usabilidad debe contarse con un mínimo de 10 o 12 participantes a los efectos de obtener resultados estadísticamente válidos. Virzi [Vir1990] propone contar con solo cuatro o cinco evaluadores, en los casos que no haga falta realizar una prueba totalmente exhaustiva, debido a que esa cantidad de evaluadores puede detectar hasta un $80 \%$ de los problemas. Landeta [Lan1999] establece que debe haber un mínimo de 5 y un máximo de 30 evaluadores. Además, señala que por cada experto que se suma a la evaluación el error disminuye exponencialmente, pero superando los 30 expertos deja de justificarse en función del costo y el tiempo que ello implica. En el caso de otros métodos como la evaluación heurística se estima que cada evaluador puede identificar un $35 \%$ de los problemas, lo que lleva a trabajar con un grupo de entre tres y cinco evaluadores [Nie1993c].

\subsection{Evaluación de producto}

Las evaluaciones de usabilidad son factibles de utilizar en diferentes tipos de sistemas y distintas fases del proceso de desarrollo de software. Muchos de los métodos o técnicas existentes pueden aplicarse en más de una fase, sin embargo, la mayoría está destinada a capturar problemas de usabilidad en etapas tempranas del desarrollo. El objetivo es resolver tempranamente estos defectos para reducir el tiempo y costo de producción.

El tema se ha tornado tan importante que existe una rama específica de la ingeniería de software que se dedica exclusivamente a atacar este problema y que se la conoce con el nombre de Ingeniería de la Usabilidad. Esta mirada se corresponde con el estándar ISO/IEC 9126-1 [ISO2001] que define a la usabilidad desde un punto de vista orientado al proceso, como una de las características de calidad interna y externa del software, junto con la funcionalidad, fiabilidad, eficiencia, mantenibilidad y portabilidad. El término es utilizado para referirse a la facilidad de uso, entendida como la capacidad para permitirle al usuario saber si la aplicación es adecuada para sus tareas y condiciones de uso particulares, si le posibilita aprender a utilizarla, operarla y controlarla, siendo al mismo 
tiempo atractiva, y sin que por ello deje de respetar los estándares, guías y convenciones internacionales.

Otra forma de analizar la usabilidad es aquella que se ocupa de evaluarla como un atributo del producto final, en lugar de tomarlo en cuenta durante el desarrollo. El estándar ISO 9241 [ISO1998c] es el más representativo en este sentido, y en cual se apoyan numerosos autores para fundamentar sus métodos de evaluación. La definición de usabilidad dada por el estándar posibilita que evaluadores, consultores, instituciones o empresas, que no necesariamente estén involucrados en su desarrollo, puedan medir su usabilidad. En este sentido se define a la usabilidad en términos de la efectividad, eficiencia y satisfacción con la que un sistema permite alcanzar los objetivos propuestos por los usuarios en un contexto de uso determinado. La eficiencia, entendida como los recursos empleados en relación con la precisión y plenitud con que los usuarios alcanzan sus objetivos propuestos, forma parte de la usabilidad, a diferencia del estándar ISO 9126-1 [ISO2001] que la considera como otra característica del mismo nivel. La definición incluye también la efectividad del mismo, es decir, la precisión y plenitud con que los usuarios alcanzan los objetivos. Sin embargo, un sistema eficiente y efectivo puede no satisfacer al usuario, si mediante su uso se siente incómodo y, producto de ello, adopta una actitud negativa hacia el mismo. Debido a esto, la satisfacción del usuario es otro de los puntos centrales a considerar en la evaluación.

Posiblemente el hecho de centrarse en el contexto de uso sea uno de los rasgos más fuertes de esta mirada ya que pone el acento en la utilización concreta que el usuario hace del sistema, analizando en ese contexto las características del mismo. El contexto de uso involucra a los tipos de usuarios, las tareas, el equipamiento y el entorno físico y social dentro del cual será utilizado el sistema. Para poder evaluarlo es necesario entonces contar con usuarios reales, situaciones reales de trabajo y condiciones específicas. Por lo tanto, el producto deberá estar concluido, o en una etapa avanzada de desarrollo, como una versión alfa o beta, por ejemplo. El usuario y el entorno en el cual se utilizará el sistema pasan a ser ejes centrales para evaluar su usabilidad.

En esta tesis interesa evaluar los EVEA actuales desde el punto de vista de su usabilidad. Si bien es permanente la evolución de estos sistemas, y se producen nuevas versiones en cortos períodos de tiempo, la propuesta de evaluación se realizará será sobre sistemas en pleno funcionamiento. El objetivo es situarse en escenarios reales de uso, teniendo especial consideración por los alumnos y docentes, los objetivos que se proponen, las tareas específicas que realizan dentro del entorno durante las actividades de enseñanza y aprendizaje, el modelo mental que utilizan, el equipamiento e infraestructura del que disponen, el lugar físico donde habitualmente se desenvuelven, y el entorno social en el cual están insertos.

Por ese motivo la evaluación estará centrada en productos finales, versiones de prueba, o en evoluciones, es decir, donde no es necesario formar parte del equipo de desarrollo del sistema para poder realizar la evaluación sino que es suficiente con tener acceso a una versión operable del mismo.

\subsection{Conclusiones}

Los métodos para evaluación de usabilidad pueden ser agrupados en tres grandes grupos: inspección, indagación, y test [Flo2000b]. Desde el punto de vista del momento de aplicación de cada método, se puede observar que los métodos de indagación están más orientados hacia las etapas tempranas de desarrollo, los métodos de inspección a las etapas medias, y los métodos de test las etapas tardías. 
En este capítulo se realizó una revisión detallada de los diferentes métodos pertenecientes a cada uno de estos grupos, de manera tal de poder decidir acerca de sus posibilidades en relación al modelo propuesto en la tesis.

La evaluación por inspección agrupa al conjunto de métodos basados en examinar los principios relacionados con la usabilidad de un software o sitio Web, confiando en la experiencia y conocimiento del evaluador [Scr1967][Nie1994b][Rii2000]. Estos métodos permiten encontrar problemas de usabilidad en el diseño del software [Mac1994] o en la interfaz de usuario [Nie1990c]. En general, sirven como complemento de otros. Las inspecciones de usabilidad son tenidas en cuenta debido a su rentabilidad y rapidez de aplicación, respecto a otros métodos tradicionales [Alv2005]. Los métodos más importantes son: evaluación heurística, recorrido cognitivo, inspección formal, e inspección de características.

Los métodos de indagación permiten identificar los requisitos tanto del usuario como del producto. De allí, que generalmente la mayoría de las propuestas están pensadas para aplicarse en etapas tempranas del proceso de desarrollo. Para ello suelen utilizarse maquetas o prototipos de la aplicación. Son muy útiles para capturar las necesidades del usuario, y posteriormente satisfacerlas de forma eficaz y efectiva, a través de las funciones del sistema. Permiten obtener información de usabilidad sobre el producto que se desea producir. De allí que se los defina como métodos contextuales que posibilitan aproximarse al usuario desde diferentes perspectivas para recopilar información y avanzar en el diseño del producto. Si bien la indagación tiene mayor sentido en las etapas tempranas de desarrollo, no se descarta su utilización en otros momentos, inclusive luego de liberado el producto. Entre los métodos más destacados se encuentran la aproximación contextual, aproximación etnográfica, y la indagación individual.

Los métodos de tests son considerados como los más importantes a la hora de recabar información de la interacción entre el usuario y el sistema. Se basan en la utilización, por parte de un grupo de usuarios, de una aplicación ya desarrollada o en uso, a los efectos de evaluarla y obtener información que no fue tenida en cuenta. También pueden aplicarse a sistemas que se encuentran en su etapa de diseño pero que poseen prototipos en funcionamiento.

Cada uno de los métodos de evaluación analizados requiere de la utilización de una o más técnicas para recolección de datos. Estas técnicas no son de uso exclusivo de un método determinado, sino que pueden ser compartidas por varios de ellos. Las técnicas más relevantes son los cuestionarios, entrevistas, y encuestas.

Actualmente existen herramientas que apoyan la evaluación de usabilidad y accesibilidad en productos Web. En el caso de usabilidad, por lo general, se trata de cuestionarios online que deben ser completados por un experto, luego de realizar la evaluación sistemática del sitio Web. La mayoría de ellos son pagos, están discontinuados, o son demasiado extensos y abarcativos. Para las revisiones de accesibilidad, existen muchos productos on-line que posibilitan la evaluación automática. Algunos de los más interesantes son: TAW, como herramienta general de soporte para el análisis de accesibilidad, ASES para evaluar visibilidad reducida, y Cynthia Says como complemento.

Los diferentes métodos de evaluación de usabilidad de aplicaciones Web requieren, entre otras cosas, de distinto tipo de evaluadores. El rol del evaluador es fundamental, ya que la opinión de ellos puede llevar a descartar el uso de un determinado producto o a sugerir cambios. Determinar adecuadamente el tipo de evaluadores a seleccionar, y los conocimientos que deben poseer, es de vital importancia para la adecuada aplicación de los métodos de evaluación. La diversidad de aspectos a analizar en un sitio Web, y en 
particular de un EVEA, hace imposible que un solo tipo de evaluador realice la tarea de forma confiable y completa. En virtud de ello es necesario contar con evaluadores dedicados al análisis del diseño de interfases, la utilización de estándares, otros abocados a los aspectos educativos generales, y finalmente aquellos que serán los beneficiarios directos del producto. Por tal motivo, de acuerdo al tipo de método de evaluación a utilizar es necesario clasificar a los usuarios en función de las tareas que llevará a cabo.

Existen diferentes propuestas sobre la forma de clasificación de los evaluadores. En general esta clasificación depende del tipo de sitios Web y del momento en que se desarrolle la evaluación. Desde una mirada centrada en la usabilidad de los sitios Web, que puede ser aplicada también a los EVEA, existe un acuerdo entre los principales referentes del área para dividir a los evaluadores en dos tipos: expertos y usuarios [Nie1993b][Lan1999][Car2002][Alv2005].

Las evaluaciones de usabilidad son factibles de utilizar en diferentes tipos de sistemas y distintas fases del proceso de desarrollo de software. El estándar ISO/IEC 9126-1 [ISO2001] define a la usabilidad desde un punto de vista orientado al proceso. En cambio, el estándar ISO 9241-11 [ISO1998b] se ocupa de evaluarla como un atributo del producto final. 



\section{Capítulo 7: MUsa: Modelo centrado en la Usabilidad para evaluación de EVEA}

\subsection{Introducción}

Los EVEA son aplicaciones informáticas del tipo cliente/servidor que funcionan vía red, generalmente Internet. Esto posibilita que puedan ser utilizados desde cualquier lugar y en cualquier momento. La interacción con los usuarios se realiza mediante páginas Web, es decir que estos entornos se presentan al usuario como un sitio. Claro está que los EVEA no son sitios Web cualesquiera, sino que poseen características particulares debido a que están pensados para mediar los procesos de enseñanza y aprendizaje. Sin embargo, al utilizar la Web como interfaz, es posible contar con una teoría desde donde partir para su análisis, debido a que los lineamientos para un buen diseño Web no deben ser perdidos de vista [Fer2007].

El éxito o el fracaso de un sistema puede depender más de su usabilidad que de lo que realmente hace. La usabilidad es un elemento clave a la hora de marcar la diferencia entre sistemas que cumplen funciones similares. En el caso de los EVEA es más importante aún, porque se supone que el objetivo es potenciar las ventajas que ofrece la Web para mejorar la calidad de la enseñanza y el aprendizaje, minimizando los inconvenientes que se le pueden presentar al usuario.

Los alumnos, generalmente, disponen de poco tiempo para capacitarse, poseen diferentes ocupaciones, acceden en horarios más bien nocturnos y con cierto cansancio producto de la actividad diaria [Dar2002]. Por tales motivos, no están interesados en cruzarse con inconvenientes tecnológicos, ni invertir demasiado tiempo en aprender cosas que no están directamente relacionadas con su temática de estudio. No les interesa ser expertos en la utilización de EVEA, sino en utilizarlos como un medio que les requiera la menor carga cognitiva posible, es decir, no necesiten de grandes conocimientos informáticos, sean fáciles de usar, de aprender, de recordar, intuitivos, sencillos, efectivos, eficientes y amenos. Estos aspectos dejan al campo de la usabilidad un gran desafío.

Los docentes y alumnos que interactúan a través de entornos virtuales se ven atravesados por tres tipos de aprendizajes: del contenido específico, de una nueva forma de enseñar y aprender, de funcionalidades propias del entorno virtual utilizado [Dar2002]. El modelo de evaluación propuesto aquí orienta su mirada sobre el aspecto funcional de los EVEA, donde la usabilidad tiene mucho para aportar a quienes abordar procesos de enseñar y aprender acompañados por esta tecnología.

\subsection{Puntos de partida propuestos para un nuevo modelo de evaluación de EVEA}

Como se mencionó anteriormente, la participación del usuario en el proceso de evaluación es fundamental para la obtención del grado de usabilidad de un software. Esto posibilita que puedan involucrarse personas ajenas a los equipos de desarrollo, tanto para evaluar productos en construcción, como así también productos terminados o nuevas versiones. Por lo tanto, es necesario que las herramientas de evaluación sean participativas y cuenten con la posibilidad cierta de incorporar a los usuarios finales en el proceso [Fer2009]. Esto no implica que sean los únicos actores involucrados, en general es necesaria también la intervención de observadores o personas expertas en el dominio, o herramientas de automatización [Gon2001]. Para lograr que el modelo sea efectivamente utilizado, los procesos de evaluación e interpretación de resultados deben poder hacerse de la forma más rápida y menos costosa posible. 
La usabilidad de un software es una característica que no puede determinarse evaluando el producto de manera aislada. Tampoco es posible medirla de una sola forma, ya que depende del tipo de producto, el conjunto de usuarios y el contexto de uso. Es una medida relativa, y por lo tanto, difícilmente existan reglas de usabilidad absolutas y aplicables por igual en todas las situaciones [Mor2005].

Los modelos de evaluación, sintetizados en el capítulo 4, analizan los EVEA poniendo el foco sobre las funcionalidades que ofrecen [Fer2007b]. Sin embargo, la validación no ha de centrarse únicamente en el acceso a las herramientas concretas sino al ensayo con alumnos reales [Sal2006]. El análisis de las funcionalidades ideales tampoco tiene demasiado en cuenta la usabilidad. Por ejemplo, se puede contar con una herramienta comunicación entre docentes y alumnos, con una gran cantidad de funcionalidades pero demasiado engorrosa de utilizar, entender o aprender por parte de usuarios no expertos. Estos modelos fueron pensados cuando las características diferían bastante entre un entorno y otro. En el mejor de los casos, restringen la usabilidad a la facilidad de uso y el cumplimiento de ciertos estándares [Fer2009]. En la actualidad, los entornos de mayor importancia poseen un núcleo común de herramientas. Donde todavía resta camino por recorrer es en cuestiones ligadas a la usabilidad, posiblemente porque son más difíciles de medir, como por ejemplo la flexibilidad para adecuar cada entorno, y sus herramientas, a distintos contextos o modelos de enseñanza y de aprendizaje.

Las definiciones y heurísticas de usabilidad presentan una idea sobre las consideraciones a tener en cuenta para alcanzar buenos niveles de usabilidad en los sitios Web. Sin embargo, no existe un modelo de evaluación de EVEA que integre ambas cuestiones. Para superar estos inconvenientes, es necesario contar con un modelo de evaluación específico. Un modelo centrado en la usabilidad debería nutrirse de los ya existentes, debido a que la evaluación de la funcionalidad es una parte importante, pero a la vez debe tenerse en cuenta a los docentes y alumnos trabajando en el entorno con cada funcionalidad disponible.

Otro aspecto de gran relevancia para alcanzar altos niveles de usabilidad es la accesibilidad. Para que un entorno sea usable, entre otras cosas, debe ser accesible. Dicho de otra manera, la accesibilidad es condición necesaria para la usabilidad. La accesibilidad tiene en cuenta factores humanos, aspectos ligados al hardware y al software. Así, adultos mayores o personas sin motricidad fina tendrán serios inconvenientes en utilizar productos basados exclusivamente en el uso del mouse. Otros usuarios, sin estas características pero con computadoras que no son de última generación, viejas versiones de navegadores, sin plugins, o conexiones lentas, estarán impedidos de utilizar el entorno si está realizado, por ejemplo, exclusivamente con tecnología multimedia.

El método de evaluación de usabilidad que se propone en el marco de esta tesis, está orientado a una evaluación de producto, es decir, sobre EVEA que ya han sido desarrollados, y están en pleno funcionamiento. El modelo se denomina MUsa, dado que se trata de un Modelo centrado en la Usabilidad. La evaluación se apoya en escenarios reales de uso, teniendo especial consideración por los alumnos y docentes, los objetivos que se proponen, las tareas específicas que realizan dentro del entorno durante las actividades de enseñanza y aprendizaje, el modelo mental que utilizan, el equipamiento e infraestructura que disponen, el lugar físico donde habitualmente se desenvuelven, y el entorno social en el cual están insertos. También puede facilitar la evaluación de nuevas versiones de un mismo sistema o la comparación entre ellas. Las ideas generales o puntos de partida para la búsqueda de este nuevo modelo se basan en una estrategia de 
cuatro niveles o capas de evaluación, que parten de lo general para llegar a lo particular, es decir, una estrategia top-down [Fer2012].

A continuación se presenta sintéticamente una descripción de cada una de ellas.

\subsubsection{Primera capa}

Está destinada a analizar gran parte de la aceptabilidad práctica del EVEA. La aceptabilidad práctica conjuga la utilidad (usefullness) con otras variables como costos, compatibilidad, confiabilidad, y soporte, entre los más importantes [Nie1993][Zur1999]. La utilidad a su vez está determinada por la utilidad práctica o funcional (utility), la usabilidad y la accesibilidad. En la primera capa abordaremos el análisis de todos los componentes de la aceptabilidad práctica, menos el referido específicamente a usabilidad. Esto no significa que la evaluación de usabilidad esté ausente por completo en esta capa, sino que de acuerdo a la clasificación propuesta por Nielsen [Nie1993] las variables que se analizarán son: utilidad práctica y accesibilidad (parte de la utilidad), junto con las características técnicas generales (antecedentes, potencial, tecnología utilizada, licencia, soporte, seguridad, acceso de usuarios), compatibilidad (servidor, usuario/cliente, formatos multimedia, integración) y robustez (integridad de funcionamiento, recuperación ante fallos, seguridad).

En este sentido se pone énfasis sobre las características funcionales del EVEA, donde se consideran cuestiones relacionadas con las facilidades para la organización académica y flexibilidad pedagógica [Fer2009b]. Un punto que toma especial relevancia es la versatilidad del entorno para adaptarse al desarrollo de cursos, grupos de cursos, carreras, comunidades virtuales, etc. También es importante evaluar la forma en que puede dar soporte a diferentes modalidades educativas, sean éstas a distancia o mixtas, y a diferentes enfoques de enseñanza y de aprendizaje. Para analizar este tipo de características es necesario contar con especialistas en educación y en tecnología. Los criterios recurrentes en los modelos de evaluación de EVEA, mencionados en el capítulo 4 , sirven como base para este primer nivel.

\subsubsection{Segunda capa}

Orientada a evaluar la forma en que el sistema interactúa con el usuario, la interfaz que presenta, y el modo en que permite realizar las tareas básicas. Los métodos de inspección, como el recorrido cognitivo [Pol1992][Lew1993] [Wha1994] y la evaluación heurística [Nie1990b][Nie1992][Mac1993][Cat2000][Man2003b][Alv2005][Con2005] resultan adecuados para este tipo de acciones. Estos métodos se apoyan en la opinión de expertos disciplinares que emiten un juicio sobre el producto, en función de una serie de parámetros predefinidos. En el recorrido cognitivo, el especialista transita un escenario de tareas determinado como lo haría un usuario tipo. Es decir, combina el recorrido del software con un modelo cognitivo de aprendizaje por exploración. La evaluación heurística analiza si cada elemento de la interfaz de usuario sigue las directrices de usabilidad establecidas. Para ello se recorren meticulosamente las tareas, teniendo en cuenta los propósitos y objetivos de los usuarios, y poniendo énfasis en el hallazgo de errores. Los dos métodos realizan recorridos desde el punto de vista del usuario, pero los paseos cognitivos ponen el énfasis en la teoría cognitiva, mientras la evaluación heurística lo hace más en las heurísticas y el hallazgo de errores. Estos dos métodos de inspección pueden ser conjugados en uno solo para simplificar la evaluación.

Para aplicar este método de inspección mixto se utilizan escenarios de uso. Los escenarios deben contemplar las tareas académicas más frecuentes durante el desarrollo 
de un proceso de enseñanza y de aprendizaje. Para que el modelo pueda ser aplicado en distintos EVEA los escenarios deben ser genéricos.

El experto es el encargado de elegir la herramienta que utilizará para realizar cada tarea. Esta elección está supeditada a las funcionalidades disponibles en el EVEA. En este sentido pueden darse situaciones en las cuales el experto deberá tomar decisiones. Por ejemplo, es necesario decidir qué hacer en los casos donde ciertas tareas no puedan llevarse a cabo, total o parcialmente, debido a que en la primera capa de evaluación se relevó que no existe una funcionalidad adecuada que posibilite completar una determinada tarea. El experto, al detectar la falencia y determinar su grado de severidad, debe simular los escenarios e intentar resolver las tareas del usuario a partir de las funcionalidades disponibles. Luego, recién informar sobre las dificultades encontradas. También deberá actuar de la misma manera si la funcionalidad existe pero es muy limitada, rústica o imposible de implementar en el contexto en que se está realizando la evaluación. Lógicamente esto impactará en la usabilidad del EVEA, que es lo que precisamente busca evaluar el método.

\subsubsection{Tercera capa}

Una vez superadas las dos capas anteriores comienza a ser imprescindible la participación del usuario. En esta etapa se plantea incorporar la opinión de los usuarios finales bajo un ambiente controlado por un evaluador. Para esto son de gran ayuda los métodos de test de usuario [Woo98], en particular, los del tipo de expresión del usuario en base a preguntas, que en realidad son una variante del test de pensamiento en voz alta [Nie1994]. Los usuarios participan de la evaluación realizando una o más tareas que forman parte de un escenario tipo. Es importante que los usuarios involucrados en los test abarquen los diferentes roles en que puede interactuarse con el EVEA (alumnos, docentes, administradores, etc.). Por otro lado, dentro de cada rol deben seleccionarse usuarios con diferente nivel de experiencia en el uso del servicio Web. A medida que el usuario interactúa con el entorno debe expresar en voz alta sus pensamientos, sensaciones y opiniones, mientras el evaluador capta y registra las impresiones y sensaciones que manifiesta oralmente, además de realizar preguntas directas cuando lo considera conveniente. En necesario también que el test de usuarios incluya capacitación previa.

\subsubsection{Cuarta capa}

Está destinada exclusivamente para que los futuros usuarios finales aporten su punto de vista dentro de un contexto o ambiente real, como por ejemplo realizar una serie de tareas desde su habitual lugar de estudio (casa, trabajo, cyber). Lógicamente, para realizar este tipo de evaluación también son adecuados los test de usuarios. En particular los test remotos son muy eficaces, rápidos y fáciles de realizar [Hom2003][Mon2006]. Sumado al test, se incorpora el análisis de log, y un recorrido por el aula virtual, a los efectos de poder realizar una evaluación pos-test y analizar los "rastros" dejados por el usuario. Es decir, analizar la navegación efectuada, las páginas que más visitó, el tiempo de permanencia, y el porcentaje de tareas que logró completar. Además, como el usuario realiza el test en su propio medio o ambiente, es posible evaluar el contexto de uso. Esto es de vital importancia debido a que todas las capas anteriores, si bien simulan el contexto de uso a través de escenarios, no posibilitan evaluar el EVEA desde una situación real. La información del contexto de uso, que pretende evaluar la cuarta capa, está relacionada principalmente con la ubicación geográfica, espacio desde donde accede (casa, trabajo, cyber, centro de estudio), día y hora en que utiliza el EVEA, edad, sexo, 
recursos técnicos (tipo de dispositivo, tipo de conexión, sistema operativo, navegador), y limitaciones físicas que posee el usuario.

Los test remotos se basan, principalmente, en el uso de cuestionarios para recolectar la información. El evaluador sólo está encargado de elaborar y suministrar el cuestionario, y posteriormente procesar los resultados recabados mediante las respuestas recibidas, el análisis de log, y el recorrido por el aula virtual utilizada durante la evaluación.

\begin{tabular}{|c|}
\hline $\begin{array}{l}\text { CAPA } 1 \text { - Características técnicas generales: } \\
\text { tipo de licencia, tecnología subyacente, } \\
\text { soporte, herramientas disponibles, } \\
\text { funcionalidades generales que provee- } \\
\text { Participan expertos }\end{array}$ \\
\hline $\begin{array}{l}\text { CAPA } 2 \text { - Aspectos centrados en la usabilidad } \\
\text { (una serie de heurísticas que se proponen), a } \\
\text { partir del trabajo con escenarios de uso. } \\
\text { Participan expertos }\end{array}$ \\
\hline $\begin{array}{l}\text { CAPA } 3 \text { - Aspectos centrados en la usabilidad } \\
\text { (una serie de heurísticas que se proponen), a } \\
\text { partir de escenarios de uso. Participan } \\
\text { usuarios finales pero en un entorno } \\
\text { controladoy simulado }\end{array}$ \\
\hline $\begin{array}{l}\text { CAPA } 4 \text { - Aspectos centrados en la usabilidad } \\
\text { (una serie de heurísticas que se proponen), a } \\
\text { partir de escenarios de uso en contextos } \\
\text { reales. Participan usuarios finales en } \\
\text { contextos reales }\end{array}$ \\
\hline
\end{tabular}

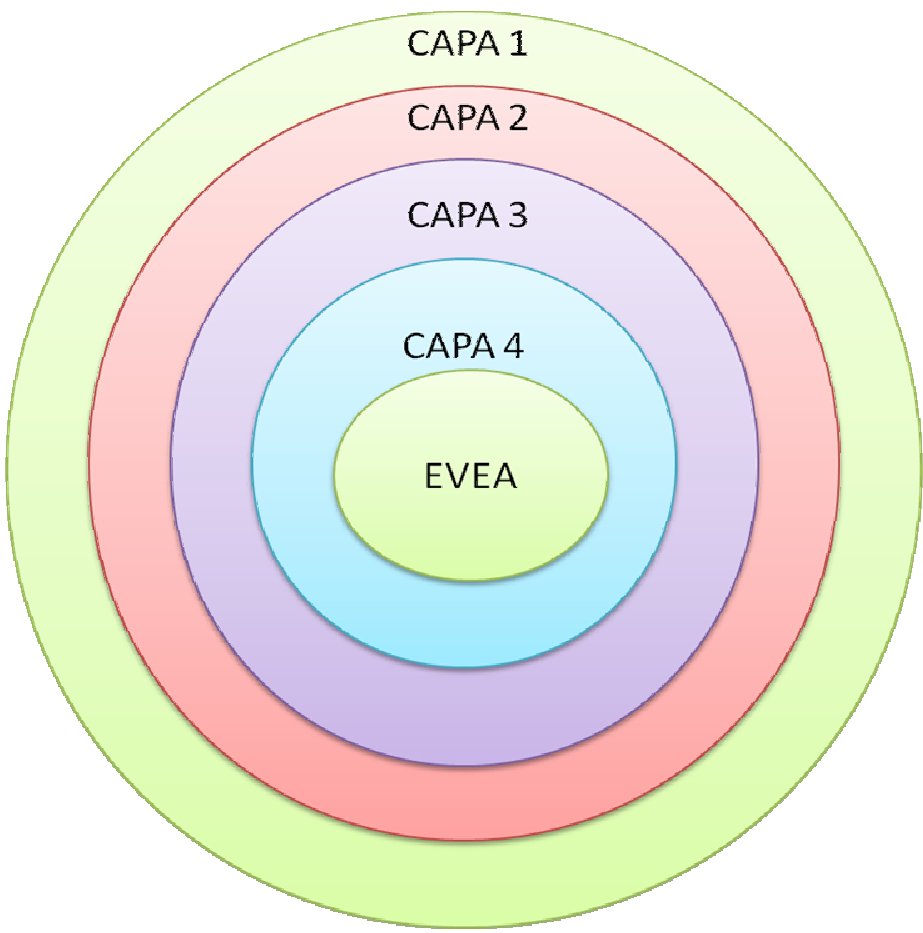

Figura 19 - Las 4 capas de MUsa y sus características principales de cada una

\subsubsection{Aplicación de MUsa a distintos contextos}

Las cuatro capas de MUsa plantean ciertos grados de acercamiento al usuario, siendo el primer nivel el más alejado. La transición de un nivel a otro estaría dada por resultados aceptables en las evaluaciones. Es decir, en el caso de productos en desarrollo, la usabilidad debería mejorar de un nivel a otro, ya que se supone que los errores y dificultades más importantes han sido detectados y corregidos en las etapas previas. Sin embargo, como mencionamos anteriormente, el modelo que se propone en esta tesis resulta más adecuado para evaluar productos terminados o para comparar nuevas versiones de un entorno respecto de las anteriores [Fer2012].

Las cuatro capas persiguen objetivos diferentes. Mientras la primera es la encargada de realizar una evaluación del entorno en general, las tres capas restantes se sitúan en un contexto de uso particular, por ejemplo, el aula virtual de un curso. Para ello, las capas más cercanas al usuario utilizan escenarios de uso que permiten guiar y sistematizar la evaluación. En cada caso se utilizan métodos y técnicas diferentes, que se complementan entre sí, y posibilitan enriquecer la evaluación.

Las capas propuestas por MUsa pueden ajustarse a distintos contextos dependiendo de la necesidad, nivel de profundidad de la evaluación, recursos y tiempo disponible [Fer2012]. El modelo puede adaptarse en dos sentidos: 
1. Prescindiendo completamente de algunas de las capas

En este caso, se puede optar por diferentes alternativas, ya que si bien la evaluación es lineal, no necesariamente hay que comenzar desde la primera capa, e incluso es posible saltear alguna de las restantes, si no fuera necesaria. La única capa imprescindible es la capa 2, posiblemente la más importante del modelo.

Las alternativas que se plantean para el modelo de evaluación son:

- Capa $1 \rightarrow$ Capa $2 \rightarrow$ Capa $3 \rightarrow$ Capa 4

- Capa $2 \rightarrow$ Capa $3 \rightarrow$ Capa 4

- Capa $2 \rightarrow$ Capa 4

La última opción, si bien es la que menos recursos demanda, presenta riesgos de sesgar la evaluación puesto que se omite el trabajo cara a cara con los usuarios finales, bajo un ambiente controlado por observadores.

2. Seleccionando diferentes alternativas dentro de la segunda capa

Este caso hace referencia a las elecciones que se deben tomar en la segunda y tercera capa. En la capa 2 se realizan evaluaciones diferentes, una orientada a la tarea y otra al diseño. En cada una de ellas es posible seleccionar la cantidad de evaluadores que participarán, lo que tiene directa relación con los roles y escenarios utilizados, e impacta directamente en la complejidad y magnitud de la evaluación. Mientras tanto, en la capa 3 , es posible realizar una evaluación real o simulada, es decir, evaluar sobre uno o varios cursos en desarrollo, o generar un espacio virtual donde alumnos y docentes participen sabiendo que se encuentran bajo un simulacro de curso.

La siguiente figura muestra los posibles flujos de trabajo entre las distintas capas de MUsa: 


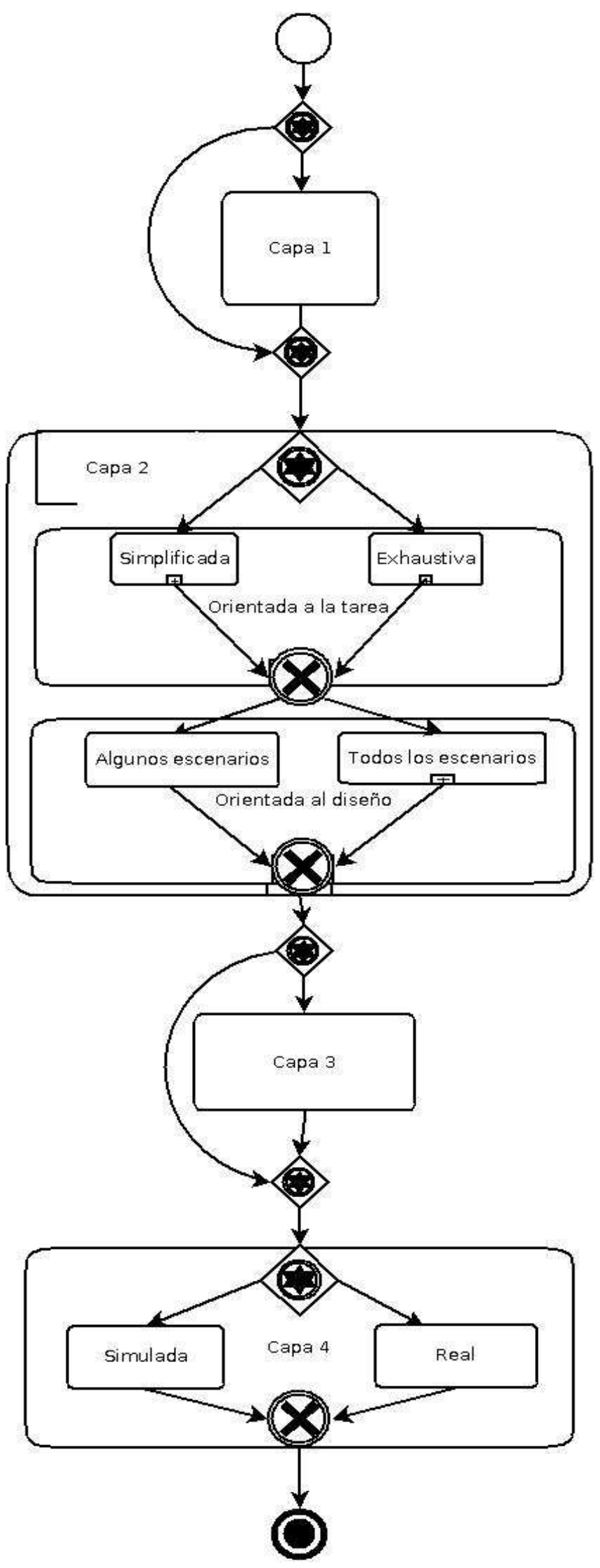

Figura 20 - Posibles flujos de trabajo entre cada capa 


\subsection{Decisiones respecto a los métodos, técnicas, herramientas y evaluadores}

\subsubsection{Decisiones respecto a los métodos}

Todos los métodos presentados, de alguna manera, resultan útiles para la evaluación de EVEA. Algunos son centrales, mientras que otros pueden aportar miradas sobre aspectos más puntuales, incluso el hecho de prescindir de ellos no afectaría, en algunos casos, la calidad de la evaluación. La búsqueda del equilibrio entre tiempo, esfuerzo y complejidad hace que el modelo ideal tenga que dar paso al modelo real. De allí que, en función de las características de la evaluación, orientada al producto y centrada en los objetivos del usuario final, resulta adecuado prestar especial atención a los métodos de inspección y de test.

Dentro de los métodos de inspección, la evaluación heurística se presenta como uno de los más adecuados para que los evaluadores expertos tomen contacto con las interfaces Web, y puedan diagnosticar sus potenciales problemas de usabilidad. Con este método se pueden evaluar una serie de aspectos técnicos en lo que respecta a la interfaz de usuario. El recorrido cognitivo es un excelente complemento a la evaluación heurística porque permite a los expertos combinar la navegación de la interfaz de usuario con los objetivos del mismo. Mediante la construcción de diferentes escenarios se deja en manos del experto la realización de las tareas, imitando a los usuarios finales de esa interfaz. La inspección de estándares y de características ayuda a evaluar aspectos más formales de la interfaz relacionados con la accesibilidad, estandarización internacional, y el diseño físico, sintáctico y semántico de la interfaz.

El protocolo de expresión de usuario en base a preguntas es uno de los test de usuario, cara a cara, más útiles para extraer la información sobre los comportamientos e intenciones de los mismos. Al basarse en la observación presencial del usuario mientras realiza una tarea, permite al evaluador la captación de impresiones y sensaciones, recurriendo a preguntas para provocar manifestaciones explícitas respecto del producto. Es más fácil de implementar que el test de usuario clásico ya que no es necesario contar con un laboratorio de usabilidad.

Otro de los test de usuario fáciles, rápidos, y baratos de aplicar, donde resulta innecesaria la presencia de un evaluador, es el test remoto. En especial son útiles cuando se desea dejar actuar libremente al usuario en su propio contexto de trabajo, sin presiones y en una situación lo más parecida posible al uso real que se le dará al sistema.

\subsubsection{Revisión respecto a las técnicas}

Existen muchas técnicas de gran utilidad para instrumentar los métodos de evaluación presentados anteriormente. Los cuestionarios pueden servir de ayuda en muchos métodos, incluso como instrumento para realizar la evaluación de nivel más general, es decir, la primera capa. Para ello es conveniente definir una serie de categorías de análisis y luego detallar las preguntas que el evaluador debe responder en cada una de ellas. Las encuestas son vitales para efectuar los test de usuario remoto y de expresión en base a preguntas. En el primer caso, las encuestas que mejor se adaptan son las autoadministradas, mientas que en el segundo son necesarias las personales. También las entrevistas sirven como complemento en este caso. El análisis de log es parte importante del test remoto ya que permite conocer cómo los usuarios realizan su trabajo real bajo diversas circunstancias o contextos, sin que se sientan observados o invadidos. El seguimiento visual es una técnica muy útil porque no depende de las expresiones y 
comentarios del usuario y además aporta información acerca de los elementos de la interfaz que son realmente vistos por el usuario. Sin embargo, es necesario contar con un laboratorio de usabilidad que provea tal equipamiento y resulta muy costoso aplicarlo a una gran cantidad de usuarios.

\subsubsection{Decisiones respecto a las herramientas}

Si bien existe una gran cantidad de herramientas orientadas a la evaluación de usabilidad de productos Web, ninguna es específica para nuestro propósito, o dicho de otra forma, se trata de cuestionarios demasiado abarcativos y extensos, alguno de los cuales se basan en la medición de ciertas características. A pesar de ello resultan de gran ayuda para pensar de qué forma se puede obtener una valoración del grado de usabilidad de un entorno virtual según los criterios específicos de los mismos.

Desde el punto de vista de la accesibilidad, el panorama es más claro porque se trata de una característica que puede ser medida de igual manera, independientemente del tipo de sitio Web del que se trate. En general, es tenida poco en cuenta, pero en los sitios educativos es muy significativo porque un defecto de accesibilidad puede significar, por ejemplo, la imposibilidad de acceder a un contenido de aprendizaje. Las herramientas existentes posibilitan medir claramente los distintos niveles de accesibilidad que poseen los sitios Web. En particular TAW [TAW2010] y WAVE [WAV2010], tanto en sus versiones on-line o como plug-in del navegador Firefox, resultan una solución rápida, concreta y sencilla para la evaluación de esta característica.

\subsubsection{Decisiones acerca del tipo de evaluadores}

Para nuestro trabajo nos basaremos en la clasificación de expertos y usuarios desarrollada en el capítulo 6. Consideramos que se trata de la clasificación más adecuada para el dominio de los EVEA, y una de las más aceptadas y utilizadas por reconocidos especialistas [Car2002]. Complementaremos al evaluador usuario con otras características adicionales no consideradas, como el rol que juega dentro del entorno virtual de enseñanza y aprendizaje (docente o alumno), el perfil, y el contexto de uso. Además, contaremos con observadores que colaboran en la aplicación del método de evaluación. Los observadores son imprescindibles ya que son los encargados (para varias de las técnicas de evaluación a implementar) de realizar la recolección de los datos, el registro, y análisis de los mismos.

\section{Expertos}

Los expertos intervendrán en las dos primeras capas del modelo de evaluación. Tendrán la particularidad de poseer muy buenos conocimientos acerca de la característica de usabilidad que se esté evaluando en cada una de las capas.

La primera de ellas evalúa las características funcionales del producto, lo más "grueso", de allí que los expertos que participarán de la evaluación serán de dos tipos: especialistas en educación y especialistas en tecnología.

En la segunda capa se realiza una evaluación desde el punto de vista de la interfaz, en combinación con los objetivos del usuario. El análisis de las heurísticas no se realiza de forma aislada sino aplicadas a lo que el usuario desea realizar con el sistema informático. Los productos educativos como los EVEA poseen características especiales que permiten llevar adelante procesos de enseñanza y aprendizaje. En este caso, los expertos asumen un doble rol, docentes y alumnos, en el contexto de realización de una serie de tareas generales dentro del entorno. 
Lo más importante es que el evaluador conozca el dominio de aplicación. Podría pensarse en contar con un solo tipo de experto que desempeñe los roles de docente y alumno, o varios tipos de acuerdo a la disponibilidad de recursos humanos, financieros y temporales. Una característica en común es que el experto posea experiencia docente.

- Un solo tipo de experto: debería tratarse de un docente que se encuentre especializado en EVEA y con alto nivel de experticia en el manejo de tecnología informática. En el caso de poder seleccionar más de un experto de este tipo, sería interesante que algunos ya utilicen el EVEA a evaluar como así también, otros que no. A esta clase de experto la denominaremos EDE (Experto Docente en Entornos).

- Varios tipos de expertos: en este caso podríamos apoyarnos en la propuesta de Nielsen [Nie1993b] y definir 3 tipos de experticia en los evaluadores docentes, a las cuales denominaremos $\mathrm{E}^{-}, \mathrm{E}, \mathrm{y} \mathrm{E}^{+}$:

- $E^{*}$ : docente sin conocimientos en EVEA y algo de experiencia en la utilización de computadoras y servicios de Internet.

- E: docente con conocimientos en EVEA y mucha experiencia en utilización de computadoras y servicios de Internet.

- $\mathrm{E}^{+}$: docente con conocimientos en EVEA, en usabilidad y mucha experiencia en utilización computadoras y servicios de Internet.

Este planteo sería el más recomendable a efectos de obtener un juicio más integral y acabado del EVEA.

\section{Usuarios}

Los usuarios intervendrán en las dos últimas capas. Al igual que en el caso de los expertos, existen diferentes roles de usuarios. Estos roles dependen de la propuesta educativa. Por ejemplo, los más recurrentes son: alumno, docente, tutor, colaborador, responsable, administrador y webmaster. Para nuestra propuesta utilizaremos dos roles básicos: uno que sintetice las labores de enseñanza que se pueden realizar en el entorno, y otro que haga lo propio con las de un alumno. Las tareas a realizar dentro del entorno pueden diferir de acuerdo a la propuesta metodológica de cada una de las actividades educativas que se implementen bajo este soporte tecnológico. Por ejemplo, una propuesta centrada en el docente no utilizará los mismos recursos y herramientas que otra centrada en el alumno, así como tampoco será igual la forma de utilizar cada medio. A los efectos de sortear estos inconvenientes, y poder realizar una evaluación lo más general posible, tomaremos como base una serie de escenarios y tareas comunes que puedan encontrarse en la mayoría de las propuestas virtuales. Designaremos a estos roles de la misma forma que lo hicimos para los expertos, es decir, docentes y alumnos, de acuerdo a la tarea que se pretenda evaluar. La diferencia principal entre los expertos y los usuarios radica en que los primeros realizan una simulación del rol docente y alumno, mientras que los usuarios son docentes y alumnos reales.

No consideraremos aquí otros roles muy importantes dentro de los EVEA como los son la administración, gestión, monitoreo y soporte técnico. El análisis de los mismos podría formar parte de una segunda etapa o refinamiento del modelo de evaluación. 
Tanto los docentes como los alumnos que formarán parte de la evaluación serán destinatarios directos del entorno evaluado. Esto lleva a incorporar en el análisis diferentes perfiles de los mismos según ciertos parámetros. Tomaremos como criterio básico para seleccionar los usuarios: la experiencia y la frecuencia en el uso de Internet.

- Novato: será aquel que posea conocimientos básicos de operación de computadoras (paquetes de oficina) y utiliza Internet de forma poco habitual, por ejemplo, para navegar por sitios de propósito general.

- Medio: consideraremos de esta forma al usuario que posee, además de conocimientos básicos, destrezas en el uso de diversas funcionalidades a nivel de sistema operativo (manejadores de archivos, configuración y personalización, manipulación de periféricos, etc.) y utiliza Internet de forma habitual, para navegar por sitios de propósito general, buscar y descargar información, manipular un webmail, participar en foros, blogs.

- Avanzado: usuario que puede manipular varios tipos de programas (oficina, diseño, etc.), posee habilidades para la administración e instalación de software, y utiliza Internet muy frecuentemente para buscar y descargar información, manipular un webmail, participar y/o administrar sitios, foros, blogs.

Para la última capa, donde se realiza una evaluación utilizando usuarios finales pero en su medio habitual de trabajo y estudio, será considerada una nueva dimensión que permita poner de manifiesto el contexto de uso en el cual se utiliza el EVEA. Los principales parámetros a considerar serán: ubicación geográfica, recursos técnicos disponibles (software, hardware, conectividad), edad, sexo, y posibles limitaciones físicas.

\subsubsection{Decisiones acerca de la cantidad de evaluadores}

\subsubsection{Primera Capa}

Por tratarse de una capa donde se evalúan las características funcionales del producto, y en la cual participarán especialistas en educación y en tecnología, será necesario contar como mínimo con dos especialistas de cada tipo, a los efectos de garantizar cierto grado de objetividad y agilidad en el proceso, es decir 4 en total.

Los especialistas en educación deberán tener conocimiento en TIC y dominio de las principales herramientas para la información y la comunicación. En el caso de los especialistas en tecnología, es necesario que sean expertos con conocimiento exhaustivo de los servicios provistos por Internet y estándares Web.

No podemos dejar de tener en cuenta que un resultado negativo de esta evaluación podría truncar las posibilidades de continuar con las siguientes etapas, ya que el producto evaluado no cumpliría con las características básicas requeridas.

\subsubsection{Segunda Capa}

De acuerdo a los tipos de expertos que decidamos tomar, tendremos situaciones diferentes:

- Un solo tipo experto: en este caso necesitamos de docentes del tipo EDE, es decir, especializados en EVEA y en tecnología. La cantidad puede variar de acuerdo a la disponibilidad y recursos. Sería recomendable que pudiera 
ser más de uno para poder seleccionar docentes que tengan experiencia con el entorno a evaluar y otros que no.

- Varios tipos de expertos: recordemos que hay tres tipos propuestos: E-, E, y E+. Acorde a los trabajos de Nielsen se recomienda contar con 3, 4 ó 5 expertos para identificar posibles problemas de usabilidad [Nie1993c]. Por este motivo, una propuesta es seleccionar tres expertos, uno de cada tipo. Otra alternativa es trabajar con cinco, de los cuales dos estén dentro de la categoría $\mathrm{E}^{-}$, dos en $\mathrm{E}^{+}$, y uno en $\mathrm{E}$.

\subsubsection{Tercera Capa}

Esta capa es muy costosa en términos de tiempo, cantidad de participantes y análisis, puesto que requiere de observaciones directas de distinto tipo de usuarios trabajando sobre el EVEA. Los usuarios evaluadores se dividen en dos tipos: docentes y alumnos. Para cada tipo se toman diferentes niveles de experiencia y frecuencia en el uso de Internet: novato, medio y avanzado.

- Docentes novatos

- Docentes medios

- Docentes avanzados

- Alumnos novatos

- Alumnos medios

- Alumnos avanzados

Alcanzar la mayor objetividad posible es una premisa a lo largo de todo el proceso de evaluación. Si bien no existe consenso sobre cuál es la cantidad óptima de evaluadores a incorporar, es necesario buscar un equilibrio para que sea factible de realizar, 10 como mínimo y 30 como máximo [Nie1993][Lan1999]. En tal sentido, para obtener un abanico de usuarios que cubra gran parte del espectro se seleccionan 10 usuarios, como mínimo, de los cuales 4 deben ser docentes y 6 alumnos, con el objetivo de cubrir los 2 roles de tutor y los 3 de alumno con al menos dos usuarios diferentes cada uno.

Como varios usuarios adquieren el mismo rol, es necesario realizar sesiones de trabajo diferentes para que éstos no se superpongan. Las sesiones de test deben organizarse de manera tal que sea posible generar un simulacro a partir de los escenarios propuestos. Los escenarios tienen cierta correlación entre ellos que debe respetarse para poder realizar las tareas previstas en los mismos. Por tal motivo los usuarios deben agruparse en dos sesiones de 5 integrantes ( 2 docentes y 3 alumnos), coordinadas y monitoreadas por dos observadores cada una.

\subsubsection{Cuarta Capa}

En este caso, los usuarios no están cara a cara con el observador sino que deben realizar las tareas de manera autónoma, y luego completar un cuestionario con el fin de volcar su opinión allí. Este tipo de evaluación posibilita el uso de herramientas tecnológicas para el suministro del cuestionario y el procesamiento de los resultados.

Como gran parte del trabajo recae sobre el usuario, y no hacen falta observaciones directas, los costos en término de tiempo, cantidad de participantes y análisis, son prácticamente los mismos, tanto para pocos como para muchos usuarios. Esto, al contrario que en la capa anterior, hace posible realizar una evaluación donde intervenga 
una cantidad importante de evaluadores. Por tal motivo, la muestra de usuarios puede ser numerosa. Tampoco se debe olvidar que aquí interviene fuertemente el contexto de uso, el cual puede ser muy diverso, y por lo tanto, es necesario contar con una muestra lo suficientemente significativa como para abarcar distintos contextos respecto al entorno donde se desarrolla la actividad, ubicación geográfica, recursos técnicos, horarios. Siguiendo la línea de las capas anteriores, distinguimos dos tipos de usuarios: docentes y alumnos. Para cada tipo se toman los mismos niveles de experiencia y frecuencia en el uso de Internet que los utilizados en la tercera capa. Es decir, tenemos seis clases diferentes de usuarios: docentes novatos, docentes medios, docentes avanzados, alumnos novatos, alumnos medios, y alumnos avanzados.

Cuantos más evaluadores participen, mayor será la confiabilidad de los resultados. Aquí, de alguna manera, "podemos darnos el lujo" que nos fue vedado en todas las capas anteriores respecto a la cantidad de participantes. Sin embargo, no existe consenso sobre cuál es la cantidad óptima de evaluadores a incorporar porque hay muchas variables en juego. Seguramente, cuantos más evaluadores participan mayor será la confiabilidad de los resultados, pero ello puede ir en desmedro de la rapidez para obtener los juicios así como también correr el riesgo de que en el momento de contar con la información haya dejado de ser útil. Por lo tanto hay que buscar un equilibrio que posibilite garantizar operatividad y objetividad de la evaluación. Existen diferentes propuestas, como la de Spyridakis [Spy1992], el cual estima que una prueba de usabilidad debe contar con un mínimo de 10 o 12 participantes a los efectos de obtener resultados estadísticamente válidos, Virzi [Vir1992], que propone contar con solo cuatro o cinco evaluadores, en los casos que no haga falta realizar una prueba totalmente exhaustiva, debido a que esa cantidad de evaluadores puede detectar hasta un $80 \%$ de los problemas, o Landeta [Lan1999], que establece 5 participantes como mínimo y 30 como máximo. En el caso de otros métodos, como la evaluación heurística, se estima que cada evaluador puede identificar un $35 \%$ de los problemas, lo que lleva a trabajar con un grupo de entre tres y cinco evaluadores, siempre y cuando la usabilidad no sea un factor clave para el éxito del sitio Web [Nie1993c].

\subsection{Definición de escenarios}

Los EVEA son productos Web que poseen una interfaz de similares características técnicas que cualquier otro sitio. Sin embargo, su objetivo general es muy claro y concreto: favorecer los procesos de enseñanza y aprendizaje por medio de la interacción entre docentes, alumnos y materiales didácticos en el marco de procesos educativos mediados por TIC. A partir de ello, podemos observar que ya no alcanza con un sitio que cubra requisitos puramente tecnológicos sino que debe estar pensado y diseñado de una manera tal que apunte a lograr el objetivo planteado anteriormente.

Para evaluar los EVEA desde el punto de vista de la usabilidad, es necesario adoptar la mirada del usuario, e incluso hacerlo participar del proceso. Para que la evaluación no se torne caótica deben establecerse una serie de parámetros y formas de realizarla. Una manera muy usual de evaluar sitios Web es mediante la técnica de escenarios de uso [Gaf2000][Man2002b]. Para construir los escenarios se necesita previamente definir los personajes que participarán, los objetivos que persigue cada uno con el uso del EVEA, y las tareas que deben desarrollar para alcanzar dicho objetivo.

La segunda, tercera y cuarta capa del modelo necesitan contar con ciertos escenarios de uso para poder efectuar, de manera sistemática, la evaluación del EVEA. La definición de estos escenarios debe basarse en un contexto determinado, donde los personajes principales realicen las tareas más importantes y frecuentes relacionadas con dicho 
contexto. A continuación se presentan los objetivos que presenta cada rol respecto al uso del EVEA.

\subsubsection{Personajes}

Dado que se trata de la evaluación de un EVEA, los personajes tienen dos roles bien definidos: docentes y alumnos. Estos personajes son considerados como principales, y serán el eje sobre cual girará la evaluación. En consecuencia, se utilizarán dos personajes, uno que represente el rol de usuario alumno y otro el rol de usuario docente.

Los personajes secundarios escapan al presente modelo de evaluación por la complejidad que introducirían. En esa categoría encontramos a los administradores, veedores, administrativos, invitados.

\subsubsection{Objetivos}

Se mencionó anteriormente que este modelo de evaluación en capas requiere definir escenarios de uso en el que intervienen personajes. Es importante especificar aquí el objetivo que tiene cada personaje en el uso del entorno a evaluar.

El objetivo del docente respecto del uso del EVEA está vinculado con la mediación total o parcial de su propuesta didáctica, de acuerdo a las necesidades que ha detectado. En este caso se focalizan los objetivos de: potenciar la comunicación y diálogo con los alumnos, realizar un seguimiento del aprendizaje de sus alumnos a través de la presentación de actividades mediadas por el entorno, y compartir materiales educativos pertinentes.

El objetivo del alumno se centra en construir su aprendizaje a partir de la propuesta presentada por el docente en dicho entorno. En tal sentido se focaliza la posibilidad de comunicarse con sus pares y docentes, aprender con el otro, acceder a los materiales y estudiar con ellos, y resolver actividades propuestas por el docente.

A continuación se detalla la forma en que pueden ser alcanzados estos objetivos, a partir de la presentación de las tareas involucradas para ambos roles, los escenarios en los cuales las tareas se deben llevar a cabo, y el contexto de uso dentro del cual se desempeñan los personajes.

\subsubsection{Tareas}

El modelo de evaluación de usabilidad está centrado en aquellos usuarios que son los actores principales en los procesos de enseñanza y aprendizaje. Como mencionamos anteriormente, nos referimos a los alumnos y los docentes. En función de ello, se han tomado sólo algunas de las tareas comunes que realizan en el marco de los procesos educativos mediados por TIC. Las tareas propuestas han sido agrupadas en dos categorías, y definidas de acuerdo a las funcionalidades deseables de un EVEA, que fueron explicitadas en la primera capa, sumado a las rutinas más importantes y frecuentes que realizan los usuarios.

Para lograr identificar las principales tareas que los alumnos y docentes realizan dentro de un EVEA, se llevó a cabo una consulta por e-mail, basada en un cuestionario abierto, destinado a docentes y alumnos pertenecientes a las carreras a distancia de la Facultad de Ciencias Económicas de la UNRC. El cuestionario solicitaba identificar las cinco tareas más importantes y las cinco más frecuentes sobre el EVEA SIAT. En el Anexo B se presenta el análisis realizado a partir de las opiniones de los usuarios. 
Las tareas definidas para los alumnos, acorde al análisis realizado, se listan a continuación:

- Acceder al aula virtual e informarse sobre los principales eventos, programación de actividades, últimas novedades, y cambios producidos a partir del ingreso anterior.

- Entregar un trabajo evaluable.

- Comunicarse de forma asincrónica: con su docente, con otro alumno o con todos los integrantes del aula.

- Acceder a los materiales de estudio.

- Participar de un debate.

- Acceder a sus calificaciones y devoluciones de trabajos.

- Compartir un material: con su docente, con otro alumno o con todos los integrantes del aula.

- Comunicarse mediante mensajes sincrónicos: con su docente, con uno o con varios alumnos.

- Participar de una clase virtual visualizando una presentación multimedia en forma simultánea con los demás usuarios.

- Participar de una conferencia en forma simultánea con los demás usuarios.

- Interactuar con sus compañeros de grupo.

- Elaborar un documento de forma colaborativa.

- Realizar una autoevaluación on-line.

- Realizar una evaluación on-line.

- Realizar una encuesta y acceder a los resultados.

Las tareas definidas para los docentes, acorde al análisis realizado, son las siguientes:

- Informar a los alumnos sobre los principales eventos, la programación de actividades y las novedades.

- Calificar los trabajos evaluables y realizar devoluciones.

- Comunicarse de forma asincrónica con un alumno o todos los integrantes del aula.

- Recibir y corregir un trabajo evaluable.

- Incorporar materiales de estudio al aula virtual en diferentes formatos.

- Generar y participar de un debate.

- Acceder a información sobre sus alumnos.

- Acceder al aula virtual e informarse sobre los principales cambios producidos a partir del ingreso anterior.

- Realizar evaluaciones on-line y visualizar los resultados.

- Comunicarse con uno o varios alumnos mediante mensajes sincrónicos. 
- Desarrollar una clase virtual mostrando una presentación multimedia en forma simultánea con los demás usuarios conectados.

- Desarrollar una conferencia en forma simultánea con los demás usuarios conectados.

- Confeccionar encuestas y acceder a los resultados.

\subsubsection{Contexto de uso}

Para la definición de los escenarios se utilizó como contexto a docentes y alumnos pertenecientes a una carrera universitaria de grado con orientación contable y 5 años de duración. La modalidad de dicha carrera es no presencial, mediada por TIC durante todo su desarrollo, con instancias presenciales únicamente para los exámenes parciales y finales. Estos escenarios se sitúan en una asignatura numerosa de primer año organizada en dos grupos, o comisiones, de alumnos. Cada grupo se encuentra bajo la supervisión de un docente tutor y un docente responsable a cargo de toda la asignatura. Los docentes trabajan de manera simultánea en las dos modalidades: presencial y no presencial. Tanto los alumnos como los docentes participan del curso desde diferentes lugares geográficos y físicos, utilizando recursos con características diversas. Los alumnos poseen diferente nivel de destrezas respecto de la tecnología utilizada. La elección de una materia numerosa, donde participan ingresantes, tiene que ver con el hecho de considerar usuarios que mayoritariamente utilizan el EVEA por primera vez. Además, la masividad juega un rol importante desde el punto de vista de la mediación, para lo cual el EVEA debe brindar posibilidades que faciliten la función docente.

\subsubsection{Escenarios}

La descripción de los escenarios trata de evitar, en la medida de lo posible, las referencias a herramientas específicas que posibilitan realizar las tareas dentro de un aula virtual. El objetivo es despegar a los escenarios de algún EVEA en particular para facilitar su adecuación a distintos entornos, e inclusive a la utilización de diferentes herramientas para llevar adelante ciertos procesos.

Los escenarios no son únicos, pueden especificarse con mayor nivel de detalle, o suplantarse por otros en caso de ser necesario.

A continuación plantearemos los escenarios generales que serán utilizados por los expertos en la segunda capa, y por los usuarios finales en la tercera y cuarta capa. Para lograr simpleza en la evaluación se han buscado escenarios que agrupan dos tipos de tareas: las necesarias y las de alta frecuencia [Fer2010].

Estos escenarios han sido tomados como guía para aplicar el modelo, son un ejemplo adaptado al contexto de uso de la Universidad Nacional de Río Cuarto.

El caso de los alumnos se han tomado tres: Ana, Agustín y Ailén. Cada alumno participa de tres escenarios, es decir, nueve escenarios. Respecto a los docentes se han considerado tres: Fabio en calidad de responsable, Nahuel y Julián en calidad de tutores. Para el caso del responsable de la asignatura se definieron cuatro escenarios, y tres para cada docente tutor.

\subsubsection{Escenarios de alumnos (EA)}

Se propone aquí un ejemplo de definición de escenarios tipos: 
EA1.1: Hoy es el día de inicio del cursado del cuatrimestre. Ana es una alumna de primer año que recién termina el secundario, vive en una pequeña localidad, y se dispone iniciar las clases. Para ello se levanta temprano, desayuna tranquila y luego se dirige su escritorio donde tiene su computadora personal conectada a Internet mediante dial-up. Ana utiliza computadoras desde la escuela primaria, e Internet desde que comenzó la educación secundaria. Ella desea ingresar al aula virtual de Análisis Matemático I, en la que se inscribió para cursar, para conocer a sus docentes y compañeros, y ponerse el tanto de las actividades planteadas. Luego pretende obtener los materiales necesarios para comenzar con el estudio y presentarse en el foro.

EA2.1: Hoy es el día de inicio del cursado del cuatrimestre. Agustín es un alumno de primer año que recién termina el secundario, vive en una ciudad y se dispone iniciar las clases. Por la tarde, cuando sale del trabajo se dirige a un cyber cercano. $\mathrm{Si}$ bien tiene computadora, no posee Internet en su casa. Agustín utiliza computadoras desde que comenzó la educación secundaria pero ha tenido poco contacto con Internet. Agustín desea ingresar al aula virtual de Análisis Matemático I, en la que se inscribió para cursar, para conocer a sus docentes y compañeros, y ponerse el tanto de las actividades planteadas. Luego pretende obtener los materiales necesarios para comenzar con el estudio y presentarse en el foro.

EA3.1: Hoy es el día de inicio del cursado del cuatrimestre. Ailén es una alumna de primer año que retoma sus estudios luego de varios años, vive en una villa serrana y se dispone iniciar las clases. Para ello, por la noche, mientras ayuda a hacer los deberes a sus hijos, conecta la computadora portátil a Internet mediante su celular. Ailén utiliza la computadora desde hace poco tiempo y para uso doméstico solamente. Ella desea ingresar al aula virtual de Análisis Matemático I, donde se inscribió para cursar, y así conocer a sus docentes, compañeros y ponerse el tanto de las actividades planteadas. Luego, pretende obtener los materiales necesarios para comenzar con el estudio y presentarse en el foro.

EA1.2: Ana se toma unos días para la lectura del material, lee las novedades, los mensajes del foro de presentación. En los días siguientes, mientras realiza la primera actividad, examina el calendario y envía un mensaje por correo al docente para consultar una duda. Luego de recibir respuesta, descarga un material complementario, completa la actividad y la entrega antes de la fecha de vencimiento. Ana desea saber si su trabajo está en manos del docente y le consulta sobre la posible fecha en que estará la corrección del mismo. Todo el trabajo lo hace desde su casa.

EA2.2: Agustín no tiene tiempo de analizar demasiado los materiales, los lee en los ratos libres. Comienza a resolver la actividad en su casa. Al constatar que no llegará a terminarla, antes que venza el plazo de entrega, le escribe a su docente desde un cyber, pidiéndole autorización para enviarle el trabajo fuera de fecha.

EA3.2: Ailén se dedica todas las noches al estudio. Al comenzar la lectura le surgen dudas que la llevan a escribirle un correo al docente. También ingresa al foro para conocer a sus compañeros de clase y, al ver que Ana se ha presentado en el foro, le escribe a ella para pedirle ayuda. Pasado unos días recibe respuesta de ambos, descarga un material complementario, lee las novedades y el foro, y verifica el plazo de entrega de la primera actividad. En días posteriores culmina la lectura de los materiales e inicia la resolución de la actividad. El mismo día de vencimiento, sobre la hora de entrega envía su trabajo. 
EA1.3: Ana recibe un correo de Ailén y lo contesta. Ingresa al aula virtual el día siguiente de vencido el plazo de entrega en busca de alguna novedad. Al cabo de unos días recibe la contestación del docente, la nota de aprobación de su trabajo y algunos comentarios sobre el mismo.

EA2.3: Agustín recibe autorización del docente para enviarle el trabajo fuera de fecha y lo entrega. Luego debe viajar a otra ciudad por razones laborales. Estando de viaje recibe los comentarios del docente sobre su trabajo en donde se le solicita que corrija parte del mismo. Lo hace inmediatamente y vuelve a entregarlo.

EA3.3: Ailén ingresa diariamente al aula a la espera de la corrección de su trabajo. Escribe un correo a su compañera Ana para saber si ella tiene alguna novedad. El mismo día que Ana recibe la nota de su trabajo, Ailén recibe el suyo.

\subsubsection{Escenarios de docente responsable (EDR)}

EDR1.1: Está próximo a comenzar el cursado del cuatrimestre. Fabio es el docente Responsable de la asignatura Análisis Matemático I. Por la mañana, cuando llega a la oficina de la Facultad, enciende su computadora, se conecta a Internet e ingresa al aula virtual para distribuir los alumnos inscriptos en dos grupos o comisiones de trabajo, colocar los materiales de estudio correspondientes al primer módulo de la asignatura, el calendario de actividades, y darles la bienvenida a los alumnos. Luego envía un correo a Nahuel y Julián, los tutores de cada una de las comisiones, para informarles que el aula virtual está lista para dar comienzo a las actividades.

EDR2.1: Hoy comenzó el cursado de la asignatura. Fabio ingresa al aula, y analiza el estado de situación de cada grupo. Luego envía un mensaje a Julián consultándole las razones por las cuales aún no ha ingresado aula.

EDR3.1: Fabio ingresa diariamente al aula para realizar el seguimiento de la actividad de cada grupo, lee el correo, los foros, y consulta la frecuencia de acceso de los docentes tutores. Cuando el segundo módulo está próximo a dar inicio informa a los alumnos sobre la fecha exacta.

EDR4.1: Una vez que venció el plazo de entrega de la primera actividad, Fabio analiza quienes son los alumnos que han entregado el trabajo, la nota que recibieron y los comentarios emitidos por los tutores. También informa sobre el inicio del segundo módulo y pone a disposición de los alumnos que entregaron la primera actividad los materiales correspondientes al nuevo módulo.

\subsubsection{Escenarios de docentes tutores (EDT)}

EDT1.1: Falta un día para comenzar el cursado del cuatrimestre. Nahuel, el docente Tutor del primer grupo de alumnos de Análisis Matemático I, regresa a la oficina luego de una clase de consulta, lee el correo enviado por Fabio, toma conocimiento con la bienvenida, los alumnos que tiene a cargo, el calendario de actividades, y los materiales correspondientes al primer módulo. Luego abre un foro para que los alumnos se conozcan, emite un mensaje de bienvenida con su presentación personal, y publica la actividad evaluable que los alumnos deben entregar al finalizar el módulo.

EDT1.2: Ayer comenzó el cursado del cuatrimestre. Julián, el docente Tutor del segundo grupo de alumnos de Análisis Matemático I, no se encuentra en la Facultad por estar participando de un curso en otra universidad. Desde el hotel lee 
los correos enviados por Fabio, se disculpa por la demora, toma conocimiento de la bienvenida, los alumnos que tiene a cargo, el calendario de actividades, y los materiales correspondientes al primer módulo. Luego abre un foro para que los alumnos se conozcan y emite un mensaje de bienvenida con su presentación personal. Finalmente publica la actividad evaluable que los alumnos deben entregar al finalizar el módulo.

EDT2.1: Nahuel ingresa diariamente al aula para realizar el seguimiento de sus alumnos. Verifica quienes no han accedido, así como también quienes aún no descargaron los materiales pertenecientes al primer módulo. A todos ellos les envía un correo consultando las razones y alentándolos a comenzar con el estudio. También lee el foro, los correos de Ailén y de Ana. Coloca un material complementario en el aula, responde las dudas y publica un mensaje para animar a los alumnos a consultar dudas, y recordar que pronto vencerá el plazo de entrega de la actividad.

EDR2.2: Julián no regresa aún a la universidad pero ingresa dos veces por semana al aula para saber si tiene alguna demanda de los alumnos. Lee el correo de Agustín y decide extenderle el plazo de entrega por considerar que las razones son fundadas.

EDT3.1: Nahuel ingresa al aula inmediatamente después que venció el plazo de entrega de la actividad. Comienza a corregir los trabajos y lo informa a sus alumnos.

EDT3.2: Julián ingresa al aula un día después de vencido el plazo de entrega de la actividad, comienza a corregir los trabajos, e informa a Agustín sobre la necesidad de rehacer parte de la actividad.

EDT4.1: Unos días después de iniciado el proceso de corrección, Nahuel califica los trabajos evaluados. Al trabajo de Ana le realiza un comentario destacando la excelente producción obtenida e informa a todos alumnos que ya están colocadas las notas de la actividad correspondiente al primer módulo.

EDT4.2: Unos días después de comenzar con las correcciones, Julián califica los trabajos evaluados e informa a todos alumnos que ya están colocadas las notas de la actividad correspondiente al primer módulo.

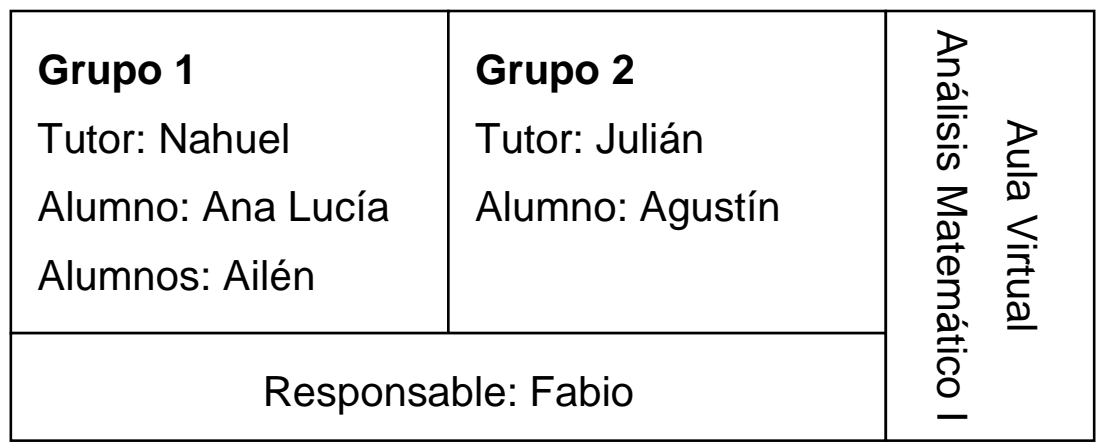




\subsubsection{Síntesis sobre los escenarios}

La definición de escenarios de uso, que resulten adecuados, es clave dentro del modelo. A partir de ellos es posible llevar a cabo la segunda, tercera, y cuarta capa de evaluación. Para construirlos es necesario conocer quiénes son los personajes involucrados, las tareas que ellos realizan con mayor frecuencia, y el contexto en que ellos se encuentran al usar el EVEA. Los escenarios pueden variar dependiendo de aquello que se pretende evaluar, ya sea una evaluación general con poca profundidad, hasta una evaluación parcial del EVEA enfocada sobre algún punto en especial. A continuación presentamos una síntesis de los escenarios desarrollados y sus componentes clave.

\subsubsection{Personajes}

Los personajes principales que se definieron son:

- Alumnos: Ana, Agustín y Ailén

- Docentes: Fabio (Responsable), Nahuel y Julián (Tutores)

\subsubsection{Tareas}

Las tareas que ellos realizan dentro del EVEA fueron clasificadas según su importancia y frecuencia, a partir de un doble análisis que contó con la opinión de un grupo de usuarios del EVEA SIAT, sumado al aporte de quienes están proponiendo el modelo. De allí surgieron las 8 (ocho) tareas consideradas como más necesarias y frecuentes para los alumnos y para los docentes.

- Tareas de los alumnos: Acceder al aula virtual e informarse. Entregar un trabajo evaluable. Comunicarse de forma asincrónica. Acceder a los materiales de estudio. Participar de un debate. Acceder a sus calificaciones y devoluciones de trabajos. Compartir un material. Comunicarse mediante mensajes sincrónicos.

- Tareas de los docentes: Informar sobre los principales eventos, programación de actividades y novedades. Calificar los trabajos evaluables y realizar devoluciones. Comunicarse de forma asincrónica. Recibir y corregir un trabajo evaluable. Incorporar materiales de estudio. Generar y participar de un debate. Acceder a información sobre sus alumnos. Acceder al aula virtual e informarse sobre los principales cambios producidos.

\subsubsection{Contexto de uso}

El contexto de uso trata de proponer situaciones diversas para que puedan estar involucrados la mayoría de los usuarios. No se pretende caracterizar a todos los usuarios sino contemplar casos que están por debajo de la media general. A raíz de ello, nos situamos en una asignatura perteneciente a una carrera universitaria de grado, con orientación contable y modalidad no presencial. Tanto los alumnos como los docentes participan del curso desde diferentes lugares geográficos y físicos, utilizando tecnología con características diversas y bajo ambientes de trabajo diferentes.

En el caso de los alumnos, Ana cursa primer año y recién termina el secundario, vive en una pequeña localidad, tiene computadora personal en su casa conectada a Internet mediante dial-up, y utiliza computadoras desde la escuela primaria, e Internet desde que comenzó la educación secundaria. Agustín es un alumno de primer año que vive en una ciudad y trabaja, tiene computadora en su casa pero accede a Internet desde un cyber 
cercano al trabajo. Ailén también cursa primer año, vive en una villa serrana, es ama de casa y tiene hijos. Ella posee computadora portátil y se conecta mediante Internet móvil.

En el caso de los docentes, Fabio es el Responsable de la asignatura, dispone de computadora e Internet en la Facultad. Nahuel es docente Tutor de uno de los grupos de alumnos, dispone de computadora e Internet en la Facultad. Julián es docente Tutor del otro grupo de alumnos, dispone computadora e Internet en la Facultad pero se encuentra realizando un curso en otra universidad durante la mayor parte del tiempo que dura el cursado.

\subsubsection{Escenarios}

A partir de las tareas se elaboraron tres escenarios para cada alumno, cuatro escenarios para el responsable de la asignatura, y cuatro escenarios para cada docente tutor. En total se propusieron 21 escenarios. La cantidad de escenarios obedece a la necesidad de plantear diferentes alternativas para que exista coherencia a la hora de poner en marcha la evaluación de la segunda capa, donde existen diferentes alternativas de acuerdo a la cantidad de evaluadores que participarán. En el caso que se opte por trabajar con sólo un experto, se utilizarán 10 escenarios, y en el caso que participen 3 ó 5 se utilizarán todos.

\subsubsection{Resumen}

\begin{tabular}{|c|c|c|c|c|c|}
\hline & Personaje & Escenario & Tarea & \multicolumn{2}{|c|}{ Contexto de uso } \\
\hline & & & & Particular & General \\
\hline \multirow[t]{4}{*}{$\begin{array}{l}\text { D } \\
\text { O } \\
\text { C } \\
\text { E } \\
\text { N } \\
\text { T } \\
\text { E } \\
\text { S }\end{array}$} & $\begin{array}{l}\text { Fabio - } \\
\text { Responsa } \\
\text { ble }\end{array}$ & EDR1.1 & $\begin{array}{l}\text { Acceder al aula virtual. } \\
\text { Dar un mensaje de bienvenida a } \\
\text { todos los alumnos. } \\
\text { Informar a todos sobre el calendario } \\
\text { de actividades del primer módulo. } \\
\text { Distribuir alumnos en comisiones de } \\
\text { trabajo } \\
\text { Incorporar los materiales de estudio } \\
\text { del primer módulo. } \\
\text { Comunicarse con los dos tutores } \\
\text { mediante correo. }\end{array}$ & \multirow{4}{*}{$\begin{array}{l}\text { Docente de primer } \\
\text { año a cargo de la } \\
\text { asignatura Análisis } \\
\text { Matemático I. } \\
\text { Ejerce la docencia } \\
\text { desde su oficina de la } \\
\text { Facultad. } \\
\text { Posee PC de } \\
\text { escritorio con Internet } \\
\text { banda ancha. } \\
\text { Poca experiencia en } \\
\text { el uso PC e Internet. } \\
\text { Accede } \\
\text { esporádicamente al } \\
\text { aula virtual. }\end{array}$} & \multirow{4}{*}{$\begin{array}{l}\text { Primer año } \\
\text { de una } \\
\text { carrera } \\
\text { universitari } \\
\text { a de grado } \\
\text { con } \\
\text { orientación } \\
\text { contable y } \\
5 \text { años de } \\
\text { duración. } \\
\text { Carrera } \\
\text { con } \\
\text { modalidad } \\
\text { no } \\
\text { presencial, } \\
\text { mediada } \\
\text { por TIC } \\
\text { durante } \\
\text { todo su } \\
\text { desarrollo, } \\
\text { con } \\
\text { instancias } \\
\text { presencial } \\
\text { es } \\
\text { únicament } \\
\text { e para los } \\
\text { exámenes } \\
\text { parciales y } \\
\text { finales. } \\
\text { Los } \\
\text { docentes } \\
\text { toman } \\
\text { contacto }\end{array}$} \\
\hline & & EDR2.1 & $\begin{array}{l}\text { Acceder al aula virtual. } \\
\text { Informarse sobre la situación de } \\
\text { cada grupo de trabajo. } \\
\text { Comunicarse con un tutor mediante } \\
\text { correo. }\end{array}$ & & \\
\hline & & EDR3.1 & $\begin{array}{l}\text { Acceder al aula virtual. } \\
\text { Realizar el seguimiento de la } \\
\text { actividad de cada grupo de trabajo. } \\
\text { Analizar la participación y frecuencia } \\
\text { de acceso de cada tutor. } \\
\text { Consultar correo. } \\
\text { Consultar foro. } \\
\text { Actualizar el calendario de } \\
\text { actividades. }\end{array}$ & & \\
\hline & & EDR4.1 & $\begin{array}{l}\text { Acceder al aula virtual. } \\
\text { Informarse sobre las actividades } \\
\text { entregadas por cada uno los } \\
\text { alumnos, calificaciones y } \\
\text { devoluciones. } \\
\text { Informar a todos sobre el calendario } \\
\text { de actividades del segundo módulo. } \\
\text { Incorporar los materiales de estudio }\end{array}$ & & \\
\hline
\end{tabular}




\begin{tabular}{|c|c|c|c|c|}
\hline & & del segundo módulo. & & \multirow{5}{*}{$\begin{array}{l}\text { por } \\
\text { primera } \\
\text { vez con el } \\
\text { EVEA. } \\
\text { Cursado } \\
\text { de una } \\
\text { asignatura } \\
\text { desde días } \\
\text { previos al } \\
\text { inicio de } \\
\text { las } \\
\text { asignatura } \\
\text { hasta la } \\
\text { finalizació } \\
\text { n del } \\
\text { primer } \\
\text { módulo. } \\
\text { Asignatura } \\
\text { con un } \\
\text { docente } \\
\text { responsabl } \\
\text { e, } \\
\text { organizad } \\
\text { a en dos } \\
\text { comisione } \\
\text { s de } \\
\text { trabajo a } \\
\text { cargo de } \\
\text { un } \\
\text { docente } \\
\text { tutor cada } \\
\text { una. } \\
\text { El docente } \\
\text { responsabl } \\
\text { e es el } \\
\text { encargado } \\
\text { de la }\end{array}$} \\
\hline \multirow[t]{4}{*}{$\begin{array}{l}\text { Nahuel - } \\
\text { Tutor }\end{array}$} & EDT1.1 & $\begin{array}{l}\text { Acceder al aula virtual } \\
\text { Informarse sobre la bienvenida, } \\
\text { programación de actividades, y } \\
\text { grupo de alumnos que tiene a cargo. } \\
\text { Acceder a los materiales de estudio. } \\
\text { Abrir un foro y agregar mensaje. } \\
\text { Consultar correo. } \\
\text { Publicar la actividad evaluable para } \\
\text { todos sus alumnos y la fecha límite } \\
\text { de entrega. }\end{array}$ & \multirow{4}{*}{$\begin{array}{l}\text { Docente de primer } \\
\text { año a cargo de los } \\
\text { trabajos prácticos de } \\
\text { la asignatura Análisis } \\
\text { Matemático I. } \\
\text { Hace docencia desde } \\
\text { su oficina de la } \\
\text { Facultad. } \\
\text { Tiene contacto } \\
\text { presencial con el } \\
\text { docente responsable } \\
\text { de la asignatura. } \\
\\
\text { Posee PC de } \\
\text { escritorio con Internet } \\
\text { con banda ancha. } \\
\text { Con experiencia en el } \\
\text { uso PC e Internet. } \\
\text { Accede } \\
\text { periódicamente al } \\
\text { aula virtual. }\end{array}$} & \\
\hline & EDT2.1 & $\begin{array}{l}\text { Acceder al aula virtual } \\
\text { Informarse sobre quienes no } \\
\text { ingresaron al aula o no descargaron } \\
\text { los materiales. } \\
\text { Enviar correo a los alumnos que no } \\
\text { han comenzado a trabajar. } \\
\text { Responder mensajes del foro. } \\
\text { Responder correo de algunos } \\
\text { alumnos. } \\
\text { Incorporar materiales de estudio } \\
\text { complementario del primer módulo. } \\
\text { Publicar un mensaje para todos los } \\
\text { alumnos. }\end{array}$ & & \\
\hline & EDT3.1 & $\begin{array}{l}\text { Acceder al aula virtual. } \\
\text { Informarse sobre la situación de } \\
\text { cada alumno. } \\
\text { Corregir trabajos. } \\
\text { Publicar un mensaje para todos los } \\
\text { alumnos. }\end{array}$ & & \\
\hline & EDT4.1 & $\begin{array}{l}\text { Acceder al aula virtual } \\
\text { Informarse sobre la situación de } \\
\text { cada alumno. } \\
\text { Calificar todos los trabajos. } \\
\text { Realizar una devolución individual. } \\
\text { Publicar un mensaje para todos los } \\
\text { alumnos. }\end{array}$ & & \\
\hline \multirow[t]{3}{*}{$\begin{array}{l}\text { Julián - } \\
\text { Tutor }\end{array}$} & EDT1.2 & $\begin{array}{l}\text { Acceder al aula virtual. } \\
\text { Consultar el correo y responder } \\
\text { mensaje al responsable. } \\
\text { Informarse sobre la programación } \\
\text { de actividades, y grupo de alumnos } \\
\text { que tiene a cargo. } \\
\text { Acceder a los materiales de estudio. } \\
\text { Abrir un foro y agregar mensaje. } \\
\text { Publicar la actividad evaluable para } \\
\text { todos sus alumnos y la fecha } \\
\text { máxima de entrega. }\end{array}$ & \multirow{3}{*}{$\begin{array}{l}\text { Docente de primer } \\
\text { año a cargo de los } \\
\text { trabajos prácticos de } \\
\text { la asignatura Análisis } \\
\text { Matemático I. } \\
\text { Hace docencia desde } \\
\text { otra ciudad por } \\
\text { encontrarse en un } \\
\text { Congreso. } \\
\text { No tiene contacto } \\
\text { presencial con el } \\
\text { resto de los docentes } \\
\text { de la asignatura. } \\
\text { Acceder a Internet } \\
\text { desde un hotel. } \\
\text { Poca experiencia en } \\
\text { el uso PC e Internet. } \\
\text { Accede dos veces } \\
\text { por semana al aula } \\
\text { virtual, no } \\
\text { periódicamente. }\end{array}$} & $\begin{array}{l}\text { programac } \\
\text { ión } \\
\text { general de } \\
\text { actividade } \\
\mathrm{s}, \mathrm{y} \\
\text { gestión de } \\
\text { materiales. } \\
\text { Los } \\
\text { docentes } \\
\text { tutores } \\
\text { están a }\end{array}$ \\
\hline & EDT2.2 & $\begin{array}{l}\text { Acceder al aula virtual } \\
\text { Informarse sobre la situación de } \\
\text { cada alumno. } \\
\text { Consultar correo y responder a un } \\
\text { alumno. } \\
\text { Extender plazo de entrega de la } \\
\text { actividad a un alumno. }\end{array}$ & & $\begin{array}{l}\text { cargo de } \\
\text { un grupo } \\
\text { de } \\
\text { alumnos o } \\
\text { comisión } \\
\text { cada uno y } \\
\text { son los }\end{array}$ \\
\hline & EDT3.2 & $\begin{array}{l}\text { Acceder al aula virtual. } \\
\text { Informarse sobre la situación de } \\
\text { cada alumno. } \\
\text { Corregir trabajos. } \\
\text { Solicitar a un alumno rehacer el }\end{array}$ & & $\begin{array}{l}\text { encargado } \\
\text { s de } \\
\text { responder } \\
\text { consultas, } \\
\text { moderar }\end{array}$ \\
\hline
\end{tabular}




\begin{tabular}{|c|c|c|c|c|c|}
\hline & & & trabajo. & & foros, \\
\hline & & EDT4.2 & $\begin{array}{l}\text { Acceder al aula virtual. } \\
\text { Informarse sobre la situación de } \\
\text { cada alumno. } \\
\text { Calificar todos los trabajos. } \\
\text { Publicar un mensaje para todos los } \\
\text { alumnos. }\end{array}$ & & $\begin{array}{l}\text { corregir, } \\
\text { calificar y } \\
\text { hacer } \\
\text { devolución } \\
\text { de las } \\
\text { actividade } \\
\text { s. }\end{array}$ \\
\hline $\begin{array}{l}\text { A } \\
L \\
U \\
M \\
N \\
O \\
S\end{array}$ & Ana & EA1.1 & $\begin{array}{l}\text { Acceder al aula virtual. } \\
\text { Informarse sobre la programación } \\
\text { de actividades y tareas a realizar. } \\
\text { Conocer a sus compañeros y } \\
\text { docentes. } \\
\text { Consultar foro y agregar un } \\
\text { mensaje. } \\
\text { Acceder a los materiales de estudio. }\end{array}$ & $\begin{array}{l}\text { Alumna de primer } \\
\text { año. } \\
\text { Recién termina el } \\
\text { secundario. } \\
\text { Vive en una pequeña } \\
\text { localidad. } \\
\text { No trabaja. } \\
\text { Estudia por la }\end{array}$ & $\begin{array}{l}\text { Primer año } \\
\text { de una } \\
\text { carrera } \\
\text { universitari } \\
\text { a de grado } \\
\text { con } \\
\text { orientación } \\
\text { contable y }\end{array}$ \\
\hline & & EA1.2 & $\begin{array}{l}\text { Acceder al aula virtual. } \\
\text { Informarse sobre la programación } \\
\text { de actividades y novedades. } \\
\text { Consultar foro. } \\
\text { Enviar un correo a su tutor. } \\
\text { Acceder a los materiales } \\
\text { complementarios. } \\
\text { Entregar un trabajo evaluable. } \\
\text { Consultar al tutor sobre la correcta } \\
\text { recepción del trabajo y posible fecha } \\
\text { de calificación. }\end{array}$ & $\begin{array}{l}\text { mañana en su casa, } \\
\text { con su PC de } \\
\text { escritorio con Internet } \\
\text { dial-up. } \\
\text { Con experiencia en el } \\
\text { uso PC e Internet. } \\
\text { Dispone de tiempo } \\
\text { para estudiar. } \\
\text { Accede } \\
\text { periódicamente al } \\
\text { aula virtual. }\end{array}$ & $\begin{array}{l}5 \text { años de } \\
\text { duración. } \\
\text { Carrera } \\
\text { con } \\
\text { modalidad } \\
\text { no } \\
\text { presencial, } \\
\text { mediada } \\
\text { por TIC } \\
\text { durante } \\
\text { todo su }\end{array}$ \\
\hline & & EA1.3 & $\begin{array}{l}\text { Consultar correo y responder a } \\
\text { Ailén. } \\
\text { Acceder al aula virtual. } \\
\text { Informarse sobre la programación } \\
\text { de actividades y novedades. } \\
\text { Acceder a la calificación y } \\
\text { devolución de su trabajo. }\end{array}$ & & $\begin{array}{l}\text { desarrollo, } \\
\text { con } \\
\text { instancias } \\
\text { presencial } \\
\text { es } \\
\text { únicament } \\
\text { e para los }\end{array}$ \\
\hline & Agustín & EA2.1 & $\begin{array}{l}\text { Acceder al aula virtual. } \\
\text { Informarse sobre la programación } \\
\text { de actividades y tareas a realizar. } \\
\text { Conocer a sus compañeros y } \\
\text { docentes. } \\
\text { Consultar foro y agregar un } \\
\text { mensaje. } \\
\text { Acceder a los materiales de estudio. }\end{array}$ & $\begin{array}{l}\text { Cursado de una } \\
\text { asignatura desde el } \\
\text { inicio hasta la } \\
\text { finalización de la } \\
\text { primera actividad. } \\
\text { Alumno de primer } \\
\text { año. } \\
\text { Recién termina el }\end{array}$ & $\begin{array}{l}\text { exámenes } \\
\text { parciales y } \\
\text { finales. } \\
\text { Los } \\
\text { alumnos } \\
\text { toman } \\
\text { contacto } \\
\text { por }\end{array}$ \\
\hline & & EA2.2 & $\begin{array}{l}\text { Acceder al aula virtual. } \\
\text { Enviar un correo a su tutor. }\end{array}$ & $\begin{array}{l}\text { secundario. } \\
\text { Vive en una ciudad, }\end{array}$ & $\begin{array}{l}\text { primera } \\
\text { vez con el }\end{array}$ \\
\hline & & EA2.3 & $\begin{array}{l}\text { Acceder al aula virtual. } \\
\text { Consultar correo y leer mensaje del } \\
\text { tutor. } \\
\text { Entregar trabajo evaluable fuera de } \\
\text { plazo. } \\
\text { Acceder a comentario del tutor } \\
\text { sobre su trabajo. } \\
\text { Entregar nuevamente trabajo } \\
\text { evaluable fuera de plazo. }\end{array}$ & $\begin{array}{l}\text { trabaja todo el día y } \\
\text { estudia por la noche. } \\
\text { Viaja mucho por } \\
\text { razones laborales. } \\
\text { Tiene PC en su casa } \\
\text { sin Internet, accede } \\
\text { desde cyber. } \\
\text { Con experiencia en el } \\
\text { uso PC, y poca en } \\
\text { Internet. } \\
\text { No dispone de } \\
\text { mucho tiempo para } \\
\text { estudiar. } \\
\text { Accede pocas veces } \\
\text { al aula. }\end{array}$ & $\begin{array}{l}\text { EVEA. } \\
\text { Cursado } \\
\text { de una } \\
\text { asignatura } \\
\text { desde el } \\
\text { inicio } \\
\text { hasta la } \\
\text { finalizació } \\
\text { n del } \\
\text { primer } \\
\text { módulo. } \\
\text { Asignatura } \\
\text { con un } \\
\text { docente } \\
\text { responsabl }\end{array}$ \\
\hline & Ailén & EA3.1 & Acceder al aula virtual. & Cursado de una & e, \\
\hline
\end{tabular}




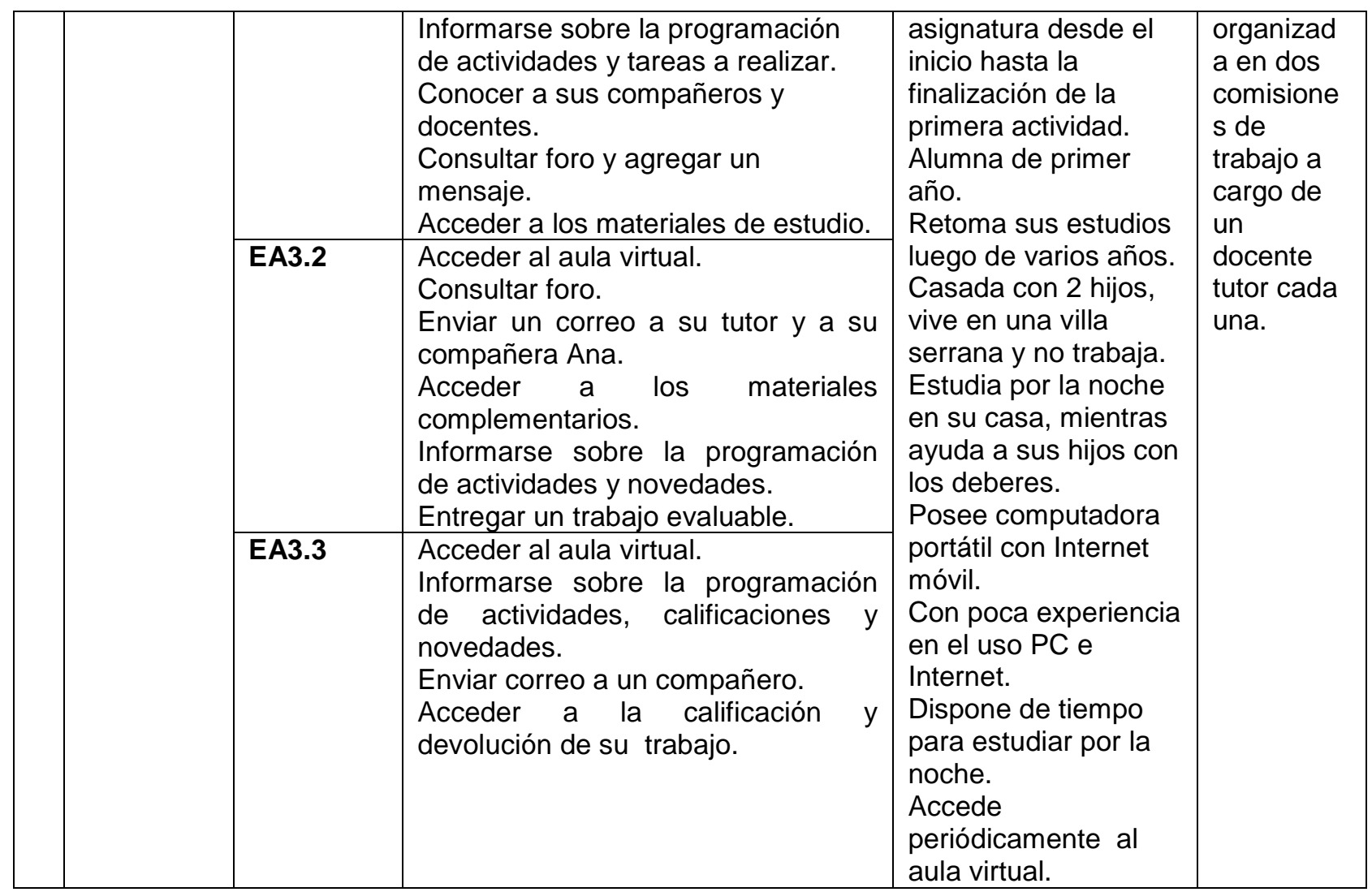

Tabla 6 - Personajes, escenarios, tareas y contextos de uso

Los escenarios, junto a todos los elementos que los componen, pueden ser ajustados acorde a las necesidades de la evaluación para el contexto propio de uso y el producto en particular. El modelo busca ser lo más abarcativo posible, pero seguramente cada contexto requerirá adaptaciones.

\subsection{Desarrollo de MUsa}

A continuación se desarrolla en detalle MUsa, el Modelo centrado en la Usabilidad para evaluación de EVEA propuesto en esta tesis, analizando cada una de sus capas.

\subsubsection{Primera capa}

Tanto la construcción como la selección de un EVEA implican la toma de decisiones de tipo técnico y de carácter educativo [DeB2000]. Si bien las cuestiones técnicas no son condición suficiente para garantizar la calidad de los procesos de enseñanza y aprendizaje, está claro que son una condición necesaria, puesto que las mismas deben favorecer, y no obstaculizar, el modelo educativo y las decisiones metodológicas que se deseen implementar.

En esta primera capa, la más general del modelo de evaluación, nos centramos en el análisis de las características funcionales de los EVEA, donde se consideran cuestiones técnicas así como también las relacionadas a las facilidades para la organización académica y flexibilidad pedagógica. En este nivel no analizaremos la forma ni la calidad con que se pueden llevar a cabo los procesos educativos, sino que más bien intentaremos determinar cuál es la riqueza que posee el EVEA desde el punto de vista de sus herramientas y posibilidades. Tampoco se abordarán cuestiones relacionadas con la creación de contenidos por entender que los EVEA no están directamente focalizados hacia la edición de materiales on-line o creación de objetos de aprendizaje, sino a la 
planificación, implementación, y evaluación de los procesos de enseñanza y aprendizaje [Fer2009b.

A este nivel toma especial relevancia la versatilidad del entorno para adaptarse al desarrollo de distintos escenarios formativos (cursos, grupos de cursos, carreras, comunidades virtuales, etc.) porque la decisión de hacer uso de un EVEA, en general, está condicionada por el tipo de institución académica de que se trate, sus modos de funcionamiento, estructura y organización. También es importante evaluar la forma en que puede dar soporte a diferentes modalidades educativas, sean éstas presenciales, con la incorporación de alguna instancia mediada (extended learning), completamente a distancia, o mixtas (blended learning), y a diferentes enfoques de enseñanza y aprendizaje. Para analizar estas características de manera integral es necesario contar con un grupo plural de especialistas provenientes de diferentes disciplinas. En especial son necesarios expertos en tecnologías de la información y la comunicación para abordar los aspectos puramente tecnológicos, y por otra parte, expertos en educación que centren su mirada sobre los aspectos pedagógicos y didácticos [Fer2009b].

Este tipo de evaluación ha sido muy común y recurrente, fundamentalmente a partir del año 2000, cuando comenzaron a proliferar un gran número de herramientas orientadas a favorecer el desarrollo de propuestas educativas on-line. En el capítulo 5 se analizaron los modelos de evaluación de EVEA más importantes. Del análisis de cada uno de ellos se advierte que:

- No existe acuerdo respecto a la clasificación o criterios a tener en cuenta para evaluar los EVEA.

- Existen criterios y clasificaciones comunes en muchos de los modelos.

Nuestra primera capa de evaluación pondrá énfasis sobre las coincidencias entre los modelos estudiados a efectos de construir un instrumento de evaluación general, centrado en los componentes tecnológicos de los EVEA, pero sin perder de vista el componente pedagógico, ya que ambos son determinantes al momento de analizar un entorno particular [DeB2005].

Se trata de un análisis descriptivo que puede efectuase a través de la documentación proporcionada por el producto, complementada con pruebas de instalación, y puesta de funcionamiento de aulas virtuales de demostración.

\subsubsection{Qué evaluar}

Para realizar un abordaje general analizaremos la flexibilidad del entorno desde el punto de vista tecnológico, organizativo, y pedagógico/didáctico, incluyendo además el nivel de estandarización y experticia necesaria de los usuarios. 

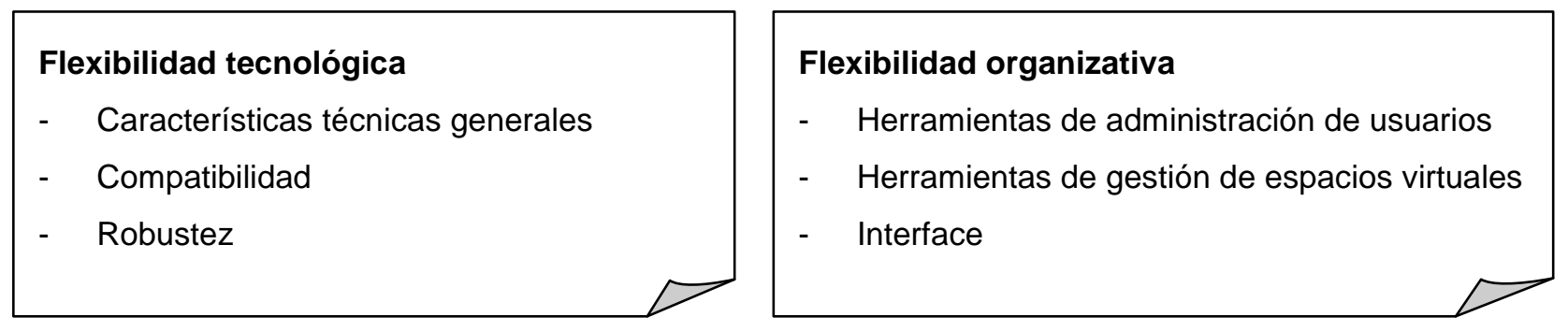

$$
\begin{aligned}
& \text { Flexibilidad pedagógico/didáctica } \\
& \text { - Herramientas de información } \\
& \text { - Herramientas de comunicación } \\
& \text { - Herramientas de colaboración } \\
& \text { - Herramientas para la evaluación } \\
& \text { - Herramientas para el alumno }
\end{aligned}
$$

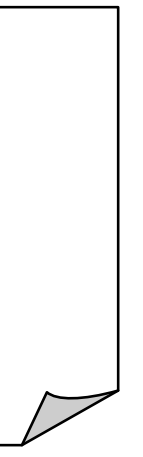

$$
\begin{aligned}
& \text { Estandarización } \\
& \text { - } \quad \text { World Wide Web } \\
& \text { - } \quad \text { e-learning }
\end{aligned}
$$

Figura 21 - Categorías de análisis

\subsection{Flexibilidad tecnológica}

Entendemos como flexibilidad tecnológica a las fortalezas y debilidades que posee el EVEA desde el punto de vista de sus características técnicas generales, compatibilidad con hardware y software, y robustez. Las características técnicas son uno de los aspectos clave que debemos tener en cuenta a la hora de seleccionar las herramientas que vamos a utilizar. Estas características deben adaptarse a las necesidades y posibilidades de cada organización o institución que decide utilizar un entorno de aprendizaje basado en redes [DeB2005]. Analiza en primer lugar las características técnicas principales del entorno en relación a sus antecedentes, potencial, tecnología en la cual está basado, requerimientos de software y de hardware, licencias, servicio y soporte técnico, seguridad, modo de acceso, compatibilidad y robustez.

\subsection{Flexibilidad organizativa}

La flexibilidad organizativa pone el acento en cuestiones administrativas y de interfaz. La administración es un punto crítico para tener éxito en la implantación del sistema. Este tipo de flexibilidad es muy importante porque puede reducir drásticamente los tiempos destinados a la administración, hacer más eficiente la puesta en funcionamiento de cada una de las instancias virtuales de formación, solucionar rápidamente problemas durante el desarrollo de las mismas, adaptar la interfaz a las necesidades institucionales, y posibilitar que, al menos, parte de las tareas administrativas puedan ser llevadas a cabo por usuarios que dispongan de mínimos conocimientos técnicos, de programación o administración de base de datos. Se consideran aquí las posibilidades para configurar perfiles de usuarios, altas, bajas, búsqueda, asignación y acceso de los mismos a sus respectivos cursos, o aulas virtuales. También se analizan las capacidades del entorno para gestionar, copiar y replicar espacios virtuales, obtener información sobre ellos, asignarle usuarios con perfiles y privilegios de acceso. Por último se tiene en consideración aspectos relacionados con la interfaz general del software, las posibilidades de personalización, ayudas, y modos de visualización. 


\subsection{Flexibilidad pedagógico/didáctica}

En esta categoría hacemos referencia a las funcionalidades que el entorno provee a docentes y alumnos para el desarrollo de los procesos de enseñanza y aprendizaje. Está centrada en el contexto particular de un aula virtual, es decir, un espacio específico para el desarrollo de una instancia educativa. Se trata de una de las flexibilidades más importantes porque está orientada al análisis del corazón del entorno, es decir, la riqueza que brinda para adaptarse a las diferentes propuestas pedagógicas y modalidades didácticas. Para un mejor detalle se han considerado diferentes tipos de herramientas clasificadas de la siguiente manera: información, comunicación, colaboración, evaluación, y específicas para el alumno. Las herramientas de información son las que ayudan a organizar las cuestiones metodológicas de un curso. En este sentido se considera importante poseer herramientas para explicitar la agenda de un curso, novedades ocurridas durante el transcurso del mismo, alertas o anuncios personalizados, pizarrón virtual, glosario de términos, información general, índice y presentación de los contenidos. Las herramientas de comunicación interpersonal son uno de los pilares fundamentales dentro de los EVEA, ya que posibilitan el intercambio de información, el diálogo y discusión entre todas las personas implicadas en el proceso, contemplando diferentes tipos de comunicación: uno a uno, uno a muchos, muchos o muchos [Har1990]. En particular, a las herramientas de comunicación las clasificamos de acuerdo a la necesidad temporal de participación de los usuarios, es decir, asincrónicas o sincrónicas. También contemplamos las herramientas que posibilitan la colaboración e interacción entre docentes y alumnos y entre los propios alumnos, y que facilitan a su vez el trabajo colaborativo a través de diferentes aplicaciones que permiten compartir información, trabajar con documentos conjuntos, etc. [DeB2006]. En lo que respecta a las herramientas para evaluación se han contemplado las que posibilitan la generación de ejercicios de evaluación, auto-evaluación, y encuestas on-line, aquellas que permiten la realización y entrega de actividades off-line o deberes, las relacionadas con la calificación y puntuación de los alumnos, las que facilitan la personalización del aprendizaje, las que se refieren a la monitorización y seguimiento de la actividad de los alumnos, y aquellas para el acceso a informes referentes a las calificaciones, ejercicios y actividades realizadas. Por último, las de apoyo al alumno involucran herramientas específicas para facilitar el proceso de aprendizaje, como por ejemplo la posibilidad de manipular los materiales, facilidad para obtener información sobre su progreso, la creación de un sitio Web personal o facilidades para almacenar sus trabajos y materiales en un espacio virtual propio.

\subsection{Estandarización}

Cualquier producto que pretenda ser de calidad debe contar con altos niveles de estandarización. Los productos software no son la excepción, y menos aún aquellos que se basan exclusivamente en la Web. El proceso de estandarización de la Web ha convergido hacia aquellos que fueron propuestos por la W3C. En particular son de interés para nuestro trabajo los estándares de la W3C orientados a la validez, accesibilidad e internacionalización del entorno. La validez está relacionada con el lenguaje que permite la generación de contenidos para la Web (XHTML) y las hojas de estilo (CSS). La accesibilidad (WCAG) se ocupa de analizar que el acceso a la Web sea lo menos restrictivo posible y tenga en cuenta a la mayoría de usuarios, independientemente de sus capacidades. La internacionalización está relacionada con el uso de pautas y códigos de índole general que puedan ser entendidos sin problemas por usuarios provenientes de otras culturas, idiomas, edades, etc. 


\subsubsection{Qué y cómo evaluar}

En función de las categorías de análisis expresadas anteriormente, la primera capa de MUsa plantea evaluar los EVEA siguiendo los criterios presentados en el anexo A.

La forma en que se evaluarán dichos criterios será mediante la aplicación de diferentes métodos y técnicas, también presentados en el anexo A. En el caso de la flexibilidad tecnológica no se tiene un método de evaluación de usabilidad que se ajuste adecuadamente. Ello se debe al tipo de características que deben analizarse: antecedentes, potencial, tecnología, licencia, seguridad, acceso, compatibilidad, y robustez. La evaluación de dichas características puede realizarse mediante un cuestionario completado a partir de la documentación disponible. Tanto la flexibilidad organizativa como la flexibilidad pedagógico/didáctica requieren al evaluador situarse en el rol de hipotético usuario para analizar si están dadas ciertas funcionalidades dentro del EVEA. Por tal motivo, el método de inspección de características resulta pertinente para la evaluación de flexibilidad organizativa y pedagógico/didáctica. Este método puede aplicarse mediante la técnica de cuestionario de tipo mixto.

Por último se encuentra la estandarización, donde es imprescindible contar con documentación técnica y verificar, una por una, las interfaces del EVEA mediante la ayuda de alguna herramienta específica. Si bien las herramientas de evaluación automática proveen una forma rápida y sencilla de realizar el análisis, no son suficientes para conocer el grado de cumplimiento real de las recomendaciones de diseño. Por otro lado, algunas de las puntuaciones obtenidas con las herramientas de evaluación están condicionadas a la supervisión de un experto, ya que no es posible automatizar ciertas comprobaciones. Aunque una página Web responda al estándar, puede tener deficiencias al momento de presentar el contenido, con lo cual deberá realizarse un análisis utilizando diferentes navegadores y versiones de los mismos. Por ello es necesario complementar la evaluación con el juicio personal de un experto, es decir, combinar técnicas manuales y automáticas. El método de inspección de estándares se presenta como adecuado para realizar este proceso debido a que se trata de un método en el cual un experto chequea la interfaz y evalúa si cumple con los estándares que rigen en la Web. Las herramientas de verificación de estándares Web y de accesibilidad que funcionan on-line pueden ayudar al experto en este proceso. En el primer caso pueden utilizarse los servicios provistos por la W3C como Markup Validation Service, para validar código XHTML, CSS Validator Service, para validar hojas de estilo en cascada, y Link Checker, para buscar enlaces rotos [W3C2011]. Para el segundo caso existen una serie de herramientas muy utilizadas como TAW, WAVE, HERA O WAC [TAW2010][WAV2010][HER2010][WAC2010]. La comprobación de estándares de e-learning puede realizarse mediante la importación y exportación de paquetes utilizando un aula virtual de prueba, y mediante la información que se brinda en la documentación del EVEA.

\subsubsection{Forma de aplicación}

Como se mencionó, para esta primera capa se propone realizar una evaluación mixta, que integre y sintetice los métodos de inspección de características y de estándares, así como la técnica de cuestionario. En tal sentido se deben llevar a cabo cuatro fases: planificación, puesta en marcha, evaluación y cierre. La fase de planificación permitirá tomar decisiones respecto a la cantidad de evaluadores que participarán, experticia de cada uno, elección de un laboratorio de usabilidad, selección de herramientas de soporte y documentación, y puesta a punto de una versión operable del EVEA a evaluar. La puesta en marcha determina la secuencia de actividades a realizar por los expertos antes de comenzar con la evaluación propiamente dicha. La evaluación es el punto central del 
proceso donde los expertos analizan el EVEA desde el punto de vista de la usabilidad. EI cierre permite obtener el informe final con la opinión de los expertos.

\section{Planificación}

i. Definición de la cantidad de evaluadores-expertos, perfil de cada uno y selección de los mismos.

Como se mencionó anteriormente, deben seleccionarse cuatro evaluadores con los siguientes perfiles:

\section{- Dos especialistas en educación: EE1 y EE2 \\ - Dos especialistas en tecnología: ET1 y ET2}

ii. Elección de un laboratorio de usabilidad.

Dependiendo de los recursos disponibles es posible poner en marcha la sesión de evaluación en un laboratorio de usabilidad real, o generar las condiciones necesarias dentro de un aula con computadoras $u$ oficina que permita albergar a los expertos. El lugar elegido debe permitir a los expertos trabajar con tranquilidad y comodidad, facilitando la concentración y evitando distracciones. Para este caso no es necesario recrear un ambiente real, de ello nos ocuparemos en las siguientes capas.

\section{iii. Puesta a punto del EVEA}

A efectos que cada uno de los evaluadores pueda realizar el análisis del entorno virtual, éste debe encontrarse instalado en un servidor y disponible para ser accedido para su evaluación desde distintas computadoras. Sin embargo, esto solo no es suficiente ya que además debe recrearse, aunque sea mínimamente, un ambiente de trabajo dentro del EVEA. Por ello, es necesario montar y configurar una o varias aulas virtuales dentro de las cuales los expertos puedan desenvolverse sin inconvenientes.

iv. Selección de herramientas de soporte y documentación

Para realizar el análisis del EVEA es necesario seleccionar un conjunto de herramientas básicas y de soporte para la evaluación. Dentro de las herramientas básicas encontramos principalmente a los navegadores. Es recomendable utilizar más de un navegador y versión del mismo. En julio de 2010 sólo tres navegadores acaparaban las preferencias de más del $90 \%$ de los usuarios: Internet Explorer (61\%), Firefox (23\%) y Chrome (7\%) [GMS2010]. Esta tendencia se mantiene aunque los porcentajes varían, siendo Internet Explorer y Firefox quienes por el momento dominan ampliamente. Las versiones son muy importantes también, siendo recomendable evaluar el EVEA con al menos dos de ellas. Las versiones más utilizadas en julio de 2010 eran: Internet Explorer 8 (23\%), Internet Explorer 6 (20\%), Firefox 3.5 (15\%), Internet Explorer 7 (14\%), Firefox 3.6 (5\%), Chrome 4.0 (5\%), Firefox 3.0 (4\%) [GMS2010]. Por tal motivo deberían seleccionarse al menos las dos versiones más utilizadas de cada navegador elegido. Esto permite abarcar una buena muestra, ya que el tiempo promedio en que los usuarios demoran en actualizar la versión de su navegador es de aproximadamente un año [Nie2000], y cada vez menor. También es necesario disponer de algún procesador de texto o herramienta on-line que permita registrar la evaluación. Como herramientas de soporte resultan indispensables aquellas que ayudan a evaluar estándares. En este sentido son 
muy útiles los plugins disponibles en varios navegadores para evaluar la adecuación de cada página a las normas internacionales de la W3C (XHTML, CSS, WCAG) o los sitios Web dedicados a analizar éstas normas como W3C HTML Validator Service, W3C CSS Validator Service, TAW, HERA, o Bobby [Tor2004]. En nuestro caso, los plugins resultan más apropiados que los sitios Web de análisis porque permiten evaluar las páginas del EVEA a medida que se navega por ellas.

En tal sentido se proponen utilizar las siguientes herramientas durante la evaluación:

- Compatibilidad con navegadores y visibilidad para usuarios con visión reducida: se deben utilizar por los menos los 6 navegadores y versiones que figuran primeros en el ranking de uso de los navegadores, al momento de realizar la evaluación. Por ejemplo, si la evaluación hubiera sido realizada a mediados de 2010, podrían haberse seleccionado: Internet Explorer 8, Internet Explorer 6, Firefox 3.5, Internet Explorer 7, Firefox 3.6, y Chrome 4.0 [GMS2010]. Para reducir la cantidad de navegadores en los cuales testear puede utilizarse la herramienta IETester que posibilita testear las páginas Web en diferentes versiones de Internet Explorer a la vez. Para analizar el nivel de visibilidad de usuarios con baja visión o ceguera pueden utilizarse herramientas libres como ASES [ASE2011] que posibilita simular baja visión, o extensiones para Mozilla Firefox como Fangs o eDesigner, las cuales crean una representación textual de la página Web similar a como lo haría un lector de pantalla.

- Adecuación al estándar XHTML de la W3C: el validador oficial del W3C denominado Markup Validation Service.

- Adecuación al estándar CSS de la W3C: el validador oficial del W3C denominado CSS Validation Service.

- Adecuación al estándar WCAG, 1.0 o 2.0: el validador de normas WCAG denominado TAW3.

v. Definición de la hoja de ruta

La aplicación de los cuestionarios requiere navegar por muchas páginas del EVEA, y en particular por las aulas virtuales configuradas para su evaluación. Al tratarse de entornos concebidos como un portal, el diseño de las páginas conserva partes en común, y por lo tanto la inspección de solo algunas de ellas posibilita la obtención de un pantallazo sobre las virtudes y falencias en el diseño general de las mismas. Por otro lado, las estadísticas realizadas en el EVEA SIAT, sobre 6.000 usuarios de la UNRC, en el período agosto/09 - agosto/10, muestran que el promedio de páginas por visita ronda las 7,5 páginas [Thü2010]. Por esta razón, sugerimos confeccionar una hoja de ruta de navegación compuesta 8 páginas, como para tener una mirada general y evitar que el proceso de inspección de estándares resulte tedioso y lleve demasiado tiempo. La hoja de ruta solo se aplica para el análisis de los estándares, no para evaluar la flexibilidad tecnológica, organizativa y pedagógico/didáctica.

\section{Puesta en marcha}


vi. Entrenamiento de los evaluadores

El sitio Web a evaluar está orientado a facilitar la comunicación pedagógica entre docentes y alumnos. Por tal motivo, los expertos, en educación o en tecnología, que no posean conocimientos sobre EVEA, deben recibir asesoramiento previo sobre las características principales del mismo. De esta manera lograremos que la evaluación sea efectiva.

vii. Designación de la evaluación a realizar por cada especialista

Uno de los especialistas en tecnología será el encargado de evaluar la flexibilidad tecnológica, y el otro los estándares. Los dos especialistas en educación tendrán a su cargo la evaluación de la flexibilidad organizativa y pedagógico/didáctica.

- EE1: flexibilidad organizativa y pedagógico/didáctica

- EE2: flexibilidad organizativa y pedagógico/didáctica

- ET1: flexibilidad tecnológica

- ET2: estándares

viii. Presentación de los cuestionarios y las herramientas a los evaluadores

En esta instancia se deben entregar los instrumentos de evaluación (cuestionarios) a los expertos y despejar las dudas que se presenten. Luego deben proveerse todas las herramientas (navegadores, validadotes, etc.) para realizar la evaluación.

\section{Evaluación}

ix. Análisis del EVEA

En esta fase se integran los métodos de inspección de características e inspección de estándares. Para ello, a partir del análisis de la documentación del EVEA, así como de la navegación realizada dentro del mismo, se analiza la interfaz y se comprueba la dificultad o imposibilidad de alcanzar las características y estándares propuestos. Tales características y estándares se explicitan en los cuestionarios provistos a los expertos.

Los expertos toman los cuestionarios correspondientes y los completan analizando el entorno desde el punto de vista de la usabilidad, utilizando las herramientas provistas. Esta evaluación puede tener una duración aproximada de 1 a 2 horas.

La evaluación de flexibilidad tecnológica, organizativa y estándares requiere que los evaluadores adopten un rol de administrador o webmaster, que le posibilite tener acceso pleno a todo el EVEA, y permisos suficientes para realizar modificaciones dentro del mismo.

Para el caso particular de la evaluación de flexibilidad pedagógico/didáctica es necesario que el EVEA sea analizado desde, por lo menos, dos miradas diferentes: el que enseña y el que aprende. Por tal motivo, los especialistas en educación deben cubrir ambas posibilidades, es decir, adoptar el rol de docentes y de alumnos.

Para la inspección de estándares, los expertos deberán recorrer varias veces el aula virtual, utilizando diferentes navegadores y las herramientas de validación 
seleccionadas. Para ello se sugiere definir la hoja de ruta de navegación compuesta por 8 páginas.

\section{Cierre}

\section{x. Informe}

Los evaluadores realizan una puesta en común a partir de los cuestionarios suministrados, debaten y elaboran un único informe donde quede reflejado el análisis realizado por cada uno de ellos, cumplimiento o no de características y estándares, sumado a los acuerdos y desacuerdos alcanzados.

En el anexo A se presentan los instrumentos específicos para la evaluación completa de la primera capa.

\subsubsection{Segunda capa}

La segunda capa está orientada a evaluar la forma en que el EVEA interactúa con el usuario, la interfaz que presenta, y el modo en que permite realizar las tareas básicas. En la actualidad, uno de los métodos más utilizados para este tipo de evaluación es el método de inspección, y particularmente la evaluación heurística y el recorrido cognitivo. Ambos métodos son generales y se utilizan para evaluar la interfaz de cualquier ambiente Web. Sin embargo, existen algunas consideraciones a tener en cuenta. En primer lugar, no debemos perder de vista que la evaluación heurística nació cuando el diseño de páginas Web se hacía de manera artesanal, con desarrolladores poco preparados, y escasas herramientas de producción. Hoy en día existen muchos ambientes de diseño Web que posibilitan la generación de contenido respetando las reglas básicas de diseño. Sumado a esto, los EVEA proveen una estructura que es enriquecida mediante el aporte de los docentes y alumnos a lo largo de todo el trayecto formativo, sin perder por ello la coherencia en el diseño, ya que el mismo entorno se encarga de garantizarlo. Dada la madurez que ha alcanzado el diseño Web, y los entornos virtuales, ignoraremos ciertas heurísticas o subheurísticas básicas. En segundo lugar, el recorrido cognitivo está pensado para evaluaciones de productos donde se conocen con precisión las acciones necesarias para realizar cada tarea. Sin embargo, nosotros no conocemos con exactitud las acciones del EVEA hasta tanto lo seleccionemos. En consecuencia, no podemos proponer al experto una serie concreta de acciones con la respuesta esperada, pero sí es posible presentar un escenario con una serie de tareas generales, que podrían ser completadas a través de diferentes acciones en función de las posibilidades ofrecidas por el entorno. Por ello, entendemos que pueden incorporarse estos dos métodos a nuestro modelo contemplando el dominio de aplicación, es decir, los entornos virtuales.

Ambos métodos poseen una serie de similitudes respecto a la utilización de expertos, escenarios para los distintos roles de usuarios, y preguntas que debe hacerse el evaluador durante la aplicación. Producto de estas coincidencias estimamos conveniente conjugarlos para efectuar la evaluación de la interfaz desde ambos puntos de vista, pero fundamentalmente desde la evaluación heurística. El especialista debería transitar una serie de escenarios de uso adoptando distintos personajes, navegando por las interfaces respectivas a los fines de determinar el grado en que son respetadas las heurísticas, tanto desde el punto de vista de los propósitos como desde los objetivos de los usuarios de un EVEA [Fer2011].

Una parte del proceso de evaluación heurística involucra la confección de un informe con la lista de problemas encontrados y su explicación de acuerdo a los principios de usabilidad, ordenados de acuerdo al grado de gravedad. Esto es necesario en aquellos 
casos donde el método se utiliza como parte del proceso de desarrollo del producto. Como nuestro modelo está orientado a la evaluación de productos desarrollados o nuevas versiones, los evaluadores solo determinarán cuál es, a su criterio, la conformidad alcanzada por cada heurística y realizarán un comentario que justifique tal decisión.

Para esta capa es necesario definir las heurísticas y subheurísticas a evaluar, pero sin olvidar que, si bien existen principios generales, cada sector suele tener sus propias normas o convenciones que se ven reflejadas en la interfaz de sus sitios y en la forma de trabajo de sus usuarios. Por tal motivo las heurísticas están organizadas en dos niveles de evaluación, uno general, orientado a la tarea, y otro particular, orientado al diseño [Vil2003]. Las heurísticas y subheurísticas forman parte de un núcleo básico obtenido en cada capa a partir del análisis de las propuestas realizadas por los autores más importantes en la materia [Fer2007b]:

- Evaluación de alto nivel orientada a la tarea: examina el aspecto y comportamiento desde el punto de vista de las tareas y objetivos propuestos por los escenarios de uso. Las heurísticas involucradas son:

\section{- Complejidad}

Dificultad u obstáculos encontrados.

\section{- Visibilidad}

Diseño natural. Información de contexto y orientación. Acciones posibles en cada momento. Información justa y necesaria para cada tarea. Jerarquización. Señales que indiquen de manera natural lo que se debe hacer. Ayuda de forma implícita.

- Intuitividad

Proporcionar un buen modelo conceptual. Reducir la necesidad de recordar. Incentivar el reconocimiento. Posibilitar búsquedas.

\section{Topografía natural}

Metáforas. Analogías con el mundo real. Familiaridad. Claridad. Objetos autoexplicativos.

- Evaluación en detalle orientada al diseño: analiza los aspectos concretos del conjunto de interfaces provistas por el EVEA para completar las tareas. Contempla las siguientes heurísticas:

\section{- $\quad$ Productividad}

Facilidad de realización de tareas habituales. Reducción del número de interacciones a usuarios frecuentes o expertos. Herramientas para trabajo masivo. Recordatorios o avisos de cambios producidos.

\section{- Retroalimentación}

Informar el resultado de las acciones. Informar los resultados exitosos en forma diferente a los fracasos. Respuesta modesta ante acciones frecuentes y de poca importancia, y elocuente ante acciones infrecuentes e importantes.

\section{- $\quad$ Control por parte del usuario}

Participación e interacción con el sistema. Autonomía. Predicción de los efectos de los actos realizados. Control del sistema en todo 
momento. Libertad para actuar. Reconocimiento de sucesos. Salidas distinguibles. Prevención de errores.

- $\quad$ Reversibilidad y manejo del error

Cancelación, revocación de acciones. Prevención de errores. Detección de errores. Reconocimiento del error. Mensajes de error visibles y claros. Mecanismos de recuperación y solución ante el error. Puntos de salida. Contacto con asistencia.

\section{- Diseño y organización}

Diseño natural. Edición con posibilidad de ver el aspecto real. Anticipación a las necesidades. Legibilidad. Interfaz visible. Mostrar trabajo pendiente. Acciones relacionadas agrupadas. Página principal como sumario. Información relevante únicamente. Reducción del número de imágenes. Información importante en la parte superior. Uso de lenguaje simple. Párrafos breves. Enlaces visibles. Información importante resaltada. Información relacionada agrupada. Longitud de página acotada. Ausencia de enlaces rotos. Mapa del sitio. Fácil exploración. Diseño general uniforme y atractivo. Ausencia de distractores. Colores armónicos. Tamaño de fuente relativo.

\section{- Consistencia}

Disposición precisa y jerárquica. Título significativo en el navegador. Enlace que refleje el título. Similares términos para similares ítems. Hipervínculos claros. Iconos entendibles. Secuencias constantes de acciones se repiten en situaciones similares. Misma terminología en avisos, menús, y pantallas de ayuda. Comandos constantes se emplean en todas partes del mismo modo. Normas y convenciones usuales de la Web en cuanto a íconos, botones, imágenes, ventanas y diálogos.

- $\quad$ Ayuda y documentación

Documentación suficiente. Ayuda en línea y orientada a las acciones del usuario. Facilidad de búsqueda. Ayuda contextual. Manuales. Foros. Soporte técnico permanente.

\section{- Estándares}

Adecuación a las especificaciones W3C. Transparencia respecto de la plataforma y navegador. Plug-ins universales. Compatibilidad con diferentes resoluciones de pantalla. Contenidos alternativos. Visualización de contenidos sin necesidad de descarga. Posibilidad de documentos PDF. Facilidad de impresión. Descarga de información en diferentes formatos.

A continuación se desarrollan los dos niveles de evaluación para la segunda capa [Fer2011].

\subsubsection{Evaluación de alto nivel orientada a la tarea}

Las tareas pueden ser evaluadas por diferente cantidad de evaluadores de acuerdo a factores tales como tiempo, disponibilidad y presupuesto. Por este motivo se proponen 
dos alternativas, una sencilla donde interviene un solo evaluador y otra donde pueden intervenir 3 ó 5 evaluadores.

- Un solo evaluador: en caso de realizar la evaluación con un solo experto debe buscarse alguna manera de simplificarla para que sea efectiva. Para ello se tomarán solo algunos de los escenarios, no todos. En particular se acotarán los escenarios a los pertenecientes a dos alumnos y un tutor, garantizando coherencia entre los mismos. Sobre estos escenarios se realizará una evaluación a nivel de tarea, es decir, tomando las tareas que se repiten entre ellos pero sin considerarlos completos. El experto utilizará un solo cuestionario con el análisis a nivel de cada tarea.

- Tres o cinco evaluadores: en caso de contar con 3 ó 5 expertos pueden utilizarse los mismos criterios, realizando el análisis a nivel de cada tarea, o distribuyendo entre los expertos los personajes, roles, tareas y contextos de uso implicados en la evaluación.

\subsection{Un solo evaluador}

El experto seleccionado debe adoptar los personajes para luego recorrer los escenarios definidos en cada caso. Para que la sesión de evaluación no sea tan larga y agotadora es conveniente acotar la cantidad de personajes, roles y escenarios.

Dentro de los docentes involucrados en los escenarios de uso tenemos un responsable y dos tutores, siendo estos últimos los que desempeñan el rol más activo e imprescindible dentro del aula virtual. Por tal motivo, el experto simulará ser el docente tutor Nahuel porque posee un contexto de uso que posibilita una mirada general sobre las tareas a realizar.

En el caso de los alumnos, todos ellos desempeñan un rol similar pero poseen contextos diferentes. El alumno seleccionado debe hacer posible una evaluación integral de las tareas seleccionadas. En tal sentido el experto simulará ser el alumno Ana.

De acuerdo a lo planteado anteriormente se utilizarán 7 escenarios en total, 4 correspondientes al docente tutor y 3 al alumno. Los escenarios seleccionados son los siguientes: ETD1.1, ETD2.1, ETD3.1, ETD4.1, EA1.1, EA1.2, EA1.3. Cada escenario involucra al menos 3 tareas. Para facilitar la evaluación se realizó una síntesis de las tareas involucradas en los escenarios correspondientes a cada personaje. Se buscó obtener una serie de tareas de mayor nivel de generalidad, importancia y frecuencia de uso. En esta búsqueda se obtuvieron 8 tareas para el docente tutor y 6 para el alumno.

\section{Tareas del Docente Tutor}

- TAREA 1: Acceder al aula virtual

- TAREA 2: Informarse sobre el curso (bienvenida, programación de actividades, y grupo de alumnos que tiene a cargo)

- TAREA 3: Escribir, publicar y modificar un mensaje informativo para todos los alumnos

- TAREA 4: Acceder a los materiales de estudio. Incorporar materiales complementarios

- TAREA 5: Abrir un foro, agregar y responder aportes

- TAREA 6: Acceder, leer, y responder correo a uno y a varios alumnos 
- TAREA 7: Publicar una actividad evaluable para todos alumnos con plazo de entrega. Corregir y calificar los trabajos. Realizar devoluciones o cometarios individuales sobre algunos trabajos

- TAREA 8: Informarse sobre la situación de cada alumno (ingreso al aula, participaciones, descarga de materiales, entrega de trabajos, calificaciones)

\section{Tareas del Alumno}

- TAREA 1: Informarse sobre la programación de actividades, novedades, tareas a realizar, y conocer a sus compañeros y docentes

- TAREA 2: Acceder a los materiales de estudio, principales y complementarios

- TAREA 3: Consultar un foro, agregar y responder aportes

- TAREA 4: Acceder, leer, y responder correo

- TAREA 5: Entregar un trabajo evaluable, acceder a la calificación y devolución

- TAREA 6: Acceder a los materiales de estudio, principales y complementarios

La situación planteada anteriormente intenta simplificar el proceso para que sea posible llevarlo a cabo con un solo evaluador. Sería sumamente agotador y poco factible que un solo experto tuviera que evaluar cada uno de los escenarios para cada personaje. Por ello se diagramaron tareas generales a partir de los escenarios definidos.

\subsection{Tres o cinco evaluadores}

En caso de contar con un mayor número de expertos, es factible utilizar la alternativa anterior u otra más exhaustiva.

- Simplificada: Evaluar a nivel de tareas, de la misma manera que con un solo experto pero asignando más roles.

- Exhaustiva: Utilizar los 21 escenarios planteados originalmente y distribuir todos los roles para cada personaje entre los expertos.

\section{Simplificada}

En el caso de la evaluación simplificada, los expertos deben realizar cada una de las tareas asignadas tomando como base el contexto de uso, general y particular, definido tanto para los docentes tutores Nahuel y Julián, como para los alumnos Ana, Ailén y Agustín. Durante dicho tránsito deben tener en cuenta las heurísticas seleccionadas para la evaluación de alto nivel orientada a la tarea: complejidad, visibilidad, intuitividad y topografía natural.

Las tareas involucradas son 14; 8 asignadas al docente tutor y 6 al alumno. En el caso de tener tres evaluadores, uno tomará el rol de Nahuel (docente tutor), y los dos restantes los de Ana y Ailén (alumnos). En el caso de cinco evaluadores, dos tomarán el rol de Nahuel y Julián, y los tres restantes los de Ana, Ailén y Agustín.

\section{Roles}

Tres evaluadores Evaluador 1: docente tutor Nahuel

Evaluador 2: alumno Ana

Evaluador 3: alumno Ailén 


\begin{tabular}{|l|l|}
\hline Cinco evaluadores & Evaluador 1: docente tutor Nahuel \\
& Evaluador 2: docente tutor Julián \\
& Evaluador 3: alumno Ana \\
& Evaluador 4: alumno Ailén \\
& Evaluador 5: alumno Agustín \\
\hline
\end{tabular}

Tabla 7 - Roles de cada evaluador en evaluación simplificada orientada a la tarea

\section{Exhaustiva}

En este caso, el uso de los escenarios, y la adopción de roles, es más real, ya que puede hacerse una suerte de "simulación" siguiendo la secuencia de escenarios planteada. Al contar con varios evaluadores es posible distribuir todos los personajes entre los expertos: Docente Responsable, Docente Tutor y Alumno. Inclusive puede otorgarse más de un personaje a cada evaluador para cubrir los diferentes roles. Debe recordarse que, para el personaje Docente Responsable se definió un solo rol (Fabio), para los Docentes Tutores dos roles (Nahuel y Julián), y para los Alumnos tres roles (Ana, Agustín y Ailén).

La evaluación con 3 ó 5 evaluadores es más completa, tiene mayor profundidad, y aprovecha al máximo la idea de los escenarios. Por otra parte, es lo recomendable para detectar un porcentaje de problemas de usabilidad cercano el 80\% [Vir1990].

En el caso de tres evaluadores, uno tomará el rol de Fabio, otro el de Nahuel y el tercero el de Ana. En el caso de cinco evaluadores, uno tomará el rol de Fabio y Agustín, dos el de Nahuel y Julián, y los dos restantes el de Ana y Ailén.

\begin{tabular}{|l|l|}
\hline \multicolumn{2}{|c|}{ Roles } \\
\hline Tres evaluadores & Evaluador 1: docente responsable Fabio \\
& Evaluador 2: docente tutor Nahuel \\
& Evaluador 3: alumno Ana \\
\hline Cinco evaluadores & Evaluador 1: docente responsable Fabio y alumno Agustín \\
& Evaluador 2: docente tutor Nahuel \\
& Evaluador 3: docente tutor Julián \\
& Evaluador 4: alumno Ana \\
& Evaluador 5: alumno Ailén \\
\hline
\end{tabular}

Tabla 8 - Roles de cada evaluador en evaluación exhaustiva orientada a la tarea

En tal sentido los escenarios utilizados serán todos los definidos, es decir:

- Responsable: EDR1.1, EDR2.1, EDR3.1, EDR4.1

- Tutor: EDT1.1, EDT1.2, EDT2.1, EDT2.2, EDT3.1, EDT3.2, EDT4.1, EDT4.2

- Alumno: EA1.1, EA2.1, EA3.1, EA1.2, EA2.2, EA3.2, EA1.3, EA2.3, EA3.3

Los expertos deben transitar cada escenario realizando las tareas incluidas en cada uno de ellos, tomando como base el contexto de uso definido para cada caso. 


\section{Contextos de uso seleccionados}

El experto debería evaluar cada una de las tareas de acuerdo a un contexto de uso específico. A continuación se presentan dos contextos, uno para el docente y otro para el alumno.

\section{Personaje Docente Tutor: Nahuel}

\section{Contexto de uso}

- General: Carrera con modalidad no presencial, mediada por TIC durante todo su desarrollo, con instancias presenciales únicamente para los exámenes parciales y finales. Los docentes toman contacto por primera vez con el EVEA. Cursado de una asignatura desde días previos al inicio de la asignatura hasta la finalización del primer módulo. Asignatura con un docente responsable, organizada en dos comisiones de trabajo a cargo de un docente tutor cada una. El docente responsable es el encargado de la programación general de actividades, y gestión de materiales. Los docentes tutores están a cargo de un grupo de alumnos o comisión cada uno y son los encargados de responder consultas, moderar foros, corregir, calificar y hacer devolución de las actividades. Carrera universitaria de grado con orientación contable y 5 años de duración.

- Particular: Docente de primer año a cargo de los trabajos prácticos de la asignatura Análisis Matemático I bajo las dos modalidades: presencial y no presencial. Hace docencia desde su oficina de la Facultad. Tiene contacto presencial con el docente responsable de la asignatura. Posee PC de escritorio con Internet con banda ancha. Con experiencia en el uso PC e Internet. Accede periódicamente al aula virtual.

\section{Personaje Alumno: Ana}

\section{Contexto de uso}

- General: Primer año de una carrera universitaria de grado con orientación contable y 5 años de duración. Carrera con modalidad no presencial, mediada por TIC durante todo su desarrollo, con instancias presenciales únicamente para los exámenes parciales y finales. Los alumnos toman contacto por primera vez con el EVEA. Cursado de una asignatura desde el inicio hasta la finalización del primer módulo. Asignatura con un docente responsable, organizada en dos comisiones de trabajo a cargo de un docente tutor cada una.

- Particular: Alumna de primer año que recientemente termina el secundario, vive en una pequeña localidad y no trabaja. Posee experiencia en el uso PC e Internet y estudia por la mañana en su casa, con su PC de escritorio que tiene conexión a Internet dial-up. Dispone de tiempo para estudiar y accede periódicamente al aula virtual.

\section{Criterios de evaluación}

Hasta ahora se presentaron las diferentes alternativas para realizar la evaluación de alto nivel orientada a la tarea. Una alternativa es adoptar el enfoque que plantea la posibilidad de analizar un conjunto de tareas generales, la otra es utilizar los escenarios completos. Sin embargo, en cualquiera de los dos casos las heurísticas a evaluar son las mismas, así como también el instrumento utilizado. 


\section{Cuestionario}

En el anexo $C$ se desarrolla el instrumento específico que debe ser proporcionado a los evaluadores para realizar esta etapa de la evaluación. Se trata de un cuestionario que puede ser aplicado tanto para el caso de evaluación simplificada como exhaustiva, a los efectos de evaluar las heurísticas de complejidad, visibilidad, e intuitividad y topografía natural.

\subsubsection{Evaluación en detalle orientada al diseño}

Esta evaluación complementa la anterior analizando los aspectos concretos de cada interfaz. Podríamos decir que se trata de una evaluación heurística clásica en el sentido que hace hincapié sobre el núcleo básico de heurísticas presentadas y seleccionadas en el capítulo 1: productividad, retroalimentación, control por parte del usuario, reversibilidad y manejo del error, diseño y organización, consistencia, ayuda y documentación, y estándares.

Existen muchas propuestas para evaluar de manera heurística las interfaces Web, desde aquellas que lo hacen de una manera general con preguntas muy abarcativas hasta aquellas minuciosas que involucran gran cantidad de preguntas. Para lograr un equilibrio y hacer factible la aplicación del método se propone una evaluación heurística acotada a los aspectos más relevantes de la interfaz, entendiendo que los EVEA actuales proporcionan herramientas de producción de contenido que garantizan el respeto por las reglas básicas de diseño y proveen una estructura básica coherente enriquecida por los actores educativos.

La cantidad de evaluadores que participan no altera la forma de evaluación. El instrumento utilizado es el mismo, la única diferencia está dada por los roles asignados y la cantidad de escenarios utilizados en cada caso.

La distribución de roles y escenarios será similar a la realizada para la evaluación orientada a la tarea de acuerdo a la cantidad de evaluadores elegidos.

\begin{tabular}{|c|c|}
\hline \multicolumn{2}{|r|}{ Roles } \\
\hline Un evaluador & Docente tutor Nahuel y alumno Ana. \\
\hline Tres evaluadores & $\begin{array}{l}\text { Evaluador 1: docente responsable Fabio } \\
\text { Evaluador 2: docente tutor Nahuel } \\
\text { Evaluador 3: alumno Ana }\end{array}$ \\
\hline Cinco evaluadores & $\begin{array}{l}\text { Evaluador 1: docente responsable Fabio y alumno Agustín } \\
\text { Evaluador 2: docente tutor Nahuel } \\
\text { Evaluador 3: docente tutor Julián } \\
\text { Evaluador 4: alumno Ana } \\
\text { Evaluador 5: alumno Ailén }\end{array}$ \\
\hline
\end{tabular}

Tabla 9 - Roles de cada evaluador en evaluación orientada al diseño

\section{Escenarios}

\begin{tabular}{l|l} 
Un evaluador & Se utilizarán los 7 escenarios previamente seleccionados: ETD1.1,
\end{tabular} 


\begin{tabular}{|l|l|}
\hline & ETD2.1, ETD3.1, ETD4.1, EA1.1, EA1.2, EA1.3. \\
\hline Tres evaluadores & Todos los escenarios definidos: EA1.1, EA2.1, EA3.1, EA1.2, \\
0 & EA2.2, EA3.2, EA1.3, EA2.3, EA3.3, EDR1.1, EDR2.1, EDR3.1, \\
Cinco evaluadores & EDR4.1, EDT1.1, EDT1.2, EDT2.1, EDT2.2, EDT3.1, EDT3.2, \\
\cline { 2 - 2 }
\end{tabular}

Tabla 10 - Escenarios de cada evaluador en evaluación orientada al diseño

Los expertos deben transitar cada escenario realizando las tareas incluidas en ellos y tomando como base el contexto uso definido para cada caso. Durante dicho tránsito deben tener en cuenta las heurísticas seleccionadas para la evaluación orientada al diseño y detallar el nivel de conformidad alcanzado para cada sub-heurística según su criterio. Las subheurísticas propuestas son las siguientes:

\begin{tabular}{|c|c|}
\hline Heurística & Sub-heurística \\
\hline Productividad & $\begin{array}{l}\text { Las tareas habituales son de fácil realización. } \\
\text { Los usuarios frecuentes o expertos tienen posibilidad de realizar las tareas } \\
\text { reduciendo el número de interacciones con el EVEA. } \\
\text { Existen mecanismos para realizar tareas masivas. } \\
\text { El EVEA provee el usuario de recordatorios o avisos sobre cambios producidos a } \\
\text { partir del último ingreso. } \\
\text { Hay atajos de teclado y están siempre disponibles. } \\
\text { El EVEA soporta tanto usuarios expertos como novicios presentando múltiples } \\
\text { niveles de detalle disponibles. } \\
\text { En cada pantalla o una caja de diálogo el cursor está posicionado en el campo } \\
\text { que más probablemente el usuario vaya a necesitar. } \\
\text { El método para mover el cursor al campo siguiente o previo es simple ya la vez } \\
\text { visible. } \\
\text { El EVEA anticipa y avisa al usuario correctamente acerca de la próxima actividad } \\
\text { que sea más probable. }\end{array}$ \\
\hline Retroalimentación & $\begin{array}{l}\text { El resultado de cada acción realizada por el usuario es informado. } \\
\text { Los resultados exitosos son informados de manera diferente a los fracasos. } \\
\text { Las acciones frecuentes y de poca importancia son informadas de manera } \\
\text { modesta. } \\
\text { Las acciones infrecuentes e importantes son informadas de manera elocuente. } \\
\text { Los errores producidos son informados claramente al usuario, de forma no } \\
\text { alarmista, y con sugerencias de de cómo solucionar el problema. }\end{array}$ \\
\hline $\begin{array}{l}\text { Control por parte } \\
\text { del usuario }\end{array}$ & $\begin{array}{l}\text { Los efectos de los actos realizados son predecibles. } \\
\text { El usuario es informado constantemente sobre lo que está ocurriendo (mensajes, } \\
\text { tiempo estimado, barra de progreso). } \\
\text { Se informa al usuario de lo que ha pasado } \\
\text { El usuario posee autonomía y libertad para actuar } \\
\text { El usuario controla el sistema en todo momento. } \\
\text { Se pregunta al usuario que confirme acciones que tendrán consecuencias } \\
\text { drásticas, negativas o destructivas. } \\
\text { Existe una forma de deshacer al nivel de cada acción simple, cada entrada de } \\
\text { datos y cada grupo de acciones completadas. }\end{array}$ \\
\hline
\end{tabular}




\begin{tabular}{|c|c|}
\hline & $\begin{array}{l}\text { Los usuarios pueden cancelar operaciones en progreso. } \\
\text { Los usuarios pueden reducir el tiempo de entrada de datos copiando y } \\
\text { modificando datos existentes. } \\
\text { El usuario puede cancelar cualquier acción. } \\
\text { Todas las páginas disponen de un punto de salida. }\end{array}$ \\
\hline $\begin{array}{l}\text { Reversibilidad y } \\
\text { Manejo del error }\end{array}$ & $\begin{array}{l}\text { Existe una forma de deshacer al nivel de cada acción simple, cada entrada de } \\
\text { datos y cada grupo de acciones completadas. } \\
\text { Los usuarios pueden cancelar operaciones en progreso } \\
\text { Los usuarios pueden revertir sus acciones de manera sencilla } \\
\text { Los mensajes de error son visibles } \\
\text { Los mensajes de error describen acciones para remediar el problema } \\
\text { Los mensajes de error proporcionan el contacto de la asistencia } \\
\text { Los mensajes de error están expresado de manera tal que es el sistema, y no el } \\
\text { usuario, quien se hace cargo de los errores } \\
\text { Los mensajes de error evitan el uso de signos de admiración, palabras violentas } \\
\text { u hostiles } \\
\text { El sistema informa el lugar donde detecta errores de entrada de datos } \\
\text { Los mensajes de error informan al usuario sobre la severidad del error cometido } \\
\text { Los mensajes de error sugieren la causa del problema que los ha ocasionado } \\
\text { El sistema previene o alerta a los usuarios de cometer errores siempre que esto } \\
\text { es posible } \\
\text { Las entradas de datos contienen valores por defecto cuando corresponde }\end{array}$ \\
\hline $\begin{array}{l}\text { Diseño y } \\
\text { organización }\end{array}$ & $\begin{array}{l}\text { Es posible comprender rápidamente cual es la estructura organizativa y el } \\
\text { contenido } \\
\text { Solo están visibles las acciones que tienen un fin específico } \\
\text { Es posible predecir los efectos de los actos realizados } \\
\text { Existe orientación y ayuda de forma implícita al usuario sobre lo que se debe } \\
\text { hacer } \\
\text { Es posible editar y ver el aspecto real } \\
\text { La información esencial para tomar decisiones es mostrada en la pantalla } \\
\text { El sistema se anticipa a las necesidades del usuario } \\
\text { Se muestra el trabajo pendiente en tareas complejas o de varias etapas } \\
\text { Las información y acciones relacionada está agrupada } \\
\text { La información importante se encuentra resaltada en la parte superior de las } \\
\text { páginas } \\
\text { El tipo de fuente, efectos tipográficos, ancho de línea y alineación empleados } \\
\text { facilitan la lectura } \\
\text { Los párrafos son breves y el lenguaje sencillo } \\
\text { La longitud de las páginas evita el scroll o posibilita ver lo más importante sin } \\
\text { necesidad de realizar acciones adicionales } \\
\text { Los enlaces están siempre visibles, indican su estado, y no hay enlaces rotos } \\
\text { No hay elementos distractores } \\
\text { La cantidad de imágenes es reducida y ayudan a comunicar mejor el mensaje }\end{array}$ \\
\hline
\end{tabular}




\begin{tabular}{|c|c|}
\hline & $\begin{array}{l}\text { Se controla que el tamaño y resolución de las imágenes } \\
\text { El diseño general es atractivo y uniforme, sin exceso de texto ni de imágenes } \\
\text { Los colores son armónicos } \\
\text { Hay un mapa del sitio y posibilita orientarse rápidamente } \\
\text { Se mantiene un equilibrio entre profundidad y anchura } \\
\text { Existen elementos que permiten al usuario estar siempre orientado y tener el } \\
\text { control de su navegación } \\
\text { Existen zonas de descanso visual entre los objetos informativos de la página } \\
\text { La velocidad de renovación de cada página adecuada y evita que el usuario se } \\
\text { impaciente o distraiga }\end{array}$ \\
\hline Consistencia & $\begin{array}{l}\text { La misma palabra o expresión se utiliza siempre para describir el mismo ítem } \\
\text { El título de página en el navegador es significativo y refleja el título de la página } \\
\text { principal } \\
\text { Cada página posee un título significativo en el navegador } \\
\text { Los enlaces son claros } \\
\text { Cada enlace refleja el título de la página a la que se refiere } \\
\text { Los íconos son entendibles y aportan significado } \\
\text { Las secuencias constantes de acciones se repiten en situaciones similares } \\
\text { Los comandos constantes se emplean en todas partes del mismo modo } \\
\text { Se utiliza siempre la misma terminología en avisos, menús, y pantallas de ayuda } \\
\text { Los íconos, botones, imágenes, ventanas y diálogos respetan las normas y } \\
\text { convenciones usuales de la plataforma Web }\end{array}$ \\
\hline $\begin{array}{l}\text { Ayuda y } \\
\text { documentación }\end{array}$ & $\begin{array}{l}\text { Se dispone de ayuda en línea, en lugar visible y orientada a las acciones del } \\
\text { usuario } \\
\text { Existe ayuda contextual en tareas complejas } \\
\text { Los usuarios pueden cambiar fácilmente entre la ayuda y su trabajo } \\
\text { Existe una mesa de ayuda o soporte técnico permanente } \\
\text { Existen manuales, foros, respuesta a preguntas frecuentes etc. } \\
\text { La documentación disponible es suficiente } \\
\text { Hay un buscador interno disponible } \\
\text { El buscador interno posibilita realizar búsquedas avanzadas } \\
\text { Los resultados de la búsqueda se muestras de forma comprensible para el } \\
\text { usuario }\end{array}$ \\
\hline Estándares & $\begin{array}{l}\text { Es posible usarlo sin necesidad de descargar elementos adicionales como plug- } \\
\text { ins } \\
\text { En caso de requerir elementos adicionales el usuario es informado de dicha } \\
\text { situación } \\
\text { En caso de requerir elementos adicionales aparece algún contenido alternativo } \\
\text { En caso de requerir elementos adicionales, éstos son universales } \\
\text { El usuario puede aumentar o reducir el tamaño de fuente según su necesidad } \\
\text { Todas las imágenes describen su contenido mediante el atributo 'alt' } \\
\text { Se respetan los estándares de la W3C (HTML, CSS, XHTML, WCAG) }\end{array}$ \\
\hline
\end{tabular}




\begin{tabular}{|l|l|}
\hline Se visualiza correctamente con cualquier sistema operativo \\
Se visualiza correctamente con cualquier navegador y versión de uso corriente \\
Se visualiza correctamente con diferentes resoluciones de pantalla \\
Los contenidos pueden visualizarse sin necesidad de descarga \\
Es posible imprimir correctamente o generar un documento PDF por cada página
\end{tabular}

Tabla 11 - Subheurísticas para evaluación orientada al diseño

Las subheurísticas, al igual que los escenarios, también pueden ser ajustadas acorde a lo que se necesita evaluar.

\subsection{Cuestionario}

El cuestionario que se provee a los expertos para realizar el proceso de evaluación posee la lista de principios heurísticos, checklist, que acabamos de presentar. Cada heurística es acompañada por el nivel de conformidad alcanzado según el criterio del evaluador, más un comentario que lo justifique en caso de ser necesario u oportuno. La conformidad es medida a través del método Likert [Tro2002], con una escala ordinal de 1 a 5 puntos, cuyo valor inferior (1) representa que la conformidad nunca fue alcanzada, y el valor superior (5) que siempre lo fue. En el anexo D se expone el instrumento específico con las preguntas que indagan sobre cada sub-heurística.

\subsection{Nivel de conformidad}

Si la evaluación orientada al diseño es realizada por más de un evaluador, se toma cada uno de los cuestionarios y se genera uno nuevo compuesto por los promedios de los valores de conformidad de cada sub-heurística. A su vez, para determinar el nivel de conformidad general de cada heurística se promedian los niveles de conformidad de las subheurísticas que la componen.

\subsubsection{Forma de aplicación}

La evaluación mixta que se propone debe llevarse a cabo en cuatro fases: planificación, puesta en marcha, evaluación y cierre. La fase de planificación permitirá tomar decisiones respecto a la cantidad de evaluadores que participarán, experticia de cada uno, personajes que le serán asignados, y preparación del lugar físico donde se desarrollará el proceso. La puesta en marcha determina la secuencia de actividades a realizar con los expertos, previo a la evaluación propiamente dicha. La evaluación es el punto central del proceso donde los expertos analizan el EVEA desde el punto de vista de la usabilidad. El cierre permite obtener el informe final con la opinión de los expertos.

\section{Planificación}

i. Definición de la cantidad de evaluadores-expertos, perfil de cada uno y selección de los mismos

Podemos implementar diferentes alternativas de acuerdo al tiempo y disponibilidad de evaluadores. En tal sentido se sugiere que:

- Un evaluador: en este caso, al tratarse de un experto que realiza toda la tarea, debe poseer conocimientos de varias áreas disciplinares. Por tal motivo debe tratarse de un evaluador EDE. El evaluador seleccionado debería ser novato en la utilización del entorno que se desea evaluar a los fines de lograr una visión lo más integral posible. 
- Tres evaluadores: tres es el número mínimo de evaluadores para garantizar cierta objetividad en el proceso [Nie1993c]. En este caso podríamos seleccionar un evaluador tipo E-, uno tipo $\mathbf{E}$ y uno tipo $\mathbf{E}+$. Como el evaluador de tipo E- no posee conocimientos en EVEA pero los otros dos sí, podría seleccionarse a un evaluador de tipo $\mathrm{E}$ que esté familiarizado con el entorno y uno de tipo $E+$ que no. De esta forma, el experto que posee mayor ventaja $\left(\mathrm{E}_{+}\right)$tendría que hacer un esfuerzo adicional respecto a los demás, y se podría analizar la facilidad de adopción de un entorno a otro.

- Cinco evaluadores: Es el número óptimo si se desea maximizar la relación costo/beneficio. Esta alternativa podría considerarse la ideal, porque la cantidad de evaluadores que participan garantiza la detección de la mayoría de los problemas de usabilidad, a la vez que posibilita que cada experto realice la tarea de forma más minuciosa [Nie1993c]. En este caso podríamos seleccionar dos expertos tipo E-, uno $\mathbf{E}$, y dos $\mathbf{E}+$. Tomando en cuenta las mismas consideraciones que en el punto anterior, podría seleccionarse a un E- y un E+ que estén familiarizados con el entorno, un E- y un E+ que no, y un E que sí lo esté.

ii. Definición del tipo de evaluación de alto nivel a realizar

En el caso de utilizar tres o cinco evaluadores, existen dos alternativas para realizar la evaluación de alto nivel orientada al diseño: simplificada o exhaustiva. Por tal motivo, debemos seleccionar alguna de ellas puesto que influyen en el proceso posterior de evaluación.

iii. Asignación de evaluadores

En función de la cantidad de evaluadores seleccionados debemos ahora determinar las características de cada uno de ellos.

- Un evaluador: $\quad$ Evaluador 1 = Experto EDE

- Tres evaluadores:

$$
\begin{aligned}
& \text { Evaluador } 1=\text { Experto } \mathrm{E}+ \\
& \text { Evaluador } 2=\text { Experto } \mathrm{E} \\
& \text { Evaluador } 3=\text { Experto E- }
\end{aligned}
$$

- Cinco evaluadores:

$$
\begin{aligned}
& \text { Evaluador } 1=\text { Experto } E+ \\
& \text { Evaluador } 2=\text { Experto } E+ \\
& \text { Evaluador } 3=\text { Experto } E \\
& \text { Evaluador } 4=\text { Experto E- } \\
& \text { Evaluador } 5=\text { Experto E- }
\end{aligned}
$$

iv. Elección de un laboratorio de usabilidad

Dependiendo de los recursos disponibles es posible poner en marcha la sesión de evaluación en un laboratorio de usabilidad real, o generar las condiciones necesarias dentro de un aula con computadoras u oficina que permita albergar a los expertos. La idea principal es poder generar un ambiente lo más similar 
posible al contexto de uso real, donde se reproduzcan las situaciones habituales que se dan durante la actividad diaria, tanto en el ambiente de trabajo como en los recursos hardware, software y conectividad.

\section{Puesta en marcha}

v. Entrenamiento de los evaluadores

El sitio Web a evaluar está orientado a facilitar la comunicación pedagógica entre docentes y alumnos. Por tal motivo, los expertos que no posean conocimientos sobre EVEA deben recibir asesoramiento previo sobre las características principales del mismo. De esta manera lograremos que la evaluación sea efectiva.

vi. Presentación de los cuestionarios a los evaluadores con las heurísticas a evaluar

En esta instancia se deben entregar los instrumentos de evaluación a los expertos y despejar las dudas que se presenten.

vii. Asignación de roles entre los evaluadores

Cada evaluador recibe su rol y personaje correspondiente para llevar a cabo el simulacro.

\section{viii. Recorrido general}

Se realiza primero un recorrido de manera tal que pueda obtenerse una visión general del mismo. Es recomendable adoptar uno de los roles más básicos para realizar este recorrido, ya que por lo general los EVEA requieren autenticación para poder ingresar a sus componentes principales.

Se solicita a cada experto que navegue integralmente el sitio Web por lo menos en dos ocasiones a efectos de familiarizarse con él. En el primer recorrido el evaluador debe centrarse en el flujo de la interacción y el desarrollo general del sistema, mientras que en el segundo pone énfasis sobre los elementos específicos de la interfaz y su modo de funcionamiento.

\section{Evaluación}

ix. Simulacro desde el punto de vista del usuario

La evaluación propiamente dicha se realiza desde dos puntos de vista: de alto nivel orientada a la tarea y en detalle orientada al diseño. En el primer caso se examina el aspecto y comportamiento desde el punto de vista de las tareas y objetivos propuestos por los escenarios de uso. En el segundo se analizan los aspectos concretos del conjunto de interfaces provistas por el EVEA para completar las tareas.

Los expertos evalúan el EVEA y completan los cuestionarios suministrados para los dos tipos de evaluaciones. En caso que el proceso de evaluación se lleve a cabo mediante varios expertos, éstos realizan el análisis por separado. Esta evaluación puede tener una duración aproximada de 1 a 2 horas.

\section{Cierre}

x. Discusión e informe 
Los evaluadores realizan una puesta en común, debaten y elaboran un único informe donde se ve reflejado el análisis realizado por cada uno de ellos y los acuerdos alcanzados.

\subsubsection{Tercera capa}

Las dos primeras capas focalizan su atención en la mirada que los expertos pueden hacer sobre el EVEA. En esta tercera capa el objetivo es nutrirse de la opinión del usuario final, pero dentro de un ambiente controlado, y con la participación de observadores que guíen y faciliten el proceso. Para ello es imprescindible la participación de usuarios reales [Fer2011].

La forma elegida para llevar a cabo esta tercera etapa de evaluación fue mediante la instrumentación de test de usuarios [Woo1998]. En este tipo de test se observa la manera en que el usuario intenta llevar a cabo una tarea dada sobre el sitio Web a evaluar, analizando los problemas con los que se encuentra. El objetivo no es aprobar o desaprobar el EVEA sino establecer en que medida se adapta el software a los estilos de trabajo reales de los usuarios, en lugar de forzar a los usuarios a adaptar sus estilos de trabajo al software. Los test de usuarios son considerados como el método de evaluación más importante, ya que proporciona información sobre el uso real del software observando a los usuarios finales mientras lo utilizan para realizar determinadas tareas, siendo la única forma válida de recoger datos fiables de usabilidad [Nie1999].

Dentro de las alternativas existentes para este tipo de métodos, se ha seleccionado una variante del test de pensamiento en voz alta denominada test de expresión del usuario en base a preguntas [Nie1994]. La metodología consiste en brindarle al usuario un escenario tipo, y solicitarle que efectúe las tareas involucradas en dicho escenario, bajo la atenta mirada de un observador. A medida que el usuario interactúa con el EVEA, el observador debe realizar preguntas directas acerca del producto o la tarea que el usuario está realizando, mientras que el usuario debe expresar en voz alta sus pensamientos, sensaciones y opiniones. El observador debe tomar registro de todo ello para procesarlo una vez concluido el test. El test de expresión del usuario en base a preguntas es uno de los test de usuario cara a cara que mejor resultado arrojan para extraer información sobre el comportamiento e intenciones del usuario. Al basarse en la observación presencial mientras un usuario realiza una tarea, permite que el observador capte impresiones y sensaciones, recurriendo a preguntas para provocar manifestaciones explícitas respecto del producto. Además, es más fácil de implementar que el test de usuario clásico, ya que no es necesario contar con un laboratorio de usabilidad.

Las encuestas son vitales para efectuar los test de usuario. Por la cercanía entre el observador y el usuario las más adecuadas son las encuestas personales. También las entrevistas sirven como complemento en este caso.

Es importante que los usuarios involucrados en los test abarquen los diferentes roles en que puede interactuarse con el EVEA (alumnos, docentes, administradores, etc.). Por otro lado, dentro de cada rol deben seleccionarse usuarios con diferente nivel de experiencia en el uso del servicio Web.

\subsubsection{Evaluadores}

De acuerdo a las seis clases de usuario propuestas, dejaremos de lado a los docentes medios y seleccionaremos dos docentes novatos, dos avanzados, y dos alumnos de cada clase. Ello hará un total de 10 usuarios, de los cuales 4 son docentes y 6 son alumnos. De esta forma se obtendrá un abanico de usuarios que cubre gran parte del espectro. 
- Docentes novatos: 2 (DN1, DN2)

- Docentes avanzados: 2 (DA1, DA2)

- Alumnos novatos: 2 (AN1, AN2)

- Alumnos medios: 2 (AM1, AM2)

- Alumnos avanzados: 2 (AA1, AA2)

Podrían haberse considerado 2 docentes medios, sin embargo entendemos que dicha incorporación no trae aparejados beneficios significativos, sino que, por el contrario, añade mayor cantidad de usuarios y complejiza el test.

Debido a la cantidad de participantes sería bueno contar con al menos cuatro observadores para llevar el registro de lo acontecido durante la evaluación. Denominaremos a cada observador $\mathrm{O} 1, \mathrm{O} 2, \mathrm{O} 3$ y $\mathrm{O} 4$.

\subsubsection{Roles}

Cada uno de los usuarios seleccionados tomará los siguientes roles:

\begin{tabular}{|l|l|}
\hline \multicolumn{2}{|c|}{ Roles } \\
\hline DN1 & Docente Tutor Julián \\
\hline DN2 & Docente Responsable Fabio \\
\hline DA1 & Docente Tutor Nahuel \\
\hline DA2 & Docente Tutor Nahuel \\
\hline AN1 & Alumno Ailén \\
\hline AN2 & Alumno Ailén \\
\hline AM1 & Alumno Agustín \\
\hline AM2 & Alumno Agustín \\
\hline AA1 & Alumno Ana \\
\hline AA2 & Alumno Ana \\
\hline
\end{tabular}

Tabla 12 - Roles de cada uno de los usuarios

\subsubsection{Escenarios}

Se utilizarán todos los escenarios definidos (21): EA1.1, EA2.1, EA3.1, EA1.2, EA2.2, EA3.2, EA1.3, EA2.3, EA3.3, EDR1.1, EDR2.1, EDR3.1, EDR4.1, EDT1.1, EDT1.2, EDT2.1, EDT2.2, EDT3.1, EDT3.2, EDT4.1, EDT4.2. La forma de distribuir los escenarios entre los diferentes roles es la siguiente:

\begin{tabular}{|l|l|l|}
\hline Evaluador & \multicolumn{1}{|c|}{ Rol } & \multicolumn{1}{c|}{ Escenarios } \\
\hline DN1 & Docente Tutor Julián & EDT2.1, EDT2.2, EDT3.2, EDT4.2 \\
\hline DN2 & $\begin{array}{l}\text { Docente Responsable } \\
\text { Fabio }\end{array}$ & EDR1.1, EDR2.1, EDR3.1, EDR4.1 \\
\hline DA1 & Docente Tutor Nahuel & EDT1.1, EDT2.1, EDT3.1, EDT4.1 \\
\hline
\end{tabular}




\begin{tabular}{|l|l|l|}
\hline DA2 & Docente Tutor Nahuel & EDT1.1, EDT2.1, EDT3.1, EDT4.1 \\
\hline AN1 & Alumno Ailén & EA3.1, EA3.2, EA3.3 \\
\hline AN2 & Alumno Ailén & EA3.1, EA3.2, EA3.3 \\
\hline AM1 & Alumno Agustín & EA2.1, EA2.2, EA2.3 \\
\hline AM2 & Alumno Agustín & EA2.1, EA2.2, EA2.3 \\
\hline AA1 & Alumno Ana & EA1.1, EA1.2, EA1.3 \\
\hline AA2 & Alumno Ana & EA1.1, EA1.2, EA1.3 \\
\hline
\end{tabular}

Tabla 13 - Distribución de escenarios entre roles

Como podemos observar, existen escenarios compartidos entre diferentes usuarios, de manera tal que sea posible evaluar su comportamiento sobre un mismo escenario y detectar así problemas comunes de usabilidad. Por ejemplo, los escenarios EA1.1, EA1.2, EA1.3, correspondientes al alumno Ana, son compartidos por los usuarios AA1 y AA2, los cuales poseen similar nivel de experticia (avanzados).

\subsubsection{Sesiones}

Como varios usuarios adquieren el mismo rol es necesario realizar sesiones de trabajo diferentes para que éstos no se superpongan. Las sesiones de test deben organizarse de manera tal que sea posible generar un simulacro a partir de los escenarios propuestos. Los escenarios tienen cierta correlación entre ellos, que debe respetarse para poder realizar las tareas previstas en los mismos. Por tal motivo, los usuarios pueden plantearse de la siguiente manera:

\section{Sesión 1: DA1, DN2, AN1, AM1, AA1 \\ Sesión 2: DN1, DA2, AN2, AM2, AA2}

Cada sesión debe ser coordinada y monitoreada por dos observadores. En tal sentido se propone que cada sesión cuente con una persona diferente para garantizar mayor objetividad.

\section{Sesión 1: a cargo de $\mathrm{O} 1$ y $\mathrm{O} 2$}

Sesión 2: a cargo de $\mathrm{O} 3$ y $\mathrm{O} 4$

\subsubsection{Qué evaluar}

El objetivo en esta tercera capa es evaluar el EVEA desde el punto de vista del usuario real a partir de la participación de los mismos. Por tal motivo elaboramos un test de expresión del usuario en base a preguntas. Dentro del test distinguimos dos tipos de evaluaciones: directa e indirecta. La primera es realizada por los usuarios y la segunda por los observadores.

- Evaluación directa: el usuario final debe situarse en un escenario concreto e interactuar con el entorno realizando tareas como si estuviera participando de un curso, asignatura, o capacitación con modalidad virtual. Luego de concluida la sesión de evaluación debe completar un cuestionario.

- Evaluación indirecta: el observador debe estar presente durante toda la sesión y registrar lo que acontece mientras el usuario realiza las tareas. El observador debe realizar preguntas directas al usuario, y éste debe expresar en voz alta sus observaciones, sugerencias, u opiniones. El usuario también 
puede realizarle preguntas al observador. Durante la sesión, y al finalizar la misma, el observador debe tomar registro y completar un cuestionario por cada usuario.

\subsubsection{Como evaluar}

El test de usuario está compuesto por dos cuestionarios, uno destinado al usuario final, para la evaluación directa, y otro al observador, para la evaluación indirecta.

\subsection{Evaluación directa}

Los criterios tomados para la evaluación directa, realizada por los usuarios finales, son idénticos a los definidos en la segunda capa para la evaluación de alto nivel orientada a la tarea que realizan los expertos. Los criterios analizados son: complejidad, visibilidad, e intuitividad y topografía natural. Al compartir los criterios también se comparte el instrumento de evaluación.

\subsection{Evaluación indirecta}

La evaluación indirecta pretende recabar información sobre un conjunto de métricas de usabilidad, basadas en el estándar ISO 9241-11 [Rod2000], que intentan medir el grado de efectividad, eficiencia, y satisfacción del entorno virtual. Para ello, en primer lugar, el observador debe tomar nota del rol y escenarios que posee cada usuario, y las observaciones, sugerencias u opiniones que vierte el mismo durante y después de la sesión. En segundo lugar debe analizar y registrar las siguientes métricas:

- Eficiencia

- Porcentaje de tareas completadas

- Efectividad

- Tiempo total invertido por el usuario en las tareas completadas

- Tiempo total ocupado en errores

- Tiempo total de aprendizaje

- Frecuencia de uso de la ayuda o documentación

- Satisfacción

- Veces que el usuario expresa frustración o enojo

- Utilidad del producto

- Satisfacción con respecto a las funciones y características

- Percepción de que la tecnología da soporte a las tareas según las necesidades del usuario

En el caso particular de satisfacción sólo se han tomado algunas características generales. Existen numerosos instrumentos específicos para medir satisfacción, SUMI [Bev1995b] por ejemplo, pero constan de una gran cantidad de preguntas que harían inmanejable la evaluación.

En el anexo $\mathrm{F}$ se desarrolla el instrumento específico. 


\subsubsection{Forma de aplicación}

El test de usuarios que se propone debe llevarse a cabo en tres fases: planificación, evaluación, y cierre. La fase de planificación permitirá tomar decisiones respecto a la cantidad de evaluadores-expertos, perfil de cada uno, selección de los mismos, asignación de roles, distribución de escenarios, puesta a punto del entorno, y preparación del laboratorio de usabilidad. La evaluación es el punto central del proceso donde los usuarios analizan el EVEA, y los observadores acompañan. El cierre permite obtener el informe final con la opinión de los usuarios y los observadores.

\section{Planificación}

i. Definición de la cantidad de evaluadores-expertos, perfil de cada uno y selección de los mismos

Como mencionamos anteriormente, para garantizar mayor objetividad, trabajaremos con usuarios evaluadores que poseen diferente nivel de experticia: novatos, medios y avanzados. En tal sentido proponemos seleccionar dos docentes novatos, dos avanzados, y dos alumnos de cada clase, es decir, un total de 10 usuarios, de los cuales 4 son docentes y 6 son alumnos. De esta forma se obtendrá un abanico de usuarios que cubre gran parte del espectro. Luego de seleccionar a los usuarios se les asignará un nombre a cada uno de la siguiente manera:

- Docentes novatos: DN1, DN2

- Docentes avanzados: DA1, DA2

- Alumnos novatos: AN1, AN2

- Alumnos medios: AM1, AM2

- Alumnos avanzados: AA1, AA2

ii. Asignación de roles a cada evaluador

Cada uno de los usuarios seleccionados tomará los siguientes roles:

- DN1: Docente Tutor Julián

- DN2: Docente Responsable Fabio

- DA1: Docente Tutor Nahuel

- DA2: Docente Tutor Nahuel

- AN1: Alumno Ailén

- AN2: Alumno Ailén

- AM1: Alumno Agustín

- AM2: Alumno Agustín

- AA1: Alumno Ana

- AA2: Alumno Ana

iii. Distribución de escenarios a los evaluadores

Cada evaluador recibirá un escenario para la evaluación. Dicho escenario contextualiza al usuario en una situación determinada. Se utilizarán todos los escenarios definidos (21): EA1.1, EA2.1, EA3.1, EA1.2, EA2.2, EA3.2, EA1.3, 
EA2.3, EA3.3, EDR1.1, EDR2.1, EDR3.1, EDR4.1, EDT1.1, EDT1.2, EDT2.1, EDT2.2, EDT3.1, EDT3.2, EDT4.1, EDT4.2, distribuidos de la siguiente manera:

- DN1: EDT2.1, EDT2.2, EDT3.2, EDT4.2

- DN2: EDR1.1, EDR2.1, EDR3.1, EDR4.1

- DA1: EDT1.1, EDT2.1, EDT3.1, EDT4.1

- DA2: EDT1.1, EDT2.1, EDT3.1, EDT4.1

- AN1: EA3.1, EA3.2, EA3.3

- AN2: EA3.1, EA3.2, EA3.3

- AM1: EA2.1, EA2.2, EA2.3

- AM2: EA2.1, EA2.2, EA2.3

- AA1: EA1.1, EA1.2, EA1.3

- AA2: EA1.1, EA1.2, EA1.3

iv. Puesta a punto del EVEA

A efectos que cada uno de los usuarios evaluadores pueda realizar el análisis del entorno virtual, éste debe encontrarse instalado en un servidor y disponible para ser accedido para su evaluación desde distintas computadoras. Sin embargo, esto solo no es suficiente ya que además debe recrearse, aunque sea mínimamente, un ambiente de trabajo dentro del EVEA. Por ello, es necesario montar y configurar un aula virtual dentro de la cual los usuarios puedan desenvolverse sin inconvenientes de acuerdo los escenarios propuestos.

v. Elección de un laboratorio de usabilidad

Dependiendo de los recursos disponibles es posible poner en marcha la sesión de evaluación en un laboratorio de usabilidad real, o generar las condiciones necesarias dentro de un aula con computadoras que permita albergar a todos los usuarios y evaluadores. La idea principal es poder generar un ambiente lo más similar posible al contexto de uso real, donde se reproduzcan las situaciones habituales que se dan durante la actividad diaria, tanto en el ambiente de trabajo como en los recursos hardware, software, y conectividad.

\section{Evaluación}

vi. Análisis del EVEA

Los usuarios toman el cuestionario y lo completan analizando el entorno desde el punto de vista de la usabilidad, utilizando los escenarios y roles asignados. Como varios usuarios adquieren el mismo rol es necesario realizar sesiones de trabajo diferentes para que éstos no se superpongan. Las sesiones de test deben organizarse de manera tal que sea posible generar un simulacro a partir de los escenarios propuestos. Los escenarios tienen cierta correlación entre ellos que debe respetarse para poder realizar las tareas previstas en los mismos. Por tal motivo los usuarios pueden plantearse de la siguiente manera:

Sesión 1: DA1, DN2, AN1, AM1, AA1

Sesión 2: DN1, DA2, AN2, AM2, AA2 
Cada sesión debe ser coordinada y monitoreada por un observador. En tal sentido se propone que cada sesión cuente con una persona diferente para garantizar mayor objetividad.

\section{Sesión 1: a cargo de $\mathrm{O} 1$ y $\mathrm{O} 2$ \\ Sesión 2: a cargo de $\mathrm{O} 3$ y $\mathrm{O} 4$}

\section{Cierre}

vii. Recopilación de datos e informe

Los observadores recopilan los cuestionarios y los analizan. Luego realizan una puesta en común de sus observaciones, debaten y elaboran un único informe donde se ve reflejado el análisis realizado por cada uno de ellos y los acuerdos alcanzados.

\subsubsection{Cuarta capa}

Se trata de una evaluación del entorno bajo condiciones reales de uso, es decir, en un contexto establecido y con usuarios reales. Recordemos que no hay usabilidad sin contexto y sin usuarios, la usabilidad se aplica a usuarios concretos en contextos determinados [Vil03].

Las dos primeras capas utilizan los expertos para evaluar el EVEA, mientras que la tercera y la cuarta hacen lo propio pero con usuarios reales. En particular, la tercera capa involucra a los usuarios a partir de un ambiente controlado, con la participación de observadores que guían, facilitan y registran el proceso. Esta cuarta, y última capa, hace lo propio pero dentro de un contexto real de uso, sin laboratorios de usabilidad, ni observadores, es decir, en un ambiente totalmente natural donde intervienen otras variables como la ubicación geográfica, puntos de acceso, tipos de equipamiento y acceso a la red, tipos de software y versiones, además de las tenidas en cuenta en la tercera capa [Fer2011].

La intención de la cuarta capa es conocer la opinión de los usuarios finales brindándoles la posibilidad de que aporten su punto de vista desde un contexto o ambiente real. Para realizar este tipo de evaluación también son adecuados los test de usuarios, en particular los test remotos porque son eficaces, rápidos y simples de suministrar [Hom03] [Mon06]. La idea es que el usuario realice el test en su propio lugar de estudio o trabajo, de manea tal que sea posible evaluar el contexto de uso. Los test remotos se basan principalmente en el uso de cuestionarios para recolectar la información. También se utilizan herramientas que analizan los "rastros" dejados por los usuarios mientras interactúan con el sistema. El evaluador es el encargado de elaborar, y suministrar el cuestionario. Luego de concluida la tarea por parte de los usuarios, y respondido el cuestionario, debe procesar los resultados. Para ello utiliza las respuestas recibidas, enriquecidas con el análisis del comportamiento del usuario dentro del entorno virtual durante el test.

Al igual que en las capas anteriores es importante que los usuarios involucrados en los test abarquen los diferentes roles y posean distintos niveles de experiencia en el uso del servicio Web.

\subsubsection{Evaluación real o simulada}

Para brindar flexibilidad al modelo de evaluación es posible aplicar esta última capa de dos maneras diferentes. La más sencilla es hacerlo sobre un EVEA que se esté utilizando, 
es decir, basarnos en el uso real del entorno virtual por parte de usuarios alumnos y docentes, en uno o varios cursos que tengan cierta semejanza con los escenarios de uso definidos anteriormente. La otra alternativa es recrear en el EVEA los escenarios que se definieron, es decir, generar espacios virtuales para contener cursos e invitar a participar a docentes y alumnos. En este caso el curso no es real sino un simulacro, donde el contenido de aprendizaje no tiene relevancia, pero los participantes son alumnos y docentes que trabajaran en sus propios contextos [Fer2011].

La evaluación real es una alternativa simple para cuando los recursos humanos son escasos, se necesita una evaluación más rápida, o el EVEA a evaluar ya está en funcionamiento dentro de la Institución, y cuenta con cursos adecuados para realizar la evaluación sin necesidad de recrear una situación hipotética. Este tipo de evaluación presenta una serie desventajas ya que al tomarse uno o varios cursos reales, algunas tareas pueden no estar presentes, la cantidad de evaluadores no será la misma que para una evaluación simulada, y tampoco existe garantía de que estén representados todos los tipos de usuarios. Para reducir estos riesgos deben seleccionarse cuidadosamente los cursos y asegurarse que la cantidad de usuarios sea representativa en cantidad y experticia [Fer2011].

A continuación se desarrolla la forma de implementar la evaluación simulada, la cual servirá como guía para el caso de optar por la evaluación real.

\subsubsection{Evaluadores}

Como los evaluadores que intervienen en esta etapa del proceso no son expertos sino usuarios finales, entendemos que cada uno aportará menos información que un experto, ya que no posee conocimiento específico sobre usabilidad y solo interactuará con el EVEA desde su propio contexto de uso. En la capa anterior propusimos trabajar con 10 usuarios en total. En esta ocasión, es factible trabajar con 15 usuarios docentes y 27 usuarios alumnos, distribuidos de acuerdo a su experticia (novato, medio, avanzado). Consideramos que es el número suficiente de evaluadores para obtener una visión general del contexto. Claro está, que es una cota mínima, pero no impide que puedan incorporarse más. Otro dato a tener en cuenta es que la evaluación no es obligatoria, y el usuario no está en contacto con el evaluador. Por tal motivo, el proceso puede dirigirse a una muestra de usuarios mayor, fundamentalmente en el caso de los alumnos, con el objetivo de alcanzar por lo menos este piso con diferente nivel de experiencia y frecuencia en el uso de Internet. A los efectos del desarrollo de la capa de evaluación tomaremos esta cantidad mínima de usuarios como referencia.

- Docentes novatos: 5 (DN1, DN2, DN3, DN4, DN5)

- Docentes medios: 5 (DM1, DM2, DM3, DM4, DM5)

- Docentes avanzados: 5 (DA1, DA2, DA3, DA4, DA5)

- Alumnos novatos: 9 (AN1, AN2, AN3, AN4, AN5, AN6, AN7, AN8, AN9,)

- Alumnos medios: 9 (AM1, AM2, AM3, AM4, AM5, AM6, AM7, AM8, AM9)

- Alumnos avanzados: 9 (AA1, AA2, AA3, AA4, AA5, AA6, AA7, AA8, AA9)

Los usuarios evaluadores no están cara a cara con el observador sino que deben realizar las tareas de manera autónoma y luego completar un cuestionario con el fin de volcar su opinión en el mismo. Este tipo de evaluación posibilita el uso de herramientas tecnológicas tanto para el suministro del cuestionario como para el procesamiento de los resultados. No debemos olvidar que aquí interviene muy fuertemente el contexto de uso, 
el cual puede ser muy diverso, y por lo tanto, es necesario contar con una muestra lo suficientemente significativa como para abarcar distintos contextos respecto al entorno donde se desarrolla la actividad, ubicación geográfica, recursos técnicos, horarios, etc. Mediante las herramientas de análisis de comportamiento del usuario puede obtenerse información respecto a la procedencia geográfica del usuario, así como también conexión, software y versión utilizados. De esta manera podemos decidir cuándo finalizar la evaluación, ya que nunca tendremos respuesta del 100\% de los usuarios muestreados.

\subsubsection{Roles}

Tres docentes, de los 15 seleccionados, tomarán el rol de responsable, y los 12 restantes el rol de los tutores. Los alumnos se distribuirán uniformemente entre los tres roles definidos. La distribución de roles entre los 42 usuarios es la siguiente:

\begin{tabular}{|l|l|}
\hline \multicolumn{1}{|c|}{ Evaluador } & \multicolumn{1}{c|}{ Rol } \\
\hline DN1, DM1, DA1 & Docente Responsable Fabio \\
\hline DN2, DN3, DM2, DM3, DA2, DA3 & Docente Tutor Julián \\
\hline DN4, DN5, DM4, DM5, DA4, DA5 & Docente Tutor Nahuel \\
\hline $\begin{array}{l}\text { AN1, AN2, AN3, AM1, AM2, AM3, AA1, AA2, } \\
\text { AA3 }\end{array}$ & Alumno Ailén \\
\hline $\begin{array}{l}\text { AN4, AN5, AN6, AM4, AM5, AM6, AA4, AA5, } \\
\text { AA6 }\end{array}$ & Alumno Agustín \\
\hline $\begin{array}{l}\text { AN7, AN8, AN9, AM7, AM8, AM9, AA7, AA8, } \\
\text { AA9 }\end{array}$ & Alumno Ana \\
\hline
\end{tabular}

Tabla 14 - Roles adjudicados a cada tipo de evaluador

\subsubsection{Escenarios}

Al situarnos en un contexto real, algunos aspectos de los escenarios pierden vigencia y otros no. Por tal motivo, es posible que los usuarios y la asignatura elegida no cumplan cabalmente con el perfil determinado en el contexto de uso particular y general desarrollado en el ítem 4.4. De todas formas, al igual que en la tercera capa, se utilizarán todos los escenarios definidos en el ítem 4.5, es decir 21, porque posibilitan otorgarle claridad y coherencia a la evaluación. Una posible forma de distribuir los escenarios entre los diferentes roles es la siguiente:

\begin{tabular}{|l|l|l|}
\hline \multicolumn{1}{|c|}{ Evaluador } & \multicolumn{1}{|c|}{ Rol } & \multicolumn{1}{c|}{ Escenarios } \\
\hline DN1, DM1, DA1 & Docente Responsable Fabio & $\begin{array}{l}\text { EDR1.1, EDR2.1, } \\
\text { EDR3.1, EDR4.1 }\end{array}$ \\
\hline $\begin{array}{l}\text { DN2, DN3, DM2, DM3, } \\
\text { DA2, DA3 }\end{array}$ & Docente Tutor Julián & $\begin{array}{l}\text { EDT2.1, EDT2.2, } \\
\text { EDT3.2, EDT4.2 }\end{array}$ \\
\hline $\begin{array}{l}\text { DN4, DN5, DM4, DM5, } \\
\text { DA4, DA5 }\end{array}$ & Docente Tutor Nahuel & $\begin{array}{l}\text { EDT1.1, EDT2.1, } \\
\text { EDT3.1, EDT4.1 }\end{array}$ \\
\hline $\begin{array}{l}\text { AN1, AN2, AN3, AM1, } \\
\text { AM2, AM3, AA1, AA2, } \\
\text { AA3 }\end{array}$ & Alumno Ailén & $\begin{array}{l}\text { EA3.1, EA3.2, } \\
\text { EA3.3 }\end{array}$ \\
\hline
\end{tabular}




\begin{tabular}{|l|l|ll|}
\hline AN4, AN5, AN6, AM4, & Alumno Agustín & EA2.1, & EA2.2, \\
AM5, AM6, AA4, AA5, & & EA2.3 & \\
AA6 & & $\begin{array}{l}\text { EA1.1, } \\
\text { AN7, AN8, AN9, AM7, }\end{array}$ & EA1.2, \\
AM8, AM9, AA7, AA8, & & EA1.3 & \\
AA9 & & \\
\hline
\end{tabular}

Tabla 15 - Escenarios adjudicados a cada evaluador por rol

Como podemos observar, existen escenarios compartidos entre diferentes usuarios, algunos de los cuales, poseen igual nivel de experticia y otro no. De esta manera, es posible evaluar su comportamiento sobre un mismo escenario y detectar así problemas comunes de usabilidad. Por ejemplo, los escenarios EA1.1, EA1.2, EA1.3 que corresponden al alumno Ana, son compartidos por AN7, AN8, AN9, AM7, AM8, AM9, AA7, AA8, AA9, entre los cuales hay tres grupos, de tres alumnos cada uno, de acuerdo al nivel de experticia (novatos, medios y avanzados). Ello marca una diferencia con la tercera capa donde la cantidad de evaluadores impedía este tipo de distribución.

Es importante señalar que el hecho de compartir un rol no equivale a reducir los usuarios a uno solo, sino que cada uno de esos usuarios posee un perfil y contexto de uso similar al otorgado.

\subsubsection{Modo de organización}

Debido a la cantidad de usuarios involucrados es importante tener en cuenta que no comparten un único espacio virtual de trabajo. Debe buscarse alguna forma de distribuirlos que sea representativa y heterogénea, es decir, donde tengan posibilidad de interactuar usuarios con diferentes roles y niveles de experticia. Para esta cantidad de usuarios, y para que la evaluación no se torne caótica, debe generarse una cantidad suficiente de cursos, compuestos de dos comisiones o grupos cada uno.

\subsubsection{Selección de usuarios}

Además de la voluntad manifiesta del usuario en participar de la evaluación, es necesario conocer sus características básicas para poder determinar su nivel de experticia (novato, medio, avanzado) y su contexto general. De esta manera se le podrá asignar un rol adecuado a cada uno. Para ello, debe realizarse un proceso de selección de los mismos que posibilite agruparlos en función de los escenarios planteados. La forma elegida para realizar esta tarea es mediante una encuesta auto-administrada de forma on-line. El instrumento respectivo se desarrolla en el Anexo G.

\subsubsection{Duración}

Los tiempos de la evaluación seguramente serán más largos que en las capas anteriores porque los evaluadores se encuentran bajo una situación real, es decir, realizan su vida cotidiana naturalmente, sin presiones, reuniones ni observadores. De todas formas, el período de evaluación debe tener un plazo máximo, aunque no todos hayan terminado las tareas por falta de tiempo o compromiso. Se estima adecuado pautar en una semana el plazo máximo para realizar las tareas planteadas en los escenarios. Cumplido ese plazo, el evaluador puede comenzar al procesamiento de los datos. 


\subsubsection{Cómo evaluar}

La cuarta capa se propone evaluar el EVEA desde el punto de vista del usuario real, a partir de la participación de los mismos desde su propio contexto. Por tal motivo, elaboramos un test de usuario remoto. El usuario final debe situarse en un escenario concreto e interactuar con el entorno realizando tareas como si estuviera participando de un curso, asignatura, o capacitación con modalidad virtual. Además debe completar un cuestionario, una vez concluidas las tareas de cada escenario, y al terminar con todas las tareas solicitadas debe completar otro.

El test de usuario remoto está compuesto por tres cuestionarios, dos destinados al usuario final, para la evaluación directa, y uno al observador, para la evaluación indirecta. En este sentido, es similar a la tercera capa pero el observador nunca toma contacto directo con el usuario.

\subsection{Evaluación directa}

Los criterios tomados para la evaluación directa son similares a los definidos en la capa 2 y 3. En tal sentido se propone una evaluación de alto nivel orientada a la tarea y otra orientada a analizar el diseño y atributos de usabilidad como: eficiencia, efectividad y satisfacción. En el caso de la evaluación orientada a la tarea, las heurísticas y forma de evaluación son idénticas, mientras que las heurísticas orientadas al diseño se mantienen, pero reduciendo la cantidad de subheurísticas.

Al compartir los criterios también se comparten algunos instrumentos de evaluación. El cuestionario orientado a la tarea, que fuera utilizado por los expertos en la capa 2, y los usuarios en la capa 3, también será utilizado en esta capa. El cuestionario orientado al diseño y atributos de usabilidad, es muy similar al utilizado en las capas 2 y 3 . Para evitar confusiones, en el anexo $\mathrm{H}$, ítem 1 , se presentan todos los instrumentos de evaluación utilizados.

\subsection{Evaluación indirecta}

La evaluación indirecta pretende recabar información sobre un conjunto de métricas de usabilidad que intentan medir el grado de efectividad, eficiencia y satisfacción del entorno virtual en un contexto de uso determinado. Para ello el observador procesa y sintetiza los cuestionarios completados por los evaluadores docentes y alumnos, accede a los datos arrojados por el análisis de log, y navega las aulas virtuales utilizadas durante el test para determinar el grado de completitud de las tareas planteadas en los escenarios. Todo ello lo vuelca en un cuestionario que resume la opinión de los usuarios finales, según su rol y experticia, sumado a las huellas que los mismos dejaron dentro de las aulas virtuales durante el proceso de realización de las tareas propuestas en cada escenario de uso. El anexo $\mathrm{H}$, ítem 2, contiene el instrumento específico.

\subsubsection{Forma de aplicación}

Al igual que en la capa anterior, se propone realizar un test de usuario dividido en tres etapas: planificación, evaluación y cierre. La fase de planificación permitirá tomar decisiones respecto al tipo de evaluación a realizar, selección de los evaluadoresusuarios, asignación de roles, distribución de escenarios, puesta a punto del entorno, y distribución de los evaluadores-usuarios en cada uno de los cursos. La evaluación es el punto central del proceso donde los usuarios reales usan y analizan el EVEA. El cierre permite obtener el informe final con la opinión de los usuarios y el análisis de log. 


\section{Planificación}

i. Elección del tipo de evaluación: real o simulada

La evaluación real es la más sencilla ya que se realiza sobre un EVEA en uso. La otra alternativa es realizar una evaluación simulada recreando en el EVEA los escenarios definidos, confeccionando cursos para tal fin, e invitando a participar a los usuarios alumnos y docentes.

a. Evaluación real

Deben seleccionarse cuidadosamente un conjunto de cursos donde se asegure que la cantidad de usuarios y experticia de los mismos sea lo más cercana posible a la evaluación simulada, y con una la distribución de los usuarios acorde a como se plantearon los escenarios de uso.

Se sugiere tomar tres cursos de dos comisiones cada uno, que poseen un docente responsable y dos tutores, 9 docentes en total. La cantidad de alumnos activos de cada curso no debería ser inferior a 10; 30 en total. Consideramos a un alumno como activo cuando participa regularmente del curso y realiza las tareas demandadas. Los tres cursos seleccionados deben poseer un contexto de uso lo más cercano posible al definido anteriormente.

b. Evaluación simulada

- Definición de la cantidad de evaluadores-usuarios y perfil de cada uno

Distinguimos dos tipos de usuarios: docentes y alumnos. Para cada tipo se toman los mismos niveles de experiencia y frecuencia en el uso de Internet que los utilizados en la tercera capa, es decir, novato, medio y avanzado. La cantidad mínima de usuarios propuesta para el test es de 42 , de los cuales 15 deben ser docentes y 27 alumnos.

- Selección de los usuarios

Para elegir a los usuarios que participarán del test es necesario realizar una invitación a un conjunto de alumnos y docentes. Los interesados no pasan automáticamente a ser evaluadores sino que deben completar una encuesta auto-administrada de forma on-line para conocer sus características básicas y contexto de uso.

Luego de obtener la muestra mínima de usuarios en base a la encuesta, deben formarse grupos de acuerdo al nivel de experticia y asignarles un nombre a cada uno:

- Docentes novatos: 5 (DN1, DN2, DN3, DN4, DN5)

- Docentes medios: 5 (DM1, DM2, DM3, DM4, DM5)

- Docentes avanzados: 5 (DA1, DA2, DA3, DA4, DA5)

- Alumnos novatos: 9 (AN1, AN2, AN3, AN4, AN5, AN6, AN7, AN8, AN9)

- Alumnos medios: 9 (AM1, AM2, AM3, AM4, AM5, AM6, AM7, AM8, AM9)

- Alumnos avanzados: 9 (AA1, AA2, AA3, AA4, AA5, AA6, AA7, AA8, AA9) 
- Asignación de roles a cada evaluador

- Cada uno de los usuarios seleccionados tomará el rol de acuerdo a lo expresado en la sección 5.4 .3

- Distribución de escenarios a los evaluadores

Al igual que en la tercera capa, se utilizarán todos los escenarios definidos porque posibilitan otorgarle claridad y coherencia a la evaluación. La distribución es acorde a cómo se plantearon los escenarios.

- Puesta a punto del EVEA

A efectos que cada uno de los usuarios evaluadores pueda realizar el análisis del entorno virtual, éste debe encontrarse instalado en un servidor y disponible para ser accedido para su evaluación desde distintas computadoras ubicadas en cualquier punto geográfico. Sin embargo, esto solo no es suficiente ya que además debe recrearse, aunque sea mínimamente, un ambiente de trabajo dentro del EVEA. Por ello, que es necesario montar y configurar una serie de cursos para que los usuarios puedan desenvolverse sin inconvenientes de acuerdo los escenarios propuestos.

- Distribución de usuarios por aula virtual

Los usuarios serán distribuidos en los cursos de manera representativa, garantizando heterogeneidad en la composición de los mismos.

\section{Evaluación}

ii. Análisis del EVEA

En caso que se haya optado por la evaluación real, cada usuario debe completar un cuestionario cuando finaliza con todas las tareas solicitadas.

La evaluación simulada, en cambio, demanda que cada usuario complete dos cuestionarios: uno cuando finaliza con las tareas de cada escenario, y otro cuando termina con todas las tareas solicitadas. El primero es completado tantas veces como escenarios tenga asignado el usuario, mientras que el segundo es completado una sola vez.

El proceso de evaluación dura una semana, pero puede extenderse en el caso que las tareas no hayan sido completadas por la cantidad mínima de evaluadores exigidos, 42 usuarios (15 docentes y 27 alumnos) para la evaluación simulada, y aproximadamente el $50 \%$ para la evaluación real. Cumplido ese plazo se da por finalizada la evaluación.

\section{Cierre}

iii. Recopilación de datos e informe

El observador procesa y sintetiza los cuestionarios completados por los docentes y alumnos, accede a los datos arrojados por el análisis de log, y navega por las aulas virtuales utilizadas durante el test a los efectos de determinar el grado de completitud de las tareas planteadas en los escenarios. Todo ello lo vuelca en un informe que resume la opinión de los usuarios finales según su rol y experticia, sumado a las huellas que los mismos dejaron dentro 
de las aulas virtuales durante el proceso de realización de las tareas propuestas en cada escenario de uso.

\subsection{Conclusiones}

El modelo que se acaba de presentar está orientado a una evaluación de producto, es decir, sobre entornos virtuales que ya han sido desarrollados, y están en pleno funcionamiento. El modelo se denomina MUsa, dado que se trata de un Modelo centrado en la Usabilidad. La evaluación se apoya en escenarios reales de uso, teniendo especial consideración por los alumnos y docentes, los objetivos que se proponen, las tareas específicas que realizan dentro del entorno durante las actividades de enseñanza y aprendizaje, el modelo mental que utilizan, el equipamiento e infraestructura que disponen, el lugar físico donde habitualmente se desenvuelven, y el entorno social en el cual están insertos. MUsa también puede facilitar la evaluación de nuevas versiones, o la comparación entre ellas.

Las ideas generales de MUsa están basadas en una estrategia de cuatro niveles o capas de evaluación, que parten de lo general para llegar a lo particular. Las cuatro capas persiguen objetivos diferentes. La primera es la encargada de realizar una evaluación del entorno en general, las tres capas restantes se sitúan en un contexto de uso particular, por ejemplo, el aula virtual de un curso. Para ello, las capas más cercanas al usuario utilizan escenarios de uso que permiten guiar y sistematizar la evaluación. En cada caso se utilizan métodos, técnicas, e instrumentos diferentes, que se complementan entre sí y posibilitan enriquecer la evaluación. Las capas propuestas pueden ajustarse a distintos contextos dependiendo de la necesidad, nivel de profundidad de la evaluación, recursos y tiempo disponible. MUsa puede adaptarse en dos sentidos, prescindiendo completamente de algunas de las capas, o seleccionando diferentes alternativas dentro de la segunda capa.

La primera capa de MUsa está destinada a analizar gran parte de la aceptabilidad práctica del EVEA. La aceptabilidad práctica conjuga la utilidad con otras variables como costos, compatibilidad, confiabilidad, y soporte. La utilidad, a su vez, está determinada por la utilidad práctica o funcional, la usabilidad, y la accesibilidad. Por este motivo se aborda el análisis de todos los componentes de la aceptabilidad práctica, menos el referido específicamente a usabilidad. Esto no significa que la evaluación de usabilidad esté ausente por completo en esta capa, sino que las variables que se analizan son: utilidad práctica y accesibilidad (parte de la utilidad), junto con las características técnicas generales (antecedentes, potencial, tecnología utilizada, licencia, soporte, seguridad, acceso de usuarios), compatibilidad (servidor, usuario/cliente, formatos multimedia, integración) y robustez (integridad de funcionamiento, recuperación ante fallos, seguridad). En este sentido se pone énfasis sobre las características funcionales del EVEA, donde se considera la flexibilidad del entorno desde el punto de vista tecnológico, organizativo, y pedagógico/didáctico, incluyendo además el nivel de estandarización. Un punto que toma especial relevancia es la versatilidad del entorno para adaptarse al desarrollo de cursos, grupos de cursos, carreras, comunidades virtuales, etc. También es importante evaluar la forma en que puede dar soporte a diferentes modalidades educativas, sean éstas a distancia o mixtas, y a diferentes enfoques de enseñanza y de aprendizaje. Para analizar este tipo de características es necesario contar con especialistas en educación y en tecnología. La primera capa de evaluación pone énfasis sobre las coincidencias entre los modelos estudiados en el capítulo 2, con la idea de construir un instrumento de evaluación general, centrado en los componentes tecnológicos de los EVEA, pero sin perder de vista los componentes organizativos, 
pedagógicos y didácticos, ya que todos son determinantes al momento de analizar un entorno particular.

La segunda capa se orienta a evaluar la forma en que el sistema interactúa con el usuario, la interfaz que presenta, y el modo en que permite realizar las tareas básicas. La conjugación de dos métodos de inspección, como el recorrido cognitivo y la evaluación heurística, resulta ser adecuada para este tipo de acciones. Las heurísticas utilizadas se organizaron en dos niveles de evaluación, uno general, orientado a la tarea, y otro particular, orientado al diseño. El primero examina el aspecto y comportamiento desde el punto de vista de las tareas y objetivos de los usuarios. Para ello se utilizan las heurísticas de complejidad, visibilidad, intuitividad, y topografía natural. El segundo analiza los aspectos concretos del conjunto de interfaces provistas por el EVEA para completar las tareas. Las heurísticas utilizadas en este caso son las de productividad, retroalimentación, control por parte del usuario, reversibilidad y manejo del error, diseño y organización, consistencia, ayuda y documentación, y estándares. La forma de evaluación se realiza por escenarios de uso. Por el tipo de evaluación, los expertos que participan son docentes con diferente grado especialización en EVEA y en tecnología.

La tercera capa incorpora, por primera vez, la opinión de los usuarios finales bajo un ambiente controlado por un observador. Por tal motivo se utiliza un laboratorio de usabilidad. La evaluación se realiza mediante test de usuario, específicamente el de expresión del usuario en base a preguntas. Las heurísticas utilizadas son las mismas que en la capa anterior (complejidad, visibilidad, intuitividad, y topografía natural). A ellas se suman una serie de las métricas relacionadas con efectividad, eficiencia, y satisfacción. Los usuarios transitan escenarios de uso para realizar las tareas que forman parte de cada escenario tipo. A medida que el usuario interactúa con el entorno, debe expresar en voz alta sus pensamientos, sensaciones y opiniones, mientras el evaluador capta y registra las impresiones que el usuario manifiesta oralmente. Además puede realizar preguntas directas cuando lo considera conveniente.

La cuarta capa es destinada exclusivamente a que los futuros usuarios finales aporten su punto de vista dentro de un contexto o ambiente real. Lógicamente, para realizar este tipo de evaluación también son adecuados los test de usuarios, en particular se utilizó el test remoto. Además, el usuario realiza el test en su propio medio o ambiente, con lo cual es posible evaluar el contexto de uso. Los test remotos se basan, principalmente, en cuestionarios para recolectar la información. Las heurísticas coinciden con las utilizadas en la segunda capa para la evaluación orientada a la tarea (complejidad, visibilidad, intuitividad, y topografía natural), y al diseño (productividad, retroalimentación, control por parte del usuario, reversibilidad y manejo del error, diseño y organización, consistencia, ayuda y documentación, y estándares). Al igual que en la segunda y tercera capa se utilizan los escenarios de uso. El evaluador es el encargado de suministrar un cuestionario a los usuarios reales, examinar las aulas virtuales luego de finalizadas las tareas, y posteriormente procesar los resultados. También completa un cuestionario que contempla las métricas de efectividad, eficiencia, y satisfacción. 


\section{Capítulo 8: Caso de estudio. Aplicación de MUsa}

\subsection{Sistema Informático de Apoyo a la Teleformación - SIAT}

Las Universidades Nacionales, en tanto activos actores educativos, no estuvieron ajenas a la inserción de las TIC en la educación. Desde los años 90 fortalecieron notablemente la investigación y el desarrollo de capacitaciones en modalidad a distancia usando Internet, particularmente entornos virtuales de enseñanza y aprendizaje. Dichos entornos fueron adquiridos o alquilados a empresas proveedoras, tanto nacionales como internacionales, desarrollados por comunidades de software libre o por las propias Universidades.

El Sistema Informático de Apoyo a la Teleformación (SIAT) es un EVEA que posibilita generar espacios de comunicación e información en Internet para que los equipos docentes puedan interactuar fluidamente con sus alumnos, ya sea durante el cursado de la asignatura o previo a las instancias de evaluación final. Está basado en tecnología Web de última generación respetando los estándares internacionales de diseño, es orientado a objetos y desarrollado en JAVA. Se trata de un desarrollo propio construido íntegramente por la Universidad Nacional de Río Cuarto (UNRC), Argentina. Actualmente su equipo de desarrollo trabajando de manera conjunta con el Instituto Nacional de Tecnología Industrial (INTI) en un proyecto para liberar el código bajo alguna licencia libre.

Este entorno permite distribuir materiales educativos en formato digital y acceder a ellos, realizar debates y discusiones on-line, integrar contenidos relevantes de la Web, publicar información en formato hipertextual, etc. A tal efecto provee una serie de herramientas a saber:

- Herramientas para facilitar el aprendizaje, la información, comunicación y la colaboración.

- Herramientas para la gestión del curso y materiales de aprendizaje.

- Herramientas para el diseño de la interfaz de usuario, la gestión de las participantes, seguimiento y evaluación del progreso de los alumnos.

- Herramientas para gestión del Campus Virtual.

EI SIAT es lo suficientemente versátil como para no condicionar la propuesta pedagógica y permitir un amplio abanico de posibilidades. Por este motivo se encuentra estructurado por niveles: Campus, Facultades, Aulas Virtuales, Comisiones, y Grupos, dentro de los cuales se pueden incorporar una serie de herramientas y de recursos. Por su parte, cada herramienta puede ser adaptada a las necesidades de los diferentes tipos de usuarios (alumnos, profesores, jefes de trabajos prácticos, auxiliares, ayudantes, etc.).

Para llevar adelante las tareas educativas el entorno SIAT pone a disposición espacios virtuales que utilizan los diferentes servicios de Internet, herramientas y recursos, registrando todo el flujo de información producido a lo largo de la actividad educativa, que luego puede ser consultada de diferentes maneras a los efectos de extraer información útil para el desarrollo, seguimiento y evaluación. Estos espacios son comúnmente denominados Aulas Virtuales. Cada Aula Virtual cuenta con los elementos necesarios a los efectos de poder cursar, tutorizar, gestionar, administrar y evaluar las actividades educativas. Además facilitan la generación de los procesos de comunicación entre docentes y alumnos que no pueden llevarse a cabo de manera presencial.

EI SIAT posibilita construir Aulas Virtuales divididas en comisiones, de manera tal que pueda reflejarse la forma organizativa actual en las asignaturas de la universidad. 
También permite generar grupos de estudio y trabajo con herramientas y recursos específicos.

Existen tres tipos distintos de Aulas Virtuales según las necesidades de la propuesta pedagógica:

- Aulas virtuales públicas: espacio educativo abierto cuyo contenido está libremente disponible en Internet. Son de acceso irrestricto por cualquier internauta y poseen cartelera virtual, materiales de aprendizaje, calendario de eventos, información general y foro.

- Aulas virtuales simples: espacio propio de una asignatura que permite relacionar a docentes y alumnos específicos mediante acceso autenticado (usuario y contraseña), una sola comisión, y herramientas básicas como cartelera de noticias, materiales de aprendizaje, calendario de eventos, foro, e información general.

- Aulas virtuales avanzadas: espacio propio de una asignatura que permite relacionar a docentes y alumnos específicos mediante acceso autenticado (usuario y contraseña), divididos en una o más comisiones, y con herramientas básicas y avanzadas como cartelera de noticias, pizarrón virtual, materiales de aprendizaje generales y particulares, calendario de eventos, grupos, foros, correo electrónico, estadísticas, preguntas frecuentes, actividades y evaluación.

El Campus Virtual está formado por todas las aulas virtuales, sean éstas públicas, simples o avanzadas, y se rige por una serie de derechos intelectuales y condiciones de utilización expresados en un acuerdo de Términos y Condiciones de Uso del Campus Virtual SIAT [TCU11].

\subsubsection{Derechos intelectuales}

La Universidad Nacional de Río Cuarto (UNRC) es titular o mantiene contratos con los titulares de los derechos intelectuales sobre la página Web, su diseño, códigos, textos, ilustraciones, nombres, signos distintivos y demás elementos que integran la Web y son susceptibles de tutela de conformidad a la legislación argentina y tratados internacionales.

La UNRC no concede licencia o autorización de uso alguno de sus derechos intelectuales sobre los elementos mencionados $u$ otros derechos relacionados, excepto los derechos sobre los materiales de enseñanza cuya utilización y divulgación está permitida bajo los términos que figuran en sus propias licencias.

La licencia permite la reutilización, traducción, adaptación o redistribución con la restricción de que las obras sean usadas sin fines comerciales, que sean atribuidos a la institución y a los autores originales y que los contenidos resultantes de su reutilización se ofrezcan bajo idénticas condiciones de uso.

\subsubsection{Condiciones de utilización}

La utilización del Campus Virtual SIAT de la UNRC está autorizada bajo los términos de una licencia Creative Commons Atribución - No Comercial - Compartir Derivadas Igual 2.5 (Argentina). Los materiales incluidos dentro de las aulas virtuales poseen sus propias licencias.

Es obligatorio que los usuarios respeten y reconozcan la autoría de las obras, haciendo mención expresa en cualquier utilización autorizada, aún en las obras derivadas, 
mediante cualquiera de las modalidades de cita usadas habitualmente en los contextos académicos o científicos.

La UNRC no se responsabiliza por las eventuales consecuencias dañosas de la utilización que los usuarios hagan de los materiales, recursos y contenidos incluidos en el Campus Virtual, siendo de la exclusiva responsabilidad de ellos.

\subsubsection{Evolución del SIAT}

La Secretaría de Extensión y Desarrollo de la UNRC comenzó durante el año 2001 el desarrollo de un sistema informático con el objetivo de generar una herramienta para ofrecer cursos a graduados en modalidad no presencial utilizando medios telemáticos, más precisamente Internet. Al sistema se lo denominó Sistema Informático de Apoyo a la Teleformación (SIAT). Los componentes principales fueron implementados y testeados en el año 2002 mediante los casos de test tradicionales y la realización de un curso "piloto" destinado a los Coordinadores de Centros Tecnológicos Comunitarios (CTC) dependientes del Programa "argentina@internet.todos" de la Secretaría de Comunicación de la Nación.

Durante el año 2002, y a partir de la interacción con docentes relacionados a la temática, la inminente implementación de cursos de grado a distancia en la Facultad de Ciencias Económicas, se consideró necesario realizar una serie de mejoras en la eficiencia, incorporación de nuevas funcionalidades y un adecuado diseño comunicacional del portal Web donde funcionaba el sistema. Hacia mediados del mismo año el SIAT se comenzó a utilizar para el desarrollo del una capacitación con modalidad a distancia organizada por la RED Universitaria Centro OESte (REDCOES). Se trató de una iniciativa interuniversitaria que surgió para impulsar la educación a distancia entre las Universidades Nacionales de Córdoba, Río Cuarto, Villa María, San Luis, San Juan, La Rioja y Cuyo. La REDCOES creó, organizó y llevó a cabo esta iniciativa mancomunada de las universidades participantes en dos ediciones del Curso Interuniversitario de Educación a Distancia, en las que se capacitaron más de 800 docentes, con la ayuda de 16 tutores y 13 comisiones o grupos de alumnos. La magnitud y modalidad de este curso permitió capturar nuevas necesidades de los cursos a distancia que no habían sido previstas hasta el momento, y una vez concluido su desarrollo, ganar en calidad y potencial.

En el año 2003 se desarrollaron nuevos módulos a partir de la experiencia adquirida durante el año anterior. Además se comenzó a delinear la nueva versión que permitiera capturar toda la experiencia recogida y brindara más flexibilidad a la hora de desarrollar y administrar cursos. Sumado al desarrollo de software propiamente dicho se trabajó en el soporte a nuevas propuestas de cursos con modalidad semipresencial y a distancia. Dentro de las mismas se destacan las materias de primer y segundo año correspondientes al Ciclo Básico de la Carreras a distancia de la Facultad de Ciencias Económicas de la Universidad.

Desde el año 2004 se comenzó con el desarrollo de la nueva versión del SIAT, logrando concluir las etapas de análisis de requerimientos y diseño. Paralelamente se realizó una personalización para el Ministerio de Educación de la Provincia de Córdoba que capacitó a 2.000 docentes de nivel medio de toda la provincia en tres temáticas diferentes.

A lo largo del año 2005 se brindó apoyo a las carreras de grado de la Facultad de Ciencias Económicas, pero también se sumaron otras Facultades de la Universidad como Agronomía y Veterinaria, Ciencias Humanas, Ingeniería y Ciencias Exactas, que realizaron actividades de pre-ingreso y apoyo a las asignaturas presenciales. 
En el año 2006 se realizaron varias tareas en paralelo. Por un lado se concluyó con el núcleo básico de la nueva versión del SIAT: agenda, alertas, materiales compartidos, calificaciones, envío y evaluación de actividades, pizarrón, noticias, preguntas frecuentes, foro, perfil, niveles de jerarquía y diseño comunicacional. Un evento destacable fue el desarrollo del curso "Entornos Virtuales", llevado a cabo por integrantes del SIAT y destinado a docentes, directivos y personal de gestión de las carreras con modalidad a distancia de la Facultad de Ciencias Económicas. Como resultado de dicho curso se capturaron nuevos requerimientos, modificaciones y mejoras de la nueva versión, algunas de las cuales fueron realizadas en ese mismo momento y otras de mayor envergadura se realizaron durante 2007.

Desde el año 2007, a la actualidad, el énfasis fue puesto exclusivamente en la mejora de la nueva versión. La idea comenzó a gestarse a finales del año 2006, producto de la cantidad de adecuaciones y nuevos requerimientos que surgían desde cada una de las unidades académicas. En ese momento se evaluó que la idea original, orientada a dar soporte a aulas virtuales, era acotada, poco flexible, y tenía problemas para dar respuesta a crecientes demandas que involucraban la necesidad de manipular carreras, lo que llevaba a ampliar la noción de aula virtual hacia la idea campus virtual. Por otra parte, la interacción con otros organismos como la REDCOES o el Ministerio de Educación de la Provincia de Córdoba corroboraron esta hipótesis, ya que en sus propuestas estaba presente la noción de organizar las aulas virtuales de alguna forma. Otras tareas que se emprendieron fueron el desarrollo de aulas de distinto tipo, definición de secciones públicas y privadas. Además se focalizó el diseño de nuevos módulos orientados al trabajo colaborativo y la evaluación on-line, tales como grupos, materiales compartidos, integración con Google Apps, exámenes, auto-exámenes, y cuestionarios [Zor11].

El SIAT ha sido utilizado para desarrollar más de 500 propuestas educativas, incorporando cada año mayor cantidad de aulas virtuales, tanto para pre-grado, grado, y posgrado, modalidades presenciales, semi-presenciales y a distancia, e innovaciones pedagógicas. Pero, por sobre todas cosas, en los últimos años tomó un auge importantísimo su utilización para formación universitaria de grado de carácter presencial, generando modalidades de aula extendida, que trajo aparejado la incorporación masiva de docentes y alumnos de la propia universidad. En solo 3 años, el crecimiento respecto a la demanda del sistema para la generación de espacios virtuales en la Web fue significativo [Fer08]. En la actualidad, el Campus Virtual SIAT es utilizado por toda la UNRC, contando con alumnos y docentes de sus cinco Facultades, tanto de grado como de posgrado. Algunas Facultades ya poseen aulas virtuales para más del $90 \%$ de sus asignaturas. La fuerte demanda puede observarse en la cantidad de usuarios, ya que aproximadamente el $60 \%$ de los alumnos de la UNRC se encuentran participando activamente. Los usuarios activos son más de 6.000, 800 de los cuales son docentes, y el resto alumnos. Solo en el año 2010, se generaron 400 aulas virtuales, 70 de las cuales pertenecen a carreras distancia y el resto son para apoyo a la presencialidad [Thü2011a].

\subsubsection{Evaluación del SIAT}

Todas estas actualizaciones, optimizaciones e incorporaciones funcionales sobre los servicios que ofrece el SIAT, han sido testeadas por los propios desarrolladores, pero estaba ausente un proceso de evaluación más amplio. En el año 2008 se realizó una primera evaluación sobre la usabilidad del EVEA SIAT en el contexto de la educación de grado presencial de la UNRC. Si bien se analizaron sólo algunos aspectos generales, los docentes valoraron la facilidad de uso, adecuación a las actividades presenciales, la conformidad de todo el equipo docente, funcionalidades provistas, capacitación, y ayuda. 
Los alumnos, por su parte, resaltaron de forma muy positiva el entorno virtual en cuanto a las herramientas ofrecidas, facilidad de uso, de aprendizaje y navegación [Fer2009]. Hacia mediados de 2010, el INTI evaluó el EVEA SIAT mediante el modelo de evaluación de calidad de productos de software MEDEPROS [Col02], cuyo objetivo es proveer mecanismos y recomendaciones para la evaluación de productos desde el punto de vista del usuario final basado en la norma ISO/IEC 14598B5 y los modelos de calidad ISO/IEC 9126 e ISO/IEC 12119. Los resultados destacaron la funcionalidad del entorno, su confiabilidad, eficiencia y la usabilidad de la interfaz de usuario. Además, señaló que la documentación y ayuda del sistema son adecuadas para que los usuarios conozcan su funcionamiento y modo de manejo [Luc10].

Siguiendo con esta línea se propone someter el EVEA SIAT al modelo de evaluación presentado en esta tesis. Ello tiene un doble objetivo: validar el modelo a través de un caso de estudio real, y aportar una valoración del entorno virtual desde el punto de vista educativo basado en la usabilidad.

\subsection{Forma de aplicación del modelo al EVEA SIAT}

\subsubsection{Introducción}

Cada capa del modelo plantea el acercamiento hacia el usuario de acuerdo al objetivo que persigue, siendo la primera la más lejana y la cuarta la más cercana. Las capas pueden ajustarse a distintos contextos dependiendo de la necesidad, nivel de profundidad de la evaluación, recursos y tiempo disponible. Puede prescindirse completamente de alguna, o utilizarlas todas y seleccionar diferentes alternativas dentro de la segunda y cuarta capa. Para la evaluación del EVEA SIAT, que es el caso de estudio abordado aquí, se adoptó la segunda modalidad, es decir, utilizar las cuatro capas [Fer2011b].

\subsubsection{Que decisiones se tomaron en los puntos abiertos}

Dentro de la capa 2 se tomaron elecciones respecto a la cantidad de evaluadores que participarían y la forma de realización de las tareas, optando por trabajar con 3 evaluadores y modalidad exhaustiva, es decir, utilizando todos los escenarios propuestos por el modelo (21). En tanto en la capa 4, se optó por una evaluación real del entorno virtual sobre 3 cursos de las carreras de la Facultad de Ciencias Económicas de la UNRC, que tenían cierta semejanza con los escenarios diseñados [Fer2011b]. En la figura 22 puede observarse el flujo seguido a lo largo de las cuatro capas de MUsa. 


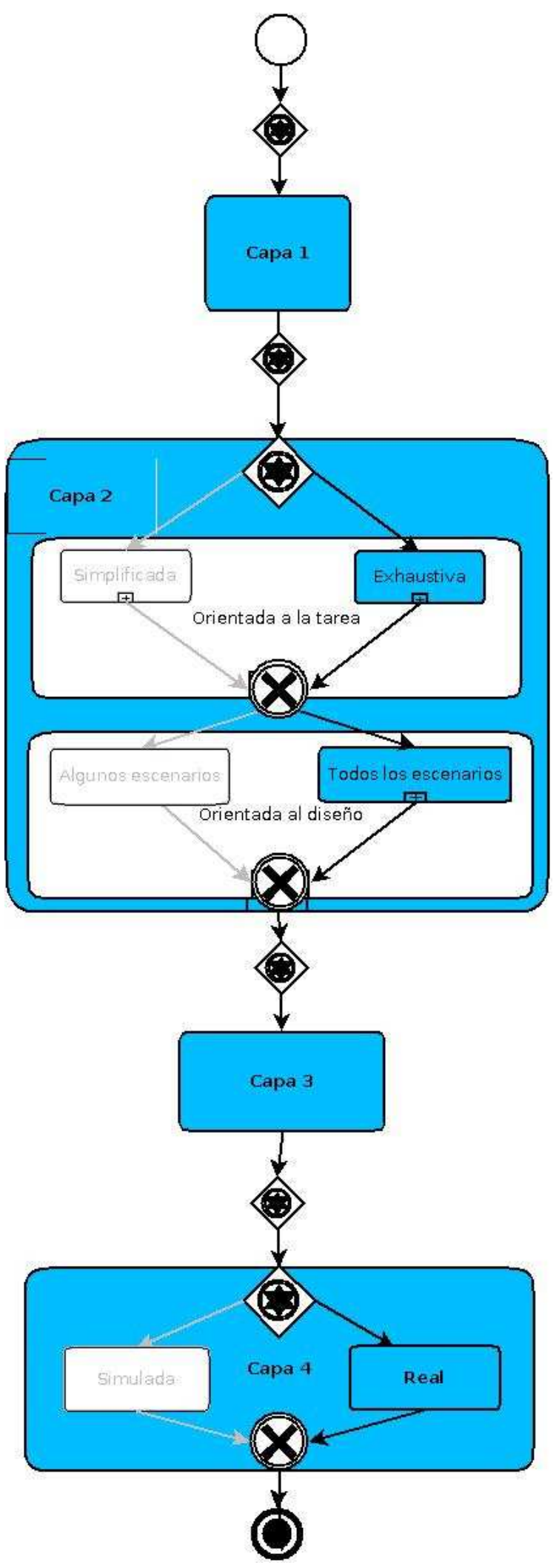

Figura 22 - Flujo de trabajo elegido para la aplicación de MUsa al caso de estudio

Una diferencia con el modelo original se presentó en la segunda capa. A cada evaluador se le asignaron dos roles en lugar de uno, de manera tal que pudieran cubrirse los cinco roles definidos: Fabio (responsable), Nahuel (tutor), Julián (tutor), Ana (alumno), Ailén (alumno), y Agustín (alumno). El Evaluador 1 tomó el rol del docente responsable Fabio y 
del alumno Ailén, el Evaluador 2 hizo lo propio con el docente tutor Nahuel y el alumno Ana, mientras que el Evaluador 3 se hizo cargo del docente tutor Julián y del alumno Agustín.

\subsubsection{Cómo se llevó adelante}

Para la puesta en marcha de la evaluación se tomó contacto con la Secretaría Académica, la Secretaría de Extensión y Desarrollo, las Facultades de Ciencias Económicas, Ciencias Humanas, y Ciencias Exactas, Físico-Químicas y Naturales, todas de la UNRC, y la Facultad de Informática de la UNLP. Dentro de cada ámbito se trabajó con diferentes áreas. Específicamente, las áreas involucradas fueron: el Área de Educación a Distancia y Tecnología Educativa de la Secretaría Académica de la UNRC, el Centro IRC que depende de la Secretaría de Extensión y Desarrollo de la UNRC, y la Dirección de Educación a Distancia de la Facultad de Ciencias Económicas. El Centro IRC es quien tiene a su cargo el desarrollo y mantenimiento del SIAT, así como la gestión de aulas virtuales, y capacitación para toda la Universidad, y otras Instituciones que mediante convenios específicos hacen uso del EVEA. La Facultad de Ciencias Económicas es la única Facultad de la UNRC que brinda capacitaciones con modalidad a distancia, en particular ofrece sus tres carreras de grado. Por tal motivo, se trabajó con la Dirección de Educación a Distancia, dependiente de la Secretaría Académica de dicha Facultad. Mediante reuniones con los responsables de cada dependencia se presentó la propuesta, y se solicitó cooperación de los equipos técnicos, así como también de docentes y alumnos de la Facultad. Las reuniones fueron muy positivas y la propuesta muy bien recibida. En el caso de las Facultades de Ciencias Humanas, y Ciencias Exactas, Físico-Químicas y Naturales de la UNRC, y la Facultad de Informática de la UNLP, se contactó a docentes con experiencia en las temáticas abordadas en la tesis para colaborar en la evaluación.

A partir de allí se comenzó con el trabajo de selección de evaluadores para cada capa del modelo.

\subsubsection{Capa 1}

La primera capa del modelo hace énfasis en las características funcionales del EVEA relacionadas con las facilidades para la organización académica y la flexibilidad pedagógica. Los actores principales de la evaluación son especialistas en educación y en tecnología a efectos de garantizar cierto grado de objetividad y agilidad en el proceso. Por tal motivo, se seleccionaron los cuatro evaluadores previstos, dos de los cuales los consideramos dentro de la categoría de especialistas en educación y TIC (EE1, EE2), y dos especialistas en tecnología (ET1, ET2). Los perfiles de cada uno son los siguientes:

- EE1: Licenciada en Psicopedagogía especializada en TIC, perteneciente al Área de Educación a Distancia y Tecnología Educativa de la Secretaría Académica de la UNRC.

- EE2: Especialista Universitario en Educación y Formación a Distancia a través de Redes Digitales: Recursos y Servicios de Internet, perteneciente a la Facultad de Ciencias Exactas, Físico-Químicas y Naturales de la UNRC.

- ET1: Licenciado en Ciencias de la Computación especializado en desarrollo Web, perteneciente a la Facultad de Ciencias Exactas, Físico-Químicas y Naturales de la UNRC. 
- ET2: Licenciado en Ciencias de la Comunicación especializado en diseño Web, perteneciente al Centro IRC de la Secretaría de Extensión y Desarrollo de la UNRC.

Como cada experto seleccionado ya poseía cuenta de usuario en el EVEA SIAT y acceso a varias aulas virtuales, no se realizó una sesión de trabajo dentro de un laboratorio de usabilidad sino que se entregó el instrumento de evaluación a cada uno para que lo analizara, accediera al EVEA las veces que considerara necesario y lo completara. Por tal motivo, tampoco hizo falta la puesta a punto del EVEA porque cada usuario disponía de acceso a varias aulas virtuales. Otro aspecto que se omitió fue el asesoramiento previo sobre las características principales del EVEA. Se acordó con cada evaluador el tiempo disponible para remitir el informe. Si bien estaba previsto recibir los informes en el plazo de un mes, el periodo se extendió por espacio de 3 meses.

Como herramientas de soporte para el análisis de estándares se seleccionaron los 3 navegadores más utilizados en la actualidad: Internet Explorer, Mozilla Firefox y Chrome. En el caso de Internet Explorer se incluyó IETester para posibilitar testear las páginas Web en las versiones 6, 7, y 8 al mismo tiempo. Para Mozilla Firefox se seleccionaron las versiones 3.6, y 4, y para Chrome la 7.0.517. A los efectos de la selección se tomó como referencia las estadísticas mundiales provistas por "Global Market Share Statistics", para el mes de noviembre de 2010 [GMS10], y las propias del EVEA SIAT generadas a través de Google Analytics, para el mismo mes [Thu10]. Ambas estadísticas coinciden respecto al ranking de los tres navegadores aunque varían respecto al porcentaje de uso:

\begin{tabular}{|c|c|c|c|}
\cline { 2 - 4 } \multicolumn{1}{c|}{} & Internet Explorer & Mozilla Firefox & Chrome \\
\hline Global Market Share Statistics & $58 \%$ & $23 \%$ & $9 \%$ \\
\hline \multirow{3}{*}{ SIAT - Google Analytics } & $46 \%$ & $30 \%$ & $21 \%$ \\
\cline { 2 - 4 } & $\begin{array}{l}\text { V. } 8: 60 \% \\
\text { V. } 7: 27 \%\end{array}$ & $\begin{array}{c}\text { V. } 3.6: 70 \% \\
\text { V. } 3.5: 7 \%\end{array}$ & V. $7.0 .517: 92 \%$ \\
\hline
\end{tabular}

Tabla 16 - Ranking de utilización de principales navegadores

Como podemos observar, dentro de los actuales alumnos y docentes del EVEA SIAT, en su mayoría de Argentina, existe una comunidad bastante importante de usuarios de cada navegador, los cuales acaparan casi el 100\% de las preferencias.

Para verificar la adecuación al estándar XHTML, y CSS de la W3C se utilizó Markup Validation Service y CSS Validation Service [W3C11], y TAW3 [TAW10] para el estándar WCAG 2.0. El estándar WCAG 1.0 no fue considerado dado que la W3C recomienda que todo contenido nuevo esté actualizado a las pautas de la WCAG 2.0. Como mencionamos, la compatibilidad con navegadores se analizó con IETester (Internet Explorer 6, 7 y 8), Internet Explorer 9, Firefox, y Chrome. El estudio de visibilidad para usuarios de visión reducida fue realizada con el "Avaliador e Simulador de AcessibilidadE para Sítios" (ASES) [ASE11].

La aplicación de los cuestionarios para análisis de estándares requiere navegar por muchas páginas del EVEA, y en particular por las aulas virtuales configuradas para su evaluación. Al tratarse de entornos concebidos como un portal, el diseño de las páginas conserva partes en común, y por lo tanto la inspección de solo algunas de ellas posibilita la obtención de un pantallazo sobre las virtudes y falencias en el diseño general de las mismas. Por otro lado, estadísticas basadas en el análisis del EVEA SIAT, realizadas 
sobre 6.000 usuarios de la UNRC en el período de agosto/09 - agosto/10, muestran que el promedio de páginas por visita ronda las 7,5 páginas [Thu10]. Estos motivos llevaron a sugerir una hoja de ruta de navegación compuesta por no más de 8 páginas, ya que resulta suficiente para tener una mirada general, y evitar que el proceso de inspección de estándares resulte tedioso y demande demasiado tiempo. La hoja de ruta incluyó las siguientes páginas:

- Home del Campus Virtual SIAT

- Inicio del aula

- Materiales del aula

- Actividades del aula

- Foros del aula

- Calificaciones del aula

- Noticias del aula

- Pizarrón del aula

La hoja de ruta solo se aplicó para el análisis de los estándares, no para evaluar la flexibilidad tecnológica, organizativa y pedagógico/didáctica.

El especialista en tecnología denominado ET1 se encargó de evaluar la flexibilidad tecnológica y organizativa, mientras que el ET2 hizo lo propio con los estándares. Los dos especialistas en educación EE1 y EE2 tuvieron a su cargo la evaluación de flexibilidad pedagógico/didáctica y organizativa. La flexibilidad organizativa, en un principio, no estaba considerada como parte de la evaluación del experto ET1, pero decidimos incluirla para tener otra mirada disciplinar, y porque el especialista conoce en detalle las potencialidades organizativas del EVEA. Otro aspecto importante a destacar es que el trabajo del experto ET2 demanda mucho más tiempo que el de los demás, dado que la evaluación de estándares es un proceso lento y tedioso [Fer2011b].

\subsubsection{Capa 2}

La segunda capa realiza una evaluación de alto nivel orientada a la tarea, y otra en detalle orientada al diseño. La idea de esta etapa del modelo es evaluar la forma en que el EVEA interactúa con el usuario, la interfaz que presenta y el modo en que permite a los usuarios realizar las tareas básicas. El especialista debe transitar una serie de escenarios de uso, adoptando distintos personajes, y navegando por las interfaces respectivas, a los fines de determinar el grado en que son respetadas las heurísticas de usabilidad, tanto desde el punto de vista de los propósitos, como desde los objetivos de los usuarios de un EVEA.

En esta capa es posible seleccionar la cantidad de evaluadores de acuerdo a factores tales como tiempo, disponibilidad, y presupuesto. Por este motivo existen dos alternativas, una sencilla donde interviene un solo evaluador, y otra donde pueden intervenir 3 ó 5 evaluadores. En nuestro caso se optó por seleccionar tres evaluadores para que, de alguna manera, pudiéramos posicionarnos en un punto medio, y lograr una evaluación que recoja opiniones de más de un experto. Los evaluadores seleccionados fueron: uno de la Facultad de Ciencias Exactas, Físico-Químicas y Naturales de la UNRC (Evaluador 1), y dos a la Facultad de Informática de la UNLP (Evaluador 2 y Evaluador 3). Los evaluadores de la UNLP no conocían el EVEA, mientras que el la UNRC sí. A su vez, para el caso de contar con 3 ó 5 expertos el modelo propone dos alternativas, una simplificada que evalúa el EVEA a nivel de tareas, y otra más exhaustiva que se basa en 
21 escenarios de uso. En éste caso se seleccionó la versión exhaustiva dado que la adopción de roles es más real, y posibilita realizar una suerte de "simulación", siguiendo la secuencia de escenarios planteada. Al contar con varios evaluadores es posible distribuir todos los personajes entre los mismos [Fer2011b].

Una diferencia con el modelo original es que a cada uno de los 3 expertos se le asignaron dos roles, en lugar de uno, para que pudieran cubrirse todos los roles definidos en el modelo: Fabio (responsable), Nahuel (tutor), Julián (tutor), Ana (alumno), Ailén (alumno), y Agustín (alumno). El Evaluador 1 tomó el rol del docente responsable Fabio y del alumno Ailén, el Evaluador 2 hizo lo propio con el docente tutor Nahuel y el alumno Ana, mientras que el Evaluador 3 se hizo cargo del docente tutor Julián y del alumno Agustín. La distribución de los escenarios entre cada evaluador fue de la siguiente manera:

- Evaluador 1: E1DR, E1DR, E1DR, E4DR; y E1A3, E2A3, E3A3

- Evaluador 2: E1DT1, E2DT1, E3DT1, E4DT1; y E1A1, E2A1, E3A1

- Evaluador 3: E1DT2, E2DT2, E3DT2, E4DT2; y E1A2, E2A2, E3A2, E4A2

Otra diferencia radicó en la experiencia de los evaluadores. En lugar de seleccionar un evaluador docente caracterizado como $\mathrm{E}$-, otro $\mathrm{E}$, y otro $\mathrm{E}_{+}$, fueron seleccionados tres de tipo E. Recordemos que $\mathrm{E}$ - es un docente sin conocimientos en EVEA, y algo de experiencia en la utilización de computadoras y servicios de Internet, el $E$ es un docente con conocimientos en EVEA y mucha experiencia en utilización de computadoras y servicios de Internet, y el E+ es un docente con conocimientos en EVEA, en usabilidad y mucha experiencia en utilización computadoras y servicios de Internet. Esta decisión se tomó porque el trabajo de evaluación es muy arduo y se apeló a la colaboración de otros investigadores cercanos que, aunque no se ajustaban al perfil, garantizaban compromiso y objetividad con la evaluación. Su categorización en $E$ se basó en el análisis de la experiencia de cada uno.

En primer lugar, se contactó a los posibles candidatos, y una vez recibido el compromiso de participar, se preparó un aula virtual que reflejara el contexto de uso y los escenarios propuestos. Luego se envió por correo electrónico a cada evaluador con todo el material. Dicho material constó de un instructivo con las explicaciones correspondientes, claves de acceso al EVEA SIAT, y escenarios, además de los instrumentos de evaluación. A medida que realizaban la evaluación fueron respondidas las dudas vía correo electrónico. Al finalizar se recibieron los informes individuales, pero por razones de lejanía geográfica y fechas diferentes de terminación de la evaluación, no se pudo hacer una puesta en común entre los tres evaluadores para confeccionar un único informe que reflejara el análisis realizado por cada uno de ellos y los acuerdos alcanzados [2011b].

\subsubsection{Capa 3}

Esta capa requiere de observaciones directas de los usuarios trabajando sobre el EVEA. De esta manera, se incorpora la opinión de los usuarios finales bajo un ambiente controlado por un observador. A medida que el usuario interactúa con el entorno debe expresar en voz alta sus pensamientos, sensaciones y opiniones, mientras el observador capta y registra las impresiones y sensaciones que el usuario manifiesta oralmente, además de realizar preguntas directas cuando lo considera conveniente. Los usuarios participantes fueron solicitados a la Directora de Educación a Distancia de la Facultad de Ciencias Económicas de la UNRC. Se propuso un grupo de 6 docentes y 9 alumnos, de acuerdo a los perfiles de usuario (novato, medio, y avanzado). En el caso de los docentes, se solicitó que 2 fueran novatos, 2 medios, y 2 avanzados, mientras que en el 
caso de los alumnos, 3 que fueran novatos, 3 medios, y 3 avanzados [Fer2011b]. Luego de recibido el listado correspondiente, se procedió a contactar a cada usuario para proponerles el trabajo y convenir un día y horario de realización. Se acordaron dos sesiones de trabajo en días y horarios diferentes. Como laboratorio de usabilidad se eligieron dos salas de informática pertenecientes a la Universidad, para la primer sesión un laboratorio con computadoras de 10 años de antigüedad, y para la segunda sesión uno que dispone de computadoras adquiridas hace 2 años. En ambos casos la conexión a Internet alcanzó características similares o inferiores a una domiciliaria de banca ancha. Los equipos informáticos utilizados contaban con Windows XP e Internet Explorer 7 en el primer caso, y Windows 98 con Firefox 2.0 en el segundo. De todos los usuarios convocados concurrieron solo un docente y un alumno por sesión. Cada sesión estuvo a cargo de un observador para llevar el registro de lo acontecido durante la evaluación. Si bien la mayoría manifestó su predisposición a participar, la concurrencia fue escasa. En función de ello se reestructuraron los roles de los usuarios de la siguiente manera, de acuerdo al perfil de los asistentes:

- Sesión 1: DA1 (Docente Avanzado 1), AA1 (Alumno Avanzado 1)

- Sesión 2: DN2 (Docente Novato 2), AN2 (Alumno Novato 2)

Tanto el docente como el alumno que participaron de la segunda sesión hacía 1 año que no utilizaban el EVEA. Este contexto posibilitó evaluar heurísticas importantes tales como la facilidad para recordar y para aprender.

Al ponerse en marcha cada sesión en el laboratorio elegido, los usuarios tomaron el cuestionario y lo completaron analizando el entorno, utilizando los escenarios y roles asignados, mientras el observador registraba los tiempos de duración de cada escenario, tomaba nota del trabajo u acotaciones de los usuarios, y respondía dudas de los mismos. Una vez concluida la sesión el observador analizó los resultados basándose en los cuestionarios propios y en los completados por los usuarios.

\subsubsection{Capa 4}

La cuarta capa involucra una evaluación bajo condiciones reales de uso, es decir, en un contexto establecido y con usuarios reales. Para ello se seleccionó un conjunto de usuarios finales pertenecientes al primer año de las tres carreras con modalidad a distancia de la Facultad de Ciencias Económicas de la UNRC, que estaban utilizando el EVEA y poseían un contexto similar al establecido por los escenarios. Cabe destacar que las materias de primer año son las mismas para las tres carreras [2011b].

Otra alternativa posible era la evaluación simulada, pero se optó por la real dado que se contaba con aulas virtuales que estaban en pleno funcionamiento y permitían acceder a resultados basados en el contexto real. La evaluación se llevó a cabo durante el segundo cuatrimestre de 2010 en las asignaturas Análisis Matemático II, Principios de Economía I, e Historia Económica y Social. Cada asignatura disponía de un aula virtual dividida en dos comisiones cada una. El test remoto se realizó, tanto por docentes como por alumnos, en su propio lugar de estudio o trabajo, de manera tal que fuera posible evaluar el contexto de uso.

Esta capa exige una cantidad mínima de evaluadores. En el caso de una evaluación simulada, son 42 usuarios, 15 de los cuales son docentes y 27 son alumnos. Para el caso de una evaluación real, como la realizada, esta cifra se reduce a la mitad, es decir, 7 docentes y 13 alumnos. La cantidad de docentes (4) fue inferior a la exigida (7), mientras que la cantidad de alumnos (15) superó escasamente el mínimo (13). 
Una diferencia importante con el modelo fue que no se realizó un proceso de selección de los usuarios para conocer sus características básicas, determinar su nivel de experticia (novato, medio, avanzado) y contexto general, sino que se suministraron los cuestionarios por correo a todos los usuarios que habían participado de dichas materias. También se entregaron personalmente a los alumnos que concurrieron a la Universidad con motivo de un encuentro presencial para consultas antes de rendir el último examen parcial [Fer2011b].

Luego se destinaron 2 meses para recibir las respuestas, y finalmente el observador realizó un resumen de las opiniones, tomando como base los dos cuestionarios realizados por cada usuario para la evaluación directa, las huellas que dejaron dentro de las aulas virtuales durante el proceso de realización de las tareas, el registro de log de cada una, y el cuestionario para la evaluación indirecta completado por él.

\subsubsection{Resultados cualitativos obtenidos por capa}

\subsubsection{Capa 1}

\subsection{Flexibilidad tecnológica}

Del análisis desde el punto de vista tecnológico rescatamos, como características generales, que el EVEA SIAT cuenta con antecedentes que lo avalan a nivel universitario, posee una década de historia, y ha sido evaluado por organismos externos (INTI) e internos a la Universidad. Posee también un grupo de desarrollo estable, frecuentemente se realizan jornadas, talleres, y charlas relacionadas con el EVEA, y pueden encontrarse muchas publicaciones de índole educativa donde se utiliza el SIAT como herramienta para la enseñanza y el aprendizaje. Su potencial va de la mano con el hardware y conectividad disponible, ya que la tecnología utilizada en su desarrollo es escalable (cliente-servidor, JSP/Java, multiplataforma). Una limitante importante es el idioma, sólo está en español, pero un hecho auspicioso es que el entorno, además de ser gratuito para su uso, está en proceso de liberar su código para posibilitar nuevos desarrollos y personalizaciones de acuerdo al ámbito donde desee utilizarse. Respecto al soporte, cuenta con una mesa de ayuda permanente, manuales, sitio oficial, y cursos de formación gratuitos. Los mecanismos de seguridad utilizados son contraseña y autenticación de usuarios. El acceso de los mismos es individual, llevándose registro de su ingreso al sistema, permanencia, y páginas visitadas. Al momento del ingreso se determinan sus privilegios y perfil. La navegación no está limitada a un sistema operativo ni un navegador particular, aunque no se han realizado pruebas exhaustivas desde dispositivos móviles, sólo teléfonos celulares. En cuanto a la compatibilidad, el EVEA SIAT requiere mínimos requisitos de hardware para funcionar en un servidor (Pentium $41.8 \mathrm{~Hz} / 512$ Mb / 80 Gb de espacio en disco / red estándar de 10/100M), aunque ello es directamente proporcional a la carga que pueda soportar. Desde el punto de vista del software también es minimalista, combina tecnología Linux + MySQL + Apache-Tomcat. El usuario puede acceder el EVEA desde una PC, notebook, netbook, o teléfono móvil. Los requisitos del hardware son básicos, cualquier dispositivo actual lo posee. La conexión a Internet puede ser incluso dial-up, y está desarrollado para utilizarse con cualquier sistema operativo, y navegador, sin necesidad de plug-ins y versiones de más de dos años de antigüedad. Los formatos multimedia permitidos son los básicos: texto, audio, video, imágenes, y animaciones. Otro punto débiles la poca integración que tiene con otros sistemas. Solo posibilita la incorporación de usuarios a las aulas virtuales de forma on-line, mediante archivos en formato CSV, o de forma individual, aunque se está estudiando la interacción por medio de webservices. En cuanto a la robustez del sistema, no se han detectado o 
relevado fallas derivadas de un mal diseño del software, posee tolerancia ante utilización poco experta, capacidad de controlar los accesos a bases de datos y herramientas que integran el entorno, los materiales almacenados están protegidos, y exige respetar cierta propiedad sobre los materiales.

\subsection{Flexibilidad organizativa}

Desde el punto de vista de las herramientas de administración de usuarios el EVEA SIAT posee las funcionalidades básicas para configurar perfiles con diferentes atribuciones y derechos de acceso, gestionar usuarios de forma individual o por lote, buscar usuarios, acceder a datos personales, modificarlos y asignar nuevas contraseñas, asignar usuarios a cada aula virtual de forma automática, mediante formulario de solicitud, mediante archivos por lote, de manera individual, acceder a todas las aulas virtuales desde un solo lugar con un único usuario y contraseña, registrar automáticamente todas las actividades realizadas, y compatibilizar con otras bases de datos de usuarios.

Lo mismo acontece con las herramientas de gestión que ofrecen la posibilidad de crear, eliminar o modificar espacios virtuales, organizarlos de manera diferenciada por facultades, carreras, áreas, temas, asignaturas, cursos, comisiones, o grupos, agregar nuevos usuarios, perfiles, privilegios y funcionalidades, realizar copias de seguridad generales, aunque no particulares, replicar espacios ya existentes, colocar información general, novedades, preguntas frecuentes, servicios generales (biblioteca, directorio de miembros, cafetería virtual) y software.

El punto más débil de flexibilidad organizativa está relacionado con la interfaz. EI EVEA permite la creación rápida y sencilla de aulas virtuales mediante un formulario on-line, así como la posibilidad para acceder directamente a ciertos espacios sin necesidad de realizar un recorrido obligado. También es posible mantener una imagen propia en general y en cada uno de los espacios virtuales, pero únicamente mediante el cambio del banner correspondiente al encabezado. Aunque posee un editor de texto con formato (WYSIWYG), sólo permite incorporar texto y enlaces. No dispone de ayuda on-line sensible al contexto de forma que el usuario acceda rápidamente a la información buscada. Tampoco es posible comprobar cómo son vistos los cambios por los diferentes perfiles sin necesidad de tener abiertas diferentes sesiones de trabajo, ni de personalizar las formas de acceder a los espacios de acuerdo a la experiencia del usuario.

\subsection{Flexibilidad pedagógico/didáctica}

Las herramientas de información son muy ricas. Cada espacio provee un calendario, aunque no está unificado a nivel de todo el campus, cartelera de novedades, alertas con anuncios al usuario sobre la existencia de cambios producidos luego del último ingreso, respuestas a preguntas frecuentes, e información general y sobre los docentes. Sin embargo, carece de pizarra virtual para la escritura a mano alzada o dibujos, glosario de términos, e índice de contenidos.

Las herramientas de comunicación sincrónica son variadas. Ofrece Google Mail (Gmail) como sistema de correo electrónico integrado al EVEA que posibilita el envío de mensajes en formato HTML, etiquetado, carpetas, y adjuntos en múltiples formatos. Sin embargo, no tiene implementado un sistema de listas de correo. También provee foros de discusión para cada espacio virtual, con la posibilidad de apertura y cierre en cualquier momento, y el anexado de archivos. Como punto a mejorar, respecto a los foros, se destaca la carencia de mecanismos de suscripción y desuscripción, formatos diferentes de visualización (lineal, rama), y moderación. Una herramienta que no está presente es el 
diario para la comunicación personalizada entre alumno y docente, y la emisión de ideas, consultas, opiniones, o pensamientos.

Las herramientas de comunicación asincrónica aparecen como otro talón de Aquiles del EVEA SIAT. No posee un sistema de Chat personalizado sino que, por ahora, usa Google Talk, que está disponible junto a Gmail. Tampoco dispone de mensajería instantánea, clases virtuales, ni sistema de videoconferencias.

Las herramientas de colaboración están compuestas por grupos, carpeta virtual, materiales compartidos, y Google Doc. Los grupos permiten conformar (de diferentes formas) espacios de trabajo compartido entre alumnos de un aula, con distintos roles y herramientas. La carpeta virtual es un espacio personal donde cada usuario puede incorporar materiales digitales y compartirlos con otros usuarios o aulas. Los materiales compartidos posibilitan el acceso a diferentes recursos que otros usuarios han querido compartir con usuarios específicos o de otras aulas. Google Docs permite crear documentos on-line, compartirlos y colaborar en grupo para su edición. Sin embargo, no posee pizarra compartida, navegación compartida, votaciones, ni otras herramientas propias de la Web 2.0.

Dentro de las herramientas para la evaluación encontramos la posibilidad de realizar ejercicios mediante auto-evaluaciones, y exámenes, con o sin temporización, cantidad de intentos con posibilidad de rehacer, calificación numérica, y cantidad ilimitada de preguntas. Las preguntas se almacenan en una base de datos de cada usuario y pueden ser compartidas con otros. Existen distintos tipos de preguntas: respuesta múltiple, relación, lógica, numérica, calculada, abierta, emparejamiento, completar frase, imagen, y respuesta corta. También provee un mecanismo para realizar encuestas obligatorias $u$ opcionales, y otro para realizar actividades o deberes de forma off-line, con la posibilidad de calificarlas de diferentes maneras y realizar devoluciones individuales. Sin embargo, carece de mecanismos para el seguimiento de los resultados, personalización de destinatarios o itinerarios de aprendizaje, estadísticas sobre el progreso del alumno y portfolio o expediente del alumno.

Las herramientas para el alumno también son acotadas ya que sobre los materiales de aprendizaje no es posible buscar contenidos, realizar anotaciones personales, registrar el último lugar visitado, o tener control del progreso personal. Las únicas herramientas disponibles son las destinadas a datos personales y carpeta virtual.

\subsection{Estandarización}

Del análisis desde el punto de vista de la estandarización se destaca que, si bien, posee niveles aceptables de adecuación a los estándares de la W3C (XHTML, CSS, WCAG), no cumple totalmente con ellos. En cambio, es compatible con los principales navegadores. La visibilidad para usuarios con visión reducida es muy buena para quienes poseen baja visión, pero no está adaptado a usuarios con ceguera. Tampoco cumple con estándares de internacionalización y de e-learning. Dado lo costoso, interesante, y exhaustivo de este análisis, detallamos a continuación la evaluación realizada por el especialista ET2.

La adecuación al estándar W3C - XHTML arrojó un promedio de 49 errores leves, ningún error grave, y 54 advertencias en la hoja de ruta analizada. El evaluador indicó que sería beneficioso contar con un validador que permita agrupar los errores por tipo para facilitar la depuración del código. El chequeo de adecuación a W3C - CSS indicó la presencia de 109 errores, y 2 advertencias promedio. Sobre este punto, el evaluador acotó que el validador utilizado no considera la posibilidad de utilizar 'hacks' en el desarrollo del CSS o propiedades específicas de un navegador como -moz o -webkit. Estas técnicas son 
utilizadas frecuentemente por los diseñadores para corregir algunos fallos de visualización que presentan algunas versiones de navegadores que no se ajustan al estándar de la W3C. En tanto que la accesibilidad respecto al W3C - WCAG 2.0 arrojó 612 problemas de prioridad 1, 651 de prioridad 2, y 193 de prioridad 3, de los cuales 214 son automáticos (81 prioridad 1, 118 prioridad 2, 15 prioridad 3) y 1242 son manuales (531 prioridad 1, 533 prioridad 2, 178 prioridad 3). En lo referido a la accesibilidad, el evaluador acotó que no hay un reporte estandarizado de los errores que detecta cada validador, la organización de la información varía y responde a diferentes criterios. Por ejemplo, Cynthiasays válida combinando prioridades y tipos de contenido (tablas, imágenes, mapas, texto). A modo de ejemplo el evaluador incluyó un reporte por separado con la información específica del validador Cynthiasays. El test se efectuó descargando las páginas para analizarlas localmente, ya que TAW y Cynthiasays no permiten chequear páginas de forma on-line que requieran autenticación. Al margen de detectarse una buena cantidad de errores, advertencias y problemas de prioridad, que están en proceso de corrección, la mayoría no afectan al normal funcionamiento del EVEA.

La compatibilidad con los navegadores es un punto fuerte, ya que la evaluación resultó exitosa en el $100 \%$ de los casos. Para Internet Explorer 6, 7, y 8 (verificados con el simulador IE Tester), el evaluador mencionó que "algunos elementos visuales secundarios (degradados, sombras, bordes redondeados) no se muestran". En el caso de Internet Explorer 9 fue necesario activar la vista de compatibilidad, mientras que en Chrome existe un pequeño fallo visual en el botón "Subir" que se muestra en una posición diferente al resto.

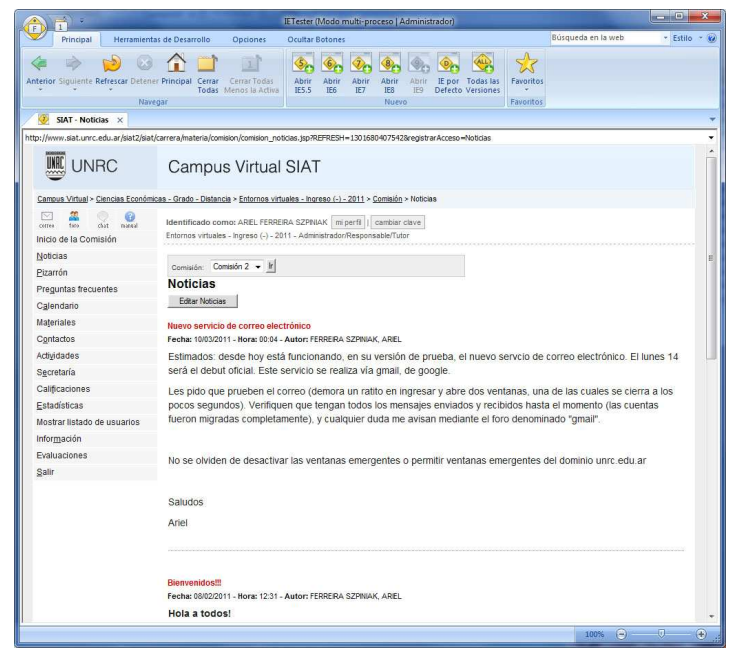

Figura 24 - IETester: Internet Explorer 7

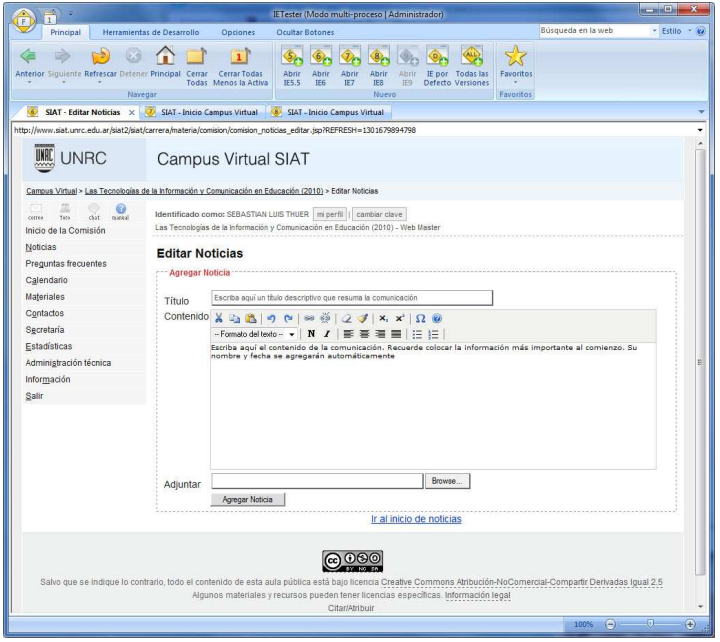

Figura 23 - IETester: Internet Explorer 6

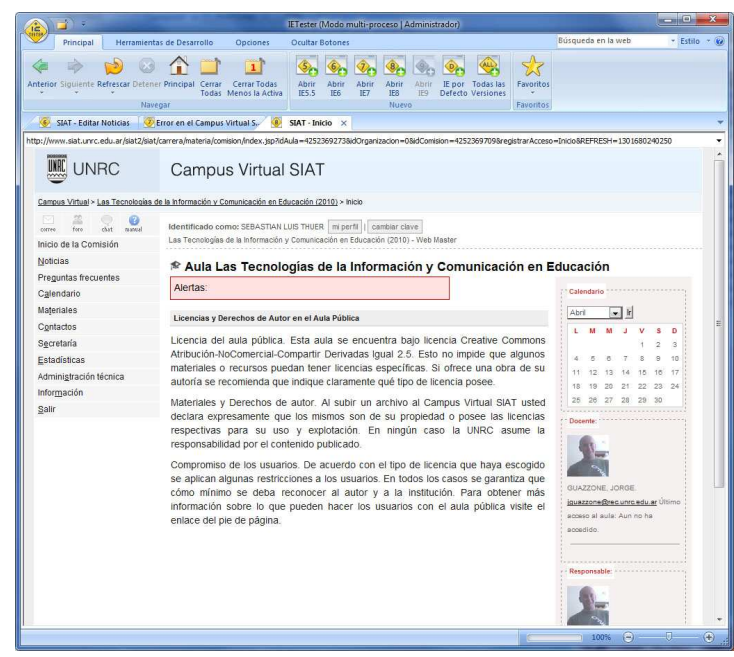

Figura 25 - IETester: Internet Explorer 8

El evaluador acotó en este ítem que el EVEA SIAT implementa algunos estándares nuevos como CSS3 que todavía no son soportados por todos los navegadores. Sin embargo, las funcionalidades implementadas son complementarias y sólo afectan al estilo 
visual, por lo cual el sistema sigue siendo operable por un usuario con navegadores desactualizados. Se soporta desde Internet Explorer 6 hasta 9, Chrome y Firefox 3.x y 4.

La evaluación de visibilidad para usuarios de visión reducida no fue sencilla, ya que la elección de un validador adecuado llevó un tiempo considerable. Finalmente se optó por utilizar ASES, por ser una herramienta que posibilita simular baja visión, entre otras cosas. El resultado de la evaluación con ASES determinó que el EVEA SIAT se adecua totalmente a los usuarios con miopía y daltonismo, parcialmente para hipermetropía, catarata, glaucoma y retinopatía, y no se cumple para ceguera.

El evaluador acotó que las páginas del EVEA SIAT debieron descargarse para poder analizarlas con el simulador ASES ya que solo permite validar páginas de forma on-line que no requieren acceso autenticado. Al tratarse de páginas JSP (JavaServer Page), se tuvieron que ejecutar en un servidor de páginas dinámicas instalado localmente. En tal sentido, se utilizó Apache Tomcat. Luego se constató que no existían diferencias importantes en la visualización puesto que todas las secciones guardaban la misma estructura (encabezado, menú, breadcrumb, contenido y pie de página). Por tal motivo se optó por realizar la comprobación solamente sobre la página de inicio del aula virtual. En general, el tamaño de la tipografía y el uso del color permiten visualizar el sitio correctamente en diferentes condiciones de visibilidad. Las patologías que presentan mayores problemas requieren de lentes y tratamientos para los cuales no es posible adaptar el sistema. Además, los lugares donde el usuario puede escribir contenido poseen restricciones para el uso del color y la tipografía a los efectos de impedir que se genere contenido con baja accesibilidad.

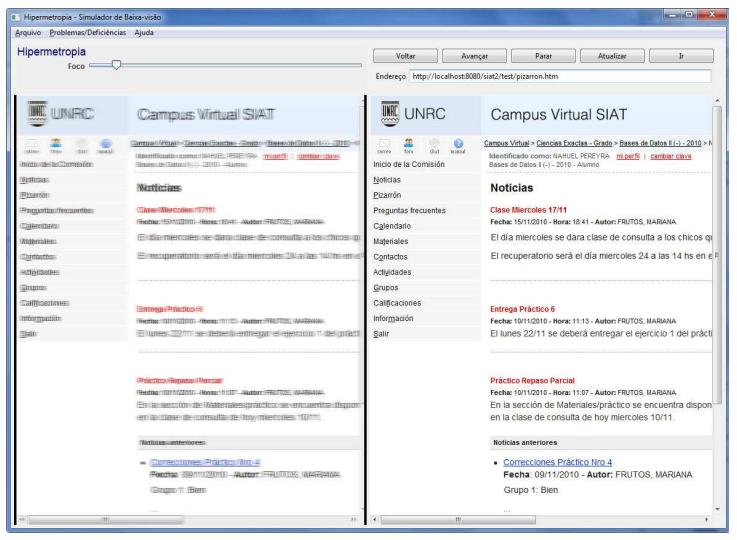

Figura 26 - Hipermetropía

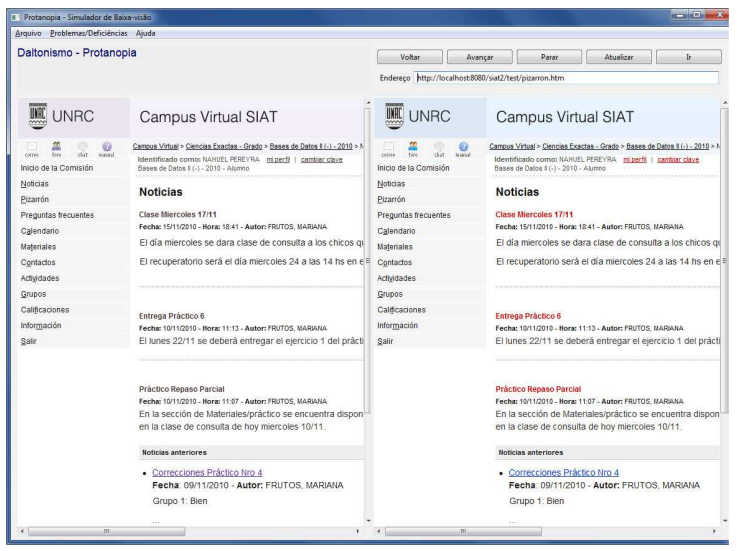

Figura 28 - Daltonismo - Protanopia

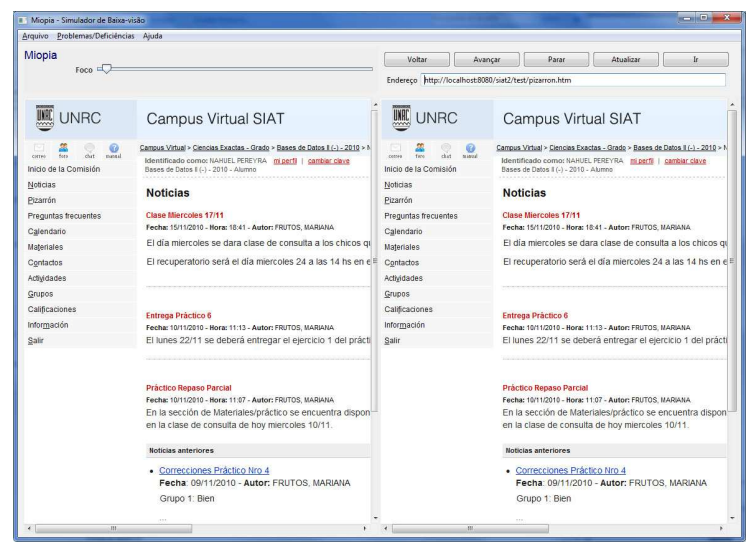

Figura 27 - Miopía

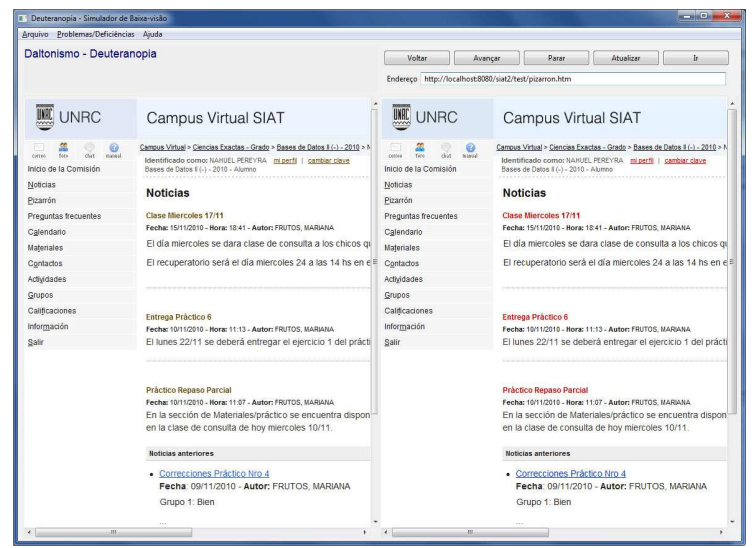

Figura 29 - Daltonismo - Deuteranopia 


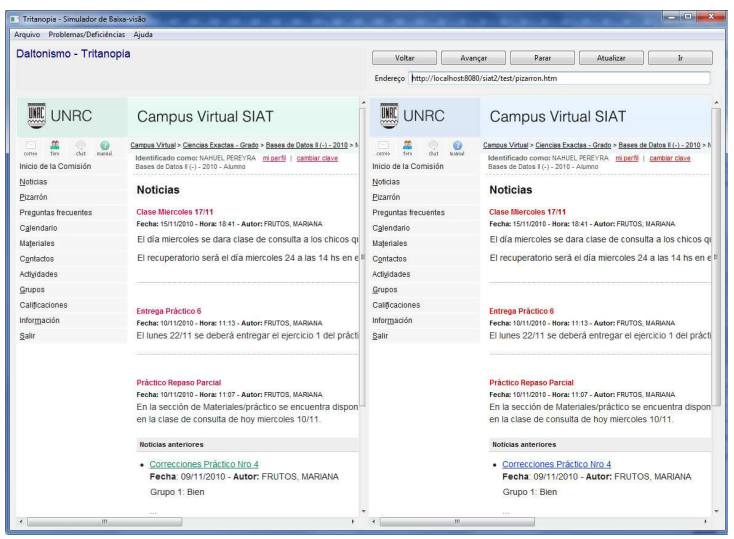

Figura 30 - Daltonismo - Tritanopia

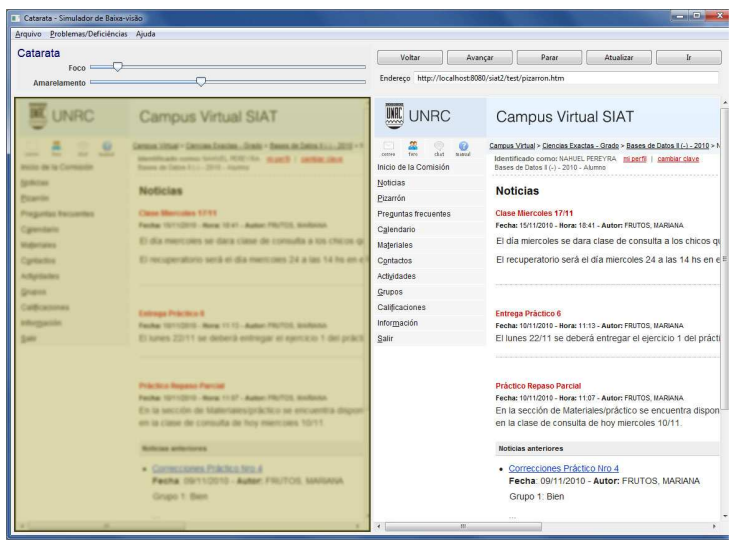

Figura 32 - Catarata

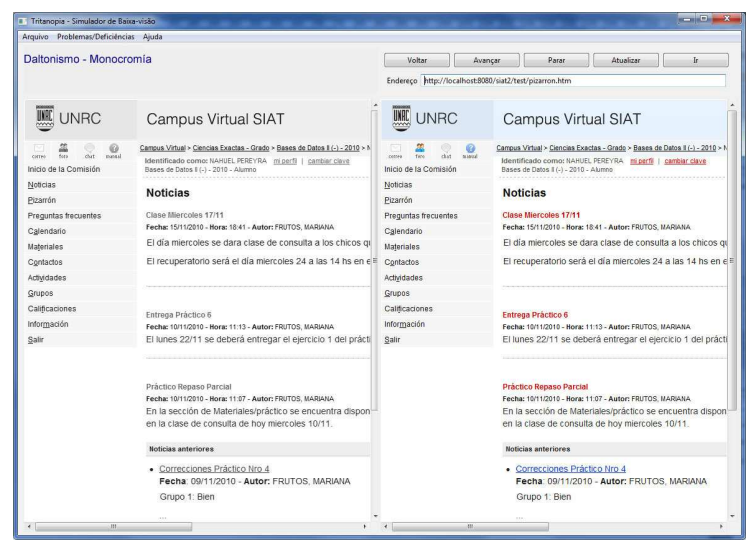

Figura 31 - Daltonismo - Monocromía

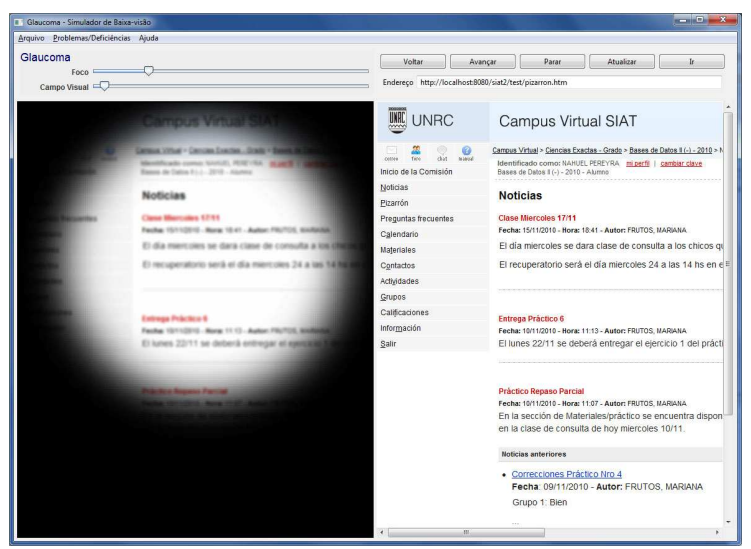

Figura 33 - Glaucoma

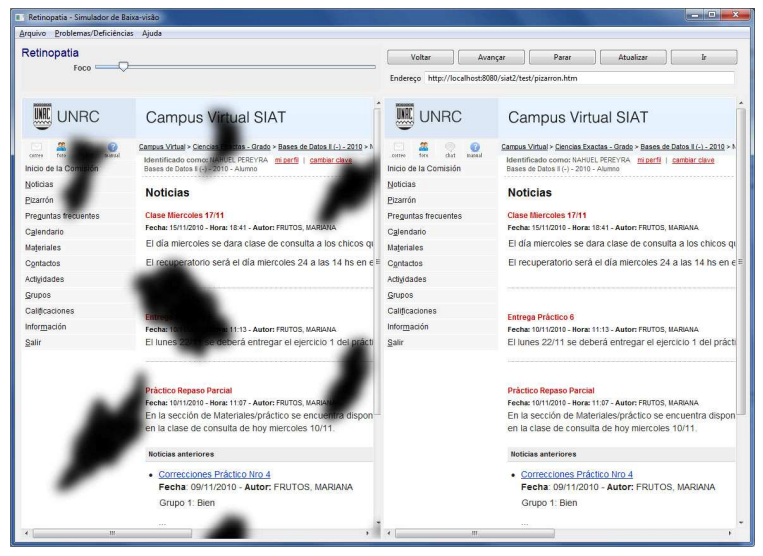

Figura 34 - Retinopatía

Por último, al ser un producto dirigido hacia una comunidad específica, como lo es la UNRC, no posee mecanismos para el intercambio de contenidos, así como tampoco uso en otros lenguajes distintos al español. Por ello no cumple con estándares de internacionalización, ni de e-learning. En tal sentido, no fue necesario realizar la evaluación de estándares para determinar si el EVEA permite y facilita el uso con diferentes lenguajes, por diversas culturas y regiones, y formatos y protocolos que no establezcan barreras a los diferentes idiomas, sistemas de escritura, códigos y otras convenciones locales. Tampoco hizo falta analizar los diferentes estándares y especificaciones como SCORM, IMS, LOM, y AICC. 


\subsubsection{Capa 2}

El Evaluador 1 realizó la tarea transitando los escenarios E1DR, E2DR, E2DR, E4DR desde el punto de vista de un docente responsable, y los escenarios E1A3, E2A3, E3A3 desde el punto de vista de un alumno.

Respecto a la complejidad de las tareas desde el punto de vista docente, la respuesta fue "muy baja", en todos lo casos. Sin embargo, en todos los escenarios se tuvieron que tomar decisiones sobre cómo realizar algunas tareas:

- Para informar a los alumnos sobre las fechas de inicio y cierre de módulos se optó por el calendario en lugar de noticias.

- Para explorar las distintas comisiones se utilizaron de forma conjunta las actividades y estadísticas.

- Para realizar el seguimiento de tutores y alumnos se utilizaron distintas herramientas de modo no estructurado, como consultar el correo y luego el foro o viceversa.

- Para informarse sobre las actividades entregadas y dar comienzo al segundo módulo no hizo falta seguir un orden determinado, por ejemplo, cargar los materiales del módulo 2 y luego revisar las actividades del módulo 1.

Para el caso de alumno la complejidad también fue "muy baja".

En cuanto a la visibilidad de las tareas, todas fueron valoradas de forma positiva, con "muy de acuerdo" o "de acuerdo". Se estuvo "muy de acuerdo" con la información justa y necesaria en cada momento, la intuitividad del diseño, la existencia de señales que indican lo que se debe hacer, y la jerarquización de la información. Con la disponibilidad de acciones posibles en cada momento hubo "acuerdo", mientras que la posibilidad de encontrar fácilmente la forma de realizar las tareas recibió como respuestas "muy de acuerdo" (3/4) y "de acuerdo" (1/4). Por último, que la información de contexto y orientación fuera adecuada se repartió entre "muy de acuerdo" (2/4) y "de acuerdo" (2/4).

La intuitividad y topografía natural obtuvo muy buenos índices de valoración, al igual que visibilidad. Los puntos más fuertes estuvieron en la analogía con el mundo real, que cosechó "muy de acuerdo" en todos los casos, la falta de necesidad de recordar, y lo predecible que son los efectos de los actos realizados, con "muy de acuerdo" (3/4) y "de acuerdo" (1/4). En el caso de los mensajes autoexplicativos, que son objetos que componen la interfaz, se obtuvieron todas valoraciones del tipo "de acuerdo".

El Evaluador 2 realizó la tarea transitando los escenarios E1DT1, E2DT1, E3DT1, E4DT1 desde el punto de vista de un docente tutor, y los E1A1, E2A1, E3A1 desde el punto de vista de un alumno. Cabe acotar que la evaluación se realizó dos veces porque en la primera instancia el evaluador no siguió el orden establecido de los escenarios. En la segunda instancia sí lo hizo, pero fue luego que los otros evaluadores concluyeran sus tareas, con lo cual algunos aspectos no pudieron ser evaluados por falta de sincronía entre los mismos.

La complejidad de las tareas desde el punto de vista docente tutor fue "normal" en los primeros escenarios y "alta" en los dos restantes. En el primer escenario el evaluador manifestó que encontró "claro el circuito y le pareció sencilla la forma de hacer las tareas requeridas", aunque le "costó ver los datos de alumnos". Mientras tanto, en el segundo encontró "una forma de hacer cada tarea". Los restantes escenarios no recibieron comentarios. Desde el punto de vista del alumno la complejidad fue "normal" en el 
primer y tercer escenario, y "alta" en el segundo. En este último caso, el evaluador manifestó que a pesar de encontrar la forma de hacer las tareas rápidamente, no encontró la forma de enviar la actividad, y lo hizo por la mensajería. Las tareas de los restantes escenarios estaban indicadas correctamente y fueron claras.

La visibilidad obtuvo resultados dispares, tanto desde el punto de vista del docente como del alumno. Los escenarios que no presentaron problemas y obtuvieron buenas valoraciones fueron: E1DT1, E1A1, E2DT1, E3A1. En el primer escenario del alumno, el evaluador observó que para identificar a los participantes en el curso (tanto docentes como alumnos) lo único que encontró fue la opción contactos, y que "en formato de icono se ve mejor". En el resto de los escenarios (E2A1, E3DT1, E4DT1) el evaluador estuvo "en desacuerdo" respecto a las subheurísticas de visibilidad.

La intuitividad y topografía natural obtuvo índices similares a la visibilidad, en los mismos escenarios.

El Evaluador 3 realizó la tarea transitando los escenarios E1DT2, E2DT2, E3DT2, y E4DT2 desde el punto de vista de un docente tutor, y los escenarios E1A2, E2A2, E3A2, y E4A2 desde el punto de vista de un alumno.

La complejidad de las tareas resultó "baja" en todos los escenarios del docente y del alumno. Sin embargo, el evaluador registró una serie importante de observaciones:

- En la tarea de "Agregar y Modificar Actividades" aparece una escala de calificación (1-10) cuando el tutor sólo debe subir la actividad y no las notas.

- No queda claro como llegar a conocer a los compañeros y docentes.

- En el caso del envío de mensajes lo hice utilizando la opción correo y no contactos. Elegí la opción correo porque no me queda claro si en contactos están solamente los integrantes de la comisión (alumnos y docentes).

- Tuve dificultad en encontrar cual es la situación de cada alumno. Para encontrar la situación de cada alumno ingresé por actividades, pero tenía dudas si en esa opción encontraría la información requerida.

- Se me presentó la duda de si la tarea de entregar trabajo es equivalente a entregar actividad. Al no encontrar otra opción similar, elegí entrar por la opción actividades.

- Al elegir la opción contactos, selecciono los destinos pero no puedo escribir el mensaje a enviarles. No queda claro como informarse sobre la situación de cada alumno. El comentario de la actividad se la hice a través de la opción correo. No encontré una opción para asociar un comentario a la actividad. ¿Se hará sobre la misma actividad que luego se adjunta? Los mails enviados los hice utilizando la opción correo y escribiendo la dirección del alumno destino. ¿La situación de cada alumno está vinculada solamente al estado de las actividades?

- ¿El acceso al comentario del tutor es a través del correo? El comentario del tutor lo encontré en la opción correo.

En cuanto a la visibilidad, hubo mucha disparidad ya que en pocos escenarios las valoraciones fueron todas positivas. Los escenarios valorados en su totalidad como "de acuerdo" fueron E1DT2 y E4DT2, en tanto que el escenario E1A2 registró acuerdo en 4 subheurísticas y desacuerdo en las 2 restantes (en la interfaz aparece la información justa y necesaria para la realización de las tareas, y se encuentra fácilmente la forma de realizar las tareas). También obtuvo mayoría de valoraciones positivas el escenario E2A2, con 4 acuerdos y 2 desacuerdos (se encuentra fácilmente la forma de realizar las tareas, 
y el diseño es intuitivo y existen señales que indican de manera natural lo que se debe hacer). En un punto neutro podríamos decir que estuvieron los escenarios E3A2 y E3DT2, ya que fueron valorados con 3 acuerdos y 3 desacuerdos (en la interfaz aparece la información justa y necesaria para la realización de las tareas, se encuentra fácilmente la forma de realizar las tareas, y la información de contexto y orientación es adecuada). Los escenarios con valoración más baja fueron el E2DT2 con 4 desacuerdos y 2 acuerdos, y el E4A2 con 5 desacuerdos y un solo "muy de acuerdo".

Por último, la intuitividad y topografía natural de las tareas en cada escenario tuvo un importante correlato con la visibilidad. Los escenarios que se destacaron positivamente fueron E1A2, con 4 acuerdos, E1DT2 y E2A2, con 3 acuerdos y un "muy de acuerdo", E3DT2 y E4DT2, con 3 acuerdos y un desacuerdo (analogía con el mundo real). Mientras que los escenarios intuitivos y naturales fueron 3. El escenario E3A2 obtuvo 2 acuerdos, un indiferente (analogía con el mundo real) y un desacuerdo (objetos de la interfaz autoexplicativos). Por último, el E2DT2 y E4A2 con solo un acuerdo (no hace falta recordar) y 3 desacuerdos.

Respecto a las heurísticas para evaluación en detalle orientada al diseño, y sus 88 subheurísticas asociadas, se agruparon las opiniones de los 3 evaluadores, debido a escala numérica de las respuestas, en lugar de hacerlo por separado como los criterios anteriores. El nivel de conformidad de los criterios generales fue bueno. En una escala de 1 a 5 puntos obtuvo 4,2 de promedio, entre los 3 evaluadores, destacándose consistencia (5), estándares $(4,6)$, ayuda $(4,5)$, y diseño y organización $(4,5)$. Los criterios que se ubicaron más alejados de la media fueron: reversibilidad y manejo del error $(3,4)$, y retroalimentación $(3,6)$. A continuación se presenta un gráfico con la valoración de cada criterio discriminada por evaluador. Cabe destacar que el Evaluador 3 fue quien tuvo, en general, la valoración más negativa y, además, una cantidad importante de subheurísticas sin valoración alguna (19/88).

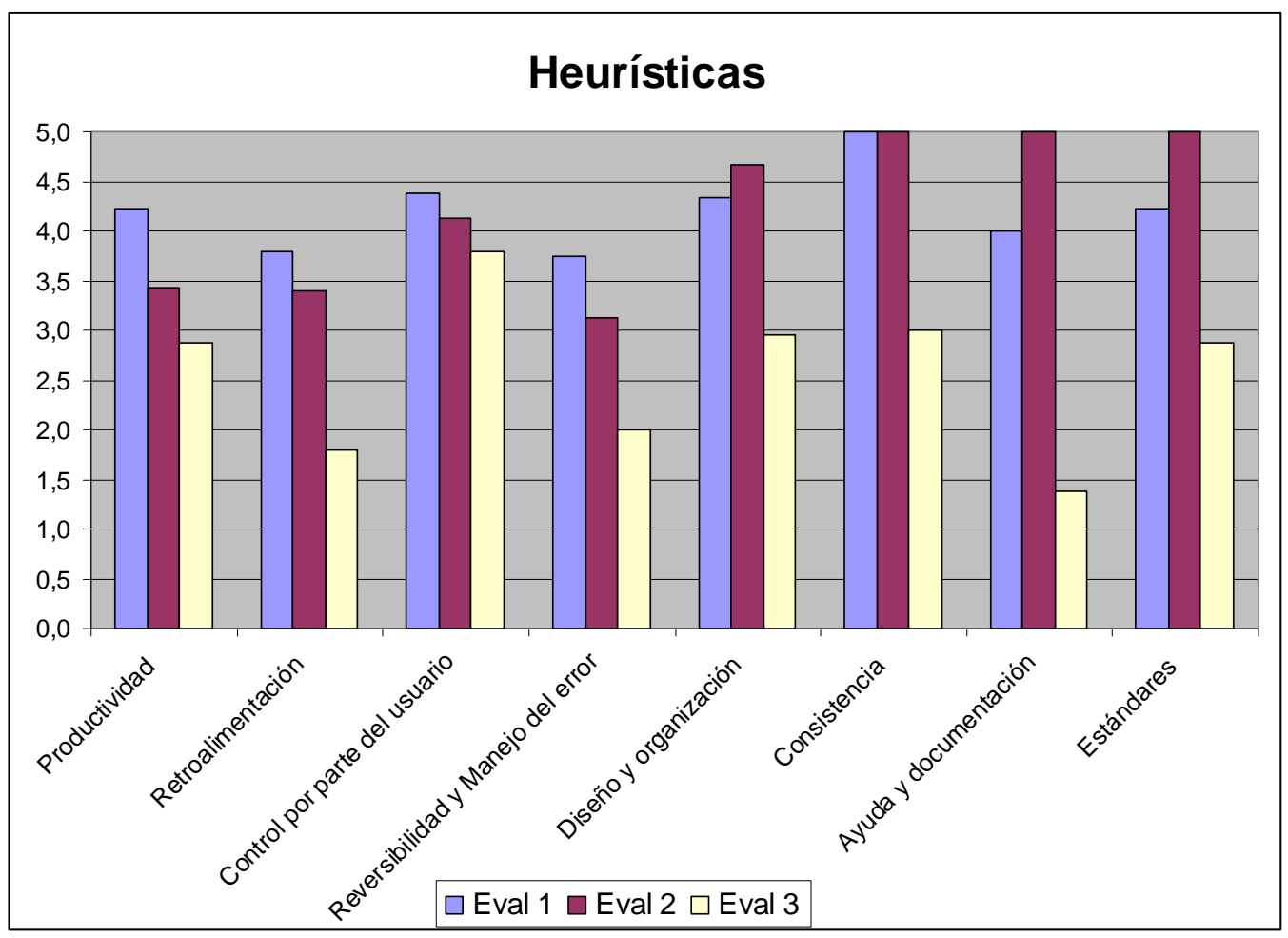

Figura 35 - Capa 2: valoración de expertos respecto a las heurísticas orientadas al diseño 
Como cierre de la segunda capa de evaluación se procedió a recorrer el aula virtual utilizada. Se pudo observar que las tareas solicitadas en cada uno de los escenarios fueron completadas en su totalidad, y como refleja el informe de cada evaluador, algunas requirieron tomar decisiones, ya que existían múltiples formas de realizarlas, otras resultaron muy simples, y algunas plantearon problemas u obstáculos que debieron ser resueltos.

\subsubsection{Capa 3}

Cuando concluyen las dos sesiones de trabajo, mediante las cuales se realiza el simulacro controlado a partir de los escenarios propuestos, el observador analiza los resultados del test de expresión del usuario en base a preguntas. Recordemos que este test está compuesto de una evaluación directa realizada por los usuarios, y otra indirecta a cargo de los observadores. Luego de concluida la sesión de evaluación, se obtiene un cuestionario completado por cada usuario y otro por el observador asignado al mismo. En este caso se obtuvieron un total de 8 cuestionarios, de los cuales 2 fueron completados por docentes, 2 por alumnos y 4 por los observadores. Los resultados alcanzados fueron los siguientes:

\subsection{Evaluadores docentes}

De los cuestionarios realizados por los docentes que participaron de la sesión 1 y 2 se desprenden los siguientes resultados respecto de cada heurística.

\subsection{Sesión 1: Docente DA1}

La complejidad de las tareas de los 4 escenarios fueron percibidos por el docente como de poca dificultad, entendiendo que la complejidad fue "baja" en dos escenarios y "normal" en los otros dos. Además manifestó que tuvo que tomar decisiones sobre cómo realizar algunas tareas. Para el escenario E1DT1 indicó que para subir una actividad y publicar un mensaje en el pizarrón, utilizó el correo y colocó la fecha de entrega en el calendario. En el escenario E2DT1 respondió que al publicar un mensaje para todos los alumnos decidió hacerlo mediante el pizarrón, aunque también podría haber utilizado el correo. En los escenarios E3DT1 y E4DT1, manifestó que antes de ir a actividades para colocar la nota, siempre se equivoca, y va a calificaciones. Esto pone de manifiesto que existe un claro problema de usabilidad, ya que el modelo conceptual no se corresponde con el modelo de usuario.

En la visibilidad de las tareas el docente estuvo "muy de acuerdo" (6/6) en el escenario E1DT1, y "muy de acuerdo" (4/6) y "de acuerdo" (2/6) en el E2DT1. Los escenarios E3DT1 y E4DT1 fueron los más bajos con "de acuerdo" (3/6) y "en desacuerdo" (3/6). El docente manifestó que hace tanto tiempo que trabaja con el EVEA que "ni miro si hay información y de qué tipos es. Podría decir que ya estoy automatizada".

La intuitividad y topografía natural recibió buenos comentarios en los dos primeros escenarios y regulares en los dos restantes. En el caso de E1DT1 y E2DT1 hubo coincidencia, obteniendo "muy de acuerdo" (3/4) y "de acuerdo" (1/4), mientras que en el caso de E3DT1 y E4DT1 las respuestas fueron "de acuerdo" (2/4) y "en desacuerdo" (2/4). La confusión entre actividades y calificaciones fue el detonante para el desacuerdo en dos de las subheurísticas.

En lo relativo al cuestionario a cargo del observador detallaremos, en primera instancia, las observaciones, sugerencias u opiniones que fue realizando el usuario a medida que 
transcurría el test, y posteriormente resumiremos los resultados alcanzados respecto a las métricas de efectividad, eficiencia, y satisfacción, sobre los 4 escenarios transitados.

Consideraciones registradas por el observador, sugerencias y opiniones del usuario:

- Al intentar descargar un material en formato pdf, el docente se encuentra con una ventana consultando sobre la actualización del Adobe Reader. Este en un hecho ajeno a los escenarios y no previsto en el contexto de uso.

- El título del foro que desea abrir es más largo que el espacio visible en el cuadro de texto correspondiente.

- El docente comenta que siempre guarda en su PC las actividades que pide a los alumnos.

- El docente no entiende algunas preguntas del cuestionario y solicita aclaraciones. Luego de comprendidas las completa.

- El docente navega rápidamente casi sin leer la información contenida en cada página.

- El intentar enviar un mensaje a varios alumnos desde la página de contactos falla la apertura del correo porque están bloqueadas las ventanas emergentes en el navegador. Como el nuevo mensaje de correo se abre automáticamente en una ventana emergente, debe configurar el navegador para desbloquearlas. Este también es un hecho ajeno los escenarios y no previsto en el contexto de uso. Sin embargo el manual on-line posee una sección específica donde explica cómo configurar cada navegador a efectos de evitar estos inconvenientes.

- El docente comenta que no puede tener dos ventanas del aula virtual abiertas de forma simultánea porque el EVEA no se lo permite. En realidad, es posible abrir cada página del aula virtual en una ventana o pestaña nueva, pero esto no se recomienda dado que puede traer inconvenientes respecto al registro de navegación y la sesión de trabajo. Solo el correo funciona independiente de las aulas virtuales disponibles.

- El docente confunde las funcionalidades de la sección actividades y calificaciones, sobre todo a la hora de colocar una nota a los trabajos recibidos.

- Las alertas también confunden al docente porque no desaparecen hasta acceder a cada una de ellas. Además se generan alertas innecesarias al usuario cuando éste genera nueva información en el aula.

En lo relativo a las métricas podemos calificar a la efectividad como "excelente" ya que se completaron la totalidad de las tareas. La eficiencia fue "aceptable" porque el tiempo total invertido en realizar las tareas no superó el doble del que necesitó un experto, el tiempo total de aprendizaje fue menor al 10\% del tiempo invertido, de la misma forma que el tiempo total necesario para recuperarse de errores. Tampoco se accedió a la ayuda, y el número de intentos y estrategias alternativas utilizadas hasta lograr las tareas fue de hasta uno por tarea, al igual que el número de errores cometidos. Finalmente, las métricas de satisfacción fueron "positivas" en todos los casos.

\subsection{Sesión 2: Docente DN2}

La complejidad de las tareas de los 4 escenarios fue percibida de igual manera que el otro docente evaluador, es decir, "baja" en dos escenarios y "normal" en los otros dos. 
En la visibilidad de las tareas respecto al escenario E1DT2 el docente estuvo "muy de acuerdo" (2/6), "de acuerdo" (3/6) e "indiferente" (1/6). Además señaló que, en el caso de la heurística sobre la aparición de la información justa y necesaria, la calificó como "indiferente" porque no se pudo inclinar por las demás opciones, pero no encontró obstáculos en la realización de las mismas. Este comentario refleja que la escala utilizada en el instrumento no es del todo adecuada. También indicó que observa en el correo una falta de señales que indiquen de manera natural lo que debe hacerse. Pasando al siguiente escenario, E2DT2, las 6 subheurísticas fueron valoradas de manera muy dispar: "de acuerdo" (2/6), "indiferente" (3/6), y "en desacuerdo" (1/6). Como comentario manifestó que el principal problema lo tuvo en la extensión del plazo de la actividad porque no se acordaba cómo hacerlo y debió solicitar ayuda. Los escenarios E3DT2 y E4DT2 no presentaron problemas, registrando valoraciones de "muy de acuerdo" en la mayoría de las subheurísticas.

La intuitividad y topografía natural recibió excelentes comentarios en el primer, tercer, y cuarto escenario, con "muy de acuerdo" en todas las subheurísticas. El segundo escenario, E2DT1, obtuvo "muy de acuerdo" (2/4) e "indiferente" (2/4), con el comentario de que la extensión del plazo de la actividad fue lo más problemático.

En lo relativo al cuestionario a cargo del observador sólo haremos mención explícita a la primera parte del cuestionario porque los resultados alcanzados respecto a las métricas de efectividad, eficiencia, y satisfacción fueron similares a los obtenidos en la sesión 1.

- El docente preguntó si él debía publicar para sus alumnos la actividad recibida de parte del responsable de la asignatura.

- También preguntó si el tema para la apertura del foro guardaba relación con la actividad planteada.

- El docente descargó, desde el correo, el archivo con el contendido de la actividad, pero el navegador se la guardó por defecto sin preguntar donde hacerlo. Esto llevó al docente a tener que buscar el archivo dentro del disco de la PC.

- Al tener que extender un plazo de entrega para un solo alumno, el docente pidió ayuda porque no recordaba donde estaba la opción para hacerlo.

- Cuando necesitó modificar una actividad se equivocó y creó una nueva.

- Para informarse de la situación de cada alumno utilizó las estadísticas generales y particulares por cada herramienta. En este caso mencionó como muy útil tener la posibilidad de acceder a una estadística por alumno, donde presente en detalle las acciones realizadas por cada uno. De esta forma se gana mucho tiempo en las tareas de seguimiento.

- Para calificar las actividades usa siempre la opción de calificación rápida.

- Para realizar un comentario a un alumno sobre la actividad entregada opta por el correo ya que no recuerda como hacerlo desde la sección de actividades recibidas.

- El docente opina que sería importante tener alertas más específicas, del tipo "el alumno tal entregó la actividad cual".

En lo relativo a las métricas, los resultados fueron similares al Docente DA1. 


\subsection{Sesión 1: AA1 y Sesión 2: AN2}

Debido que los resultados obtenidos para los dos alumnos fueron muy similares, sintetizaremos los cuestionarios sin discriminar la sesión.

La complejidad de las tareas de los 4 escenarios fue percibida como "muy baja" en los dos primeros y como "baja" en los dos restantes. El alumno AN2 menciona que para enviar un mensaje por correo opta por ingresar a los contactos del aula, en lugar de ir al correo, y cliquear sobre el enlace que indica la dirección del docente. Prefiere hacerlo de esta forma porque así le aparece directamente la ventana para enviar un nuevo mensaje y la dirección del docente en el campo del destinatario.

En la visibilidad de las tareas obtuvo valoraciones de "muy de acuerdo" en la mayoría de los casos. En las restantes subheurísticas los alumnos estuvieron "de acuerdo", aunque fueron muy pocos los casos: una subheurística del escenario E2A2, dos del E3A2, y una del E4A2. En este último caso el alumno AN2 acotó que a pesar que el diseño es intuitivo y hay señales que indican de manera natural lo que se debe hacer, es necesario indicar más explícitamente que la actividad está pendiente de realizarse.

La intuitividad y topografía natural recibió muy buenos comentarios en el primer escenario, con dos "muy de acuerdo" y dos "de acuerdo", y excelentes en los tres restantes, con "muy de acuerdo" en todas las subheurísticas.

En lo relativo el cuestionario a cargo del observador se destaca que son mucho menores las observaciones, sugerencias u opiniones relevadas. Esto tiene su explicación en que las tareas son más sencillas para los alumnos que para los docentes, cosa que se ve reflejada en el análisis anterior.

Consideraciones registradas por el observador, sugerencias y opiniones de los usuarios alumnos:

- Para la descarga de materiales no se utilizó la opción de descarga normal sino la que comprime y luego descarga. La fundamentación del alumno fue que demora menos tiempo.

- La ventana del correo es problemática porque dependiendo la computadora y el navegador que se use, a veces se abre y a veces no. Cuando uno usa su propia computadora este problema pasa desapercibido porque ya tiene hechas las configuraciones básicas.

- Está bien que el icono de rehacer una actividad contenga un hint que aclare el significado del mismo.

- El diseño, lugar, y color de las alertas es considerado como adecuado.

En lo relativo a las métricas, en ambos casos, se obtuvieron muy buenos resultados. La efectividad fue "excelente" porque se completaron la totalidad de las tareas. En el caso de la eficiencia, todas las métricas obtuvieron la mejor valoración. El tiempo total invertido en realizar las tareas no superó el doble del que necesitó un experto, el tiempo total de aprendizaje fue menor al $10 \%$ del tiempo invertido, de la misma forma que el tiempo total necesario para recuperarse de errores, no se usó la ayuda on-line, y el número de intentos y estrategias alternativas utilizadas hasta lograr las tareas fue de hasta uno por tarea, al igual que el número de errores cometidos. También las métricas de satisfacción fueron positivas en todos los casos. 


\subsubsection{Capa 4}

Luego de concluido el test, el observador a cargo debe resumir la opinión de los usuarios reales. Para ello utiliza como base los cuestionarios realizados por los docentes y alumnos, las huellas que dejaron dentro de las aulas virtuales durante el proceso de realización de las tareas, y el registro de log de cada una. A continuación se desarrolla la información obtenida a partir de los cuestionarios para los usuarios y para el observador.

\subsection{Evaluadores docentes}

Los 4 docentes indicaron que lograron realizar la mayoría de las tareas sugeridas. Las que fueron señaladas como de menor frecuencia fueron:

- Enviar correo a los alumnos que no han comenzado a trabajar (1 docente).

- Realizar una devolución individual (1 docente).

- Solicitar a un alumno rehacer el trabajo.

La valoración general fue buena, aunque existen muchos puntos por mejorar.

Respecto a la complejidad de las tareas, las respuestas fueron: "normal" (2), "baja" (1), "muy baja" (1). Ningún docente observó "alta" o "muy alta" complejidad. Varios coincidieron en que tuvieron que tomar decisiones sobre cómo realizar algunas tareas. Por ejemplo, para publicar información en pizarrón y foros, algunos optaron por escribirla primero en el procesador de textos que utilizan habitualmente, darle formato, y luego pegarla en el aula virtual o directamente adjuntar el archivo. Para utilizar videos didácticos decidieron subirlos dentro del aula virtual en un formato adecuado. En los casos donde debían publicar varios mensajes, un docente optó por generar uno solo en el pizarrón e ir agregando nueva información dentro del mismo mensaje. Justificó su decisión basada en que el último mensaje agregado en el pizarrón aparece en la página de inicio, mientras que los anteriores deben accederse desde la sección Pizarrón, y los alumnos pueden pasarlos por alto. Además, la misma información fue incorporada al primer foro de presentación. Otra docente indicó que cada mensaje publicado en el pizarrón, o nuevo material digital incorporado al curso, también lo envía por correo electrónico. Ello lo hace para reforzar la comunicación, pero podría evitarse si el sistema de alertas permitiera enviar un resumen periódico de la actividad del curso al correo electrónico personal de cada alumno.

En cuanto a la visibilidad de las tareas, mayoritariamente estuvieron "de acuerdo" con las heurísticas. Donde se dio mayor disparidad fue respecto a la intuitividad del diseño, la existencia de señales que indiquen lo que se debe hacer, y la jerarquización de la información. En estos casos las opiniones se repartieron equitativamente entre "de acuerdo" (1), "indiferente" (1) y "en desacuerdo" (2). Una docente no respondió sobre la heurística "solo están disponibles las acciones posibles en cada momento" por no comprender el significado de la misma.

La intuitividad y topografía natural fue la heurística de valoración más negativa. Los puntos más débiles fueron si los objetos que componen la interfaz son autoexplicativos, y si los efectos de los actos realizados son predecibles. En el primer caso las opiniones se repartieron entre: "de acuerdo" (1), "indiferente" (1) y "en desacuerdo" (2), mientras que el segundo recibió las siguientes valoraciones: "de acuerdo" (1) y "en desacuerdo" (2), y "no contesta" (1).

Respecto al instrumento en sí, un docente realizó una interesante observación respecto a la escala de valoración en las grillas de visibilidad, e intuitividad y topografía natural: 
"estimo que la valoración de indiferente podría ser más aprovechada por no tan de acuerdo o algo similar puesto que no deja otra opción que poner en desacuerdo cuando en la mayoría de los casos no es totalmente de esa manera sino que podrían mejorarse algunos de los aspectos consultados de la grilla" (sic). Entendemos que tiene razón y se puede dar lugar a la observación a efectos de mejorar la captura de opiniones. Por ello proponemos cambiar en el instrumento la valoración indiferente por no tan de acuerdo.

El nivel de conformidad de los criterios generales que todo sitio Web debería tener fue bueno. En una escala de 1 a 5 puntos obtuvo 3,7 de promedio, destacándose estándares $(4,5)$, consistencia $(4,1)$, y retroalimentación (4). Los criterios que se ubicaron más alejados de la media fueron: reversibilidad y manejo del error $(3,5)$, ayuda y documentación $(3,3)$, y productividad $(3,2)$. En tanto que control por parte del usuario, y diseño y organización obtuvieron valores similares a la media $(3,7)$.

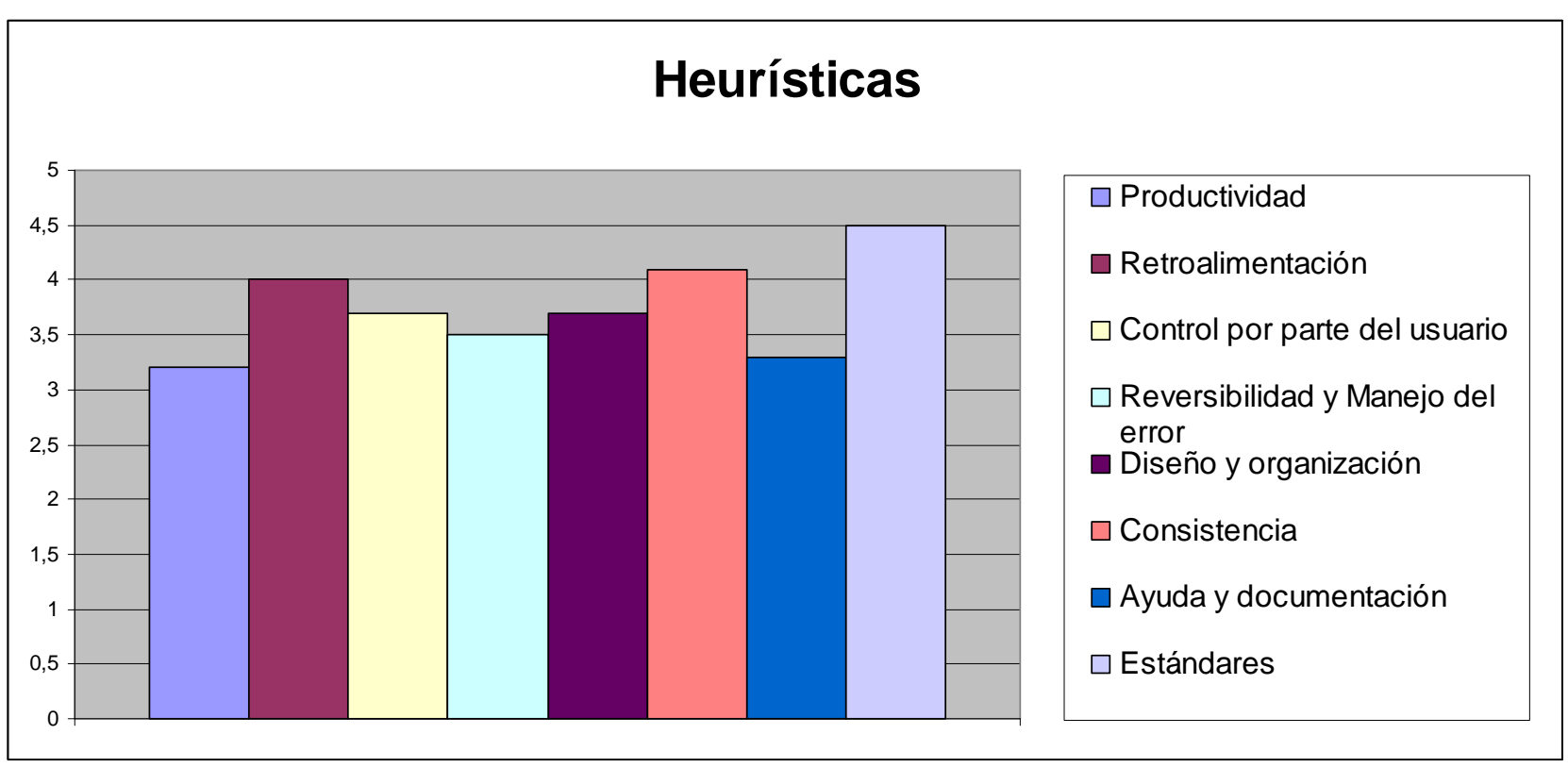

Figura 36 - Capa 4: valoración de docentes respecto a las heurísticas orientadas al diseño

En cuanto a la efectividad del EVEA para completar las tareas, los docentes respondieron que lograron realizarlas "casi todas" (50\%), y "todas" (50\%). No hubo respuestas enmarcadas dentro del resto de la escala: "ninguna", "algunas" o "la mitad". Respecto a la eficiencia el $75 \%$ consideró como "aceptable" el tiempo invertido en completar las tareas y el $25 \%$ restante como "no aceptable". El tiempo total ocupado en errores fue punto más débil con $0 \%$ en "nada", $0 \%$ en "muy poco", $50 \%$ en "poco", $50 \%$ en "bastante", y $0 \%$ en "mucho". El tiempo total de aprendizaje fue considerado como "aceptable" en el $100 \%$ de los casos. En relación a la frecuencia de uso de la ayuda y documentación, el 25\% manifestó usarla "nunca", y el 75\% "entre 1 y 4 veces". El número de intentos y estrategias alternativas utilizadas hasta lograr completar las tareas, el número de errores cometidos, y el tiempo total necesario para recuperarse de errores recibieron una opinión "aceptable" en el $75 \%$ y "no aceptable" en el 25\%.

Las métricas de satisfacción registraron opiniones positivas. En el caso de la consulta sobre las veces en que sintió frustración o enojo, el 100\% respondió que fueron "pocas" (entre 1 y 4 veces), 0\% "nunca", y 0\% "muchas" (más de 4 veces). El producto fue considerado como "muy útil" por un $75 \%$, y "bastante útil" por un $25 \%$. El $100 \%$ de los docentes se mostró "bastante satisfecho" con las funciones y características del EVEA. 
Por último, el 100\% opina que "casi siempre" tienen la percepción que las tecnologías dan soporte a las tareas según sus propias necesidades.

Dentro de los comentarios generales, un docente realizó el siguiente aporte: "considero que la plataforma SIAT brinda el herramental necesario para desarrollar las actividades a distancia. A pesar del poco tiempo de inicio en el uso de esta plataforma, se observa que la mayor deficiencia radica en la comunicación individual entre el tutor y el alumno. Algunas herramientas que provee son de poco uso en el proceso, tal es el caso del foro y grupo" (sic).

\subsection{Evaluadores alumnos}

Los 15 alumnos participantes señalaron que realizan la mayoría de las tareas sugeridas, salvo las siguientes:

- Consultar al tutor sobre la correcta recepción del trabajo y posible fecha de calificación (6 alumnos).

- Entregar un trabajo evaluable fuera de plazo (5 alumnos).

Al igual que en caso de los docentes la valoración en general fue "buena".

Respecto a la complejidad de las tareas, las respuestas fueron: "normal" (7), "muy baja" (6), "alta" (1), y "muy alta" (1). La mayoría indicó que "no tuvo que tomar decisiones sobre cómo realizar algunas tareas" (9), y el resto "no contestó" (5).

En cuanto a la visibilidad de las tareas, mayoritariamente estuvieron "muy de acuerdo" con las heurísticas, o "de acuerdo". La que menos valoración obtuvo fue la relacionada con la disponibilidad de las acciones posibles en cada momento que registró: "muy de acuerdo" (6), "de acuerdo" (4), "indiferente" (2), "muy en desacuerdo" (1), y 2 "no contestaron".

Al contrario de la opinión de los docentes, la intuitividad y topografía natural fue la heurística con valoración más positiva. No tuvo valoraciones "en desacuerdo", ni "muy en desacuerdo", y la mayoría se repartió entre "muy de acuerdo" y "de acuerdo".

El nivel de conformidad de los criterios generales que todo sitio Web debería tener fue bueno. En una escala de 1 a 5 puntos obtuvo 4,1 de promedio, por encima de los docentes $(3,7)$. En este caso, se destacó nuevamente estándares $(4,8)$, y consistencia $(4,8)$. También superó los 4 puntos diseño y organización $(4,4)$ y ayuda y documentación $(4,4)$. En este punto es interesante destacar que los alumnos valoraron la ayuda y documentación recibida casi un punto por encima de los docentes. El criterio que se ubicó nuevamente más alejado de la media fue reversibilidad y manejo del error $(2,7)$, dentro del cual un $27 \%$ "no contestó" y marca un fuerte indicio sobre la dificultad para entender el criterio. El resto estuvo cercano a la media: productividad $(4,2)$, retroalimentación $(3,8)$, y control por parte del usuario (4). 


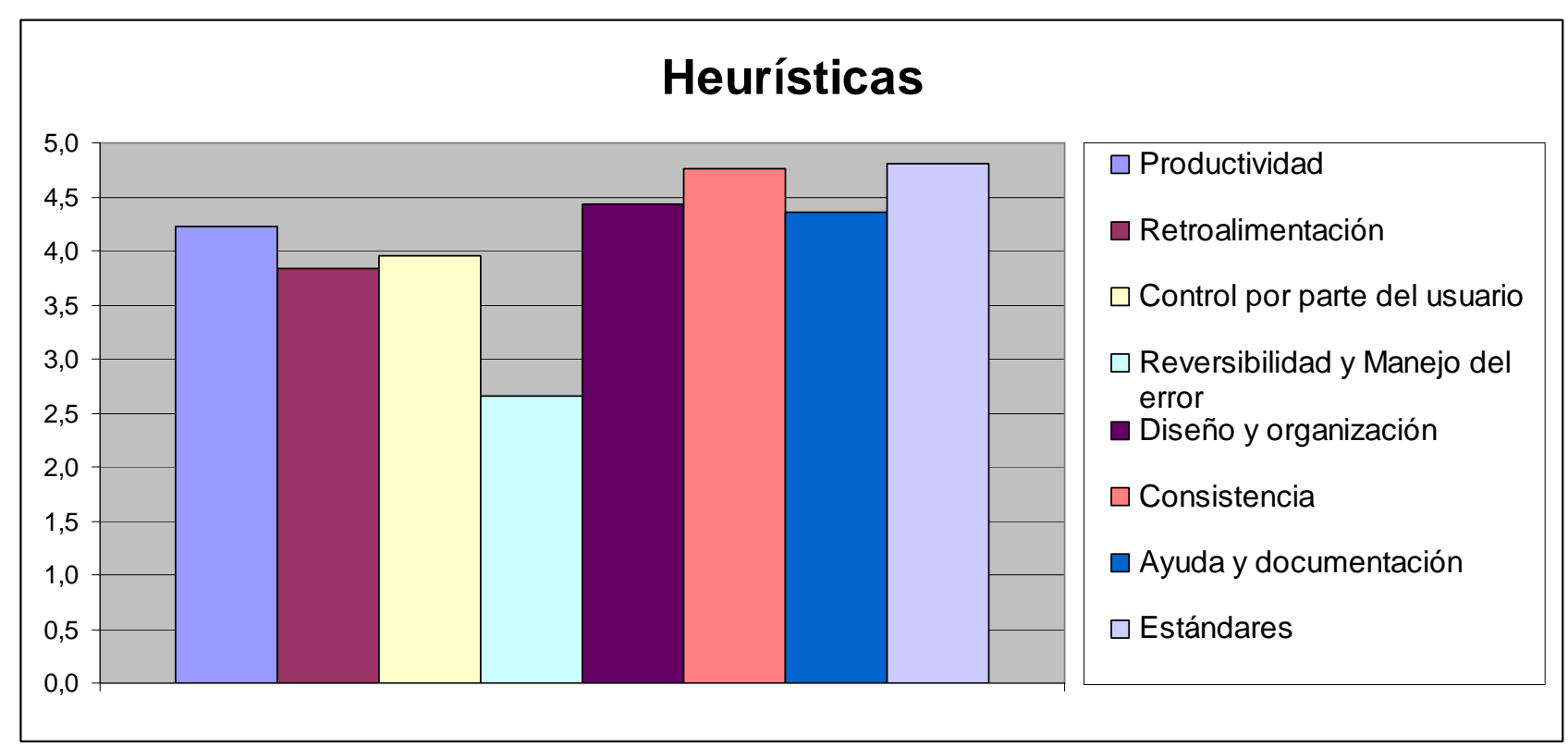

Figura 37 - Capa 4: valoración de alumnos respecto a las heurísticas orientadas al diseño

Dentro de las observaciones realizadas por los alumnos, que fueron muy pocas, podemos mencionar las siguientes:

- Desconozco las normas y convenciones usuales de la Web.

- Nunca usé la ayuda.

- No conozco el significado de "plug-ins" y no soy amiga de la tecnología.

- Navegar en Mozilla cuesta más.

- El sistema es excelente para educación a distancia.

En cuanto a la efectividad del EVEA para completar las tareas, los alumnos respondieron que lograron realizarlas "casi todas" (13\%), y "todas" (87\%). No hubo respuestas enmarcadas dentro del resto de la escala: "ninguna", "algunas" o "la mitad". Respecto a la eficiencia, el $100 \%$ consideró como "aceptable" el tiempo invertido en completar las tareas. El tiempo total ocupado en errores nuevamente no fue un punto débil, al igual que en docentes, dado que obtuvo un 13\% en "nada", 53\% en "muy poco", $27 \%$ en "poco", $7 \%$ en "bastante", y $0 \%$ en "mucho". El tiempo total de aprendizaje también fue considerado como "aceptable" en el $100 \%$ de los casos. En relación a la frecuencia de uso de la ayuda y documentación, el 34\% manifestó usarla "nunca", el 53\% "entre 1 y 4 veces", y el 13\% "más de 4 veces". El número de intentos y estrategias alternativas utilizadas hasta lograr completar las tareas obtuvo una consideración de "aceptable" en el 93\% de los casos, y $7 \%$ como "no aceptable". El número de errores cometidos, y el tiempo total necesario para recuperarse de errores registraron una opinión de "aceptable" en el 100\% de los casos.

Las métricas de satisfacción registraron, al igual que en docentes, opiniones positivas. Sobre las veces en que sintió frustración o enojo los alumnos respondieron que fueron "pocas" (entre 1 y 4 veces) 27\%, 66\% "nunca", y 7\% "muchas" (más de 4 veces). El producto fue considerado como "muy útil" en un $87 \%$, y "bastante útil" en un $13 \%$. En cuanto a las funciones y características el 66\% se mostró "satisfecho", y el 34\% "bastante satisfecho", mientras que en la percepción a cerca de que las tecnologías dan soporte a las tareas según las propias necesidades del alumno, el $66 \%$ opinó que "siempre", el $27 \%$ "casi siempre", y el 7\% "a veces". 


\subsubsection{A modo de síntesis}

En general se observa que los docentes valoraron los criterios por debajo de los alumnos, excepto en retroalimentación, y en reversibilidad y manejo del error. Las diferencias más significativas estuvieron en ayuda y documentación (1,1 punto), y productividad (1 punto). Lo mismo sucedió con las métricas de efectividad, eficiencia y satisfacción. Esto pone en evidencia que las tareas realizadas por los docentes necesitan mayor atención, a los efectos de incorporar mecanismos que le posibiliten a los que usan el EVEA con mayor frecuencia, o han adquirido más experticia, realizar de forma más ágil las tareas habituales y masivas, máxime cuando son los docentes quienes más tiempo dedican al trabajo dentro del EVEA.

En el mismo sentido, si comparamos la evaluación realizada en la capa 2 por los expertos, en este mismo punto, podemos observar que los usuarios reales, promediando docentes y alumnos, han sido más severos respecto a las valoraciones realizadas, aunque con una tendencia similar a los expertos. En efecto, el promedio obtenido en la capa 2 fue de 4,2 contra 3,9 de la capa 4. De las 8 heurísticas, sólo 2 fueron mejor valoradas por los usuarios finales, por muy poco margen, (estándares y retroalimentación), y las 6 restantes recibieron menor puntuación. Estos resultados confirman cierto grado de objetividad en la evaluación y avalan el estilo propuesto por el modelo.

\begin{tabular}{|l|c|c|}
\hline \multicolumn{1}{|c|}{ Heurística } & $\begin{array}{c}\text { Capa 2 } \\
\text { Expertos }\end{array}$ & $\begin{array}{c}\text { Capa 4 } \\
\text { Alumnos y docentes reales }\end{array}$ \\
\hline Ayuda y documentación & 4,5 & 3,9 \\
\hline Consistencia & 5 & 4,5 \\
\hline Control por parte del usuario & 4,3 & 3,9 \\
\hline Diseño y organización & 4,5 & 4,1 \\
\hline Estándares & 4,6 & 4,7 \\
\hline Productividad & 3,8 & 3,7 \\
\hline Retroalimentación & 3,6 & 3,9 \\
\hline Reversibilidad y manejo del error & 3,4 & 3,1 \\
\hline Promedio & 4,2 & 3,9 \\
\hline
\end{tabular}

Tabla 17 - Comparación entre capa 2 y capa 4 respecto a las heurísticas aplicadas 


\subsubsection{Problemas, trabas o conflictos}

Durante la puesta en práctica del modelo de evaluación surgieron una serie de inconvenientes, y se dieron algunas situaciones que merecen ser comentadas porque ponen una cuota de realismo al modelo respecto a su implementación en un contexto real, y por ende enriquecen la propuesta.

\subsubsection{Capa1}

- El tiempo de evaluación se extendió por más de tres meses.

- El evaluador de estándares dedicó más tiempo que los 3 expertos restantes juntos.

\subsubsection{Capa 2}

- Los evaluadores seleccionados no respondieron cabalmente al perfil propuesto en el modelo.

- El tiempo de evaluación se extendió por más de un mes.

- Los expertos seleccionados estaban dispersos en diferentes lugares geográficos. No compartieron sesiones conjuntas de trabajo sino que cada uno realizó la evaluación por su cuenta.

- El análisis pormenorizado de los escenarios produjo cambios en la secuencia porque no era correcta.

- Se debió preparar un documento especial para explicar a cada evaluador el contexto de uso y los escenarios.

- La coordinación entre evaluadores fue muy dificultosa. Los escenarios deberían permitir que cada evaluador no dependa de los demás.

- Falta particularizar un poco más las tareas de acuerdo al EVEA que se pretenda evaluar, pero sin llegar a inducir ciertos usos. Por ejemplo, aclarando el significado de "conocer la situación de cada alumno", o si "tarea es lo mismo que actividad", en el caso del SIAT.

- Es demasiado engorroso solicitar que se utilicen varios navegadores y conexiones a Internet para transitar todos los escenarios. Inclusive hay escenarios que no pueden repetirse dos veces de forma idéntica. En todo caso debería pedirse que ciertos escenarios se evalúen con un navegador y versión determinada, y los restantes escenarios con otro. La conexión a Internet debería ser la de menor calidad posible.

- Uno de los evaluadores realizó en serie los escenarios correspondientes a cada rol, con lo cual muchas tareas no podían realizarse debido a que necesitaban de otras previas. Por ejemplo, el docente-tutor no puede evaluar una actividad si el alumno no la subió previamente.

- El mismo evaluador planteó que llevaba mucho tiempo realizar todo el proceso de manera exhaustiva.

- Los escenarios deberían ser lo menos dependiente posible entre cada rol. De esa manera se podrían realizar evaluaciones independientes, aumentar la cantidad de evaluadores, reducir la cantidad de escenarios evaluados por cada uno, y, de esa forma, reducir el tiempo dedicado por cada uno de ellos. 
- Por razones de lejanía geográfica, y fechas diferentes de culminación de la evaluación, no se pudo hacer una puesta en común entre los tres evaluadores para confeccionar un único informe que reflejara el análisis realizado por cada uno y los acuerdos alcanzados.

\subsubsection{Capa 3}

- La cantidad de observadores es insuficiente. Mientras el usuario realiza las tareas, el observador debe estar presente para registrar lo que éste expresa, y realizar preguntas directas cuando lo considere necesario. Durante la sesión, el observador debe tomar registro y completar, por cada usuario, la primera parte del cuestionario. Luego de finalizada la misma debe completar la segunda mitad. Este cuestionario detalla un conjunto de métricas de usabilidad que intentan medir el grado de efectividad, eficiencia y satisfacción del entorno virtual. Para poder registrar correctamente toda la información es necesario que cada usuario tenga asignado un evaluador. Para llevar esto a la práctica pueden evaluarse diferentes opciones:

- Contar con la participación de 10 observadores en lugar de 4.

- Reducir la cantidad de usuarios a 6 (3 docentes y 3 alumnos) y aumentar los observadores a 6.

- Aumentar la cantidad de sesiones y hacer participar varias veces al mismo observador. Para lograr esto, los escenarios, de acuerdo al rol, deberían ser más independientes.

- La asistencia y coordinación de cada sesión es dificultosa. La elección de un día y horario que conforme a todos los usuarios es casi imposible de llevar a cabo. También lo es lograr la participación de todos los usuarios comprometidos. Para suplir la falta de algún usuario a la sesión de evaluación es necesario incorporar un ayudante que haga las veces de docente o de alumno sin necesidad de ser observado ni que complete los cuestionarios.

- La concurrencia fue escasa, solo participaron 4 de los 15 convocados.

- La guía entregada a los evaluadores, donde constan los escenarios y el contexto de uso, debería agrupar a los escenarios de acuerdo el rol que desempeña cada evaluador para aportarle mayor claridad a la persona que asume dicho rol.

\subsubsection{Capa 4}

- No se cubrió la cantidad mínima de usuarios docentes, ya que participaron 4 en lugar de 7.

- La cantidad de usuarios alumnos se cubrió ajustadamente, 15 voluntarios sobre 13 de mínima.

- No se realizó la selección de usuarios para determinar su nivel de experticia (novato, medio, avanzado) y contexto general, sino que se apeló a usuarios voluntarios.

- Los tiempos en recibir las respuestas fueron mayores a lo esperado. 


\subsection{Conclusiones}

Para tener dimensión de las cualidades y defectos de MUsa, se lo aplicó sobre un EVEA real, en el contexto institucional de la Universidad Nacional de Río Cuarto. De esta forma se puso a prueba la propuesta, que a su vez sirvió para validar el EVEA SIAT, desarrollado y utilizado por esta Universidad desde hace más de 10 años. El caso de estudio sirvió para realizar un recorrido completo por las cuatro capas del modelo de evaluación, tomar las decisiones correspondientes en cada una de ellas de acuerdo a la magnitud de la evaluación, tiempo y recursos disponibles, y afrontar una aplicación efectiva del mismo dentro de un contexto conocido y acotado.

La primera capa de evaluación, realizada por especialistas en educación y tecnología, permitió observar que el EVEA SIAT posee las características funcionales básicas, buenos niveles de adecuación a los estándares de navegación, no así de e-learning e internacionalización, y es flexible desde el punto de vista tecnológico, organizativo y pedagógico/didáctico.

La segunda capa aportó la opinión de expertos en las temáticas relacionadas con EVEA. Para el caso de la evaluación orientada a la tarea, los expertos destacaron que el SIAT no es complejo desde el punto de vista de su utilización de un docente o de un alumno, aunque fueron dispares las opiniones respecto de la visibilidad y topografía natural, sin duda un aspecto a mejorar. Desde el punto de vista del diseño de interfaces, el nivel de conformidad fue muy bueno.

La tercera capa incorporó la opinión de usuarios finales, docentes y alumnos, en el marco de un laboratorio de usabilidad. En este caso se observó que las tareas no fueron complejas, pero resultaron de menor complejidad en el caso de los alumnos, la visibilidad obtuvo muy buenas valoraciones en ambos casos, mientras que la intuitividad y topografía natural fue valorada positivamente, pero mejor aún en alumnos.

En la cuarta y última capa intervinieron usuarios finales dentro de un contexto real. La complejidad de las tareas fue un obstáculo, pero los docentes evidenciaron mayores problemas que los alumnos. La visibilidad tampoco mostró problema alguno en ninguno de los dos casos. Los docentes señalaron a la intuitividad y topografía natural como la heurística con valoración más negativa, todo lo contrario a los alumnos. Respecto a las heurísticas relacionadas con el diseño de interfaces, el nivel de conformidad fue bueno entre los docentes y muy bueno entre los alumnos.

En general, podemos decir que el EVEA SIAT posee un grado de usabilidad aceptable, aunque los resultados ponen en evidencia que las tareas realizadas por los docentes necesitan mayor atención, a los efectos de incorporar mecanismos que posibiliten agilizar las tareas habituales y más complejas que éstos usuarios realizan con mayor frecuencia.

En cuanto al modelo en sí, los resultados obtenidos a partir de la evaluación han permitido rescatar información útil para la mejora del EVEA SIAT, pero fundamentalmente, para realizar ajustes a MUsa en función de la experiencia adquirida durante la aplicación y la opinión de los expertos, observadores, docentes, y alumnos participantes de la misma. Se pudo observar que el modelo se comportó acorde a las expectativas. Sin embargo, hay cuestiones por pulir y mejorar a los efectos de dotarlo de mayor capacidad de adaptación ante diferentes circunstancias. Algunas de los problemas que necesitan ser abordados están relacionados con los tiempos destinados a la evaluación, que fueron mucho mayores a los esperados, el orden de algunas tareas pertenecientes a los escenarios de uso que sufrieron modificaciones, los instrumentos que recibieron críticas en las escalas de valoración, y las adaptaciones que debieron realizarse en la tercera y cuarta capa, por 
no contar con la cantidad y calidad de evaluadores necesarios [Fer2012]. En este punto es importante destacar que todos los participantes (expertos, docentes, alumnos, observadores) han sido voluntarios, no recibieron compensación alguna por el trabajo, ni dispusieron de tiempos específicos para realizar la evaluación, sino que fueron desarrollando las tareas asignadas a medida que se lo permitían sus actividades cotidianas. Los próximos pasos a seguir están relacionados con la revisión de todo el modelo de evaluación, la mejora del mismo de acuerdo a la información recogida a partir del caso de estudio y la presentación formal para su efectiva utilización. En tal sentido, podemos considerar al caso de estudio realizado con el EVEA SIAT como un primer paso para testear y mejorar el modelo, antes de ponerlo en práctica de manera real. 



\section{Capítulo 9: Resultados, conclusiones, trabajos futuros}

\subsection{Resultados y conclusiones}

En esta tesis se ha propuesto enfocar el concepto de usabilidad para poder encontrar un modelo de evaluación de EVEA centrado en dicho concepto, de suma importancia en la calidad de los productos. Para ello fue necesario contextualizar el concepto de usabilidad desde el punto de vista de las aplicaciones Web, en particular desde entornos virtuales relacionados con las actividades de enseñanza y de aprendizaje. A partir del análisis del concepto de usabilidad se obtuvo una síntesis de heurísticas, criterios, y métricas, que resultan adecuadas para el contexto educativo.

Luego se estudiaron diferentes modelos de evaluación, ya existentes, aplicados a los EVEA. En función de dicho estudio, se observó que la mayoría estaban orientados hacia las funcionalidades que ofrecen, inclusive sin la participación del usuario final, sino solo de expertos. En dos de ellos, se encontró algún grado de inclusión de la usabilidad, pero de manera muy acotada. Por ese motivo se consideró necesario definir un nuevo modelo, que tomando las experiencias e investigaciones existentes, propusiera otra forma de evaluar los EVEA desde una mirada centrada en la usabilidad.

A partir del análisis realizado se comenzó a investigar sobre los mecanismos para evaluar usabilidad en un sitio Web, los métodos aplicados normalmente, las técnicas y herramientas utilizadas, y el tipo de evaluadores involucrados.

Las investigaciones previas, permitieron llegar a tener como resultado la construcción de un modelo orientado a una evaluación de producto, es decir, sobre entornos virtuales que ya han sido desarrollados, y están en pleno funcionamiento. Se lo denominó MUsa, dado que se trata de un Modelo centrado en la Usabilidad. La evaluación se apoya en escenarios reales de uso, teniendo especial consideración por los alumnos y docentes, los objetivos que se proponen, las tareas específicas que realizan dentro del entorno durante las actividades de enseñanza y aprendizaje, el modelo mental que utilizan, el equipamiento e infraestructura que disponen, el lugar físico donde habitualmente se desenvuelven, y el entorno social en el cual están insertos. MUsa también puede facilitar la evaluación de nuevas versiones, o la comparación entre ellas.

Las ideas generales de MUsa están basadas en una estrategia de cuatro niveles o capas de evaluación, que parten de lo general para llegar a lo particular. Las cuatro capas persiguen objetivos diferentes. La primera es la encargada de realizar una evaluación del entorno en general, las tres capas restantes se sitúan en un contexto de uso particular, por ejemplo, el aula virtual de un curso. Para ello, las capas más cercanas al usuario utilizan escenarios de uso que permiten guiar y sistematizar la evaluación. En cada caso se utilizan métodos, técnicas, e instrumentos diferentes, que se complementan entre sí y posibilitan enriquecer la evaluación. Las capas propuestas pueden ajustarse a distintos contextos dependiendo de la necesidad, nivel de profundidad de la evaluación, recursos y tiempo disponible. MUsa puede adaptarse en dos sentidos, prescindiendo completamente de algunas de las capas, o seleccionando diferentes alternativas dentro de la segunda capa.

Las capas han sido explicadas detalladamente a lo largo de este informe de tesis. Se han planificado para lograr un modelo que pueda considerar de manera integral la evaluación de un EVEA. 
La primera capa de MUsa está destinada a analizar gran parte de la aceptabilidad práctica del EVEA. La aceptabilidad práctica conjuga la utilidad con otras variables como costos, compatibilidad, confiabilidad, y soporte. La utilidad, a su vez, está determinada por la utilidad práctica o funcional, la usabilidad, y la accesibilidad. Por este motivo se aborda el análisis de todos los componentes de la aceptabilidad práctica, menos el referido específicamente a usabilidad. Esto no significa que la evaluación de usabilidad esté ausente por completo en esta capa, sino que las variables que se analizan son: utilidad práctica y accesibilidad (parte de la utilidad), junto con las características técnicas generales (antecedentes, potencial, tecnología utilizada, licencia, soporte, seguridad, acceso de usuarios), compatibilidad (servidor, usuario/cliente, formatos multimedia, integración) y robustez (integridad de funcionamiento, recuperación ante fallos, seguridad). En este sentido se pone énfasis sobre las características funcionales del EVEA, donde se considera la flexibilidad del entorno desde el punto de vista tecnológico, organizativo, y pedagógico/didáctico, incluyendo además el nivel de estandarización. Un punto que toma especial relevancia es la versatilidad del entorno para adaptarse al desarrollo de cursos, grupos de cursos, carreras, comunidades virtuales, etc. También es importante evaluar la forma en que puede dar soporte a diferentes modalidades educativas, sean éstas a distancia o mixtas, y a diferentes enfoques de enseñanza y de aprendizaje. Para analizar este tipo de características es necesario contar con especialistas en educación y en tecnología. La primera capa de evaluación pone énfasis sobre las coincidencias entre los modelos estudiados en el capítulo 2, con la idea de construir un instrumento de evaluación general, centrado en los componentes tecnológicos de los EVEA, pero sin perder de vista los componentes organizativos, pedagógicos y didácticos, ya que todos son determinantes al momento de analizar un entorno particular.

La segunda capa se orienta a evaluar la forma en que el sistema interactúa con el usuario, la interfaz que presenta, y el modo en que permite realizar las tareas básicas. La conjugación de dos métodos de inspección, como el recorrido cognitivo y la evaluación heurística, resulta ser adecuada para este tipo de acciones. Las heurísticas utilizadas se organizaron en dos niveles de evaluación, uno general, orientado a la tarea, y otro particular, orientado al diseño. El primero examina el aspecto y comportamiento desde el punto de vista de las tareas y objetivos de los usuarios. Para ello se utilizan las heurísticas de complejidad, visibilidad, intuitividad, y topografía natural. El segundo analiza los aspectos concretos del conjunto de interfaces provistas por el EVEA para completar las tareas. Las heurísticas utilizadas en este caso son las de productividad, retroalimentación, control por parte del usuario, reversibilidad y manejo del error, diseño y organización, consistencia, ayuda y documentación, y estándares. La forma de evaluación se realiza por escenarios de uso. Por el tipo de evaluación, los expertos que participan son docentes con diferente grado especialización en EVEA y en tecnología.

La tercera capa incorpora, por primera vez, la opinión de los usuarios finales bajo un ambiente controlado por un observador. Por tal motivo se utiliza un laboratorio de usabilidad. La evaluación se realiza mediante test de usuario, específicamente el de expresión del usuario en base a preguntas. Las heurísticas utilizadas son las mismas que en la capa anterior (complejidad, visibilidad, intuitividad, y topografía natural). A ellas se suman una serie de las métricas relacionadas con efectividad, eficiencia, y satisfacción. Los usuarios transitan escenarios de uso para realizar las tareas que forman parte de cada escenario tipo. A medida que el usuario interactúa con el entorno, debe expresar en voz alta sus pensamientos, sensaciones y opiniones, mientras el evaluador capta y 
registra las impresiones que el usuario manifiesta oralmente. Además puede realizar preguntas directas cuando lo considera conveniente.

La cuarta capa es destinada exclusivamente a que los futuros usuarios finales aporten su punto de vista dentro de un contexto o ambiente real. Lógicamente, para realizar este tipo de evaluación también son adecuados los test de usuarios, en particular se utilizó el test remoto. Además, el usuario realiza el test en su propio medio o ambiente, con lo cual es posible evaluar el contexto de uso. Los test remotos se basan, principalmente, en cuestionarios para recolectar la información. Las heurísticas coinciden con las utilizadas en la segunda capa para la evaluación orientada a la tarea (complejidad, visibilidad, intuitividad, y topografía natural), y al diseño (productividad, retroalimentación, control por parte del usuario, reversibilidad y manejo del error, diseño y organización, consistencia, ayuda y documentación, y estándares). Al igual que en la segunda y tercera capa se utilizan los escenarios de uso. El evaluador es el encargado de suministrar un cuestionario a los usuarios reales, examinar las aulas virtuales luego de finalizadas las tareas, y posteriormente procesar los resultados. También completa un cuestionario que contempla las métricas de efectividad, eficiencia, y satisfacción.

Para tener dimensión de las cualidades y defectos de MUsa, se lo aplicó sobre un EVEA real, en el contexto institucional de la Universidad Nacional de Río Cuarto. De esta forma se puso a prueba la propuesta, que a su vez sirvió para validar el EVEA SIAT, desarrollado y utilizado por esta Universidad desde hace más de 10 años. El caso de estudio sirvió para realizar un recorrido completo por las cuatro capas del modelo de evaluación, tomar las decisiones correspondientes en cada una de ellas de acuerdo a la magnitud de la evaluación, tiempo y recursos disponibles, y afrontar una aplicación efectiva del mismo dentro de un contexto conocido y acotado.

La primera capa de evaluación, realizada por especialistas en educación y tecnología, permitió observar que el EVEA SIAT posee las características funcionales básicas, buenos niveles de adecuación a los estándares de navegación, no así de e-learning e internacionalización, y es flexible desde el punto de vista tecnológico, organizativo y pedagógico/didáctico. La segunda capa aportó la opinión de expertos en las temáticas relacionadas con EVEA. Para el caso de la evaluación orientada a la tarea, los expertos destacaron que el SIAT no es complejo desde el punto de vista de su utilización de un docente o de un alumno, aunque fueron dispares las opiniones respecto a las heurísticas referidas a la visibilidad y topografía natural, sin duda un aspecto a mejorar. Desde el punto de vista del diseño de interfaces, el nivel de conformidad fue muy bueno. La tercera capa incorporó la opinión de usuarios finales, docentes y alumnos, en el marco de un laboratorio de usabilidad. En este caso se observó que las tareas no fueron complejas, pero resultaron de menor complejidad en el caso de los alumnos, la visibilidad obtuvo muy buenas valoraciones en ambos casos, mientras que la intuitividad y topografía natural fue valorada positivamente, pero mejor aún en alumnos. En la cuarta y última capa intervinieron usuarios finales dentro de un contexto real. La complejidad de las tareas fue un obstáculo, pero los docentes evidenciaron mayores problemas que los alumnos. La visibilidad tampoco mostró problema alguno en ninguno de los dos casos. Los docentes señalaron a la intuitividad y topografía natural como la heurística con valoración más negativa, todo lo contrario a los alumnos. Respecto a las heurísticas relacionadas con el diseño de interfaces, el nivel de conformidad fue bueno entre los docentes y muy bueno entre los alumnos. En general, podemos decir que el EVEA SIAT posee un grado de usabilidad aceptable, aunque los resultados ponen en evidencia que las tareas realizadas por los docentes necesitan mayor atención, a los efectos de incorporar mecanismos que 
posibiliten agilizar las tareas habituales y más complejas que éstos usuarios realizan con mayor frecuencia.

En cuanto al modelo en sí, los resultados obtenidos a partir de la evaluación han permitido rescatar información útil para la mejora del EVEA SIAT, pero fundamentalmente, para realizar ajustes a MUsa en función de la experiencia adquirida durante la aplicación y la opinión de los expertos, observadores, docentes, y alumnos participantes de la misma. Se pudo observar que el modelo se comportó acorde a las expectativas. Sin embargo, hay cuestiones por pulir y mejorar a los efectos de dotarlo de mayor capacidad de adaptación ante diferentes circunstancias. Algunas de los problemas que necesitan ser abordados están relacionados con los tiempos destinados a la evaluación, que fueron mucho mayores a los esperados, el orden de algunas tareas pertenecientes a los escenarios de uso que sufrieron modificaciones, los instrumentos que recibieron críticas en las escalas de valoración, y las adaptaciones que debieron realizarse en la tercera y cuarta capa, por no contar con la cantidad y calidad de evaluadores necesarios. En este punto es importante destacar que todos los participantes (expertos, docentes, alumnos, observadores) han sido voluntarios, no recibieron compensación alguna por el trabajo, ni dispusieron de tiempos específicos para realizar la evaluación, sino que fueron desarrollando las tareas asignadas a medida que se lo permitían sus actividades cotidianas. Los próximos pasos a seguir están relacionados con la revisión de todo el modelo de evaluación, la mejora del mismo de acuerdo a la información recogida a partir del caso de estudio y la presentación formal para su efectiva utilización. En tal sentido, podemos considerar al caso de estudio realizado con el EVEA SIAT como un primer paso para testear y mejorar el modelo, antes de ponerlo en práctica de manera real.

\subsection{Trabajos Futuros}

\subsubsection{Grado de usabilidad}

Los parámetros a tener en cuenta para determinar la usabilidad del EVEA los decide cada equipo de evaluación. En general, cuando se habla de medir la usabilidad de un producto se hace referencia al nivel o grado de usabilidad del mismo. El grado de usabilidad es una medida empírica y relativa. Habitualmente se basa en opiniones de expertos, pruebas de laboratorio, observaciones de campo, y pruebas de usuarios. El resultado depende de las metas planteadas para un contexto de uso determinado, o de una comparación con otras versiones o productos similares.

En muchas ocasiones se intenta medir este grado de usabilidad mediante escalas cualitativas o cuantitativas. Una pequeña aproximación a este aspecto es señalada cuando decimos que el avance de una capa a la siguiente debe estar respaldado por una evaluación favorable. Cada capa debería tener un resultado, por ejemplo: muy aceptable, aceptable, no aceptable. La evaluación desfavorable de una capa seguramente tendrá consecuencias importantes sobre la evaluación total, ya que difícilmente en las capas posteriores se mejore el grado de usabilidad del EVEA. Sin embargo, la amplitud del tema escapa los alcances de esta tesis, por lo cual no está planteado y se lo considera como un aspecto abierto.

\subsubsection{Ajustes del modelo y análisis por expertos}

A lo largo del caso de estudio se encontraron puntos del modelo que deben ser revisados, mejorados o detallados con mayor claridad. Algunos instrumentos no fueron utilizados por la magnitud del caso de estudio, y otros recibieron sugerencias o presentaron falencias para su real utilización. Un punto central para trabajos futuros es aplicar la experiencia 
recogida mediante la evaluación del EVEA SIAT para refinar el modelo en base al caso de estudio, y de forma sucesiva en función de varias aplicaciones de éste para evaluar otros EVEA.

Por otro lado, la usabilidad involucra varias áreas de conocimiento, en particular si es aplicada a productos con sentido educativo. Por tal motivo sería saludable que el modelo sea examinado por expertos en áreas relacionadas con educación, psicología, evaluación, tecnología informática, comunicación, diseño Web, e ingeniería, entre las más importantes.

\subsubsection{Extender la aplicación del modelo}

Una vez refinado el modelo podría ser puesto en práctica para comparar un EVEA con otro, nuevas versiones de uno en particular, nuevos módulos, o contextos específicos de utilización. En este caso, una ardua tarea es la definición de los escenarios de uso para poner en práctica la evaluación. Los escenarios de uso son parte central del modelo, las tres últimas capas se basan en ellos. Por último, es posible extenderlo para trabajar con otros espacios Web como comunidades virtuales o redes sociales que se vinculen con educación, aunque de cada uno habrá que analizar especificidades. Dada la importancia que el tema tiene a futuro, a continuación desarrollamos algunas ideas relacionadas con Web 2.0.

\subsubsection{Tendencias actuales}

La evolución de los EVEA va de la mano con la evolución tecnológica y de Internet, aunque los cambios se perciban como más lentos. A finales de la década de los '90 la Web estaba dominada por la presencia de portales y grandes medios de comunicación que se abrían a Internet y comenzaban, en una primera etapa, a mover sus contenidos al entorno digital sin demasiada preocupación por las características y lenguajes del espacio digital [Thü2011b]. La crisis de las puntocom a comienzos del 2000 marcó un punto de inflexión, no solo en el mercado tecnológico que se desplomó. Hubo un replanteo sobre cómo las organizaciones y empresas usan el espacio de Internet. Los grandes portales dejaron de ser los sitios de referencia y comenzaron a emerger espacios donde el usuario se constituye como protagonista y la información se gestiona de un modo mucho más eficiente [O'R2005]:

- La Web ha dejado de ser un canal direccional para constituirse en una red de lectura-escrita, es decir, se lee pero también se participa en la construcción del contenido. El valor se genera por la presencia y el aporte de contenidos por parte de los usuarios que también se transforma en productor. El sentido de comunidad es uno de los aspectos más valiosos de la Web 2.0.

- Se favorece la comunicación abierta, la participación, la transparencia y la libre expresión. Uno de los ejemplos más claros son los blogs. Autor y comentaristas dialogan acerca de las ideas que se exponen, intercambian puntos de vista de los cuales pueden surgir nuevos textos y comentarios.

- Se valora la inteligencia colectiva al aprovechar el poder de las comunidades online que con su trabajo alimentan y dan vida a un sitio. El caso más notorio es el de Wikipedia, la enciclopedia que basa su desarrollo en el aporte de millones de usuarios que escriben los artículos.

Uno de los principales cambios que trae la Web 2.0 es la descentralización de las fuentes de información. Las diferentes herramientas y servicios como blogs, wikis, redes sociales 
y demás recursos para el trabajo colaborativo y el intercambio proporcionan a las personas vías de acceso a la información que no son las tradicionales [Cas2007]. A partir de ello comienza a hablarse de Entornos Personales de Aprendizaje (EPA), como una experiencia donde el uso personal que cada alumno hace de dichas herramientas, en torno a un curso, y el tipo las conexiones que el propio alumno puede establecer con diferentes herramientas, de las que recibe o en las que publica información, enriquece su aprendizaje [Cas2009].

A diferencia de los EVEA administrados por una organización, los EPA no tienen que ver con el software sino que constituyen una nueva aproximación al uso de la tecnología, donde se favorece el aprendizaje permanente e informal, se respetan los estilos de aprendizaje de cada alumno, y se permiten nuevos enfoques para el reconocimiento de dicho aprendizaje [Att2007].

Los EPA proporcionan a los usuarios un ambiente de aprendizaje que reúne las fuentes de información y el contexto. Estos ambientes motivan al alumno a tomar la responsabilidad de su propio aprendizaje y favorecen su autonomía y alfabetización [Thü2011b].

Sin embargo, no son pocas las voces críticas hacia la Web $2.0 \mathrm{y}$, particularmente, de las posibilidades que brindan estos recursos para la educación. Existe un cuestionamiento al presupuesto de que las nuevas generaciones saben utilizar adecuadamente las nuevas tecnologías y pueden incorporarlas a su proceso educativo. Si bien los nativos digitales han nacido en un mundo en red, todavía subsisten importantes diferencias intrageneracionales, donde los procesos de apropiación y representación de las tecnologías de la información no son simétricos. Por otra parte, muchas veces se ignora el contexto cultural y socioeconómico dentro del cual estas tecnologías son accedidas y utilizadas [All2008].

Al mismo tiempo, algunos investigadores están comenzando a interrogarse sobre los resultados de la introducción de herramientas Web 2.0 como redes sociales o juegos al contexto del aula. Estudios recientes concluyeron que no todos los jóvenes se involucran del mismo modo en la utilización de estas herramientas. Además, señalan la necesidad de crear programas de evaluación que permitan cuantificar el impacto real que tiene la incorporación de estos recursos en el aula [Van2011].

Se propone analizar MUsa con el fin de revisar si es necesario su adaptación para lograr evaluar los actuales avances que los EVEA están teniendo en relación a la integración con software social y herramientas de la Web2.0, en general. 


\section{Bibliografía}

- [Ade1998] Adell, J. Redes y educación. En J. De Pablos y J. Jiménez (coord.) Nuevas Tecnologías. Comunicación audiovisual y educación. pp. 177-211. Barcelona. 1998

- [Ade2004] Adell, J. Selección de un entorno virtual de enseñanza / aprendizaje de código fuente abierto para la Universitat Jaume I. Centre d'Educació i Noves Tecnologies de la UJI con la colaboración del Servei d'Informàtica y del Gabinet Tècnic del Rectorat. 2004

- [AEN2004] AENOR. Requisitos de Accesibilidad para Contenidos en la Web. UNE 139803:2004. 2004

- [All2008] Allen, M. Web 2.0: An argument against convergence. First Monday; Volume 13, Number $3-3$. http://www.uic.edu/htbin/cgiwrap/bin/ojs/index.php/fm/article/view/2139/1946. 2008

- [Alv2005] Alva Obeso, M. E. Metodología de Medición y Evaluación de la Usabilidad en Sitios Web Educativos. 2005

- [Alv2006] Alvarado, A., Rodríguez, A. (Editores). La formación sin distancia. Madrid: Servicio Público de empleo estatal. 2006

- [Ant1995] Antipolis S. Human Factors: Guide for usability evaluations of telecommunications systems and services. European telecommunications standards institute. ETSI ETR095, France. 1995

- [ASE2011] http://www.governoeletronico.gov.br/acoes-e-projetos/e-MAG/asesavaliador-e-simulador-de-acessibilidade-sitios

- [Att2007] Attwell, G. Personal Learning Environments - the future of eLearning? eLearning Papers 2 (1). 2007

- [Bae2002] Baeza Yates, R, Rivera Loaiza, C. Ubicuidad y Usabilidad en la Web. 2002

- [Bau2002] Baumgartner, P., Häfele, H., et al. E-Learning Praxishandbuch: Auswahl von Lernplattformen. Marktübersicht - Funktionen - Fachbegriffe. Innsbruck-Wien, StudienVerlag. 2002

- [Bel1992] Bell, B. Using programming walkthroughs to design a visual language. Technical Report CU-CS-581-92 (Ph.D. Thesis), University of Colorado, USA. 1992

- [Ber2000] Berry, D. The user experience: The iceberg analogy of usability. http://www128.ibm.com/developerworks/library/w-berry/. 2000

- [Ber1999] Berners-Lee, T. Weaving the Web. http://www.w3.org/People/BernersLee/Weaving/glossary.html. 1999

- [Bev1991] Bevan, N., Kirakowski, J., Maissel, J. What is Usability. Proceedings of the 4th International Conference on HCl. Stuttgart, September 1991. 1991

- [Bev1995]. Bevan, N. Usability is Quality in Use. Proceedings of the 6th International Conference on Human Computer Interaction. Yokohama, Anzai \& Ogawa Eds., Elsevier. 1995.

- [Bev1995b] Bevan, N. Measuring usability as quality of use. Software Quality journal, 4, pp. 115-150. NPL Usability Services. National Physical Laboratory, Teddington Middx. TW11 OLW. 1995

- [Bev1997] Bevan, N. Azuma, M.: Quality in use: Incorporating human factors into the software engineering lifecycle. In: Proceedings of the Third IEEE International Software Engineering Standards Symposium and Forum ISESS'97), pp. 169-179. 1997

- [Bev1999] Bevan, N. Quality in use: Meeting user needs for quality. Serco Usability Services, Alderney House, 4 Sandy Lane, Teddington, Middlesex TW11 ODU, UK. 1999

- [Bev2005] Bevan, N. Guidelines and Standards for Web Usability. 2005 
- [Bev2006] Bevan, N. International Standards for HCl. 2006

- [Bev2007] Bevan, N., Spinhof, L. Are guidelines and standards for web usability comprehensive. 2007

- [Bia1994b] Bias, R. G. The Pluralistic Usability Walkthrough: Coordinated Empathies. IBM Corporation. In Usability InspectionMethods chapter 3. pp. 63-76. 1994

- [Bias1994] Bias, R. G., Mayhew, D. J. Cost-Justifying Usability. Academic Press, 1994

- [Bok2001] Boklaschuk, K., Caisse, K. Evaluation of educational Web site. Educational communications and technology- University of Saskatchewan. http://members.fortunecity.com/vqf99. 2001

- [Boo1989] Booth, P. Anintroduction to Human-Computer Interaction. London: Lawrence Erlbaum Associates. 1989

- [BOB2011] Bobby. http://www.cast.org/learningtools/Bobby/index.html

- [Bra2003] Braun. K. Usabilidad. Anaya Multimedia. ISBN: 8441514763. 1ª edición. 2003

- [Bre2001] Brewer, J. How People with Disabilities Use the Web W3C Working Draft. http://www.w3.org/WAl/EO/Drafts/PWD-Use-Web/20010104. 2001

- [Bre2005] Brewer, J. How People with Disabilities Use the Web. Working-Group Internal Draft. Editors: Judy Brewer. W3C. 2005.

- [Cab2009] Cabero, J. Educación 2.0 ¿Marca, moda o nueva visión de la educación? Web 2.0. El uso de la Web en la Sociedad del Conocimiento. C. Castaño. Caracas (Venezuela), Universidad Metropolitana: 9-30. 2009

- [Cab2010] Cabero Almenara, J., Llorente Cejudo, M. del C., Marín Díaz, V. Hacia el diseño de un instrumento de diagnóstico de competencias tecnológicas del profesorado universitario. Revista Iberoamericana de Educación / Revista Iberoamericana de Educação ISSN: 1681-5653 n. $52 / 7$ - 10/06/10. 2010

- [Car2002] Carvalho, A. Usability testing of educational software methods, techniques and evaluators. 3ํㅗ Simposio Internacional de Informática Educativa. Portugal. 2002

- [Car2004] Carnoy, M. Las TIC en la enseñanza: posibilidades y retos.. http://www.uoc.edu/inaugural04/dt/esp/carnoy1004.pdf. 2004

- [Cas2004] Casanovas, J. Usabilidad y arquitectura del software. http://www.alzado.org/articulo.php?id_art=355. 2004

- [Cat2000] Catalán Vega, M. Metodologías de evaluación de interfaces gráficas de usuario. http://eprints.rclis.org/archive/00004718. 2000

- [Cas2007] Castañeda, L. Software social para la escuela 2.0: más allá de los Blogs y las Wikis. X Congreso Internacional EDUTEC. Buenos Aires, Argentina. 2007

- [Cas2009] Castañeda, L., Sánchez, M. Entornos e-learning para la enseñanza superior: entre lo institucional y lo personalizado. Pixel-Bit. Revista de Medios y Educación 35: 175-191. 2009

- [Car2012] Carreras Montoto, O. Estándares formales de usabilidad y su aplicación práctica en una evaluación heurística.

http://olgacarreras.blogspot.com.es/2012/03/estandares-formales-de-usabilidad-ysu.html. 2012

- [Cer2005] Cercas, E. Consultor SEO, Usabilidad y Estadísticas Web. Reglas de usabilidad web.

http://www.entraenlared.com/usabilidad_en_buscadores/reglas_de_usabilidad.asp. 2005

- [Cla1999] Clarke, A., Concejero, P., Ramos, R. ACTS usability evaluation guideline. USINACTS - AC224/TID/HF/DR/P/007/b1. http://innova.cicei.com/historia. 1999

- [Cle2011] ClearView. http://www.tobii.com. 2011 
- [Cob2005] Cobo Romaní, C. Organización de la información y su impacto en la usabilidad de las tecnologías interactivas. México. 2005

- [Col2002] Colombo R., Cervigni A. The evaluation method for software product. Proceedings of the 15th International Conference Software \& Systems Engineering and their Applications (ICSSEA '2002). 2002

- [Com2003] COL LMS Open Source Report. The Commonwealth of Learning, 3waynet. http://www.developmentgateway.org/download/201768/. 2003

- [Con1999] Constantine, L., Lockwood, L. Software for Use: A Practical Guide to the Models and Methods of Usage-Centered Design. Addison-Wesley, Nueva York, NY. 1999

- [Cov2005] Covella, G. Medición y Evaluación de Calidad en Uso de Aplicaciones Web. Facultad de Informática. Universidad Nacional de La Plata. Argentina. 2005

- [CYN2011] The HiSoftware CynthiaSays portal. http://www.cynthiasays.com/

- [Dar2002] Darriba, J. La usabilidad en el e-learning, más necesaria que nunca. Xperience Consulting. 2002

- [DeB2000b] De Benito, B. Herramientas web por entorno de enseñanza-aprendizaje, en CABERO, J. y otros (coods): Medios audiovisuales y nuevas tecnologías para la formación en el siglo XXI, Murcia, Diego Marín, pp. 209-221. 2000

- [DeB2005] De Benito, B., Salinas, J. Situaciones didácticas en los entornos virtuales de enseñanza-aprendizaje (EVEA) en la enseñanza superior: elaboración de un instrumento de análisis. Congreso Internacional EDUTEC, 2005

- [DeB2006] De Benito, B.,Salinas, J. Situaciones didácticas en los entornos virtuales de enseñanza-aprendizaje (EVEA) en la enseñanza superior: elaboración de un instrumento de análisis. Congreso EDUTEC. 2006

- [Dea2007] Dearstyne, B. Blogs, Mashups \& Wikis: Oh, My! Information Management Journal. 41 (4): 25.2007

- [Des1991] Desurvire, H., Lawrence, D., Atwood, M. Empiricism versus judgement: Comparing user interface evaluation methods on a new telephone-based interface. ACM SIGCHI Bulletin, 23, 4, pp. 58-59. 1991

- [Dey2002] Dey, A. An Accessibility Audit of WebCT. Information Technology Services. Monash University. Victoria, Australia. http://ausweb.scu.edu.au/aw02/papers/refereed/alexander/paper.html. 2002

- [Dey2002] Dey, A. An Accessibility Audit of WebCT. Information Technology Services. Monash University. Victoria, Australia. 2002

- [Dil1999] Dillon, A.; Morris, M. P3: modeling and measuring the human determinants of information systems usage. Proceedings of the 43rd Annual Meeting of the Human Factors and Ergonomics Society, Paper presented at the Annual Meeting of HFES in Texas, Santa Monica, CA: HFES, September. 1999

- [Dix2003] Dix, A., Ramduny, D., Rayson P., Onditi, V., Sommerville,l., Mackenzie, A. Finding Decisions Trhough Artefacts. Human-Computer Interaction: theory and Practice (vol. 1). Lawrence Erlbaum Associates. 2003

- [Dix1998] Dix, A., Finlay, J., Abows, G., Beale, R. Human-Computer Interaction. London: Prentice-Hall Europe. 1998

- [Edu2006] Edutools. WCET - Western Cooperative for Educational Telecommunications. Centre for Curriculum, Technology \& Transfer. British Columbia's University. Canadá. http://www.edutools.info/course/index.jsp. 2006

- [Eji1991] Ejiogo, L. Software Engineering whit Formal Metrics, QED Technical Publishing Group. 1991

- [Fer2001] Ferré, X., Juristo, N., Windl, H., Constantine, L. Usability Basics for Software Developers. IEEE Software, vol 18 (11). 2001 
- [Fer2003] Fernández, F., Montero, Y., Rodríguez, O. Limitaciones y problemas de usabilidad en plataformas de formación virtual: el caso de WebCT. Universidad de Granada. España. 2003

- [Fer2007] Ferreira Szpiniak, A., Sanz, C. Entornos Virtuales de Enseñanza y Aprendizaje: análisis y tendencias. Trabajo Final de Especialista en Tecnología Informática Aplicada en Educación. Facultad de Informática - UNLP. La Plata. Argentina. 2007

- [Fer2008] Ferreira, A., Guazzone, J. La incorporación de un Entorno Virtual en la Educación Presencial de la Universidad Nacional de Río Cuarto. Anales de las 1ras Jornadas de Educación a Distancia del NOA. Catamarca. Argentina. 2008

- [Fer2009c] Ferreira, A., Guazzone, J., Asaad, C. Análisis de la usabilidad del entorno virtual SIAT como innovación educativa en la formación universitaria de grado.

Encuentro Internacional BTM 2009: Sociedad de la Información y la incorporación de las TICs en los procesos de enseñanza-aprendizaje. Maldonado. Uruguay. 2009

- [Fil1998] File, J. Distance Learning Environments Feature List. Instructional Software Development Group, Information Technologies, University of lowa. http://www.ncsa.uiuc.edu/ jfile/learnenv. 1998

- [Fir2011] Mozilla Firefox. http://www.mozilla.org/es-ES/firefox. 2011

- [Flo2000] Floría Cortés, A. Pero ¿qué es, realmente, la usabilidad? http://www.sidar.org/recur/desdi/traduc/es/visitable/quees/usab.htm. 2000

- [Flo2000b] Floría Cortés, A. Recopilación de Métodos de Usabilidad. http://www.sidar.org/recur/desdi/traduc/es/visitable/quees/Herramientas.htm. 2000

- [Fra1997] Franklin, T. Application of MUSiC to the evaluation of dVISE (VR Authoring Software) mplemented on an immersive display platform. Experiment 1: Participant Instructions or NASA TLX. JTAP Project 305- Human-Computer Interface Aspects of Virtual Design Environments for Engineering Education. University of Manchester. 1997

- [Gab2002] Gabinete de Tele-Educación. Plataformas de tele-enseñanza. Universidad Politécnica de Madrid. http://www.gate.upm.es. 2002

- [Gaf2000] Gaffney, G. What is a Scenario? Information \& Design. www.infodesign.com.au. 2000

- [Gaf1999] Gaffney, G. Usability Techniques series: Participatory design workshops. Information \& Design 1999.

- [Ged1999] Gedica, G., Hamborg, K., Duentsch, I. The IsoMetrics usability inventory: an operationalization of ISO 9241-10 supporting summative and formative evaluation of software systems. Fachbereich Psychologie, UniversitaĖ t OsnabruĖ ck, D-46069 OsnabruĖ ck, Germany.Co. Antrim, BT37 0QB, Northern Ireland; Behaviour \& Information Technology, vol. 18, NO. 3, pp. 151-164. 1999

- [Ghe91] Ghezzi, C., Fuggetta, A., Morasca, S., Morzenti, A., Pezzè, M. Ingegneria del Software. Mondadori Informatica. 1991.

- [Gis1998] Gisbert Cervera, M., Adell Segura, A., Rallo Moya, R., Bellver Torlà, A. Entornos virtuales de enseñanza y aprendizaje. En Cuadernos de Divulgación Multimedia. Multimedia y Documentación Informativa: Tendencias actuales. Las nuevas tecnologías y su aplicación a la enseñanza. Universidad Complutense de Madrid. Número especial 6-7. ISSN: 1575-9733. 1998

- [GMS2010] Global Market Share Statistics. http://marketshare.hitslink.com/browsermarket-share.aspx?qprid=0. Agosto, 2010. 2010

- [Goi2004] Goikoetxea, I. Accesibilidad y usabilidad web no son una moda políticamente correcta. http://www.webestilo.com/guia/articulo.phtml?art=47. 2004 
- [Gon2001] González Rodríguez, J., Olsina, L. Hacia la Medición de Calidad en Uso Web. http://www.dlsi.ua.es/webe01/articulos/s222.pdf. 2001

- [Gon2003] González, M. Evaluación de software educativo: orientaciones para su uso pedagógico. Proyecto Conexiones Colombia. 2003

- [Gon2006] González, C. Evaluación de calidad web: Métodos, técnicas y uso de métricas de usabilidad. Consultoría en Usabilidad y Estándares web.www.usabilidadweb.com.ar. 2006

- [Gon2006b] Gonzalez, M. P. Lorés, J,. Pascual, A. Evaluación heurística. Universitat de Lleida. http://griho.udl.es/ipo/pdf/15-Evaluacion-Heuristica.pdf. 2006

- [Gon2007] Ingeniería de accesibilidad a la web. Carlos D. González. Consultoría en Usabilidad y Estándares web. www.usabilidadweb.com.ar. 2007

- [Goo2011] Google Analytics. http://www.google.com/intl/es/analytics. 2011

- [Gra2005] Granollers i Saltiveri, T., Lorés Vidal, J., Cañas Delgado, J. J. Diseño de Sistemas Interactivos Centrados en el Usuario. Editorial UOC. ISBN: 8497883209. http://griho.udl.es/mpiua/index.htm. 2005

- [Gra2005b] Grau, J. Pensando en el usuario: la usabilidad. http://www.thinkepi.net/repositorio/pensando-en-el-usuario-la-usabilidad. 2005

- [Gut2004] Gutierrez, A., Recena Soto, M. Introducción a la accesibilidad y usabilidad. www.manuelrecena.com/docs/accesibilidad_usabilidad_w3c_041211.pdf. 2004

- [Har1995] Harasim, L., Roxane, S., Teles, L. y Turoff, M. Learning networks.A fiel guide to teaching and learning on line. Cambridge: MIT Press. 1995

- [Has2006] Hassan-Montero, Y. Factores del Diseño Web Orientado a la Satisfacción y No-Frustración de Uso. Revista Española de Documentación Científica, 29, 2, AbrilJunio, pp. 239-257. Disponible en: http://redc.revistas.csic.es/index.php/redc/article/viewFile/291/353. 2006

- [Has2009] Hassan-Montero, Y., \& Ortega-Santamaría, S. Informe APEI sobre usabilidad. APEI, Asociación Profesional de Especialistas en Información. 2009

- [Haz2002] Hazari, S. Evaluation and Selection of Web Course Management Tools. Robert H. Smith School of Business University of Maryland, College Park. http://www.sunil.umd.edu/Webct. 2002

- [Haz2002b] Hazari, S. Evaluation of Blackboard Course Tool. Robert H. Smith School of Business, University of Maryland, College Park. http://www.sunilhazari.com/education/webct/bb.htm. 2002

- [Hen2002] Shawn Lawton, H. Understanding Web Accessibility. En Constructing Accessible Web Sites. Glasshaus. ISBN: 1904151000. http://www.macromedia.com/macromedia/accessibility/pub/acc_sites_chap01.pdf. 2002

- [Her2002] Hernández Schäfer, L. E. Estado actual y futuro de las plataformas elearning: estándares y especificaciones IMS. Universidad Católica del Norte. Chile. 2002

- [HER2010] Hojas de Estilos para Revisión de la Accesibilidad (HERA) http://www.sidar.org/hera

- [Hew1992] Hewett, T. ACM SIGCHI Curriculum for Human-Computer Interaction. ACM Press. 1992

- [Hix1993] Hix, D., Hartson, H.R. Developing User Interfaces: Ensuring Usability Through Product and Process. John Wiley and Sons. 1993

- [Hom2003] Hom, J. The Usability Methods Toolbox. http://www.best.com/ jthom/usability/usable.htm. 2003 
- [Hug1995] Hugh, B. Holtzblatt K.: Apprenticing with the Customer: A Collaborative Approach to Requirements Definition. Communications of the ACM, 38(5), pp. 45-52. 1995

- [Hug1997] Hugh, B., Holtzblatt K. Contextual Design: A Customer-Centered Approach to Systems Designs. Morgan Kaufman Publishers, ISBN: 1558604111. 1997

- [INA2010] INADI. Se aprobó la Ley de Accesibilidad de la información en las páginas web http://inadi.gob.ar/2010/11/se-aprobo-la-ley-de-accesibilidad-de-la-informacion-enlas-paginas-web. 2010

- [Ins1997a] Instone, K. Site Usability Heuristics for the Web. http://www.webreview.com/1997/10_10/strategists/10_10_97_2.shtml Webreview.com. 1997

- [Ins1997b] Instone, K. Usability engineering for the Web. Instone K. (ed), World Wide Web Journal 2(1). pp. 163-171. http://www.instone.org/node/12. 1997

- [ISO1995] ISO 8402. Quality management and quality assurance. Vocabulary. British Standard. European Standard. International Organization for Standardization. ISBN: 0580245004. 1995

- [ISO1998a] ISO 14598-1.Information Technology - Evaluation of Software Products General Guide. ISO. 1998

- [ISO1998b] ISO 9241-11. Ergonomic requirements for office work with visual display terminals. Guidance on Usability. ISO. 1998

- [ISO1998c] ISO 9241-10. Ergonomic requirements for office work with visual display terminals. Dialogue principles. ISO. 1998

- [ISO1998d] ISO/IEC 14598-5:1998 Information technology -- Software product evaluation -- Part 5: Process for evaluators.1998

- [ISO1999a] ISO/IEC 14598:1999 Information technology -- Software product evaluation -- Part 1: General overview. 1999

- [ISO1999b] ISO 13407: Human-centred design processes for interactive systems. 1999

- [ISO1999c] ISO/IEC 14598-1:1999 Information technology -- Software product evaluation -- Part 1: General overview. 1999

- [ISO1999d] ISO/IEC 14598-4:1999 Software engineering -- Product evaluation -- Part 4: Process for acquirers. 1999

- [ISO2000a] ISO/IEC 14598-2:2000 Software engineering -- Product evaluation -- Part 2: Planning and management. 2000

- [ISO2000b] ISO/IEC 14598-3:2000 Software engineering -- Product evaluation -- Part 3: Process for developers. 2000

- [ISO2001] ISO/IEC 9126-1 (E). International Standard. "Software Engineering Product Quality - Part 1: Quality Model". 2001

- [ISO2001b] ISO/IEC 14598-6:2001 Software engineering -- Product evaluation -- Part 6: Documentation of evaluation modules. 2001

- [ISO2003] International Standard -Technical Specification-. ISO/TS 16071. Ergonomics of human-system interaction-Guidance on accessibility for human-computer interfaces. Primera Edición 1-02-2003. 2003

- [ISO2005] ISO/IEC 25000 Software Engineering -- Software product Quality Requirements and Evaluation (SQuaRE) -- Guide to SquaRE. 2005

- [ISO2010] ISO 9241-210:2010 Ergonomics of human-system interaction - Part 210: Human-centred design for interactive systems. 2010

- [Itu1995] ITU-R BT.500-7: Methodology for the subjective assessment of the quality of television pictures. International Telecommunications Union, Geneva. 1995

- [Jac2001] Jackson, R. H. Web based learning resources library. http://www. outreach.utk.edu/weblearning. 2001 
- [Jac2002] Jackson-Sanborn, E. Web site accessibility: a study of six genres. Library Hi-Tech, Volume 20, № 3, pp. 308-317. http://www.emeraldinsight.com/0737-8831.htm. 2002

- [Jac1998] Jacobsen, N., Hertzum, M., John, B. The evaluator effect in usability tests. In ACM CHI'98 Conference Summary. Reading, MA: Addison-Wesley, pp. 255- 256. 1998

- [Jef2002] Jeffries, R., Miller, J., Wharton, C., Uyeda, K. User interface evaluation in the real world: a comparison of four techniques, Proceedings of the SIGCHI conference on Human factors in computing systems: Reaching through technology, pp.119-124. New Orleans, Louisiana, United States. 2002

- [Jur2006] Juristo, N., Moreno, A., Vegas, S. Técnicas de Evaluación de Software. http://is.Is.fi.upm.es/udis/docencia/erdsi/Documentacion_Evaluacion_7.pdf. 2006

- [Kei2003] Keinonen, T. Usabilidad de los productos interactivos. http://www2.uiah.fi/projects/metodi/258.htm. 2003

- [Kel2001] Kellogg, W. The dimensions of consistency. En: Coordinating user interfaces for consistency, editor: Jakob Nielsen, Boston: Academic Press. 2001

- [Kir1998] Kirakowski, J., Claridge, N., Whitehand, R. Human centered measures of success in Web site design. Human Factors and the Web Workshop, Basking Ridge, NJ. 1998

- [Kru2000] Krug, S. Don't make me think! A common sense approach to web usability. ISBN: 84-205-3252-5. 2000

- [Lan1999] Landeta, J. El método Delphi: Una técnica de previsión para la incertidumbre. Ed. Ariel Practicum. 1999

- [Lau1995] Landauer, T. The Trouble with Computers: Usefulness, Usability and Productivity. Massachusetts: Massachusetts Institute of Technology. 1995

- [Lec1998] Lecerof, A., Paternò, F. Automatic support for usability evaluation. IEEE Transactions on Software Engineering. October 1998. p. 863-889. 1998

- [Lei2003] Leighton Álvarez, H., García Peñalvo, F. Calidad en los Sitios Web Educativos. Departamento de Informática y Automática. Universidad de Salamanca. 2003

- [Lew1990] Lewis, C., Polson, P. Wharton, C., Rieman, J. Testing a walkthrough methodology for theory-based design of walk-up-and-use interfaces, Proceedings of the SIGCHI conference on Human factors in computing systems: Empowering people, pp. 235-242, April 01-05, Seattle, Washington, United States. 1990

- [Lew1993] Lewis, C., Rieman, J. Task-centrered user interface design QA Practical introduction. 1993

- [Llo2008] Llorente Cejudo, M. del C., Cabero Almenara, J. Desarrollo de un instrumento sobre competencias tic en alumnos universitarios. Dpto. Didáctica y Organización Educativa, Universidad de Sevilla. 2008

- [Lop2003] López Carrasco, M. Plataformas Virtuales de Aprendizaje. Athenea. Puebla, México. www.athenea.com.mx/swf/plataformas\%20virtuales.pdf. 2003

- [Loz2003] Lozano, M, Montero, F. Nuevos Mecanismos para el Desarrollo de Sistemas Interactivos de Calidad. En Tendencias actuales en la interacción persona-ordenador: accesibilidad, adaptabilidad y nuevos paradigmas. XIII Escuela de Verano de Informática. Universidad de Castilla-La Mancha. www.infob.uclm.es/personal/caballer/download/papers/CursoVerano2003.pdf. 2003

- [Luc2010] Lucero, G., Grosso L. MEDE-PROS. Informe de Evaluación de Producto de Software Campus Virtual SIAT. Laboratorio de Calidad en Tecnologías de la Información, INTI, Mendoza. Argentina. 2010

- [Mac1993] Mack, R., Nielsen, J. Usability inspection methods. ACM SIGCHI BulletinJune, pp. 28-33. 1993 
- [Mac1994] Mack, R., Montaniz, F. Observing, predicting and analyzing usability problems. In Nielsen, J., and Mack, R. L. (Eds.), Usability Inspection Methods, John Wiley \& Sons, New York, pp. 293-336. 1994

- [Mac1994b] Mack, R., Nielsen, J. Executive summary, Nielsen, J. and Mack, , R.L. (eds) Usability Inspection Methods, New York: John Wiley \& Sons. 1994

- [Man2002] Manchón, E. Usabilidad, diseño web fácil de usar. http://www.ainda.info/que_es_usabilidad.html. 2002

- [Man2002b] Manchón, E. Forma: Planificación y desarrollo de sitios Web El enfoque persona y los escenarios. www.ainda.info. 2002

- [Coo2003] Cooper, A. About Face 2.0, Página 22. Wiley Publishing Inc. Indianápolis, USA. 2003

- [Man2003] Manchón, E. ¿Qué es la usabilidad? Definición de Usabilidad. http://www.alzado.org/articulo.php?id_art=39. 2003

- [Man2003b] Manchón, E. Evaluación heurística (o por expertos) de la usabilidad. http://www.alzado.org/articulo.php?id_art=74. 2003

- [Man2004] Manrique, F. Métodos de recolección de datos. Universidad de Carabobo. Valencia. 2004.

- [Man1997] Mandel, T. Elements of User Interface Design. New York: John Wiley \& Sons. 1997

- [Mar2001] Marquès Graels, P. Criterios de calidad para los sistemas de teleformación. 2001

- [Mar2007] Marquès Graels, P. La Web 2.0 y sus aplicaciones didácticas. http://peremarques.blogspot.com/2007/11/la-web-20-y-sus-aplicaciones-didcticas.html. 2007

- [Mar2003] Martín Fernández, F., Hassan Montero, Y. Conociendo a nuestros usuarios. http://www.nosolousabilidad.com/articulos/conocer_usuarios.htm. 2003

- [Mar2005] Marcos, M., Rovira, C. Evaluación de la usabilidad en sistemas de información web municipales: metodología de análisis y desarrollo. En: Gascon, J., Burguillod F. y Pons A. (ed.). La dimensión humana de la organización del conocimiento. Universitat de Barcelona, Barcelona, España. 2005

- [Mar2006] Martinez, J, y otros. Prácticas de E-learning. Ediciones Octaedro. Barcelona. 2006.

- [May1992] Mayhew, D. Principles and Guidelines in Software User Interface Design. Prentice-Hall. 1992

- [May1999] Mayhew, D. The Usability Engineering Lifecycle: A Practitioner's Handbook for User Interface Design. The Morgan Kaufmann Series in Interactive Technologies. 1999

- [Mcc1977] McCall J. Factors in software quality, vols. I, II y III. NTIS. 1977.

- [Mcl1993] Macleod, M., Rengger, R. The Development of DRUM: A Software Tool for Videoassisted Usability Evaluation. In People and Computers VII, Cambridge University Press. 1993

- [Mcl1994b] Macleod, M. Benefits of improved usability. Usability: Practical Methods for Testing and Improvement. National Physical Laboratory, Teddington, Middlesex, TW11 OLW, UK. To appear in Proceedings of the Norwegian Computer Society Software 94 Conference. 1994

- [Mer1999] Mercovich, E. Workshop: cómo hacer un test de usabilidad de un sitio. http://www.gaiasur.com.ar/infoteca/siggraph99/test-de-usabilidad-de-un-sitio.html. 1999

- [Mon2002] Introducción a la Usabilidad. Yusef Hassan Montero. 2002. Universidad de Granada. http://www.nosolousabilidad.com/articulos/introduccion_usabilidad.htm 
- $\quad$ [Mon2003] Montero, Y., Martín Fernández, F. Políticas de Accesibilidad. http://www.nosolousabilidad.com/articulos/politicas_accesibilidad.htm. 2003

- [Mon2003b] Montero, Y., Martín Fernández, F. Que es la accesibilidad Web. No Solo Usabilidad journal, № 2. Julio de 2003. ISSN 1886-8592. 2003

- [Mon2004] Montero, Y., Martín Fernández, F. Propuesta de adaptación de la metodología de diseño centrado en el usuario para el desarrollo de sitios web accesibles. Revista Española de Documentación Científica, Vol. 27-№3. JulioSeptiembre. ISSN 0210-0614330. 2004

- [Mon2006] Montero, F. Usabilidad: ¿Qué? ¿Cómo? ¿Cuándo? ¿Dónde? ¿Para qué? Universidad de Castilla-La Mancha. España.

http://www.dsi.uclm.es/personal/victor/mipagina/index.htm. 2006

- [Mor2004] Moreno, A., Sánchez-Segura, M. Patrones de Usabilidad: Mejora de la Usabilidad del Software desde el momento de Arquitectónico. http://is.Is.fi.upm.es/status/results/MorenoSanchezJISBD2003.pdf. 2004

- $\quad$ Mor2004b] Mordecki, D. Pensar primero. 2004 [DeB2000] De Benito, B. Posibilidades educativas de las webtools, Palma de Mallorca, Universidad de las Islas Baleares. 2000

- [Mot2011] Motigo Webstats. http://webstats.motigo.com. 2011

- [Mum2003] Human Factors Research Group.: MUMMS: Measuring the usability of multi-media systems. University College Cork, Ireland.

http://www.ucc.ie/hfrg/questionnaires/mumms/info.html. 2003

- [Mur1999] Murray, G., Costanzo, T. Usability and the Web: An Overview. http://www.nlc-bnc.ca/9/1/p1-260-e.html Information Technology Services, National Library of Canada. 1999

- $\quad$ Nie1990] Nielsen, J. Ten Usability Heuristics. http://www.useit.com/papers/heuristic/heuristic_list.html. 1990

- [Nie1990b] Nielsen, J., Molich, R. Heuristic evaluation of user interfaces. Proceedings of the CHI'90, ACM Press, pp. 249-256. 1990

- [Nie1990c] Nielsen, J. Paper versus computer implementations as mockup scenarios for heuristic evaluation. Proc. IFIP INTERACT'90 Third Intl. Conf. Human-Computer Interaction pp. 315-320. 1990

- [Nie1992] Nielsen, J. Finding usability problems through heuristic evaluation. Proceedings of the CHI'92, ACM Press, pp. 373-380. 1992

- [Nie1992b] Nielsen J. The usability engineering life cycle. COMPUTER p. 12, Bellcore. 1992

- [Nie1993] Nielsen, J. Iterative User-Interface Design. IEEE Computer. 1993

- $\quad$ Nie1993b] Nielsen, J. Usability Engineering. Boston, AP Professional. 1993

- [Nie 1994] Nielsen, J., Mack, R. Usability inspection methods. New York: Wiley. Published by John Wiley \& Sons, New York. 1994

- [Nie1994b] Nielsen, J. Guerilla HCl: Using discount usability engineering to penetrate the intimidation barrier. In R.G. Bias \& D.J. Mayhew (Eds.), Cost-justifying usability. pp. 242-272. Boston: Academic Press. 1994

- [Nie1995] Nielsen, J. Severity Ratings for Usability Problems. Alertbox. http://www.useit.com/alertbox/papers/huerristic/severityrating.html. 1994

- [Nie1999] Nielsen, J. Voodoo Usability. Alertbox. http://www.useit.com/alertbox/991212.html. 1999

- [Nie2000] Nielsen, J. Usabilidad. Diseño de sitios web. Prentice Hall PTR. ISBN: 8420530085. 2001

- [Nie2003] Nielsen, J. Alertbox. Usability 101: Introduction to Usability. http://www.useit.com/alertbox/20030825.html. 2003 
- [Nor2004] Norman, D. Emotional Design: Why we love (or hate) everyday things". Basic Books. 2004

- [Nor1998] Norman, D. Psicología de los objetos cotidianos. Editorial Nerea. ISBN: 8489569-18-5. 1998

- [Nor1998b] Norman, D. The invisible computer. MIT Press. 1998.

- [Ols1999] Olsina, L. Metodología cuantitativa para la evaluación y comparación de la calidad de sitios Web. Tesis Doctoral. Facultad de Ciencias Exactas de la Universidad Nacional de la Plata- Argentina. 1999

- [Ols1999b] Olsina, L., Godoy. D., Lafuente, G.J., Rossi, G. Assessing the Quality of Academic Websites: a Case Study. New Review of Hypermedia and Multimedia (NRHM) Journal, Taylor Graham Publishers. UK/USA Vol. 5, pp. 81-103. 1999.

- [Ols2001]. Olsina, L., Papa, M.F., Souto, M.E., Rossi, G. Providing Automated Support for the Web Quality Evaluation Methodology. 4th Workshop on Web Engineering, at the 10th International WWW Conference, Hong Kong, pp. 1-11. 2001

- [Ols2001b] Olsina, L., Lafuente, G., Rossi, G. Specifying Quality Characteristic and Attributes for Web Sites. En S. Murugesan y Y. Deshpande (Eds): Web Engineering. Managing Diversity and Complexity of Web Application Development. Lecture Notes in Computer Science. LNCS 2016. pp. 266-278. Springer Verlag. 2001

- [Ols2002] Olsina, L. Métricas, Criterios y Estrategias para Evaluar Calidad Web. En Jornadas de Actualización en Informática de la Facultad de Ingeniería, JAIFl'02. http://www.ing.unlpam.edu.ar/jaifi2002/Jaifi2002.pdf. 2002

- [ONU2001] http://www.un.org/

- [O'R2005] O'Reilly, T. What's web 2.0. Design Patterns and Business Models for the Next Generation of Software. http://www.oreilly.com/pub/a/oreilly/tim/news/ 2005/09/30/what-is-web-20.html. 2005

- [Ort2000] Ortega Carrillo, J. Planificación de ambientes de aprendizaje interactivos on line: Las aulas virtuales como espacios para la organización y el desarrollo del teletrabajo educativo. En J. Cabero (Ed.) Nuevas Tecnologías aplicadas a la Educación. Sevilla: Universidad de Sevilla-FETE-UGT (Edición en CD-Rom). 2000

- [Oso2000] Osorio Rojas, R. El Cuestionario. http://www.nodo50.org/sindpitagoras/Likert.htm. 2000

- [Pal2001] Pallof, R.M. y Pratt, K. Lessons from the cyberspace classroom. San Francisco: Jossey-Bass. 2001

- [Pem2005] Pemberton, S. En directo desde Fundamentos web 2005. http://www.torresburriel.com/weblog/index.php?p=776. 2005

- [Pie1995] Pierotti, D. Heuristic Evaluation: A System Checklist. In Usability Analysis and Design. Xerox Corporation. 1995.

- [Pol1992] Polson, P.G., Lewis, C., Rieman, J., Wharton C. Cognitive walkthroughs: A method for theory- based evaluation of user interfaces. International Journal of ManMachine Studies 36, pp. 741-773. 1992

- [Pre1994] Preece, J., Rogers, Y., Sharp, H., Benyon, D,. Holland, S., Carey, T. HumanComputer Interaction. Addison Wesley. 1994

- [Pre1995] Pressman, R. Ingeniería del software, un enfoque práctico, McGraw Hill, 1995.

- [Pog2006] Poggi, M. La integración de las Tecnologías de la Información y la Comunicación en los Sistemas Educativos. UNESCO. 2006.

- [Que2006] Quesada Ruiz, E. http://www.w3c.es/Prensa/2006/nota061211_validaccesibilidad. 2006 
- [Qui2003] QUIS-Questionnaire for user interaction satisfaction. Human Computer Interaction Lab/University of Maryland - Human-Computer Interaction Lab (HCIL) at the University of Maryland. 2003

- [Qui1996] Quinn, C. Pragmatic evaluation: lessons from usability. 13th Annual Conference of the Australasian Society for Computers in Learning in Tertiary Education, Australasian Society for Computers in Learning in Tertiary Education. 1996

- [RAA1998] Rehabilitation Act - Section 508. http://www.section508.gov. 1998

- [Red1995] Redish, J. Are we really entering a post-usability era?. ACM SIGDOC Asterisk Journal of Computer Documentation, vol. 19 (1), pp. 18-24. 1995

- [Red1999] Redish, J., Dumas, J. A Practical Guide to Usability Testing, 1999

- [Rey2007] Reyero, E. Encuesta-cuestionario. http://wwff.thespacer.net/blog/encuestacuestionario. 2007

- [Rho2000] Rhodes, J. Usability Metrics. http://webword.com/moving/metrics.html. 2000

- [Rii2000] Riihiaho, S. Experiences with usability evaluation. Helsinki University of Technology Laboratory of Information Processing Science. Licentiate's thesis. 2000

- [Rit2002] Ritzel, L. eLearning is Learning. 2002.

- [Rod2000] Rodríguez, M. Una arquitectura cognitiva para el diseño de entornos telemáticos de enseñanza y aprendizaje. Tesis Doctoral, Universidad Nacional de Educación a Distancia, España. 2000

- [Rod2001] Rodeiro, J. Representación y Análisis de la componente visual de la interfaz de usuario. Tesis doctoral. Universidad de Vigo. 2001

- [Rod2006] Rodriguez Gabaldon, D. http://pozonline.blogspot.com/feeds/posts/default?start-index=76. 2006

- [Rom2001] Romero Zúnica, R. Usabilidad y accesibilidad, dos enfoques complementarios. http://acceso.uv.es/accesibilidad/artics/01-usabilidadaccesibilidad.htm. 2001

- [Rom2001] Romero Zúnica, R. Usabilidad y accesibilidad, dos enfoques complementarios. Unidad de Investigación ACCESO. Universidad de Valencia. 2001

- [Rom2001b] Romero Zúnica, R. Pautas WAl de diseño accesible de páginas web. Unidad de Investigación ACCESO. Universidad de Valencia. 2001

- [Rom2001c] Romero Zúnica, R. Los dos principios básicos del diseño web accesible. Unidad de Investigación ACCESO. Universidad de Valencia. 2001

- [Row1992] Rowley, D., Rhoades, D. The Cognitive Jogthrough: A Fast-Paced User Interface Evaluation Procedure.' CHI `92 Proceedings. pp. 389-395. 1992

- [Rub1994] Rubin, J. Handbook of usability testing: How to plan, design and contact effective tests. New York: John Wiley \& Sons. 1994

- [Rub2003] Rubio, M. Enfoques y modelos de evaluación del e-learning. Revista Electrónica de Investigación y Evaluación Educativa, v. 9, n. 2. http://www.uv.es/RELIEVE/v9n2/RELIEVEv9n2_1.htm. 2003

- [Rui2009] Riuz Morilla, J. ISO 9126 vs. SquaRE. 2009

- [Sal2006] Laboratorio de Validación de sistemas Virtual de Formación. Universidad de Islas Baleares. http://gte.uib.es/LVSV/act.htm. 2006

- [San2001] Sanz, J. ISO-9241(EN-ISO 9241) Manual de normas técnicas para el diseño ergonómico de puestos con pantallas de visualización (2ª Edición). http://www.mtas.es/insht/practice/pvd.htm

- [Sar2001] Sarkioja, M. Usability in incremental software design- A use case method. Master's Thesis. University of Helsinki-Finland. 2001

- [Say2003] Sayago, S., Navarrete, T., Blat, J. Técnicas de Ingeniería de Usabilidad y metodología de diseño conceptual en algunas aplicaciones informáticas. IV Congreso 
Internacional de Interacción-Persona Ordenador. ISBN: 84-932887. pp. 4-8. Vigo, España. 2003

- [Sch1993] Schuler, D., Namioka, A. Participatory Design: Principles and Practices. Lawrence Erlbaum Associates. 1993

- [Sch1998] Schneiderman, B. Designing the User Interface: Strategies for Effective Human-Computer Interaction. Third edition, Addison Wesley Iberoamericana.1998

- [Scr1967] Scriven, M. The Methodology of Evaluation. In R. Tyler, R. Gagne, \& M. Scriven (Eds.), Perspectives of Curriculum Evaluation. Chicago: Rand McNally, pp. 3983. 1967

- [Ser2008] Serrano Mascaraque, E., Moratilla Ocaña, A., Olmeda Martos, I. Métrica para la evaluación de la accesibilidad en Internet: propuesta y testeo. Revista Española de Documentación Científica, 33, 3, julio-septiembre, pp. 378-396. 2010

- [Sha2006] Shawn Lawton, H. Policies Relating to Web Accessibility. Education and Outreach Working Group. http://www.w3.org/WAl/Policy. 2006

- [Sha1991] Shackel, B. Usability - context, framework, design and evaluation. En Human Factors for Informatics Usability. pp. 21-38. Shackel, B and Richardson, S (eds.). Cambridge University Press. 1991

- [She2001] Sherman, P. Cost-Justifying Accessibility. Austin: Austin Usability. http://www.gslis.utexas.edu/ /385t21/AU_WP_Cost_Justifying_Accessibility.pdf. 2001

- [Sig2001] Sigales, C. El potencial interactivo de los entornos virtuales de enseñanza y aprendizaje en la educación a distancia. X encuentro Internacional de Educación a Distancia. Guadalajara. México. 2001

- [Spy1992] Spyridakis, J. H. Conducting Research in Technical Communication: the application of true experimental designs. Technical Communications, Fourth Quarter, 607-624. 1992

- [STA2001] STATUS project: EU funded project IST-2001-32298. 2001

- [TAW2010] Test de Accesibilidad Web (TAW) http://www.tawdis.net. 2010

- [TCU2011] http://www.siat.unrc.edu.ar/siat2/terminos.jsp

- [Tog2003] Tognazzini, B. First Principles of Interaction Design. Ask Tog. http://www.asktog.com/basics/firstPrinciples.html. 2003

- [Tor2003] Torres Toro, S., Ortega Carrillo, J. A. Indicadores de calidad en las plataformas de formación virtual: una aproximación sistemática. Publicación en línea. Granada (España). Número 1. ISSN: 1695-324X. www.ugr.es/ sevimeco/revistaeticanet/Numero\%201/Cultura\%20eval/CalidadeneLear ning.pdf. 2003

- [Tor2004] Torres Barzabal, L. Accesibilidad al contenido Web para todas las personas. Comunicación y Pedagogía (ISSN: 1136-7733), № 194, pp. 13-19. 2004

- [Tra2011] Travis, D. ISO 13407 is dead. Long live ISO 9241-210! Userfocus. 2011

- [Tre1998] Trenner, L., Bawa, J. The Politics of Usability. Springer-Verlag. 1998

- [Tro2002] Trochim W. Likert scaling. http://www.socialresearchmethods.net/kb/scallik.htm. 2002

- [Thü2010] Thüer, S. Análisis del comportamiento de los usuarios del EVEA SIAT basado en Google Analytics. Reporte técnico. www.siat.unrc.edu.ar. 2010

- [Thü2011a] Thüer, S., Ferreira Szpiniak, A. Abriendo las aulas virtuales a la Web 2.0: Un análisis a partir del diseño centrado en el usuario. Congreso de Educación a Distancia CREAD Mercosur/sul 2010 sobre "Aprendizajes 2.0: Nuevos ambientes, nueva cultura". Trelew, Chubut. Argentina. 2010

- [Thü2011b] Thüer, S., Ferreira Szpiniak, A. Entornos Virtuales de Aprendizaje: Diseño de experiencias de usuario para la web 2.0. Conferencia Internacional ICDE - UNQ 
2011 "Educación a distancia, TIC y universidad: calidad, equidad y acceso a la educación superior". Bernal, Buenos Aires. Argentina. 2011

- [Van2011] Van den Beemt, A., Akkerman, S., y Simons, P. Patterns of interactive media use among contemporary youth. Journal of Computer Assisted Learning, 27: 103-118. doi: 10.1111/j.1365-2729.2010.00384.x. 2011

- [Van2000] Vanderheiden, G. Fundamental Principles and Priority Setting for Universal Usability. En: Proceedings of Conference on Universal Usability (CUU) 2000, Association for Computing Machinery, pp. 32-38. http://trace.wisc.edu/docs/fundamental_princ_and_priority_acmcuu2000. 2000

- [Vil2003] Villa, L. Usabilidad sin usuarios: heurística. www.alzado.org/articulo.php?id_art=221. 2003

- [Vir1992] Robert A. Virzi, R. A. Refining the test phase of usability evaluation: how many subjects is enough? Hum. Factors, 34(4):457-468. 1992

- [Vis2011] VisioAnalyzer. http://www.ergoestudio.com/visioanalyzer/introduccion. 2011

- [WAB2006] WAB cluster. Methodology to evaluate websites for accessibility. http://www.technosite.es/SRV/metodologia/procedimientos.html. 2006

- [WAC2010] Web Accessibility Checker (WAC) http://www.achecker.ca

- [WAI2005] Web Accessibility Initiative (WAI). http://www.w3.org/WAl. 2005

- [WAV2010] Web Accessibility Tool (WAVE) http://wave.webaim.org

- [Wha1992] Wharton, C. Cognitive Walkthroughs: Instructions, Forms and Examples. Institute of Cognitive Science. Technical Report CU-ICS-92-17. University of Colorado, Boulder. 1992

- [Wha1994] Wharton, C., Rieman, J., Lewis, C., Polson, P. The cognitive walkthrough method: A practitioner's guide. In usability inspection methods. J. Nielsen and R.L. Mack (Eds.), New York: John Wiley \& Sons, pp.105-141. 1994

- [Whi2000] Whitmyer, C, Grimes, G. T. Comparative Features Analysis of Leading Course Management Software. The University of the Future, LLC. 2000

- [Whi1988] Whiteside, J., Bennett, J., Holtzblatt, K. Usability Engineering: Our Experience and Evolution. Handbook of Human-Computer Interaction. Elsevier NorthHolland. 1988

- [Woo1998] Woodward, B. Evaluation methods in usability Testing. 1998

- [Zap2003] Zapata Ros, M. Evaluación de un Sistema de Gestión del Aprendizaje. www.um.es/ead/red/9/eval_SGA_1.pdf. 2003

- [Zij1993] Zijlstra, F. Efficiency in work behaviour: A design approach for modern tools. Delft: elft University Press. 1993

- [Zor2011] Análisis de nuevas herramientas incorporadas al entorno virtual SIAT como innovación educativa en la formación universitaria de grado. Fabio Zorzan, Ariel Ferreira Szpiniak, Jorge Guazzone. VI Encuentro Internacional BTM 2011: La Educación en la Sociedad de la Información. Punta del Este, Maldonado. Uruguay. 2011

- [Zul2000] Zülch, G., Stowasser, S. Usability evaluation of user interfaces with the computer aided- evaluation tool- PROKUS-. Institut für Arbeitswissenschaft und Betriebsorganisation (ifab),- Universität Karlsruhe (TH), Kaiserstraße 12, 76128 MMIInteraktiv, Nr. 3, Juni/00, ISSN 1439-7854, Zülch \& Stowasser. Germany. 2000

- [Zur1999] Zurita G., Sánchez J, Nussbaum M. Taller Internacional de Software Educativo TISE'99. Universidad de Chile. http://www.tise.cl/archivos/tise99/html/papers/gameboy/index.htm. 1999

- [W3C2011] http://www.w3.org 


\section{Publicaciones realizadas en vinculación con la tesis}

- [Fer2007b] Ferreira Szpiniak, A., Sanz, C. Hacia un modelo de evaluación de entornos virtuales de enseñanza y aprendizaje. La importancia de la usabilidad. VI Workshop de Tecnología Informática Aplicada en Educación - CACIC 2007. Corrientes y Resistencia, Argentina Octubre 2007. ISBN 978-950-656-109-3. Full paper. Proceeding - CD Rom. Páginas 932-947. 2007

- [Fer2009] Ferreira Szpiniak, A., Sanz, C. Un Modelo de Evaluación de Entornos Virtuales de Enseñanza y Aprendizaje basado en la Usabilidad. IV Congreso de Tecnología en Educación y Educación en Tecnología (TE\&ET’09). La Plata, Argentina. Julio 2009. ISBN 978-950-34-0573-4. Full paper. Páginas 382-392. 2009

- [Fer2009b] Ferreira Szpiniak, A., Sanz, C. Hacia un modelo de evaluación de entornos virtuales de enseñanza y aprendizaje basado en la usabilidad. Revista Iberoamericana de Tecnología en Educación y Educación en Tecnología - TE\&ET. Número 4. pp 1021. ISSN 1850-9959. 2009

- [Fer2010] Ferreira Szpiniak, A., Sanz, C. Propuesta de un Modelo de Evaluación de Entornos Virtuales de Enseñanza y Aprendizaje. Escenarios de uso. V Congreso de Tecnología en Educación y Educación en Tecnología (TE\&ET'10), El Calafate, Argentina. Mayo 2010. ISBN 978-987-1242-42-9. Full paper. 2010

- [Fer2011] Ferreira Szpiniak, A., Sanz, C. Usabilidad de los Entornos Virtuales de Enseñanza y Aprendizaje. Evaluación por capas. VI Congreso de Tecnología en Educación y Educación en Tecnología (TE\&ET'11). Salta, Argentina. Junio de 2011. Full paper. 2011

- [Fer2011b] Ferreira Szpiniak, A., Sanz, C. Validación de un modelo de evaluación de Entornos Virtuales de Enseñanza y Aprendizaje centrado en la usabilidad, a partir de su aplicación a un caso de estudio. XVII Congreso Argentino de Ciencias de la Computación. La Plata, Argentina. Octubre de 2011. ISBN 978-950-34-0756-1. Full paper. Páginas 661-671. 2011

- [Fer2012] Ferreira Szpiniak, A., Sanz, C. MUsa un modelo de evaluación de Entornos virtuales de enseñanza y aprendizaje. Aplicación a un caso de estudio. Revista Iberoamericana de Tecnología en Educación y Educación en Tecnología - TE\&ET. Número 8. En prensa. ISSN 1850-9959. 2012 


\section{Glosario}

\section{Funcionalidad}

Su definición está dada como "la capacidad del software de proveer funciones establecidas que responden a las necesidades del usuario cuando el software es usado bajo condiciones específicas" [ISO2001]. Las sub-características que intervienen en la funcionalidad son:

Adecuación: capacidad del software para proporcionar un conjunto apropiado de funciones para las tareas y objetivos que persigue el usuario.

Exactitud: capacidad del software para proporcionar los resultados o efectos correctos o acordados, con el grado necesario de precisión.

Interoperabilidad: capacidad del software para interactuar con uno o más sistemas especificados.

Cumplimiento funcional: capacidad del software para adherirse a normas, convenciones o regulaciones.

Seguridad de las tareas realizadas por el usuario con el sistema: capacidad del software para proteger información y datos de manera que los usuarios o sistemas no autorizados no puedan leerlos o modificarlos mientras que los autorizados sí.

Para Olsina [Ols1999] la funcionalidad es una característica de calidad de alto nivel que representa la existencia de un conjunto de funciones y comportamientos de un sistema que satisfacen los requisitos de un dominio determinado y de un perfil de usuario. En base a esta definición se identifican una serie de sub-características como la capacidad de recuperación y de búsqueda de información, los servicios de búsqueda y navegación, y los servicios relacionados con el dominio de la aplicación [Ols2001b]. La funcionalidad puede medirse mediante cálculos a partir de métricas directas e indirectas. Las métricas directas son obtenidas a partir de un atributo no compuesto, como por ejemplo la cantidad de enlaces rotos, mientras que las indirectas corresponden a la asociación de atributos directos, que se relacionan en una ecuación matemática, como por ejemplo el porcentaje de enlaces rotos. Algunas de las métricas que se pueden utilizar para determinar la funcionalidad de un sistema bajo el entorno Web son [Ols1999] son: posibilidad de realizar búsquedas (restringidas o globales), posibilidad de recuperar información, orientación (indicación del camino, posición actual), controles contextuales, y promedio de enlaces por página.

\section{Fiabilidad}

Este concepto es considerado en algunos casos como un atributo relacionado con la efectividad. Puede definirse como "la capacidad del software de mantener los niveles de rendimiento cuando éste es usado bajo condiciones específicas" [ISO2001]. Se basa en cuatro factores relacionados directamente con el sistema: madurez, tolerancia a fallos, capacidad de recuperación, y disponibilidad. La madurez es la capacidad del software para no fallar como resultado de problemas en el tiempo de ejecución. La tolerancia a fallos es la capacidad del software para mantener un nivel especificado de prestaciones en caso de problemas. Finalmente, la capacidad de recuperación es entendida como la capacidad del software para reestablecer un nivel de prestaciones especificado y de recuperar los datos directamente afectados, en caso de una falla. La medición de la fiabilidad es relativamente sencilla utilizando datos preferentemente cuantitativos, 
referidos a la proporción de errores del sistema o al tiempo de funcionamiento sin errores del mismo.

\section{Usabilidad}

Es considerado como el esfuerzo necesario para el uso y la valoración individual en la experiencia del usuario con el sistema. Las sub-características que intervienen en la usabilidad son: comprensibilidad, aprendibilidad, operatividad y atractividad. La comprensibilidad se refiere a la capacidad del software para permitir al usuario entender si el software es adecuado y cómo puede ser usado para unas tareas o condiciones de uso particulares. La aprendibilidad es la capacidad del software para permitir al usuario aprender sobre su aplicación. Por operatividad se entiende a la capacidad del software para permitir al usuario operarlo y controlarlo sin mayores inconvenientes. La atractividad es la capacidad del software para lograr que el usuario se sienta motivado a utilizarlo. En esto último influirá el uso de colores adecuados, imágenes, tipografías, etc.

\section{Eficiencia}

La eficiencia depende de tres aspectos: el comportamiento en el tiempo, los recursos de que dispone y de la utilización de los mismos. Se define como "la capacidad del software de proveer las funciones necesarias en relación a la cantidad de recursos usados bajo condiciones establecidas" [ISO2001]. En caso de la Web, la eficiencia responde a tres características: el rendimiento del tiempo de respuesta, la velocidad de generación de páginas, y la velocidad de generación de gráficos [Ols2001].

\section{Mantenibilidad}

La mantenibilidad se define como "la capacidad del software para ser modificado. Las modificaciones pueden incluir correcciones, mejoras o adaptaciones del software a cambios en el ambiente, y en requisitos y especificaciones funcionales" [ISO2001]. La modificabilidad está relacionada con la posibilidad de alterar su código. La posibilidad de evitar efectos inesperados a causa de las modificaciones realizadas es lo que se conoce como estabilidad, mientras que la capacidad de prueba es la posibilidad de validar los cambios realizados.

\section{Portabilidad}

Este atributo es definido como "la capacidad del software de poder ser transferido desde un ambiente a otro" [ISO2001]. Esto es, el grado de adaptabilidad, las características de instalación, su capacidad de coexistencia y de sustitución. La adaptabilidad está relacionada con la posibilidad de adaptar el software a diferentes entornos, sin que sea necesario aplicar acciones o mecanismos distintos de aquellos proporcionados para este propósito por el mismo software. La instalabilidad es la capacidad del producto software para ser puesto en funcionamiento en un entorno determinado. La coexistencia hace referencia a la factibilidad para compartir los recursos con otro software independiente en un entorno común. La sustitución tiene que ver con la posibilidad de que el software pueda ser usado en lugar de otro, para el mismo propósito y en el mismo entorno. 


\section{Anexos}

\subsection{Anexo A}

\section{Capa 1}

\subsubsection{Categorías de análisis}

Dentro de las categorías de análisis definidas, flexibilidad tecnológica, organizativa, pedagógico/didáctica, y estandarización, se plantean evaluar los siguientes aspectos:

\section{- Flexibilidad tecnológica}

\section{- Características técnicas generales}

\section{- Antecedentes}

* Historial. Determinar los antecedentes que posee en EVEA para evaluar las posibilidades de continuidad en el futuro.

* Disponibilidad de versiones que permitan realizar pruebas bajo situaciones reales.

* Grado de utilización. El número y prestigio de las instituciones que utilizan el entorno.

* Evaluación: existencia de evaluaciones realizadas por organismos e instituciones independientes y resultados obtenidos.

* Actividades de intercambio de experiencias. Existencia de una masa crítica que se materializa en congresos, foros, artículos, comunidades virtuales, etc.

○ Potencial

* Número de usuarios permitidos. Globales o simultáneos.

* Número de cursos. Número de ofertas educativas que se pueden gestionar simultáneamente.

* Idiomas. Ayuda en el idioma propio, capacidad multi-lenguaje.

* Escalabilidad: Posibilidad de crecimiento en cantidad de usuarios, cursos y utilización simultánea.

\section{- Tecnología}

Arquitectura cliente-servidor.

Lenguaje de programación utilizado.

- Código abierto o Propietario.

- Multiplataforma.

- Software necesario: servidor de páginas estáticas y dinámicas, servidor de base de datos, administrador de base de datos, servidor de correo, servidor de listas, antivirus, Webmail, etc.

* Instalación

- Modo: en cualquier servidor, centralizada. 
- Forma: manual, instalador, "wizard", etc.

* Actualización: automática, manual, por módulos, sin actualización.

* Libro o no libre.

* Modalidad: pago, gratuita, otras.

* Costo: anual, por cantidad de cursos, por cantidad de usuarios, servicio de hosting, capacitación.

- Soporte

* Documentación: tutoriales, manuales, informes técnicos, sitio Web oficial, foros de ayuda, newsletter.

* Cursos de formación.

* Servicio y soporte técnico.

* Presencia de un distribuidor y calidad de sus servicios en la resolución de problemas.

* Costo del soporte técnico, mantenimiento, y actualizaciones.

○ Seguridad

* Encriptación

* Autentificación de usuarios: con, sin, ambas

- Acceso de usuarios

* Usuario y contraseñas individuales o grupales

* Registración

* Asignación de privilegios

* Asignación de perfiles

\section{- Compatibilidad}

\section{- Servidor}

* Requisitos de hardware

- Procesador

- Memoria

- Disco

- Red

- Otros

* Requisitos de software:

- Sistemas Operativos

- Servidores de bases de datos

- Servidores de páginas Web (estáticos y/o dinámicos)

- Otros 
Usuario/Cliente

* Requisitos de hardware:

- Procesador

- Memoria

- Disco

- Red

- Otros

* Requisitos mínimos de conexión a Internet: Dial-up, ADSL, etc.

* Requisitos de software:

- Sistemas Operativos

- Navegadores

- Plugins

- Otros

- Formatos multimedia: diferentes medios que pueden ser utilizados: audio, video, imágenes, animaciones, objetos $3 \mathrm{D}$, applets.

- Integración: mecanismos que permiten la relación con otros sistemas mediante archivos, protocolos, servicios Web, otros.

- Interoperabilidad: respeto por la infraestructura previa, manteniendo la compatibilidad con datos, protocolos y lenguajes de programación.

\section{- Robustez}

○ Integridad de funcionamiento: fallas derivadas de un mal diseño del software.

- Recuperación ante fallos: tolerancia ante utilización poco experta.

- Seguridad: capacidad de controlar los accesos a las bases de datos y herramientas que integran el entorno. Propiedad y protección de los materiales almacenados.

\section{- Flexibilidad organizativa}

\section{- Herramientas de administración de usuarios}

- Perfiles: posibilidad de configurar perfiles con diferentes atribuciones y derechos de acceso.

- Gestión: capacidad para dar de alta o baja usuarios de forma individual o por lote. Buscar usuarios, acceder a sus datos personales, modificarlos y asignar nuevas contraseñas.

- Inscripción: capacidad de asignación de usuarios a cada espacio virtual de forma automática, mediante formulario de solicitud, mediante archivos por lote, de manera individual.

- Acceso centralizado: acceso a todos las aulas virtuales desde un solo lugar con un único usuario y contraseña.

- Seguimiento: registro automático de todas las actividades realizadas. 
- Integración: compatibilidad con otras bases de datos de usuarios.

\section{- Herramientas de gestión de espacios virtuales}

- Gestión: capacidad para dar de alta, baja y modificar espacios virtuales: asignaturas, cursos, seminarios, talleres, carreras.

- Organización: capacidad para organizar los espacios virtuales de manera diferenciada por Facultades, Carreras, Áreas, Temas, Asignaturas, Cursos, Comisiones, etc.

- Flexibilidad: capacidad para agregar en los diferentes espacios virtuales nuevos usuarios, perfiles, privilegios y funcionalidades.

- Backup: capacidad para realizar copias de seguridad.

- Clonación: capacidad para realizar réplicas de espacios ya existentes.

- Campus: información, novedades, preguntas frecuentes, servicios generales (biblioteca, directorio de miembros, cafetería virtual, etc.) y repositorio de software de uso general.

\section{- Interface}

- Personalización: posibilidades de mantener una imagen propia en general y en cada uno de los espacios virtuales.

- Plantillas: creación rápida y sencilla de aulas virtuales.

- Ayuda on-line: sensibilidad al contexto de forma que permitan un rápido acceso a la información buscada.

- Modos de vista: capacidad para comprobar on-line cómo son vistos los cambios por los diferentes perfiles sin necesidad de tener abiertas diferentes sesiones de trabajo.

- Editor on-line: disponibilidad de un editor de texto con formato (WYSIWYG), que esté integrado al entorno, y posibilite incorporar código HTML, texto, imágenes, enlaces, y otros recursos, viendo directamente el resultado final.

- Accesos rápidos

* Caminos abreviados: posibilidad para acceder directamente a ciertos espacios sin necesidad de realizar un recorrido obligado.

* Caminos personalizados: posibilidad de personalizar las formas de acceder a los espacios de acuerdo a la experticia del usuario.

\section{- Flexibilidad pedagógico/didáctica}

\section{- Herramientas de información}

- Calendario o agenda: resumen de los principales eventos propios de la organización y programación de actividades (fechas de examen, de clase, de entrega de trabajos, de inicio y fin de módulos, unidades, prácticos, etc.). Posibilidad de incorporar anotaciones privadas.

- Cartelera de novedades: noticias fechadas de carácter general e índole organizativa.

- Alertas: anuncios al usuario, luego de cada ingreso, sobre la existencia de 
cambios producidos dentro del espacio virtual a partir del último ingreso (eventos, noticias, exámenes, mensajes, calificaciones, vencimientos, nuevos materiales, etc.).

- Pizarra virtual: escritura a mano alzada o dibujos como en un editor de imágenes.

- Respuestas a preguntas frecuentes: respuesta única por cada una de las preguntas que realizan de forma reiterada los alumnos.

- Glosario de términos: conjunto de términos propios de la disciplina junto con su descripción. Posibilidad de enlace desde los lugares donde aparece el término.

- Información general o guía: elementos básicos de la planificación como programa, metodología, bibliografía, etc.

- Información sobre los docentes: perfil, foto, últimos accesos, actividades realizadas por los docentes a cargo del espacio.

- Índice: generación automática de un índice de contenidos.

\section{- Herramientas de comunicación}

- Asincrónicas

* Correo electrónico

- Integrado dentro del entorno o no

- Mensajes en formato solo texto, texto html, html con enlaces, tablas, imágenes, etc.

- Etiquetado de mensajes

- Carpetas

- Libreta de direcciones

- Adjuntos

- Cantidad permitida

- Formatos posibles

- Tamaño máximo de los archivos

\section{Listas de correo}

- Única o múltiples

- Abiertas o cerradas

- Moderadas o no moderadas

* Foros de discusión: flexibilidad en su apertura, generación de foros generales o por grupos, incorporación de archivos, seguimiento de las intervenciones. Formatos de visualización de aportes en el foro. Diferentes tipos de foro acorde al objetivo pedagógico.

- Diarios: forma privada de comunicarse entre el alumno y el docente, con posibilidad para el alumno de emitir ideas, consultas, opiniones, pensamientos, y recibir una respuesta por parte del 
docente.

\section{- Sincrónicas}

* Chat

- Solo texto, con audio / con audio y video / con pizarra para la graficación sincrónica.

- Número de salas disponibles: una por espacio, ilimitado.

- Almacenamiento de las conversaciones.

- Archivos adjuntos.

- Moderación.

- Límite en la cantidad de participantes.

* Mensajería instantánea

- Solo texto, con audio, con audio y video.

- Almacenamiento de las conversaciones.

- Archivos adjuntos.

* Clases virtuales: visualización simultánea de una presentación multimedia por parte de todos los usuarios conectados en un mismo momento.

\section{* Conferencia:}

- Audio solamente, audio y video.

- Interacción con el auditorio: sin interacción, preguntas por parte de los participantes, otra.

\section{- Herramientas de colaboración}

- Grupos: generación de espacios que permitan interactuar entre sí a algunos de los participantes de un aula virtual.

- Pizarra compartida: manipulación de un dibujo, gráfico o esquema por todo el grupo de forma simultánea.

- Discos o carpetas virtuales

* Individuales

* Grupales

* Por aula o curso

* Generales

○ Web 2.0

- Blog: sitio que recopila cronológicamente textos o artículos de uno o varios autores, donde el autor conserva siempre la libertad de dejar publicado lo que crea pertinente.

* Pertenencia: individual, grupal o ambos.

* Visualización: abiertos, cerrados a un grupo de participantes o ambos. 
- Comentarios: abiertos/cerrados, moderados/no moderados.

- Wiki: sitio cuyas páginas pueden ser editadas por múltiples usuarios. Los usuarios pueden crear, modificar o borrar un mismo texto que comparten.

* Formato: grupales/generales/temáticas.

- Redes sociales: posibilidad de integrar las redes sociales en las cuales participa el usuario como facebook, myspace, twitter, etc.

- Aplicaciones 2.0: factibilidad de incorporar información publicada mediante aplicaciones como Slideshare, YouTube, Flickr, Picasa, etc.

- Navegación compartida: Seguimiento simultáneo, por un grupo de participantes, de un itinerario de navegación propuesto por otro participante.

- Votaciones: Mecanismo de toma de decisiones por parte del grupo, normalmente con una respuesta afirmativa 0 negativa, exponiendo seguidamente los resultados de la votación.

\section{- Herramientas para la evaluación}

- Ejercicios

* Autoevaluación o tests

* Exámenes:

- Temporización: con tiempo límite, sin tiempo límite, o ambas.

- Cantidad de intentos: libre, acotado, fijo.

- Tipo de calificación: numérica, porcentual, conceptual, etc.

- Superación: calificaciones aceptables para acceder a otra instancia de evaluación.

* Preguntas

- Cantidad: fija, ilimitada

- Tipos:

- Respuesta múltiple

- Relación

- Lógicas

- Numérica

- Calculada

- Abiertas

- Emparejamiento

- Completar frases

- Mapas de imágenes

- Respuesta corta

- Tablas 
- Otras

- Riqueza de recursos: variedad de recursos que se pueden incluir en cada pregunta: gráficos, imágenes, ecuaciones, ayudas, retroalimentaciones.

- Bases de datos: posibilidad de guardar las preguntas y volverlas a utilizar en cualquier momento.

○ Encuestas

- Actividades o deberes

- Calificación: posibilidad de evaluar y calificar cada examen y cada alumno.

- Seguimiento de los resultados: estado de avance de los alumnos respecto de las evaluaciones propuestas.

- Personalización

* Itinerarios de aprendizaje: generación de itinerario de trabajo compuesto por el acceso a ciertos materiales, la realización de tests, exámenes o actividades.

* Destinatarios: asignación individual, o por grupos, de ejercicios, encuestas y actividades.

- Estadísticas: monitoreo del trabajo y progreso de los alumnos en función de diferentes fechas y criterios, incluyendo el tiempo dedicado a los módulos de aprendizaje y actividades, accesos, duración de las sesiones, lugares visitados, recorridos realizados, etc.

- Portafolio o expediente del alumno: resumen y acceso a toda la información de un alumno procedente de las diferentes herramientas utilizadas.

- Herramientas para el alumno

- Materiales de aprendizaje:

* Buscador de contenidos

* Anotaciones personales en las páginas de contenidos

* Marcador de último lugar visitado

* Información sobre los materiales descargados o recorridos

* Acceso a bibliotecas virtuales

* Enlaces a páginas Web externas al entorno.

- Trabajo off-line: posibilidad de descarga de ciertos recursos para trabajo local.

* Actualización de cambios: manual, por parte del alumno, o automáticamente sincronizada al volver a conectarse.

- Control de progreso: información de su aprendizaje y comparativa con otros alumnos.

- Datos personales: acceso de los usuarios a los datos de su propiedad y posibilidad para modificarlos, hacerlos públicos o privados para el resto 
de los usuarios.

- Web personal: espacio propio que puede servir tanto de presentación como de puerta de acceso a comunicaciones entre alumnos. Posibilidad de compartir la información colocada en su Web personal.

- Carpeta personal: facilidades para que el alumno pueda seguir el curso desde diferentes lugares sin necesidad de transportar sus archivos de trabajo. Posibilidad de compartir la información colocada en su carpeta personal.

\section{- Estandarización}

- Adopción de estándares propuestos por la W3C:

- Validez: que el código cumpla con un estándar.

* Lenguaje de Marcado de Hipertexto Extensible (XHTML)

* Hojas de Estilo en Cascada (CSS).

- Accesibilidad: acceso a la Web por cualquier usuario, independientemente de sus discapacidades.

Nivel de adecuación en la Web Content Accessibility Guidelines (WCAG)

- WCAG 1.0

- A: cumple todos los puntos de verificación de prioridad 1.

- AA: cumple todos los puntos de verificación de prioridad 1 y 2 .

- AAA: cumple todos los puntos de verificación de prioridad 1,2 y 3.

- WCAG 2.0

- Nivel A: cumple todos los criterios de éxito de nivel 1 (A) y de nivel 2 (AA) de todas las directrices o se proporciona una versión alternativa conforme al nivel AA.

- Nivel AA: cumple todos los criterios de éxito de nivel 1 (A) de todas las directrices o se proporciona una versión alternativa conforme al nivel $A$.

- Nivel AAA: cumple todos los criterios de éxito de nivel 1 (A), de nivel 2 (AA) y de nivel 3 (AAA) de todas las directrices, o se proporciona una versión alternativa conforme al nivel AAA.

- Internacionalización: permitir y facilitar el uso con diferentes lenguajes, por diversas culturas y regiones. Utilización de formatos y protocolos que no establezcan barreras a los diferentes idiomas, sistemas de escritura, códigos y otras convenciones locales.

- Adopción de los principales estándares de e-learning :

- SCORM (Shareable Content Object Reference Model)

○ IMS (Instructional Management Systems) 
* Learning Resource Metadata (LRM)

* Content Packaging (CP)

* Question \& Test Interoperability (QTI)

* Enterprise (E).

* Enterprise Servises (ES).

* Learner Information Packaging (LIP)

* Learning Design (LD)

* Shareable State Persistente (SSP)

* Resource List Interoperability (RLI)

* Simple Sequencing (SS)

* Otras especificaciones IMS

- IEEE (Institute of Electrical and Electronics Engineers)

* Learning Object Metadata (LOM)

- AICC (Aviation Industry Computer-Based Training Committee)

* Course Structure

* Package Exchange Notification Services

- Packaging

\subsubsection{Instrumentos de evaluación}

\subsubsection{Cuestionario para evaluar flexibilidad tecnológica}

Entendemos como flexibilidad tecnológica a las fortalezas y debilidades que posee el EVEA desde el punto de vista de sus características técnicas generales, compatibilidad con hardware y software, y robustez.

\section{Características técnicas generales}

○ Antecedentes

* Historial

a. ¿EI EVEA posee antecedentes? SI/NO

b. ¿Hace cuántos años se originó el proyecto? Menos de 2/Entre 2 y $5 /$ Más de 5

c. ¿El proyecto pertenece a una Institución educativa de relevancia? Local/Regional/Nacional/Internacional

* Versiones

a. ¿Dispone de versiones on-line o para instalar que permitan realizar pruebas bajo situaciones reales? SI/NO

* Grado de utilización en entornos similares

a. ¿Cuántas Instituciones lo han adoptado? Menos de 10/Entre 10 y 30/Más de 30 
b. ¿Las Instituciones son de diferentes países? SI/NO

c. ¿Qué tipo de Instituciones son? Universitarias/Terciarias/Institutos/Centros/Otros

d. En general, ¿son Instituciones de cierto prestigio?

* Evaluación

a. ¿Existen evaluaciones previas realizadas por organismos e instituciones independientes? SI/NO

b. ¿Qué resultados obtuvieron? Muy Buenos/Buenos/Regulares/Malos

* Actividades de intercambio de experiencias

a. ¿Existe un núcleo de desarrolladores agrupados bajo cierto proyecto de carácter institucional? SI/NO

b. ¿Existen comunidades virtuales de usuarios? SI/NO

c. ¿Se realizan jornadas, talleres, charlas o congresos relacionados con el EVEA? Nunca/A veces/Siempre

d. ¿Hay artículos educativos publicados donde se utiliza el EVEA como herramienta de enseñanza y aprendizaje? Ninguno/Pocos/Muchos

\section{$\circ$ Potencial}

Número de usuarios permitidos

a. Globales: sin restricciones específicas/limitado a $\ldots$. $/$ no identificado/dependiente del HW disponible

b. Simultáneos: limitado a ..../no identificado/sin restricciones específicas/ dependiente del HW disponible

* Número de aulas virtuales que se pueden gestionar simultáneamente: limitado a ..../no identificado/sin restricciones específicas/dependiente del HW disponible

* Idiomas

a. Capacidad multi-lenguaje: SI/NO

b. Ayuda en el idioma propio: SI/NO

c. Cantidad de idiomas disponibles actualmente: 1/Entre 2 y 5/Más de 5

- Escalabilidad

a. Posibilidad de crecimiento en cantidad de usuarios, aulas virtuales y utilización simultánea: SI/NO

- Tecnología

* Arquitectura cliente-servidor: SI/NO

* Lenguaje de programación utilizado: PHP/JSP/Otro:

* Código: ABIERTO/PROPIETARIO 
* Multiplataforma: SI/NO

* Software necesario: servidor de páginas estáticas / servidor de páginas dinámicas / servidor de base de datos / administrador de base de datos / servidor de correo / servidor de listas / antivirus / webmail / Otros:

* Instalación

- Modo: en cualquier servidor / centralizada.

- Forma: manual / instalador / "wizard" / Otra:

* Modo de actualización: automática / manual / por módulos / sin actualización.

- Licencia

* Modalidad: pago / gratuita / Otra:

* Costo: Anual / por cantidad de cursos / por cantidad de usuarios / por servicio de hosting / por capacitación / por asistencia / sin costo / Otro:

- Soporte

* Documentación: Tutoriales, manuales, informes técnicos, sitio Web oficial, foros de ayuda, newsletter.

* Cursos de formación.

* Servicio y soporte técnico.

* Presencia de un distribuidor y la calidad de sus servicios en la resolución de problemas.

* Costo del soporte técnico, mantenimiento, y actualizaciones.

$\circ$ Seguridad

* Encriptación: contraseñas / datos almacenados / transmisión de datos / sin encriptación

* Autentificación de usuarios: con autentificación / sin autentificación / ambas

- Acceso de usuarios

* Usuario y contraseña: individual / grupal / sin restricciones

* Registración: SI/NO

* Asignación de privilegios: SI/NO

* Asignación de perfiles: SI/NO

* Requisitos mínimos de software:

- Sistemas Operativos: Linux/Windows/Otros:

- Navegadores: Firefox / Internet Explorer / Chrome / Opera / Safari / Otros:

- Servidores de bases de datos: MSQL / POSGRES / ORACLE / INFORMIX / Otros:

- Otro software:

\section{Compatibilidad}


○

\section{Servidor}

* Requisitos de hardware

- Procesador:

- Memoria:

- Disco:

- Red:

- Otros:

* Requisitos de software:

- Sistemas Operativos: Linux / Windows / Todos / Otros:

- Servidores de bases de datos: MSQL / POSGRES / ORACLE/ INFORMIX / TODOS / Otras:

- Servidores Web:

- Otros:

\section{- Usuario/Cliente}

* Tipo de hardware: PC / Notebook / Netbook / Dispositivos móviles: Teléfono móvil o celular, Smartphone, PDA, Tablet PC, Otros:

* Requisitos de hardware:

- Procesador:

- Memoria:

- Disco:

- Red:

- Otros:

Requisitos mínimos de conexión a Internet: Dial-up / ADSL / Otro:

* Requisitos de software:

- Sistemas Operativos: LINUX / WINDOWS / MAC / Cualquiera / Otros:

- Navegadores: Firefox / Internet Explorer / Chrome / Opera / Safari / Otros:

- Plugins:

- Otros:

- Formatos multimedia: audio / video / imágenes / animaciones / objetos 3D / applets.

○ Integración:

a. ¿Posee mecanismos que permiten la relación con otros sistemas?

b. ¿Cuales? Archivos / protocolos / RMI / API / Web Service / Otros:

○ Interoperabilidad:

a. ¿Mantiene la compatibilidad con datos, protocolos y lenguajes de programación ya existentes en el lugar de implantación? SI/NO 


\section{- $\quad$ Robustez}

- Integridad de funcionamiento

a. ¿Se han detectado o relevado fallas derivadas de un mal diseño del software? $\mathrm{SI} / \mathrm{NO}$

\section{- Recuperación ante fallos}

a. ¿Posee tolerancia ante utilización poco experta? SI/NO

\section{○ Seguridad}

a. ¿Posee la capacidad de controlar los accesos a bases de datos y herramientas que integran el entorno? SI/NO

b. ¿Los materiales almacenados están protegidos? SI/NO

c. ¿Exige respetar cierta propiedad sobre los materiales? SI/NO

\subsubsection{Cuestionario para evaluar flexibilidad organizativa}

La flexibilidad organizativa pone el acento en cuestiones administrativas y de interfaz. La administración es un punto crítico para tener éxito en la implantación del sistema. Este tipo de flexibilidad es muy importante porque puede reducir drásticamente los tiempos destinados a la administración, hacer más eficiente la puesta en funcionamiento de cada una de las instancias virtuales de formación, solucionar rápidamente problemas durante el desarrollo de las mismas, adaptar la interfaz a las necesidades institucionales, y permitir delegar parte de las tareas administrativas a usuarios que dispongan de mínimos conocimientos técnicos.

\begin{tabular}{|l|l|}
\hline Herramientas de administración de usuarios & SI/NO \\
\hline $\begin{array}{l}\text { Perfiles: Posibilidad de configurar perfiles con diferentes } \\
\text { atribuciones y derechos de acceso. }\end{array}$ & \\
\hline $\begin{array}{l}\text { Gestión: Capacidad para dar de alta o baja usuarios de } \\
\text { forma individual o por lote, buscar usuarios, acceder a sus } \\
\text { datos personales, modificarlos y asignar nuevas } \\
\text { contraseñas. }\end{array}$ & \\
\hline $\begin{array}{l}\text { Inscripción: Capacidad de asignación de usuarios a cada } \\
\text { aula virtual de forma automática, mediante formulario de } \\
\text { solicitud, mediante archivos por lote, de manera individual. }\end{array}$ & \\
\hline $\begin{array}{l}\text { Acceso: Posibilidad de acceder a todas las aulas virtuales } \\
\text { desde un solo lugar con un único usuario y contraseña. }\end{array}$ & \\
\hline $\begin{array}{l}\text { Seguimiento: Registro automático de todas las actividades } \\
\text { realizadas. }\end{array}$ & \\
\hline $\begin{array}{l}\text { Integración: Compatibilidad con otras bases de datos de } \\
\text { usuarios. }\end{array}$ & \\
\hline
\end{tabular}

Herramientas de gestión de espacios virtuales SI/NO

Gestión: Capacidad para dar de alta, baja y modificar espacios virtuales: asignaturas, cursos, seminarios, talleres, 


\begin{tabular}{|l|l|}
\hline carreras. & \\
$\begin{array}{l}\text { Organización: Capacidad para organizar los espacios } \\
\text { virtuales de manera diferenciada por Facultades, Carreras, }\end{array}$ & \\
Áreas, Temas, Asignaturas, Cursos, Comisiones, etc. & \\
\hline $\begin{array}{l}\text { Flexibilidad: Capacidad para agregar en los diferentes } \\
\text { espacios virtuales nuevos usuarios, perfiles, privilegios y } \\
\text { funcionalidades. }\end{array}$ & \\
\hline $\begin{array}{l}\text { Backup: Capacidad para realizar copias de seguridad } \\
\text { generales o particulares. }\end{array}$ & \\
\hline $\begin{array}{l}\text { Clonación: Capacidad para realizar réplicas de espacios ya } \\
\text { existentes. }\end{array}$ & \\
\hline $\begin{array}{l}\text { Campus: Posibilidad de colocar información general, } \\
\text { novedades, preguntas frecuentes, servicios generales } \\
\text { (biblioteca, directorio de miembros, cafetería virtual, etc.) y }\end{array}$ & \\
repositorio de software.
\end{tabular}

\begin{tabular}{|l|l|}
\hline Interface & SI/NO \\
\hline $\begin{array}{l}\text { Personalización: Posibilidades de mantener una imagen } \\
\text { propia en general y en cada uno de los espacios virtuales. }\end{array}$ & \\
\hline Plantillas: Creación rápida y sencilla de aulas virtuales. & \\
\hline $\begin{array}{l}\text { Ayuda on-line: Sensibilidad al contexto de forma que } \\
\text { permitan un rápido acceso a la información buscada. }\end{array}$ & \\
\hline $\begin{array}{l}\text { Modos de vista: Capacidad para comprobar on-line cómo } \\
\text { son vistos los cambios por los diferentes perfiles sin } \\
\text { necesidad de tener abiertas diferentes sesiones de trabajo. }\end{array}$ & \\
\hline $\begin{array}{l}\text { Editor on-line: Disponibilidad de un editor de texto con } \\
\text { formato (WYSIWYG), que esté integrado al entorno, y } \\
\text { posibilite incorporar código HTML, texto y otros recursos } \\
\text { viendo directamente el resultado final. }\end{array}$ & \\
\hline $\begin{array}{l}\text { Caminos abreviados: posibilidad para acceder } \\
\text { directamente a ciertos espacios sin necesidad de realizar un } \\
\text { recorrido obligado. }\end{array}$ & \\
\hline $\begin{array}{l}\text { Caminos personalizados: posibilidad de personalizar las } \\
\text { formas de acceder a los espacios de acuerdo a la expertise } \\
\text { del usuario. }\end{array}$ & \\
\hline
\end{tabular}

\subsubsection{Cuestionario para evaluar flexibilidad pedagógico/didáctica}

En esta categoría hacemos referencia a las funcionalidades que el entorno provee a docentes y alumnos para el desarrollo del proceso de enseñanza y aprendizaje. Está centrada en el contexto particular de un aula virtual, es decir, un espacio virtual específico para el desarrollo de una instancia educativa. Se trata de una de las flexibilidades más 
importantes porque está orientada al análisis del corazón del entorno, es decir, la riqueza que brinda para adaptarse a las diferentes propuestas pedagógicas y modalidades didácticas.

\begin{tabular}{|c|c|}
\hline Herramientas de información & SI/NO \\
\hline $\begin{array}{l}\text { Calendario o agenda: Resumen de los principales eventos } \\
\text { propios de la organización y programación de actividades } \\
\text { (fechas de examen, de clase, de entrega de trabajos, de } \\
\text { inicio y fin de módulos, unidades, prácticos, etc.). Posibilidad } \\
\text { de incorporar anotaciones privadas. }\end{array}$ & \\
\hline $\begin{array}{l}\text { Cartelera de novedades: Noticias fechadas de carácter } \\
\text { general e índole organizativa. }\end{array}$ & \\
\hline $\begin{array}{l}\text { Alertas: Anuncios al usuario, luego de cada ingreso, sobre } \\
\text { la existencia de cambios producidos dentro del espacio } \\
\text { virtual a partir del último ingreso (eventos, noticias, } \\
\text { exámenes, mensajes, calificaciones, vencimientos, nuevos } \\
\text { materiales, etc.). }\end{array}$ & \\
\hline $\begin{array}{l}\text { Pizarra virtual: Escritura a mano alzada o dibujos como en } \\
\text { un editor de imágenes. }\end{array}$ & \\
\hline $\begin{array}{l}\text { Respuestas a preguntas frecuentes: Respuesta única por } \\
\text { cada una de las preguntas que realizan de forma reiterada } \\
\text { los alumnos. }\end{array}$ & \\
\hline $\begin{array}{l}\text { Glosario de términos: Conjunto de términos propios de la } \\
\text { disciplina junto con su descripción. Posibilidad de enlace } \\
\text { desde los lugares donde aparece el término. }\end{array}$ & \\
\hline $\begin{array}{l}\text { Información general o guía: Elementos básicos de la } \\
\text { planificación como programa, metodología, bibliografía, etc. }\end{array}$ & \\
\hline $\begin{array}{l}\text { Información sobre los docentes: Perfil, foto, últimos } \\
\text { accesos, actividades realizadas por los docentes a cargo del } \\
\text { espacio. }\end{array}$ & \\
\hline Índice: Generación automática de un índice de contenidos. & \\
\hline
\end{tabular}

- Herramientas de comunicación

- Asincrónicas

* Correo electrónico: SI/NO

- Integrado: SI/NO

- Formato de mensajes: texto plano / texto HTML básico / texto HTML con enlaces, tablas, imágenes, etc.

- Etiquetado de mensajes: SI/NO

- Carpetas: SI/NO

- Libreta de direcciones: SI/NO

- Adjuntos: SI/NO 
- Cantidad permitida: $1 /$ más de 1

- Formatos posibles: PDF / ZIP / RAR / DOC / RTF / ODT / PPT / ODF / XLS / Otros:

- Formatos no permitidos: EXE / ZIP / RAR / Otros:

- Tamaño máximo de los archivos: menos de $2 \mathrm{Mb} / m e n o s$ de $5 \mathrm{mb} / \mathrm{menos}$ de $10 \mathrm{Mb} / \mathrm{menos}$ de $20 \mathrm{Mb} / \mathrm{sin}$ límite/Otro:

Listas de correo: $\mathrm{SI} / \mathrm{NO}$

- Cantidad: una por aula / múltiples

- Formato: abiertas / cerradas

- Moderación: SI/NO

- Mecanismos de suscripción y desuscripción: SI/NO

Foros de discusión: SI/NO

- Flexibilidad en su apertura y cierre: SI/NO

- Foros por aula, por grupos: SI/NO

- Mecanismos de suscripción y desuscripción: SI/NO

- Incorporación de archivos: SI/NO

- Seguimiento de las intervenciones: SI/NO

- Formatos diferentes de visualización (lineal, rama, etc.): SI/NO

- Moderación: SI/NO

Diario: SI/NO

- Comunicación personalizada entre alumno y docente: SI/NO

- Posibilidad emitir ideas, consultas, opiniones, pensamientos, y recibir respuesta: SI/NO

\section{- Sincrónicas}

* Chat: SI/NO

- Multimedia: solo texto / texto y audio / texto, audio y video / pizarra virtual.

- Número de salas disponibles: una por espacio / ilimitado.

- Almacenamiento de las conversaciones: SI/NO

- Archivos adjuntos: SI/NO

- Moderación: SI/NO

- Límite en la cantidad de participantes: SI/NO

* Mensajería instantánea: SI/NO

- Multimedia: solo texto / texto y audio / texto, audio y video.

- Almacenamiento de las conversaciones: SI/NO

- Archivos adjuntos: SI/NO 
* Clases virtuales: SI/NO

* Conferencia: SI/NO

- Multimedia: audio / audio y video.

- Interacción con el auditorio: sin interacción / preguntas por parte de los participantes / Otras:

- Herramientas de colaboración

- Grupos: SI/NO

- Espacio de trabajo compartido entre diferentes alumnos de un aula: $\mathrm{SI} / \mathrm{NO}$

- Diferentes roles: SI/NO

- Selección de herramientas y recursos para cada grupo: SI/NO

- Mecanismos de conformación: automático/por elección del docente/por elección del alumno/Otros:

- Pizarra compartida: SI/NO

- Carpeta virtual: SI/NO

* Formato: individual / grupal / por aula / general

* Posibilidad de compartir con otros usuarios: $\mathrm{SI} / \mathrm{NO}$

○ Web 2.0

- Blog: SI/NO

* Pertenencia: individual / grupal / por aula / general

* Visualización: abiertos / cerrados a un grupo de participantes

* Comentarios: abiertos/cerrados, moderados/no moderados.

- Wiki: SI/NO

* Formato: grupal / general / por aula / por temática.

- Redes sociales: SI/NO

- Aplicaciones 2.0: SI/NO

○ Navegación compartida: S/NO

- Votaciones: SI/NO

- Herramientas para la evaluación

○ Ejercicios

* Autoevaluación o tests: SI/NO

* Exámenes: SI/NO

- Temporización: tiempo límite / sin tiempo límite

- Cantidad de intentos: libre / acotado / fijo

- Tipo de calificación: numérica / porcentual / conceptual / Otras: 


\section{* Preguntas}

- Cantidad: fija / ilimitada

- Tipos: respuesta múltiple / relación / lógicas / numérica / calculada / abierta / emparejamiento / completar frases / mapas de imágenes / respuesta corta / tablas/ Otras:

- Riqueza de recursos: gráficos / imágenes / ecuaciones / ayudas

- Bases de datos de preguntas: $\mathrm{SI} / \mathrm{NO}$

- Encuestas: SI/NO

- Actividades o deberes: SI/NO

- Calificación de cada examen: SI/NO

- Seguimiento de los resultados: SI/NO

- Personalización

* Destinatarios: asignación individual / grupal / a todos

* Itinerarios de aprendizaje: SI/NO

- Estadísticas de progreso del alumno: SI/NO

- Portafolio o expediente del alumno: SI/NO

- Herramientas para el alumno

- Materiales de aprendizaje

* Buscador de contenidos: SI/NO

* Anotaciones personales en las páginas de contenidos: SI/NO

* Marcador de último lugar visitado: SI/NO

* Información sobre los materiales descargados o recorridos: $\mathrm{SI} / \mathrm{NO}$

* Acceso a bibliotecas virtuales: SI/NO

* Enlaces a páginas Web externas al entorno : SI/NO

○ Trabajo off-line

* Producción fuera del aula virtual: SI/NO

* Actualización de cambios: manual / sincronizada.

- Control de progreso personal: SI/NO

- Datos personales: SI/NO

- Web personal: SI/NO

- Carpeta personal: SI/NO

\subsubsection{Cuestionario para evaluar estandarización}

Cualquier producto que pretenda ser de calidad debe posee altos niveles de estandarización. Los productos software no son la excepción, y menos aún aquellos que se basan exclusivamente en la Web. El proceso de estandarización de la Web ha 
convergido hacia aquellos que fueron propuestos por la World Wide Web Consortium (W3C). En particular son de interés para nuestro trabajo los estándares de la W3C orientados a la validez, accesibilidad e internacionalización del entorno.

\begin{tabular}{|c|c|c|c|}
\hline W3C - XHTML & & \multicolumn{2}{|c|}{ Cumplimiento con el estándar } \\
\hline Adecuación al estándar & & \multicolumn{2}{|c|}{ SI / NO / Parcialmente } \\
\hline \multicolumn{4}{|c|}{ Detalle } \\
\hline \multicolumn{4}{|l|}{ Validador utilizado } \\
\hline Páginas analizadas & $\begin{array}{c}\text { Errores } \\
\text { leves }\end{array}$ & $\begin{array}{c}\text { Errores } \\
\text { graves }\end{array}$ & Advertencias \\
\hline & & & \\
\hline & & & \\
\hline & & & \\
\hline & & & \\
\hline & & & \\
\hline & & & \\
\hline
\end{tabular}

\begin{tabular}{|c|c|c|}
\hline W3C - CSS & \multicolumn{2}{c|}{ Cumplimiento con el estándar } \\
\hline Adecuación al estándar & SI / NO / Parcialmente \\
\hline \multicolumn{2}{|c|}{ Detalle } \\
\hline Validador utilizado & Errores & Advertencias \\
\hline Páginas analizadas & & \\
\hline & & \\
\hline & & \\
\hline & & \\
\hline
\end{tabular}




\begin{tabular}{|c|c|c|c|c|}
\hline \multicolumn{3}{|c|}{ Adecuación al estándar } & \multicolumn{2}{|c|}{ A / AA / AAA - NO } \\
\hline \multicolumn{5}{|c|}{ Detalle } \\
\hline \multicolumn{5}{|l|}{$\begin{array}{l}\text { Validador } \\
\text { utilizado }\end{array}$} \\
\hline \multirow{4}{*}{$\begin{array}{c}\text { Páginas } \\
\text { analizadas }\end{array}$} & \multicolumn{4}{|c|}{ Problemas encontrados } \\
\hline & & Prioridad 1 & Prioridad 2 & Prioridad 3 \\
\hline & Automático & & & \\
\hline & Manual & & & \\
\hline & Automático & & & \\
\hline & Manual & & & \\
\hline & Automático & & & \\
\hline & Manual & & & \\
\hline & Automático & & & \\
\hline & Manual & & & \\
\hline & Automático & & & \\
\hline & Manual & & & \\
\hline
\end{tabular}

\begin{tabular}{|c|c|c|c|c|}
\hline \multicolumn{3}{|c|}{ W3C - WCAG 2.0} & \multicolumn{2}{|c|}{ umplimiento con el estándar } \\
\hline \multicolumn{3}{|c|}{ Adecuación al estándar } & \multicolumn{2}{|c|}{ A / AA / AAA - NO } \\
\hline \multicolumn{5}{|c|}{ Detalle } \\
\hline \multicolumn{5}{|l|}{$\begin{array}{l}\text { Validador } \\
\text { utilizado }\end{array}$} \\
\hline \multirow{4}{*}{$\begin{array}{l}\text { Páginas } \\
\text { analizadas }\end{array}$} & \multicolumn{4}{|c|}{ Problemas encontrados } \\
\hline & & Prioridad 1 & Prioridad 2 & Prioridad 3 \\
\hline & Automático & & & \\
\hline & Manual & & & \\
\hline
\end{tabular}




\begin{tabular}{|l|l|l|l|l|}
\hline & Automático & & & \\
\hline & Manual & & & \\
\hline & Automático & & & \\
\hline & Manual & & & \\
\hline & Automático & & & \\
\hline & Manual & & & \\
\hline & Automático & & & \\
\hline & Manual & & & \\
\hline
\end{tabular}

\begin{tabular}{|c|c|c|c|}
\hline \multicolumn{3}{|c|}{ Compatibilidad con navegadores } \\
\hline $\begin{array}{c}\text { Nombre y } \\
\text { versión }\end{array}$ & Compatible & Cantidad & Descripción de los problemas \\
\hline & $\begin{array}{c}\text { SI / NO / } \\
\text { Parcialmente }\end{array}$ & & \\
\hline & $\begin{array}{c}\text { SI / NO / } \\
\text { Parcialmente }\end{array}$ & & \\
\hline & $\begin{array}{c}\text { SI / NO / } \\
\text { Parcialmente }\end{array}$ & & \\
\hline & $\begin{array}{c}\text { SI / NO / } \\
\text { Parcialmente }\end{array}$ & & \\
\hline & $\begin{array}{c}\text { SI / NO / } \\
\text { Parcialmente }\end{array}$ & $\begin{array}{c}\text { SI / NO / } \\
\text { Parcialmente }\end{array}$ & \\
\hline
\end{tabular}

\section{Visibilidad para usuarios de visión reducida}

Validador utilizado 


\begin{tabular}{|l|c|c|c|}
\hline & Ceguera & Baja visión & Daltonismo \\
\hline & SI / NO / Parcialmente & SI / NO / Parcialmente & SI / NO / Parcialmente \\
\hline
\end{tabular}

\begin{tabular}{|l|c|}
\hline Internacionalización & Cumplimiento \\
\hline $\begin{array}{l}\text { Permitir y facilitar el uso con diferentes } \\
\text { lenguajes, por diversas culturas y } \\
\text { regiones. }\end{array}$ & SI / NO / Parcialmente \\
\hline $\begin{array}{l}\text { Utilización de formatos y protocolos } \\
\text { que no establezcan barreras a los } \\
\text { diferentes idiomas, sistemas de } \\
\text { escritura, códigos y otras } \\
\text { convenciones locales. }\end{array}$ \\
\hline
\end{tabular}

\begin{tabular}{|c|c|}
\hline E-learning & Cumplimiento \\
\hline $\begin{array}{l}\text { SCORM (Shareable Content Object } \\
\text { Reference Model) }\end{array}$ & SI / NO / Parcialmente \\
\hline $\begin{array}{l}\text { IMS (Instructional Management } \\
\text { Systems) }\end{array}$ & SI / NO / Parcialmente \\
\hline * Learning Resource Metadata (LRM) & SI / NO / Parcialmente \\
\hline * Content Packaging (CP) & SI / NO / Parcialmente \\
\hline * Question \& Test Interoperability (QTI) & SI / NO / Parcialmente \\
\hline * Enterprise (E) & SI / NO / Parcialmente \\
\hline * Enterprise Servises (ES) & SI / NO / Parcialmente \\
\hline * Learner Information Packaging (LIP) & SI / NO / Parcialmente \\
\hline Learning Design (LD) & SI / NO / Parcialmente \\
\hline * Shareable State Persistente (SSP) & SI / NO / Parcialmente \\
\hline * Resource List Interoperability (RLI) & SI / NO / Parcialmente \\
\hline - Simple Sequencing (SS) & SI / NO / Parcialmente \\
\hline * Otras especificaciones IMS: & SI / NO / Parcialmente \\
\hline IEEE Learning Object Metadata (LOM) & SI / NO / Parcialmente \\
\hline $\begin{array}{l}\text { AICC (Aviation Industry Computer- } \\
\text { Based Training Committee) }\end{array}$ & SI / NO / Parcialmente \\
\hline * Course Structure & SI / NO / Parcialmente \\
\hline * Package Exchange Notification Services & SI / NO / Parcialmente \\
\hline
\end{tabular}




\subsection{Anexo B}

\subsubsection{Identificación de tareas importantes y frecuentes en el EVEA SIAT}

Para lograr identificar las principales tareas que los alumnos y docentes realizan dentro de un EVEA, se llevó a cabo una consulta por e-mail, basada en un cuestionario abierto, y destinada a docentes y alumnos pertenecientes a las carreras a distancia de la Facultad de Ciencias Económicas de la UNRC. En dicho cuestionario se solicitaba al usuario identificar cuales eran las cinco tareas más importantes y las cinco más frecuentes que realizaban en el EVEA SIAT. Para ello se tomó una muestra aleatoria de usuarios del EVEA SIAT compuesta por 214 alumnos pertenecientes a las carreras a distancia de la Facultad de Ciencias Económicas de la UNRC (FCE-UNRC), de primero a quinto año, y 72 docentes.

El cuestionario fue respondido por el $18 \%$ de los alumnos (39) y el $21 \%$ de los docentes (15). En cuanto a los alumnos, el mayor índice de respuestas correspondió a los que cursan primer año con un $21 \%$, seguido de los alumnos de cuarto con $17 \%$, segundo con $15 \%$, tercero y quinto con $12 \%$.

Los resultados no pueden generalizarse debido a que el sistema de Educación a Distancia desarrollado en la FCE-UNRC está estructurado con ciertas pautas que deben ser respetadas por los docentes en cuanto al uso del EVEA SIAT y la metodología aplicada. Sin embargo, aporta información muy valiosa que ayuda en la búsqueda de las tareas que serán parte de los escenarios para los test de usuarios.

Es notorio observar la gran coincidencia en cuanto a las tareas realizadas por los usuarios y a la importancia y frecuencia dada por ellos. En base a las respuestas de los alumnos se lograron identificar seis tareas principales y siete en el caso de los docentes. Luego de categorizadas las respuestas, ya que el cuestionario era abierto, y realizada la sistematización correspondiente, se arribó a los siguientes resultados.

\subsubsection{Alumnos}

Las tareas que los alumnos identifican como las 6 más importantes se corresponden también con las 6 más frecuentes, aunque difieren en el orden. Tampoco hay variación respecto a las tareas entre alumnos de primero a quinto año. El $38 \%$ de los alumnos no encontraron diferencia entre las tareas, destacando que las consideradas por ellos como más importantes son también las que más frecuentemente realizan. Las tareas más importantes que fueron identificadas a partir de este cuestionario son las siguientes, ordenadas por orden de importancia:

Tareas que los alumnos consideran como más importantes

\begin{tabular}{|l|c|}
\hline $\begin{array}{l}\text { Acceder al aula virtual e informarse sobre los principales eventos, } \\
\text { programación de actividades, últimas novedades y cambios producidos a } \\
\text { partir del ingreso anterior. }\end{array}$ & $27 \%$ \\
\hline Entregar un trabajo evaluable. & $23 \%$ \\
\hline Comunicarse de forma asincrónica con su docente. & $19 \%$ \\
\hline Acceder a los materiales de estudio. & $18 \%$ \\
\hline Participar de un debate. & $8 \%$ \\
\hline Acceder a sus calificaciones y devoluciones de trabajos & $5 \%$ \\
\hline
\end{tabular}


Es de destacar que los usuarios alumnos atribuyen a las dos primeras tareas el $50 \%$ de las preferencias y a las cuatro primeras el $87 \%$.

Las 6 tareas más frecuentes que fueron identificadas a partir de este cuestionario son las mismas que las anteriores. Solo varía el orden de importancia entre 2 de ellas "Entregar un trabajo evaluable" y "Comunicarse de forma asincrónica con su docente":

Tareas que los alumnos consideran como más frecuentes

\begin{tabular}{|l|c|}
\hline $\begin{array}{l}\text { Informarse sobre los principales eventos, programación de actividades, } \\
\text { últimas novedades y cambios producidos dentro del aula virtual a partir del } \\
\text { ingreso anterior: pizarrón, noticias, calendario e información. }\end{array}$ & $30 \%$ \\
\hline Comunicarse de forma asincrónica con su docente. & $20 \%$ \\
\hline Entregar un trabajo evaluable. & $17 \%$ \\
\hline Acceder a los materiales de estudio. & $14 \%$ \\
\hline Participar de un debate. & $13 \%$ \\
\hline Acceder a sus calificaciones y devoluciones de trabajos & $5 \%$ \\
\hline
\end{tabular}

Al igual que las tareas más importantes, existe una marcada brecha entre las dos primeras tareas y el resto ya que concentran el $50 \%$ de las opiniones.

\subsubsection{Docentes}

Las tareas que los docentes identifican como las 7 más importantes también se corresponden con las 7 más frecuentes, aunque difieren en el orden. Todas las tareas planteadas por los docentes se corresponden con las identificadas por los alumnos en el sentido que unas son la contraparte de las otras. Tampoco hay variación respecto a las tareas entre docentes de primero a quinto año. El $40 \%$ de los docentes no encontraron diferencia entre las tareas, destacando que las consideradas por ellos como más importantes son también las que más frecuentemente realizan. Las 7 tareas de mayor importancia que fueron identificadas a partir de este cuestionario son las siguientes, ordenadas por orden de importancia:

Tareas que los docentes consideran como más importantes

\begin{tabular}{|l|c|}
\hline \multicolumn{2}{|c|}{ Tareas que los docentes consideran como más importantes } \\
\hline $\begin{array}{l}\text { Informar a los alumnos sobre los principales eventos, la programación de } \\
\text { actividades y las novedades. }\end{array}$ & $23 \%$ \\
\hline Calificar los trabajos evaluables y realizar devoluciones & $19 \%$ \\
\hline Recibir y corregir un trabajo evaluable. & $18 \%$ \\
\hline Comunicarse de forma asincrónica con sus alumnos. & $16 \%$ \\
\hline Incorporar materiales de estudio al aula virtual en diferentes formatos & $15 \%$ \\
\hline Generar y participar de un debate. & $7 \%$ \\
\hline Acceder a información sobre sus alumnos & $2 \%$ \\
\hline
\end{tabular}

En este caso también se observa cierta predominancia en algunas tareas, aunque no tan marcada como en el caso de los alumnos. Las 5 tareas más importantes representan el $91 \%$.

Las 7 tareas más frecuentes que fueron identificadas a partir de este cuestionario son las mismas que las anteriores. Solo varía el orden de importancia entre 2 de ellas "Comunicarse de forma asincrónica con su docente" y "Recibir y corregir un trabajo evaluable": 
Tareas que los alumnos consideran como más frecuentes

Informar a los alumnos sobre los principales eventos, la programación de actividades y las novedades.

Calificar los trabajos evaluables y realizar devoluciones $22 \%$

Comunicarse de forma asincrónica con sus alumnos. $16 \%$

Recibir y corregir un trabajo evaluable. $14 \%$ Incorporar materiales de estudio al aula virtual en diferentes formatos $14 \%$

Generar y participar de un debate. $9 \%$

Acceder a información sobre sus alumnos $1 \%$

Al igual que las tareas más importantes, existe una brecha importante entre las cinco primeras y el resto ya que concentran el $90 \%$ de las opiniones. 


\subsection{Anexo C}

\section{Capa 2}

\subsubsection{Evaluación de alto nivel orientada a la tarea}

\subsubsection{Forma de aplicación con tareas}

A continuación se detallan las tareas a ser realizadas por el evaluador, en calidad de docente y de alumno.

\section{Tareas del Docente Tutor}

- TAREA 1: Acceder al aula virtual

- TAREA 2: Informarse sobre el curso (bienvenida, programación de actividades, y grupo de alumnos que tiene a cargo)

- TAREA 3: Escribir, publicar y modificar un mensaje informativo para todos los alumnos

- TAREA 4: Acceder a los materiales de estudio. Incorporar materiales complementarios

- $\quad$ TAREA 5: Abrir un foro, agregar y responder aportes

- $\quad$ TAREA 6: Acceder, leer, y responder correo a uno y a varios alumnos

- TAREA 7: Publicar una actividad evaluable para todos alumnos con plazo de entrega. Corregir y calificar los trabajos. Realizar devoluciones o cometarios individuales sobre algunos trabajos

- TAREA 8: Informarse sobre la situación de cada alumno (ingreso al aula, participaciones, descarga de materiales, entrega de trabajos, calificaciones)

\section{Tareas del Alumno}

- TAREA 1: Informarse sobre la programación de actividades, novedades, tareas a realizar, y conocer a sus compañeros y docentes

- $\quad$ TAREA 2: Acceder a los materiales de estudio, principales y complementarios

- TAREA 3: Consultar un foro, agregar y responder aportes

- TAREA 4: Acceder, leer, y responder correo

- TAREA 5: Entregar un trabajo evaluable, acceder a la calificación y devolución

- $\quad$ TAREA 6: Acceder a los materiales de estudio, principales y complementarios 


\subsection{Cuestionario}

TAREA:

Indicar la tarea evaluada

\section{Complejidad}

a. La complejidad de la tarea resultó:

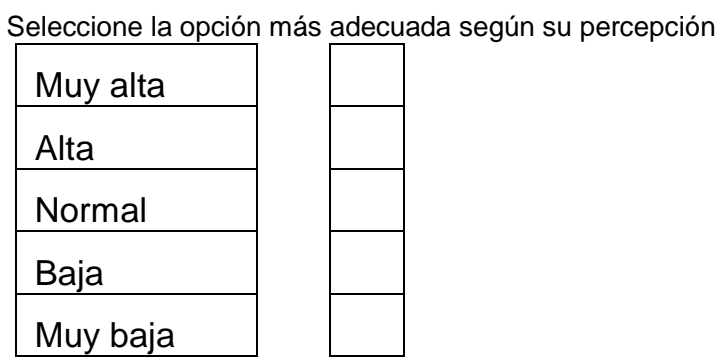

b. Responda las siguientes preguntas:

¿Debió tomar decisiones sobre cómo realizar la tarea debido a la posibilidad de hacerlo de diferentes formas?¿Cuáles?

¿Podría realizar una descripción de la secuencia de pasos recorridos para efectuar la tarea.

\section{Visibilidad}

a. Complete la siguiente grilla:

\begin{tabular}{|l|l|l|l|l|l|}
\hline & $\begin{array}{c}\text { Muy de } \\
\text { acuerdo }\end{array}$ & $\begin{array}{c}\text { De } \\
\text { acuerdo }\end{array}$ & Indiferente & $\begin{array}{c}\text { En } \\
\text { desacuerdo }\end{array}$ & $\begin{array}{c}\text { Muy en } \\
\text { desacuerdo }\end{array}$ \\
\hline $\begin{array}{l}\text { En la interfaz aparece la } \\
\text { información justa y } \\
\text { necesaria para la } \\
\text { realización de la tarea. }\end{array}$ & & & & & \\
\hline $\begin{array}{l}\text { Se encuentra fácilmente la } \\
\text { forma de realizar la tarea. }\end{array}$ & & & & & \\
\hline $\begin{array}{l}\text { La información de contexto } \\
\text { y orientación es adecuada. }\end{array}$ & & & & & \\
\hline $\begin{array}{l}\text { El diseño es intuitivo y } \\
\text { existen señales que } \\
\text { indican de manera natural } \\
\text { lo que se debe hacer. }\end{array}$ & & & & & \\
\hline Solo están disponibles las & & & & & \\
\hline
\end{tabular}




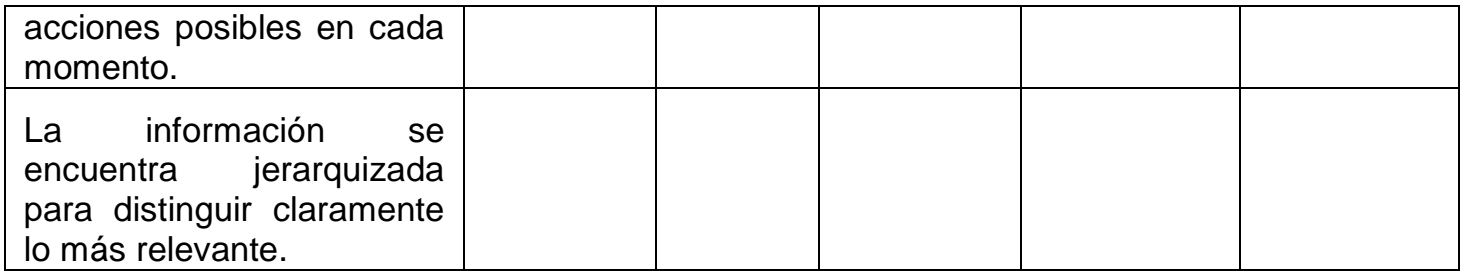

b. Comentario del evaluador:

\section{Intuitividad y Topografía Natural}

a. Complete la siguiente grilla:

\begin{tabular}{|l|l|l|l|l|l|}
\hline & $\begin{array}{c}\text { Muy de } \\
\text { acuerdo }\end{array}$ & $\begin{array}{c}\text { De } \\
\text { acuerdo }\end{array}$ & Indiferente & $\begin{array}{c}\text { En } \\
\text { desacuerdo }\end{array}$ & $\begin{array}{c}\text { Muy en } \\
\text { desacuerdo }\end{array}$ \\
\hline $\begin{array}{l}\text { No hace falta recordar } \\
\text { información para volver a } \\
\text { realizar la tarea. }\end{array}$ & & & & \\
\hline $\begin{array}{l}\text { Hay analogías con el } \\
\text { mundo real u otros } \\
\text { sistemas e interfaces que } \\
\text { generan familiaridad. }\end{array}$ & & & & & \\
\hline $\begin{array}{l}\text { Los objetos que componen } \\
\text { la interfaz } \\
\text { autoexplicativos. }\end{array}$ & & & & & \\
\hline $\begin{array}{l}\text { El modelo conceptual } \\
\text { proporcionado } \\
\text { adecuado. }\end{array}$ & & & & \\
\hline
\end{tabular}

b. Comentario del evaluador: 


\subsubsection{Forma de aplicación con escenarios}

A continuación se detallan los escenarios utilizados por el evaluador, en calidad de docente y de alumno.

\begin{tabular}{|c|c|c|c|c|}
\hline \multirow[t]{2}{*}{ Personaje } & \multirow[t]{2}{*}{ Escenario } & \multirow[t]{2}{*}{ Tarea } & \multicolumn{2}{|c|}{ Contexto de uso } \\
\hline & & & Particular & General \\
\hline \multirow[t]{4}{*}{$\begin{array}{l}\text { Fabio } \\
\text { Responsable }\end{array}$} & EDR1.1 & $\begin{array}{l}\text { Acceder al aula virtual. } \\
\text { Dar un mensaje de bienvenida a } \\
\text { todos los alumnos. } \\
\text { Informar a todos sobre el calendario } \\
\text { de actividades del primer módulo. } \\
\text { Distribuir alumnos en comisiones de } \\
\text { trabajo } \\
\text { Incorporar los materiales de estudio } \\
\text { del primer módulo. } \\
\text { Comunicarse con los dos tutores } \\
\text { mediante correo. }\end{array}$ & \multirow{2}{*}{$\begin{array}{l}\text { Docente de primer } \\
\text { año a cargo de la } \\
\text { asignatura Análisis } \\
\text { Matemático I bajo las } \\
\text { dos modalidades: } \\
\text { presencial y no } \\
\text { presencial. } \\
\text { Hace docencia desde } \\
\text { su oficina de la } \\
\text { Facultad. } \\
\text { Posee PC de } \\
\text { escritorio con Internet } \\
\text { con banda ancha. } \\
\text { Con experiencia en el } \\
\text { uso PC e Internet. } \\
\text { Accede a } \\
\text { periódicamente al } \\
\text { aula virtual. }\end{array}$} & \multirow{6}{*}{ 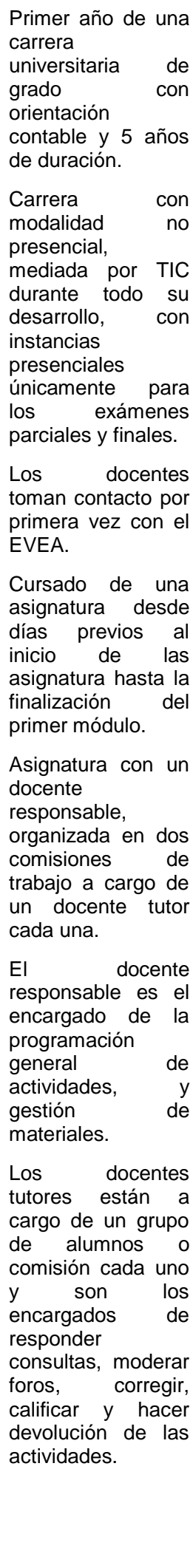 } \\
\hline & EDR2.1 & $\begin{array}{l}\text { Acceder al aula virtual. } \\
\text { Informarse sobre la situación de } \\
\text { cada grupo de trabajo. } \\
\text { Comunicarse con un tutor mediante } \\
\text { correo. }\end{array}$ & & \\
\hline & EDR3.1 & $\begin{array}{l}\text { Acceder al aula virtual. } \\
\text { Realizar el seguimiento de la } \\
\text { actividad de cada grupo de trabajo. } \\
\text { Analizar la participación y frecuencia } \\
\text { de acceso de cada tutor. } \\
\text { Consultar correo. } \\
\text { Consultar foro. } \\
\text { Actualizar el calendario de } \\
\text { actividades. }\end{array}$ & & \\
\hline & EDR4.1 & $\begin{array}{l}\text { Acceder al aula virtual. } \\
\text { Informarse sobre las actividades } \\
\text { entregadas por cada uno los } \\
\text { alumnos, calificaciones y } \\
\text { devoluciones. } \\
\text { Informar a todos sobre el calendario } \\
\text { de actividades del segundo módulo. } \\
\text { Incorporar los materiales de estudio } \\
\text { del segundo módulo. }\end{array}$ & & \\
\hline \multirow[t]{2}{*}{$\begin{array}{l}\text { Nahuel } \\
\text { Tutor }\end{array}$} & EDT1.1 & $\begin{array}{l}\text { Acceder al aula virtual } \\
\text { Informarse sobre la bienvenida, } \\
\text { programación de actividades, y } \\
\text { grupo de alumnos que tiene a } \\
\text { cargo. } \\
\text { Acceder a los materiales de estudio. } \\
\text { Abrir un foro y agregar aporte. } \\
\text { Consultar correo. } \\
\text { Publicar la actividad evaluable para } \\
\text { todos sus alumnos y la fecha } \\
\text { máxima de entrega. }\end{array}$ & \multirow[t]{2}{*}{$\begin{array}{l}\text { Docente de primer } \\
\text { año a cargo de los } \\
\text { trabajos prácticos de } \\
\text { la asignatura Análisis } \\
\text { Matemático I bajo las } \\
\text { dos modalidades: } \\
\text { presencial y no } \\
\text { presencial. } \\
\text { Hace docencia desde } \\
\text { su oficina de la } \\
\text { Facultad. } \\
\text { Tiene contacto } \\
\text { presencial con el } \\
\text { docente responsable } \\
\text { de la asignatura. }\end{array}$} & \\
\hline & EDT2.1 & $\begin{array}{l}\text { Acceder al aula virtual } \\
\text { Informarse sobre quienes no } \\
\text { ingresaron al aula o no descargaron } \\
\text { los materiales. }\end{array}$ & & \\
\hline
\end{tabular}




\begin{tabular}{|c|c|c|c|c|}
\hline & & $\begin{array}{l}\text { Enviar correo a los alumnos que no } \\
\text { han comenzado a trabajar. } \\
\text { Responder aportes del foro. } \\
\text { Responder correo de algunos } \\
\text { alumnos. } \\
\text { Incorporar materiales de estudio } \\
\text { complementario del primer módulo. } \\
\text { Publicar un mensaje para todos los } \\
\text { alumnos. }\end{array}$ & $\begin{array}{l}\text { escritorio con Internet } \\
\text { con banda ancha. } \\
\text { Con experiencia en el } \\
\text { uso PC e Internet. } \\
\text { Accede } \\
\text { periódicamente al } \\
\text { aula virtual. }\end{array}$ & \\
\hline & EDT3.1 & $\begin{array}{l}\text { Acceder al aula virtual. } \\
\text { Informarse sobre la situación de } \\
\text { cada alumno. } \\
\text { Corregir trabajos. } \\
\text { Publicar un mensaje para todos los } \\
\text { alumnos. }\end{array}$ & & \\
\hline & EDT4.1 & $\begin{array}{l}\text { Acceder al aula virtual } \\
\text { Informarse sobre la situación de } \\
\text { cada alumno. } \\
\text { Calificar todos los trabajos. } \\
\text { Realizar una devolución individual. } \\
\text { Publicar un mensaje para todos los } \\
\text { alumnos. }\end{array}$ & & \\
\hline \multirow[t]{4}{*}{$\begin{array}{l}\text { Julián } \\
\text { Tutor }\end{array}$} & EDT1.2 & $\begin{array}{l}\text { Acceder al aula virtual. } \\
\text { Consultar el correo y responder } \\
\text { mensaje al responsable. } \\
\text { Informarse sobre la programación } \\
\text { de actividades, y grupo de alumnos } \\
\text { que tiene a cargo. } \\
\text { Acceder a los materiales de estudio. } \\
\text { Abrir un foro y agregar aporte. } \\
\text { Publicar la actividad evaluable para } \\
\text { todos sus alumnos y la fecha } \\
\text { máxima de entrega. }\end{array}$ & \multirow{4}{*}{$\begin{array}{l}\text { Docente de primer } \\
\text { año a cargo de los } \\
\text { trabajos prácticos de } \\
\text { la asignatura Análisis } \\
\text { Matemático I bajo las } \\
\text { dos modalidades: } \\
\text { presencial y no } \\
\text { presencial. } \\
\text { Hace docencia desde } \\
\text { otra ciudad por } \\
\text { encontrarse en un } \\
\text { Congreso. } \\
\text { No tiene contacto } \\
\text { presencial con el } \\
\text { resto de los docentes } \\
\text { de la asignatura. } \\
\text { Acceder a Internet } \\
\text { desde un hotel. } \\
\text { Con experiencia en el } \\
\text { uso PC e Internet. } \\
\text { Accede dos veces por } \\
\text { semana al aula } \\
\text { virtual, no no } \\
\text { periódicamente. }\end{array}$} & \\
\hline & EDT2.2 & $\begin{array}{l}\text { Acceder al aula virtual } \\
\text { Informarse sobre la situación de } \\
\text { cada alumno. } \\
\text { Consultar correo y responder a un } \\
\text { alumno. } \\
\text { Extender plazo de entrega de la } \\
\text { actividad a un alumno. }\end{array}$ & & \\
\hline & EDT3.2 & $\begin{array}{l}\text { Acceder al aula virtual. } \\
\text { Informarse sobre la situación de } \\
\text { cada alumno. } \\
\text { Corregir trabajos. } \\
\text { Solicitar a un alumno rehacer el } \\
\text { trabajo. }\end{array}$ & & \\
\hline & EDT4.2 & $\begin{array}{l}\text { Acceder al aula virtual. } \\
\text { Informarse sobre la situación de } \\
\text { cada alumno. } \\
\text { Calificar todos los trabajos. } \\
\text { Publicar un mensaje para todos los } \\
\text { alumnos. }\end{array}$ & & \\
\hline Ana & EA1.1 & Acceder al aula virtual. & Alumna de primer & Primer año de una \\
\hline
\end{tabular}




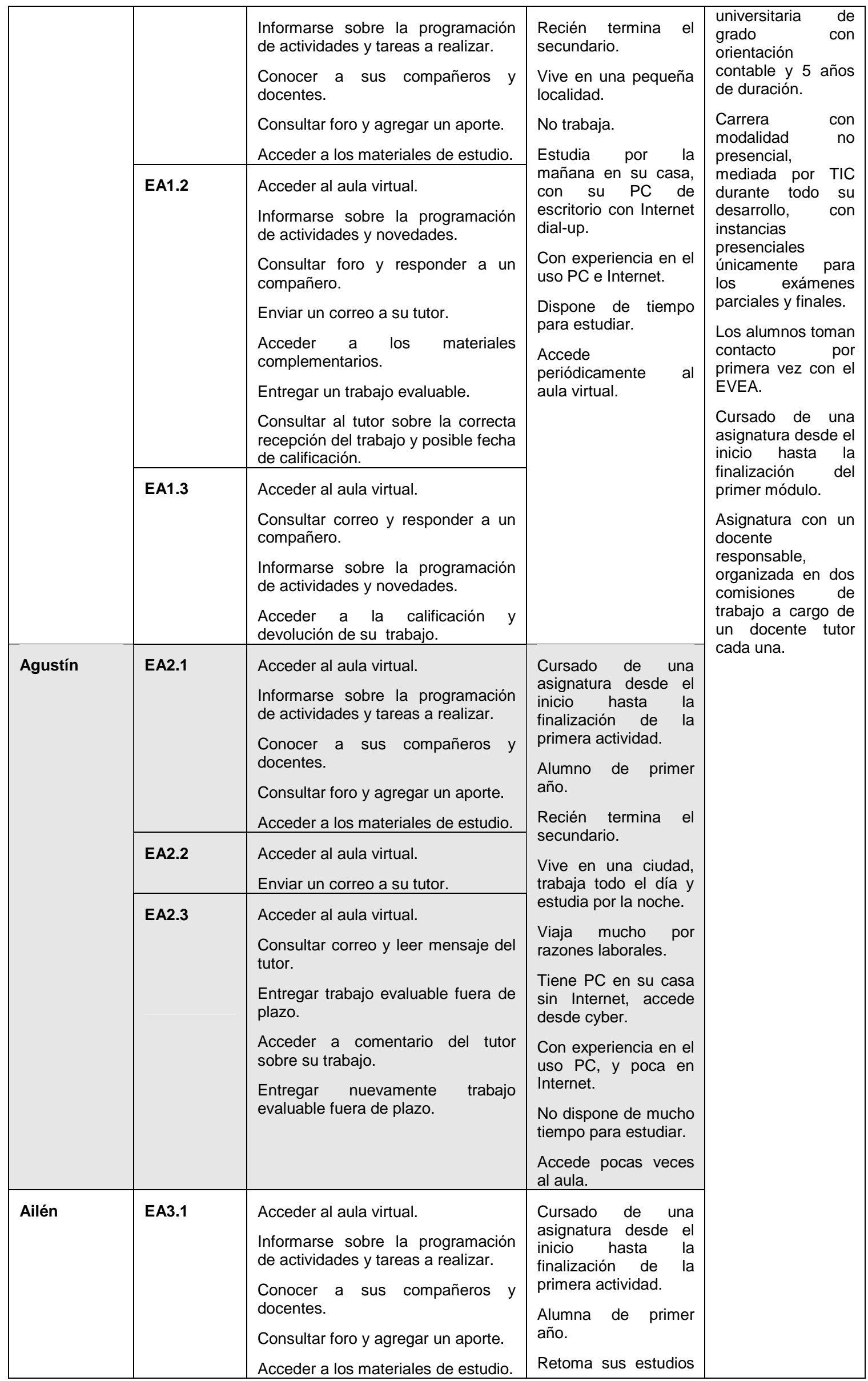




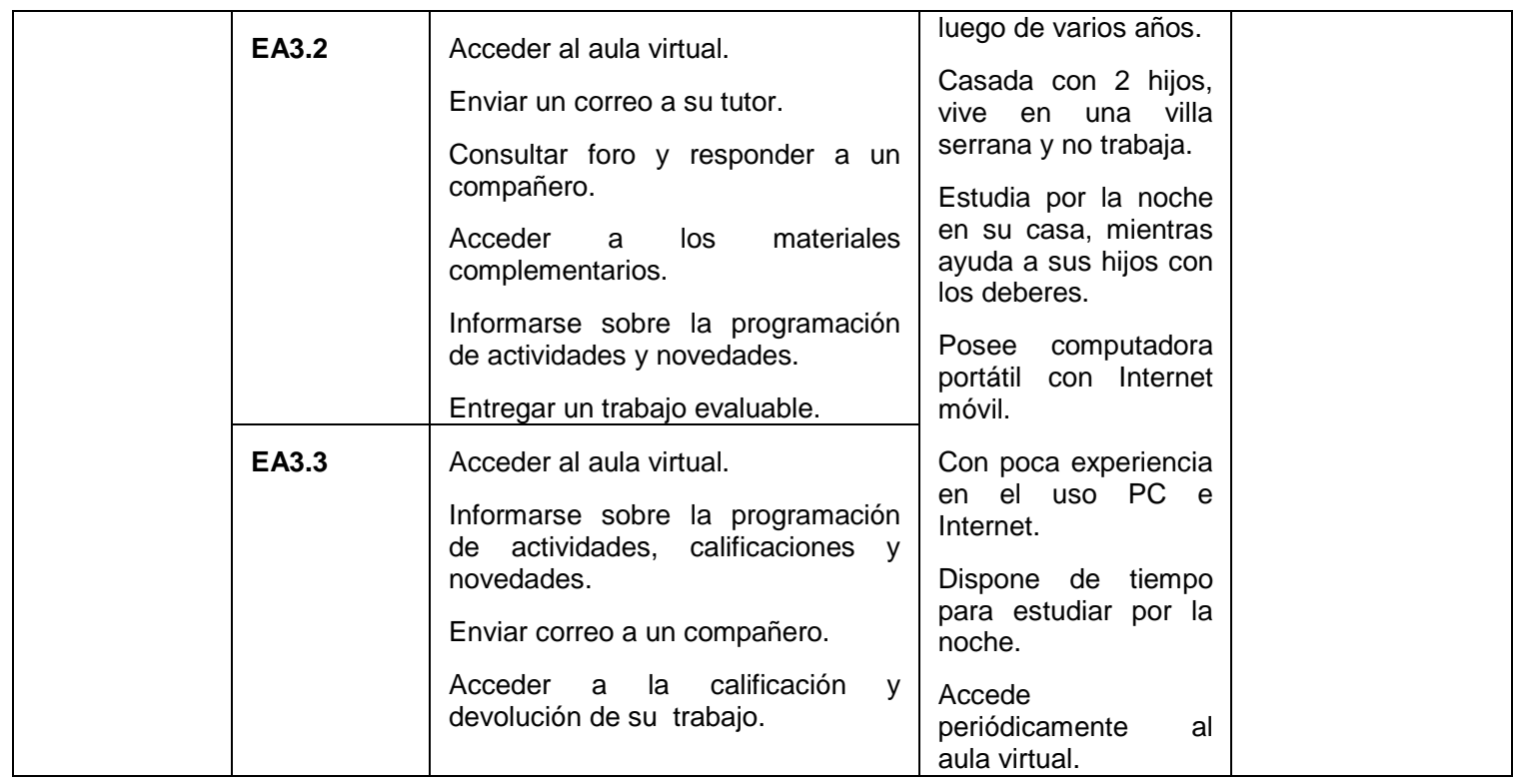

\subsection{Cuestionario}

ESCENARIO DE USO: Indicar el escenario evaluado

\section{Puntos a EVALUAR}

\section{Complejidad}

a. La complejidad de la tarea resultó:

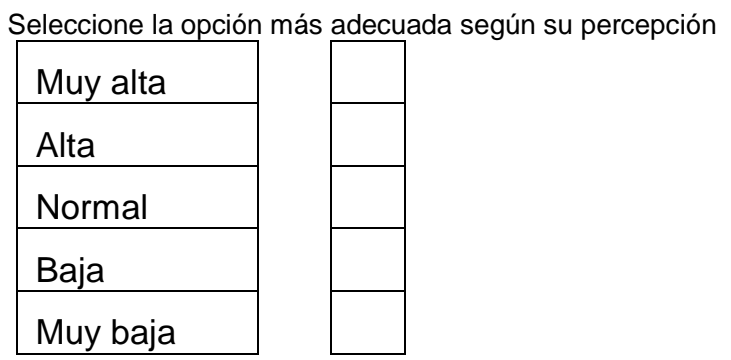

b. Responda las siguientes preguntas:

¿Debió tomar decisiones sobre cómo realizar la tarea debido a la posibilidad de hacerlo de diferentes formas?¿Cuáles?

¿Podría realizar una descripción de la secuencia de pasos recorridos para efectuar la tarea. 


\section{Visibilidad}

a. Complete la siguiente grilla:

\begin{tabular}{|l|l|l|l|l|l|}
\hline & $\begin{array}{c}\text { Muy de } \\
\text { acuerdo }\end{array}$ & $\begin{array}{c}\text { De } \\
\text { acuerdo }\end{array}$ & Indiferente & $\begin{array}{c}\text { En } \\
\text { desacuerdo }\end{array}$ & $\begin{array}{c}\text { Muy en } \\
\text { desacuerdo }\end{array}$ \\
\hline $\begin{array}{l}\text { En la interfaz aparece la } \\
\text { información justa y } \\
\text { necesaria para la } \\
\text { realización de la tarea. }\end{array}$ & & & & & \\
\hline $\begin{array}{l}\text { Se encuentra fácilmente la } \\
\text { forma de realizar la tarea. }\end{array}$ & & & & & \\
\hline $\begin{array}{l}\text { La información de contexto } \\
\text { y orientación es adecuada. }\end{array}$ & & & & & \\
\hline $\begin{array}{l}\text { El diseño es intuitivo y } \\
\text { existen señales que } \\
\text { indican de manera natural } \\
\text { lo que se debe hacer. }\end{array}$ & & & & & \\
\hline $\begin{array}{l}\text { Solo están disponibles las } \\
\text { acciones posibles en cada } \\
\text { momento. }\end{array}$ & & & & & \\
\hline $\begin{array}{l}\text { La información se } \\
\text { encuentra jerarquizada } \\
\text { para distinguir claramente } \\
\text { lo más relevante. }\end{array}$ & & & & & \\
\hline
\end{tabular}

b. Comentario del evaluador:

\section{Intuitividad y Topografía Natural}

a. Complete la siguiente grilla:

\begin{tabular}{|l|l|l|l|l|l|}
\hline & $\begin{array}{c}\text { Muy de } \\
\text { acuerdo }\end{array}$ & $\begin{array}{c}\text { De } \\
\text { acuerdo }\end{array}$ & Indiferente & $\begin{array}{c}\text { En } \\
\text { desacuerdo }\end{array}$ & $\begin{array}{c}\text { Muy en } \\
\text { desacuerdo }\end{array}$ \\
\hline $\begin{array}{l}\text { No hace falta recordar } \\
\text { información para volver a } \\
\text { realizar la tarea. }\end{array}$ & & & & \\
\hline $\begin{array}{l}\text { Hay analogías con el } \\
\text { mundo real u otros } \\
\text { sistemas e interfaces que } \\
\text { generan familiaridad. }\end{array}$ & & & & & \\
\hline $\begin{array}{l}\text { Los objetos que componen } \\
\text { la interfaz son }\end{array}$ & & & & & \\
\hline
\end{tabular}


autoexplicativos.

El modelo conceptual

proporcionado

adecuado.

es

b. Comentario del evaluador: 


\subsection{Anexo D}

\section{Capa 2}

\subsubsection{Introducción}

El cuestionario que se provee a los expertos para realizar el proceso de evaluación orientado al diseño posee la lista de principios heurísticos. Cada heurística es acompañada por el nivel de conformidad alcanzado según el criterio del evaluador, más un comentario que lo justifique en caso de ser necesario u oportuno. La conformidad es medida a través del método Likert [Tro02], con una escala ordinal de 1 a 5 puntos, cuyo valor inferior (1) representa que la conformidad nunca fue alcanzada, y el valor superior (5) que siempre lo fue.

\subsubsection{Cuestionario para evaluación en detalle orientada al diseño}

\begin{tabular}{|l|l|l|}
\hline \multicolumn{1}{|c|}{ Heurística } & Comentario \\
& $\begin{array}{l}\text { Conformidad } \\
\text { 1. Nunca } \\
\text { 2. Casi nunca } \\
\text { 3. A veces } \\
\text { 4. Casi siempre } \\
\text { 5. Siempre }\end{array}$ & \\
\hline Productividad & \\
\hline $\begin{array}{l}\text { Las tareas habituales son de fácil } \\
\text { realización. }\end{array}$ & \\
\hline $\begin{array}{l}\text { Los usuarios frecuentes o expertos } \\
\text { tienen posibilidad de realizar las } \\
\text { tareas reduciendo el número de } \\
\text { interacciones con el EVEA. }\end{array}$ & \\
\hline $\begin{array}{l}\text { Existen mecanismos para realizar } \\
\text { tareas masivas. }\end{array}$ & \\
\hline $\begin{array}{l}\text { El EVEA provee el usuario de } \\
\text { recordatorios o avisos sobre cambios } \\
\text { producidos a partir del último ingreso. }\end{array}$ & \\
\hline $\begin{array}{l}\text { Los atajos de teclado están siempre } \\
\text { disponibles. }\end{array}$ & \\
\hline $\begin{array}{l}\text { El EVEA soporta tanto usuarios } \\
\text { expertos como novicios presentando } \\
\text { múltiples niveles de detalle } \\
\text { disponibles. }\end{array}$ & \\
\hline $\begin{array}{l}\text { En cada pantalla o una caja de diálogo } \\
\text { el cursor está posicionado en el } \\
\text { campo que más probablemente el } \\
\text { usuario vaya a necesitar. }\end{array}$ & \\
\hline $\begin{array}{l}\text { El método para mover el cursor al } \\
\text { campo siguiente o previo es simple ya } \\
\text { la vez visible. }\end{array}$ & \\
\hline $\begin{array}{l}\text { El EVEA anticipa y avisa al usuario } \\
\text { correctamente acerca de la próxima }\end{array}$ & \\
\end{tabular}




\begin{tabular}{|c|c|c|}
\hline actividad que sea más probable. & & \\
\hline \multicolumn{3}{|l|}{ Retroalimentación } \\
\hline \multicolumn{3}{|l|}{$\begin{array}{l}\text { El resultado de cada acción realizada } \\
\text { por el usuario es informado. }\end{array}$} \\
\hline \multicolumn{3}{|l|}{$\begin{array}{l}\text { Los resultados exitosos son } \\
\text { informados de manera diferente a los } \\
\text { fracasos. }\end{array}$} \\
\hline \multicolumn{3}{|l|}{$\begin{array}{l}\text { Las acciones frecuentes y de poca } \\
\text { importancia son informadas de } \\
\text { manera modesta. }\end{array}$} \\
\hline \multicolumn{3}{|l|}{$\begin{array}{l}\begin{array}{l}\text { Las acciones infrecuentes } \\
\text { importantes son } \\
\text { informadas } \\
\text { manera elocuente. }\end{array} \\
\end{array}$} \\
\hline \multicolumn{3}{|l|}{$\begin{array}{l}\text { Los errores producidos son } \\
\text { informados claramente al usuario, de } \\
\text { forma no alarmista, y con sugerencias } \\
\text { de de cómo solucionar el problema. }\end{array}$} \\
\hline \multicolumn{3}{|l|}{ Control por parte del usuario } \\
\hline \multicolumn{3}{|l|}{$\begin{array}{l}\text { Los efectos de los actos realizados } \\
\text { son predecibles. }\end{array}$} \\
\hline \multicolumn{3}{|l|}{$\begin{array}{l}\text { El usuario es } r \text { informado } \\
\text { constantemente sobre lo que está } \\
\text { ocurriendo (mensajes, } \\
\text { estimado, barra de progreso). }\end{array}$} \\
\hline \multicolumn{3}{|l|}{$\begin{array}{l}\text { Se informa al usuario de lo que ha } \\
\text { pasado }\end{array}$} \\
\hline \multicolumn{3}{|l|}{$\begin{array}{l}\text { El usuario posee autonomía y libertad } \\
\text { para actuar }\end{array}$} \\
\hline \multicolumn{3}{|l|}{$\begin{array}{l}\text { El usuario controla el sistema en todo } \\
\text { momento. }\end{array}$} \\
\hline \multicolumn{3}{|l|}{$\begin{array}{l}\text { Se pregunta al usuario que confirme } \\
\text { acciones que tendrán consecuencias } \\
\text { drásticas, negativas o destructivas. }\end{array}$} \\
\hline \multicolumn{3}{|l|}{$\begin{array}{l}\text { Los usuarios pueden reducir el tiempo } \\
\text { de entrada de datos copiando y } \\
\text { modificando datos existentes. }\end{array}$} \\
\hline \multicolumn{3}{|l|}{$\begin{array}{l}\text { El usuario puede cancelar cualquier } \\
\text { acción. }\end{array}$} \\
\hline \multicolumn{3}{|l|}{$\begin{array}{l}\text { Todas las páginas disponen de un } \\
\text { punto de salida. }\end{array}$} \\
\hline \multicolumn{3}{|l|}{ Reversibilidad y Manejo del error } \\
\hline \multicolumn{3}{|l|}{$\begin{array}{l}\text { Existe una forma de deshacer al nivel } \\
\text { de cada acción simple, cada entrada } \\
\text { de datos y cada grupo de acciones } \\
\text { completadas. }\end{array}$} \\
\hline \multicolumn{3}{|l|}{$\begin{array}{l}\text { Los usuarios pueden cancelar } \\
\text { operaciones en progreso }\end{array}$} \\
\hline Los mensajes de error son visibles & & \\
\hline
\end{tabular}




\begin{tabular}{|c|c|c|}
\hline \\
\hline \multicolumn{3}{|l|}{$\begin{array}{l}\text { Los mensajes de error son claros } \\
\text { Los mensajes de error describen } \\
\text { acciones para remediar el problema }\end{array}$} \\
\hline \multicolumn{3}{|l|}{$\begin{array}{l}\text { Los mensajes de error proporcionan el } \\
\text { contacto de la asistencia }\end{array}$} \\
\hline \multicolumn{3}{|l|}{$\begin{array}{l}\text { Los mensajes de error proporcionan } \\
\text { un punto de salida }\end{array}$} \\
\hline \multicolumn{3}{|l|}{$\begin{array}{l}\text { Los usuarios pueden revertir sus } \\
\text { acciones de manera sencilla }\end{array}$} \\
\hline \multicolumn{3}{|l|}{$\begin{array}{l}\text { Los mensajes de error están } \\
\text { expresado de manera tal que es el } \\
\text { sistema, y no el usuario, quien se } \\
\text { hace cargo de los errores }\end{array}$} \\
\hline \multicolumn{3}{|l|}{$\begin{array}{l}\text { Los mensajes de error evitan el uso de } \\
\text { signos de admiración, palabras } \\
\text { violentas u hostiles }\end{array}$} \\
\hline \multicolumn{3}{|l|}{$\begin{array}{l}\text { el sistema informa el lugar donde } \\
\text { detecta errores de entrada de datos }\end{array}$} \\
\hline \multicolumn{3}{|l|}{$\begin{array}{l}\text { Los mensajes de error informan al } \\
\text { usuario sobre la severidad del error } \\
\text { cometido }\end{array}$} \\
\hline \multicolumn{3}{|l|}{$\begin{array}{l}\text { Los mensajes de error sugieren la } \\
\text { causa del problema que los ha } \\
\text { ocasionado }\end{array}$} \\
\hline \multicolumn{3}{|l|}{$\begin{array}{l}\text { Los mensajes de error indican que } \\
\text { acción debe realizar el usuario para } \\
\text { corregir el error correspondiente }\end{array}$} \\
\hline \multicolumn{3}{|l|}{$\begin{array}{l}\text { El sistema previene a los usuarios de } \\
\text { cometer errores siempre que esto es } \\
\text { posible }\end{array}$} \\
\hline \multicolumn{3}{|l|}{$\begin{array}{l}\text { El sistema alerta a los usuarios si } \\
\text { están a punto de cometer un error } \\
\text { potencialmente serio }\end{array}$} \\
\hline $\begin{array}{l}\text { Las entradas de datos } \\
\text { valores pontienen } \\
\text { corresponde }\end{array}$ & & \\
\hline \multicolumn{3}{|l|}{ Diseño y organización } \\
\hline \multicolumn{3}{|l|}{$\begin{array}{l}\text { Es posible comprender rápidamente } \\
\text { cual es la estructura organizativa y el } \\
\text { contenido. }\end{array}$} \\
\hline \multicolumn{3}{|l|}{$\begin{array}{l}\text { Solo están visibles las acciones que } \\
\text { tienen un fin específico }\end{array}$} \\
\hline \multicolumn{3}{|l|}{$\begin{array}{l}\text { Es posible predecir los efectos de los } \\
\text { actos realizados }\end{array}$} \\
\hline $\begin{array}{l}\text { Existe orientación y ayuda de forma } \\
\text { implícita al usuario sobre lo que se } \\
\text { debe hacer }\end{array}$ & & \\
\hline
\end{tabular}




\begin{tabular}{|c|c|c|}
\hline \multicolumn{3}{|l|}{ Es posible editar y ver el aspecto real } \\
\hline $\begin{array}{l}\text { La información esencial para tomar } \\
\text { decisiones es mostrada en la pantalla }\end{array}$ & & \\
\hline $\begin{array}{l}\text { El sistema se anticipa a las } \\
\text { necesidades del usuario }\end{array}$ & & \\
\hline $\begin{array}{l}\text { Se muestra el trabajo pendiente en } \\
\text { tareas complejas o de varias etapas }\end{array}$ & & \\
\hline $\begin{array}{l}\text { Las información y acciones } \\
\text { relacionada está agrupada }\end{array}$ & & \\
\hline $\begin{array}{l}\text { La información importante se } \\
\text { encuentra resaltada en la parte } \\
\text { superior de las páginas }\end{array}$ & & \\
\hline $\begin{array}{l}\text { El tipo de fuente, efectos tipográficos, } \\
\text { ancho de línea y alineación } \\
\text { empleados facilitan la lectura }\end{array}$ & & \\
\hline $\begin{array}{l}\text { Los párrafos son breves y el lenguaje } \\
\text { sencillo }\end{array}$ & & \\
\hline $\begin{array}{l}\text { La longitud de las páginas evita el } \\
\text { scroll o posibilita ver lo más importante } \\
\text { sin necesidad de realizar acciones } \\
\text { adicionales }\end{array}$ & & \\
\hline $\begin{array}{l}\text { Los enlaces están siempre visibles, } \\
\text { indican su estado, y no hay enlaces } \\
\text { rotos }\end{array}$ & & \\
\hline No hay elementos distractores & & \\
\hline $\begin{array}{l}\text { La cantidad de imágenes es reducida } \\
\text { y ayudan a comunicar mejor el } \\
\text { mensaje }\end{array}$ & & \\
\hline $\begin{array}{l}\text { Se controla que el tamaño y } \\
\text { resolución de las imágenes }\end{array}$ & & \\
\hline $\begin{array}{l}\text { El diseño general es atractivo y } \\
\text { uniforme, sin exceso de texto ni de } \\
\text { imágenes }\end{array}$ & & \\
\hline Los colores son armónicos & & \\
\hline $\begin{array}{l}\text { Hay un mapa del sitio y posibilita } \\
\text { orientarse rápidamente }\end{array}$ & & \\
\hline $\begin{array}{l}\text { Se mantiene un equilibrio entre } \\
\text { profundidad y anchura }\end{array}$ & & \\
\hline $\begin{array}{l}\text { Existen elementos que permiten al } \\
\text { usuario estar siempre orientado y } \\
\text { tener el control de su navegación }\end{array}$ & & \\
\hline $\begin{array}{l}\text { Existen zonas de descanso visual } \\
\text { entre los objetos informativos de la } \\
\text { página }\end{array}$ & & \\
\hline $\begin{array}{l}\text { La velocidad de renovación de cada } \\
\text { página adecuada y evita que el } \\
\text { usuario se impaciente o distraiga }\end{array}$ & & \\
\hline Consistencia & & \\
\hline
\end{tabular}




\begin{tabular}{|c|c|c|}
\hline \multicolumn{3}{|l|}{$\begin{array}{l}\text { La misma palabra o expresión se } \\
\text { utiliza siempre para describir el mismo } \\
\text { ítem }\end{array}$} \\
\hline $\begin{array}{l}\text { El título de página en el navegador es } \\
\text { significativo y refleja el título de la } \\
\text { página principal }\end{array}$ & & \\
\hline \multicolumn{3}{|l|}{ Los enlaces son claros } \\
\hline \multicolumn{3}{|l|}{$\begin{array}{l}\text { Cada enlace refleja el título de la } \\
\text { página a la que se refiere }\end{array}$} \\
\hline \multicolumn{3}{|l|}{$\begin{array}{l}\text { Los íconos son entendibles y aportan } \\
\text { significado }\end{array}$} \\
\hline \multicolumn{3}{|l|}{$\begin{array}{l}\text { Las secuencias constantes de } \\
\text { acciones se repiten en situaciones } \\
\text { similares }\end{array}$} \\
\hline \multicolumn{3}{|l|}{$\begin{array}{l}\text { Los comandos constantes se emplean } \\
\text { en todas partes del mismo modo }\end{array}$} \\
\hline \multicolumn{3}{|l|}{$\begin{array}{l}\text { Se utiliza siempre la misma } \\
\text { terminología en avisos, menús, y } \\
\text { pantallas de ayuda }\end{array}$} \\
\hline \multicolumn{3}{|l|}{$\begin{array}{l}\text { Los íconos, botones, imágenes, } \\
\text { ventanas y diálogos respetan las } \\
\text { normas y convenciones usuales de la } \\
\text { plataforma Web }\end{array}$} \\
\hline \multicolumn{3}{|l|}{ Ayuda y documentación } \\
\hline \multicolumn{3}{|l|}{$\begin{array}{l}\text { Se dispone de ayuda en línea, en } \\
\text { lugar visible y orientada a las acciones } \\
\text { del usuario }\end{array}$} \\
\hline \multicolumn{3}{|l|}{$\begin{array}{l}\text { Existe ayuda contextual en tareas } \\
\text { complejas }\end{array}$} \\
\hline \multicolumn{3}{|l|}{$\begin{array}{l}\text { Los usuarios pueden cambiar } \\
\text { fácilmente entre la ayuda y su trabajo }\end{array}$} \\
\hline \multicolumn{3}{|l|}{$\begin{array}{l}\text { Existe una mesa de ayuda o soporte } \\
\text { técnico permanente }\end{array}$} \\
\hline \multicolumn{3}{|l|}{$\begin{array}{l}\text { Existen manuales, foros, respuesta a } \\
\text { preguntas frecuentes etc. }\end{array}$} \\
\hline \multicolumn{3}{|l|}{$\begin{array}{l}\text { La documentación disponible es } \\
\text { suficiente }\end{array}$} \\
\hline \multicolumn{3}{|l|}{ Hay un buscador interno disponible } \\
\hline \multicolumn{3}{|l|}{$\begin{array}{l}\text { El buscador interno posibilita realizar } \\
\text { búsquedas avanzadas }\end{array}$} \\
\hline \multicolumn{3}{|l|}{$\begin{array}{l}\text { Los resultados de la búsqueda se } \\
\text { muestras de forma comprensible para } \\
\text { el usuario }\end{array}$} \\
\hline \multicolumn{3}{|l|}{ Estándares } \\
\hline $\begin{array}{l}\text { Es posible usarlo sin necesidad de } \\
\text { descargar elementos adicionales } \\
\text { como plug-ins }\end{array}$ & & \\
\hline
\end{tabular}




\begin{tabular}{|l|l|l|}
\hline $\begin{array}{l}\text { En caso de requerir elementos } \\
\text { adicionales el usuario es informado de } \\
\text { dicha situación }\end{array}$ & \\
\hline $\begin{array}{l}\text { En caso de requerir elementos } \\
\text { adicionales aparece algún contenido } \\
\text { alternativo }\end{array}$ & & \\
\hline $\begin{array}{l}\text { En caso de requerir elementos } \\
\text { adicionales, éstos son universales }\end{array}$ & & \\
\hline $\begin{array}{l}\text { El usuario puede aumentar o reducir el } \\
\text { tamaño de fuente según su necesidad }\end{array}$ & & \\
\hline $\begin{array}{l}\text { Todas las imágenes describen su } \\
\text { contenido mediante el atributo 'alt' }\end{array}$ & & \\
\hline $\begin{array}{l}\text { Se respetan los estándares de la W3C } \\
\text { (HTML, CSS, XHTML, WCAG) }\end{array}$ & \\
\hline $\begin{array}{l}\text { Se visualiza correctamente con } \\
\text { cualquier sistema operativo }\end{array}$ & \\
\hline $\begin{array}{l}\text { Se visualiza correctamente con } \\
\text { cualquier navegador y versión de uso } \\
\text { corriente }\end{array}$ & & \\
\hline $\begin{array}{l}\text { Se visualiza correctamente con } \\
\text { diferentes resoluciones de pantalla }\end{array}$ & & \\
\hline $\begin{array}{l}\text { Los contenidos pueden visualizarse } \\
\text { sin necesidad de descarga }\end{array}$ & \\
\hline $\begin{array}{l}\text { Es posible imprimir correctamente o } \\
\text { generar un documento PDF por cada } \\
\text { página }\end{array}$ & \\
\hline
\end{tabular}




\subsection{Anexo F}

\section{Capa 3}

\subsubsection{Introducción}

El test de expresión del usuario en base a preguntas perteneciente a la Capa 3 está compuesto por dos cuestionarios, uno destinado al usuario final, para la evaluación directa, y otro al observador, para la evaluación indirecta.

\subsubsection{Usuarios finales}

El usuario final debe situarse en cada escenario e interactuar con el entorno realizando tareas como si estuviera participando de un curso. Luego de concluida la sesión de evaluación debe completar un cuestionario por cada escenario.

\subsubsection{Cuestionario para evaluación directa orientado a la tarea}

ESCENARIO DE USO: Indicar el escenario evaluado

\section{Puntos a EVALUAR}

\section{Complejidad}

La complejidad de la tarea resultó:

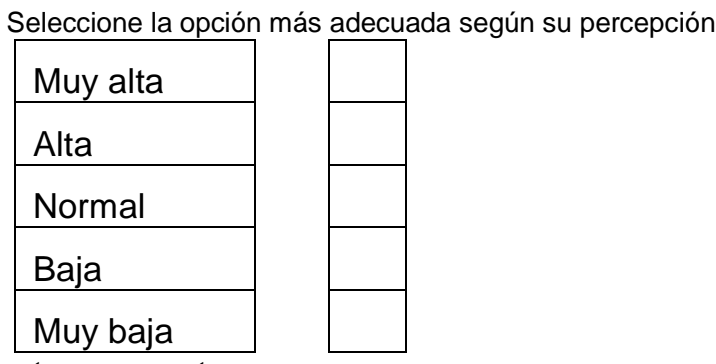

- Responda las siguientes preguntas:

¿Debió tomar decisiones sobre cómo realizar la tarea debido a la posibilidad de hacerlo de diferentes formas? ¿Cuáles?

¿Podría realizar una descripción de la secuencia de pasos recorridos para efectuar la tarea. 


\section{Visibilidad}

- Complete la siguiente grilla:

\begin{tabular}{|c|c|c|c|c|c|}
\hline & $\begin{array}{l}\text { Muy de } \\
\text { acuerdo }\end{array}$ & De acuerdo & Indiferente & $\begin{array}{c}\text { En } \\
\text { desacuerdo }\end{array}$ & $\begin{array}{c}\text { Muy en } \\
\text { desacuerdo }\end{array}$ \\
\hline $\begin{array}{ll}\text { En la interfaz aparece la } \\
\text { información justa y } \\
\text { necesaria para la } \\
\text { realización de la tarea. }\end{array}$ & & & & & \\
\hline $\begin{array}{l}\text { Se encuentra fácilmente la } \\
\text { forma de realizar la tarea. }\end{array}$ & & & & & \\
\hline $\begin{array}{l}\text { La información de contexto } \\
\text { y orientación es adecuada. }\end{array}$ & & & & & \\
\hline $\begin{array}{l}\text { El diseño es intuitivo y } \\
\text { existen señales que } \\
\text { indican de manera natural } \\
\text { lo que se debe hacer. }\end{array}$ & & & & & \\
\hline $\begin{array}{l}\text { Solo están disponibles las } \\
\text { acciones posibles en cada } \\
\text { momento. }\end{array}$ & & & & & \\
\hline $\begin{array}{l}\text { La información se } \\
\text { encuentra jerarquizada } \\
\text { para distinguir claramente } \\
\text { lo más relevante. }\end{array}$ & & & & & \\
\hline
\end{tabular}

- Comentario del evaluador:

Intuitividad y Topografía Natural

- Complete la siguiente grilla:

\begin{tabular}{|c|c|c|c|c|c|}
\hline & $\begin{array}{l}\text { Muy de } \\
\text { acuerdo }\end{array}$ & $\begin{array}{c}\text { De } \\
\text { acuerdo }\end{array}$ & Indiferente & $\begin{array}{c}\text { En } \\
\text { desacuerdo }\end{array}$ & $\begin{array}{l}\text { Muy en } \\
\text { desacuer } \\
\text { do }\end{array}$ \\
\hline $\begin{array}{l}\text { No hace falta recordar } \\
\text { información para volver a } \\
\text { realizar la tarea. }\end{array}$ & & & & & \\
\hline $\begin{array}{l}\text { Hay analogías con el } \\
\text { mundo real u otros } \\
\text { sistemas e interfaces que } \\
\text { generan familiaridad. }\end{array}$ & & & & & \\
\hline $\begin{array}{l}\text { Los objetos que componen } \\
\text { la interfaz son } \\
\text { autoexplicativos. }\end{array}$ & & & & & \\
\hline $\begin{array}{lr}\text { El modelo } & \text { conceptual } \\
\text { proporcionado } & \text { es } \\
\text { adecuado. } & \end{array}$ & & & & & \\
\hline
\end{tabular}

- Comentario del evaluador: 


\subsubsection{Observadores}

Mientras el usuario realiza las tareas, el observador debe estar presente para registrar lo que éste expresa y realizando preguntas directas cuando lo considere necesario. Durante la sesión el observador debe tomar registro y completar, por cada usuario, la primera parte del cuestionario. Luego de finalizada la misma debe completar la segunda.

En este cuestionario se detallan un conjunto de métricas de usabilidad que intentan medir el grado de efectividad, eficiencia y satisfacción del entorno virtual.

Para utilizar este instrumento debe estimarse el tiempo que le demandaría a un usuario experto completar las tareas de cada escenario. A este tiempo lo denominaremos tiempo experto $_{\text {, }}$ para $\mathrm{i} \in[1 .$. CantEsc], donde CantEsc representa cada uno de los escenarios propuestos (21 en nuestra propuesta). A partir de dichos períodos de tiempo debe determinarse el tiempo aceptable para un usuario novato y para un usuario medio.

Una posibilidad para llevar adelante esta estimación es considerar que un usuario novato tardará a lo sumo el doble que un experto en completar una tarea, mientras que un usuario medio tardará como máximo una vez y media el tiempo de un experto.

Eficiencia usuario novato $=\left(\sum i: 1 \leq i \leq\right.$ CantEsc: $\left.\left(\left(\text { tiempo experto }_{i} / \text { tiempo novato }_{i}\right)^{*} 100\right)\right) /$ CantEsc

Eficiencia usuario medio $=\left(\sum i: 1 \leq i \leq\right.$ CantEsc: $\left.\left(\left(\text { tiempo experto }_{i} / \text { tiempo medio }_{i}\right)^{*} 100\right)\right) /$ CantEsc

Tiempo aceptable usuario novato $=(50<=$ Eficiencia usuario novato $<=100)$

Tiempo aceptable usuario medio $=(66<=$ Eficiencia usuario medio $<=100)$

Sin embargo, esto puede ajustarse de acuerdo a las necesidades, tipos de usuarios, complejidad de las tareas, ausencia de capacitación previa, y experiencias anteriores.

A continuación se presenta la distribución de evaluadores propuesta:

\begin{tabular}{|l|l|l|}
\hline Evaluador & \multicolumn{1}{|c|}{ Rol } & \multicolumn{1}{c|}{ Escenarios } \\
\hline DN1 & Docente Tutor Julián & EDT2.1, EDT2.2, EDT3.2, EDT4.2 \\
\hline DN2 & $\begin{array}{l}\text { Docente Responsable } \\
\text { Fabio }\end{array}$ & EDR1.1, EDR2.1, EDR3.1, EDR4.1 \\
\hline DA1 & Docente Tutor Nahuel & EDT1.1, EDT2.1, EDT3.1, EDT4.1 \\
\hline DA2 & Docente Tutor Nahuel & EDT1.1, EDT2.1, EDT3.1, EDT4.1 \\
\hline AN1 & Alumno Ailén & EA3.1, EA3.2, EA3.3 \\
\hline AN2 & Alumno Ailén & EA3.1, EA3.2, EA3.3 \\
\hline AM1 & Alumno Agustín & EA2.1, EA2.2, EA2.3 \\
\hline AM2 & Alumno Agustín & EA2.1, EA2.2, EA2.3 \\
\hline AA1 & Alumno Ana & EA1.1, EA1.2, EA1.3 \\
\hline AA2 & Alumno Ana & EA1.1, EA1.2, EA1.3 \\
\hline
\end{tabular}


12.5.3.1 Cuestionario para evaluación indirecta de atributos de usabilidad - Observador: 01 / 02 / 03 / 04

Primera Parte

\begin{tabular}{|l|l|l|}
\hline \multicolumn{2}{|l|}{ Usuario observado } & \\
\hline Rol & \\
\hline Escenarios & \\
\hline \multicolumn{2}{|l|}{ Nombre del usuario } & \\
\hline & Observación (Ob), sugerencia (Su), opinión (Op) & Descripción \\
\hline 1. & & \\
\hline 2. & & \\
\hline 3. & & \\
\hline 4. & & \\
\hline 5. & & \\
\hline 6. & & \\
\hline
\end{tabular}

Segunda Parte

\begin{tabular}{|l|l|l|l|l|}
\hline \multicolumn{2}{|c|}{ Efectividad } \\
\hline & & \multicolumn{3}{|c|}{ Escenarios } \\
\cline { 2 - 5 } & & & & \\
\hline Cantidad total de tareas & & & & \\
\hline Cantidad de tareas completadas & & & & \\
\hline
\end{tabular}




\begin{tabular}{|c|c|c|c|c|}
\hline Cantidad de tareas no completadas & & & & \\
\hline $\begin{array}{l}\begin{array}{l}\text { Porcentaje total de } \\
\text { completadas }\end{array} \\
\end{array}$ & \multicolumn{4}{|c|}{$\begin{array}{l}\text { Malo }(0 \% \text { a } 30 \%) \text { - Regular }(31 \% \text { a } 60 \%)- \\
\text { Bueno }(61 \% \text { a } 80 \%) \text { - Muy Bueno }(81 \% \text { a } \\
90 \%) \text { - Excelente }(91 \% \text { a } 100 \%){ }^{*}\end{array}$} \\
\hline \multicolumn{5}{|c|}{ Eficiencia } \\
\hline & \multicolumn{4}{|c|}{ Escenarios } \\
\hline $\begin{array}{l}\text { Tiempo invertido por un experto en } \\
\text { completar todas las tareas }\end{array}$ & & & & \\
\hline $\begin{array}{l}\text { Tiempo invertido por el usuario en } \\
\text { las tareas completadas }\end{array}$ & & & & \\
\hline $\begin{array}{l}\text { Tiempo total invertido por el } \\
\text { usuario en las tareas completadas }\end{array}$ & \multicolumn{4}{|c|}{ Aceptable / No aceptable ${ }^{+}$} \\
\hline Tiempo total de aprendizaje & \multicolumn{4}{|c|}{$\begin{array}{l}\text { Aceptable (hasta un } 10 \% \text { del tiempo total } \\
\text { invertido) / No aceptable (más de un } 10 \% \text { del } \\
\text { tiempo total invertido) }{ }^{*}\end{array}$} \\
\hline $\begin{array}{l}\text { Frecuencia de uso de la ayuda o } \\
\text { documentación }\end{array}$ & \multicolumn{4}{|c|}{$\begin{array}{l}\text { Nunca }(0 \text { veces }) / \text { Pocas (1 a } 4) / \text { Muchas } \\
(\text { más de } 4)^{*}\end{array}$} \\
\hline $\begin{array}{l}\text { Número de intentos y estrategias } \\
\text { alternativas utilizadas hasta lograr } \\
\text { completar las tareas }\end{array}$ & \multicolumn{4}{|c|}{$\begin{array}{l}\text { Aceptable (hasta } 1 \text { por tarea) / No aceptable } \\
\text { (más de } 1 \text { por tarea) }{ }^{*}\end{array}$} \\
\hline $\begin{array}{l}\text { Número de errores cometidos por } \\
\text { el usuario }\end{array}$ & \multicolumn{4}{|c|}{$\begin{array}{l}\text { Aceptable (hasta } 1 \text { por tarea) / No aceptable } \\
\text { (más de } 1 \text { por tarea) }{ }^{*}\end{array}$} \\
\hline $\begin{array}{l}\text { Tiempo total necesario para } \\
\text { recuperarse de errores }\end{array}$ & \multicolumn{4}{|c|}{$\begin{array}{l}\text { Aceptable (hasta un } 10 \% \text { del tiempo total } \\
\text { invertido) / No aceptable (más de un } 10 \% \text { del } \\
\text { tiempo total invertido) * }\end{array}$} \\
\hline \multicolumn{5}{|c|}{ Satisfacción } \\
\hline & EDT1.1 & EDT2.1 & EDT3.1 & EDT4.1 \\
\hline $\begin{array}{l}\text { Número de comentarios negativos } \\
\text { (frustración, enojo) expresados por } \\
\text { el usuario }\end{array}$ & \multicolumn{4}{|c|}{$\begin{array}{l}\text { Ninguno (0 veces) / Pocos (1 a 4) / Muchos } \\
\text { (más de 4)* }\end{array}$} \\
\hline $\begin{array}{l}\text { Número de comentarios positivos } \\
\text { expresados por el usuario }\end{array}$ & \multicolumn{4}{|c|}{$\begin{array}{l}\text { Ninguno (0 veces) / Pocos (1 a 4) / Muchos } \\
\text { (más de } 4)^{*}\end{array}$} \\
\hline Utilidad del producto & \multicolumn{4}{|c|}{$\begin{array}{c}\text { Inútil / Poco útil / Algo útil / Bastante útil / Muy } \\
\text { útil * }\end{array}$} \\
\hline Satisfacción con respecto a las & & echo / P & sfe & Algo \\
\hline
\end{tabular}




\begin{tabular}{|l|c|}
\hline funciones y características & $\begin{array}{c}\text { satisfecho / Bastante satisfecho muy } \\
\text { satisfecho * }\end{array}$ \\
\hline $\begin{array}{l}\text { Percepción de que la tecnología da } \\
\text { soporte a las tareas según las } \\
\text { necesidades del usuario }\end{array}$ & $\begin{array}{c}\text { Nunca / Casi nunca / A veces / Casi siempre / } \\
\text { Siempre * }\end{array}$ \\
\hline
\end{tabular}

+ Tiempo aceptable usuario novato $=(50<=$ Eficiencia usuario novato $<=100)$

${ }^{+}$Tiempo aceptable usuario medio $=(66<=$ Eficiencia usuario medio $<=100)$

* Las escalas de valoración han sido elaboradas en base al tipo de métrica, producto evaluado, y experiencia del tesista. 


\subsection{Anexo G}

\section{Capa 4}

\subsubsection{Introducción}

Para elegir a los usuarios que participarán del test es necesario realizar una invitación a un conjunto de alumnos y docentes. Los interesados deben completar una encuesta autoadministrada de forma on-line para conocer sus características básicas y contexto de uso. De esta manera se determina su nivel de experticia (novato, medio, avanzado) y contexto a los efectos de asignarles un rol adecuado a cada uno.

\subsubsection{Selección de alumnos evaluadores}

Cuestionario para alumnos de primer año de la carrera Licenciatura en Administración de Empresas, modalidad no presencial. Basado en el cuestionario sobre competencias TIC en alumnos universitarios realizado por Llorente Cejudo y Cabero Almenara [Llo08].

\subsubsection{Cuestionario sobre competencias tecnológicas de los alumnos}

- Edad:

- ¿Estado civil?

- ¿Eres mujer? Si/No

- ¿Ama de casa? Si/No

○ ¿Hijos? Si/No ¿Cuántos?

- ¿Trabajas todos los días? Si/No

- ¿Terminaste el secundario el año pasado? Si/No

- ¿Vivís en una localidad con menos de 10.000? Si/No

- ¿Tienes computadora en tu casa? Si/No

○ ¿PC convencional, portátil o ambas?

- ¿Tienes Internet en tu casa?

- ¿Con qué tipo de conexión? Telefónica Dial-up/Telefónica Banda Ancha(ADSL)/Empresa de Cable/Otro

- ¿Tienes Internet móvil? Si/No

- ¿Usas computadoras desde hace más de 2 años? Si/No

- ¿Usas Internet desde hace más de 2 años? Si/No

- ¿Desde donde accedes generalmente a Internet? hogar/cyberlocutorio/trabajo/universidad/cualquier lugar (Wi Fi o celular)

Las preguntas que figuran a continuación poseen una escala de 0 a 10, donde el cero hace referencia a que te sientes completamente ineficaz para realizar lo que se presenta, el 5 te consideras moderadamente competente para realizarlo, y 10 que crees que lo dominas completamente. Además puedes utilizar la opción NC (por si desconoces lo que se te pregunta). Antes de contestar lee con tranquilidad la pregunta, y recuerda que no debes preocuparte por no sentirte muy competente en alguna cuestión. 


\begin{tabular}{|c|c|}
\hline Pregunta & Escala \\
\hline $\begin{array}{l}\text { Tengo conocimientos básicos sobre el } \\
\text { funcionamiento de la computadora. }\end{array}$ & 012345678910 \\
\hline $\begin{array}{l}\text { Sé conectar impresora, cámaras digitales, } \\
\text { filmadoras, etc. a la computadora. }\end{array}$ & 012345678910 \\
\hline $\begin{array}{l}\text { Resuelvo problemas como configurar el correo } \\
\text { electrónico, configurar antivirus, conectarme a } \\
\text { Internet. }\end{array}$ & 012345678910 \\
\hline $\begin{array}{l}\text { Sé usar de forma apropiada combinaciones de } \\
\text { teclas para conseguir signos alfanuméricos y de } \\
\text { puntuación desde el teclado. }\end{array}$ & 012345678910 \\
\hline $\begin{array}{l}\text { Soy capaz de instalar y desinstalar programas } \\
\text { informáticos }\end{array}$ & 012345678910 \\
\hline $\begin{array}{l}\text { Puedo cambiar de formatos los archivos (por } \\
\text { ejemplo convertir un archivo doc a rtf). }\end{array}$ & 012345678910 \\
\hline $\begin{array}{l}\text { Realizo un sencillo documento con un procesador } \\
\text { de texto (Word, Writer, Word perfect, Abiword, etc), } \\
\text { usando formatos básicos de fuente, de párrafo, y } \\
\text { de página. }\end{array}$ & 012345678910 \\
\hline $\begin{array}{l}\text { Sin usar el mouse soy capaz de acceder a un } \\
\text { procesador de texto, escribir una pequeña carta, } \\
\text { mover párrafos de lugar, corregir errores, cambiar } \\
\text { formatos, guardar la carta en el disco de mi } \\
\text { computadora e imprimirla. }\end{array}$ & 012345678910 \\
\hline $\begin{array}{l}\text { Realizo un documento con un procesador de texto } \\
\text { usando técnicas avanzadas del mismo para poner } \\
\text { encabezamiento o pie de página, numeración, } \\
\text { tablas, imágenes. }\end{array}$ & 012345678910 \\
\hline $\begin{array}{l}\text { Sé utilizar los correctores ortográficos de los } \\
\text { procesadores de texto, para editar y revisar mis } \\
\text { trabajos. }\end{array}$ & 012345678910 \\
\hline $\begin{array}{l}\text { Sé diseñar, crear y modificar hojas de cálculo con } \\
\text { algún programa informático (Excel, Calc, Gnumeric, } \\
\text { etc), para propósitos específicos, usando fórmulas } \\
\text { elementales. }\end{array}$ & 012345678910 \\
\hline $\begin{array}{l}\text { Sé diseñar, crear y modificar hojas de cálculo con } \\
\text { algún programa informático para propósitos } \\
\text { específicos, usando formato de celdas, realizar } \\
\text { tablas dinámicas, aplicar filtros, usar fórmulas } \\
\text { complejas y funciones. }\end{array}$ & 012345678910 \\
\hline $\begin{array}{l}\text { Sé usar diferentes programas que incluyen } \\
\text { herramientas para dibujar gráficos. }\end{array}$ & 012345678910 \\
\hline $\begin{array}{l}\text { Sé crear imágenes y gráficos mediante algún } \\
\text { programa informático. }\end{array}$ & 012345678910 \\
\hline $\begin{array}{l}\text { Sé crear clip de audio con algún programa } \\
\text { informático. }\end{array}$ & 012345678910 \\
\hline $\begin{array}{l}\text { Sé crear una presentación multimedia mediante } \\
\text { algún programa, incluyendo imágenes estáticas, }\end{array}$ & 012345678910 \\
\hline
\end{tabular}




\begin{tabular}{|c|c|}
\hline \multirow{2}{*}{\begin{tabular}{|l} 
textos, clip de audio, clip de vídeo. \\
Identifico aspectos de estilos en una presentación \\
(Power Point, Impress), realizada por otra persona.
\end{tabular}} & \\
\hline & 012345678910 \\
\hline $\begin{array}{l}\text { Sé modificar imágenes mediante algún programa } \\
\text { de diseño gráfico (Coreldraw, Photoshop, Gimp, } \\
\text { etc). }\end{array}$ & 012345678910 \\
\hline $\begin{array}{l}\text { Sé comprimir y descomprimir archivos (WinZip, } \\
\text { WinRar, etc). }\end{array}$ & 012345678910 \\
\hline Realizo grabaciones en CD y CVD (Nero, etc.) & 012345678910 \\
\hline $\begin{array}{l}\text { Puedo realizar conversiones de mis archivos a } \\
\text { formato PDF. }\end{array}$ & 012345678910 \\
\hline $\begin{array}{l}\text { Navego por Internet con diferentes navegadores } \\
\text { (Internet Explorer, Mozilla, Opera, Safari, etc). }\end{array}$ & 012345678910 \\
\hline $\begin{array}{l}\text { Navego por Internet de forma paralela con distintas } \\
\text { ventanas o pestañas abiertas al mismo tiempo. }\end{array}$ & 012345678910 \\
\hline $\begin{array}{l}\text { Sé diseñar páginas Web, utilizando algún programa } \\
\text { informático, incluyendo textos, imágenes, tablas. }\end{array}$ & 012345678910 \\
\hline $\begin{array}{l}\text { Sé diseñar páginas Web utilizando algún programa } \\
\text { informático, incluyendo diferentes links, al propio } \\
\text { documento o a otros. }\end{array}$ & 012345678910 \\
\hline $\begin{array}{l}\text { Soy capaz de descargar de Internet, programas, } \\
\text { imágenes, clips de audio. }\end{array}$ & 0123456 \\
\hline $\begin{array}{l}\text { Soy capaz de utilizar diferentes buscadores de } \\
\text { Internet (Google, Yahoo, Altavista). }\end{array}$ & 012345678910 \\
\hline $\begin{array}{l}\text { Soy capaz de utilizar las opciones de búsqueda } \\
\text { avanzada en diferentes buscadores de Internet } \\
\text { para refinar la búsqueda de información. }\end{array}$ & 012345678910 \\
\hline $\begin{array}{l}\text { Puedo organizar la información recogida de } \\
\text { Internet, agregando las páginas que me interesan a } \\
\text { favoritos, y clasificarlas en subcarpetas bajo algún } \\
\text { criterio de ordenación. }\end{array}$ & 012345678910 \\
\hline $\begin{array}{l}\text { Sé enviar archivos de una computadora a otra por } \\
\text { Internet mediante FTP. }\end{array}$ & 012345678910 \\
\hline $\begin{array}{l}\text { Soy capaz de realizar videoconferencias a través } \\
\text { de Internet (Netmeeting, Messenger, etc). }\end{array}$ & 012345678910 \\
\hline $\begin{array}{l}\text { Me puedo comunicar con otras personas mediante } \\
\text { las herramientas de comunicación usuales de } \\
\text { Internet (correo electrónico, chat, mensajería } \\
\text { instantánea, foros de distribución). }\end{array}$ & 012345678910 \\
\hline $\begin{array}{l}\text { Utilizo recursos de la Web } 2.0 \text { (Youtube, Facebook, } \\
\text { Blogs, Wikis, etc). }\end{array}$ & 012345678910 \\
\hline Sé utilizar manuales de ayuda en línea. & 012345678910 \\
\hline $\begin{array}{l}\text { Conozco las herramientas que me proporciona el } \\
\text { sistema operativo para compartir recursos en la red } \\
\text { del aula (carpetas, unidades, periféricos,...). }\end{array}$ & 012345678910 \\
\hline $\begin{array}{l}\text { Sé crear una cuenta de correo electrónico a través } \\
\text { de diferentes programas: Yahoo, Hotmail, Gmail,... }\end{array}$ & 012345678910 \\
\hline $\begin{array}{l}\text { Se enviar y leer mensajes de correo electrónico con } \\
\text { archivos adjuntos. }\end{array}$ & 10 \\
\hline
\end{tabular}




\begin{tabular}{|l|l|}
\hline Se enviar mensajes de correo electrónico a otras & 012345678910 \\
personas usando las opciones de CC, CCO, y & \\
conozco las diferencias entre ambas.
\end{tabular}

\subsubsection{Selección de docentes evaluadores}

Cuestionario para docentes de primer año de la carrera Licenciatura en Administración de Empresas, modalidad no presencial. Basado en el cuestionario sobre competencias tecnológicas del profesorado realizado por Cabero Almenara, Llorente Cejudo y Marín Díaz [Cab10].

\subsubsection{Competencias tecnológicas de los docentes}

- ¿Responsable de la asignatura o tutor?

- ¿Dispone de computadora e Internet en la Facultad? Si/No

- ¿Las actividades relacionadas con el desarrollo de la asignatura en modalidad no presencial las realiza mayoritariamente desde la Facultad? Si/No

Las preguntas que figuran a continuación poseen una escala de 0 a 10, donde el 0 hacía referencia a sentirse completamente ineficaz para realizar lo que se presenta y el 10 a la creencia de dominarlo completamente, pudiendo utilizar la opción NC (por si desconoce lo solicitado).

\begin{tabular}{|l|c|}
\hline \multicolumn{1}{|c|}{ Pregunta } & \multicolumn{1}{|c|}{ Escala } \\
\hline $\begin{array}{l}\text { Tengo conocimientos básicos sobre el } \\
\text { funcionamiento de la computadora. }\end{array}$ & 012345678910 \\
\hline $\begin{array}{l}\text { Sé conectar impresora, cámaras digitales, } \\
\text { filmadoras, etc. a la computadora. }\end{array}$ & 012345678910 \\
\hline $\begin{array}{l}\text { Resuelvo problemas como configurar el correo } \\
\text { electrónico, configurar antivirus, conectarme a } \\
\text { Internet. }\end{array}$ & 012345678910 \\
\hline $\begin{array}{l}\text { Sé usar de forma apropiada combinaciones de } \\
\text { teclas para conseguir signos alfanuméricos y de } \\
\text { puntuación desde el teclado. }\end{array}$ & 012345678910 \\
\hline $\begin{array}{l}\text { Soy capaz de instalar y desinstalar programas } \\
\text { informáticos }\end{array}$ & 012345678910 \\
\hline $\begin{array}{l}\text { Puedo cambiar de formatos los archivos (por } \\
\text { ejemplo convertir un archivo doc a rtf). }\end{array}$ & 012345678910 \\
\hline $\begin{array}{l}\text { Realizo un sencillo documento con un procesador } \\
\text { de texto (Word, Writer, Word perfect, Abiword, etc), } \\
\text { usando formatos básicos de fuente, de párrafo, y } \\
\text { de página. }\end{array}$ & 012345678910 \\
\hline $\begin{array}{l}\text { Sin usar el mouse soy capaz de acceder a un } \\
\text { procesador de texto, escribir una pequeña carta, } \\
\text { mover párrafos de lugar, corregir errores, cambiar } \\
\text { formatos, guardar la carta en el disco de mi } \\
\text { computadora e imprimirla. }\end{array}$ & 012345678910 \\
\hline $\begin{array}{l}\text { Realizo un documento con un procesador de texto } \\
\text { usando técnicas avanzadas del mismo para poner } \\
\text { encabezamiento o pie de página, numeración, }\end{array}$ & 012345678910 \\
\hline
\end{tabular}




\begin{tabular}{|c|c|}
\hline imá & \\
\hline $\begin{array}{l}\text { Sé utilizar los correctores ortográficos de los } \\
\text { procesadores de texto, para editar y revisar mis } \\
\text { trabajos. }\end{array}$ & 012345678910 \\
\hline $\begin{array}{l}\text { Sé diseñar, crear y modificar hojas de cálculo con } \\
\text { algún programa informático (Excel, Calc, Gnumeric, } \\
\text { etc), para propósitos específicos, usando fórmulas } \\
\text { elementales. }\end{array}$ & 012345678910 \\
\hline $\begin{array}{l}\text { Sé diseñar, crear y modificar hojas de cálculo con } \\
\text { algún programa informático para propósitos } \\
\text { específicos, usando formato de celdas, realizar } \\
\text { tablas dinámicas, aplicar filtros, usar fórmulas } \\
\text { complejas y funciones. }\end{array}$ & 012345678910 \\
\hline $\begin{array}{l}\text { Sé usar diferentes programas que incluyen } \\
\text { herramientas para dibujar gráficos. }\end{array}$ & 012345678910 \\
\hline $\begin{array}{l}\text { Sé crear imágenes y gráficos mediante algún } \\
\text { programa informático. }\end{array}$ & 012345678910 \\
\hline $\begin{array}{l}\text { Sé crear clip de audio con algún programa } \\
\text { informático. }\end{array}$ & 012345678910 \\
\hline $\begin{array}{l}\text { Sé crear una presentación multimedia mediante } \\
\text { algún programa, incluyendo imágenes estáticas, } \\
\text { textos, clip de audio, clip de vídeo. }\end{array}$ & 012345678910 \\
\hline $\begin{array}{l}\text { Identifico aspectos de estilos en una presentación } \\
\text { (Power Point, Impress), realizada por otra persona. }\end{array}$ & 012345678910 \\
\hline $\begin{array}{l}\text { Sé modificar imágenes mediante algún programa } \\
\text { de diseño gráfico (Coreldraw, Photoshop, Gimp, } \\
\text { etc). }\end{array}$ & 012345678910 \\
\hline $\begin{array}{l}\text { Sé comprimir y descomprimir archivos (WinZip, } \\
\text { WinRar, etc). }\end{array}$ & 012345678910 \\
\hline Realizo grabaciones en CD y CVD (Nero, etc.) & 012345678910 \\
\hline $\begin{array}{l}\text { Puedo realizar conversiones de mis archivos a } \\
\text { formato PDF. }\end{array}$ & 012345678910 \\
\hline $\begin{array}{l}\text { Navego por Internet con diferentes navegadores } \\
\text { (Internet Explorer, Mozilla, Opera, Safari, etc). }\end{array}$ & 012345678910 \\
\hline $\begin{array}{l}\text { Navego por Internet de forma paralela con distintas } \\
\text { ventanas o pestañas abiertas al mismo tiempo. }\end{array}$ & 012345678910 \\
\hline $\begin{array}{l}\text { Sé diseñar páginas Web, utilizando algún programa } \\
\text { informático, incluyendo textos, imágenes, tablas. }\end{array}$ & 012345678910 \\
\hline $\begin{array}{l}\text { Sé diseñar páginas Web utilizando algún programa } \\
\text { informático, incluyendo diferentes links, al propio } \\
\text { documento o a otros. }\end{array}$ & 012345678910 \\
\hline $\begin{array}{l}\text { Soy capaz de descargar de Internet, programas, } \\
\text { imágenes, clips de audio. }\end{array}$ & 012345678910 \\
\hline $\begin{array}{l}\text { Soy capaz de utilizar diferentes buscadores de } \\
\text { Internet (Google, Yahoo, Altavista). }\end{array}$ & 012345678910 \\
\hline $\begin{array}{l}\text { Soy capaz de utilizar las opciones de búsqueda } \\
\text { avanzada en diferentes buscadores de Internet } \\
\text { para refinar la búsqueda de información. }\end{array}$ & 012345678910 \\
\hline Puedo organizar la información recogida de & 012345678910 \\
\hline
\end{tabular}




\begin{tabular}{|c|c|}
\hline $\begin{array}{l}\text { Internet, agregando las páginas que me interesan a } \\
\text { favoritos, y clasificarlas en subcarpetas bajo algún } \\
\text { criterio de ordenación. }\end{array}$ & \\
\hline $\begin{array}{l}\text { Sé enviar archivos de una computadora a otra por } \\
\text { Internet mediante FTP. }\end{array}$ & 012345678910 \\
\hline $\begin{array}{l}\text { Soy capaz de realizar videoconferencias a través } \\
\text { de Internet (Netmeeting, Messenger, etc). }\end{array}$ & 012345678910 \\
\hline $\begin{array}{l}\text { Soy capaz de acceder, buscar y recuperar } \\
\text { información utilizando diferentes formas de } \\
\text { accesibilidad y formatos (CD, DVD, vídeo). }\end{array}$ & 012345678910 \\
\hline $\begin{array}{l}\text { Me puedo comunicar con otras personas mediante } \\
\text { las herramientas de comunicación usuales de } \\
\text { Internet (correo electrónico, chat, mensajería } \\
\text { instantánea, foros de distribución). }\end{array}$ & 012345678910 \\
\hline $\begin{array}{l}\text { Utilizo recursos de la Web } 2.0 \text { (Youtube, Facebook, } \\
\text { Blogs, Wikis, etc). }\end{array}$ & 012345678910 \\
\hline Sé utilizar manuales de ayuda en línea. & 012345678910 \\
\hline $\begin{array}{l}\text { Conozco las herramientas que me proporciona el } \\
\text { sistema operativo para compartir recursos en la red } \\
\text { del aula (carpetas, unidades, periféricos,...). }\end{array}$ & 012345678910 \\
\hline $\begin{array}{l}\text { Sé crear una cuenta de correo electrónico a través } \\
\text { de diferentes programas: Yahoo, Hotmail, Gmail,... }\end{array}$ & 012345678910 \\
\hline $\begin{array}{l}\text { Me considero competente para saber discriminar en } \\
\text { la mayoría de los casos, correo electrónico con } \\
\text { virus, basura o spam. }\end{array}$ & 012345678910 \\
\hline $\begin{array}{l}\text { Se enviar y leer mensajes de correo electrónico con } \\
\text { archivos adjuntos. }\end{array}$ & 012345678910 \\
\hline $\begin{array}{l}\text { Se enviar mensajes de correo electrónico a otras } \\
\text { personas usando las opciones de CC, CCO, y } \\
\text { conozco las diferencias entre ambas. }\end{array}$ & 012345678910 \\
\hline $\begin{array}{l}\text { Soy capaz de organizar, analizar y sintetizar la } \\
\text { información mediante tablas, gráficos o esquemas } \\
\text { para presentar información a mis estudiantes. }\end{array}$ & 012345678910 \\
\hline $\begin{array}{l}\text { Soy capaz de organizar la información, usando } \\
\text { herramientas como bases de datos, hojas de } \\
\text { cálculo o programas similares para presentar } \\
\text { información a mis estudiantes. }\end{array}$ & 012345678910 \\
\hline $\begin{array}{l}\text { Conozco y sé manejar, programas informáticos } \\
\text { para compartir información en la red con mis } \\
\text { compañeros profesores. }\end{array}$ & 012345678910 \\
\hline $\begin{array}{l}\text { Soy capaz de usar las TIC para investigar, explorar, } \\
\text { interpretar información o resolver problemas en } \\
\text { diversidad de materias y contextos, relacionados } \\
\text { con mi disciplina. }\end{array}$ & 012345678910 \\
\hline $\begin{array}{l}\text { Soy capaz de evaluar la autoría y fiabilidad de la } \\
\text { información encontrada en Internet; es decir, } \\
\text { evaluar la relevancia de la información localizada } \\
\text { en Internet. }\end{array}$ & 012345678910 \\
\hline Me considero capaz de utilizar diferentes TIC, para & $01234567 \varepsilon$ \\
\hline
\end{tabular}




\begin{tabular}{|l|l|}
\hline $\begin{array}{l}\text { alcanzar aprendizajes específicos en mis } \\
\text { estudiantes. }\end{array}$ & \\
\hline $\begin{array}{l}\text { Soy capaz de aplicar diferentes estrategias y } \\
\text { metodologías sobre las TIC, como por ejemplo } \\
\text { favorecer un modelo transmisivo de información o } \\
\text { un modelo cooperativo, entre mis estudiantes. }\end{array}$ & \\
\hline $\begin{array}{l}\text { Sé analizar el impacto de las TIC en diferentes } \\
\text { ámbitos de la formación universitaria. }\end{array}$ & 01234567878910 \\
\hline $\begin{array}{l}\text { Sé localizar en Internet documentos científicos y } \\
\text { educativos referidos con mi área de conocimiento, } \\
\text { tanto para mí como para mis estudiantes. }\end{array}$ & 012345678910 \\
\hline $\begin{array}{l}\text { Participo en foros, Blogs y Wikis de mi disciplina } \\
\text { científica. }\end{array}$ & 012345678910 \\
\hline $\begin{array}{l}\text { Conozco distintas metodologías para desarrollar y } \\
\text { apoyar el trabajo colaborativo en red. }\end{array}$ & 012345678910 \\
\hline $\begin{array}{l}\text { Utilizo recursos de la Web 2.0 (Youtube, Facebook, } \\
\text { Blogs, Wikis, etc). }\end{array}$ & 012345678910 \\
\hline $\begin{array}{l}\text { Me considero capaz de establecer normas y reglas } \\
\text { de funcionamiento con las distintas herramientas de } \\
\text { comunicación disponibles en cualquier entorno } \\
\text { virtual de formación (correo electrónico, foro de } \\
\text { discusión, chat, etc). }\end{array}$ & 012345678910 \\
\hline $\begin{array}{l}\text { Soy capaz de manejar una sesión de chat de } \\
\text { manera adecuada, estableciendo pautas de } \\
\text { moderación y gestionar las intervenciones de los } \\
\text { alumnos. }\end{array}$ & 012345678910 \\
\hline $\begin{array}{l}\text { Me considero capaz de diseñar, publicar y } \\
\text { mantener páginas Web de contenidos relacionados } \\
\text { con las asignaturas que imparto. }\end{array}$ & 012345678910 \\
\hline $\begin{array}{l}\text { He promovido actividades de aprendizaje con mis } \\
\text { estudiantes utilizando algún recurso de } \\
\text { comunicación como: foros, chat, listas de } \\
\text { distribución, correo electrónico, etc. }\end{array}$ & 012345678910 \\
\hline $\begin{array}{l}\text { Incorporo para mi formación profesional el trabajo } \\
\text { con vídeos, materiales multimedia y páginas Web. }\end{array}$ & 012345678910 \\
\hline
\end{tabular}




\subsection{Anexo H}

\section{Capa4}

\subsubsection{Introducción}

El test de usuario remoto perteneciente a la Capa 4 está compuesto por cuatro cuestionarios, tres destinados al usuario final para la evaluación directa, y uno destinado al evaluador para la evaluación indirecta.

\subsubsection{Cuestionarios para usuarios finales}

\subsubsection{Cuestionario para evaluación directa orientado a la tarea}

El usuario final debe situarse en un escenario concreto e interactuar con el entorno realizando las tareas como si estuviera participando de un curso (o si está participando en un curso), asignatura, o capacitación con modalidad virtual. Una vez concluidas las tareas de cada escenario debe completar el presente cuestionario, es decir, que el usuario final debe entregar tantos cuestionarios como escenarios haya evaluado.

ESCENARIO DE USO: Indicar el escenario evaluado

\section{Puntos a EVALUAR}

\section{Complejidad}

- La complejidad de la tarea resultó:

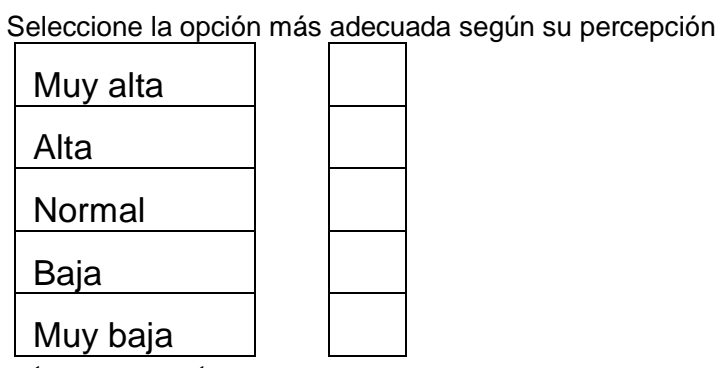

- Responda las siguientes preguntas:

¿Debió tomar decisiones sobre cómo realizar la tarea debido a la posibilidad de hacerlo de diferentes formas?¿Cuáles?

¿Podría realizar una descripción de la secuencia de pasos recorridos para efectuar la tarea. 
Visibilidad

- Complete la siguiente grilla:

\begin{tabular}{|l|l|l|l|l|l|}
\hline & $\begin{array}{c}\text { Muy de } \\
\text { acuerdo }\end{array}$ & $\begin{array}{c}\text { De } \\
\text { acuerdo }\end{array}$ & Indiferente & $\begin{array}{c}\text { En } \\
\text { desacuerdo }\end{array}$ & $\begin{array}{c}\text { Muy en } \\
\text { desacuer } \\
\text { do }\end{array}$ \\
\hline $\begin{array}{l}\text { En la interfaz aparece la } \\
\text { información justa y } \\
\text { necesaria para la } \\
\text { realización de la tarea. }\end{array}$ & & & & & \\
\hline $\begin{array}{l}\text { Se encuentra fácilmente la } \\
\text { forma de realizar la tarea. }\end{array}$ & & & & & \\
\hline $\begin{array}{l}\text { La información de contexto } \\
\text { y orientación es adecuada. }\end{array}$ & & & & & \\
\hline $\begin{array}{l}\text { El diseño es intuitivo y } \\
\text { existen señales que } \\
\text { indican de manera natural } \\
\text { lo que se debe hacer. }\end{array}$ & & & & & \\
\hline $\begin{array}{l}\text { Solo están disponibles las } \\
\text { acciones posibles en cada } \\
\text { momento. }\end{array}$ & & & & & \\
\hline $\begin{array}{l}\text { La información se } \\
\text { encuentra jerarquizada } \\
\text { para distinguir claramente } \\
\text { lo más relevante. }\end{array}$ & & & & & \\
\hline
\end{tabular}

- Comentario del evaluador:

\section{Intuitividad y Topografía Natural}

\begin{tabular}{|l|l|l|l|l|l|}
\hline Complete la siguiente grilla: & $\begin{array}{c}\text { Muy de } \\
\text { acuerdo }\end{array}$ & $\begin{array}{c}\text { De } \\
\text { acuerdo }\end{array}$ & Indiferente & $\begin{array}{c}\text { En } \\
\text { desacuerdo }\end{array}$ & $\begin{array}{c}\text { Muy en } \\
\text { desacuer } \\
\text { do }\end{array}$ \\
\hline $\begin{array}{l}\text { No hace falta recordar } \\
\text { información para volver a } \\
\text { realizar la tarea. }\end{array}$ & & & & \\
\hline $\begin{array}{l}\text { Hay analogías con el } \\
\text { mundo real u otros } \\
\text { sistemas e interfaces que } \\
\text { generan familiaridad. }\end{array}$ & & & & & \\
\hline $\begin{array}{l}\text { Los objetos que componen } \\
\text { la interfaz son } \\
\text { autoexplicativos. }\end{array}$ & & & & & \\
\hline $\begin{array}{l}\text { El modelo conceptual } \\
\text { proporcionado es } \\
\text { adecuado. }\end{array}$ & & & & \\
\hline
\end{tabular}


- Comentario del evaluador:

\subsubsection{Cuestionario para evaluación directa orientada al diseño}

Luego de concluir todos los escenarios de uso, el usuario debe completar el siguiente cuestionario.

\begin{tabular}{|c|c|c|}
\hline Heurística & $\begin{array}{l}\text { Conformidad } \\
\text { 6. Nunca } \\
\text { 7. Casi nunca } \\
\text { 8. A veces } \\
\text { 9. Casi siempre } \\
\text { 10. Siempre } \\
\end{array}$ & $\begin{array}{c}\text { Comentario } \\
\text { (opcional) }\end{array}$ \\
\hline \multicolumn{3}{|l|}{ Productividad } \\
\hline \multicolumn{3}{|l|}{$\begin{array}{l}\text { Las tareas habituales son de fácil } \\
\text { realización. }\end{array}$} \\
\hline \multicolumn{3}{|l|}{$\begin{array}{l}\text { Los usuarios frecuentes o expertos } \\
\text { tienen posibilidad de realizar las } \\
\text { tareas reduciendo el número de } \\
\text { interacciones con el EVEA. }\end{array}$} \\
\hline \multicolumn{3}{|l|}{$\begin{array}{l}\text { Existen mecanismos para realizar } \\
\text { tareas masivas. }\end{array}$} \\
\hline \multicolumn{3}{|l|}{$\begin{array}{l}\text { El EVEA provee el usuario de } \\
\text { recordatorios o avisos sobre cambios } \\
\text { producidos a partir del último ingreso. }\end{array}$} \\
\hline \multicolumn{3}{|l|}{$\begin{array}{l}\text { Hay atajos de teclado y están } \\
\text { siempre disponibles. }\end{array}$} \\
\hline \multicolumn{3}{|l|}{ Retroalimentación } \\
\hline \multicolumn{3}{|l|}{$\begin{array}{l}\text { El resultado de cada acción realizada } \\
\text { por el usuario es informado. }\end{array}$} \\
\hline \multicolumn{3}{|l|}{$\begin{array}{l}\text { Los resultados exitosos son } \\
\text { informados de manera diferente a los } \\
\text { fracasos. }\end{array}$} \\
\hline \multicolumn{3}{|l|}{$\begin{array}{l}\text { Los errores producidos son } \\
\text { informados claramente al usuario, de } \\
\text { forma no alarmista, y con sugerencias } \\
\text { de de cómo solucionar el problema. }\end{array}$} \\
\hline \multicolumn{3}{|l|}{ Control por parte del usuario } \\
\hline \multicolumn{3}{|l|}{$\begin{array}{l}\text { Los efectos de los actos realizados } \\
\text { son predecibles. }\end{array}$} \\
\hline $\begin{array}{l}\text { El usuario es } \text { informado } \\
\text { constantemente sobre lo que está } \\
\text { ocurriendo (mensajes, tiempo }\end{array}$ & & \\
\hline
\end{tabular}




\begin{tabular}{|c|c|c|}
\hline estimado, barra de progreso). & & \\
\hline $\begin{array}{l}\text { El usuario posee autonomía, libertad } \\
\text { para actuar y controla el EVEA en } \\
\text { todo momento. }\end{array}$ & & \\
\hline $\begin{array}{l}\text { Se pregunta al usuario que confirme } \\
\text { acciones que tendrán consecuencias } \\
\text { drásticas, negativas o destructivas. }\end{array}$ & & \\
\hline $\begin{array}{l}\text { El usuario puede cancelar cualquier } \\
\text { acción. }\end{array}$ & & \\
\hline Reversibilidad y Manejo del err & ror & \\
\hline $\begin{array}{l}\text { Existe una forma de deshacer al nivel } \\
\text { de cada acción simple, cada entrada } \\
\text { de datos y cada grupo de acciones } \\
\text { completadas. }\end{array}$ & & \\
\hline $\begin{array}{l}\text { Los mensajes de error son visibles, } \\
\text { describen acciones para remediar el } \\
\text { problema, o proporcionan el contacto } \\
\text { de la asistencia }\end{array}$ & & \\
\hline $\begin{array}{l}\text { Los mensajes de error informan al } \\
\text { usuario sobre la severidad del error } \\
\text { cometido }\end{array}$ & & \\
\hline $\begin{array}{l}\text { Los mensajes de error sugieren la } \\
\text { causa del problema que los ha } \\
\text { ocasionado }\end{array}$ & & \\
\hline $\begin{array}{l}\text { El EVEA previene o alerta a los } \\
\text { usuarios de cometer errores siempre } \\
\text { que esto es posible }\end{array}$ & & \\
\hline Diseño y organización & & \\
\hline $\begin{array}{l}\text { Es posible comprender rápidamente } \\
\text { cual es la estructura organizativa y el } \\
\text { contenido }\end{array}$ & & \\
\hline $\begin{array}{l}\text { Solo están visibles las acciones que } \\
\text { tienen un fin específico }\end{array}$ & & \\
\hline Es posible editar y ver el aspecto real & & \\
\hline $\begin{array}{l}\text { La información esencial para tomar } \\
\text { decisiones es mostrada en la pantalla }\end{array}$ & & \\
\hline $\begin{array}{l}\text { Se muestra el trabajo pendiente en } \\
\text { tareas complejas o de varias etapas }\end{array}$ & & \\
\hline $\begin{array}{l}\text { El diseño general es atractivo y } \\
\text { uniforme, sin exceso de texto ni de } \\
\text { imágenes }\end{array}$ & & \\
\hline $\begin{array}{l}\text { Existen elementos que permiten al } \\
\text { usuario estar siempre orientado y } \\
\text { tener el control de su navegación }\end{array}$ & & \\
\hline $\begin{array}{l}\text { La velocidad de renovación de cada } \\
\text { página adecuada y evita que el } \\
\text { usuario se impaciente o distraiga }\end{array}$ & & \\
\hline Consistencia & & \\
\hline
\end{tabular}




\begin{tabular}{|c|c|c|}
\hline \multicolumn{3}{|l|}{$\begin{array}{l}\text { El título de página en el navegador es } \\
\text { significativo y refleja el título de la } \\
\text { página principal }\end{array}$} \\
\hline \multicolumn{3}{|l|}{$\begin{array}{l}\text { Los enlaces son claros y reflejan el } \\
\text { título de la página a la que se refiere }\end{array}$} \\
\hline \multicolumn{3}{|l|}{$\begin{array}{l}\text { Los íconos son entendibles y aportan } \\
\text { significado }\end{array}$} \\
\hline \multicolumn{3}{|l|}{$\begin{array}{l}\text { Las secuencias constantes de } \\
\text { acciones se repiten en situaciones } \\
\text { similares }\end{array}$} \\
\hline \multicolumn{3}{|l|}{$\begin{array}{l}\text { Los comandos constantes se } \\
\text { emplean en todas partes del mismo } \\
\text { modo }\end{array}$} \\
\hline \multicolumn{3}{|l|}{$\begin{array}{l}\text { Se utiliza siempre la misma } \\
\text { terminología en avisos, menús, y } \\
\text { pantallas de ayuda }\end{array}$} \\
\hline \multicolumn{3}{|l|}{$\begin{array}{l}\text { Los íconos, botones, imágenes, } \\
\text { ventanas y diálogos respetan las } \\
\text { normas y convenciones usuales de la } \\
\text { plataforma Web }\end{array}$} \\
\hline \multicolumn{3}{|l|}{ Ayuda y documentación } \\
\hline \multicolumn{3}{|l|}{$\begin{array}{l}\text { Se dispone de ayuda en línea, en } \\
\text { lugar visible y orientada a las } \\
\text { acciones del usuario }\end{array}$} \\
\hline \multicolumn{3}{|l|}{$\begin{array}{l}\text { Existe ayuda contextual en tareas } \\
\text { complejas }\end{array}$} \\
\hline \multicolumn{3}{|l|}{$\begin{array}{l}\text { Los usuarios pueden cambiar } \\
\text { fácilmente entre la ayuda y su trabajo }\end{array}$} \\
\hline \multicolumn{3}{|l|}{$\begin{array}{l}\text { Existe una mesa de ayuda o soporte } \\
\text { técnico permanente }\end{array}$} \\
\hline \multicolumn{3}{|l|}{$\begin{array}{l}\text { Existen manuales, foros, respuesta a } \\
\text { preguntas frecuentes etc. }\end{array}$} \\
\hline \multicolumn{3}{|l|}{$\begin{array}{l}\text { La documentación disponible es } \\
\text { suficiente }\end{array}$} \\
\hline \multicolumn{3}{|l|}{ Estándares } \\
\hline \multicolumn{3}{|l|}{$\begin{array}{l}\text { Es posible usarlo sin necesidad de } \\
\text { descargar elementos adicionales } \\
\text { como plug-ins }\end{array}$} \\
\hline \multicolumn{3}{|l|}{$\begin{array}{l}\text { En caso de requerir elementos } \\
\text { adicionales, el usuario es informado } \\
\text { de dicha situación }\end{array}$} \\
\hline \multicolumn{3}{|l|}{$\begin{array}{l}\text { En caso de requerir elementos } \\
\text { adicionales, éstos son universales }\end{array}$} \\
\hline \multicolumn{3}{|l|}{$\begin{array}{l}\text { Se visualiza correctamente el } \\
\text { contenido }\end{array}$} \\
\hline $\begin{array}{l}\text { Se puede navegar correctamente con } \\
\text { diferentes navegadores, versiones y } \\
\text { conexiones a Internet. }\end{array}$ & & \\
\hline
\end{tabular}




\subsubsection{Cuestionario para evaluación directa de atributos de usabilidad}

Por último debe contestar el siguiente cuestionario final.

\begin{tabular}{|c|c|}
\hline \multicolumn{2}{|c|}{ Efectividad } \\
\hline Tareas completadas & $\begin{array}{c}\text { Ninguna / Algunas / La mitad / Casi todas / } \\
\text { Todas }\end{array}$ \\
\hline \multicolumn{2}{|c|}{ Eficiencia } \\
\hline $\begin{array}{l}\text { Tiempo total invertido en } \\
\text { completar las tareas }\end{array}$ & Aceptable / No aceptable ${ }^{+}$ \\
\hline Tiempo total ocupado en errores & Nada / Muy poco / Poco / Bastante / Mucho * \\
\hline Tiempo total de aprendizaje & $\begin{array}{l}\text { Aceptable (hasta un } 10 \% \text { del tiempo total } \\
\text { invertido) / No aceptable (más de un 10\% del } \\
\text { tiempo total invertido) * }\end{array}$ \\
\hline $\begin{array}{l}\text { Frecuencia de uso de la ayuda o } \\
\text { documentación }\end{array}$ & $\begin{array}{l}\text { Nunca (0 veces) / Pocas (1 a 4) / Muchas } \\
\text { (más de } 4)^{*}\end{array}$ \\
\hline $\begin{array}{l}\text { Número de intentos y estrategias } \\
\text { alternativas utilizadas hasta lograr } \\
\text { completar las tareas }\end{array}$ & $\begin{array}{l}\text { Aceptable (hasta } 1 \text { por tarea) / No aceptable } \\
\text { (más de } 1 \text { por tarea) * }\end{array}$ \\
\hline Número de errores cometidos & $\begin{array}{l}\text { Aceptable (hasta } 1 \text { por tarea) / No aceptable } \\
\text { (más de } 1 \text { por tarea) * }\end{array}$ \\
\hline $\begin{array}{l}\text { Tiempo total necesario para } \\
\text { recuperarse de errores }\end{array}$ & $\begin{array}{l}\text { Aceptable (hasta un } 10 \% \text { del tiempo total } \\
\text { invertido) / No aceptable (más de un 10\% del } \\
\text { tiempo total invertido) * }\end{array}$ \\
\hline \multicolumn{2}{|c|}{ Satisfacción } \\
\hline $\begin{array}{l}\text { Veces que el sentí frustración o } \\
\text { enojo }\end{array}$ & $\begin{array}{l}\text { Nunca (0 veces) / Pocas (1 a 4) / Muchas } \\
\text { (más de } 4) \text { / }\end{array}$ \\
\hline Utilidad del producto & $\begin{array}{c}\text { Inútil / Poco útil / Algo útil / Bastante útil / } \\
\text { Muy útil * }\end{array}$ \\
\hline $\begin{array}{l}\text { Satisfacción con respecto a las } \\
\text { funciones y características }\end{array}$ & $\begin{array}{l}\text { Insatisfecho / Poco satisfecho / Algo } \\
\text { satisfecho / Bastante satisfecho muy } \\
\text { satisfecho * }\end{array}$ \\
\hline $\begin{array}{l}\text { Percepción de que la tecnología da } \\
\text { soporte a las tareas según mis } \\
\text { necesidades }\end{array}$ & $\begin{array}{c}\text { Nunca / Casi nunca / A veces / Casi siempre } \\
\qquad / \text { Siempre }{ }^{*}\end{array}$ \\
\hline
\end{tabular}




\subsubsection{Cuestionario para evaluadores}

\subsubsection{Cuestionario para evaluación indirecta de atributos de usabilidad}

Luego de concluido el test, el evaluador debe agrupar los usuarios de acuerdo a su rol y nivel de experticia, y resumir la opinión de los mismos tomando como base la siguiente información:

1. Cuestionarios realizados por los usuarios

2. Huellas que los usuarios dejaron dentro de los cursos durante el proceso de realización de las tareas

3. Log de cada curso

\begin{tabular}{|c|c|}
\hline \multicolumn{2}{|l|}{ Usuarios } \\
\hline \multicolumn{2}{|l|}{ Rol } \\
\hline \multicolumn{2}{|l|}{ Escenarios } \\
\hline \multicolumn{2}{|c|}{ Efectividad } \\
\hline \multicolumn{2}{|l|}{ Cantidad total de tareas } \\
\hline \multicolumn{2}{|l|}{ Cantidad de tareas completadas } \\
\hline $\begin{array}{l}\text { Porcentaje total de tareas } \\
\text { completadas }\end{array}$ & $\begin{array}{l}\text { Malo }(0 \% \text { a } 30 \%) \text { - Regular }(31 \% \text { a } 60 \%)- \\
\text { Bueno }(61 \% \text { a } 80 \%) \text { - Muy Bueno }(81 \% \text { a } \\
90 \%) \text { - Excelente }(91 \% \text { a } 100 \%)^{*}\end{array}$ \\
\hline \multicolumn{2}{|c|}{ Eficiencia } \\
\hline $\begin{array}{l}\text { Tiempo total invertido por el } \\
\text { usuario en completar las tareas }\end{array}$ & Aceptable / No aceptable ${ }^{+}$ \\
\hline Tiempo total ocupado en errores & Nada / Muy poco / Poco / Bastante / Mucho \\
\hline Tiempo total de aprendizaje & $\begin{array}{l}\text { Aceptable (hasta un } 10 \% \text { del tiempo total } \\
\text { invertido) / No aceptable (más de un } 10 \% \\
\text { del tiempo total invertido) * }\end{array}$ \\
\hline $\begin{array}{l}\text { Frecuencia de uso de la ayuda o } \\
\text { documentación }\end{array}$ & $\begin{array}{l}\text { Nunca }(0 \text { veces) / Pocas (1 a 4) / Muchas } \\
\text { (más de } 4)^{*}\end{array}$ \\
\hline $\begin{array}{l}\text { Número de intentos y estrategias } \\
\text { alternativas utilizadas hasta lograr } \\
\text { completar las tareas }\end{array}$ & $\begin{array}{l}\text { Aceptable (hasta } 1 \text { por tarea) / No } \\
\text { aceptable (más de } 1 \text { por tarea) * }\end{array}$ \\
\hline $\begin{array}{l}\text { Número de errores cometidos por } \\
\text { el usuario }\end{array}$ & $\begin{array}{l}\text { Aceptable (hasta } 1 \text { por tarea) / No } \\
\text { aceptable (más de } 1 \text { por tarea) * }\end{array}$ \\
\hline Tiempo total necesario para & Aceptable (hasta un $10 \%$ del tiempo total \\
\hline
\end{tabular}




\begin{tabular}{|l|l|}
\hline recuperarse de errores & $\begin{array}{l}\text { invertido) / No aceptable (más de un 10\% } \\
\text { del tiempo total invertido) * }\end{array}$ \\
\hline $\begin{array}{l}\text { Veces que el usuario sintió } \\
\text { frustración o enojo }\end{array}$ & $\begin{array}{l}\text { Nunca (0 veces) / Pocas (1 a 4) / Muchas } \\
\text { (más de 4) * }\end{array}$ \\
\hline $\begin{array}{l}\text { Utilidad del producto } \\
\begin{array}{l}\text { Satisfacción con respecto a las } \\
\text { funciones y características }\end{array}\end{array}$ & $\begin{array}{c}\text { Insatil / Poco útil / Algo útil / Bastante útil / } \\
\text { Muy útil * } \\
\text { satisfecho / Bastante satisfecho muy } \\
\text { satisfecho * }\end{array}$ \\
\hline $\begin{array}{l}\text { Percepción de que la tecnología da da } \\
\text { soporte a las tareas según las } \\
\text { necesidades del usuario }\end{array}$ & $\begin{array}{c}\text { Nunca / Casi nunca / A veces / Casi siempre } \\
\text { / Siempre * }\end{array}$ \\
\hline
\end{tabular}

${ }^{+}$Tiempo aceptable usuario novato $=(50<=$ Eficiencia usuario novato $<=100)$

${ }^{+}$Tiempo aceptable usuario medio $=(66<=$ Eficiencia usuario medio $<=100)$

* Las escalas de valoración han sido elaboradas en base al tipo de métrica, producto evaluado, y experiencia del tesista. 


\subsection{Anexo I}

\subsubsection{Selección de un entorno virtual para la Universitat Jaume I}

En este estudio, que posteriormente fue utilizado para la selección de un entorno de enseñanza / aprendizaje de código fuente abierto para la Universitat Jaume I de España, los autores sostienen que los criterios planteados están pensados conforme con las necesidades y los tipos de uso educativo que se pretende realizar del entorno. Se trata de un análisis de corte más cualitativo realizado en función de tres criterios: flexibilidad didáctica, usabilidad, y flexibilidad tecnológica [Ade2004].

\subsubsection{Aspectos generales}

\section{Filosofía y características generales del entorno}

Características generales: Filosofía, arquitectura y objetivos del entorno. ¿Se trata de un entorno de apoyo a cursos presenciales, un entorno de enseñanza a distancia, un entorno de aprendizaje cooperativo? ¿Cómo se organiza el entorno? ¿Alrededor de cursos? ¿Alrededor del usuario?

Apoyo: ¿Quién es responsable del desarrollo de este software? ¿Hay una comunidad de usuarios y una comunidad de desarrollo activas que garanticen el apoyo técnico y la continuidad y la evolución del producto?

\subsubsection{Flexibilidad didáctica}

Este criterio tiene una importancia sustancial en tanto la herramienta a utilizar debe ser útil y adecuada para la diversidad que presenta una Universidad, ofreciendo valor añadido a procesos formativos que difieren en diversos aspectos: nivel educativo, modalidades, estilos de enseñanza de los docentes, estilos de aprendizaje de los alumnos, pluralidad de materias y asignaturas, contenidos y formatos diversos, niveles y objetivos variados, y a su vez, debe facilitar activamente las buenas prácticas en la enseñanza y el aprendizaje, mejorando las oportunidades de comunicación y colaboración en la construcción de conocimientos entre los participantes en el proceso educativo y una relación significativa con los materiales de aprendizaje [Alv2004].

\section{Herramientas para el diseño y el desarrollo del currículum y para la evaluación}

Diseño del currículum: Acceso a los cursos. Posibilidades de diseño y organización del curso: organización temporal, por temas, etc.

\section{Herramientas de aprendizaje}

Foros: Foros de debate.

Materiales: Posibilidades de gestión de archivos, enlaces externos, etc.

Mensajería: ¿Existe un sistema de mensajería interno? Características principales.

Chat: ¿Existe un sistema de chat? Características principales.

Ejercicios: ¿Se pueden crear tests, cuestionarios o ejercicios autocorrectivos?

Deberes: ¿Se pueden poner tareas on-line/offline a los estudiantes? 
Otras herramientas de enseñanza/ aprendizaje relevantes: diarios, wikis, weblogs, etc.

Extensibilidad: ¿Cabe la posibilidad de incorporar otras herramientas de aprendizaje adicionales?

Multimedia: ¿Hay alguna facilidad especial para distribuir contenidos de audio o video?

Grupos: ¿Cabe la posibilidad de gestionar grupos de estudiantes dentro de un curso?

Copias: ¿Los profesores pueden crear copias de seguridad de sus cursos?

Compatibilidad de contenidos: ¿Es posible compartir / importar cursos o partes de cursos? ¿Se pueden incorporar contenidos procedentes de otros entornos? ¿Es compatible con estándares IMS/SCORM/otros?

Seguimiento y evaluación del aprendizaje: ¿El profesor puede monitorizar la actividad de los estudiantes dentro del curso? ¿Puede evaluar y calificar a los estudiantes dentro del entorno?

\subsubsection{Usabilidad}

Un entorno debe ser fácil de utilizar para los profesores (como creadores de cursos, dinamizadores de la participación y la comunicación didáctica y gestores de información académica) y para los estudiantes (como protagonistas principales de su propia formación). La complejidad de manejo no es una consecuencia inevitable de la riqueza de funcionalidades, sino generalmente del mal diseño. El entorno ideal no debería precisar un "manual del estudiante" ni requerir sesiones de formación para los alumnos: debe aprenderse a utilizarlo, utilizándolo, y con pocas instrucciones previas. Debe ser un entorno sencillo, intuitivo, cómodo y amigable. Un estudiante acostumbrado a navegar y usar aplicaciones Web tiene que ser capaz de utilizar sin mayores problemas el entorno de la Universidad. Un profesor con la misma base de conocimientos informáticos tiene que ser capaz de crear y gestionar un curso [Alv2004].

La facilidad de uso no puede ser un requisito secundario. La experiencia del usuario es uno de los factores esenciales para la generalización de este tipo de entornos y uno de los principales problemas que presentan numerosos sistemas. Si profesores y estudiantes tienen la percepción de que el entorno les complica la vida y no aporta un valor añadido a sus actividades, el rechazo será inevitable. Por este motivo, un sistema modular que permita una configuración progresiva y a medida, en función de las necesidades de cada momento, y que oculte aquellas herramientas o recursos no utilizados, resultará notablemente más efectivo que un sistema complejo y pletórico de funcionalidades no aprovechadas [Alv2004].

La usabilidad abarca también, entre otros elementos clave, la accesibilidad. En la medida de las posibilidades tecnológicas, el entorno debe cumplir la normativa y estándares sobre accesibilidad a fin de garantizar que no sea una nueva barrera para los estudiantes con algún tipo de discapacidad [Alv2004]. 


\section{Condiciones y medidas de usabilidad y accesibilidad.}

Facilidad de uso: Facilidad de uso percibida por los usuarios.

Conocimientos técnicos: ¿Qué nivel de conocimientos técnicos es necesario que tengan los usuarios (profesorado y estudiantado)?

Ayuda: ¿Hay un sistema de ayuda en línea?

Trabajo off-line: ¿Hay alguna manera de trabajar sin estar conectado al entorno y de sincronizar dicho trabajo cuando el alumno se vuelva a conectar?

Accesibilidad: ¿El entorno cumple los estándares de accesibilidad?

Idiomas: ¿Se puede cambiar el idioma de la interfaz? ¿Qué idiomas están disponibles?

\subsubsection{Flexibilidad tecnológica}

Si bien los dos criterios descriptos anteriormente son los más importantes, también debe tomarse en consideración la base tecnológica, en lo que respecta a la viabilidad y por sus consecuencias en las funcionalidades y facilidad de uso. En este sentido, se deben tener en cuenta los siguientes aspectos [Alv2004]:

a) Las especificaciones técnicas (requisitos de base de datos, entorno de desarrollo, interfaces, etc.) deben permitir su integración con los sistemas de información de la Universidad, de modo que se establezca una comunicación directa con los datos de matrícula, los planes de organización docente, actas, etc. Esta integración deberá ser también efectiva en el nivel de la interfaz de usuario. Un usuario no tendría que autenticarse más de una vez con los distintos servicios en línea, o usar más de una contraseña. Debería ser dado de alta automáticamente en el entorno virtual de las asignaturas en las que está matriculado.

b) Debe permitir, en primer lugar, una fácil incorporación de la enorme cantidad de recursos de interés formativo que pueden encontrarse en Internet, y en segundo lugar, si así lo deciden los participantes, el libre acceso a los recursos formativos creados en la propia Universidad, que contribuiría de este modo al desarrollo general del conocimiento.

c) Debe seguir modelos de referencia de los estándares internacionales de e-learning más extendidos y estables relativos tanto al empaquetado de materiales (IMS Content Packaging) como a los que aspiran a describir cualquier tipo de actividad de enseñanza / aprendizaje (IMS Learning Design).

d) Debe admitir aportaciones y participación en la toma de decisiones que garantice la aparición de nuevas funcionalidades, la solución de problemas, la puesta a punto de nuevas versiones, la creatividad y la innovación.

Requisitos: Requisitos de hardware / sistema operativo / servidor de bases de datos / otros.

Escalabilidad: ¿El servidor puede hacerse cargo del número previsible de cursos / estudiantes / profesores durante los próximos años? 
Integración: Posibilidades de integración con los sistemas de información de la Unidad Académica que utiliza el entorno. ¿Se puede crear automáticamente un curso basado en una asignatura existente, incluyendo a los estudiantes matriculados en la asignatura? ¿Se pueden incorporar los datos personales de los estudiantes? ¿Se pueden conectar los datos de evaluación y calificaciones del entorno con las preactas?

Autenticación: Mecanismos de autenticación de los usuarios.

Imagen: ¿Se puede adaptar la imagen del entorno a los requisitos de identidad visual de la Unidad Académica?

Costes de implementación: Valoración del costo de implementación del servicio.

Costes de mantenimiento: Valoración del coste de administración y mantenimiento del servicio.

\subsubsection{Clases en el ciberespacio}

En esta propuesta se sugiere tomar en cuenta cinco aspectos que deberían estar presentes en un buen entorno de e-learning [Pal2001]: interacción, introspección, innovación, integración, e información.

La interacción tiene que ver con los aditamentos necesarios para establecer procesos comunicacionales sincrónicos y asincrónicos entre todos los participantes: correo electrónico, enlaces Web, foros de discusión, chats, desarrollo de páginas Web personales, etc.

La introspección se asocia con la posibilidad de que las herramientas comunicacionales permitan generar el desarrollo de pensamiento crítico y creativo por medio de una serie de recursos, en donde se acompañe de audio, video y texto, junto con espacios para actividades a desarrollar por parte de los estudiantes. Sin embargo, la propuesta didáctica sigue siendo un elemento fundamental en estos casos, ya que la herramienta puede contar con las mejores características pero ser usada de forma inadecuada.

La innovación permite al profesor generar actividades diferentes a las acostumbradas en una clase convencional, permitiendo a los estudiantes participar cada vez más, sacando provecho de su propio estilo de aprendizaje. De la misma manera, el proceso de evaluación del curso amplía su gama de alternativas, gracias al apoyo de la tecnología. Si bien se puede mantener el proceso clásico de evaluación por medio de exámenes (presenciales o en-línea), el trabajo colaborativo basado en herramientas informáticas permite establecer nuevas estrategias al respecto.

La integración tiene que ver con la manera en que los recursos tecnológicos incorporan la información a un proceso de generación de conocimientos, partiendo de una base relacional (entre todos los participantes del curso), lejos de posturas eminentemente individualistas.

La información refiere a la posibilidad de contar con aquellos hechos o datos necesarios para el buen desarrollo del curso a la mano del estudiante, sin importar en qué lugar se encuentre: bases de datos especializadas, bibliotecas digitales, portafolios electrónicos, datos del curso, producciones del docente, etc. 


\subsubsection{Indicadores para evaluar entornos para la formación por Internet}

La Universidad Politécnica de Madrid, a través del Gabinete de Tele-Educación, elaboró una serie de indicadores para evaluar entornos integrados para la formación por Internet. Estos indicadores, agrupados en cinco niveles, pretenden ser una ayuda para establecer una relación entre los objetivos que se buscan y la oferta disponible. Ellos son: información técnica, edición de materiales, proceso de enseñanza - aprendizaje, administración y gestión académica, y otras características [Gab2002].

\section{Información Técnica}

\subsection{Características Generales}

Agrupa una serie de indicadores que posibilitan determinar la adaptabilidad a las necesidades y posibilidades institucionales.

a) Idiomas. Ayuda en el idioma propio, capacidad multi-lenguaje.

b) Número de usuarios permitidos. Globales o simultáneos.

c) Número de cursos. Número de ofertas educativas que se pueden gestionar simultáneamente.

d) Adaptable. Arquitectura escalable que permita una mejor adaptación a las necesidades del momento y su posible transformación a necesidades futuras.

e) Precio. Anual, por cantidad de cursos, o por cantidad de usuarios.

f) Servicio técnico. Presencia de un distribuidor y la calidad de sus servicios en la resolución de problemas.

\subsection{Compatibilidad}

Evalúa el carácter universal y no propietario de la Plataforma. Como principales parámetros a considerar se proponen:

a) Requisitos Hw/Sw. Desde el punto de vista del servidor y del cliente. Es muy importante la compatibilidad del lado del cliente respecto al sistema operativo, al "navegador" y a la necesidad de "plug-ins".

b) Soporte de formatos multimedia. Diferentes medios que pueden ser utilizados: audio, video, imágenes, animaciones, objetos 3D, applets.

c) Interoperabilidad con una infraestructura existente. La integración de la plataforma es respetuosa con la infraestructura previa y mantiene compatibilidad con datos, protocolos y lenguajes de programación.

d) Estándares IMS, AICC, ADL-SCORM y otros. Protocolos y normas que permitan la importación y exportación de cursos y/o contenidos con otros entornos.

e) Accesibilidad. Facilidades para personas con discapacidad.

\subsection{Robustez}

Fiabilidad de la plataforma tanto en su consistencia como en la protección ante usos indebidos:

a) Integridad de funcionamiento. Fallas derivadas de un mal diseño del 
software.

b) Recuperación ante fallos. Tolerancia ante utilización poco experta.

c) Seguridad. Capacidad de controlar los accesos a las bases de datos y herramientas que integran la plataforma. Propiedad y protección de los materiales depositados en la plataforma.

\section{Edición de Materiales}

\subsection{Edición de contenidos}

Evalúa las herramientas y sus capacidades para la edición de contenidos pedagógicos.

a) Disponibilidad de entorno de autor. Adaptación a los estándares para elaborar contenidos. Nivel de conocimientos técnicos requeridos para su utilización, su facilidad de aprendizaje y su capacidad.

b) Capacidad de integración multimedia. Facilidad para crear documentos con una amplia variedad de recursos multimedia. Posibilidad de mantener una interactividad con contenidos off-line.

c) Capacidad de reedición-actualización. Flexibilidad para modificar los módulos de contenido de un curso, una vez que estén on-line.

d) Manejo de archivos para trabajar en remoto. Posibilidad de importar y convertir archivos elaborados de forma local, respetando los links entre documentos HTML.

f) Posibilidad de participar múltiples autores. Diseño de los cursos por parte de varios autores (utilidad de bloqueo de archivos, anotaciones personales para cada autor, etc.)

\section{g) Capacidad de integrar en la plataforma archivos generados en otro entorno.}

\subsection{Edición de elementos de evaluación}

Orientado a analizar tipo de plantillas disponibles para generar evaluaciones y actividades de refuerzo.

a) Tipos de preguntas. Posibilidad de adaptar el instrumento de evaluación al tipo de conocimiento que se desea evaluar.

b) Riqueza de recursos. Variedad de recursos que se puede incluir en cada pregunta: gráficos, imágenes, ecuaciones, ayudas, retroalimentaciones.

c) Gestión de las Bases de datos. Capacidad de crear cuestionarios a partir de una base de datos de preguntas, incorporación de cuestionarios implementados en otros lenguajes y el manejo simultáneo de diversas bases de datos.

d) Tipos de cuestionarios. Capacidad de la plataforma para llevar a cabo distintos modelos de evaluación, con objetivos claramente diferenciados: pruebas de auto evaluación, evaluación parcial, evaluación global. Capacidad de desarrollo off-line.

e) Interacción con simuladores. Posibilidad de integrar el uso de simuladores como parte de la evaluación. 


\subsection{Creación de otros elementos complementarios}

a) Tipos de actividades. Riqueza de la plataforma en cuanto a las actividades de aprendizaje que se pueden incorporar, como son la realización de trabajos, prácticas, etc.

b) Gestión de Bibliografía y URL's. Capacidad para incluir recursos externos a los módulos de contenido propios del curso.

c) Glosario. Existencia de herramientas para crear un glosario, así como los enlaces directos desde los contenidos del curso donde aparece el término.

d) Índice. Generación automática de un índice de los contenidos del curso.

\section{Proceso de enseñanza - aprendizaje}

Se refiere a los indicadores necesarios para evaluar las prestaciones que ofrece la plataforma en lo referente a: desarrollo y funcionamiento de los cursos, herramientas que dispone el profesor para efectuar una monitorización del trabajo de los alumnos, comunicación entre los alumnos y entre éstos y los profesores, y herramientas que dispone el alumno para la realización de sus actividades de aprendizaje.

\subsection{Planificación de un curso}

a) Guía del curso a través de la cual definir los elementos básicos de la planificación (objetivos, contenidos, actividades, bibliografía, etc.)

b) Integración de forma flexible de los contenidos, actividades, recursos y herramientas.

c) Creación de itinerarios curriculares para adaptar los cursos a las distintas características e intereses de los estudiantes y para facilitar una secuencia adecuada entre la realización de actividades y el estudio de cada módulo o tema.

d) Flexibilidad en el diseño de pruebas de evaluación con capacidad para controlar aspectos tales como: puntuación, número de intentos, duración, así como la posibilidad de crear puertas de acceso condicionado a su superación.

e) Capacidad para incluir diferentes instructores con el mismo perfil que los profesores o como ayudantes con diferentes privilegios y funcionalidad.

\subsection{Supervisión y control del desarrollo del curso}

a) Seguimiento y monitorización del trabajo y progreso de los alumnos, incluyendo el tiempo dedicado a los módulos de aprendizaje y actividades, de la presencia de alumnos, etc.

b) Capacidad de automatizar tareas de control. Prestaciones que posee la plataforma para efectuar de forma automática el seguimiento del trabajo de los alumnos. La contabilización del tiempo, registro de logs, formularios para el seguimiento que permitan hacer búsquedas por criterios (por ejemplo listado de alumnos que no se han conectado en la última semana).

c) Personalización de la formación. La asignación individual, o por grupos, de materiales, trabajos y actividades. 
d) Generación de un expediente del alumno. Integración de las herramientas de evaluación en un único expediente de cada alumno.

\subsection{Herramientas específicas del alumno}

a) Acceso al material. Se consideran los siguientes elementos: bloc de notas privado, herramientas de búsqueda de contenidos, "Bookmarks" de los materiales del curso, posibilidad de memorizar la última sesión de estudio, capacidad de impresión de los contenidos elaborados por el profesor y de su bloc de notas.

b) Control de su progreso con información de su aprendizaje y comparativa con otros alumnos.

c) Creación de páginas personales en las que los alumnos puedan crear su espacio personal que pueda servir tanto de presentación, como de puerta de acceso a comunicaciones entre alumnos.

d) Posibilidad de tener un "desktop" propio para almacenar sus archivos. Facilidades para que el alumno pueda seguir el curso desde diferentes lugares sin necesidad de transportar sus archivos de trabajo.

\subsection{Servicios de comunicación}

* Calendario que resume los principales eventos de la programación del curso señalados por el profesor y en el que el alumno puede incorporar sus anotaciones privadas.

* Correo electrónico propio.

* Foros de discusión. Flexibilidad en su apertura, generación de foros generales o por grupos, incorporación de archivos, seguimiento de las intervenciones.

* Trabajo en grupos incluyendo áreas de presentación de sus resultados.

* Chat. Número de salas disponibles, así como la capacidad de archivar los contenidos.

* Pizarra compartida.

* Tablón de anuncios.

* Audioconferencia.

* Videoconferencia.

\section{Administración y Gestión académica}

4.1. Gestión de usuarios

a) Inclusión de herramientas para tareas de actualización y mantenimiento.

b) Posibilidad de configurar perfiles con diferentes atribuciones y derechos de acceso.

c) Capacidad de matriculación de alumnos on-line.

d) Gestión de la matriculación de los alumnos a las asignaturas. El acceso a todas las asignaturas en las que el alumno está matriculado es único y desde la misma página puede acceder a todas ellas. 
e) Compatibilidad con otras bases de datos de usuarios.

f) Posibilidad de creación de una cuenta de invitado.

g) Posibilidad de que los usuarios puedan cambiar el password.

\subsection{Ordenación académica}

a) Capacidad para dar de alta cursos.

b) Capacidad para obtener listados de alumnos.

c) Disponibilidad de espacio para la información institucional y tablón de anuncios.

d) Posibilidad de expedición de certificados y rendimiento académico.

e) Capacidad para backup y copias de los cursos.

\subsection{Informes}

a) Elaboración de estadísticas e informes sobre el trabajo y aprendizaje de alumnos.

b) Evaluación de las bases de preguntas de los cuestionarios sobre su dificultad y carácter discriminatorio.

c) Capacidad para recoger las sugerencias de los usuarios.

\section{Otras características}

Se refiere a una serie de indicadores que son poco utilizados en otros estudios comparativos. Pretenden evaluar aspectos subjetivos y que están relacionados con la confianza que ofrece la plataforma y con su calidad ergonómica.

\subsection{Madurez y Difusión}

Evalúa aspectos indirectos tales como la evolución de la plataforma, sus propietarios y la opinión y aceptación de terceras personas.

a) Historial de la Plataforma. El objetivo fundamental es evaluar las posibilidades de continuidad de futuro a partir de valorar el pasado y el presente.

b) Disponibilidad de versiones freeware que permitan probar la plataforma en situaciones reales.

c) Grado de utilización en entornos similares. El número y prestigio de las instituciones que utilizan la plataforma.

d) Evaluaciones realizadas por organismos e instituciones independientes.

e) Actividades de intercambio de experiencias. Existencia de una masa crítica que se materializa en congresos, foros, etc.

5.2. Interface de usuario 
Evalúa tanto la sencillez de manejo como la comodidad y amabilidad de uso.

a) Diseño y Navegación. El diseño del entorno visto no sólo desde su calidad artística sino de su funcionalidad, debe resultar intuitivo, homogéneo y fácil de comprender por su similitud con el software de amplia difusión.

b) Personalización del entorno. Posibilidades de mantener una imagen corporativa y una oferta diferenciada por cursos, especialidades, convocatorias, etc.

c) Banderas de novedades. Anuncios al usuario, luego de cada ingreso, sobre la existencia de novedades que debe atender: exámenes, mensajes, calificaciones, vencimientos.

d) Trabajo off-line. Posibilidad de descarga del curso o parte de él y trabajo local con actualización de cambios automáticamente sincronizados o replicados al volver a conectar.

e) Modos de vista. Capacidad del profesor para comprobar on-line cómo son vistos por el alumno los cambios que está realizando sin necesidad de tener abiertas diferentes sesiones de trabajo.

\subsection{Orientaciones para su correcto manejo}

a) Tutoriales y documentación. Orientada a todos los perfiles de la plataforma, especialmente para el alumno.

b) Ayudas on line. Sensibilidad al contexto de forma que permitan un rápido acceso a la información buscada.

c) Cursos de formación en el uso de la herramienta.

d) Centro de recursos. Disponibilidad de material pedagógico que resulte compatible con la plataforma.

\subsubsection{Indicadores de calidad en las plataformas de formación virtual}

En este caso los autores, basándose en investigaciones propias y de otros colegas, proponen cuatro categorías para analizar la calidad de un entorno virtual: calidad técnica, calidad organizativa y creativa, calidad comunicacional, y calidad didáctica [Tor2003].

\section{Calidad Técnica}

Características técnicas que debe tener la plataforma para garantizar la solidez y estabilidad de los procesos de gestión y de enseñanza-aprendizaje:

- Infraestructura tecnológica necesaria, accesibilidad y complejidad.

- Necesidades de hardware y software del servidor.

- Necesidades de hardware y software para el usuario.

- Número de usuarios on-line que soporta.

- $\quad$ Coste de mantenimiento.

- Conocimientos técnicos necesarios para su utilización.

- Interface sencilla.

- $\quad$ Sistemas de seguridad y acceso a los materiales.

- $\quad$ Eficacia de gestión de cursos.

- Versatilidad de administración de usuarios. 
- $\quad$ Modalidades de contratación de las licencias de uso o gratuidad.

\section{Calidad Organizativa y Creativa}

Organización y desarrollo del proceso de enseñanza-aprendizaje

- $\quad$ Flexibilidad en la elección del proceso de enseñanza-aprendizaje (ya sea constructivista, conductual, etc.).

- Posibilidad de adaptación a otros entornos formativos (educación no formal, comunidades virtuales de aprendizaje, etc.).

- Versatilidad en el diseño e implementación del sistema de ayuda y refuerzo para el alumnado atendiendo a dificultades de aprendizaje, opcionalidad curricular, etc.

- Herramientas de diseño de contenidos sencillas de utilizar.

- Posibilidad de organizar automáticamente los contenidos en índices y mapas conceptuales.

- Posibilidad de creación automática de glosarios.

- Integración de elementos multimedia (videoestreaming).

- Herramientas de evaluación, de auto-evaluación e inter-evaluación grupal.

- Evaluación del proceso de enseñanza-aprendizaje:

- Evaluación Inicial: herramientas que permitan realizar este tipo de evaluación.

- Evaluación Formativa o Continua: herramientas que permitan la monitorización de las actividades de los alumnos, herramientas de observación y seguimiento, herramientas de auto evaluación de los alumnos.

- Evaluación Final o Sumativa: algunos tipos de pruebas: de respuesta múltiple, de relación, de cubrir espacios en blanco, de verdadero y falso, de respuesta corta, de respuesta abierta, etc.

- Herramienta de búsqueda de contenidos.

- Disponibilidad de herramientas de seguimiento del curso, mantenimiento y actualización.

\section{Calidad Comunicacional}

Comunicación asincrónica, sincrónica profesor-alumno, alumno-alumno y docentedocente:

- Herramientas de comunicación asincrónicas

- La posibilidad de crear foros o grupos de discusión (por parte del profesorado y del alumnado).

- La eficiencia de los sistemas de correo electrónico (interno y externo).

- La calidad y versatilidad del tablón de noticias.

- La eficiencia del calendario y su personalización.

- Herramientas de comunicación sincrónicas

La posibilidad de organizar sesiones de chat tanto entre tutores y alumnos como de tutores entre sí o entre todos y de archivar su contenido.

- La posibilidad de establecer audio conferencia y de archivar su contenido en formato comprimido.

- La necesidad de un área de presentación de estudiantes que humanice especialmente los momentos iniciales, ayudando al establecimiento de ciberrelaciones afectivas. 
La posibilidad de organizar actividades de intercambio cultural (interculturalidad) y de ocio (tertulia virtual, cibercafé, certamen musical / fotográfico, etc.)

\section{Calidad Didáctica}

Principales aportaciones de las teorías cognitivistas y constructivistas al diseño de materiales curriculares virtuales:

- Principio del aprendizaje activo: los contenidos y las actividades deben estar diseñados con la mayor riqueza lingüística posible mediante la inserción de archivos de texto, de audio, de vídeo, etc. Igualmente supone que el alumno puede elaborar sus actividades usando esta riqueza expresiva, para lo que es necesario dotarlo de un adecuado nivel de alfabetización hipermedia.

- Principio del aprendizaje inductivo por descubrimiento: el diseño de los materiales curriculares virtuales ha de favorecer la realización de indagaciones e investigaciones basadas en situaciones problematizadoras, bien propuestas por el alumno o sugeridas por el profesor.

- Principio de la significatividad del aprendizaje: este principio exige la personalización de los contenidos y actividades adaptándolas a las necesidades e intereses previos de los alumnos.

- Principio del aprendizaje cooperativo: las aulas virtuales deben ofrecer espacios de comunicación asincrónicos y sincrónicos.

- Principio de la versatilidad de los ambientes formativos: hace referencia a la simulación de ambientes de aprendizaje.

- Principio de la autonomía organizativa y del equilibrio cognoscitivo: el contenido y la organización de los materiales didácticos virtuales ha de favorecer el autoaprendizaje, el interaprendizaje y el aprender a aprender.

- Principio de la secuencialidad conceptual: los diseños curriculares deben ofrecer al alumno la posibilidad de construir el mapa conceptual como fórmula vertebradora de los contenidos.

- Principio del andamiaje cognoscitivo: tanto la acción tutorial como el contenido de las unidades didácticas han de incluir la presencia de estímulos que permitan al estudiante vincular los esquemas conceptuales previos con los nuevos conceptos que ofrece el material curricular.

- Principio del orden y la claridad didáctica: para un eficaz desarrollo del proceso de enseñanza-aprendizaje, deben estar delimitados con claridad, los objetivos, los contenidos, las actividades, la evaluación, y todos ellos interrelacionados entre sí.

Principio de la comunicación multimedia eficaz: que garantice la eliminación de ruidos e interferencias en las comunicaciones sincrónicas y asincrónicas.

\subsubsection{Evaluación de un Sistema de Gestión del Aprendizaje}

El autor propone cinco categorías para la evaluación, las cuales posibilitan examinar de forma muy pormenorizada las características de un entorno. En general, cada categoría se desglosa en una serie de preguntas o items que pueden ser identificados o no dentro de la herramienta analizada [Zap2003]:

- Características básicas

- Utilidades que generan ambientes de comunicación y de trabajo

- Funciones formativas que permite desarrollar

- Roles que se identifican 
- Evaluación sobre la intervención psicopedagógica del sistema que soporta

\section{a. Características básicas}

- Es una herramienta informática y telemática.

- Posibilita el acceso remoto.

- Utiliza un navegador.

- El acceso es independiente de plataforma.

- Tiene estructura servidor / cliente.

- El acceso es restringido y selectivo.

- Incluye como elemento básico una interfaz gráfica común.

- Utiliza páginas elaboradas con un estándar aceptado por el protocolo HTTP.

- Realiza la presentación de la información en formato multimedia.

- Permite al usuario acceder a recursos y a cualquier información disponible en Internet.

- Permite la actualización y la edición de la información con los medios propios.

- Tiene estructurada la información y los espacios, en formato hipertextual, de manera que la información esté organizada y estructurada a través de enlaces y asociaciones de tipo conceptual y funcional.

- Permite establecer diferentes niveles de usuarios con distintos privilegios de acceso.

- Contempla al menos los siguientes perfiles: administrador, coordinador o responsable de curso, profesores tutores, alumnos.

\section{b. Utilidades de la plataforma que generan ambientes de comunicación y de trabajo}

Mediante una tabla de doble entrada se relevan características sobre listas de correo, foros, respositorios, editores de documentos y guías didácticas [Zap2003].

\section{c. Funciones formativas que permite desarrollar}

\section{Propuesta de itinerario formativo}

- Permite al alumno usuario elegir o establecer distintos itinerarios formativos alternativos.

- El sistema va provisto de itinerarios conformados, así como de criterios de articulación: incompatibilidades, requisitos, orientaciones, pautas, etc.

- El alumno puede diseñar según sus expectativas e intereses los cursos, materias, seminarios u otras acciones formativas.

- El alumno puede establecer la secuencia de las materias, los cursos u otras acciones formativas.

\section{Propuesta de guía curricular}

- Está provista de editor de guías.

- Hay un lugar en el diseño de cursos para las guías.

- Este lugar ocupa una posición preeminente, visible y de acceso fácil.

- El editor lleva prevista una herramienta que permita establecer enlaces con los materiales que se utilizan en las tareas, recursos en Internet y con otros módulos (o permite editar HTML). 


\section{Apoyo en la formación}

\section{Seguimiento del progreso del estudiante}

- Fichas de anotaciones personalizadas del alumno.

- Test de auto evaluación realizados por los estudiantes.

- Pruebas objetivas con módulo de edición, módulo de ejecución y modulo de corrección.

- Estadísticas sobre los itinerarios seguidos.

- Estadísticas de los accesos practicados en los materiales de aprendizaje.

- Estadísticas de la participación de los alumnos a través de herramientas de comunicación, número de veces que ha accedido el alumno al sistema, tiempo invertido, etc.

- ¿Generan gráficas sobre cada una de las variables reseñadas?

\section{Comunicación interpersonal}

Es el aspecto más importante y definitorio dentro de los entornos de aprendizaje en redes. De cada herramienta de comunicación se analiza que tipo de herramientas es (estándar, específica o ambas), si es síncrona (on-line, off-line) o asíncrona y si es punto a punto o multipunto.

- Correo.

- Correo con adjuntos.

- Listas.

- Foros.

- Audioconferencia.

- Videoconferencia, pizarra electrónica, espacios virtuales.

- Chat (único, por materia).

- Noticias.

- Tablero electrónico.

\section{Trabajo colaborativo}

- Incorpora repositorio de archivos y documentos.

- Lleva editor individualizado.

- Permite compartir información, elaborar, modificar, adicionar, documentos conjuntos.

- Incorpora facilidades que establezcan actualizaciones simultáneas y diferentes versiones.

- Lleva opciones específicas orientadas al trabajo cooperativo, como son aplicaciones compartidas.

- Calendario.

- Convocatoria de reuniones.

- Lluvia de ideas.

- Mapas conceptuales.

- Navegación compartida.

- Notas.

- Pizarra compartida.

- Videoconferencia interna. 
Creación de ejercicios de evaluación y auto evaluación

- Tipos de ejercicios: de respuesta múltiple, de relación, ejercicios cloze, de respuestas booleanas, de observación visual, ejercicios abiertos que puede contrastarse con otros ejercicios de plantilla.

Acceso y procesamiento de información y de contenidos de aprendizaje

- Permite editar enlaces y categorías.

- Lleva guía propia de recursos de Internet con una categorización de enlaces por materias.

- Lleva guía propia de recursos de Internet con otro tipo de categorización estándar.

- Lleva acceso a enlaces de Internet personalizados (bookmarks o favoritos).

- Lleva acceso a enlaces de Internet.

\section{Interacción}

- Permite visualizar al usuario, sea profesor o alumno, quien está conectado en cada momento (profesor alumno).

- Permite visualizar quien está conectado en cada momento, pero con limitaciones: solo a los profesores, solo permite detectar qué alumnos están conectados.

- Tiene portafolio vinculado al resto de herramientas de forma que se pueda congregar toda la información de un alumno procedente del correo, las listas, los repositorios de documentos, etc.

- Tiene recursos automatizados vinculados con la gestión docente personalizada. Por ejemplo, enviar mensajes tipo a alumnos que no hayan presentado la tarea en un plazo, u otros similares.

\section{Gestión y administración educativa de los alumnos}

- Dispone de un interface practicable por el coordinador o equivalente que permite conceder y retirar privilegios al resto de usuarios según perfiles y funciones atribuidas, modificando los perfiles docentes y alumnos.

- Dispone de un interface practicable por el tutor dando acceso a los alumnos a los espacios docentes y altas/bajas y otras funciones determinadas en la programación.

- Dispone de un interface practicable por el administrador de las listas y los foros regulando la participación en los debates (concediendo y retirando privilegios de participación: todos, solo lectura, lectura y escritura moderada, etc.).

- Permite la creación de grupos, en general o de alguna forma:

- A todos los profesores sobre los alumnos que tiene responsabilidad.

- Solo al administrador y al coordinador.

- A cualquier profesor.

- Permite el acceso a la información sobre alumnos, fichas de alumnos.

- Permite la creación de listas y plantillas para seguir y evaluar el progreso en el aprendizaje. 
- Permite la elaboración, diseño y gestión de espacios virtuales distintos del curso: Unidades, lecciones, temas, capítulos, etc.

\section{Utilidades vinculadas a funciones}

- Seguimiento del progreso del estudiante: portafolio / pruebas objetivas / análisis de tarea / análisis de intervenciones en debates.

- Comunicación interpersonal: profesor - alumno / alumno - alumno / profesor - profesor.

- Trabajo colaborativo: compartir información / elaborar, modificar, adicionar, documentos conjuntos / facilita y entrena para la solución de problemas.

- Facilita y entrena para la toma de decisiones.

- Facilita y entrena para la el trabajo en grupo.

\section{d. Roles que se identifican}

- Alumno.

- Tutor personal.

- Tutor de aprendizaje.

- Profesor responsable o titular de materia.

- Coordinador.

- Administrador.

- Especialista en elaboración de material educativo multimedia.

- Colaborador remoto, en sedes locales.

- Evaluador u observador externo.

- Otros perfiles docentes.

- Otros perfiles no docentes.

\section{Términos}

Los descriptores de un perfil son precisos, únicos y sin ambigüedades en todos los puntos de la plataforma donde se citan. Y corresponden a la misma conceptualización.

\section{Relaciones}

- Alumno

- Informaciones en relación con la situación en que se encuentra en el contexto del curso (Unidad, tareas pendientes, tareas propuestas, y enlace con comunicaciones recientes no vistas).

- Acceso a tutores, material, herramientas de comunicación interpersonal o grupal.

- Tutor personal

- Todas las informaciones y posibilidades de acceso que disponen los participantes tutelados.

- Acceso a las bases de datos de alumnos.

- Tutor de aprendizaje

- Todas las informaciones y posibilidades de acceso que disponen los participantes tutelados. 
- Acceder a la información de los alumnos asignados.

- Acceso a las herramientas de gestión del aprendizaje de forma diferenciada: Editores de ejercicios, pruebas de evaluación, guías de aprendizaje, fichas de los alumnos, portafolios.

- Profesor responsable o titular de materia

- Todas las informaciones y posibilidades de acceso que disponen los participantes asignados.

- Acceder a la información de los alumnos (como cliente).

- Acceso a las herramientas de gestión de los recursos y guías didácticas de la materia, de forma diferenciada: editores, guías didácticas.

- Coordinador: acceso al interface de coordinador, donde están las herramientas que le permiten ejercer sus privilegios y funciones.

- Administrador: acceso al interface de administrador, donde están las herramientas que le permiten ejercer sus privilegios y funciones.

- Especialista en elaboración de material educativo multimedia

- Acceso a un interface propio para colocar materiales de prueba.

- Todas las informaciones y posibilidades de acceso que disponen los participantes.

- Colaborador remoto, en sedes locales

- Todas las informaciones y posibilidades de acceso que disponen los participantes tutelados.

- Acceder a la información de los alumnos asignados.

- Evaluador u observador externo

\section{Privilegios}

- Alumno: disponer de un espacio cliente al que pueda acceder depositando materiales y modificando su estructura, el árbol de carpetas y directorios de ahí para abajo.

- Tutor personal

- Disponer de un espacio cliente al que pueda acceder depositando materiales y modificando su estructura, el árbol de carpetas y directorios de ahí para abajo.

- Acceder a información de los alumnos asignados.

- Editar fichas de alumnos.

- Tutor de aprendizaje

- Disponer de un espacio cliente al que pueda acceder depositando materiales y modificando su estructura, el árbol de carpetas y directorios de ahí para abajo.

- Acceder a información de los alumnos asignados.

- Editar fichas de alumnos.

- Acceder a espacio de los alumnos como cliente / servidor.

- Dar altas y bajas de alumnos.

- Profesor responsable o titular de materia

- Dispone de los privilegios propios de un tutor de aprendizaje.

- Acceso cliente único al repositorio de materiales de la materia.

- Administrar recursos de la materia, foros, listas.

- Coordinador: acceso cliente único a las guías didácticas

- Administrador

- Conceder retirar privilegios. 
- Diseño de espacios.

- Asignar espacios.

- Especialista en elaboración de material multimedia: disponer de un espacio cliente al que pueda acceder depositando materiales y modificando su estructura, el árbol de carpetas y directorios de ahí para abajo.

- Colaborador remoto, en sedes locales

- Disponer de un espacio cliente al que pueda acceder depositando materiales y modificando su estructura, el árbol de carpetas y directorios de ahí para abajo.

- Acceder a información de los alumnos asignados.

- Editar fichas de alumnos.

- Evaluador u observador externo

e. Evaluación sobre la intervención psicopedagógica del sistema que soporta.

- ¿Contiene la plataforma espacio para la información sobre las características curriculares del curso?

- Es accesible desde todos los puntos, o al menos desde el menú principal.

- Es editable por el Coordinador.

- Contiene información sobre objetivos formativos.

- Contenidos.

- Metodología.

- Actividades.

- Evaluación: de proceso, de aprendizajes, criterios de evaluación, de promoción.

- Recursos.

- ¿Contempla la plataforma la posibilidad de incluir en la programación adaptaciones a situaciones especiales, con actividades, evaluaciones, etc.?

\subsubsection{Criterios de calidad para los sistemas de teleformación}

Estos criterios no abordan únicamente la herramienta sino también la calidad de los materiales formativos, la labor de los docentes y tutores, el plan docente y la metodología del curso [Mar2001]. Esta concepción sostiene que la calidad del entorno dependerá en gran manera de la actuación de los elementos humanos (profesores, tutores, etc.) que interactúan con los estudiantes en el marco de un determinado modelo pedagógico. Los criterios están agrupados en: aspectos relacionados con el entorno telemático, aspectos funcionales del curso on-line, aspectos relacionados con el plan docente y el modelo pedagógico, aspectos relacionados con los servicios complementarios. De todas formas podría tomarse solo el primer aspecto, aplicando los restantes en los casos de evaluación específica de cursos. Presentaremos a continuación los relacionados al entorno.

\section{- Sencillez:}

- La utilización de los servicios que ofrece el sistema debe resultar sencilla y agradable.

- La instalación del software que pueda necesitar el entorno se hará de manera automática, previa información al usuario. 
- El usuario se orientará bien en el entorno virtual y tendrá la posibilidad de moverse según sus preferencias. Un sistema de ayuda on-line siempre será un buen complemento, así como la posibilidad de hacer consultas on-line.

- Calidad del entorno audiovisual:

- Presentación atractiva. Diseño claro y atractivo de las pantallas, sin exceso de texto ni de imágenes.

- Calidad técnica y estética en sus elementos:

- títulos y barras de estado (para facilitar la orientación en la Web).

- frames, tablas, ventanas (para organizar la información y estructurar el sistema de navegación).

- fondo (puede ayudar a identificar las secciones del espacio Web).

- iconos (intuitivos y adecuados a los destinatarios).

- espacios de texto-imagen (las imágenes siempre tendrán una alternativa textual), formularios botones, barras de navegación, menús de opciones (siempre en el mismo lugar).

- tipografía (legible y sin abusar de mayúsculas), color, composición (que permita una buena impresión).

- elementos multimedia (gráficos, fotografías, animaciones, vídeos, audio).

- textos con un lenguaje adecuado, sin faltas de ortografía y sin discriminaciones por razón de sexo, clase social, etc.

- Navegación e interacción con el entorno:

- Mapa de navegación. Buena estructuración del espacio Web que permite acceder a los contenidos, secciones, actividades y prestaciones en general. Conviene que todas las páginas Web tengan un título. Puede ser: lineal, ramificado o tipo entorno.

- Sistema de navegación. Entorno transparente que permite que el usuario esté siempre orientado y tenga el control de su navegación. Será eficaz pero sin llamar la atención sobre si mismo:

- uso de metáforas intuitivas y adecuadas a los destinatarios.

- destacado del enlace que se están visitando, o de los enlaces visitados.

- agrupación de los botones con funciones similares en barras de navegación.

- con enlaces que permitan acceder al nivel superior en todas las páginas.

- índice hipertextual de contenidos al inicio del documento en las páginas de cierta extensión.

- hipervínculos (incluirán la descripción y el enlace).

- no utilizar más de 3 niveles de hipertextualidad.

- velocidad adecuada en la renovación de páginas, animaciones.

- Interacción. Uso transparente del teclado (los caracteres escritos se pueden ver y corregir en la pantalla), adecuada gestión de las respuestas y acciones de los usuarios.

- Hipertextos / hipermedios: Enlaces con imágenes o textos descriptivos y bien actualizados.

- Comunicación interpersonal y trabajo colaborativo:

- Dispone de buenos canales sincrónicos (salas de chat, mensajería instantánea, videoconferencia) y asincrónicos (foros) para facilitar la comunicación entre los estudiantes y con los profesores. 
- Ofrece herramientas para el trabajo colaborativo: discos duros virtuales, Weblogs, etc.

- Originalidad y tecnología avanzada:

- Entornos originales, que aprovechen las prestaciones de las tecnologías multimedia e hipertexto yuxtaponiendo diversos sistemas simbólicos, de manera que resulten atractivos e intuitivos.

- Adopción de estándares sobre diseño y navegación: W3C.

- Adopción de estándares sobre e-learning: IMS, IEEE P1484.

- Fiabilidad y seguridad del entorno:

- El entorno de teleformación funciona de manera estable y gestiona adecuadamente las carpetas y los archivos.

- Filtra los archivos para evitar la entrada de virus en el sistema.

\subsubsection{Análisis comparativo de características}

En este estudio los autores identifican un extenso conjunto de características deseables, 94 en total, para dar un correcto soporte a la enseñanza y el aprendizaje en línea [Whi2000]. El propósito de sus investigaciones está orientado en dos sentidos, por un lado ayudar a las instituciones académicas a tomar decisiones sobre el entorno más conveniente a utilizar, y por el otro orientar a los desarrolladores respecto a nuevas funcionalidades que serían interesantes contemplar a futuro. Los criterios están agrupados en tres grandes categorías, cada una de las cuales posee detallados indicadores sobre lo que debería ser un entorno "ideal". Cada característica señalada puede estar presente o no en el entorno analizado, con lo cual la cantidad encontrada permite dar una señal sobre la integralidad de la misma:

\section{a) Herramientas para el estudio}

\section{Herramientas para el aprendizaje}

- $\quad$ Marcador de último lugar visitado

- Área del estudiante

- Carpeta personal

- Subida de archivos por lote

- Trabajo compartido (ver área de trabajo grupal)

- Construcción de equipos

- $\quad$ Acceso a biblioteca

- Anotador

- Glosario propio

- I Índice del curso / buscador

- Guías de aprendizaje

- Acceso para poseer las calidades

- Rastreador de progreso

- Recordatorios de asignaciones pendientes

- Comparación con el promedio de la clase

- Guía de estudio

- $\quad$ Ejercicios de auto evaluación

- $\quad$ Construcción de habilidades de estudio

- $\quad$ Página Web personal 


\section{Herramientas para la colaboración}

- Opciones de discusión

- Asincrónica

- $\quad$ Correo electrónico (una a uno)

- $\quad$ Listas de distribución (muchos a muchos)

- $\quad$ Conferencia basada en texto (muchos a muchos) o Tablón de anuncios (uno a muchos)

- Sincrónica

- Chat

- Archivo de sesiones

- Pizarra compartida

- Archivo de sesiones

- Teleconferencia

- Video

- Audio

- Conferencia en vivo basada en texto

- Archivos compartidos

- Adjuntos por correo electrónico

- Adjuntos a mensajes

- Almacenamiento de archivos

- Directorio privado en el servidor del curso

- Librería de archivos públicos

- Áreas de trabajo en grupo

- Página Web del grupo

- Conferencias en grupo

- Equipos de trabajo

b) Herramientas para la docencia

\section{Herramientas de autoría}

- Planificación del curso

- $\quad$ Diseño del curso

- $\quad$ Plantilla del curso

- Glosario automático

- $\quad$ Índice automático

- $\quad$ Motor de búsqueda del curso

- Manejo de archivos

- Almacenamiento de archivos para el instructor

- Subida por lote

- Borrado por lote

- Guía para el instructor

- Ejemplos de cursos

- $\quad$ Herramientas de búsqueda en la Web

- $\quad$ Capacidades Multimedia

\section{Herramientas de gestión}

- Página de información sobre el instructor

- Información del curso

- $\quad$ Calendario y planificación del curso

- Anuncios 
- $\quad$ Gestión del estudiante

- Página de presentación del estudiante

- Registro

- Subida por lote

- Borrado por lote

- Rastreo de asistencia y participación

- Asistencia

- Participación

- Evaluación

- Exámenes

- Temporizados

- Repetibles

- Ejercicios

- Temporizados

- Repetibles

- $\quad$ Backup del curso

- Replicación del curso

- Revisión del curso

- $\quad$ Ayuda y respuestas a preguntas frecuentes

c) Herramientas para la administración

- $\quad$ Registro automático

- $\quad$ Seguridad

- $\quad$ Soporte técnico

- $\quad$ Resumen de participación del estudiante

- Standard

- Código abierto

- Propietario

- Costos

- Servicio de hosting

- Demo del curso

- Curso de ejemplo

- Curso gratuito

- Entrenamiento

- Licencia

- Versión demo gratuita

- On-line por versión

- Anual

- Soporte gratuito

- Actualizaciones

- $\quad$ Plataforma

- Windows NT

- Unix

- Otros

- Licencia libre anual

- Para un número ilimitado de estudiantes 


\subsubsection{Criterios para EVEA de código abierto}

Los siguientes criterios surgen de un trabajo realizado para la Commonwealth of Learning (COL) de la 3waynet con el objetivo de evaluar entornos de código abierto, pero tomando como base todos los componentes encontrados en las plataformas comerciales.

Los criterios de la evaluación fueron desarrollados sobre la base de la experiencia propia del personal del COL, búsquedas usando "COL Knowledge Finder", comparación de productos, y discusión para establecer un contexto para desarrollar criterios generales, así como una lista de características o rasgos detallados. Los criterios están agrupados en generales y específicos [Com2003].

\section{- Generales}

- Características y funcionalidades

- Costos, soporte, asistencia, nivel de experticia

- Mantenimiento

- Usabilidad y documentación de usuario

- Adopción de los usuarios / Comunidad de usuarios actuales

- Modificabilidad

- Estandarización

- Capacidad de integración

- Integración con Learning Objects Models (LOM)

- Confiabilidad

- Escalabilidad

- Seguridad de propiedad intelectual

- Consideraciones de hardware y software

- Soporte multilenguaje

- Específicos

- Seguridad

- Encriptación

- Autentificación

- Acceso

- Usuario y contraseñas individuales o grupales

- Asignación de privilegios

- Accesible mediante navegador

- Autorización para cursado

- Registración

- Requisitos mínimos de hardware del estudiante, tipos de

conexión a Internet, posibilidad de trabajo fuera de línea.

- Diseño, desarrollo e integración del curso

- Mantenimiento sencillo del curso

- Interface personalizable y adaptable

- Soporte para clases y cursos virtuales

- Plantillas de cursos

- Soporte de características multimedia

- Accesibilidad

- Herramientas para diseño instruccional

- Soporte para especificación instruccional

- Administración de curriculum

- Navegación Simple 
- Estructura del curso simple

- Arquitectura extensible

- Monitoreo del curso

- Soporte para hojas de estilo

- Descripción del curso

- Listado de cursos

- Diseño de evaluaciones

- Control de Planificación y disponibilidad

- Facilidad para la creación de exámenes y ejercicios y seguimiento de los resultados

- Creación de tests de preguntas y facilidades para la administración de tests

- Testeo y resultados automatizado

- Seguimiento del progreso de aprendizaje

- Competency Mapping/Skill Gap Analysis

- Creación de certificados

- Auto-evaluación

- Herramientas de graduación on-line

- Registro de actividades

- Colaboración y comunicación on-line

- Comunidad de aprendizaje o componentes de colaboración que soporten comunicación

- Mensajería: integración con mensajes de texto de teléfonos celulares

- E-mail: habilidad para integrarse con e-mails enviados desde cuentas de correo POP

- Salas de chat

- Tablón de anuncios

- Grupos de noticias

- Soporte on-line / mesa de ayuda

- Intercambios de archivos

- Noticias de periódicos on-line

- Pizarra compartida

- Grupos de discusión / Foros de trabajo en grupo

- Herramientas de productividad

- Marcadores

- Calendario

- Revisión de progreso

- Orientación / ayuda

- Búsqueda

- Trabajo off-line sincronizado 


\subsubsection{Evaluación de herramientas para gestión de cursos Web}

Los criterios de evaluación desarrollados por Hazarim están agrupados en tres grupos: rasgos generales, características técnicas y otros [Haz2002][Haz2002b]. El autor considera a estos criterios como los ideales, entendiendo que es muy probable que ninguna herramienta los tenga en cuenta a todos ellos. Fueron los utilizados para la selección de un entorno virtual para el campus virtual de la Universidad de Maryland.

- Rasgos generales

- Anotador

- Soporte para navegación

- Tablón de anuncios

- Calendario

- Chat

- E-mail

- Subida de archivos

- Enlaces HTML

- Capacidades de importación / exportación

- Personalización del instructor

- Soporte para listas de distribución

- Contraseña de seguridad

- Soporte Multimedia

- Múltiples niveles de seguridad

- Graduación on-line

- Ayuda on-line

- Seguimiento de progreso

- Autoevaluaciones

- Configuración guiada

- Grupos de estudiantes

- Interface de usuario

- Pizarra compartida

- Requerimientos técnicos

- Scripts CGI

- Archivado y backup del curso

- Acceso a base de datos

- Plataforma de funcionamiento (sistema operativo / navegador)

- Soporte de archivos ejecutables

- Java

- Logeo

- Seguridad

- Tipo de servidor

- Compatibilidad con SSL

- Alta de estudiantes por lote

- Otros

- Costo

- Compatibilidad IMS

- Licencia

- Entrenamiento

- Actualizaciones

- Empresas proveedoras 


\subsubsection{Edutools}

Estos indicadores pertenecen a la Western Cooperative for Educational Telecommunications (WCET). Fueron utilizados en el sitio Web www.edutools.info desarrollado por el Centre for Curriculum, Technology \& Transfer de la Universidad British Columbia de Canadá, que provee facilidades para analizar, comparar, ponderar y tomar decisiones sobre el entorno a utilizar. Es posible acceder a una evaluación on-line de los entornos más conocidos en el ámbito mundial. Edutools es uno de los lugares más visitados en la Web a los efectos de evaluar o conocer las características principales de los entornos de aprendizaje más importantes. Los indicadores están agrupados en 8 criterios, además del registro del nombre del producto y del desarrollador del mismo [Edu2006].

- Herramientas de comunicación

- Foros de discusión

- Intercambio de archivos

- Carga de archivos

- Mail interno

- Apuntes on-line

- Chat en tiempo real

- Servicios de video

- Pizarra compartida

- Herramientas de productividad que muestran la evolución del estudiante

- Marcadores

- Ayuda / orientación

- Búsqueda dentro de un curso

- Calendario de progreso

- Revisión de trabajos off-line/sincronizado

- Herramientas que involucran al estudiante

- Grupos de trabajo

- Auto-ayuda

- Comunidad de estudiantes

- Carpeta del estudiante

- Herramientas de administración

- Autentificación

- Acceso autorizado a cursos

- Servicio de hospedaje de cursos

- Matriculación / integración

- Herramientas para el manejo del curso

- Gestión de cursos

- Mesa de ayuda para el instructor

- Herramientas de graduación on-line

- Testeo y puntuación automática

- Seguimiento del progreso del estudiante

- Diseño del curriculum

- Accesibilidad

- Plantillas de cursos

- Gestión de Curriculum

- Look and feel personalizable

- Estándares instruccionales 
- Herramientas de diseño instruccional

- Contenido reutilizable/compartido

- Hardware/Software

- Navegador requerido del lado del cliente

- Base de Datos requerida

- Software del Servidor

- Servidor UNIX

- Servidor Windows

- Precio/Licencia

- Perfil de la compañía

- Costos

- Código Abierto

- Opciones extras

- Estándares

- Versión del software

- Idioma 
